Universidade de São Paulo

Instituto de Astronomia, Geofísica e Ciências Atmosféricas

Departamento de Astronomia

Núcleos de galáxias gêmeas morfológicas da

Via Láctea: uma amostra completa de 10 objetos

Patrícia da Silva

São Paulo 

Patrícia da Silva

Núcleos de galáxias gêmeas morfológicas da Via Láctea: uma amostra completa de 10 objetos

Tese apresentada ao Departamento de Astronomia do Instituto de Astronomia, Geofísica e Ciências Atmosféricas da Universidade de São Paulo como requisito parcial para a obtenção do título de Doutora em Ciências.

Versão corrigida. O original encontra-se disponível na Unidade.

Área de Concentração: Astronomia Orientador: Prof. Dr. João E. Steiner

São Paulo 



\section{Agradecimentos}

Agradeço à Deus por me dar oportunidade de realizar este trabalho e por ter condições de finalizá-lo. Agradeço ao meu orientador, Prof. João Steiner, por seus ensinamentos e pelo apoio prestado durante todos estes anos. Agradeço também ao Prof. Roberto B. Menezes pela ajuda e pelas preciosas sugestões que ele ofereceu durante o projeto. Agradeço a Prof. Beatriz Barbuy pelo apoio durante estes últimos meses e ao Prof. Laerte Sodré, relator deste projeto, por suas sugestões, atenção e apoio. Agradeço ao IAG pela oportunidade, pela estrutura e por me permitir realizar este sonho. Por fim, agradeço a CNPq pelo apoio financeiro ao projeto de número 141766/2016-6.

Esta tese/dissertação foi escrita em IATEX com a classe IAGTESE, para teses e dissertações do IAG. 

"Como é feliz o homem que acha a sabedoria, o homem que obtém entendimento, pois a sabedoria é mais proveitosa do que a prata, e rende mais do que o ouro. É mais preciosa do que rubis; nada do que você possa desejar se compara a ela."

Provérbios 3:13-15. 



\section{Resumo}

Neste trabalho é conduzido o estudo das regiões nucleares das galáxias de mesmo tipo morfológico da Via Láctea (SABbc e SBbc): NGC 613, NGC 6744, NGC 1566, NGC 134, NGC 157, NGC 2442, NGC 2207, NGC 1255, NGC 1300 e NGC 7314. Essas galáxias são as 10 mais brilhantes da sub amostra de gêmeas morfológicas da Via Láctea do survey DIVING $^{3 D}$ (Deep IFS View of Nuclei of Galaxies). Utilizando cubos de dados observados com o IFU (Integral Field Unit) do GMOS (Gemini Multi-Object Spectrograph) e dados complementares, incluindo dados de outras bandas espectrais, o objetivo é estudar as propriedades das linhas de emissão na região nuclear e na região circumnuclear, as propriedades cinemáticas da componente estelar e do gás e a arqueologia estelar para descrever os ambientes nucleares a fim de inferir características comuns e a diversidade com que os fenômenos observados se apresentam nesta amostra de núcleos de galáxias e compará-los com o que foi observado na região central da Via Láctea. 



\section{Abstract}

This work presents the study of nuclei of galaxies with the same morphological type as that of the Milky Way (SABbc and SBbc): NGC 613, NGC 6744, NGC 1566, NGC 134, NGC 157, NGC 2442, NGC 2207, NGC 1255, NGC 1300 and NGC 7314. This sample comprises the 10 brightest galaxies of the sub-sample of Milky Way morphological twins of the DIVING ${ }^{3 D}$ survey (Deep IFS View of Nuclei of Galaxies). By using data cubes taken with the IFU (Integral Field Unit) from GMOS (Gemini Multi-Object Spectrograph) and complementary data, including data from other spectral bands, the goal is to study the properties of line emission of the nuclear and circumnuclear regions, the kinematic properties of the stars and gas and the stellar archaeology, in order to determine the environment properties of those nuclei and infer the most common characteristics and the diversity of the phenomena of this sample of nuclei of galaxies and compare them to the properties of the central regions the Milky Way. 



\section{Lista de Figuras}

2.1 Composição de imagens dos telescópios espaciais Chandra, HST e Spitzer do núcleo da Via Láctea . . . . . . . . . . . . . . . . . . 35

3.1 Dados brutos ........................ 40

3.2 Exemplo da filtragem Butterworth . . . . . . . . . . . . . . 43

3.3 Exemplo do fingerprint espacial no cubo de dados de NGC 157 . . . . . . 44

3.4 Exemplo do método de deconvolução no cubo de dados de NGC 2442 . . 45

5.1 Image of GMOS data cube . . . . . . . . . . . . . . . . . . 58

5.2 Image of SINFONI data cube on the $K$-band . . . . . . . . . . . . . 58

5.3 Image of SINFONI data cube on the $J$-band . . . . . . . . . . . . 58

5.4 PCA results from the GMOS data cube . . . . . . . . . . . . . . 62

5.5 PCA results from the GMOS data cube . . . . . . . . . . . . . . 63 63

5.6 'Scree test' from the PCA applied to the GMOS data cube . . . . . . . . 64

5.7 Eigenspectrum E2 from the PCA tomography . . . . . . . . . . . 65

5.8 HST images from NGC $1566 \ldots \ldots \ldots$

5.9 Difference of filters $\mathrm{V}$ and I from $\mathrm{HST} \ldots \ldots \ldots \ldots$

5.10 Regions 1 and 2 of NGC $1566 \ldots \ldots \ldots \ldots$

5.11 Optical spectrum of Region $1 \ldots \ldots \ldots$

5.12 Optical spectrum of Region $2 \ldots \ldots \ldots$. . . . . . . . . . . 70

$5.13 \quad J$-band spectra of regions 1 and $2 \ldots \ldots \ldots \ldots$

$5.14 K$-band spectra of regions 1 and $2 \ldots \ldots \ldots \ldots$

5.15 Gaussian fits of emission-lines . . . . . . . . . . . . . . . 71

5.16 Diagnostic diagrams of NGC 1566 nuclear regions . . . . . . . . . . 71 
5.17 Gaussian fit of $[\mathrm{O}$ III $] \lambda 5007$ emission line of Region $2 \ldots \ldots$

5.18 Gaussian fit of $\mathrm{Pa} \beta$ emission line of Region $1 \ldots \ldots$. . . . . . . 76

5.19 Broad components of $\mathrm{H} \alpha$ and $\mathrm{H} \beta$ of Region $1 \ldots \ldots$. . . . . . . 77

5.20 FWHM versus redshift of the broad components of Region 1 . . . . . 79

5.21 HII region in NGC 1566 nucleus . . . . . . . . . . . . . . . 80

5.22 Channel maps of $\mathrm{Pa} \beta$ in the HII region . . . . . . . . . . . . 80

$5.23[\mathrm{O}$ III $] \lambda 5007$ channel maps . . . . . . . . . . . . . . . . . . 81

$5.24 \quad H_{2} \lambda 21218$ channel maps . . . . . . . . . . . . . . . . . . 82

5.25 Velocity map of $\mathrm{H}_{2}$ with its velocity curve . . . . . . . . . . 83

5.26 Nuclear spiral in NGC $1566 \ldots \ldots$. . . . . . . . . . . . . 84

5.27 pPXF results . . . . . . . . . . . . . . . . . 86

$5.28 \mathrm{CO}(3-2)$ emission $\ldots \ldots \ldots \ldots \ldots$

5.29 STARLIGHT fit on the average spectrum of NGC 1566 nucleus . . . . . . 96

5.30 Histogram of starlight of NGC $1566 \ldots \ldots \ldots 7 . \ldots \ldots$

5.31 Flux maps of the stellar populations detected on NGC 1566 . . . . . . 9 98

5.32 Extinction, $\chi^{2}, \mathrm{~S} / \mathrm{N}$ and featureless continuum maps obtained with starlight 99

5.33 Radial profile of the featureless continuum map . . . . . . . . . . 99

5.34 Integrated stellar continuum image . . . . . . . . . . . . . 101

5.35 Stellar populations in the center and circumnuclear area . . . . . . . 102

7.1 Image of NGC 6744 and GMOS FOV . . . . . . . . . . . . . 106

7.2 NGC 6744 GMOS data cube . . . . . . . . . . . . . . . 108

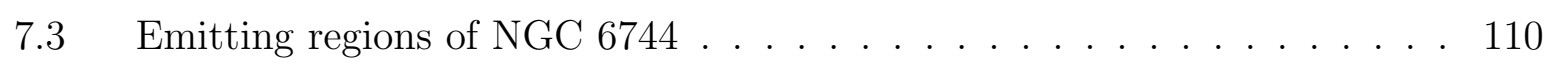

7.4 Spectra of the emitting regions of NGC $6744 \ldots \ldots$. . . . . . . 111

7.5 Diagnostic diagrams of the observed regions in NGC 6744 nucleus . . . . 113

7.6 Channel maps of $[\mathrm{OI}] \lambda 6300, \mathrm{H} \alpha,[\mathrm{NII}] \lambda 6584$, and $[\mathrm{OIII}] \lambda 5007 \ldots \ldots$

7.7 Velocity map of $\mathrm{H} \alpha \ldots \ldots \ldots$. . . . . . . . . . . . . . . . . . . .

7.8 Spectral synthesis results of the nuclear and circumnuclear regions of NGC

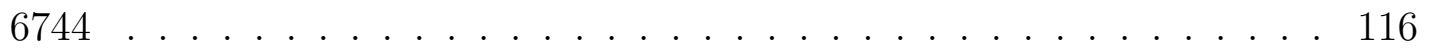

7.9 Stellar kinematics of NGC $6744 \ldots \ldots$. . . . . . . . . . . . . . . . . . .

7.10 HST images of NGC $6744 \ldots \ldots \ldots$. . . . . . . . . . . . . . . . . . . .

7.11 Stellar continuum and the position of the blue source . . . . . . . . . 121 
9.1 The comparison of the FOV of the data cubes of NGC $613 \ldots \ldots$

9.2 The GMOS data cube of NGC $613 \ldots \ldots$. . . . . . . . . . . . . . . . . . . . .

9.3 The SIFS data cube of NGC $613 \ldots \ldots$. . . . . . . . . . . . . . . . . . . . . . .

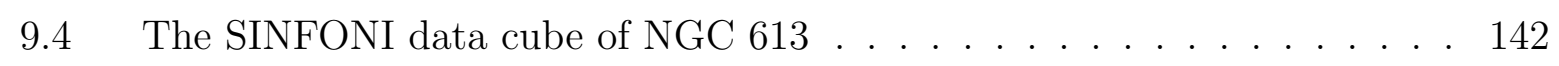

9.5 Regions N1 and N2 from GMOS and HST . . . . . . . . . . . 149

9.6 Evidence of $\mathrm{N} 1$ and $\mathrm{N} 2$ in the SINFONI data cube . . . . . . . . . . 151

9.7 The circumnuclear ring emission in $\mathrm{H}_{2} \lambda 21218$ from SINFONI and $\mathrm{CO}(3-2)$ from ALMA data cubes . . . . . . . . . . . . . . . . . . 153

9.8 Variability of source V2 . . . . . . . . . . . . . . . 154

9.9 Variability of source V1 . . . . . . . . . . . . . . . . 155

9.10 Emitting regions of $\mathrm{NGC} 613 \ldots \ldots \ldots \ldots$

9.11 Diagnostic diagram from the 10 regions of the nucleus of NGC 613 . . . 158

$9.12[\mathrm{O}$ III $] \lambda 5007$ image obtained from the SIFS data cube . . . . . . . . . 160

9.13 Chandra spectra of NGC $613 \ldots \ldots \ldots$. . . . . . . . . . . . . . . . . . . . .

9.14 Hard X-ray image from Chandra of NGC 613 nucleus . . . . . . . . . . 162

9.15 Soft X-ray of NGC 613 and the ionization cone . . . . . . . . . 162

9.16 General scenario of the NGC 613 nucleus . . . . . . . . . . . . . 168

9.17 HST and ALMA composition . . . . . . . . . . . . . 169

9.18 Spectra of $\mathrm{N} 1$ and $\mathrm{N} 2 \ldots \ldots \ldots \ldots$. . . . . . . . . . . . . . . . . . . .

9.19 Gaussian fits of the blended lines of N1 and N2 spectra . . . . . . . . 174

9.20 Spectra of regions 1 to $5 \ldots \ldots \ldots \ldots$. . . . . . . . . . . . . . . . .

9.21 Spectra of regions 6 to $10 \ldots \ldots \ldots \ldots \ldots \ldots$

9.22 Gaussian fits of the blended lines of the spectra of regions 2, 3, 7 and 8 . 177

10.1 Channel maps of $\mathrm{H} \alpha$ in $\mathrm{NGC} 613 \ldots \ldots$. . . . . . . . . . . . . . . . . .

10.2 Image of the $[\mathrm{OIII}] \lambda 5007$ outflow in the GMOS FOV . . . . . . . . . . 186

10.3 RGBs of $\mathrm{Br}_{\gamma}$ and $[\mathrm{Fe} \mathrm{II}] \lambda 16436$ emission lines . . . . . . . . . . . . . 187

10.4 RGBs of $\mathrm{H}_{2} \lambda 21218$ from SINFONI and $\mathrm{CO}(3-2)$ from ALMA . . . . . . . 189

10.5 Channel maps of [O III $] \lambda 5007$ emission line of the SIFS data cube . . . . 189

$10.6 \mathrm{H} \alpha$ channel maps obtained from SIFS data cube . . . . . . . . . . . . 190

10.7 Spectral synthesis results of $\mathrm{N} 1$ and $\mathrm{N} 2 \ldots \ldots$. . . . . . . . . . . . . . . . . .

10.8 Circumnuclear $10^{9}$ years old stellar populations of high metallicity . . . . 192 
10.9 Spectral synthesis results of regions 1 to $10 \ldots \ldots$. . . . . . . . . . .

10.10 pPXF of the GMOS data cube of NGC $613 \ldots \ldots$. . . . . . . . 195

10.11 pPXF of the SIFS data cube of NGC $613 \ldots \ldots$. . . . . . . . . . . . . . . . .

10.12 Velocity dispersion curve from SINFONI data cube . . . . . . . . . 199

$10.1310^{9}$ stellar populations of SIFS data cube . . . . . . . . . . . . . 201

10.14 Histogram of the spectral synthesis results of SIFS data cube . . . . . . 207

10.15 Flux maps of the stellar populations detected in SIFS data cube . . . . . 208

10.16 Flux fractions of high and low metallicities . . . . . . . . . . . 209

10.17 Maps of extinction, $\chi^{2}$ and S/N of SIFS data cube . . . . . . . . 210

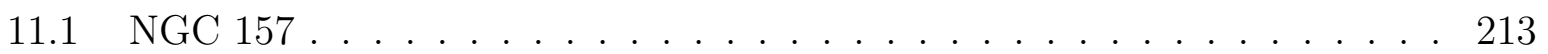

11.2 Imagem do cubo colapsado e espectro do núcleo de NGC 157 . . . . . . 214

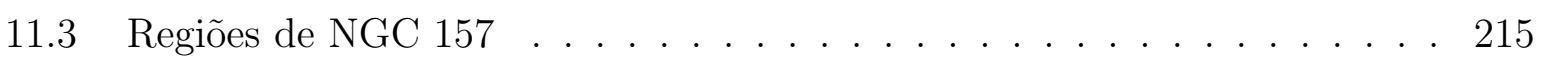

11.4 Diagrama de diagnóstico de NGC $157 \ldots \ldots$. . . . . . . . . 216

11.5 Tomograma e autovetor 2 do cubo de gás de NGC 157 . . . . . . . . 217

11.6 RGB de $\mathrm{H} \alpha$ de NGC 157 . . . . . . . . . . . . . . . . . . . . 218

11.7 Resultados da Síntese Espectral em NGC 157 . . . . . . . . . . . . 219

11.8 Mapas de extinção, $\chi^{2}$ e S/N da síntese espectral de NGC 157 . . . . . . 220

11.9 Mapas da cinemática estelar de NGC 157 . . . . . . . . . . . . . . 221

$12.1 \quad \mathrm{NGC} 2442 \ldots \ldots \ldots \ldots \ldots \ldots \ldots$

12.2 Espectro do núcleo e imagem colapsada do cubo de dados de NGC 2442 . 224

12.3 Regiões emissoras em NGC $2442 \ldots$. . . . . . . . . . . . . 226

12.4 Diagrama de diagnóstico de NGC $2442 \ldots \ldots$. . . . . . . . . . . 226

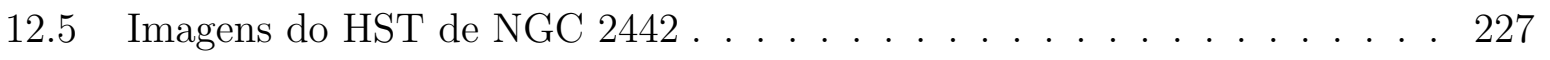

12.6 Imagem de I-H $\alpha$ de NGC2442 obtida com o HST . . . . . . . . . . . 228

12.7 Dados em raios-X de NGC $2442 \ldots \ldots$. . . . . . . . . . . . . . 229

12.8 RGBs das linhas de emissão em NGC 2442 . . . . . . . . . . . . . . . . . 230

12.9 Resultados do Starlight de NGC 2442 . . . . . . . . . . . . . . . 231

12.10 Mapas de extinção, $\chi^{2}$ e S/N de NGC 2442 . . . . . . . . . . . . . 232

12.11 Mapas da cinemática estelar de NGC 2442 . . . . . . . . . . . . . 233

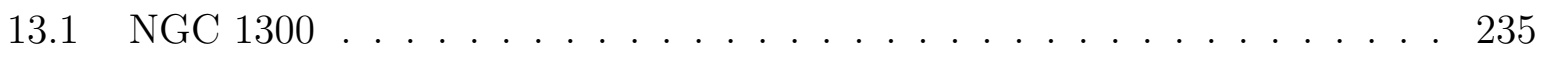


13.2 Imagem do cubo colapsado e espectro do núcleo de NGC 1300 . . . . . . 237

13.3 Imagens das principais linhas de emissão de NGC 1300 . . . . . . . . . 238

13.4 Diagrama de diagnóstico de NGC 1300 . . . . . . . . . . . . . 239

13.5 Dados em raios-X de NGC 1300 . . . . . . . . . . . . . . . . 240

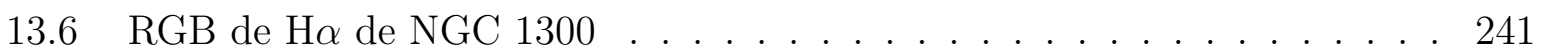

13.7 Resultados do Starlight de NGC 1300 . . . . . . . . . . . . . . . . . 242

13.8 Mapas de extinção, $\chi^{2}$ e S/N de NGC 1300 . . . . . . . . . . . . 243

13.9 Resultados do pPXF de NGC 1300 . . . . . . . . . . . . . . . . . . . 244

$14.1 \quad$ NGC $7314 \ldots \ldots \ldots \ldots \ldots \ldots \ldots \ldots$

14.2 Imagem do cubo tratado de NGC $7314 \ldots \ldots$. . . . . . . . . . . . . 248

14.3 Espectro do núcleo de NGC 7314 . . . . . . . . . . . . . . . . . . . . 249

14.4 Imagens de linhas de emissão de NGC 7314 . . . . . . . . . . . . . . 251

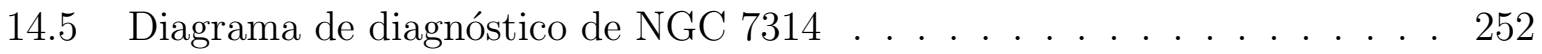

14.6 Emissão em raios-X de NGC 7314 . . . . . . . . . . . . . . . . . . . 253

14.7 RGBs das imagens do HST, ALMA e GMOS NGC 7314 . . . . . . . . 254

14.8 ALMA e HST NGC $7314 \ldots \ldots \ldots \ldots \ldots \ldots$

14.9 Composições RGBs de NGC 7314 . . . . . . . . . . . . . . . . . . . . . . 256

14.10 Channel maps de CO(3-2) em NGC 7314 . . . . . . . . . . . . . . 257

$15.1 \quad$ NGC $2207 \ldots \ldots \ldots \ldots \ldots \ldots \ldots \ldots$

15.2 Integral do cubo de dados e espectro do núcleo de NGC 2207 . . . . . . . 260

15.3 Regiões de emissão de linhas de NGC 2207 . . . . . . . . . . . . . . 261

15.4 Diagrama de diagnóstico de NGC 2207 . . . . . . . . . . . . . . . . . 263

15.5 Mapas de baixa e alta densidades de NGC 2207 . . . . . . . . . . 264

15.6 Channel maps de NGC $2207 \ldots \ldots$. . . . . . . . . . . . 264

15.7 Rotação do gás em NGC 2207 . . . . . . . . . . . . . . . . 265

15.8 Outflow em NGC $2207 \ldots \ldots \ldots \ldots$. . . . . . . . . . . . . . . . . . . . . .

15.9 Resultados da síntese espectral de NGC 2207 . . . . . . . . . . . . . 267

15.10 Mapas de extinção, $\chi^{2}$ e S/N de NGC 2207 . . . . . . . . . . . . . . . 268

15.11 Cinemática estelar de NGC $2207 \ldots \ldots \ldots$. . . . . . . . . . . . . . . .

$16.1 \quad$ NGC $1255 \ldots \ldots \ldots \ldots \ldots \ldots \ldots \ldots \ldots$ 
16.2 Imagem representativa do cubo do GMOS de NGC $1255 \ldots \ldots$. . . . 272

16.3 Imagem das principais linhas de emissão do núcleo de NGC 1255, juntamente com a imagem do HST . . . . . . . . . . . . . . . . . 273

16.4 Diagrama de diagnóstico de NGC $1255 \ldots \ldots$. . . . . . . . . . . 275

16.5 Cinemática do gás em NGC $1255 \ldots \ldots$. . . . . . . . . 275

17.1 Diagrama de diagnóstico das gêmeas morfológicas da Via Láctea . . . . . 278

17.2 Diagrama de diagnóstico das regiões emissoras circumnucleares das gêmeas morfológicas da Via Láctea . . . . . . . . . . . . . . . . . . . . . . . . 281

17.3 Resultados das sínteses espectrais aplicadas as gêmeas morfológicas da Via Láctea . . . . . . . . . . . . . . . . . . . . . . 282

17.4 Média das metalicidades versus média das idades das populações estelares das gêmeas morfológicas da Via Láctea . . . . . . . . . . . . . . . 283

17.5 Dispersão de velocidades estelar versus média das metalicidades das populações estelares das gêmeas morfológicas da Via Láctea . . . . . . . . . 286 


\section{Lista de Tabelas}

3.1 Tabela de idades da síntese espectral . . . . . . . . . . . . . . 47

5.1 Emission-line ratios of the regions of NGC $1566 \ldots \ldots$. . . . . . . .

5.2 Properties of the broad components of the emission lines of Region 1 . . 78

7.1 Projected distances of the regions detected in NGC $6744 \ldots \ldots$. . . . 112

7.2 FWHM, H $\alpha$ luminosities, electronic densities of the observed regions . . . 112

7.3 Emission Line Ratios for the Four Observed Regions . . . . . . . . . . . . 112

$9.1 \quad \mathrm{RA}$ and $\mathrm{DEC}$ of $\mathrm{N} 1$ and $\mathrm{N} 2 \ldots \ldots \ldots \ldots \ldots$

9.2 Emission-line rations of the 10 regions in NGC 613 nucleus . . . . . . . . 156

9.3 FWHM and luminosity of the $\mathrm{H} \alpha$ line determined for the 10 regions from NGC 613 nucleus . . . . . . . . . . . . . . . . . . . 159

9.4 Parameters of the circumnuclear ring . . . . . . . . . . . . 167

11.1 Tabela de propriedades de NGC $157 \ldots \ldots$. . . . . . . . . 213

11.2 Tabela das razões de linhas de NGC $157 \ldots \ldots$. . . . . . . . . . . . 216

12.1 Tabela de propriedades de NGC $2442 \ldots \ldots$. . . . . . . . . 225

12.2 Tabela das razões de linhas de NGC $2442 \ldots \ldots$. . . . . . . . . . . . 225

13.1 Tabela de propriedades de NGC $1300 \ldots \ldots$. . . . . . . . . 236

13.2 Tabela das razões de linhas de NGC 1300 . . . . . . . . . . . . . . . . 239

14.1 Tabela de propriedades de NGC $7314 \ldots \ldots$. . . . . . . . . 249

14.2 Tabela das razões de linhas de NGC 7314 . . . . . . . . . . . . . . . . . . 252 
15.1 Tabela de propriedades de NGC $2207 \ldots \ldots \ldots \ldots$

15.2 Tabela das razões de linhas de NGC $2207 \ldots \ldots$. . . . . . . . . . 262

16.1 Tabela de propriedades de NGC $1255 \ldots \ldots \ldots \ldots \ldots$. . . . . . 272

16.2 Tabela das razões de linhas de NGC $1255 \ldots \ldots$. . . . . . . . 274

17.1 Tabela das propriedades obtidas pela sínteses espectrais aplicadas às galáxias da amostra . . . . . . . . . . . . . . 285 


\section{Sumário}

1. Introdução . . . . . . . . . . . . . . . . . . . . . 27

2. A região nuclear da Via Láctea . . . . . . . . . . . . . . . . . . . . . . . . 31

2.1 O cenário geral . . . . . . . . . . . . . . . . . . . . 31

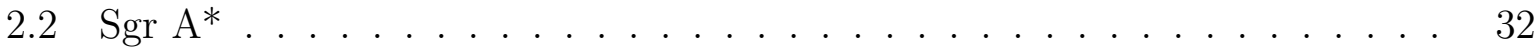

2.3 Morfologia e populações estelares do bojo . . . . . . . . . . . . . . . 33

2.4 Populações estelares do núcleo da Via Láctea . . . . . . . . . . . . . . . . . 34

2.4 .1 Cinemática estelar e do gás . . . . . . . . . . . . 36

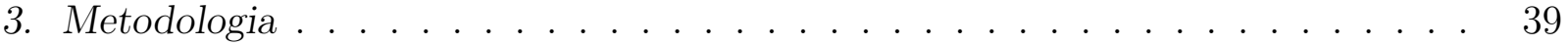

3.1 Observações . . . . . . . . . . . . . . . . . . . . . . . . 39

3.2 Descrição instrumental . . . . . . . . . . . . . . . . . . . . . . . . . 39

3.3 Redução . . . . . . . . . . . . . . . . . . . . . . . . . 40

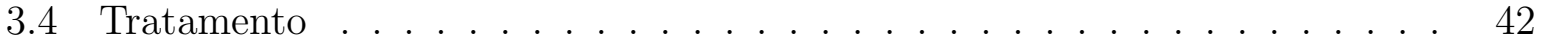

3.4.1 Correção da refração atmosférica diferencial . . . . . . . . . . 42

3.4.2 Combinação dos cubos de dados . . . . . . . . . . . . . . 42

3.4.3 Filtragem espacial de Butterworth . . . . . . . . . . . . 42

3.4.4 Remoção do fingerprint instrumental . . . . . . . . . . . . . . 43

3.4.5 Deconvolução Richardson-Lucy . . . . . . . . . . . . 44

3.5 Métodos de análise dos dados . . . . . . . . . . . . . . 45

3.5.1 Tomografia PCA ...................... 46

3.5.2 Síntese espectral . . . . . . . . . . . . . . 46

3.5.3 Obtenção do cubo de gás . . . . . . . . . . . . 47

3.5.4 Cálculo das incertezas das razões de linhas . . . . . . . . . . 48 
3.5.5 Cinemática estelar . . . . . . . . . . . . . . . . . 48

3.5.6 Cálculo da dispersão de velocidades . . . . . . . . . . . . . . . 49

3.6 Tratamento dos cubos de dados do telescópio espacial Chandra . . . . . . 49

4. Resumo do paper sobre NGC $1566 \ldots \ldots \ldots \ldots$. . . . . . . . . . 51

5. NGC 1566: analysis of the nuclear region from optical and NIR Integral Field Unit

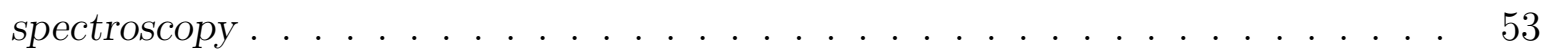

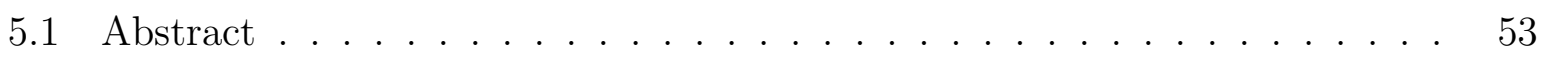

5.2 Introduction . . . . . . . . . . . . . . . . . 54

5.3 Observations, reduction and data treatment . . . . . . . . . . 59

5.3 .1 Optical data . . . . . . . . . . . . . . . . . . . 5 59

5.3 .2 Near-infrared data $\ldots \ldots \ldots \ldots$

5.4 PCA Tomography . . . . . . . . . . . . . . . . . . . 61

5.4 .1 Eigenvectors and tomograms . . . . . . . . . . . . . 63 63

5.4 .2 Featureless continuum . . . . . . . . . . . . 65

5.5 Analysis of $H S T$ images $\ldots \ldots \ldots \ldots \ldots \ldots$

5.6 AGN and the H II region . . . . . . . . . . . . . . . . . 72

5.6.1 Analysis of optical spectra . . . . . . . . . . . . . 72

5.6 .2 Analysis of NIR spectra $\ldots \ldots \ldots \ldots \ldots$

5.6 .3 Gravitational redshift . . . . . . . . . . . . . . . 76

5.7 Gas kinematics . . . . . . . . . . . . . . . . . . . . . . 79

5.7.1 Highly ionized gas in the optical . . . . . . . . . 79

$5.7 .2 \quad$ H II Region . . . . . . . . . . . . . . . . . . . 8 83

$5.7 .3 \quad$ NIR molecular gas $\ldots \ldots \ldots \ldots$

5.8 Stellar kinematics . . . . . . . . . . . . . . . . . . . . . 85

5.9 Discussion . . . . . . . . . . . . . . . . . . . . . . . . . 87

5.10 Conclusions . . . . . . . . . . . . . . . . . . . . 99

5.11 Spectral synthesis . . . . . . . . . . . . . . . . . . 95

5.11.1 Spectral synthesis of the nuclear and circumnuclear regions . . . . 101

6. Resumo do paper sobre NGC $6744 \ldots \ldots$. . . . . . . . . . . . 103 
7. NGC 6744 - A nearby Milky Way twin with a very low-luminosity AGN . . . . 105

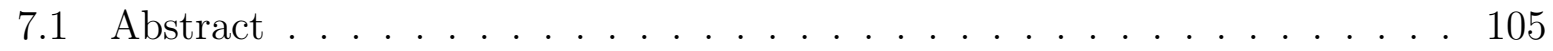

7.2 Introduction . . . . . . . . . . . . . . . . . 106

7.3 Observations and data reduction . . . . . . . . . . . . . 107

7.4 Nuclear and circumnuclear emission line properties . . . . . . . . . . . 109

7.4.1 Spectral synthesis and subtraction of stellar continuum . . . . . . 109

7.4 .2 The line emitting regions . . . . . . . . . . . . . 109

7.4 .3 Diagnostic diagrams . . . . . . . . . . . . . . . . 114

7.5 Gas Kinematics . . . . . . . . . . . . . . . . . . . . . . 114

7.6 Stellar archeology . . . . . . . . . . . . . . . . . 118

7.7 Stellar Kinematics . . . . . . . . . . . . . . . . . . 122

$7.8 H S T$ images: the smoking gun . . . . . . . . . . . . . . . . . . . . 122

7.9 Discussion . . . . . . . . . . . . . . . . . . . . . . 124

7.9.1 Photoionization or Shocks? . . . . . . . . . . . . 125

7.9 .2 One or Two AGNs? . . . . . . . . . . . . . . . . . . . 126

7.9.3 A Very Low-luminosity AGN, Fossil of a More Luminous Phase . . 126

7.9 .4 Evidence of a Merger . . . . . . . . . . . . . . 127

7.9 .5 Gas Kinematics . . . . . . . . . . . . . . . . . . 128

7.9.6 Stellar Kinematics . . . . . . . . . . . . . . . . . . 129

7.10 Conclusions . . . . . . . . . . . . . . . . . . . 129

7.11 Acknowledgments . . . . . . . . . . . . . . . 131

8. Resumo dos artigos sobre NGC $613 \ldots \ldots$. . . . . . . . . . . . . . . . . . . . .

9. The nuclear region of NGC 613. I - Multiwavelength analysis . . . . . . . . . . 137

9.1 Abstract . . . . . . . . . . . . . . . . . 137

9.2 Introduction . . . . . . . . . . . . . . . . . . . . . . . . . . . . . .

9.3 Observations and data reduction . . . . . . . . . . . . . . . 142

9.3.1 Hubble Space Telescope images . . . . . . . . . . . . . . . . . 142

9.3 .2 Optical data cubes . . . . . . . . . . . . . . 143

9.3.2.1 GMOS data . . . . . . . . . . . . . . 143

$9.3 .2 .2 \quad$ SIFS data . . . . . . . . . . . . . . . . . 144

9.3.3 SINFONI data . . . . . . . . . . . . . . . . . . . . . 145 
9.3.4 Optical and NIR data cubes treatment . . . . . . . . . 146

9.3.5 Optical and NIR gas data cubes . . . . . . . . . . . 147

9.3 .6 Chandra data . . . . . . . . . . . . . . . 148

9.3.7 ALMA data . . . . . . . . . . . . . . . . . . . 148

9.4 Emitting regions . . . . . . . . . . . . . . . . . . . . . . 149

9.4.1 Nuclear emission - matching the images of distinct instruments . . 149

9.4 .2 Nuclear variability . . . . . . . . . . . . . . . 152

9.4.3 Optical emission-line ratios . . . . . . . . . . . 155

9.4.4 H II regions . . . . . . . . . . . . . . . . . . 156

9.4.5 Absence of featureless continuum emission in the $K$ band . . . . . . 160

9.5 The X-ray emission . . . . . . . . . . . . . . . . . . 161

9.6 Discussion . . . . . . . . . . . . . . . . . . . . . . . . 163

9.6.1 The double stellar nucleus and the AGN . . . . . . . . . . . 164

9.6.2 Circumnuclear ring and nuclear spiral . . . . . . . . . . . 167

9.6.3 The global scenario for the central region . . . . . . . . . . . . . 170

9.7 Conclusions . . . . . . . . . . . . . . . . . . . . . . . . . . . 170

9.8 Spectra of the observed regions and emission-line decompositions . . . . . 172

10. The nuclear region of NGC 613. II - Kinematics and stellar archaeology . . . . 179

10.1 Abstract . . . . . . . . . . . . . . . . . . . . 179

10.2 Introduction . . . . . . . . . . . . . . . . . . 180

10.3 Observations and data reduction . . . . . . . . . . . . . 182

10.3.1 Spectral synthesis methods . . . . . . . . . . . . . 183

10.4 Gas kinematics . . . . . . . . . . . . . . . . . . . 184

10.4.1 General scenario . . . . . . . . . . . . . . . 184

10.4.2 Inner central optical gas kinematics (GMOS) . . . . . . . . . 185

10.4.3 Near-infrared and molecular gas kinematics (SINFONI and ALMA) 187

10.4.4 Circumnuclear optical gas kinematics (SIFS) . . . . . . . . . 188

10.5 Stellar archaeology . . . . . . . . . . . . . . . . . . 190

10.5.1 Results from the GMOS data cube . . . . . . . . . . . . 191

10.5.2 Results from the SIFS data cube . . . . . . . . . . . . 193

10.6 Stellar kinematics . . . . . . . . . . . . . . . . . . . 193 
10.6.1 Inner central stellar kinematics obtained from the GMOS data cube 196

10.6.2 Circumnuclear stellar kinematics obtained from the SIFS data cube 196

10.6.3 Near-infrared stellar velocity dispersion obtained from SINFONI data

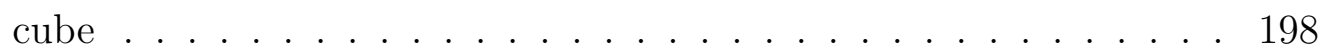

10.7 Discussion . . . . . . . . . . . . . . . . . . . 199

10.7.1 Stellar archaeology . . . . . . . . . . . . . . 199

10.7.1.1 The intermediate age inner circumnuclear ring . . . . . . 200

10.7.2 Gas kinematics . . . . . . . . . . . . . . 202

10.7.3 Stellar kinematics . . . . . . . . . . . . . . . . . . 203

10.8 Conclusions . . . . . . . . . . . . . . . . . . . 205

10.9 Spectral Synthesis on SIFS data cube . . . . . . . . . . . . 207

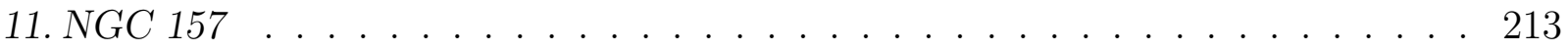

11.1 Emissão do gás . . . . . . . . . . . . . . . . . . . . . . . . 215

11.2 Cinemática do gás . . . . . . . . . . . . . . . . 217

11.3 Arqueologia estelar . . . . . . . . . . . . . . . . . . . 218

11.4 Cinemática estelar . . . . . . . . . . . . . . . . . . . 220

11.5 Conclusões . . . . . . . . . . . . . . . . . . . . . . . 221

12. NGC $2442 \ldots \ldots \ldots \ldots \ldots \ldots \ldots \ldots \ldots$

12.1 Emissão do gás . . . . . . . . . . . . . . . . . . . . 225

12.1.1 Imagens do Hubble Space Telescope . . . . . . . . . . . . . . . . . 227

12.1.2 Emissão em raios-X . . . . . . . . . . . . . . . . . . . . . . 229

12.2 Cinemática do gás . . . . . . . . . . . . . . . . . 230

12.3 Arqueologia estelar . . . . . . . . . . . . . . . . . . 231

12.4 Cinemática estelar . . . . . . . . . . . . . . . . . . . . . . . . . . 232

12.5 Conclusões . . . . . . . . . . . . . . . . . . . . . . . . 232

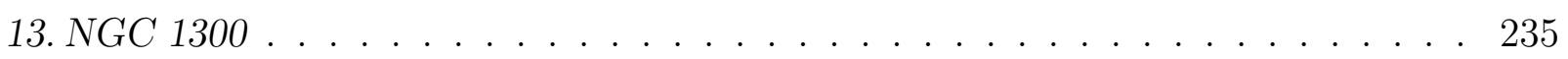

13.1 Emissão do gás . . . . . . . . . . . . . . . . . . . . . 237

13.1.1 Emissão em raios-X . . . . . . . . . . . . . . . . . . 238

13.2 Cinemática do gás . . . . . . . . . . . . . . . . . . . . 240

13.3 Arqueologia Estelar . . . . . . . . . . . . . . . . . . . 241 
13.4 Cinemática estelar . . . . . . . . . . . . . . . . . . . . . . . . 2 243

13.5 Conclusões . . . . . . . . . . . . . . . . . . . . . . . 245

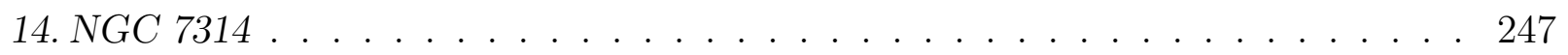

14.1 Arqueologia e cinemática estelar . . . . . . . . . . . . . 250

14.2 Emissão do gás . . . . . . . . . . . . . . . . . . . . . . . 250

14.2 .1 Emissão em raios-X . . . . . . . . . . . . . . . . . . 252

14.2.2 Imagens do HST e do ALMA . . . . . . . . . . . . . 253

14.3 Cinemática do gás . . . . . . . . . . . . . . . . . . . 2 256

14.3.1 Cinemática do gás molecular . . . . . . . . . . . . . 256

14.4 Conclusões . . . . . . . . . . . . . . . . . . . . . . . . . . . . 257

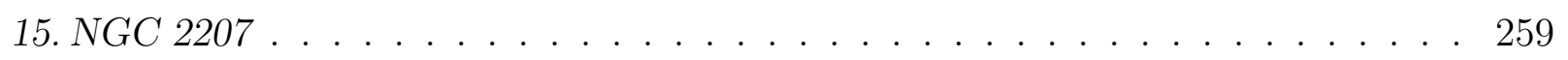

15.1 Emissão do gás … . . . . . . . . . . . . . . . . . . . 261

15.2 Cinemática do gás . . . . . . . . . . . . . . . . 265

15.3 Arqueologia Estelar . . . . . . . . . . . . . . . . . . . . 267

15.4 Cinemática estelar . . . . . . . . . . . . . . . . 268

15.5 Conclusões . . . . . . . . . . . . . . . . . . . . . . . . . . . . . 2 269

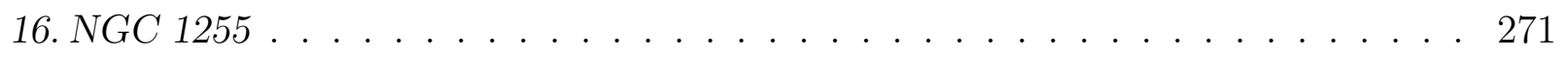

16.1 Arqueologia e cinemática estelar . . . . . . . . . . . . . . . . 272

16.2 Emissão do gás . . . . . . . . . . . . . . . . . . . . . . . 2 273

16.3 Cinemática do gás . . . . . . . . . . . . . . . . . 274

16.4 Conclusões . . . . . . . . . . . . . . . . . . . . . . . . 276

17. Discussão estatística das gêmeas morfológicas da Via Láctea . . . . . . . . . . 277

17.1 Linhas de emissão nucleares . . . . . . . . . . . . . . . . . . 277

17.2 Regiões emissoras circumnucleares . . . . . . . . . . . . . . . 280

17.3 Cinemática do gás . . . . . . . . . . . . . . . . . . . 2 282

17.4 Arqueologia estelar . . . . . . . . . . . . . . . . . 282

17.5 Cinemática estelar . . . . . . . . . . . . . . . . 2284

18. Conclusões e Perspectivas . . . . . . . . . . . . . . . . . . . . 289

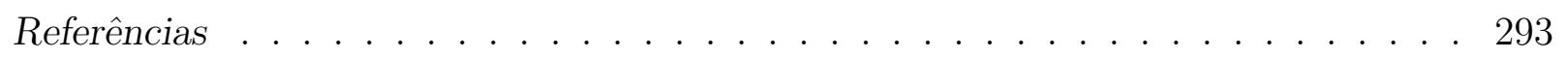


A. Resumo dos artigos publicados em co-autoria . . . . . . . . . . . . . . . 321 

Capítulo 1

\section{Introdução}

O estudo da região nuclear das galáxias é de fundamental importância, já que essa região pode fornecer informações de grande relevância sobre a origem e evolução desses objetos. Acredita-se que buracos negros supermassivos (SMBHs) estejam presentes na maior parte dos núcleos das galáxias massivas (Kormendy e Richstone, 1995, Richstone et al., 1998) e as massas desses SMBHs apresentam correlações com certos parâmetros da galáxia hospedeira, como, por exemplo, a dispersão de velocidades estelar do bojo da galáxia (relação M- $\sigma$; Ferrarese e Merritt 2000; Gebhardt et al. 2000; Gültekin et al.|2009; Kormendy e Ho 2013). Correlações como essas revelam aparentes conexões dos SMBHs com o restante das galáxias hospedeiras, o que mostra a importância da região nuclear para a formação e evolução de galáxias.

No contexto do estudo de núcleos de galáxias, o núcleo da Via Láctea merece atenção especial. É o núcleo mais próximo, o que resulta numa grande resolução espacial, que não é acessada em objetos a longas distâncias. Por outro lado, há o problema da grande extinção interestelar na linha de visada, o que faz com que observações relevantes deste núcleo só sejam possíveis em comprimentos de onda mais elevados (infravermelho, micro-ondas e rádio) ou extremamente baixos (raios-X e raios- $\gamma$ ).

Outra questão fundamental para entender a evolução dos núcleos das galáxias é que não há como determinar esta evolução numa escala de tempo praticável. Mudanças significativas podem levar milhões de anos.

Para estabelecer a evolução de núcleos de galáxias e entender os mecanismos do núcleo da Via Láctea são necessárias observações extragalácticas estabelecendo um parâmetro de semelhança entre a Via Láctea e as demais galáxias para, então, fazer uma comparação dos fenômenos observados. Neste caso, escolher galáxias com o mesmo tipo morfológico da Via 
Láctea é uma estratégia muito lógica, já que o tipo morfológico de uma galáxia representa como a mesma foi formada e acredita-se que galáxias do mesmo tipo morfológico passaram por processos de evolução, pelo menos, similares. A pergunta que surge então é: será que seus núcleos também acompanham os mesmos processos evolutivos?

O presente projeto consiste no estudo de 10 galáxias do mesmo tipo morfológico da Via Láctea obtidas do survey Deep IFS View of Nuclei of Galaxies (DIVING ${ }^{3 D}$ ). Este survey tem como objetivo estudar todas as galáxias do hemisfério Sul, cujas magnitudes na banda B são menores do que 12. No total, o survey dispõe de 170 núcleos de galáxias de diversos tipos morfológicos. As gêmeas morfológicas da Via Láctea fazem parte de uma sub-amostra do survey que corresponde a um total de 15 galáxias. A amostra de 10 galáxias aqui analisada é completa, pois não possui bias, estando os objetos a diferentes distâncias e correspondendo às 10 galáxias mais brilhantes dessa sub-amostra.

O estudo do survey é focado em cubos de dados com alta resolução espacial ( full width half-maximum - FWHM médio da point spread function -PSF $\sim 0$ 0"63) obtidos com o Integral Field Unit (IFU) do Gemini Multi-Object Spectrograph (GMOS) dos telescópios Gemini-Sul e Gemini-Norte. O estudo de um survey com cubos de dados com esta resolução é inédito e haverá um grande impacto no estudo do núcleos de galáxias, quando o survey estiver concluído, provando que a resolução espacial juntamente com dados espectrais de alto sinal-ruído são fundamentais para o avanço do entendimento destes objetos.

Os objetivos principais deste projeto são:

- Estudo das propriedades das linhas em emissão nuclear. Determinar a atividade do núcleo a partir do estudo de razões de linhas da fonte central e classificar entre Seyfert, Low-Ionization Nuclear Emission Region (LINER), starburst, objeto de transição ou núcleo sem linhas em emissão.

- Estudo das propriedades das linhas de emissão de regiões circumnucleares. Identificar possíveis regiões circumnucleares, com o uso da grande resolução espacial dos dados e determinar a natureza da emissão dessas regiões, a fim de estabelecer os ambientes nucleares das galáxias estudadas.

- Estudo das propriedades cinemáticas do gás. A partir de imagens de emissão do perfil das linhas é possível identificar diferentes componentes cinemáticas do gás. Além disso, com uso de mapas de velocidades de linhas de emissão e channel maps, determina-se o comportamento dessas regiões emissoras, se há relações entre o núcleo e a galáxia ou entre 
as regiões circumnucleares e o objeto central.

- Estudo das propriedades da arqueologia estelar. A partir da síntese espectral do contínuo estelar do cubo de dados é possível obter uma vasta informação da emissão estelar nas regiões observadas e inferir características evolutivas na amostra.

- Estudo das propriedades cinemáticas da componente estelar. Com auxílio da síntese espectral é possível também obter informações sobre a cinemática das estrelas na região central das galáxias, o que possivelmente também permitirá inferir os cenários mais prováveis de formação e evolução desses objetos.

- Comparar os resultados com o que se sabe da Via Láctea na literatura. Determinar as diferenças/semelhanças entre as galáxias do survey, incluindo a Via Láctea. Se possível, estabelecer cenários evolutivos ou relações entre elas e os parâmetros observados.

As conclusões deste projeto são ainda preliminares, pois, para se ter resultados mais concretos, é necessário uma amostra maior. Porém, a tendência observada nos resultados é algo a se levar em consideração, tanto para comparação futura com dados mais numerosos (para ver se há confirmação ou não) quanto para uma prévia do que haverá de ocorrer para os demais dados a serem observados. 
Capítulo 2

\section{A região nuclear da Via Láctea}

O núcleo da Via Láctea é uma região especial para ser estudada. Por ser o núcleo mais próximo, possui uma grande resolução espacial, permitindo diferenciar e analisar com detalhes todos seus elementos. Nos parsecs centrais ao redor do núcleo há uma grande variedade de estruturas, como um denso aglomerado estelar e várias componentes de gás neutro e ionizado (e.g. Becklin e Neugebauer 1968; Genzel et al. 1994; Mezger et al.1996). O estudo desse cenário é de grande relevância, já que pode fornecer informações importantes sobre a formação e a evolução da nossa galáxia e também de outras galáxias similares. Apesar das observações da região central da Via Láctea serem facilitadas por conta da menor distância (em comparação com outras galáxias), a grande extinção interestelar (decorrente da grande quantidade de gás e poeira) em direção ao núcleo de nossa galáxia (que pode chegar a 30 magnitudes no visível - Genzel et al. 2010) faz com que observações em comprimentos de onda mais elevados (infravermelho, micro-ondas e rádio) ou extremamente baixos (raios-X e raios- $\gamma$ ) sejam as mais úteis para o avanço no conhecimento dessa região.

\subsection{O cenário geral}

Na região central da Via Láctea há um luminoso aglomerado estelar (Launhardt et al. 2002). No núcleo há uma fonte em rádio bastante compacta, chamada SgrA* (e.g. YusefZadeh et al. 1986). O parsec central é composto, sobretudo, por gás ionizado. Lá está presente a região H II SgrA Oeste e também uma grande quantidade de gás emissor em raios-X, com uma temperatura de $10^{6} \mathrm{~K}$ (Baganoff et al., 2001; Muno et al., 2004). Toda essa área é conhecida como central cavity.

Logo ao redor da central cavity, filamentos de gás ionizado orbitantes compõem o que é 
conhecido como mini-spiral (Lo e Claussen, 1983). Mais externamente (a uma distância de 1.5 - 4 pc do núcleo), streamers de gás molecular denso formam o chamado circumnuclear disk (CND - e.g.Becklin et al. 1982; Christopher et al. 2005). A distâncias maiores do núcleo, entre 5 - 100 pc, existe um remanescente de supernova (a chamada SgrA East) e várias nuvens de gás molecular (Güsten e Downes, 1980; Mezger et al., 1996).

\section{$2.2 \operatorname{Sgr} A^{*}$}

Sgr A* foi primeiramente detectado por Ekers e Lynden-Bell (1971). Utilizando dados em rádio $(5 \mathrm{GHz})$, eles observaram uma fonte compacta localizada no centro do aglomerado estelar no núcleo. Alguns anos depois, Balick e Brown (1974) observaram que essa fonte tem uma dimensão aparente inferior a 0".1 e recentes observações mostraram que seu tamanho intrínseco é de 3 a 10 minutos-luz (Genzel et al., 2010). A determinação de órbitas de estrelas individuais ao redor de $\operatorname{Sgr} A^{*}$ revelou não apenas a presença de um SMBH central ali, mas também permitiu que fosse obtida uma estimativa muito precisa da massa desse SMBH. Em particular, a determinação da primeira órbita da estrela S2 teve grande importância nesse contexto. As primeiras análises orbitais resultaram em massas de $4.1 \times 10^{6} M_{\odot}($ Schödel et al., 2002$)$ e $4.6 \times 10^{6} M_{\odot}$ (Ghez et al. 2003) para o SMBH. Com dados mais precisos, Ghez et al. (2008) obtiveram uma massa de $4.5 \pm 0.4 \times 10^{6} M_{\odot}$ e Gillessen et al. (2009) determinaram uma massa de $4.3 \pm 0.2 \pm 0.3 \times 10^{6} M_{\odot}$. Estudos multi-orbitais mais recentes envolvendo as estrelas ao redor do SMBH permitiram refinar ainda mais essas determinações de massa. Boehle et al. (2016) obtiveram um valor de 4.02 $\pm 0.16 \pm 0.04 \times 10^{6} M_{\odot}$ e Gillessen et al. (2017) determinaram um valor de $4.28 \pm 0.10 \pm$ $0.21 \times 10^{6} M_{\odot}$. A medida mais precisa até o momento é do estudo da órbita da estrela S2, monitorada por 27 anos, feito pelo Gravity Collaboration et al. (2019), que obteve 4.148 $\pm 0.014 \times 10^{6} M_{\odot}$.

SgrA* possui baixa luminosidade em todas bandas espectrais, exceto em rádio Falcke et al. 1998). É uma fonte variável no infravermelho próximo (NIR) e apresenta ocasionalmente flares com alta luminosidade em raios-X (The GRAVITY Collaboration et al. 2020). A luminosidade de SgrA* é provavelmente devida sobretudo à acreção no SMBH a partir de ventos estelares na sua vizinhança. Maiores taxas de acreção podem ocorrer de tempos em tempos, quando nuvens de gás caem em direção ao núcleo. Porém, o núcleo da 
Via Láctea não é considerado ativo. Utilizando dados de espectros no ultravioleta, foram descobertas evidências de um outflow que se estende até $6.3 \mathrm{kpc}$ de distância do centro da Via Láctea e que tem uma idade entre 6 a 9 milhões de anos (Bordoloi et al. 2017). Isso indica que Sgr $\mathrm{A}^{*}$ já esteve ativo no passado.

O espectro de emissão observado da região central da Via Láctea pode ser bem explicado como sendo devido à radiação combinada de estrelas quentes e massivas ali presente Genzel et al., 2010). Dessa forma, o núcleo da Via Láctea provavelmente seria classificado como um starburst por um observador extragaláctico (Shields e Ferland, 1994).

A Fig. 2 de Murchikova et al. (2019) mostra um esquema das várias estruturas dos parsecs centrais. Esses autores encontraram um disco de acreção frio $\left(10^{4} \mathrm{~K}\right)$ ao redor de SgrA* dentro de um raio de 0".23, detectado com o ALMA (Atacama Large Millimeter/submillimeter Array) na frequência de He30 $\alpha$.

\subsection{Morfologia e populações estelares do bojo}

Nas centenas de parsecs centrais do bojo da Via Láctea, além do aglomerado estelar nuclear, também é encontrado um disco estelar nuclear com raio de $\sim 230$ pc (Launhardt et al., 2002).

Simulações em 3D sugerem que o Bojo da Via Láctea seja um pseudo-bojo com morfologia box-peanut e rotação cilíndrica (Shen et al., 2010; Wegg e Gerhard, 2013). Por outro lado, alguns estudos sugerem uma composição de bojo clássico e pseudo-bojo, mas maiores investigações são necessárias para averiguar a existência da componente clássica (ver Barbuy et al. 2018).

A massa total do bojo é $2.0 \pm 0.3 \times 10^{10} \mathrm{M}_{\odot}$ (Valenti et al., 2016). Clarkson et al. (2008) observaram que o bojo da Via Láctea é dominado por estrelas velhas (11 \pm 3 bilhões de anos) com metalicidade média de $[\mathrm{Fe} / \mathrm{H}]=0.0 \pm 0.4$ (solar) e a fração numérica de estrelas jovens é de 3.5\%, porém esta fração de estrelas jovens pode ser maior (Barbuy et al. 2018). O intervalo de metalicidades dominante no bojo da Via Láctea varia entre $-1.5 \lesssim[\mathrm{Fe} / \mathrm{H}] \lesssim+0.5$ (Barbuy et al. 2018$)$. Existe um gradiente de metalicidade que cresce para o centro, onde as estrelas possuem, em sua maioria, metalicidade solar. As estrelas com maior metalicidade fazem parte de uma estrutura box/peanut, enquanto que as estrelas metal-poor podem fazer parte do disco espesso ou do halo, ou até mesmo de um 'esferoide 
velho' ou uma componente clássica do bojo (Ness e Freeman, 2016). A existência da barra e o fato do bojo não ser clássico são evidências de que a Via Láctea não passou por nenhum merger significativo (ao ponto de formar um bojo clássico) depois do disco ter sido formado (Kunder et al., 2012). A formação do bojo ocorreu em vários episódios de formação estelar há 11, 6, 8 e 3 bilhões de anos atrás. Os eventos mais recentes podem estar associados à barra (Bensby et al., 2017).

A Via Láctea, então, apresenta muitas evidências (cinemáticas e morfológicas) da presença de um pseudo-bojo, embora a formação deste bojo pareça ser mais complexa do que apenas a de um pseudo-bojo. Embora estejam localizados na região central das galáxias, as características dos pseudo-bojos os tornam mais similares a discos do que a bojos clássicos. Primeiramente, eles possuem um aspecto mais achatado (Fathi e Peletier, 2003; Kormendy, 1993), e perfis de brilho aproximadamente exponenciais (Andredakis e Sanders, 1994), com índices de Sérsic entre 1 e 2. Ainda do ponto de vista morfológico, os pseudo-bojos tendem a apresentar uma barra nuclear (Erwin e Sparke, 2002). Em galáxias edge-on, tais estruturas geralmente resultam em bojos com morfologias boxy-peanut, que também revelam estruturas com forma de "X". Cinematicamente, os pseudo-bojos são mais dominados pela rotação Kormendy, 1993), o que é detectado por maiores valores da razão $V_{\max } / \sigma$. Além disso, os pseudo-bojos também costumam apresentar populações estelares mais jovens, geralmente associadas a starbursts. Para uma revisão detalhada das propriedades dos pseudo-bojos, ver Kormendy e Kennicutt (2004). Os bojos clássicos, por outro lado, possuem um formato mais esférico (similar a galáxias elípticas de baixa luminosidade), índices de Sérsic próximos a 4 (novamente, da mesma forma que galáxias elípticas), pouca ou nenhuma formação estelar e órbitas estelares mais caóticas, o que resulta em menores valores da razão $V_{\max } / \sigma$. Acredita-se que os pseudo-bojos sejam formados por processos de evolução secular na galáxia (ao contrário de bojos clássicos, que provavelmente resultam de mergers).

\subsection{Populações estelares do núcleo da Via Láctea}

A obtenção de imagens com alta resolução espacial e também o uso de instrumentos como IFUs, sobretudo com óptica adaptativa, permitiram estudos bastante detalhados das populações estelares nas regiões centrais da Via Láctea. A maior parte das estrelas detec- 


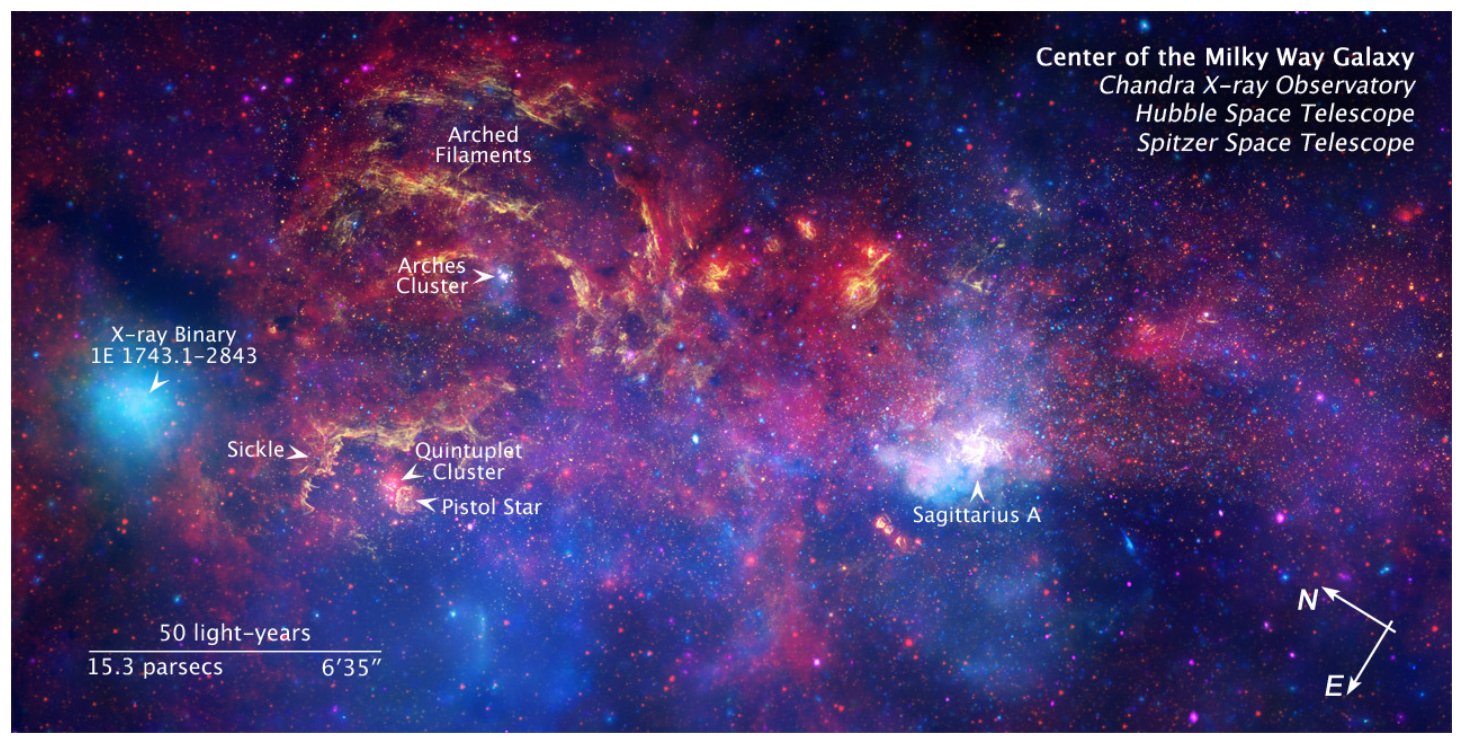

Figura 2.1: Composição das imagens do núcleo da Via Láctea tomadas pelos telescópios espaciais Chandra (em azul), Hubble Space Telescope (amarelo) e Spitzer (vermelho). Na imagem estão indicados os principais aglomerados do núcleo da galáxia e a posição de $\operatorname{Sgr} A^{* 1}$.

tadas são velhas, como gigantes vermelhas, supergigantes, estrelas no Ramo Assimptótico das Gigantes (Asymptotic Giant Branch - AGB), o que é esperado para um aglomerado nuclear em uma galáxia. 96\% das estrelas observadas nos parsecs centrais possuem idades superiores a 1 bilhão de anos e massas entre 0.5 e $4 \mathrm{M}_{\odot}$ (Genzel et al., 2010).

Entre 26 e 32 pc de distância projetada de Sgr A* (Stolte et al., 2014) estão localizados 2 aglomerados jovens: Arches e Quintuplet (ver Fig. 2.1 1. O aglomerado Arches contém 160 estrelas tipo $\mathrm{O}$, possui raio de $\sim 0.2$ pc e idade de $2 \pm 1$ Myr e contém $5 \%$ de todas estrelas Wolf-Rayet (WR) conhecidas da galáxia (Figer et al., 2002). Já o aglomerado Quintuplet possui idade $\sim 4 \pm 1$ milhões de anos e $\sim 1$ pc de raio, contendo estrelas WR e estrelas tipo OB (Figer et al. 1999a e Figer et al. 1999b). A partir de uma simulação de $N$-body, foi previsto que existam 50 aglomerados parecido com estes dentro dos 200 pc centrais (Portegies Zwart et al., 2001).

Uma fração de $80 \%$ das estrelas na região central da Via Láctea se formaram em aproximadamente em 5 bilhões de anos atrás. Em $\sim 1-2$ bilhões de anos atrás houve uma diminuição na taxa de formação estelar, que aumentou novamente nas últimas centenas de

\footnotetext{
${ }^{1}$ Spitzer Data: The Spitzer Space Telescope data were courtesy of NASA, Jet Propulsion Laboratory, and S. Stolovy (Spitzer Science Center/California Institute of Technology). Hubble Data: proposal 11120: Q.D. Wang et al., Chandra Data: The science team was led by Q.D. Wang. Image courtesy of NASA/CXC/UMass/Q.D. Wang et al.
} 
milhões de anos (Pfuhl et al., 2011). O evento mais recente de formação estelar é estimado entre 2.5 e 8.5 milhões de anos (Lu et al., 2013).

Apesar dessa região central da Via Láctea ter grande abundância de estrelas velhas, também foram detectadas estrelas early-type, como supergigantes azuis e WR, com idades entre 2 e 8 milhões de anos (Genzel, 2006, Paumard et al., 2001, Tanner et al., 2006). Segundo Rate et al. (2020) a região nuclear da Via Láctea (raio $\sim 140$ pc) contém 110 estrelas WR, sendo 68 delas pertencentes a aglomerados (Quintuplets, Arches e o aglomerado nuclear) e 42 isoladas. Atualmente há dois modelos plausíveis para explicar a presença dessas estrelas jovens nessa região central. O primeiro assume que o gás denso caiu em direção ao núcleo cerca de 6 milhões de anos atrás e formou um disco ao redor do SMBH. Instabilidades gravitacionais subsequentes nesse disco resultaram em um intenso episódio de formação estelar (Morris, 1993; Genzel et al., 1996; Levin e Beloborodov, 2003). O segundo modelo assume que um aglomerado estelar denso e massivo se formou fora dos parsecs centrais, espiralou e caiu na região central por fricção dinâmica. Lá ele se dispersou, o que resultou nas estrelas jovens observadas (Gerhard, 2001).

\subsubsection{Cinemática estelar e do gás}

Diversas observações mostraram que estrelas massivas jovens nos parsecs centrais estão em blueshift ao norte e em redshift ao sul de SgrA*, sugerindo uma rotação estelar no sentido oposto ao do disco da Via Láctea e ao das estrelas velhas do aglomerado nuclear (Genzel et al., 2000; Tanner et al., 2006). Estudos mais recentes, e com maior resolução espacial, mostraram que a maior parte das estrelas early-type apresentam rotação no sentido horário. No entanto, algumas também foram observadas em rotação no sentido antihorário. Genzel et al. (2003); Tanner et al. (2006); Paumard et al. (2006) propuseram a existência de dois discos ou anéis estelares em rotação, que não coincidem com nenhuma outra orientação na região central da Via Láctea. Não existe diferença de idade significativa entre os dois discos/anéis (Bartko et al. 2009). O sistema em rotação no sentido horário é muito melhor definido e há controvérsias quanto à existência do sistema em rotação no sentido anti-horário. É possível que esse modelo envolvendo dois discos (ou anéis) seja uma aproximação demasiadamente simplificada.

A partir de observações da cinemática de estrelas individuais, levando em conta a luminosidade, foi estimado que a dispersão de velocidades estelar no núcleo da Via Láctea 
é de $105 \pm 20 \mathrm{~km} / \mathrm{s}$ (Ghez et al., 2008; Gillessen et al., 2009). Enquanto que, em maiores escalas, a dispersão de velocidades do bojo da Via Láctea, levando em conta as estrelas com alta metalicidade (que representam a maioria), chega a um pico de $145 \mathrm{~km} / \mathrm{s}$ (Zoccali et al., 2017). Ness et al. (2016); Zoccali et al. (2017), a partir de mapas de dispersão de velocidades estelares do bojo, detectaram que os valores decaem para fora do núcleo.

A morfologia e a cinemática da mini-spiral são bem descritas por um sistema de filamentos orbitando SgrA* (e.g. Paumard et al. 2004; Zhao et al. 2009). Alguns desses filamentos podem apresentar órbitas circulares.

A cinemática do CND é consistente com a de um disco em rotação ou um grupo de filamentos, com inclinação em relação à linha de visada de $60^{\circ}-70^{\circ}$ (Genzel et al., 2010). 
Capítulo 3

\section{Metodologia}

\subsection{Observações}

As observações dos objetos da amostra foram feitas no período de 2013 a 2015, com o IFU do GMOS dos telescópios Gemini-Sul e Norte (no caso de NGC 7314), no modo one-slit. Para cada objeto, foram feitas 3 exposições de 15 minutos, com dithering espacial (com passos de 0".2). A rede utilizada foi R831+G5322, no comprimento de onda central de $5850 \AA$. A cobertura espectral dos cubos resultantes é $4800 \AA$ a $6890 \AA$, com resolução espectral de $1.3 \AA$.

\subsection{Descrição instrumental}

Os telescópios Gemini Norte e Sul, localizados no Havaí (Maunakea) e Chile (Cerro Pachón) possuem diâmetro de 8.1 metros e foco Cassegrain. O GMOS é um espectrógrafo destes telescópios, cujo detector é constituído de três charge-couple devices (CCDs) de $2048 \times 4176$ pixels. O IFU do GMOS possui dois modos de funcionamento: one-slit e double-slit. O modo double-slit possui campo de observação maior e é amostrado por um número maior de lenslets do que o one-slit. Neste último modo, o campo de visão de ciência possui $5 " \times 3.5$ ", sendo amostrado por 500 lenslets, e o do céu (localizado a 1' do campo de ciência) é de $5 " \times 1 " .75$, sendo amostrado por 250 lenslets.

A luz do objeto observado primeiramente incide sobre o espelho primário (côncavo hiperbólico) do Gemini e depois é refletida para o espelho secundário (convexo hiperbólico). Em seguida, a luz é direcionada para o foco Cassegrain do telescópio, onde se encontra o IFU do GMOS. Após isso, a luz incidente no campo de visão do IFU é amostrada pelas lenslets (mencionadas acima). Cada uma delas conduz a luz para uma fibra correspondente, 
que, por sua vez, direciona a luz para grupos de fendas. Então, a luz sofre dispersão na rede de difração (neste caso, R831+G5322) e, por fim, atinge o detector.

O resultado da observação são espectros bidimensionais dispostos horizontalmente ao longo dos 3 CCDs (ver Fig. 3.1)

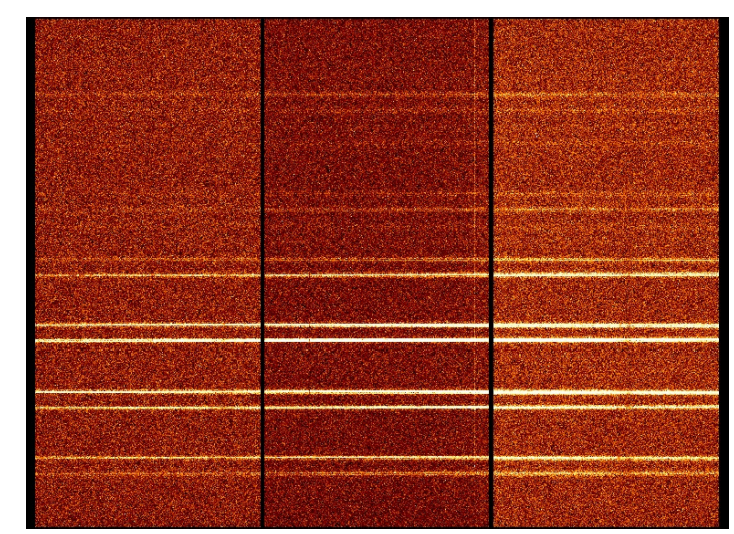

Figura 3.1: Exemplo de dados brutos da estrela HD26154 obtidos com o IFU do GMOS, no modo one-slit, do telescópio Gemini-Sul (imagem retirada de Menezes 2012).

\subsection{Redução}

A redução foi realizada em ambiente IRAF, usando o pacote de tarefas do Gemini e consistiu em:

- Determinação do trim: consiste em localizar e remover regiões das bordas dos arquivos brutos onde não há informação aproveitável (como se pode ver na Fig. 3.1, que possui bordas pretas).

- Subtração do bias: essencialmente todos os detectores apresentam um número não nulo de contagens em exposições de 0 segundos; essas contagem são chamadas de bias. A fim de remover essa assinatura eletrônica do instrumento, faz-se a subtração de exposições de 0 segundos da exposição de ciência.

- Correção de bad pixels: remoção de pixels defeituosos presentes na imagem bruta. Esse procedimento é feito utilizando-se um mapa de bad pixels, construído a partir de arquivos de calibração apropriados. Com esse mapa, os pixels defeituosos são substituídos por uma interpolação dos valores dos pixels vizinhos.

- Remoção de raios cósmicos: os raios cósmicos são partículas altamente energéticas que geram um alto número de contagens ao atingirem o CCD. A remoção deles é feita 
utilizando-se a rotina L.A.Cosmic (van Dokkum, 2001). Essa rotina visa detectar variações abruptas de alta frequência nos perfis de brilho dos dados.

- Correção de flat-field: é comum que haja variações de ganho entre os pixels da imagem obtida. Para corrigir esse problema, a imagem de ciência é dividida pela chamada imagem de flat-field. No caso de cubos de dados obtidos com o IFU do GMOS, a divisão é feita por "mapas de flat-field". Tais imagens de calibração contêm curvas de resposta (obtidas a partir das imagens de GCAL-flat), com o propósito de corrigir variações de ganho pixel a pixel ao longo do eixo espectral do cubo, e também mapas de resposta (obtidos a partir das imagens de twilight), com o propósito de corrigir variações de ganho fibra a fibra e também padrões de iluminação do instrumento.

- Calibração em comprimento de onda: um espectro obtido da observação não possui valores de comprimento de onda associados. É preciso utilizar uma calibração baseada num espectro com linhas conhecidas, que é obtido apontando o telescópio para uma lâmpada, neste caso, de $\mathrm{CuAr}$.

- Subtração de céu: remove a emissão da atmosfera terrestre nas imagens obtidas. É feita subtraindo-se a imagem de uma região do céu, na qual não há nenhum objeto celeste, da imagem do objeto em questão. No caso de cubos de dados obtidos com o GMOS, esse procedimento consiste na subtração de um espectro médio, obtido a partir do campo destinado à observação do céu, dos dados de ciência.

-Calibração em fluxo: consiste em associar valores de fluxo a cada comprimento de onda do espectro observado. Isso é feito utilizando-se uma relação entre o número de contagens e o fluxo correspondente, a qual é obtida a partir da observação de uma estrela padrão.

- Montagem do cubo de dados: um cubo de dados consiste em um objeto com três dimensões $(\mathrm{x}, \mathrm{y}, \mathrm{z})$ : o plano xy corresponde às dimensões espaciais e o eixo z representa o eixo espectral do cubo. Essa etapa consiste em associar cada espectro obtido com o pixel espacial (spaxel) correspondente para obtenção do cubo de dados.

Para todos os objetos, foram obtidos, no fim do processo de redução, três cubos de dados com spaxels com 0".05. 


\subsection{Tratamento}

Após a criação dos cubos de dados, foi dado início ao tratamento desses cubos utilizando scripts escritos em Interactive Data Language (IDL). Para maiores detalhes, consultar Menezes (2012), Ricci (2013), Menezes et al. (2014), Menezes et al. (2015) e Menezes et al. (2019).

\subsubsection{Correção da refração atmosférica diferencial}

Sabe-se que todo objeto observado com telescópios terrestres sofre o efeito da refração atmosférica. No entanto, o índice de refração depende do comprimento de onda da observação. Como em um cubo de dados é possível ver a imagem de um objeto em diferentes comprimentos de onda, conclui-se que o efeito da refração atmosférica é diferente para cada um desses comprimentos de onda. Como resultado disso, a posição do objeto muda ao longo do eixo espectral do cubo de dados, dando origem ao efeito da refração atmosférica diferencial.

Para corrigir esse efeito, utilizou-se um programa que aplica sequencialmente "pequenos deslocamentos" a cada uma das imagens dos cubos de dados, de modo que a posição do objeto não se alterasse ao longo do eixo espectral.

\subsubsection{Combinação dos cubos de dados}

Os cubos foram combinados em forma de medianas, a fim de remover qualquer bad pixel remanescente, gerando um único cubo para cada galáxia.

\subsubsection{Filtragem espacial de Butterworth}

Esse método (Gonzalez e Woods, 2002) consiste em uma filtragem realizada diretamente no domínio de frequências, com intuito de se remover componentes de determinada frequência. Neste caso, esse método foi aplicado para se remover as componentes de alta frequência das imagens.

Para se aplicar essa filtragem, primeiramente, foram calculadas as transformadas de Fourier para cada uma das imagens do cubo de dados, a fim de se passá-las para o domínio de frequências espaciais. Em seguida, cada uma dessas transformadas foi multiplicada pela imagem correspondente ao filtro, no qual os valores eram iguais a 1 na região central 
e decresciam para zero nas regiões mais afastadas do centro. A razão de o filtro ser construído dessa forma é que as transformadas de Fourier das imagens do cubo de dados foram dispostas de modo a apresentar as componentes de baixa frequência (que devem ser preservadas) na região central e as componentes de alta frequência nas regiões mais afastadas. Por fim, foi aplicada a transformada de Fourier inversa nas imagens após a multiplicação pelo filtro, retornando-as para o domínio espacial. O filtro de Butterworth utilizado corresponde ao produto de dois filtros circulares idênticos. A ordem de filtragem utilizada foi $n=2$.
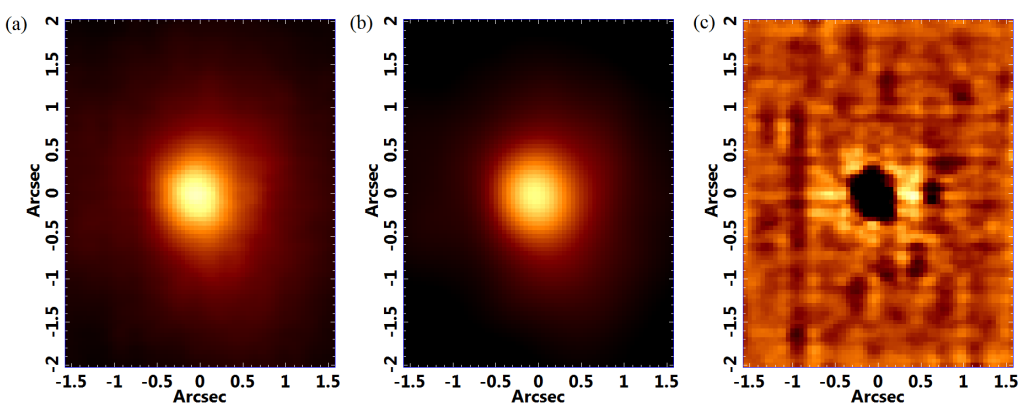

Figura 3.2: Imagem do contínuo espectral de NGC 6744 no intervalo de $5618 \AA$ até $5787 \AA$ (a) do cubo antes da filtragem Butterworth (os valores desta imagem variam de, aproximadamente, 4.4 a 21.8), (b) do cubo filtrado (os valores desta imagem variam de, aproximadamente, 4.5 a 20) e (c) da subtração entre o cubo depois e antes da filtragem (os valores desta imagem variam de, aproximadamente, -1.5 a 0.65 ).

A Fig. 3.2 mostra a melhora que a filtragem Butterworth traz para os cubos de dados. O cubo antes o tratamento possui muitos ruídos de alta frequência espacial, como se pode ver na Fig. 3.2(a). Após a filtragem (Fig. 3.2b), vê-se claramente que esses ruídos foram removidos e a diferença entre as duas imagem (Fig. 3.2 ) mostra que as componentes de alta frequência espacial foram removidas sem alterar significamente a PSF da observação. Considerando a morfologia espacial desse ruído, é provável que seja de natureza instrumental, possivelmente associado às fibras do instrumento.

\subsubsection{Remoção do fingerprint instrumental}

Os cubos de dados obtidos com o IFU do GMOS apresentam estruturas com uma morfologia espacial e uma assinatura espectral específicas, chamadas de fingerprints instrumentais. Espacialmente, o fingerprint aparece como faixas verticais com larguras características (ver Fig. 3.3) e, espectralmente, como largas ondulações no espectro. 
A fim de remover essas estruturas, aplicou-se a Tomografia PCA (ver seção 3.5.1) ao cubo do qual foram removidas todas as principais linhas de emissão e absorção. Foram selecionados apenas os tomogramas com seus autovetores que apresentavam o fingerprint e foram ajustados splines ao contínuo desses autovetores para descrever as largas ondulações.

A partir desses splines e dos tomogramas foi construído um cubo de dados apenas com o fingerprint. Então subtraiu-se esse cubo com o fingerprint do cubo de dados original e obteve-se um cubo sem fingerprint.
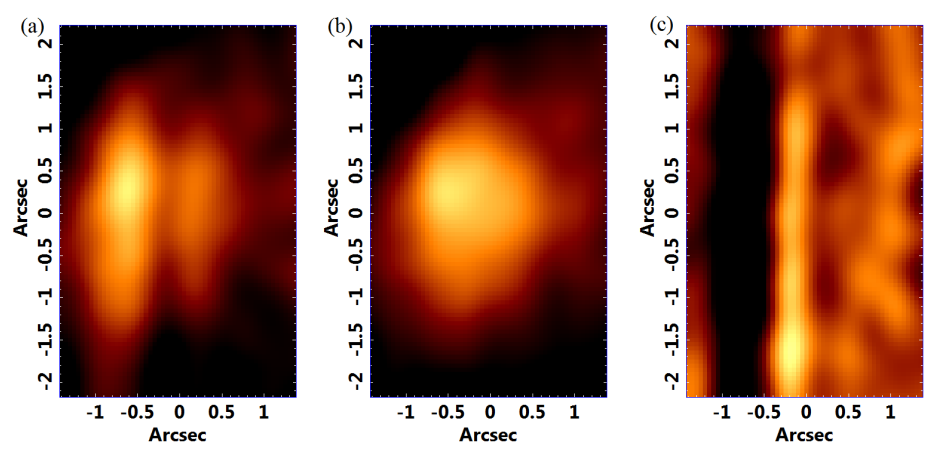

Figura 3.3: Imagem do contínuo espectral de NGC 157 no intervalo de $5580 \AA$ até $5700 \AA$ (a) do cubo antes da remoção do fingerprint, (b) do cubo depois da remoção do fingerprint e (c) da subtração do cubo sem fingerprint do cubo com fingerprint.

A Fig. 3.3 mostra claramente o efeito que o fingerprint causa (Fig. 3.3 ) nas imagens do cubo de dados. Após a remoção, pode-se observar a morfologia real da fonte central emissora (Fig. 3.3p) e o quanto o fingerprint distorceu tal morfologia. A diferença entre imagem após a remoção do fingerprint e a imagem antes da remoção (Fig. 3.3.) mostra o padrão vertical mencionado anteriormente.

\subsubsection{Deconvolução Richardson-Lucy}

Sabe-se que imagens de objetos observados com telescópios terrestres sofrem o efeito da turbulência atmosférica. Esse efeito gera o chamado seeing, que corresponde a um diâmetro aparente apresentado por uma fonte puntual observada através da atmosfera terrestre. Matematicamente, o que ocorre é uma convolução entre a imagem original do objeto e a PSF correspondente à atmosfera terrestre (e também ao instrumento utilizado). A deconvolução corresponde a um processo iterativo que tem como objetivo reverter os efeitos de uma convolução; e, obviamente, pode ser utilizada, nesse caso, para tentar obter a imagem original do objeto. Existem muitos métodos de deconvolução com aplicações em 
Astronomia. Neste estudo foi utilizado o método de Richardson-Lucy (Richardson, 1972; Lucy, 1974). Para aplicar esse processo, é necessário conhecer a PSF, que apresenta uma variação com o comprimento de onda de acordo com a equação 3.1. Para todos os objetos, tal variação foi estimada a partir dos cubos de dados das estrelas padrão (utilizadas durante a redução dos dados para calibração em fluxo). O tamanho da PSF em um comprimento de onda de referência foi estimado para cada objeto de maneiras diferentes e será informado em seus respectivos capítulos. O valor do coeficiente $\alpha$ médio da amostra é de $\sim 0.3$.

$$
F W H M(\lambda)=F W H M_{r e f}\left(\frac{\lambda}{\lambda_{r e f}}\right)^{\alpha}
$$
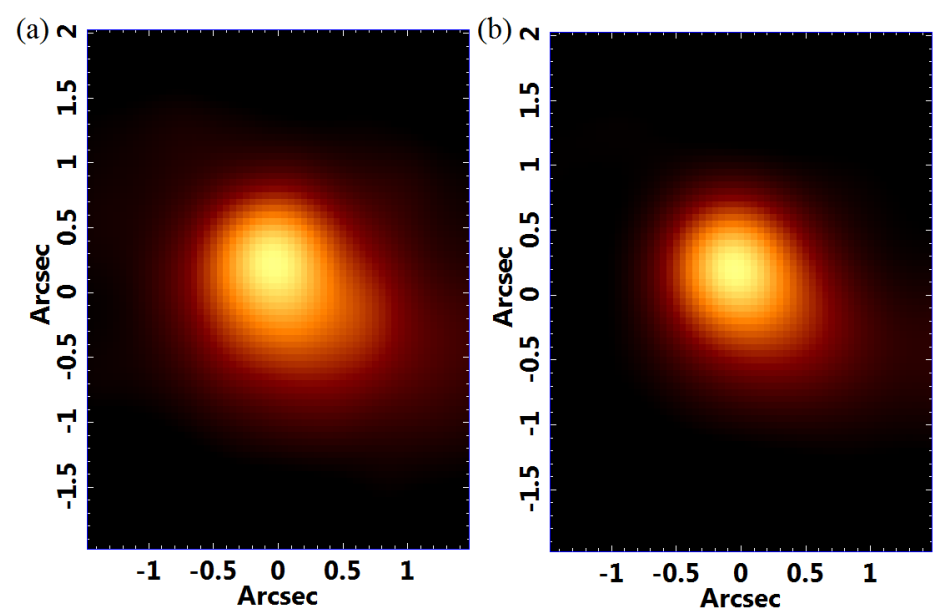

Figura 3.4: Imagem do contínuo espectral de NGC 2442 no intervalo de $6027 \AA$ até $6164 \AA$ (a) do cubo antes deconvolução e (b) do cubo depois da deconvolução. A LUT não foi alterada entre as duas imagens.

A Fig. 3.4 mostra o antes e depois da deconvolução. A LUT (look up table- relação entre o valor do pixel e sua intensidade) não foi alterada entre as imagens, ou seja, o valor da PSF foi mesmo reduzido sem alterar a morfologia espacial das estruturas na imagem.

\subsection{Métodos de análise dos dados}

Após o tratamento dos dados, foram aplicados os seguintes métodos básicos (isto é, feitos igualmente para todos os objetos) para análise dos cubos de dados obtidos. 


\subsubsection{Tomografia PCA}

PCA (Principal Component Analysis) é uma transformação de sistemas de coordenadas na qual as novas coordenadas são os autovetores da matriz de covariância em ordem de variância explicada. Na Tomografia PCA, que é o PCA aplicado a cubo de dados (Steiner et al., 2009b), as variáveis do sistema são os pixels espectrais do cubo de dados e os spaxels são os observáveis. Com isso, os autovetores da Tomografia PCA são combinações lineares dos pixels espectrais e, por apresentarem aspectos similares a espectros, são chamados de auto-espectros. Os tomogramas são imagens correspondentes às projeções dos spaxels nos autovetores. A análise da Tomografia PCA revela uma grande variedade de fenômenos presentes no cubo de dados, sendo muitos deles difíceis de serem detectados com métodos tradicionais. Sua interpretação deve ser feita levando-se em conta auto-espectros e tomogramas simultaneamente.

\subsubsection{Síntese espectral}

O software StARlight (Cid Fernandes et al., 2005) realiza uma combinação linear de espectros de populações estelares de uma base para ajustar o contínuo estelar dos espectros do cubo de dados analisado. Tais espectros de base são convoluídos com uma função gaussiana, a fim de reproduzir a dispersão de velocidades estelar do espectro observado. Neste caso, a base utilizada foi construída a partir da Medium-resolution Isaac Newton Telescope library of empirical spectra (MILES Sánchez-Blázquez et al. 2006), chamada de CB2007. Também foi adicionado à base do STARLight um espectro na forma de lei de potência com índice espectral igual a 1.5, a fim de representar o featureless continuum emitido por um possível núcleo ativo (active galactic nucleus - AGN) no cubo de dados analisado.

A partir dos resultados obtidos com a síntese espectral do STARLIGHT, foi possível fazer o mapeamento do fluxo total emitido pelas populações estelares. Nos casos em que um AGN foi detectado no cubo de dados, foi também feito o mapeamento do fluxo associado ao featureless continuum emitido pelo AGN (representado pela lei de potência mencionada). Por fim, foram feitos histogramas contendo as frações do fluxo associadas a cada uma das populações estelares (e ao featureless continuum) levadas em conta na síntese espectral, considerando todo o campo de visão do IFU do GMOS. A construção de tais histogramas foi 
possível porque, a partir da síntese espectral aplicada ao espectro de cada spaxel do cubo, obteve-se o fluxo estelar total devido a cada população estelar (e também o fluxo estelar total considerando-se todas as populações estelares) para cada spaxel. Consequentemente, foi possível obter então as frações de fluxo devidas a cada uma das populações estelares, considerando-se todo o campo visual.

Os intervalos aproximados de idades considerados na síntese espectral com as idades representativas estão na tabela 3.1 e os valores de metalicidade utilizados são, para baixa metalicidade, 0.0001 e 0.0004 , para média metalicidade, 0.004 e 0.008 e, para alta metalicidade, 0.02 e 0.05 .

Tabela 3.1 - Tabela de idades consideradas na síntese espectral.

\begin{tabular}{|c|c|}
\hline $\begin{array}{c}\text { Idades } \\
\text { representativas }\end{array}$ & $\begin{array}{c}\text { Intervalo de idades } \\
\text { considerado na síntese espectral }\end{array}$ \\
\hline $10^{6}$ & $1 \times 10^{6} \mathrm{a} 9 \times 10^{6}$ \\
\hline $10^{7}$ & $1 \times 10^{7} \mathrm{a} 6 \times 10^{7}$ \\
\hline $10^{8}$ & $1 \times 10^{8} \mathrm{a} 9 \times 10^{8}$ \\
\hline $10^{9}$ & $1 \times 10^{9} \mathrm{a} 8 \times 10^{9}$ \\
\hline $10^{10}$ & $1 \times 10^{10} \mathrm{a} 1.8 \times 10^{10}$ \\
\hline
\end{tabular}

\subsubsection{Obtenção do cubo de gás}

Utilizando-se os espectros obtidos com a síntese espectral para cada spaxel do cubo de dados, foi criado um cubo estelar sintético. Esse cubo foi, então, subtraído do cubo original (após a deconvolução) com objetivo de obter um cubo com, essencialmente, apenas emissão do gás, que é chamado de cubo de gás. Esse cubo é útil para a construção de imagens de linhas de emissão de gás, as quais podem revelar as morfologias das fontes emissoras. A aplicação da Tomografia PCA a esse cubo pode fornecer informações relevantes sobre a cinemática do gás.

O cubo de gás é utilizado para o cálculo de razões de linhas. Os espectros extraídos deste cubo foram corrigidos da extinção interestelar, estimada pela razão dos fluxos integrados das linhas $\mathrm{H} \alpha$ e $\mathrm{H} \beta$. Essa correção é eficaz devido ao fato da extinção ser maior nos comprimentos de onda menores quando comparada a maiores comprimentos de onda. Quanto maior a extinção, menor será o valor de $\mathrm{H} \beta$ com relação a $\mathrm{H} \alpha$, por isso a razão entre as duas linhas é um bom indicativo de extinção. 


\subsubsection{Cálculo das incertezas das razões de linhas}

A incerteza dos fluxos integrados das linhas de emissão foi obtida levando-se em conta tanto o ruído espectral quanto os resíduos de ajuste restantes após a subtração do contínuo estelar. Para cada linha de emissão, primeiramente determinaram-se três possíveis intervalos espectrais para o cálculo do fluxo integrado. Em seguida, utilizando-se um intervalo espectral sem linhas de emissão, obteve-se uma distribuição gaussiana representativa dos ruídos espectrais e construíram-se distribuições gaussianas de ruídos aleatórios com a mesma largura da gaussiana da distribuições de ruídos inicial. Essas distribuições de ruído foram adicionadas à linha de emissão original, nos três intervalos espectrais escolhidos para o cálculo do fluxo, o que resultou em várias linhas de emissão "ruidosas". Os fluxos integrados de tais linhas ruidosas foram calculados e o desvio padrão dos valores obtidos foi tomado como a incerteza do fluxo integrado da linha. Por fim, a incerteza de cada razão de linhas foi obtida a partir de uma propagação das incertezas dos fluxos das linhas da razão em questão.

\subsubsection{Cinemática estelar}

A fim de se obter mais detalhes sobre a cinemática estelar existente nas regiões centrais dos objetos estudados, aplicou-se o processo Penalized Pixel Fitting (pPXF- Cappellari e Emsellem 2004) aos espectros dos cubos de dados. Esse procedimento, assim como a síntese espectral aplicada com o software STARLIGHT, também consiste no ajuste do contínuo estelar observado com uma combinação linear de espectros de populações estelares de uma determinada base (neste caso, a mesma utilizada para aplicar o software STARLIGHT, baseada na MILES). Porém, esses espectros de base são convoluídos com uma expansão de Gauss-Hermite. Isso permite a obtenção dos seguintes parâmetros: velocidade radial estelar $\left(V_{*}\right)$, dispersão de velocidades estelar $\left(\sigma_{*}\right)$ e o coeficiente de Gauss-Hermite $h_{3}$ (assimetria das linhas com relação a um perfil simétrico), entre outros.

As incertezas dos parâmetros cinemáticos obtidos com a aplicação do pPXF foram estimadas utilizando-se uma simulação de Monte Carlo. Para isso, primeiramente, para cada spaxel do cubo de dados, foi subtraído o espectro sintético obtido com o pPXF do espectro original. Em seguida, foi estimada uma distribuição gaussiana representativa dos ruídos espectrais do espectro residual obtido. Após isso, foram criadas diferentes distri- 
buições gaussianas de ruídos aleatórios com a mesma largura da gaussiana da distribuição de ruídos inicial. Essas distribuições de ruído foram adicionadas ao espectro sintético fornecido pelo ajuste inicial e o pPXF foi aplicado sequencialmente a cada um dos espectros resultantes. Por fim, para cada um dos parâmetros cinemáticos, a incerteza final foi tomada como o desvio padrão dos valores encontrados em todos esses diferentes ajustes sucessivos.

\subsubsection{Cálculo da dispersão de velocidades}

Para definir a dispersão de velocidades central, visto que, em muitos mapas de dispersão de velocidades, os valores não seguiram nenhuma tendência, uma média ponderada em intensidade foi calculada. Para isso, o valor da dispersão de velocidade estelar foi multiplicado pelo valor do fluxo total integrado em cada spaxel do cubo de dados. Então, a soma desses valores foi divida pelo fluxo integrado total do cubo de dados. Com isso, obteve-se um valor de dispersão de velocidades estelar ponderado em intensidade para o cubo de dados analisado.

O valor de incerteza da dispersão foi determinada a partir dos mapas de incertezas criados como descrito anteriormente. A partir desse mapa, foram criados dois mapas: $\sigma+$ incerteza, $\sigma$-incerteza (onde $\sigma$ é o mapa de dispersão original e incerteza é o mapa de incertezas). Foi calculada então uma média ponderada em intensidade para cada mapa, incluindo o mapa de dispersão. A incerteza resultante foi o desvio padrão dos valores das médias.

\subsection{Tratamento dos cubos de dados do telescópio espacial Chandra}

Os cubos de dados do telescópio espacial Chandra, em raios-X, deste estudo foram obtidos do arquivo público deste telescópio. Os dados foram coletados com o instrumento ACIS. Os cubos de dados foram então dimensionados para que apenas o field of view (FOV) central fosse considerado.

Após o redimensionamento, os cubos foram reamostrados espacialmente de forma linear para que o tamanho dos spaxels fossem a metade do cubo original, neste caso, 0".246. O processo de reamostragem espacial introduz componentes de alta frequências nas imagens, que foram removidas com uma filtragem Butterworth (assim como nos cubos de dados do GMOS), mas neste caso, com filtros de ordem 1, pois foram os únicos que removeram as 
componentes de alta frequência sem comprometer os dados. Os espectros foram cortados para que o intervalo de energias ficasse entre 0 e $10 \mathrm{keV}$. 
Capítulo 4

\section{Resumo do paper sobre NGC 1566}

\section{NGC 1566: analysis of the nuclear region from optical and NIR Integral Field Unit spectroscopy}

Este artigo é sobre o estudo do núcleo de NGC 1566 (da Silva et al., 2017), conduzido com auxílio de cubos de dados do IFU do GMOS do telescópio Gemini-Sul, cubos de dados do Spectrograph for Integral Field Observations in the Near Infrared (SINFONI) do Very Large Telescope (VLT) e imagens do Hubble Space Telescope (HST).

Além da região nuclear central, foi detectada uma região HII próxima (distância projetada: $73.3 \pm 1.9$ pc). O núcleo possui razões de linhas compatíveis com as de Seyferts e componentes largas das linhas de Balmer, indicando um AGN tipo 1. Por outro lado, a região HII próxima possui razões de linhas compatíveis com as de objeto de transição, indicando uma possível contaminação da emissão do AGN no espectro extraído desta região.

A partir dos resultados obtidos a partir da Tomografia PCA foi possível isolar a emissão do featureless continuum deste AGN. O FWHM da PSF da emissão do featureless continuum (0" .75) é maior do que o da observação dos dados (0".66), sugerindo que esta emissão pode também estar associada a estrelas jovens no núcleo (também detectadas pela síntese espectral).

Foi observado um outflow de gás em direção à região HII em [OIII] $\lambda 5007$. Além disso, a região HII possui um gradiente de velocidades e possui muitas estruturas, o que sugere que seja um complexo de nuvens localizado em um aparente braço espiral.

Há um disco de rotação estelar ao redor do AGN e há um decréscimo de valores da dispersão de velocidades estelares em direção ao centro (chamado de $\sigma-d r o p$ ). Isso pode estar associado à presença de estrelas jovens que herdaram a cinemática fria de suas nuvens 
progenitoras.

Foi detectado também um disco de gás molecular e uma espiral em blueshift. Esse disco molecular pode ser a parte estendida de uma estrutura compacta (como um toro), já que é perpendicular ao outflow de gás observado em [OIII] $\lambda 5007$.

NGC 1566 é uma galáxia muito conhecida na literatura por sua variabilidade. Esta variabilidade foi observada nos perfis das linhas dos dados do infravermelho quando comparados com os dados do óptico. Foi observado que todas as componentes largas das linhas da broad line region (BLR) do AGN de NGC 1566 possuem um deslocamento para o vermelho, interpretado como redshift gravitacional. Com isso, foi possível estimar, a partir de um modelo simples, que o limite máximo da massa do buraco negro está entre $3.4 \times 10^{7}$ e $4 \times 10^{8} \mathrm{M}_{\odot}$ e o limite máximo do raio da BLR é de 20 dias-luz. 
Capítulo 5

\title{
NGC 1566: analysis of the nuclear region from optical and NIR Integral Field Unit spectroscopy
}

\author{
Patrícia da Silva, J. E. Steiner, R. B. Menezes \\ 2017, MNRAS, 470, 3850
}

\subsection{Abstract}

We analysed the centre of NGC 1566, which hosts a well-studied active galactic nucleus (AGN), known for its variability. With the aid of techniques such as Principal Component Analysis Tomography, analysis of the emission-line spectra, channel maps, Penalized Pixel Fitting and spectral synthesis applied to the optical and near-infrared data cubes, besides the analysis of Hubble Space Telescope images, we found that: (1) the AGN has a Seyfert 1 emission, with a very strong featureless continuum that we described as a power law with spectral index of 1.7. However, this emission may come not only from the AGN [as its point spread function (PSF) is broader than the PSF of the broad-line region (BLR)], but from hot and young stars, the same ones that probably account for the observed $\sigma$-drop. (2) There is a correlation between redshift and the full width at half-maximum of the BLR emission lines. With a simple model assuming gravitational redshift, we described it as an emitting ring with varying emitting radii and small inclination angles. (3) There is an $\mathrm{H}$ II region close to the AGN, which is composed of many substructures forming an apparent spiral with a velocity gradient. (4) We also detected a probable outflow coming from the AGN and it seems to contaminate the $\mathrm{H}$ II region emission. (5) We identified an $\mathrm{H}_{2}$ rotating disc with orientation approximately perpendicular to this outflow. This suggests that the 
rotating disc is an extension of an inner torus/disc structure, which collimates the outflow emission, according to the Unified Model.

\subsection{Introduction}

Active galactic nuclei (AGNs) are characterized by their spectral emission, which cannot be attributed only to stars. The study of these objects is very important, as they can provide relevant information about the origin and evolution of galaxies. NGC 1566 is a galaxy that has a very well-studied active nucleus, notorious for its variability. It is a nearly face-on grand design spiral galaxy with morphological type SAB(s)bc (like the Milky Way). It is the brightest galaxy of the Dorado group and it presents a small bar of 1.7 kpc (32".5) of length de Vaucouleurs, 1973; Hackwell e Schweizer, 1983; Comerón et al. 2010). Observed in the near-infrared (NIR), the orientation of this bar is north-south. The galaxy's distance is about $10.8 \mathrm{Mpc}$ (NASA Extralagactic Database - NED). In the radio (8.6 GHz), NGC 1566 shows a compact nuclear emission and a 'blob' at 3" north of the centre (Morganti et al. 1999). This galaxy also has an outer stellar formation ring, $10 \mathrm{kpc}$ from the nucleus, and two other similar rings, between 1 and $3 \mathrm{kpc}$ from the nucleus (Agüero et al., 2004). The spiral arms have a strong star formation, with dust features in their inner lanes (Garrison e Walborn, 1974); they have many H II regions, whose luminosity function, based on $\mathrm{H} \alpha$ relative flux scale, is well described by a power law (Comte e Duquennoy, 1982).

The NGC 1566 nucleus has a Seyfert emission (de Vaucouleurs e de Vaucouleurs, 1961; Shobbrook, 1966) that was later classified as type 1, based on optical spectra observations, that showed that the $\mathrm{H} \alpha$ and $\mathrm{H} \beta$ profiles have broad components with strong asymmetry towards the red (Osmer et al., 1974). In the literature one can find that $4.2 \lesssim \mathrm{H} \alpha / \mathrm{H} \beta$ $\lesssim 4.7$ (Osmer et al., 1974; Hawley e Phillips, 1980; Martin, 1974), but broad-line region (BLR) photoionization models, assuming that it is composed by a high temperature region $\left(T_{e}=15000 \mathrm{~K}\right)$ and a low temperature region $\left(T_{e}=10000 \mathrm{~K}\right)$, resulted in an $\mathrm{H} \alpha / \mathrm{H} \beta$ ratio of about 3.2 (Clavel e Joly, 1984).

In the NIR, the nucleus presents $\operatorname{Br} \gamma$ emission with a broad and a narrow component, besides evidence of a dust torus with temperature of 1000K (Smajić et al., 2015), which was determined by $K$-band continuum fit, from a combination of stellar spectra, a power 
law and a blackbody curve. In the mid-infrared, both continuum and spectral structures between 10 and $18 \mu \mathrm{m}$ (from the emission of silicates) are consistent with the thermal emission from a dust torus with clumpy morphology (Thompson et al., 2009).

NGC 1566's nuclear spectrum in X-rays $(0.5-195 \mathrm{keV})$ is well reproduced by models that consist of a sum of partially or completely transmitted nuclear emission, its reflection on the accretion disc and the reprocessed emission from the dust torus, followed by a strong emission of $\mathrm{Fe} \mathrm{K} \alpha$ (Kawamuro et al., 2013). Ehle et al. (1996) verified that the nucleus' luminosity, in the spectral region between 0.1 and $2.4 \mathrm{keV}$, is $L_{x}=10^{41} \mathrm{erg} \mathrm{s}^{-1}$, the nuclear spectrum being well fitted by a power law with spectral index of 2.3 .

This galaxy is known by the variability of its nuclear activity. Variations were observed both in the $B$-band nuclear apparent magnitude - from 13.5 to 14.6 mag (de Vaucouleurs, 1973) - and in the nuclear spectrum, in which an $\mathrm{H} \beta$ intensity decrease relative to [O III] was observed, in a time-scale of years (Pastoriza e Gerola, 1970). This variability was also observed in $\mathrm{H} \alpha$ and $\mathrm{H} \beta$ profiles and in the non-stellar continuum of the nuclear emission, which varied from Seyfert 1.9 to 1.2 in four months. The explanation for this rapid increase of the Balmer lines and of the broad component of $\mathrm{H} \alpha\left(7000 \mathrm{~km} \mathrm{~s}^{-1}\right)$ is a recurrent outburst in the nuclear region (Alloin et al., 1986).

The variability of the nuclear spectrum was also observed from X-rays to IR, the IR variation having a delay of some months to a year relative to the optical and ultraviolet emission (Clavel et al., 2000).

Agüero et al. (2004) detected, based on deviations from the Satoh model fitted to the kinematic optical data of ionized gas, an apparent outflow located at the edges of the galaxy's bar. Besides that, other non-circular motions were detected in some regions (10" from the nucleus). Such motions probably represent an inflow of gas to the nucleus, which could be a feeding mechanism of the AGN. Davies et al. (2016) analysed optical integral field observations centred on the nucleus of NGC 1566 and verified that, in ther inner regions (where the ionization parameter is $\log U \sim 0$ ), the environment is radiation pressure dominated, which can lead to outflows that can affect areas far beyond the radius of influence of the black hole.

Hawley e Phillips (1980) found evidences of a decrease of the $[\mathrm{O} \mathrm{III}] / \mathrm{H} \beta$ ratio and of an increase of the $[\mathrm{N} \mathrm{II}] /[\mathrm{O} \mathrm{II}]$ ratio towards the nucleus. This can be due to an increase of oxygen abundance, which cools the gas, leading to a lower electronic temperature and 
thus to a decrease of the [O III] flux.

Beckman et al. (1986) analysed photometric ( $V, R$ and $I$ filters) and optical spectral data and verified that the nucleus and the spiral arms of NGC 1566 have bluer colours than the other parts of the galaxy. The bluer colour of the nucleus is probably due to the Seyfert nuclear activity. The $M / L$ ratio values, obtained up to the distance of $13.5 \mathrm{kpc}$ from the nucleus, can be explained by taking into account only the main-sequence stellar populations, without the need to assume the presence of giant stars or dark matter. Based on the observed values of $V-R$ and $V$ - $I$, it was possible to infer the presence of O-, B- and A-type stars in the nucleus.

$K$-band data in the NIR, observed with the Spectrograph for Integral Field Observations in the Near Infrared (SINFONI) and with Naos-Conica, both instruments of the Very Large Telescope, showed a circular emission of $\mathrm{H}_{2}$ molecular gas somewhat off-centred along the east-west direction and with a radius of less than 1" (Mezcua et al. 2015). Additional SINFONI data in the $K$-band, analysed by Smajić et al. (2015), showed that the NGC 1566 circumnuclear region is composed of molecular gas, dust and old stellar populations. The molecular gas and the stellar populations are rotating around the nucleus, although there is a disturbance in the molecular gas velocity field towards the nucleus. A star-forming region was observed southwest from the nucleus, with $[\mathrm{SFR}]=2.6 \times 10^{-3} \mathrm{M}_{\odot}$ $\mathrm{yr}^{-1}$. Using both SINFONI and Atacama Large Millimeter Array (ALMA) $350 \mathrm{GHz}$ data, Smajić et al. (2015) verified that there is a cold and warm molecular gas spiral that may indicate feeding of the AGN. A molecular gas spiral towards the nucleus was also observed by Combes et al. (2014), using ALMA data with spatial resolution of 25 pc. That spiral is very similar to the dust spiral observed in the Hubble Space Telescope's (HST) extinction images. Combes et al. (2014) proposed that the black hole must be influencing the gas dynamics, in order to reverse gravitation torques. These torques are directing the gas towards the nucleus, which may result in the feeding of the AGN. The authors also observed a nuclear disc of dense molecular gas, with deficiency of H II regions and atomic gas. This molecular gas displays a well-behaved rotation, without the presence of outflows, feedback or feeding of the AGN.

In X-rays, an extended emission was discovered around the nucleus, certainly associated with the nuclear activity (Elvis et al., 1990). According to Ehle et al. (1996), this emission is similar to the extended radio emission, suggesting a link between the hot gas and the 
magnetic field.

A stellar kinematic study performed by Bottema (1993) revealed that the stellar velocity dispersion is smaller at the edges of the galaxy and increases towards the nucleus, where it reaches a constant value of $115 \mathrm{~km} \mathrm{~s}^{-1}$. Smajić et al. (2015) observed a stellar rotation around the nucleus of NGC 1566. The authors also observed a slight decrease in the velocity dispersion in the nucleus. The black hole's mass, estimated from the $M-\sigma$ relation, with the stellar velocity dispersion value equal to $100 \mathrm{~km} \mathrm{~s}^{-1}$ (Nelson e Whittle, 1995), is $8.3 \times 10^{6} \mathrm{M}_{\odot}$ (Woo e Urry, 2002).

The goal of this work is to analyse the nuclear region of NGC 1566, using a data cube observed in the optical with the Integral Field Unit (IFU) of the Gemini MultiObject Spectrograph (GMOS), installed at the Gemini-South telescope. This study was complemented with a re-analysis of the SINFONI data observed in the $K$ and $J$ bands, obtained from the SINFONI data archive, and with HST images of this galaxy, obtained from the HST data archive. This work is focused on the properties of: the emission-line spectrum, the AGN's featureless continuum, the stellar kinematics and the ionized and molecular gas kinematics.

The sections of this paper are divided as follows: section 5.3 describes the conditions of the observations and presents a brief description of the data reduction and treatment. Section 5.4 shows the results obtained with our first analysis tool, Principal Component Analysis (PCA) Tomography, applied to the optical data cube, and also shows the characterization of the featureless continuum detected in this galaxy. In section 5.5, we present the analysis of the HST images. In section 5.6, we calculate the emission-line ratios of the two sources found in the nuclear region of NGC 1566. The gas kinematics (ionized and molecular) and the stellar kinematics are analysed in Sections 5.7 and 5.8 , respectively. In section 5.9 we discuss the results of this work and, in section 5.10 , we present the main conclusions. In Appendix 5.11 we show the results of the spectral synthesis applied to the GMOS data cube. 

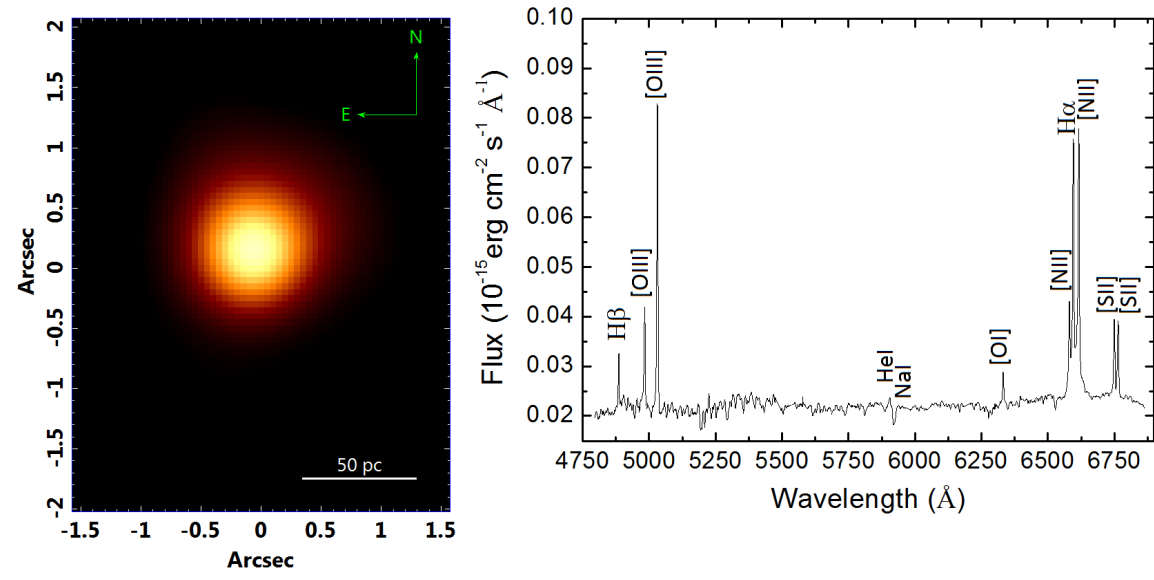

Figura 5.1: Image of the GMOS data cube collapsed along the spectral axis (left) and its average spectrum (right).
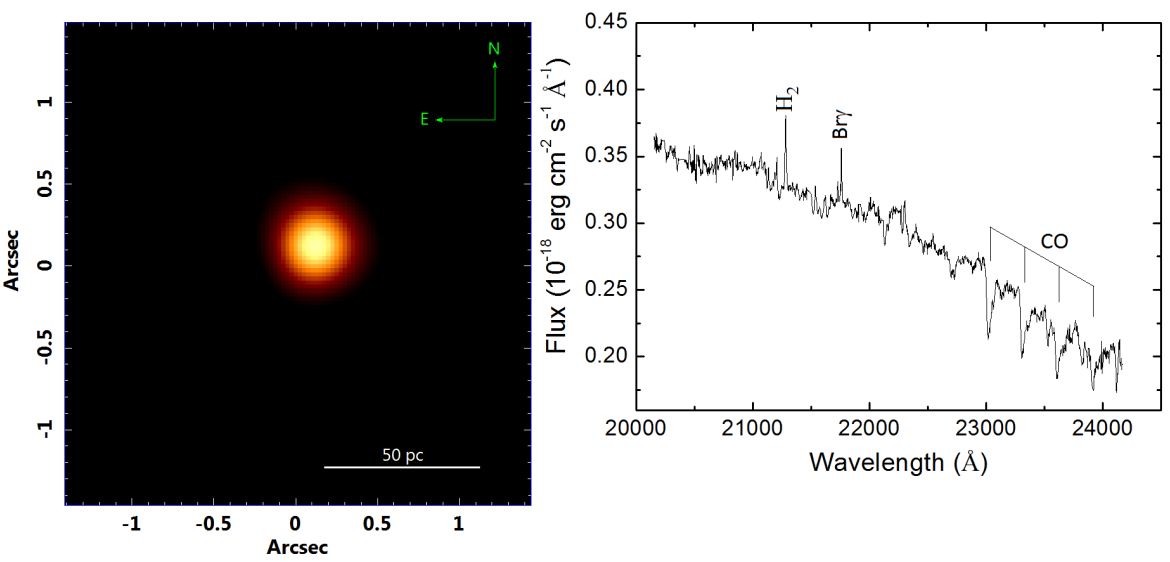

Figura 5.2: Image of the $K$-band SINFONI data cube collapsed along the spectral axis (left) and its average spectrum (right).
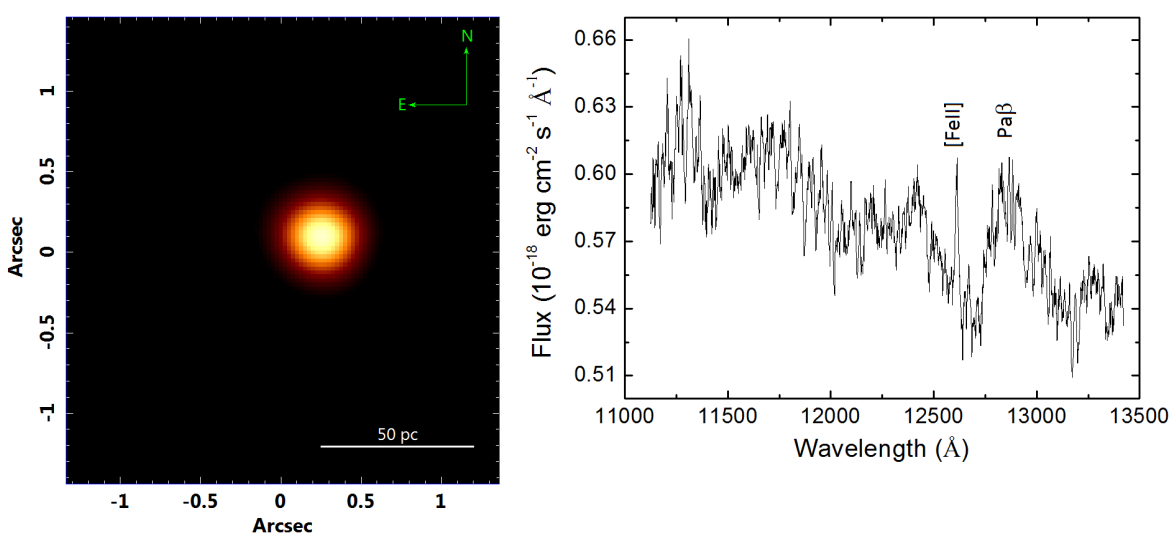

Figura 5.3: Image of the $J$-band SINFONI data cube collapsed along the spectral axis (left) and its average spectrum (right). 


\subsection{Observations, reduction and data treatment}

\subsubsection{Optical data}

The optical observations of the nucleus of NGC 1566 were made on 2013 October 10, using the IFU of GMOS, installed on the Gemini-South telescope, in one-slit mode. The observation program was GS-2013B-Q-3. The field of view (FOV) has 5" × 3".5 and three exposures of $910 \mathrm{~s}$ were taken, with spectral resolution of $\mathrm{R}=4340$. The grating used for the observations was R831+G5322, with a central wavelength of $5850 \AA$.

The data reduction was made in IRAF environment and consisted of the determination of trim, bias subtraction, cosmic ray rejection with the LACOS routine van Dokkum, 2001), spectra extraction, correction of pixel-to-pixel gain variations (with response curves obtained with GCAL-flat images), correction of fiber-to-fiber gain variations and of asymmetric illumination patterns of the instrument (with response maps obtained with twilight flat images), wavelength calibration (using the CuAr lamp images), sky subtraction, atmospheric extinction correction, telluric absorptions removal, flux calibration and data cube construction.

Three data cubes were constructed, with spatial pixels (spaxels) of 0".05 × 0".05 and a

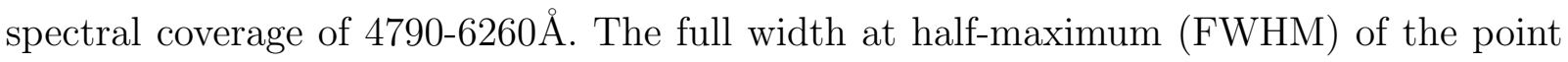
spread function (PSF) of the reduced data cubes, estimated with the image of the red wing of the broad component of $\mathrm{H} \alpha$, is $0 " .75$.

Following the process described in Menezes et al. (2014) and Menezes et al. (2015), the treatment of the data cubes was performed after the reduction, with scripts written in Interactive Data Language (IDL). This treatment consisted, first of all, of the differential atmospheric refraction correction. The three data cubes were, then, combined in the form of a median. After that, a Butterworth spatial filtering (Gonzalez e Woods, 2002), the instrumental fingerprint removal (using PCA Tomography - see the next section) and the Richardson-Lucy deconvolution (Richardson, 1972; Lucy, 1974) were applied. This last step required a variation law of the FWHM of the PSF with the wavelength, which was estimated from the standard star data cube. After the deconvolution, with 10 interactions, the FWHM of the image of the red wing of H $\alpha$ 's broad component was 0".66.

Fig. 5.1 shows the image of the data cube collapsed along the spectral axis, herewith its average spectrum. Possible broad components of the $\mathrm{H} \alpha$ and $\mathrm{H} \beta$ lines can be observed, 
together with a strong emission of [O III $] \lambda 5007$ and other narrow emission lines.

With the goal of characterizing the emission-line spectra, we performed a stellar continuum subtraction, using the synthetic stellar spectra provided by the spectral synthesis (see Appendix 5.11). This procedure resulted in a data cube mainly with gas emission.

The optical data cube of NGC 1566 described above was used in this work to analyse: the emission-line spectrum of the ionized gas, the AGN featureless continuum emission, the current stellar populations (with spectral synthesis), the stellar kinematics and the ionized gas kinematics.

\subsubsection{Near-infrared data}

The observations in the NIR, obtained from the SINFONI data archive, were made on 2008 October 2 ( $J$ band) and on 2008 November 1 ( $K$ band). The observation program was 082.B-0709(A) (PI: Beckert). The fore optics of 0".1 was used, which resulted in a FOV of $3 " .2 \times 3 " .2$. Two $300 \mathrm{~s}$ observations were made for the $J$ and $K$ bands, with central wavelengths of 12500 and $22000 \AA$, respectively.

The data reduction was made with the GASGANO software ${ }^{1}$ and included bad pixel correction, flat-field correction, spatial rectification (using distortion-fibre images), wavelength calibration, sky subtraction and data cube construction. At the end, data cubes with spaxels of 0".05 were obtained. The FWHM of PSF of the $J$ - and $K$-band data cubes were $\sim 0 " 41$ and $\sim 0 " .40$, respectively. These estimates were taken from images of $\mathrm{Pa} \beta$ and $\operatorname{Br} \gamma$ broad component red wings.

After the reduction, a data treatment similar to the one used for the optical data cubes was applied -see Menezes et al. (2014, 2015). First, a differential atmospheric refraction correction was performed and the resulting data cubes were combined in the form of a mean. Then, a spatial re-sampling was carried out, resulting in spaxels of 0".025. After that, a Butterworth spatial filtering was applied, the instrumental fingerprint was removed and the data cube was deconvolved using the Richardson-Lucy procedure. The estimate of the PSFs of the data cubes, required for the deconvolution, was obtained from images of the red wings of $\mathrm{Pa} \beta$ and $\mathrm{Br} \gamma$ broad components. Using these same images, we verified that the FWHM of the PSFs of the treated data cubes, in the $J$ and $K$ bands, was $\sim 0$ ".33.

Fig. 5.2 shows the collapsed image and the mean spectrum of the data cube in the $K$

\footnotetext{
1 http://www.eso.org/sci/software/gasgano.html
} 
band. The CO molecular bands are very prominent in this spectrum. Fig. 5.3 shows the collapsed image and mean spectrum of the data cube in the $J$ band. One may notice that $\mathrm{Pa} \beta$ is the only emission line clearly visible in this spectrum, which is considerably noisier than the one in the $K$ band.

The stellar continuum of the data cubes in the $J$ and $K$ bands was subtracted, as well as it was done for the optical data cube, to allow a more detailed analysis of the emission-line spectrum. In the $K$ band, the subtraction was made using synthetic stellar spectra provided by the Penalized Pixel Fitting (pPXF) method (Cappellari e Emsellem, 2004). This procedure involves the stellar continuum fit, using spectra of a given base (for more details, see section 5.8). On the other hand, the stellar continuum subtraction in the $J$-band data cube was performed simply by subtracting splines fitted to the spectra (with masked emission lines), since, in this case, there is no suitable stellar spectra base to be used.

The NIR data cubes of the central region of NGC 1566 were used to analyse the emission-line spectrum, the ionized gas kinematics in some areas of the FOV and also the molecular gas kinematics (using the $\mathrm{H}_{2} \lambda 21218$ line, in the $K$ band).

\subsection{PCA Tomography}

After the treatment, PCA Tomography (Steiner et al., 2009b) was applied to the optical data cube. PCA is an orthogonal linear transformation of coordinates that passes the data to a new system in which the coordinates are the eigenvectors of the covariance matrix, in order of the explained variance. In the case of PCA Tomography (which consists of PCA applied to data cubes), the variables of the system are the spectral pixels, while the observables are the spaxels. As a consequence, the eigenvectors of PCA Tomography are linear combinations of the spectral pixels and are very similar to the spectra. Because of that, we call them eigenspectra. Tomograms are the projections of the spaxels on the eigenvectors, being, then, images that indicate the degree of correlation between each spaxel and the associated eigenspectrum. It is important to analyse eigenspectra and tomograms simultaneously for a complete interpretation of the data. The PCA Tomography analysis reveals a large variety of phenomena in the data cube, many of them hard to detect with traditional methods (Ricci et al., 2011; Menezes et al., 2013; Ricci et al., 2014). 

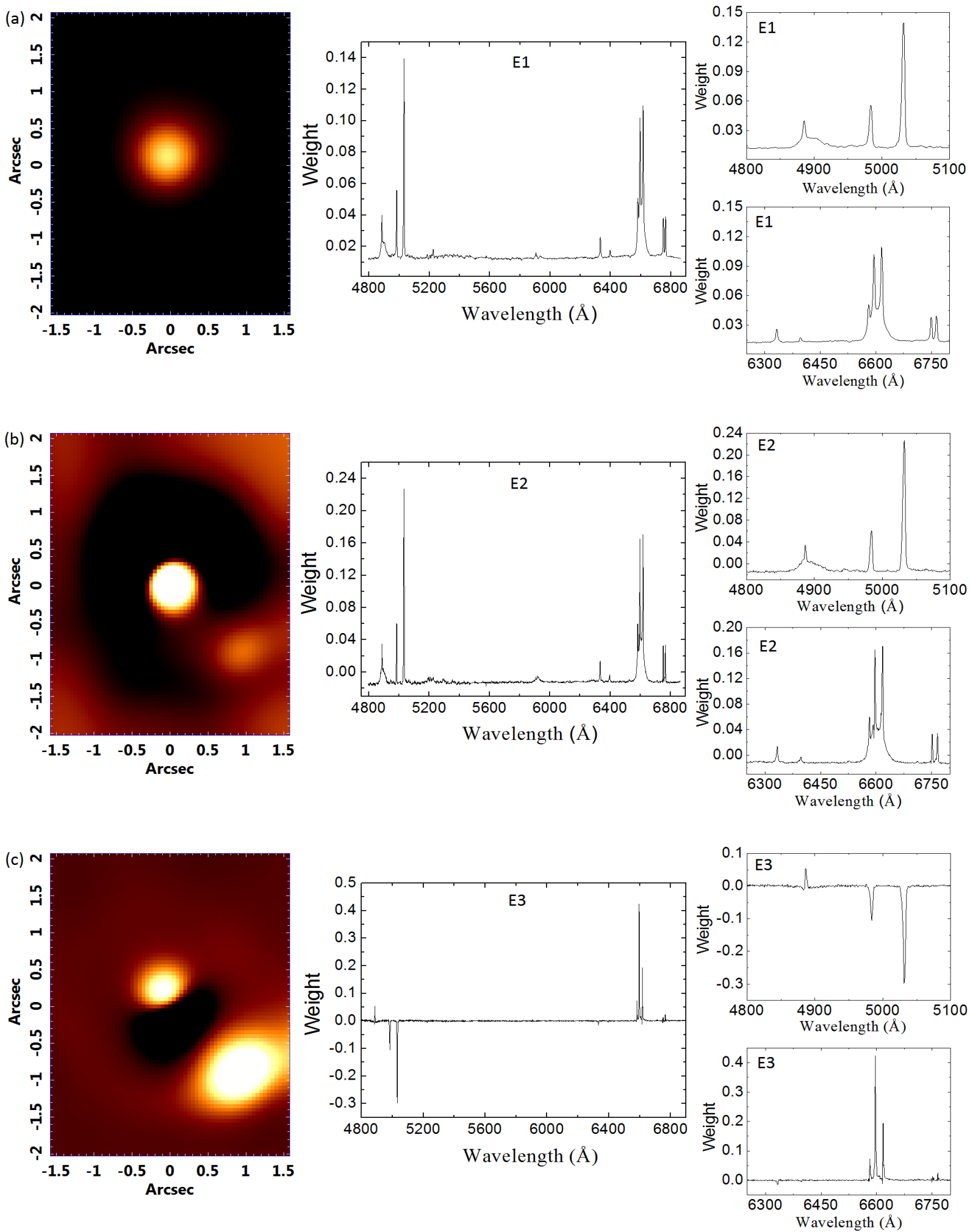

Figura 5.4: Tomograms and eigenspectra obtained with PCA Tomography applied to the GMOS data cube of NGC 1566. (a) Tomogram and eigenspectrum 1, (b) tomogram and eigenspectrum 2 and (c) tomogram and eigenspectrum 3 . The eigenspectra are not redshift corrected. 

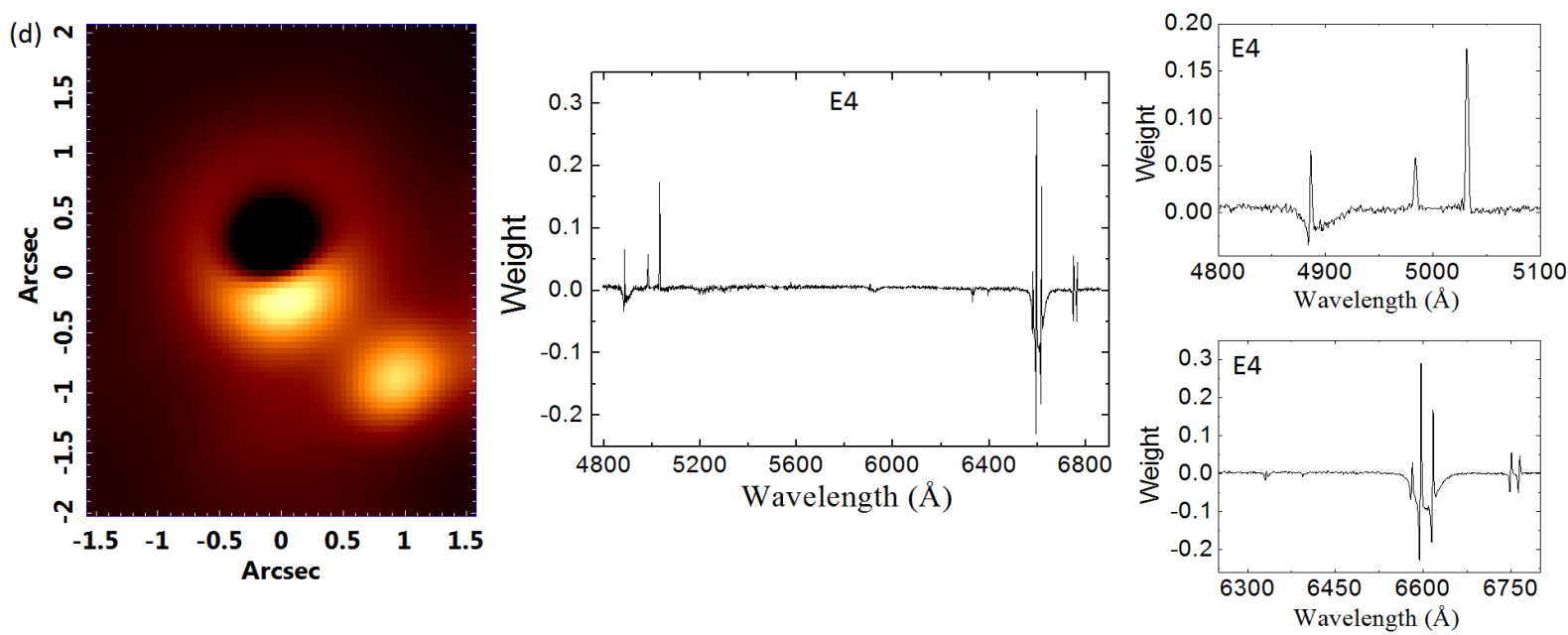

Figura 5.5: (d) Tomogram and eigenspectrum 4. The eigenspectrum is not redshift corrected.

\subsubsection{Eigenvectors and tomograms}

The first set of tomogram/eigenvector (Fig. 5.4 a) represents the characteristics associated with most of the data cube variance. This eigenspectrum resembles the data cube's average spectrum, which reveals the data redundancy (see Fig. 5.1). However, this eigenspectrum displays less structures compatible with the absorption lines than the average spectrum, indicating that it is less related to the stellar population's emission than the average spectrum. It is possible to see correlations compatible with the emission lines coming from the central region (bright) of the tomogram (correlated to the eigenspectrum). Structures compatible with the broad components of $\mathrm{H} \alpha$ and $\mathrm{H} \beta$ lines are evident, with a strong emission of $[\mathrm{O}$ III $] \lambda 5007$ and with the emission of the typical lines of partial ionization regions $([\mathrm{O} \mathrm{I}] \lambda 6300,[\mathrm{~S}$ II $] \lambda \lambda 6716,6731$ and $[\mathrm{N}$ II $] \lambda \lambda 6548,6584)$. All these characteristics reveal the existence of an AGN in the bright region of the associated tomogram. The variance fraction explained by this eigenvector is about 95 per cent.

The second eigenvector (see Fig. 5.4 b) is correlated to the main emission lines of this spectral region and to the broad components of $\mathrm{H} \alpha$ e $\mathrm{H} \beta$. There is, also, an anticorrelation with many stellar absorption lines in this spectral region. Based on that, it is possible to infer that the tomogram's bright regions represent the main areas from where the emission lines are emitted. At the same time, one may notice that the stellar absorptions are more accentuated in the tomogram's dark region (anticorrelated to the eigenspectrum) than in the bright regions. One of the bright regions, Region 1, is centred on the galaxy's nucleus 


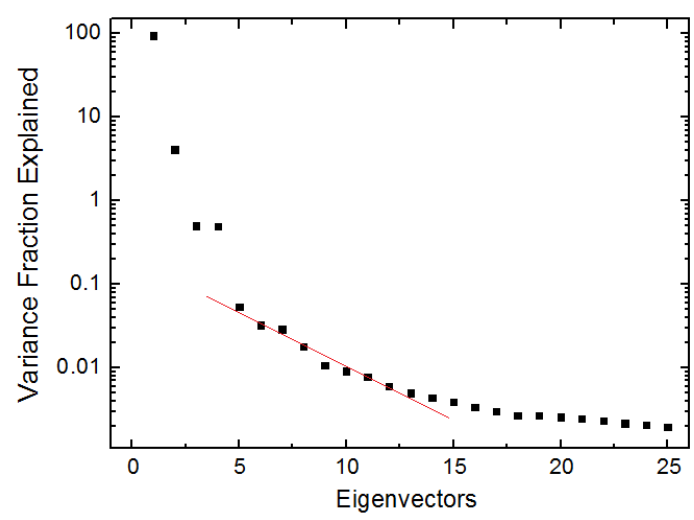

Figura 5.6: 'Scree test'. The red line shows that, from eigenvector E5 onwards, the decrease rate of variance fraction explained becomes constant. This shows that the noise is relevant in the data from this eigenvector onwards, making interpretation difficult.

(centre of the FOV), while the second region, Region 2 , is centred at $\Delta_{x}=1$ " and $\Delta_{y}=$ $-1 "$. This eigenvector explains about 4 per cent of the data cube variance.

Eigenvector $\mathrm{E} 3$ is correlated to the low ionization lines $(\mathrm{H} \beta, \mathrm{H} \alpha,[\mathrm{N}$ II $] \lambda \lambda 6548,6584$, [S II $] \lambda \lambda 6716,6731)$ and anticorrelated to the higher ionization lines ([O III $] \lambda \lambda 4959,5007)$. So, the tomogram's bright regions (see Fig. 5.4k), which are correlated to eigenvector E3, are regions of lower ionization and the tomogram's central dark region emits the higher ionization lines. In other words, this set of tomogram/eigenvector is differentiating the regions of high and low ionization and explains 0.5 per cent of the variance.

Eigenspectrum E4 (see Fig. 5.4d) is anticorrelated to the broad components of the $\mathrm{H} \alpha$ e $\mathrm{H} \beta$ lines. With the exception of the $[\mathrm{O}$ III $] \lambda \lambda 4959,5007$ and $[\mathrm{O} \mathrm{I}] \lambda 6300$ lines, there are anticorrelations to the blue wings of all the emission lines and correlations to the red wings of the same lines. In view of this, the set tomogram/eigenvector 4 represents certain phenomena: the kinematics of the low ionization lines, the location of the BLR and the emission of the higher ionization lines. The central bright region is the same one observed in tomogram 3, therefore, indicating again the location from where the higher ionization emission lines are emitted. In addition, eigenspectrum E4 also has correlations to the red wings of all other emission lines. Therefore, it is possible that at least part of this region is in redshift. The second bright area in the tomogram, which coincides with Region 2, is not correlated to the higher ionization lines (see tomogram 3), so it must be associated with the correlations to the red wings of the emission lines observed in eigenspectrum E4. Based on that, Region 2 should also be in redshift. The dark area, besides indicating the 

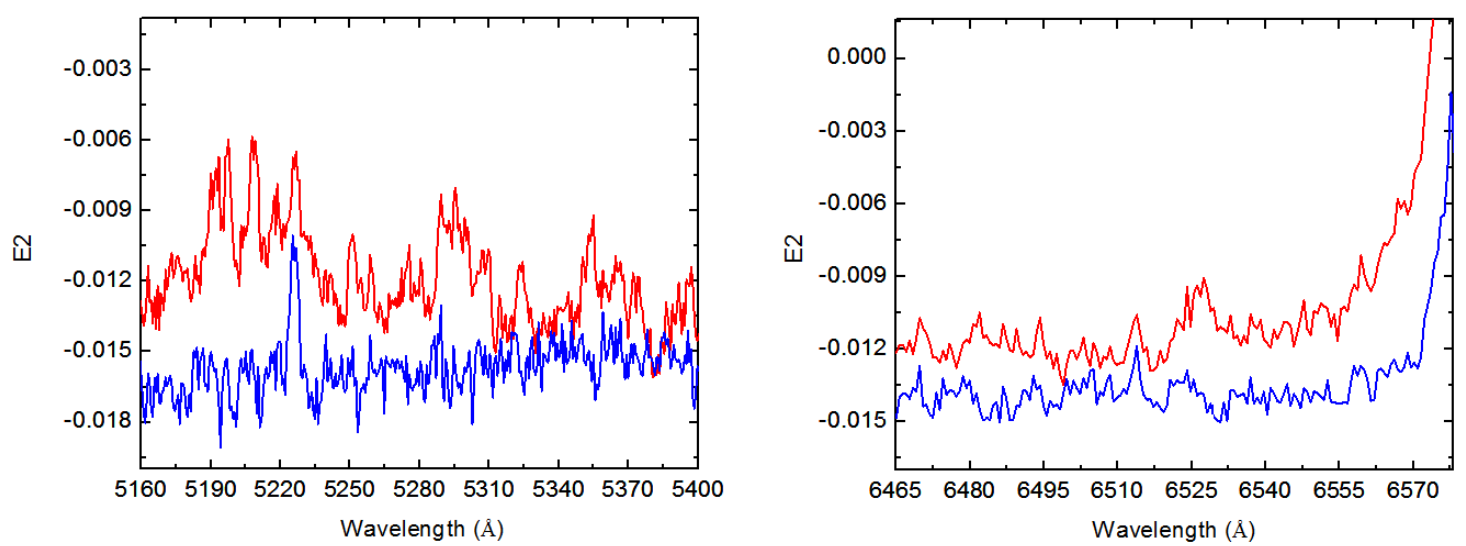

Figura 5.7: Two wavelength ranges of eigenspectrum E2 (not redshift corrected): in red, the original eigenspectrum E2 and, in blue, the same eigenspectrum obtained from the data cube after the removal of the featureless continuum contamination, whose determined spectral index is 1.7.

location of the BLR, as it is anticorrelated to the broad components of the $\mathrm{H} \alpha$ and $\mathrm{H} \beta$ lines, also coincides with the area where the gas is in blueshift. The possible correlation of the bright part of the central region to the red wings of the lines and the anticorrelation of the other part, which shows the blueshift area, suggests the existence of a kinematic phenomenon, being an outflow or a gas rotation. This eigenvector explains about 0.49 per cent of the variance.

It is not possible to interpret the data clearly from the set of tomogram/eigenvector 5 onwards. This is because noise becomes dominant as the variance fraction decreases. By summing the variance fractions of all other eigenvectors, we have 0.24 per cent; so, there is little information shrouded in a lot of noise. A way to see that is through the 'scree test'. Generally, when the rate of decrease of the explained variance fraction reaches a nearly constant value (which happens here from eigenvector E5 onwards - Fig. 5.6), the noise dominates the eigenvectors, making their interpretation more difficult. But it is also possible to see that from eigenvector E15 onwards, the decreasing rate is flatter and there is little difference between the variance fractions of the eigenvectors, which shows that the noise is even more expressive in the data from this eigenvector onwards.

\subsubsection{Featureless continuum}

Great part of the AGN emission occurs in the form of a featureless continuum, which behaves mathematically as a power law, 

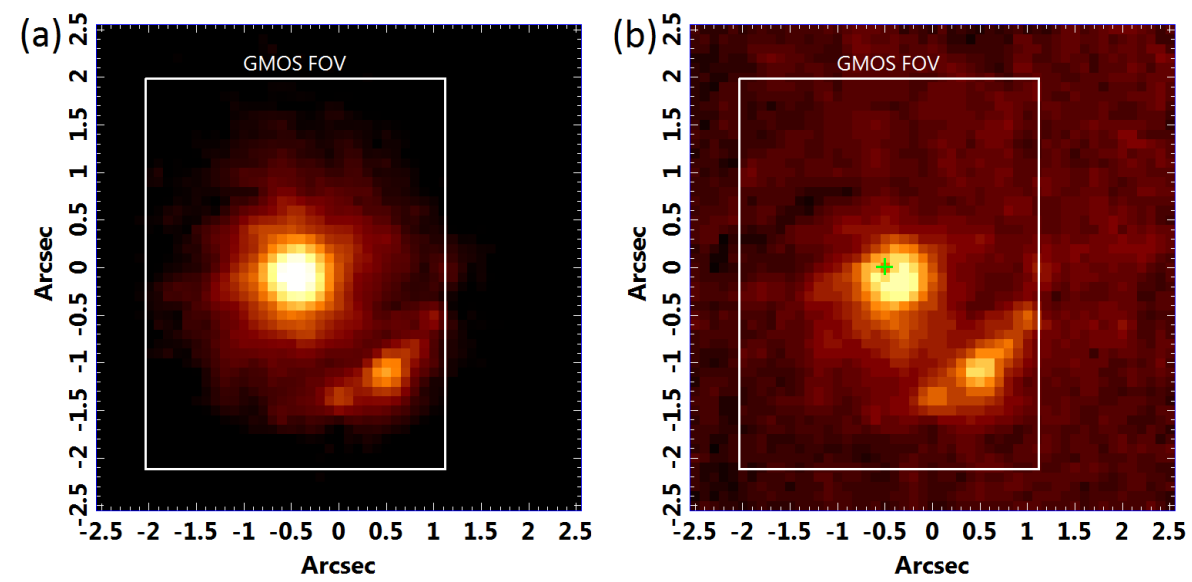

Figura 5.8: (a) Filter F658N image obtained with WFPC2 of the HST, at the wavelength $6562 \AA$, without the stellar emission (represented by the filter F555W image multiplied by a constant). In this image, it is possible to see the central region, which corresponds to the AGN, and the $\mathrm{H}$ II region, according to Fig. 5.10. A square representing the size of GMOS/IFU FOV was added to the image. (b) H $\alpha / \mathrm{F} 555 \mathrm{~W}$ ratio image, with the green cross representing the emission peak in the filter F555W. The size of the cross represents the position uncertainty of $2 \sigma$.
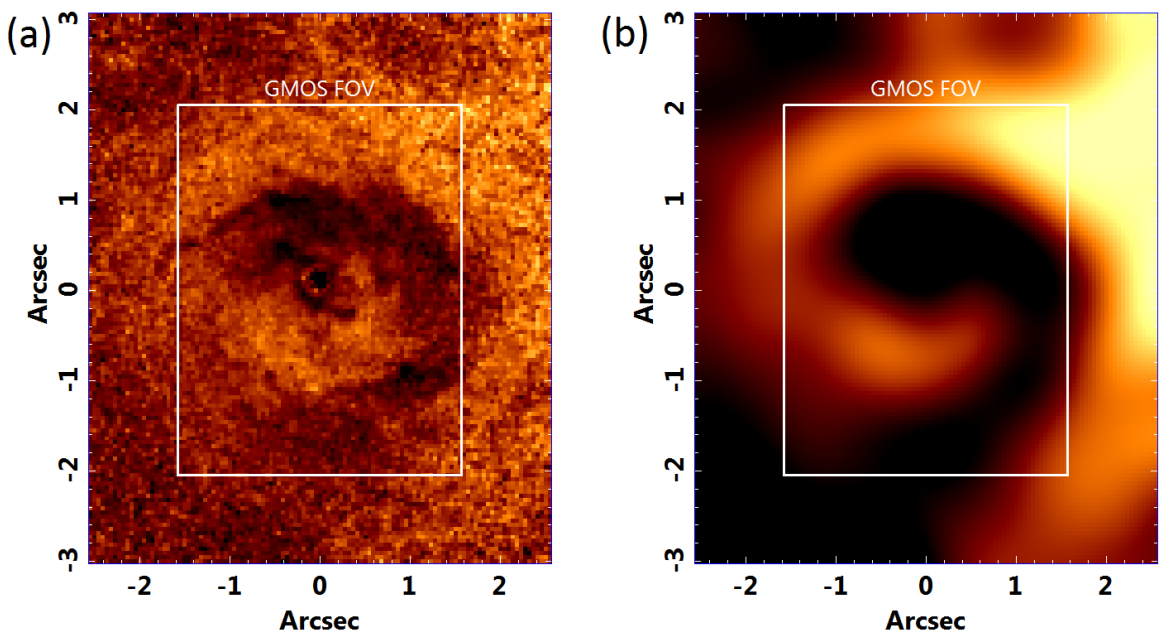

Figura 5.9: (a)HST image corresponding to the subtraction F555W-F814W (equivalent to $V-I$ ). (b)The same image convolved with the PSF of the optical data cube. Both images have the indication of the size of the GMOS/IFU FOV. The bright areas indicate regions where spectra are redder and the dark areas indicate regions where spectra are bluer. 


$$
F_{\nu}=A \nu^{-\alpha}
$$

where the exponent $\alpha$ is called spectral index.

Eigenspectrum 2 (Fig. 5.4 b) reveals that the stellar absorption lines are less intense in the AGN region than in its surroundings. We believe that this is due to the obfuscation of these lines by the featureless continuum emitted by the AGN. In order to find an appropriate spectral index to describe this emission, synthetic data cubes containing power laws at the AGN position were built, with different spectral indexes and different multiplicative constants. All the others values in the synthetic data cubes were assumed to be 0 . After that, each frame of the synthetic data cube was convolved with a PSF, with FWHM given by the variation law estimated from the data cube of the standard star used during the data reduction. This variation law requires a value for FWHM at a reference wavelength. We took the wavelength of $\mathrm{H} \alpha$ as reference and we also convolved the synthetic data cubes assuming different values for the reference FWHM. The convolved synthetic data cubes were then subtracted from the original one. Lastly, PCA Tomography was applied to the resulting data cubes. Fig. 5.7 shows the eigenvector E2 obtained from the PCA Tomography of the data cube before the subtraction of the featureless continuum, as well as the same eigenvector obtained with the PCA Tomography of the data cube that revealed the best subtraction, which was achieved assuming a featureless continuum with a spectral index of 1.7. The reference FWHM (at the wavelength of $\mathrm{H} \alpha$ ) for the variation law of the PSF convolved with the synthetic data cube that best removed the absorption lines obfuscation in the central region (FWHM $\sim 0 " .75)$ is higher than the FWHM of the PSF (estimated from the image of the broad component of $\mathrm{H} \alpha$ ) of the treated data cube of NGC $1566(\mathrm{FWHM}=0$ 0"66). This suggests that the detected emission, with the approximate form of a power law, is not coming from the AGN alone (see Appendix 5.11).

\subsection{Analysis of HST images}

In order to analyse with greater detail the circumnuclear structures in this galaxy, we compared our data with some HST archive images, observed with the Wide-Field Planetary Camera 2 (WFPC2) using the broad-band F555W and F814W filters (Erwin, 2004; Georgiev e Böker, 2014), which correspond, approximately, to the $V$ and $I$ bands, 


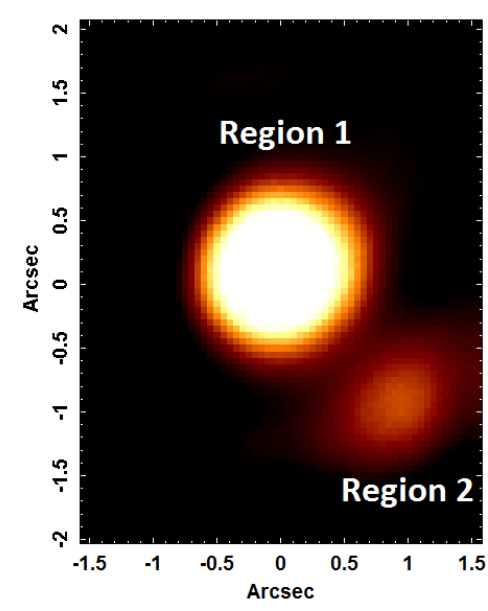

Figura 5.10: Image of the data cube collapsed along the spectral region of the $[\mathrm{N}$ II $] \lambda 6548, \mathrm{H} \alpha$ and $[\mathrm{N}$ II] $\lambda 6584$ lines. In this figure, the two main emitting regions are indicated: Region 1 (AGN), centred on the nucleus, and Region 2 (H II region), centred on $\Delta_{x}=1$ " and $\Delta_{y}=-1 "$.

respectively. The images were taken on 1995 August 30 and three exposures of $100 \mathrm{~s}$ were made for each filter. We also retrieved, from the HST data archive, three 600-s exposures, taken with WFPC2, on 2009 September 9, using the narrow-band F658N filter.

An $\mathrm{H} \alpha$ image was obtained with the $\mathrm{F} 658 \mathrm{~N}$ filter, after the subtraction of the image in the F555W filter (multiplied by a constant), which represents the stellar emission. The result obtained after rotating the subtracted image, so that it had the same GMOS data orientation presented here, is shown in Fig. 5.8(a). We can see that, besides the central emitting region (Region 1), there are other significant emitting regions southwest from the nucleus, which correspond to Region 2, observed in the optical data cube (see Fig. 5.10). An interesting detail is that these emitting regions, located at about 1".4 from the nucleus, are placed along a structure that is similar to a spiral arm in the central region of NGC 1566. In section 5.6, we see that Region 1 represents the AGN, which has Seyfert emission, and Region 2 is an $\mathrm{H}$ II region close to the nucleus.

Fig. 5.8(b) corresponds to the ratio between the $\mathrm{H} \alpha$ and $\mathrm{F} 555 \mathrm{~W}$ filter images $(\mathrm{H} \alpha / \mathrm{F} 555 \mathrm{~W})$. It shows exactly the same structures depicted in Fig. 5.8(a), and it is possible to visualize in greater detail that Region 2 has many emitting areas. Furthermore, we noticed that the point corresponding to the emitting peak in the F555W filter image is not coincident with the emitting peak in the $\mathrm{H} \alpha$ image. Another characteristic that we cannot see very well in Fig. 5.8(a) is the extended emission to the south-west, which coincides with the outflow direction observed in the [O III] images (see section 5.7). 


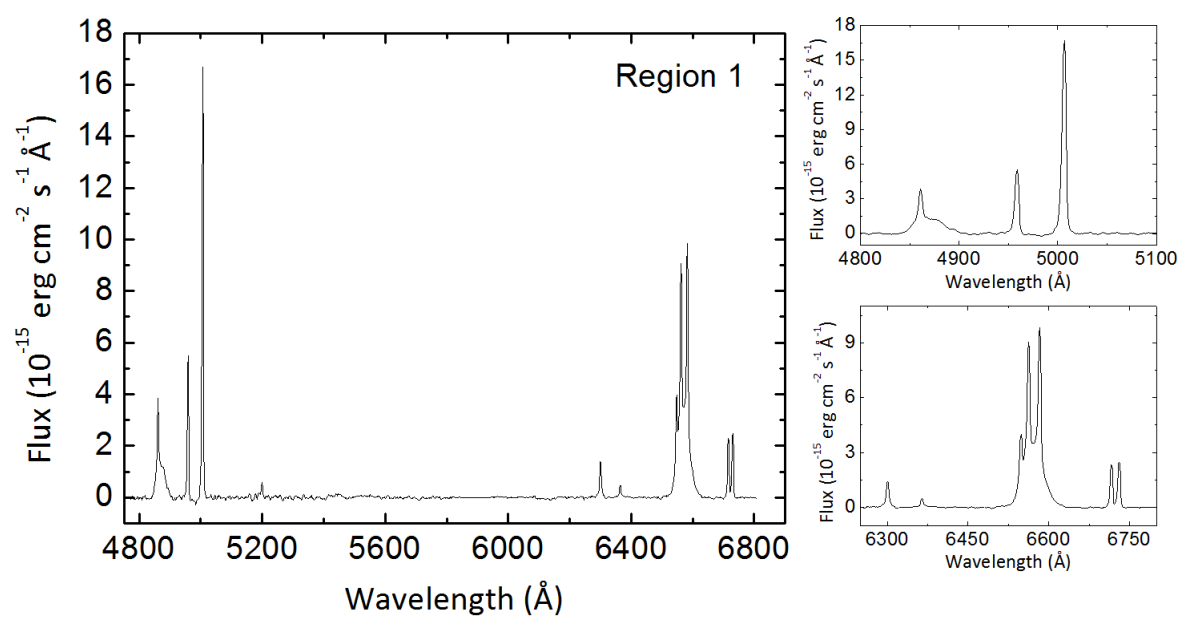

Figura 5.11: Spectrum of the NGC 1566 nucleus (Region 1: AGN) extracted from the GMOS/IFU data cube.

Tabela 5.1 - Emission-line ratios of Regions 1 (AGN) and 2 (H II region).

\begin{tabular}{lll}
\hline Emission-line ratios & Region 1 & Region 2 \\
\hline$[\mathrm{O}$ III $] \lambda 5007 / \mathrm{H} \beta$ & $6.2 \pm 0.5$ & $0.50 \pm 0.06$ \\
{$[\mathrm{~N}$ II $] \lambda 6584 / \mathrm{H} \alpha$} & $1.18 \pm 0.08$ & $0.65 \pm 0.05$ \\
$([\mathrm{~S}$ II $] \lambda 6716+6731) / \mathrm{H} \alpha$ & $0.78 \pm 0.16$ & $0.267 \pm 0.017$ \\
{$[\mathrm{O}$ I $] \lambda 6300 / \mathrm{H} \alpha$} & $0.29 \pm 0.03$ & $0.024 \pm 0.004$ \\
{$[\mathrm{~S}$ II $] \lambda 6716 /[\mathrm{S} \mathrm{II}] \lambda 6731$} & $0.9 \pm 0.4$ & $1.07 \pm 0.08$ \\
\hline
\end{tabular}

An image equivalent to $V-I$ was made by subtracting, in scale of magnitude, the images in the F555W and F814W filters (see Fig. 5.9a). It is easy to see that the bright areas, which represent the redder spectral emission, are arranged in a pattern around the central region that closely resembles a spiral. By convolving this HST image with the GMOS PSF of the data analysed here, we obtain the image shown in Fig. 5.9(b), which reveals clearly the spiral structure mentioned before. We also notice that the bluer regions, with a similar spiral pattern, include the central region (due to the featureless continuum emission from the AGN and to the presence of young stellar populations there) and the H II region (possibly due to the presence of young stellar populations at the spiral arm). 

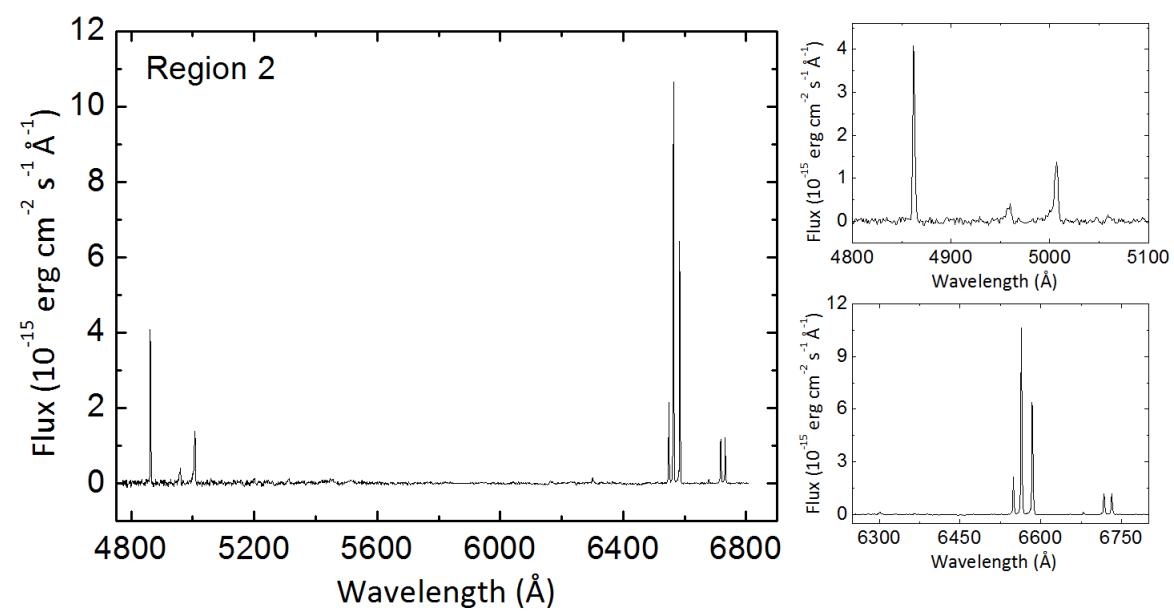

Figura 5.12: Spectrum of the emitting region found close to the nucleus of NGC 1566 (Region 2: H II region) extracted from the GMOS/IFU data cube.
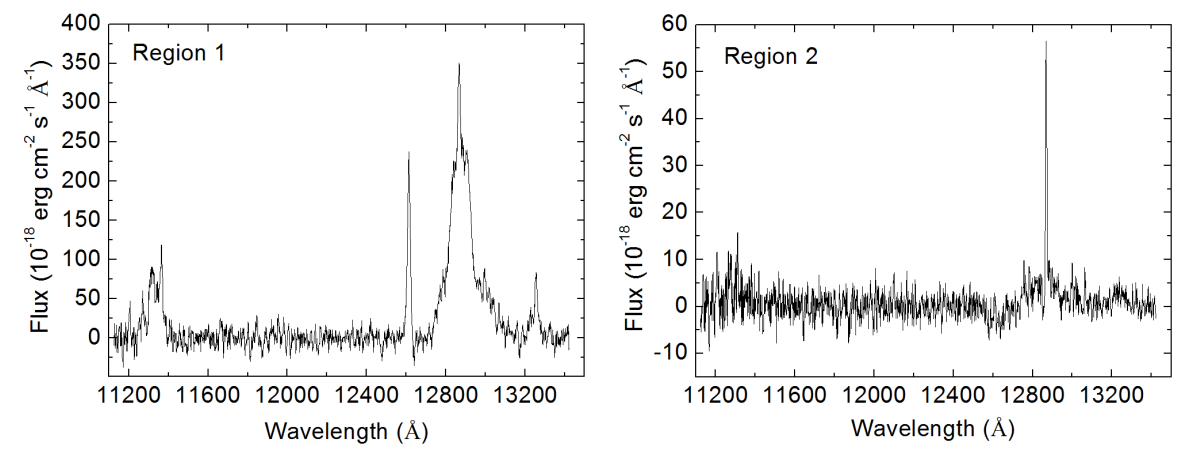

Figura 5.13: Spectrum of the NGC 1566 nucleus (Region 1: AGN) and of the H II region found close to the nucleus (Region 2: $\mathrm{H}$ II region) extracted from the $J$-band SINFONI data cube.
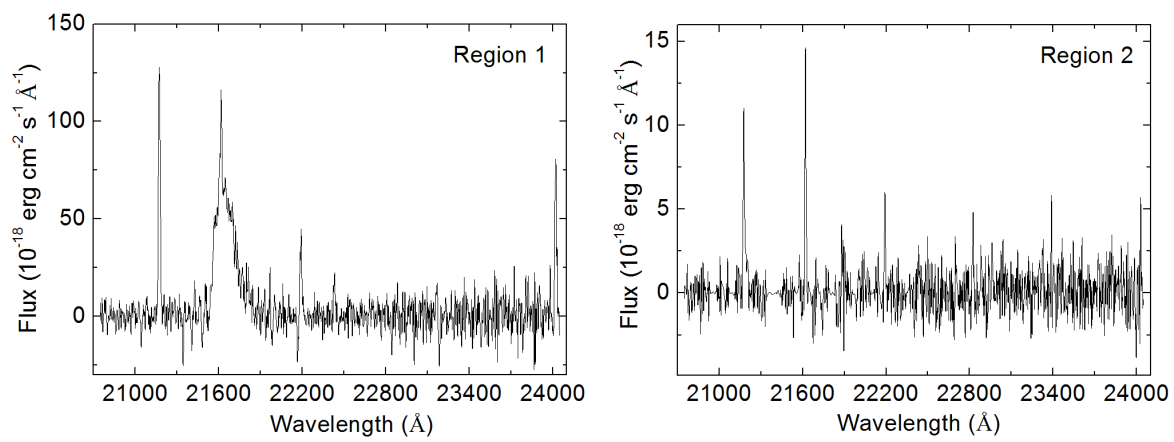

Figura 5.14: Spectrum of the NGC 1566 nucleus (Region 1: AGN) and of the H II region found close to the nucleus (Region 2: $\mathrm{H}$ II region) extracted from the $K$-band SINFONI data cube. 

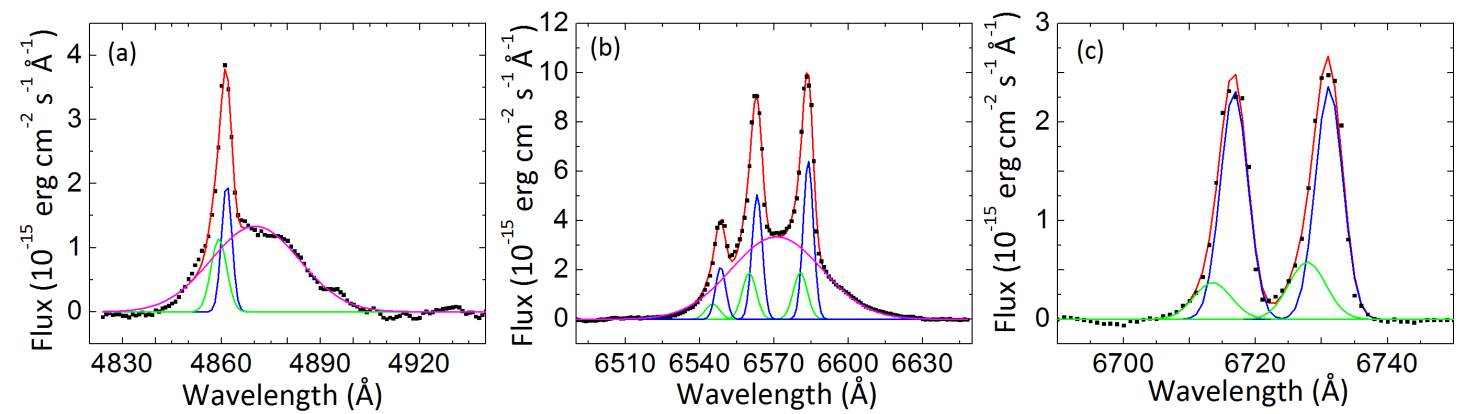

Figura 5.15: Gaussian fits of the following lines: (a) $\mathrm{H} \beta$, (b) [N II] $] 6548, \mathrm{H} \alpha$ and [N II] $] 6584$ and (c) [S II] $\lambda \lambda 6716,6731$. The black points correspond to the observed data. The blue and green lines represent the narrow components of the emission lines. The pink curves are the broad components of the $\mathrm{H} \alpha$ and $\mathrm{H} \beta$ lines and the red curves represent the final fits of the Gaussian compositions.
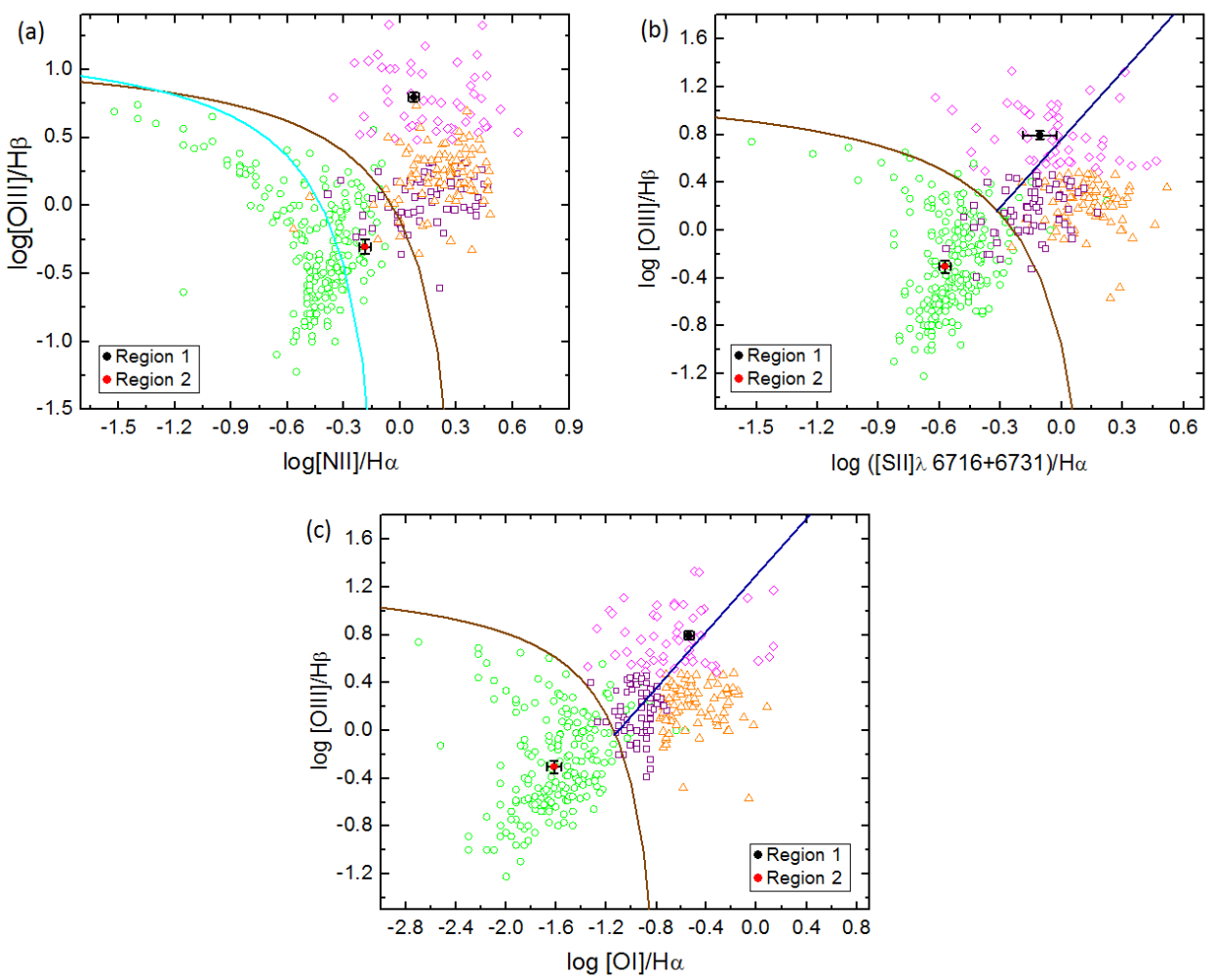

Figura 5.16: Diagnostic diagrams of the main emission-line ratios in the optical data cube of NGC 1566. The central emitting region (Region 1) is represented by the black point and Region 2, by the red square. All other points correspond to the objects analysed by Ho et al. (1997): the green circles are H II regions, the orange triangles are LINERs (low-ionization nuclear emission-line regions), the violet squares are transition objects and the pink diamonds represent Seyfert galaxies. The brown line in the diagrams (a)-(c) shows the maximum limit of ionization by a starburst obtained by Kewley et al. (2001). The cyan line represents the division between H II regions and AGNs made by Kauffmann et al. (2003) and the blue line represents the division between Seyfert galaxies and LINERs obtained by Kewley et al. (2006). 


\subsection{AGN and the H II region}

\subsubsection{Analysis of optical spectra}

In order to make a detailed analysis of the emission lines of the data cube, a stellar continuum subtraction was performed. After applying the spectral synthesis (see Appendix 5.11), the resulting synthetic stellar spectra were subtracted from the original data cube, which resulted in a data cube with mainly emission lines (gas data cube).

The PCA Tomography results (see section 5.4) show two distinct emitting regions (see Fig 5.10): one centred on the nucleus (Region 1) and the other (Region 2) centred on $\Delta_{x}=1 "$ and $\Delta_{y}=-1$ ", whose projected distance from the nucleus is about $73.3 \pm 1.9 \mathrm{pc}$ $(1 " .40 \pm 0 " .04)$. In order to study the spectral properties of the second emitting region, we extracted a spectrum from a circular region of the gas data cube, centred on $\Delta_{x}=1$ " and $\Delta_{y}=-1$ ", whose radius (0".3) is equal to half of the PSF's FWHM. We likewise extracted a spectrum with the same radius from Region 1 (see Figs 5.11 and 5.12). The two extracted spectra were corrected for the interstellar extinction, using the values of the $\mathrm{H} \alpha / \mathrm{H} \beta$ ratio (considering only the narrow components of the lines) and the extinction law of Cardelli et al. (1989).

The spectrum of Region 1 shows, clearly, $\mathrm{H} \alpha$ and $\mathrm{H} \beta$ broad components. In order to separate the blended lines of this spectrum, first of all, we fitted the [S II] 66716,6731 lines with a sum of two Gaussian sets (set 1 and set 2). In each set, we assumed a velocity $(V)$ and a width $(\sigma)$ for the Gaussians. Thus, each [S II] line was fitted with two Gaussian functions with different values of $V$ and $\sigma$. The resulting fits, shown in Fig. 5.15(c), reproduced the $[\mathrm{S}$ II] lines with good precision. The Gaussian widths (FWHM) of each set, corrected for the instrumental resolution, are $207 \pm 10$ and $290 \pm 44 \mathrm{~km} \mathrm{~s}^{-1}$. After that, we fitted the $[\mathrm{N} \mathrm{II}] \lambda 6548 ; 6584+\mathrm{H} \alpha$ lines with another Gaussian sum (Fig. 5.15b). In this case, we used two sets (blue and green Gaussians - see Fig. 5.15b) of three Gaussians (two Gaussians for each line), each set having the same values of $V$ and $\sigma$ obtained in the [S II] fit. In other words, the [S II] lines were taken as a template to determine the main kinematic parameters of the Gaussians used to fit the other lines. A broad Gaussian was added to represent the $\mathrm{H} \alpha$ broad component. One may notice that the Gaussians describe the $[\mathrm{N}$ II $]+\mathrm{H} \alpha$ lines very well. The Gaussian representing the $\mathrm{H} \alpha$ broad component has a luminosity of $(5.6 \pm 0.5) \times 10^{5} L_{\odot}$ and its FWHM is indicated in Table 5.2. The $\mathrm{H} \beta$ 
line was fitted with a sum of two narrow Gaussians, with the same kinematic parameters provided by the fit of the [S II] lines, and with a broad Gaussian, with the same width and velocity obtained from the fit of the $\mathrm{H} \alpha$ broad component (Fig. 5.15a). Although the $\mathrm{H} \beta$ line has a more irregular profile relative to the others, due to the lower signal-to-noise $(\mathrm{S} / \mathrm{N})$ of this spectral region, the main characteristics of this line were well reproduced. The velocities ( $V$ parameter) relative to the central wavelength of each line were: for the broad component, $375 \pm 6 \mathrm{~km} \mathrm{~s}^{-1}$; for set 1, $15 \pm 6 \mathrm{~km} \mathrm{~s}^{-1}$; and, for set 2, -132 $\pm 75 \mathrm{~km}$ $\mathrm{s}^{-1}$.

From the Gaussian fits obtained for the spectrum of Region 1 we know that the $\mathrm{H} \alpha$ and $\mathrm{H} \beta$ line profiles are compatible, since the same parameters were used to fit those lines. Another way to prove this is by subtracting, from the original spectrum, the Gaussian fits representing the narrow components of $\mathrm{H} \beta$ and $\mathrm{H} \alpha+[\mathrm{N} \mathrm{II}] \lambda \lambda 6548 ; 6584$. This procedure allowed us to isolate the $\mathrm{H} \alpha$ and $\mathrm{H} \beta$ broad components. Fig. 5.19 shows the overlap of the profiles of those broad components, in the velocity space. In this figure, the $\mathrm{H} \alpha$ flux was divided by 2.81 (which is the minimum value for the $\mathrm{H} \alpha / \mathrm{H} \beta$ ratio, which occurs in the absence of extinction, assuming case B of recombination, with density of $10^{6} \mathrm{~cm}^{-3}$ and temperature equal to $10^{4} \mathrm{~K}$ ) for a better visualization. We notice that the ratio between the two broad components is, in fact, compatible with 2.81, which indicates that there is little extinction internal to the AGN's BLR in this galaxy. All the observed extinction is associated with the narrow components of the lines and, consequently, with the narrow-line region (NLR), and had already been corrected, based on $\mathrm{H} \alpha / \mathrm{H} \beta$ values. The widths of the broad components are compatible at $1 \sigma$ level - see Table 5.2. This result is consistent with that obtained by fitting these lines with Gaussian sums, as explained before.

Region 2 spectrum does not have blended lines that require Gaussian fits for a decomposition. However, the $[\mathrm{O}$ III $] \lambda 5007$ line presents a probable contamination by the AGN emission, which appears as a prominent blue wing. In order to determine the $[\mathrm{O}$ III $] \lambda 5007$ flux without the contamination, we fitted it as a sum of two Gaussians: one representing the contamination and the other the emission of [O III $] \lambda 5007$ coming from Region 2 (see Fig. 5.17). The values obtained for the FWHM of the Gaussians representing the [O III] 25007 line and the contamination by the AGN are $227 \pm 12$ and $544 \pm 110 \mathrm{~km} \mathrm{~s}^{-1}$, respectively. The FWHM of all other lines is $55 \pm 10 \mathrm{~km} \mathrm{~s}^{-1}$. The velocity ( $V$ parameter) relative to the central wavelength of the $[\mathrm{O}$ III $] \lambda 5007$ line, for the narrow component, is -4 


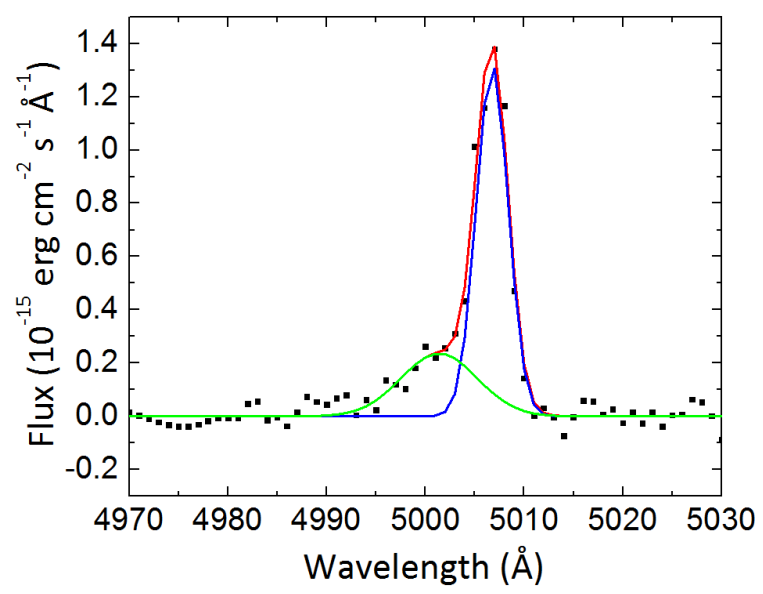

Figura 5.17: Region 2 [O III] $] 5007$ line Gaussian fit. This was the only line in the region's spectrum that presented considerable contamination coming from the AGN. The black points are the observed data. The green line represents the contamination due to the AGN emission; the blue line, the [O III] $\lambda 5007$ line emitted by the H II region; and the red curve is the total fit, which consists of the sum of the Gaussian fits.

$\pm 5 \mathrm{~km} \mathrm{~s}^{-1}$ and, for the Gaussian representing the contamination, is $-326 \pm 63 \mathrm{~km} \mathrm{~s}^{-1}$. The velocity of all other lines is $51 \pm 5 \mathrm{~km} \mathrm{~s}^{-1}$.

We calculated the following emission-line ratios for the two emitting regions: $[\mathrm{O}$ III $] \lambda 5007 / \mathrm{H} \beta$, $[\mathrm{N}$ II $] \lambda 6584 / \mathrm{H} \alpha,([\mathrm{S} \mathrm{II}] \lambda 6716+\lambda 6731) / \mathrm{H} \alpha,[\mathrm{O}$ I $] \lambda / \mathrm{H} \alpha$ and $[\mathrm{S}$ II $] \lambda 6716 /[\mathrm{S}$ II $] \lambda 6731$ (see Table 5.1). Only the narrow components of the lines of the AGN spectrum (Region 1) were taken into account and, in the case of the Region 2 spectrum, the contamination of the [O III $] \lambda 5007$ line by the AGN was not considered. The resulting diagnostic diagrams (Figs $5.16 \mathrm{a}-\mathrm{c})$ show the points representing the two emitting regions of NGC 1566 and also the points corresponding to the objects analysed by Ho et al. (1997). One can see that Region 1 has emission-line ratios typical of a Seyfert galaxy, while Region 2, taking into account the criteria of Kewley et al. (2001), can be classified as an H II region (diagrams b and c of Fig. 5.16) or as a transition object (Fig. 5.16a). We believe that Region 2 is an $\mathrm{H}$ II region contaminated by the emission from the AGN. Although the contamination was more significant in the $[\mathrm{O}$ III $] \lambda 5007$ line and was removed, there can still be contamination in other lines, more difficult to identify, and also to remove.

We verified from the previous Gaussian fits that the velocity of the $\mathrm{H}$ II region relative to the centre $(\mathrm{AGN})$ is $36 \pm 8 \mathrm{~km} \mathrm{~s}^{-1}$. 


\subsubsection{Analysis of NIR spectra}

As mentioned above, the subtraction of the stellar continuum of the $K$-band data cube used the synthetic stellar spectra obtained with the pPXF method. In the $J$-band data cube, this procedure was carried out by fitting and subtracting splines from the stellar continuum. We then extracted the resulting emission-line spectra from circular regions, with radius equal to half of the FWHM of the PSF of the data cubes, centred on Regions 1 and 2 of the gas cubes obtained in the $J$ and $K$ bands. The extracted spectra are shown in Figs 5.13 and 5.14 .

Region 1 spectrum of the $J$-band data cube shows a very broad $\mathrm{Pa} \beta$ line and a narrow [Fe II $] \lambda 12570$ line. We fitted the $\mathrm{Pa} \beta$ line with a sum of three Gaussians. Fig. 5.18(a) shows the resulting fitting. Unlike the other fitted lines, the narrow component of the $\mathrm{Pa} \beta$ line was satisfactorily represented by only one Gaussian curve (in blue). The broad component corresponds to the sum of two Gaussians (in magenta, the broad component; and in purple, the very broad component, in Fig. 5.18 a) with different FWHMs (see Table 5.2). The broader Gaussian (in purple) does not appear in the Region 1 spectra of the other data cubes. The FWHM of the narrow component is $231 \pm 14 \mathrm{~km} \mathrm{~s}^{-1}$ and its velocity is 3 $\pm 5 \mathrm{~km} \mathrm{~s}^{-1}$. The velocities of the magenta and purple broad components (see Fig. 5.18a) are $98 \pm 6 \mathrm{~km} \mathrm{~s}^{-1}$ and $1107 \pm 10 \mathrm{~km} \mathrm{~s}^{-1}$, respectively, and their FWHM are shown in Table 5.2 .

Region 2 spectrum of the $J$-band data cube shows only one visible emission line: narrow $\mathrm{Pa} \beta$, with FWHM of $168 \pm 12 \mathrm{~km} \mathrm{~s}^{-1}$ and velocity of $64 \pm 5 \mathrm{~km} \mathrm{~s}^{-1}$.

Region 1 spectrum of the $K$-band data cube shows the $\mathrm{H}_{2} \lambda \lambda 21218,22234,24084$ and the $\operatorname{Br} \gamma$ lines. Similarly to the procedure applied to $\operatorname{Pa} \beta$, we fitted the $\operatorname{Br} \gamma$ line with a sum of Gaussians, but, in this case, only two Gaussians were necessary: a narrow one, with FWHM of $250 \pm 15 \mathrm{~km} \mathrm{~s}^{-1}$ and $V$ parameter of $5 \pm 5 \mathrm{~km} \mathrm{~s}^{-1}$, and a broad one, with $V$ parameter of $432 \pm 5 \mathrm{~km} \mathrm{~s}^{-1}$ and FWHM shown in Table 5.2. Although the spectrum is very noisy in this region, the fitting results were satisfactory for our purposes.

Region 2 spectrum of the $K$-band data cube shows narrow $\mathrm{H}_{2}$ and $\mathrm{Br} \gamma$ lines, with velocity of $71 \pm 7 \mathrm{~km} \mathrm{~s}^{-1}$ and FWHM of $124 \pm 12 \mathrm{~km} \mathrm{~s}^{-1}$. 

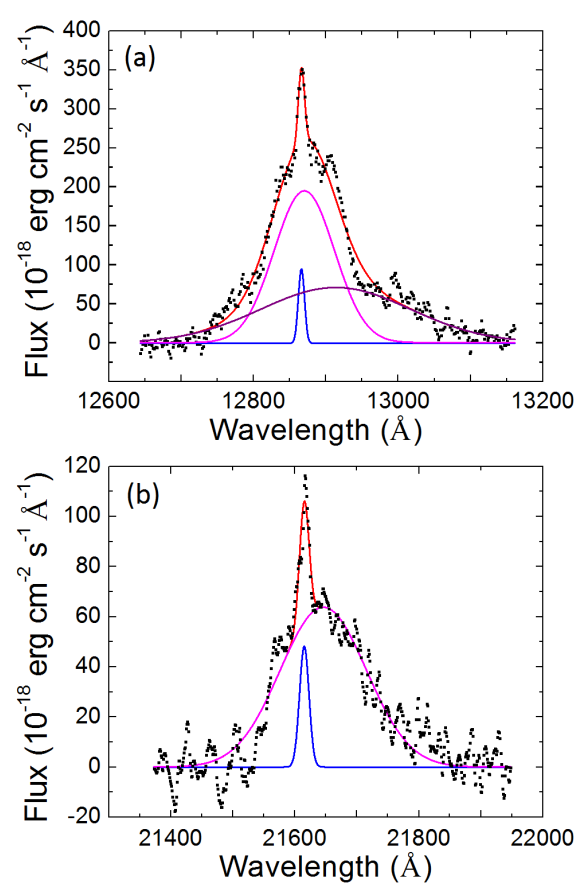

Figura 5.18: (a) Gaussian fit of the $\mathrm{Pa} \beta$ line of Region 1 spectrum. Besides one narrow and one broad component, the fit detected a very broad component (in purple) which does not appear in the fits of all the other lines of Region 1. (b) Gaussian fit of the Br $\gamma$ line of Region 1.

\subsubsection{Gravitational redshift}

An important aspect to be noted in Table 5.2 is that there is an evident correlation between the width of the lines (FWHM) and their respective redshifts (see Fig. 5.20). That can be explained by gravitational redshift: the closer to the AGN, the greater the redshift and the wider the lines, as long as the velocities have a Keplerian nature. The distinct values could be explained by the fact that the lines are emitted at different distances from the central object. This fact might be the result of different emissivities of the many regions of the BLR, or of the AGN's variability, since the spectra were taken in different epochs.

The hypothesis to explain the red asymmetries in the permitted lines of AGN spectra as being due to the gravitational redshift has already been discussed many times in the literature. Netzer (1977) created a simple model of a rotating disc with velocity $(v)$ between 5000 and $15000 \mathrm{~km} \mathrm{~s}^{-1}$, with some inclination angles and many radii, assuming gravitational redshift, and obtained line profiles shifted to the red. Further works also analysed the gravitational redshift influence in the AGN emission-line profiles, using more detailed models - see Bon et al. (2015) and the references therein. 


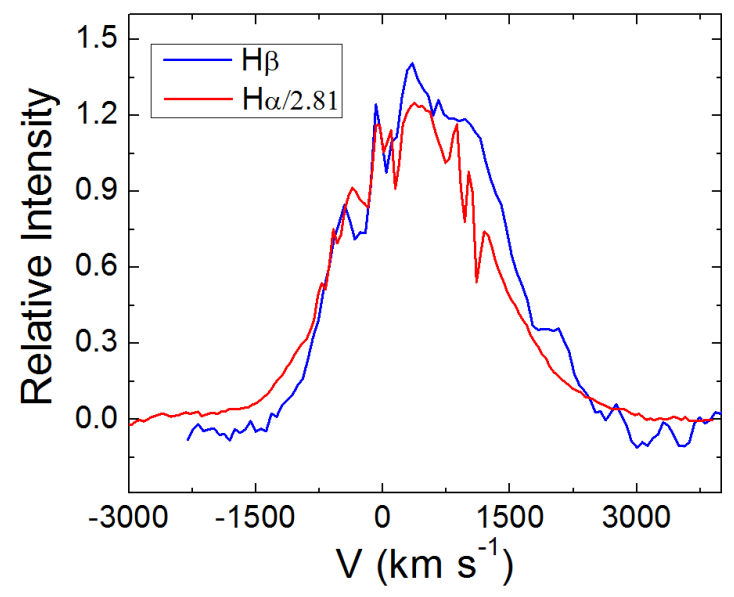

Figura 5.19: Broad components of the $\mathrm{H} \beta$ (in blue) and $\mathrm{H} \alpha$ (in red) lines in the velocity space. The $\mathrm{H} \alpha$ line flux was divided by 2.81 (minimum value of the $\mathrm{H} \alpha / \mathrm{H} \beta$ ratio, assuming the case $\mathrm{B}$ of recombination, with $T=10^{4} \mathrm{~K}$ and density of $10^{6} \mathrm{~cm}^{-3}$, which indicates absence of extinction) so that the lines are in the same scale.

Assuming that the redshift of the broad components of the observed lines is due to gravitational redshift, it is possible to determine the $R_{B L R} / R_{S}$ ratio from the following equation:

$$
1+z=\left(1-\frac{R_{s}}{R_{B L R}}\right)^{-1 / 2},
$$

where $z$ is the redshift of the line (in this case, the gravitational redshift), $R_{B L R}$ is the line emitting radius and $R_{s}$ is the black hole's Schwarzschild radius. The $R_{B L R} / R_{S}$ ratios calculated for all broad components of the emission lines of the AGN spectrum (which are, therefore, being emitted from the BLR) are shown in Table 5.2. In order to evaluate whether the AGN's variability can, in fact, result in the observed pattern of the broad components of the emission lines, we elaborated a toy model, assuming the existence of a circular ring of gas, emitter of a determined spectral line, rotating around the central black hole. Along this ring, the line is emitted with a Gaussian profile, with constant width and with the redshifts given by the combination of Keplerian values and gravitation redshift. The final observed line profile corresponds to the superposition of all the line emissions along the ring. The free parameters of this toy model are the ring's inclination relative to the line of sight, $i$, and the gravitational redshift, $z$, which is related to the gas' orbital velocity through the following expression (obtained from the equation 5.2): 
Tabela 5.2 - FWHMs, redshifts and the $R_{B L R} / R_{S}$ ratios of the broad components of the lines in Region 1 spectra.

\begin{tabular}{llll}
\hline Emission lines & FWHM $\left(\mathrm{km} \mathrm{s}^{-1}\right)$ & Redshift $\left(\times 10^{-3}\right)$ & $R_{B L R} / R_{S}$ \\
\hline $\mathrm{H} \beta$ & $1950 \pm 20$ & $1.80 \pm 0.10$ & 279 \\
$\mathrm{H} \alpha$ & $1970 \pm 10$ & $1.25 \pm 0.13$ & 401 \\
$\mathrm{Br} \gamma$ & $2273 \pm 40$ & $1.43 \pm 0.05$ & 350 \\
$\mathrm{~Pa} \beta$ (broad) & $615 \pm 40$ & $0.32 \pm 0.05$ & 1563 \\
$\mathrm{~Pa} \beta$ (very broad) & $5681 \pm 130$ & $3.69 \pm 0.19$ & 136 \\
\hline
\end{tabular}

$$
1+z=\left(1-\frac{2 v^{2}}{c^{2}}\right)^{-1 / 2} .
$$

To each combination of $z$ and $i$ considered in the model, the Gaussian width emitted along the ring was taken as being equal to the necessary value, so that the final profile is compatible with the observed one. The FWHM of all the resulting profiles were obtained with this toy model. The points corresponding to the observed parameters of the broad components, together with the traced curves from the toy model results, are shown in Fig. 5.20, One may notice a correlation between $z$ and FWHM. The curves obtained from the toy model reproduce reasonably well the observed correlation, as long as the inclination is low $\left(i \sim 5^{\circ}\right)$. It is important to emphasize that the different values of $z$ taken into account in the toy model are equivalent to different radii of the emitting gas ring. We are assuming that these different radii values where the line is emitted are a consequence of the AGN's variability.

We also tried to reproduce the observed correlation (Fig. 5.20) with a second toy model, assuming the existence of a spherical shell of gas, with only radial velocities, around the central black hole. In this case, however, all the obtained parameters were incompatible with the observed ones.

From the temporal variation of the profiles of the BLR lines, Alloin et al. (1985) estimated the BLR size as being less than 0.01 pc. If we assume that the BLR radius is half of this value, using the calculated values of the $R_{B L R} / R_{s}$ ratio (Table 5.2 , we conclude that the upper limit of the black hole's mass is between 1.3 and $4 \times 10^{8} \mathrm{M}_{\odot}$. The upper limit of the mass calculated by using the broader component of $\mathrm{Pa} \beta$ line is $3.4 \times 10^{7} \mathrm{M}_{\odot}$. Being upper limits, all the values obtained here are compatible with the value of the inner mass calculated from the $\mathrm{H}_{2}$ velocity curve (see section 5.7), which is of the order of $10^{7} \mathrm{M}_{\odot}$, 


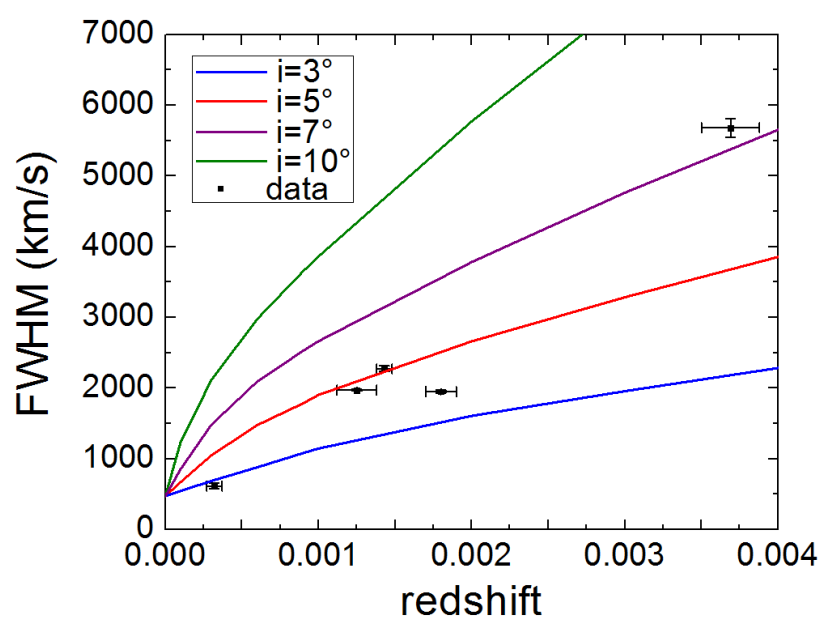

Figura 5.20: FWHM versus redshift of all the broad components of the emission lines presented in Table 5.2. The curves correspond to the results obtained with a toy model, which considers the emission of a gas ring around a central black hole, with different radii and inclination angles.

assuming that the inclination angle of this gas rotation is not close to zero. These values are also compatible with those obtained by Woo e Urry (2002) and Smajić et al. (2015). If we assume that the black hole mass is $8.3 \times 10^{6} \mathrm{M}_{\odot}$ (Woo e Urry, 2002), the BLR radius is between 1 and 15 light-days, which is within the upper limit of 20 light-days found by Alloin et al. (1985).

\subsection{Gas kinematics}

\subsubsection{Highly ionized gas in the optical}

By observing the line profiles of [O III $] \lambda 5007$ from the AGN spectrum and also from the H II region spectrum (see Fig. 5.17), one may notice an asymmetry, with a more pronounced blue wing. In order to analyse in greater detail this line's kinematics, we made the channel maps shown in Fig. 5.23. It is easy to see the existence of an extended emission, with a maximum at southeast from the nucleus, with velocities between -860 and $-500 \mathrm{~km}$ $\mathrm{s}^{-1}$. The emission from clouds with more positive velocities is considerably more compact and centred approximately on the nucleus. A possible explanation for this blueshifted extended emission is that it is associated with an outflow coming from the AGN. The emission associated with this apparent outflow also seems to extend towards Region 2, which suggests a possible contamination of the $\mathrm{H}$ II region emission by the outflow. In this case, the prominent blue wing of the $[\mathrm{O}$ III $] \lambda 5007$ line of the $\mathrm{H}$ II region spectrum could 

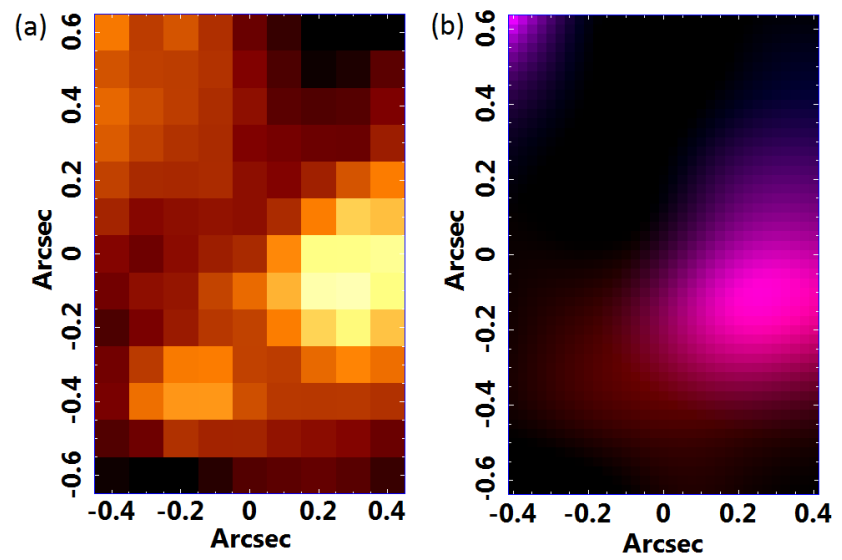

Figura 5.21: (a) Image of the $\mathrm{H} \alpha / \mathrm{F} 555 \mathrm{~W}$ ratio cut in the $\mathrm{H}$ II region. (b) $\mathrm{RB}$ composition of the $J$-band SINFONI data cube cut on the $\mathrm{H}$ II region: in red, the image of the red wing of the narrow component of $\mathrm{Pa} \beta$ and, in blue, the image of the blue wing of the same component. The orientation is north up and east to the left, as for the GMOS/IFU data cube.

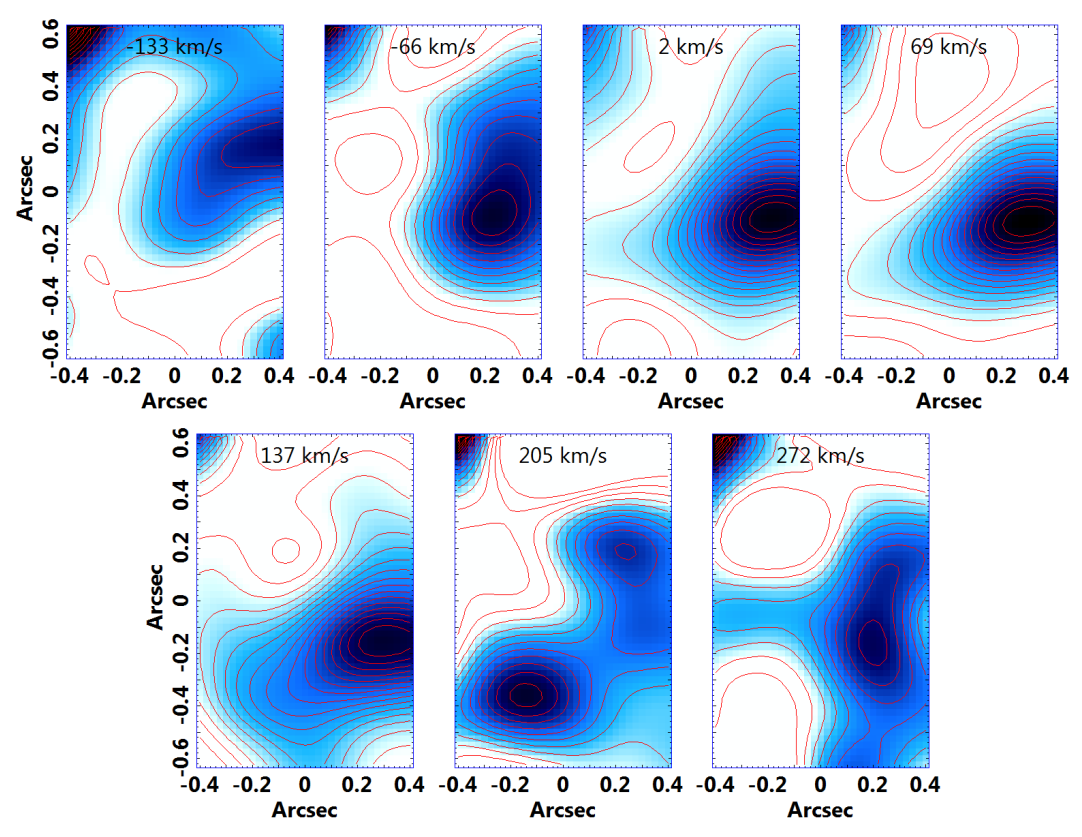

Figura 5.22: Channel maps of the $\mathrm{Pa} \beta$ line in the area corresponding to the $\mathrm{H}$ II region data cube. The isocontours of the positive values (higher than zero) are shown in red. The images were made at intervals of $1.45 \AA$ and the velocity values were obtained from the mean wavelength of the intervals relative to the $\mathrm{Pa} \beta$ central wavelength of the nuclear spectrum. 


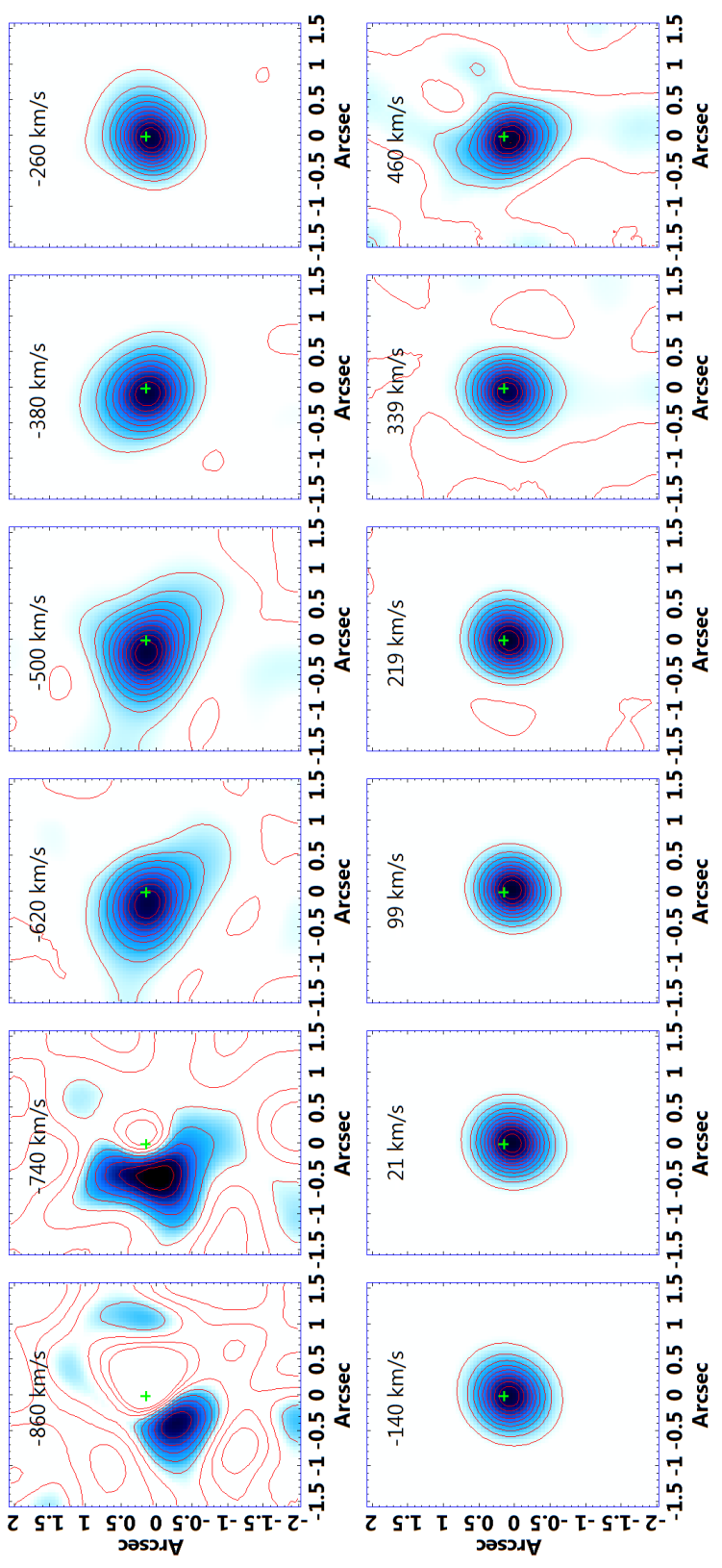

Figura 5.23: $[\mathrm{O} \mathrm{III}] \lambda 5007$ channel maps. The isocontours of the positive values are shown in red. The green cross indicates the AGN position and its size represents the $3 \sigma$ uncertainty. The images were taken at intervals of $2 \AA$ and the velocity values were obtained from the mean wavelengths of the intervals relative to the rest wavelength of $[\mathrm{O}$ III $] \lambda 5007$. 


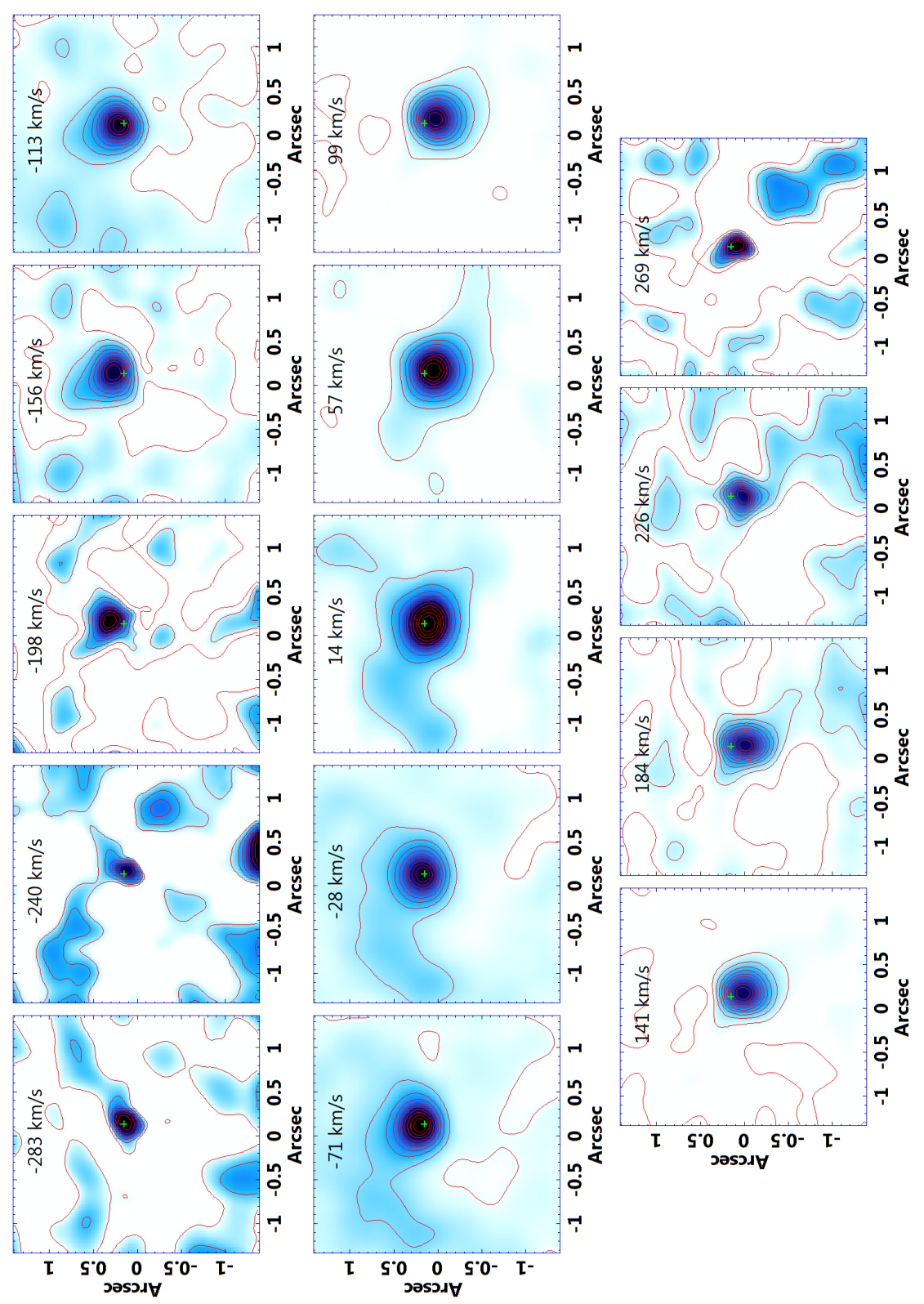

Figura 5.24: $H_{2} \lambda 21218$ channel maps. The isocontours of the positive values are shown in red. The green cross indicates the position of the AGN and its size represents the $3 \sigma$ uncertainty. The images were taken at intervals of $2 \AA$ and the velocities were obtained from the interval's mean wavelength relative to the central wavelength of $\mathrm{H}_{2} \lambda 21218$ of the nuclear spectrum. 

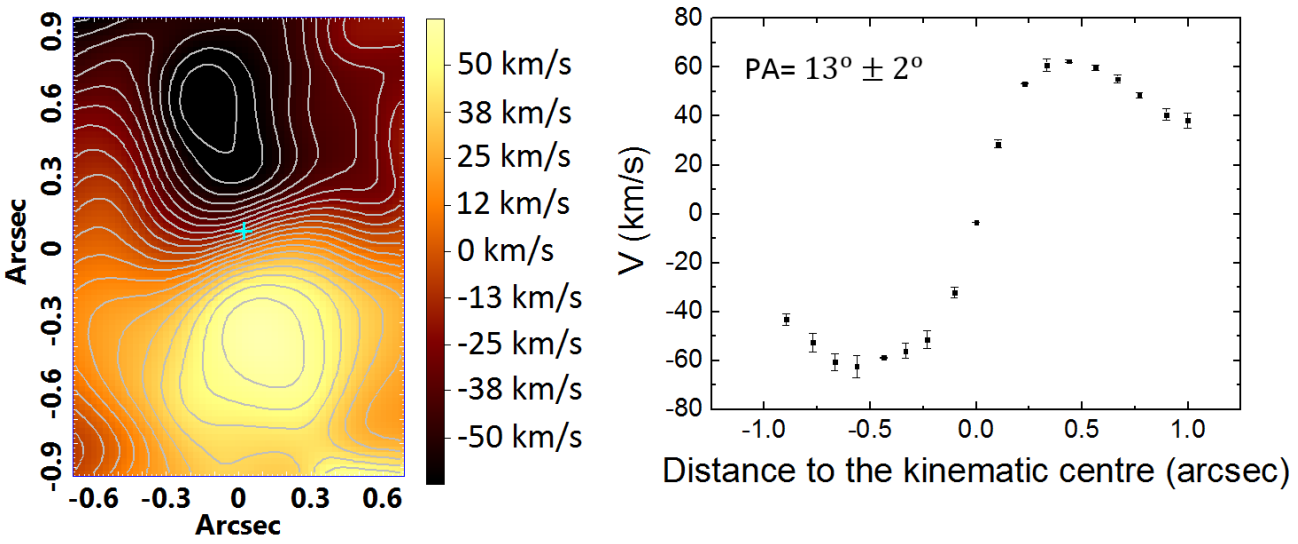

Figura 5.25: Velocity map of $\mathrm{H}_{2}$ with its velocity curve. The cyan cross indicates the position of the AGN, which was determined from the image of $\operatorname{Br} \gamma$. The cross size represents the uncertainty of $3 \sigma$.

be due to this contamination by the outflow. The average position angle (PA) of the first two channels is $122^{\circ} \pm 16^{\circ}$. We will see next that this value suggests that the molecular gas disc is approximately perpendicular to the outflow.

\subsubsection{H II Region}

The previous analysis showed that the detected $\mathrm{H}$ II region in the optical data cube of NGC 1566 is in redshift relative to the central AGN. Furthermore, an RB composition obtained from the images of the red and blue wings of the $\mathrm{Pa} \beta$ line in the $J$-band data cube (Fig. $5.21 \mathrm{~b}$ ) shows that this H II region also seems to have a velocity gradient. The north-west portion of this area (shown in blue in Fig. 5.21 b) presents lower radial velocities than the southeast portion (shown in red).

In order to perform a more detailed analysis of this apparent velocity gradient, we compared this result with the $\mathrm{H} \alpha / \mathrm{F} 555 \mathrm{~W}$ image obtained with HST (Fig. 5.21a). We immediately notice that the two brightest components of this $\mathrm{H}$ II region have different radial velocities (with the brightest component having lower radial velocities than the other one), originating the observed gradient. We also made channel maps of the $\mathrm{Pa} \beta$ line in the area corresponding to the $\mathrm{H}$ II region (Fig. 5.22). The result shows with more detail the pattern already observed in the RB composition in Fig. 5.21(b). The observed lower velocities (in the brightest component of the $\mathrm{H}$ II region) were $\sim-133 \mathrm{~km} \mathrm{~s}^{-1}$, while the highest velocities (in the other component of the $\mathrm{H}$ II region) were $\sim 205 \mathrm{~km} \mathrm{~s}^{-1}$. 


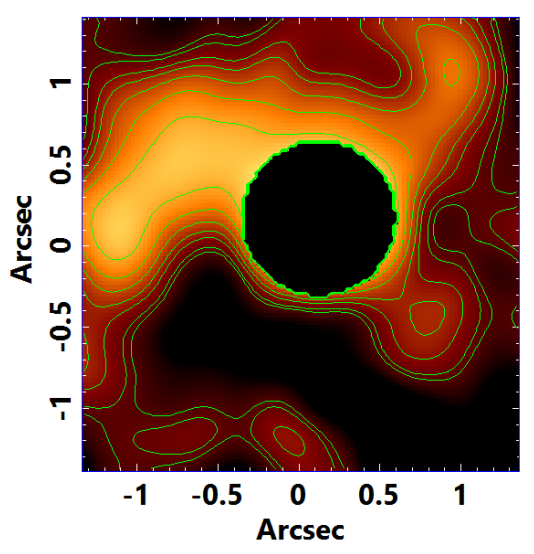

Figura 5.26: Image of the sum of the three channels with velocities close to zero $(-71,-28$ and $14 \mathrm{~km}$ $\left.\mathrm{s}^{-1}\right)$. The spiral is better seen in images of low velocities and slightly blueshifted. To a better visualization and adjustment of LUT (look-up table), the values of the central region were masked and isocontours of positive values are shown in green.

\subsubsection{NIR molecular gas}

The $K$-band data cube revealed a significant emission of the $\mathrm{H}_{2} \lambda 21218$ line. In order to analyse the molecular gas kinematics in the central region of NGC 1566, we made a radial velocity map, obtained from the Gaussian fits of the $\mathrm{H}_{2} \lambda 21218$ line of each spectrum of the data cube. We verified that an amplitude/noise $(A / N)$ ratio greater than 5 was necessary to obtain reliable values of the radial velocity from the Gaussian fit. However, the values of the $A / N$ ratio were lower than 5 in a large part of the FOV. So, we re-sized the obtained velocity map, keeping only areas where the $A / N$ ratio of the $\mathrm{H}_{2} \lambda 21218$ line was greater than 5. We assumed that the systemic velocity is equal to the arithmetic mean of the minimum and maximum velocities of the velocity map. The centre of the velocity map was taken as being equal to the point along the line of nodes where the measured velocity was equal to the systemic velocity, which was subtracted from the map. The result of this subtraction is shown in Fig. 5.25, together with the velocity curve extracted along the line of nodes. One may notice that the observed pattern is consistent with a rotation around the kinematic centre, whose position is compatible, at $1 \sigma$ level, with the AGN position (estimated from the image of the broad wing of $\operatorname{Br} \gamma$ ). The PA of the line of nodes of the velocity map is $13^{\circ} \pm 2^{\circ}$.

The velocity uncertainties were obtained by a Monte Carlo simulation. For that, a representative Gaussian distribution of the spectral noise was estimated. We then created different Gaussian distributions of random noise with the same width of the initial noise 
distribution. These distributions were added to the initial Gaussian fitted to the line, and new Gaussian fits were made sequentially. At last, the final uncertainty was taken as the standard deviation of the values found for the velocity in all the obtained fits.

The inner mass calculated from the $\mathrm{H}_{2}$ velocity curve is $M_{\text {int }}=(2.67 \pm 0.08) / \sin i \times$ $10^{7} M_{\odot}$, where $i$ is the inclination of the molecular gas rotating disc.

We also made channel maps of the $\mathrm{H}_{2} \lambda 21218$ line, shown in Fig. 5.24. The images provide a more detailed visualization of the rotational pattern revealed by the velocity map. Significant emission of $\mathrm{H}_{2}$ was detected at velocities between -283 and $269 \mathrm{~km} \mathrm{~s}^{-1}$. We notice that the channels with velocities close to zero show a pattern similar to a spiral, that is better seen in Fig. 5.26, which is the sum of the three channels with velocities centred in $-71,-28$ and $14 \mathrm{~km} \mathrm{~s}^{-1}$. The morphology of this spiral is very similar to the one observed by Combes et al. (2014) and by Smajić et al. (2015), who observed the molecular gas spiral from the $\mathrm{CO}(3-2)$ and $\mathrm{H}_{2}$ emission, respectively.

\subsection{Stellar kinematics}

In order to describe the stellar kinematics of the central region of NGC 1566, we applied the pPXF procedure (Cappellari e Emsellem, 2004) to the data cube with the emission lines masked, that is, to the data cube containing only the stellar continuum. pPXF is a method that uses a combination of template spectra of a given base, convolved with a Gauss-Hermite expansion, in order to reproduce the stellar spectrum of an object. In this case, a stellar population spectral base created from the Medium-resolution Isaac Newton Telescope Library of Empirical Spectra (MILES, Sánchez-Blázquez et al. 2006) was used. This procedure allows one to obtain the stellar radial velocity $\left(V_{*}\right)$, the stellar velocity dispersion $\left(\sigma_{*}\right)$ and the Gauss-Hermite coefficient $h_{3}$, which reveals the profile asymmetries of the stellar absorption lines relative to Gaussian profiles. As this method was applied to each spectrum of the data cube, we obtained maps of all the parameters mentioned above.

Similarly to what was done in the case of the $\mathrm{H}_{2}$ radial velocity map, the systemic $V_{*}$ was taken as being equal to the arithmetic mean of the maximum and minimum velocities of the $V_{*}$ map. We also assumed that the centre of the $V_{*}$ map was the point along the line of nodes in which the measured velocity is equal to the systemic velocity. The $V_{*}$ map, 
(a)

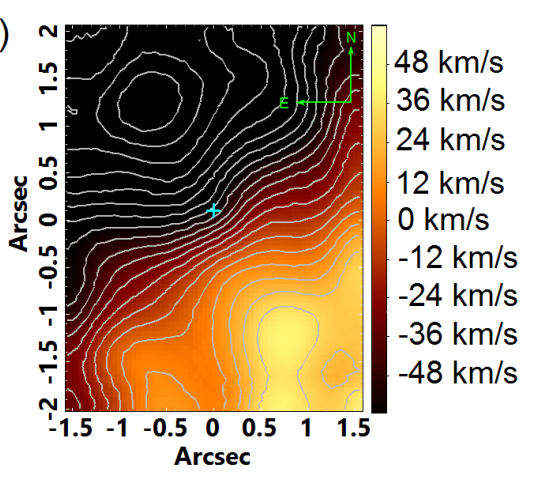

(b)

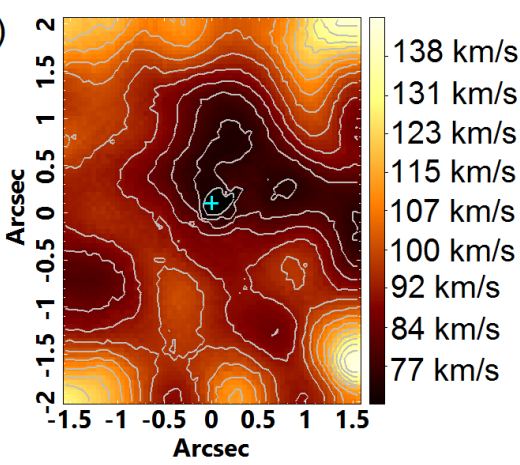

(c)

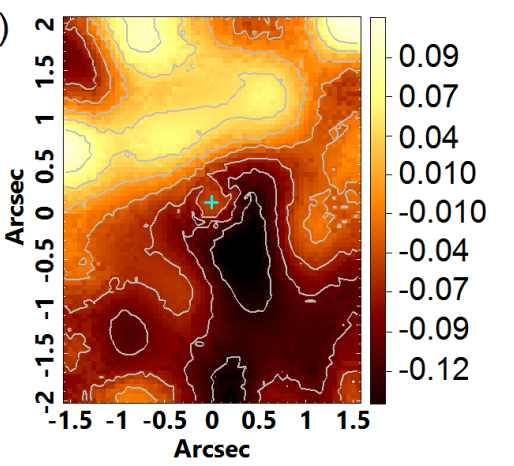

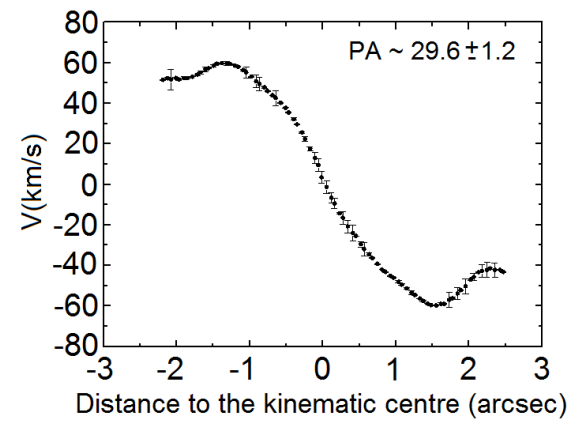
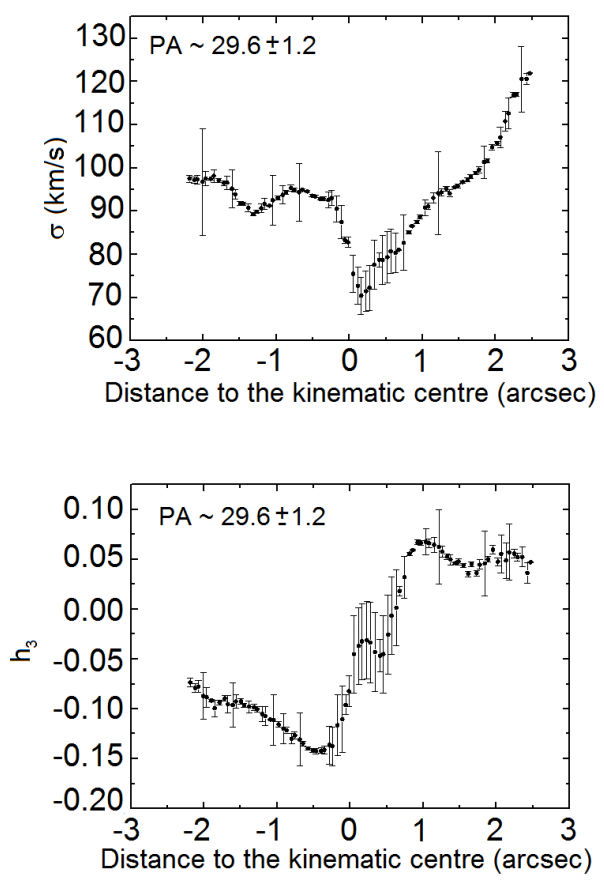

Figura 5.27: pPXF results: (a) $V_{*}$ map, (b) $\sigma_{*}$ map and (c) $h_{3}$ map, which measures the deviation of the stellar absorption profile relative to a Gaussian profile.(a) also shows the orientation of the observations and all the figures have isocontours and a light blue cross, which indicates the position of the AGN, the size of which depicts the uncertainty of $3 \sigma$ of the position. The radial curve of each map was extracted along the kinematic axis, whose PA is indicated. 
after the subtraction of the systemic velocity, together with the $\sigma_{*}$ and $h_{3}$ maps and also their extracted curves along the line of nodes of the $V_{*}$ map, are shown in Fig. 5.27.

The obtained $V_{*}$ map (Fig. 5.27a) shows a bipolar velocity distribution, with negative values at northeast from the nucleus and positive values at southwest. As observed for the molecular gas, this pattern is consistent with a stellar rotation around the kinematic centre, which is compatible with the AGN position (estimated from the image of the broad wing of $\mathrm{H} \alpha$ ), at $1 \sigma$ level. The PA found for the line of nodes is $29.6^{\circ} \pm 1.2^{\circ}$.

The $\sigma_{*}$ map (Fig. 5.27b) shows an abrupt decrease of the values in the central region. We believe that such decrease is a consequence of imprecisions in the fit caused by the obfuscation of the absorption lines in this area due to the featureless continuum emitted by the AGN. In addition the map shows a generalized decrease of $\sigma_{*}$ towards the nucleus. The minimum value of $\sigma_{*}$ is found approximately at the position of the AGN.

The $h_{3}$ map (Fig. 5.27k) shows an anticorrelation with the $V_{*}$ map, which is more evident in the extracted curve. This behaviour is typical of a stellar rotation superposed to a stellar background with approximately null radial velocities. The uncertainties are higher at the central region due to, possibly, the obfuscation caused by the featureless continuum, which may have hampered the fits obtained with the pPXF procedure.

The uncertainties of the kinematic parameters obtained with the pPXF were estimated using a Monte Carlo simulation, in a similar way to what was done for the $\mathrm{H}_{2}$ velocity map. First, we subtracted the synthetic spectrum obtained with the pPXF from the original spectrum, for each spaxel of the data cube. We then estimated a representative Gaussian distribution of the noise of the obtained residual spectrum. After that, we created different Gaussian noise distributions with the same width of the initial noise distribution. These distributions were added to the initial synthetic spectrum and the pPXF was applied sequentially to each resulting spectrum. Finally, for each kinematic parameter, the final uncertainty was taken as the standard deviation of the obtained values.

\subsection{Discussion}

NGC 1566 has a well-studied nucleus in the literature, since de Vaucouleurs e de Vaucouleurs (1961). We know that this nucleus has a variable activity and we found that, at the time of the observation reported here, it has a Seyfert type 1 activity. When we 
compare the line profiles of the optical and NIR spectra of the AGN analysed here, we see that there is a significant variation, which we attributed to the variability of this object, since the observations were taken at different epochs. As evidence of this, while the $\mathrm{H} \alpha$, $\mathrm{H} \beta$ and $\operatorname{Br} \gamma$ lines (see Figs 5.15 and $5.18 \mathrm{~b}$ ) can be decomposed with only one broad component, the $\mathrm{Pa} \beta$ line decomposition requires two broad components (Fig. 5.18a). Another evidence of this variability concerns the relation between the FWHM and the redshift, as shown in the graph of Fig. 5.20, A change in the AGN activity could result in a variation of the values of the emitting radii of the BLR lines. A simple toy model of a ring of gas rotating around the central black hole, assuming different values for $z$ (implying different emitting radii) and $i$, was capable of reproducing the observed relation between the FWHM and the redshift. All the results indicate low values of $i$, that is, an almost face-on ring. More sophisticated models are needed to characterize in greater detail the detected broad component emitting region. However, such modelling is beyond the scope of this paper.

From the broad components of the $\mathrm{H} \alpha$ and $\mathrm{H} \beta$ lines isolated with the aid of Gaussian fits (see Fig. 5.19), we verified that the ratio between them is compatible with 2.81, which is the value corresponding to case $\mathrm{B}$ of recombination, with $T=10^{4} \mathrm{~K}$ and density equals $10^{6}$ $\mathrm{cm}^{-3}$. This suggests that there is no inner extinction in the BLR. Furthermore, we noticed that the profiles of these lines are compatible; thus, the statement of the discrepancy between the line profiles of $\mathrm{H} \alpha$ and $\mathrm{H} \beta$, made by Osmer et al. (1974), is not consistent with what we see here. This inconsistency is probably due to the fact that the authors worked with lower resolution and data quality.

The position of the AGN (estimated from the image of the broad component of the $\mathrm{H} \alpha$ line) is compatible, at the $1 \sigma$ level, with the stellar bulge centre (determined from the synthetic data cube obtained with the spectral synthesis fits) - see Fig. 5.34.

The featureless continuum emission of this AGN is very strong and is concentrated in the central region of the data cube, that is, there is no evidence of scattering (see Appendix 5.11 and section 5.4.2). This emission was so relevant in the data cube that, in the results of the PCA Tomography of the data cube after the deconvolution, eigenvector E2 (which is the second most relevant eigenvector obtained with PCA Tomography) revealed an anticorrelation with the stellar absorption lines in the central region. In view of this result, we subtracted data cubes containing various power laws (with different spectral indexes and PSFs) describing this featureless continuum from the original data cube, in order 
to nullify this effect in the results provided by PCA Tomography. The best result was obtained with a power law with a spectral index of 1.7 and with a PSF with a FWHM, at the wavelength of $\mathrm{H} \alpha$, slightly greater $(\sim 0 " .75)$ than the one corresponding to the image of the broad component of $\mathrm{H} \alpha$, as mentioned before. The featureless continuum map provided by the spectral synthesis with the STARLIGHT software (see Appendix 5.11: Figs 5.32 $\mathrm{d}$ and $5.33)$ also revealed a central source with a FWHM $(\sim 0 " .94)$ larger than the one obtained with the $\mathrm{H} \alpha$ broad component image. A possible explanation is that part of the emission detected with PCA Tomography and with the spectral synthesis comes from hot and young stars, whose spectra (with few absorption lines), in certain circumstances, may resemble a power law. The fact that the FWHM of the central source detected with the spectral synthesis is larger than the one revealed by PCA Tomography suggests that the spectral synthesis was more affected by the resemblance between the featureless continuum and the young stellar population spectra than PCA Tomography. The featureless continuum emission is so important in this object that it compromises the pPXF and STARLIGHT (see Appendix 5.11) fits in the most central region, having obfuscated the stellar absorption lines and made it impossible both to identify stellar populations and to determine precisely the kinematic parameters.

An H II region was observed near the central AGN (at a projected distance of $73 \mathrm{pc}$ ). This region was also detected by Combes et al. (2014) and Smajić et al. (2015). The spectrum of this $\mathrm{H}$ II region seems to present a contamination associated with the AGN emission, which manifests itself as a prominent blue wing of the [O III $] \lambda 5007$ line. Fig. 5.28 shows a superposition between the map of the integrated flux of $\mathrm{CO}(3-2)$ (molecular gas), obtained by Combes et al. (2014), and tomogram 3 (Fig. 5.4c), which shows that the $\mathrm{H}$ II region is centred on $\Delta_{x}=1$ " and $\Delta_{y}=-1$ ". We notice that the $\mathrm{H}$ II region is very close, or even aligned, to one of the concentrations of molecular gas associated with the arms of a spiral in the central region of NGC 1566. The image of $\mathrm{H} \alpha$ obtained with the HST (Figs 5.8 a and b) revealed that the H II region detected in the optical data cube is actually formed by many components located along an emitting structure that is also related to a probable spiral arm in the central region of this galaxy. A velocity gradient was observed along this H II region, which is probably due to this spiral arm's own kinematics (Fig. 5.21). However, we cannot discard the possibility that an eventual influence of the AGN's outflow (detected over the H II region as well) is associated with the observed 


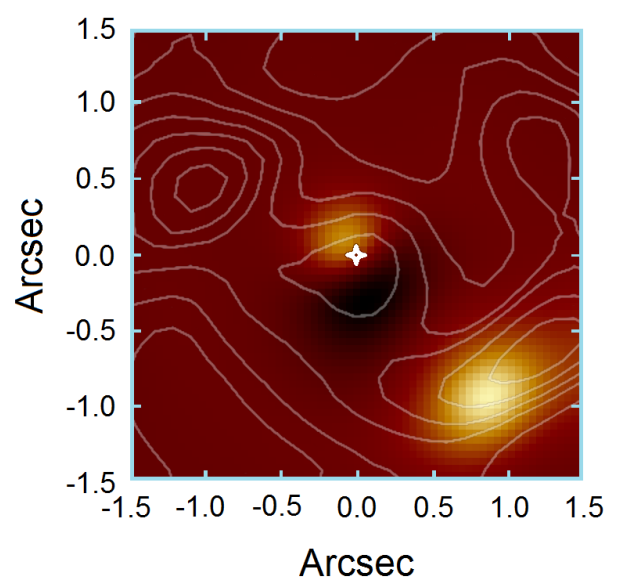

Figura 5.28: Isocontours of the integrated flux of $\mathrm{CO}(3-2)$ obtained by Combes et al. 2014 (the white cross is the AGN position, according to the authors) superposed to tomogram 3, which shows the H II region centred on $\Delta_{x}=1$ " and $\Delta_{y}=-1$ ".

velocity gradient (which can also be the responsible for the prominent blue wing observed in the $[\mathrm{O}$ III $] \lambda 5007$ line of this region). When we compared the $\mathrm{H} \alpha / \mathrm{F} 555 \mathrm{~W}$ and the velocity gradient images (Figs 5.21 a and b), we saw that there are possibly two regions of gas with different velocities, the superior portion having lower radial velocity values than the inferior portion. The PCA Tomography of the optical data cube showed that the H II region, as a whole, is in redshift relative to the nucleus, with a radial velocity, also relative to the nucleus, of $V=36 \pm 8 \mathrm{~km} \mathrm{~s}^{-1}$. This value was obtained from the analysis of the nucleus and of the $\mathrm{H}$ II region spectra (involving Gaussian fits) extracted from the optical data cube.

When analysing the HST F555W-F814W image (equivalent to $V$ - $I$ ), one may notice that the areas with redder spectra in the central region present a morphology similar to a spiral (as can be seen in Fig. 5.9). When we compare the images of Fig. 5.9 with the extinction image provided by the spectral synthesis (see Fig. 5.32 a), we see that the extinction pattern is very similar to the pattern of this spiral, with redder spectra. So we may say that this morphology detected through analysis of the HST images is probably due to extinction, possibly by dust, in the areas along the spiral. Similar results were obtained by Mezcua et al. (2015) and Combes et al. (2014). As mentioned before, spiral patterns associated with the emission of ionized gas (Fig. 5.8 a ) and of molecular gas (Combes et al. 2014) were also observed in the central region of this galaxy.

The $\mathrm{H}_{2}$ velocity map, obtained from the $K$-band data cube (Fig. 5.25), revealed the 
presence of a molecular gas disc around the AGN, as the kinematic centre of this disc is compatible with the AGN position, at $1 \sigma$ level. The existence of a molecular gas disc in the central region of NGC 1566 has already been verified in previous studies. Using images of the $\mathrm{CO}(3-2)$ emission obtained with ALMA, Combes et al. 2014) detected a molecular gas disc, with radius of 3", which presents a spiral pattern. The same disc was also analysed by Smajić et al. (2015), using, besides ALMA data, measurements of the $\mathrm{H}_{2} \lambda 21218$ line of a $K$-band data cube observed with SINFONI, obtained with a fore-optics with FOV of $8 " \times 8 "$.

The PA values of the line of nodes of the molecular gas disc determined by Combes et al. (2014) and by Smajić et al. (2015) were $\sim 44^{\circ}$ and $\sim 45^{\circ}$, respectively. These values are not compatible with the one obtained in this present work $\left(\mathrm{PA}=13^{\circ} \pm 2^{\circ}\right)$, even at the $3 \sigma$ level. The reason of this discrepancy probably concerns the fact that the $\mathrm{H}_{2}$ velocity map analysed here has a smaller FOV than the velocity maps analysed by Combes et al. (2014) and Smajić et al. (2015). Therefore, only the central part of the molecular gas disc analysed in these works was seen here. This result reveals that the PA of the line of nodes of this molecular disc varies with the distance from the nucleus. In fact, Smajić et al. (2015) had already detected an apparent variation in the PA of the line of nodes in the inner parts of the molecular disc, but the greater spatial resolution of the data analysed here allows a better visualization of the kinematics of those regions. Smajić et al. (2015) also say that the apparent variation of the PA can be due to the bar or to an spiral density wave. The authors, indeed, observed a molecular gas spiral in the central region and this structure leads to a perturbation in the molecular gas rotation pattern. We detected a very similar spiral (see Fig. 5.26), which Smajić et al. (2015) observed in a slightly large scale, and, based on what has been said, the kinematic perturbation caused by this spiral can explain the variations in the PA of the molecular disc line of nodes. Another possible cause for this variation is the observed outflow, but the PA associated with this outflow $\left(122^{\circ} \pm 16^{\circ}\right)$ does not indicate any relation to the molecular gas kinematics in the central region, which makes this scenario improbable. A molecular gas flux through a bar can also change the PA of the line of nodes of the molecular disc, however, the observed molecular gas kinematic pattern in the central region of this galaxy seems much more compatible with an spiral wave (Combes et al. 2014, Smajić et al. 2015) than with a coherent flux of gas through a bar. Thus, the hypothesis of the bar influence is also unlikely. Finally, one cannot discard 
the possibility of that PA variation being due to a warped disc. Nevertheless, redoing this observation with full adaptive optics, to obtain a better resolution, would be necessary to find out if this emission of molecular gas has some relation with the torus.

The emitting region of ionized gas (with radial velocity, relative to the nucleus, between -860 and $-740 \mathrm{~km} \mathrm{~s}^{-1}$ ) southeast from the central AGN, detected by the channel maps of the $[\mathrm{O}$ III $] \lambda 5007$ line (Fig. 5.23), is probably associated with an outflow from the AGN. The apparent direction of this possible outflow (with a mean PA of $122^{\circ} \pm 16^{\circ}$ ) is approximately perpendicular to the line of nodes of the radial velocity map obtained from the $\mathrm{H}_{2} \lambda 21218$ line. This direction also seems to be aligned with the extended emission detected in the H $\alpha /$ F555W image (Fig. 5.8). This same extended emission, probably associated with the NLR of the AGN, was observed by Schmitt e Kinney (1996). A possible scenario to explain these observations is the following: the detected molecular disc corresponds to an extension of a type torus/disc structure more compact and near the AGN. This structure collimates the emission (and also the outflows) from the AGN, originating the observed morphology. This scenario is compatible with the Unified Model. Although the probable outflow has been detected mainly southeast from the AGN, as mentioned before, the outflow also seems to extend towards Region 2 (the H II region). This may indicate some influence of this phenomenon on the $\mathrm{H}$ II region and, consequently, could explain the prominent blue wing of the $[\mathrm{O}$ III $] \lambda 5007$ line, detected in the spectrum of this area, which was also observed in many emission lines of Region 1 spectrum, associated with the AGN.

The $V_{*}$ and $\sigma_{*}$ maps obtained from the optical data cube (Fig. 5.27) are consistent with what was found by Smajić et al. (2015). However, the $\sigma_{*}$ map analysed here seems to be slightly less noisy and allows a better visualization of the $\sigma_{*}$ drop, which was not discussed by Smajić et al. (2015). $\sigma_{*}$ drops in galactic nuclei have been observed with increasing frequency (e.g., Emsellem et al., 2001; de Zeeuw et al., 2002; Márquez et al., 2003; Shapiro et al., 2003; Falcón-Barroso et al., 2006; Ganda et al., 2006). The most accepted model to explain such behaviour in the values of $\sigma_{*}$ assumes that the stars in the nuclear region of the galaxy were formed from circumnuclear cold gas. The recently born stars remain with the velocity dispersion values of their progenitor gas clouds, thus giving rise to stellar populations with low values of $\sigma_{*}$. The observed stellar spectrum and, consequently, the calculated values of $\sigma_{*}$ are dominated by the younger stars, originating the $\sigma_{*}$-drop phenomenon (Wozniak et al., 2003; Allard et al., 2005, 2006). Although part 
of the observed $\sigma_{*} d r o p$ in the map of Fig. 5.27 may be caused by the obfuscation of the absorption lines due to the featureless continuum emission from the AGN, it is probable that the model described above is applicable to the central region of NGC 1566. It is also possible that these same young stars are responsible for part of the featureless continuum emission, since its PSF, as mentioned before, is larger than the PSF obtained with the image of the broad component of $\mathrm{H} \alpha$ (see Fig. 5.33 and section 5.4.2). The difference between the PA values obtained for the $V_{*}$ and $\mathrm{H}_{2} \lambda 21218$ velocity maps suggests that the molecular gas and the stellar discs are not coplanar.

\subsection{Conclusions}

We analysed an optical data cube of the central region of NGC 1566 (obtained with the IFU of GMOS) and also the NIR data cubes in the $J$ and $K$ bands (retrieved from the SINFONI archive), in order to evaluate the properties of the emission-line spectrum, of the featureless continuum, of the stellar kinematics and of the ionized and molecular gas kinematics. The main conclusions of our analysis are the following:

(1) Two emitting regions were found: the central region, whose spectrum is that of a Seyfert 1 , and the region centred on $\Delta_{x}=1$ " and $\Delta_{y}=-1$ ", with a spectrum typical of an $\mathrm{H}$ II region. The projected distance between these two regions is $73.3 \pm 1.9$ pc. Furthermore, the $\mathrm{H}$ II region is in redshift relative to the nucleus, with a radial velocity (also relative to the nucleus) of $36 \pm 8 \mathrm{~km} \mathrm{~s}^{-1}$.

(2) Analysis of HST images revealed that the H II region is composed of many substructures and is located along an apparent spiral arm. Although it is, as a whole, in redshift, the $\mathrm{H}$ II region has a velocity gradient, which may be due to the kinematics of this probable spiral arm, although one cannot discard the possibility of an influence of the AGN outflow on the H II region.

(3) An outflow from the AGN was detected with the analysis of the [O III $] \lambda 5007$ line kinematics, and it seems to extend towards the H II region, which explains the prominent blue wing that was seen in this region's spectrum. The mean PA found for this outflow was $122^{\circ} \pm 16^{\circ}$. The $H S T$ image of $\mathrm{H} \alpha / \mathrm{F} 555 \mathrm{~W}$ suggests the existence of an elongated emission that seems to coincide with the position of the outflow.

(4) PCA Tomography revealed an obfuscation of the nuclear absorption lines of this 
object by the emission of the featureless continuum coming from the AGN. An analysis, also made with PCA Tomography, revealed that this featureless continuum may be represented by a power law with a spectral index of 1.7. The FWHM of the PSF, at the wavelength of $\mathrm{H} \alpha$, corresponding to the featureless continuum emission, $\sim 0 " .75$, is larger than the FWHM of the PSF of the data cube, 0".66, estimated from the image of the broad component of $\mathrm{H} \alpha$, suggesting that part of this emission is associated not only with the AGN, but also with hot and young stars in the central region, whose spectrum can be similar to a powerlaw. The power-law map corresponding to the featureless continuum obtained with the spectral synthesis revealed a central source with a FWHM of $\sim 0$ ".94, also larger than the FWHM of the PSF of the data cube.

(5) The kinematic maps provided by the pPXF revealed the presence of a stellar disc rotating around the AGN (the position of the kinematic centre is compatible, at $2 \sigma$ level, with the position of the AGN). One may notice a decrease in the velocity dispersion towards the nucleus, which may be due to the presence of stars formed from cold gas clouds that inherited the low values of velocity dispersion of this gas. Possibly, these young stars are the same ones responsible for the emission of the fake featureless continuum mentioned before.

(6) $\mathrm{An}_{2}$ rotating disc was identified in the $K$-band data cube. This disc is rotating around the central region and the PA of its line of nodes is $\sim 13^{\circ} \pm 2^{\circ}$. This PA is not compatible with the values obtained for the same disc (in larger scales) by Combes et al. (2014) and Smajić et al. (2015). This may indicate that the PA of the line of nodes of this disc varies with the distance from the nucleus and is perhaps due to the spiral molecular gas perturbation in the inner central region.

(7) We detected a slightly blueshifted molecular gas spiral from the images of $\mathrm{H}_{2} \lambda 21218$.

(8) The line of nodes observed in the $\mathrm{H}_{2}$ velocity map is approximately perpendicular to the probable outflow of the AGN, which may indicate that this molecular disc corresponds to the extension of a more compact structure of a torus/disc type, which collimates the outflow of the AGN. This scenario is consistent with the Unified Model.

(9) From the analysis of the BLR emission lines in the AGN spectra of the optical and NIR data cubes, we saw first that there is a variation in the optical and NIR line profiles. There is also a relevant difference between $\mathrm{Pa} \beta$ and all others line profiles, and it was possible to identify a second broad component in $\mathrm{Pa} \beta$. As the observations were made at 
different epochs, it is possible that the difference in the profiles is due to the variability of the AGN activity. In addition, we also see that the FWHMs of the lines increase with the redshift. This relation can be explained overall by a simple toy model of a gas ring rotating around a central black hole, with small inclination angles, assuming the influence of the gravitational redshift and a variation of the distances of the emitting clouds from the centre, the latter caused by the variability of the AGN. If the upper limit of the BLR size is $0.01 \mathrm{pc}$, as determined by Alloin et al. (1985), we conclude that the upper limit for the black hole mass is between $3.4 \times 10^{7}$ and $4 \times 10^{8} \mathrm{M}_{\odot}$.

\section{Acknowledgements}

This work is based on observations obtained at the Gemini Observatory (processed using the Gemini IRAF package), which is operated by the Association of Universities for Research in Astronomy, Inc., under a cooperative agreement with the NSF on behalf of the Gemini partnership: the National Science Foundation (United States), the National Research Council (Canada), CONICYT (Chile), the Australian Research Council (Australia), Ministério da Ciência, Tecnologia e Inovação (Brazil) and Ministerio de Ciencia, Tecnología e Innovación Productiva (Argentina). A special thanks to Dr. D. May for constructing Fig 5.28 and to CNPq (Conselho Nacional de Desenvolvimento Científico e Tecnológico), CAPES (Coordenação de Aperfeiçoamento de Pessoal de Nível Superior) and FAPESP (Fundação de Amparo à Pesquisa do Estado de São Paulo), under grant 2011/51680-6, for supporting this work.

\section{Appendix}

\subsection{Spectral synthesis}

The spectral synthesis aims to fit, with a linear combination of stellar population spectra of a base (convolved with Gaussian functions), the stellar continuum of a given object. In order to apply this method to the optical data cube of NGC 1566, we used the STARLIGHT software and a stellar population base created from MILES (Sánchez-Blázquez et al., 2006), the same one used to apply the pPXF procedure. We added to this base a spectrum with 


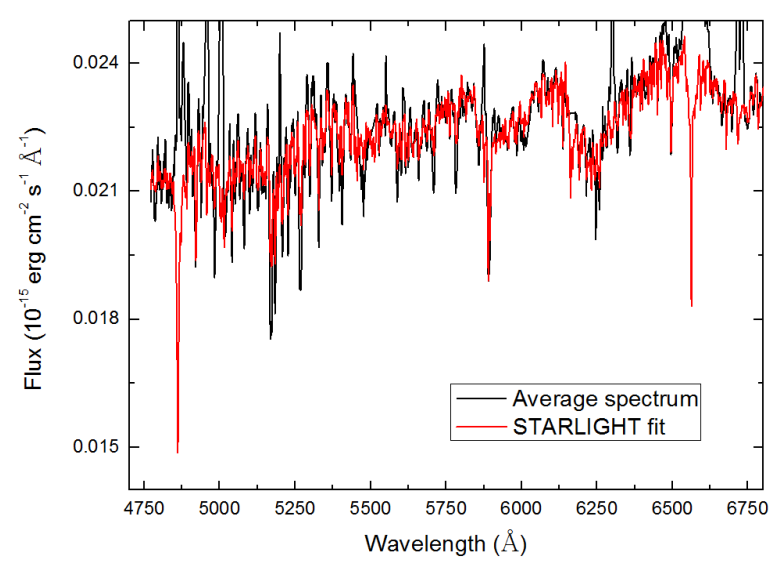

Figura 5.29: Result of the STARLIGHT fit applied to the average spectrum of NGC 1566. This gives an idea of the quality of the fits obtained with this method.

a power law representing the featureless continuum emission from the AGN, in this case with a spectral index of 1.7 .

When we apply the spectral synthesis to a data cube, we obtain, for each spectrum of the data cube, the flux fractions attributed to the stellar populations used in the fit and, as we have a spectrum for each spaxel, we also obtain flux maps of these populations. Likewise, it is possible to draw a histogram of the flux fractions of the stellar populations found, in terms of metallicity and age, considering the entire FOV of the data cube. The spectral synthesis also calculates the interstellar extinction, attributed to each spectrum, resulting in a map of the extinction at the observed object. Other maps resulting from the spectral synthesis have the values of $\chi^{2}$ of the fits and of the $\mathrm{S} / \mathrm{N}$ ratio of the spectra. As we added to the base a power law representing the featureless continuum emission, we also obtain a flux map of this emission. Fig 5.29 shows the fit made with STARLIGHT on the mean spectrum of NGC 1566 data cube.

The histogram of Fig. 5.30 shows that the highest flux fractions are from the young $\left(10^{7} \mathrm{yr}\right), \sim 43$ per cent of total, and old $\left(10^{10} \mathrm{yr}\right), \sim 28$ per cent of total, stellar populations with high metallicity (0.02 and $0.05 ; 0.02$ being the solar metallicity). There is also a large flux fraction attributed to the featureless continuum, $\sim 22$ per cent of total, which is a very relevant emission in this galaxy.

Figs 5.31(a) and (b) show the flux maps representing the stellar populations with $10^{6}$ and $10^{7} \mathrm{yr}$, respectively. Both maps show a central concentration of stellar populations with high metallicity. 


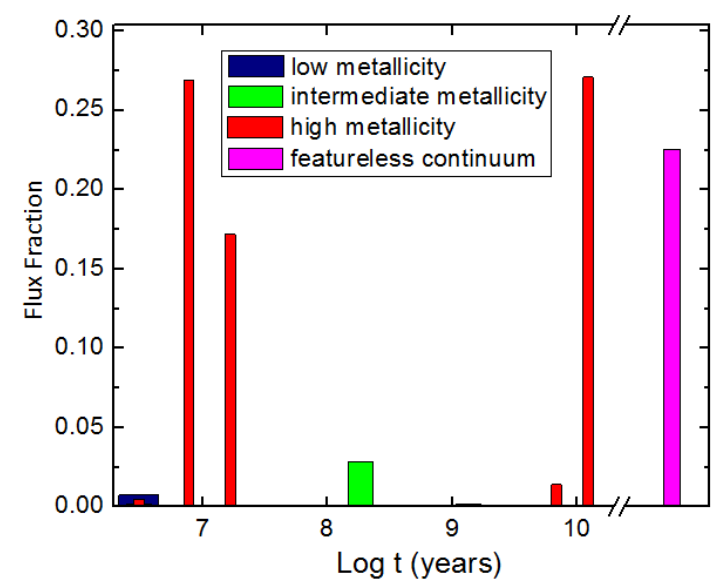

Figura 5.30: Histogram of the flux fractions of the stellar populations detected with the spectral synthesis. In red, the populations with high metallicity (0.02 and 0.05), whose flux fractions are higher for ages of about $10^{7}$ and $10^{10} \mathrm{yr}$. In blue, the populations with low metallicity $\left(10^{-4}\right.$ and $10^{-4}$ and $\left.4 \times 10^{-4}\right)$, which have flux fractions too low to be identified, in this case. In green, stellar populations with intermediate metallicity $\left(4 \times 10^{-3}\right.$ and $\left.8 \times 10^{-3}\right)$, with higher fractions at ages of about $10^{8} \mathrm{yr}$. In magenta, the flux fraction attributed to the power law with spectral index of 1.7, corresponding to the featureless continuum emission of the AGN in this galaxy.

A very low flux fraction was detected, $\sim 3$ per cent, associated with intermediate metallicity. As we can see in Fig. 5.31(c), these populations are scattered throughout the circumnuclear regions.

The representative flux map of stellar populations with $10^{10} \mathrm{yr}$ is shown in Fig. 5.31(d). It is possible to notice that these populations, most of which having high metallicity, are scattered along the entire FOV, but were not detected in the central region. The absence of flux from these populations in this region may derive from a possible obfuscation of their absorption lines due to featureless continuum emission.

The extinction map (Fig. 5.32a) shows a pattern that, at first, resembles a ring-like emission. However, as indicated in section 5.5, when we compare this map to the $V-I$ image convolved with the PSF of GMOS data cube, we clearly see that this pattern is a spiral composed of regions with redder spectra.

Great part of the spectral synthesis maps show possible contamination from the featureless continuum emission. This contamination is visible in the extinction map and in the flux maps of populations with $10^{6}, 10^{7}$ and $10^{10} \mathrm{yr}$. Possible damages to the fits caused by the obfuscation due to the featureless continuum may be one of the reasons for the values of $\chi^{2}$ to be higher in the central region (see Fig. $5.32 \mathrm{~b}$ ). Another reason is that the 

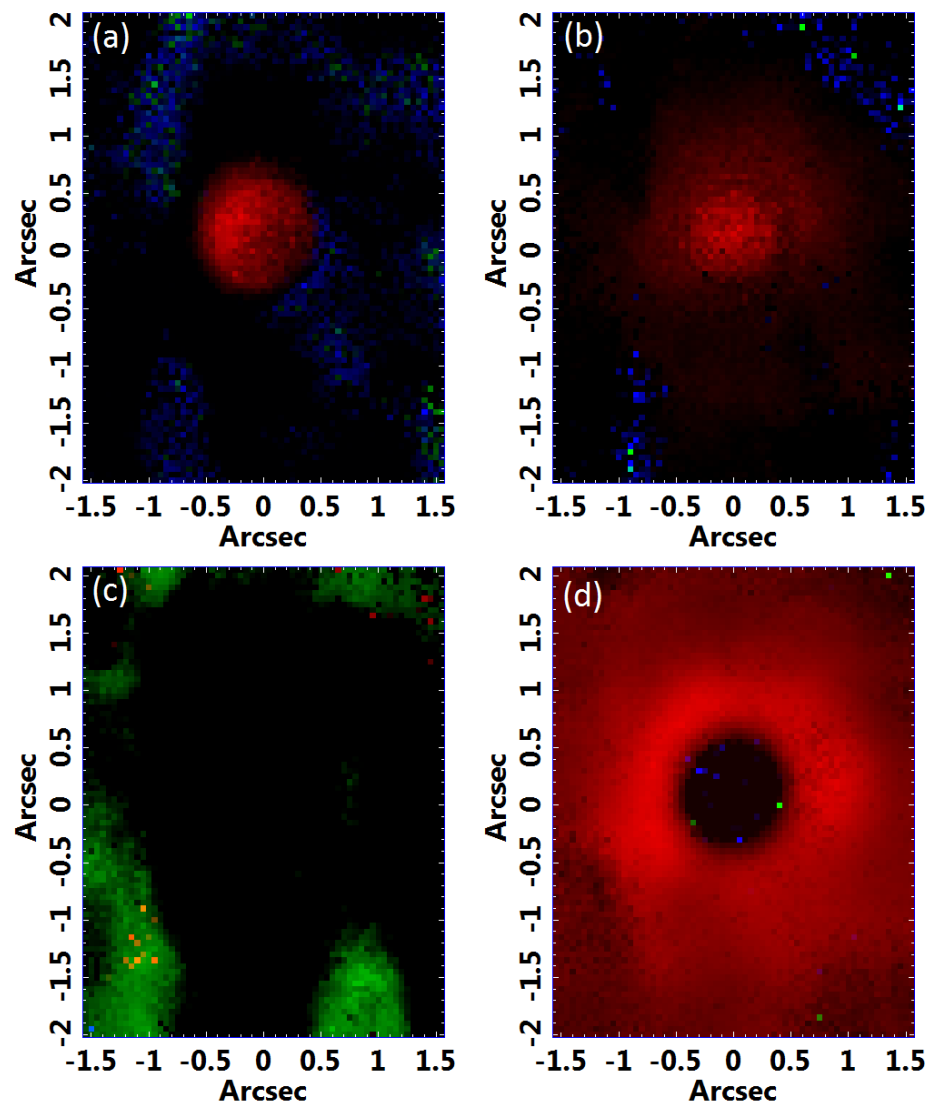

Figura 5.31: Flux maps associated with the stellar populations detected with the spectral synthesis. In red, populations with high metallicity (0.02 and 0.05$)$; in blue, populations with low metallicity $\left(10^{-4}\right.$ and $\left.10^{-4}\right)$; and, in green, stellar populations with intermediate metallicity $\left(4 \times 10^{-3}\right.$ and $\left.8 \times 10^{-3}\right)$. (a) represents populations with $10^{6} \mathrm{yr}$, (b) $10^{7} \mathrm{yr}$, (c) $10^{8} \mathrm{yr}$, and (d) $10^{10} \mathrm{yr}$. 

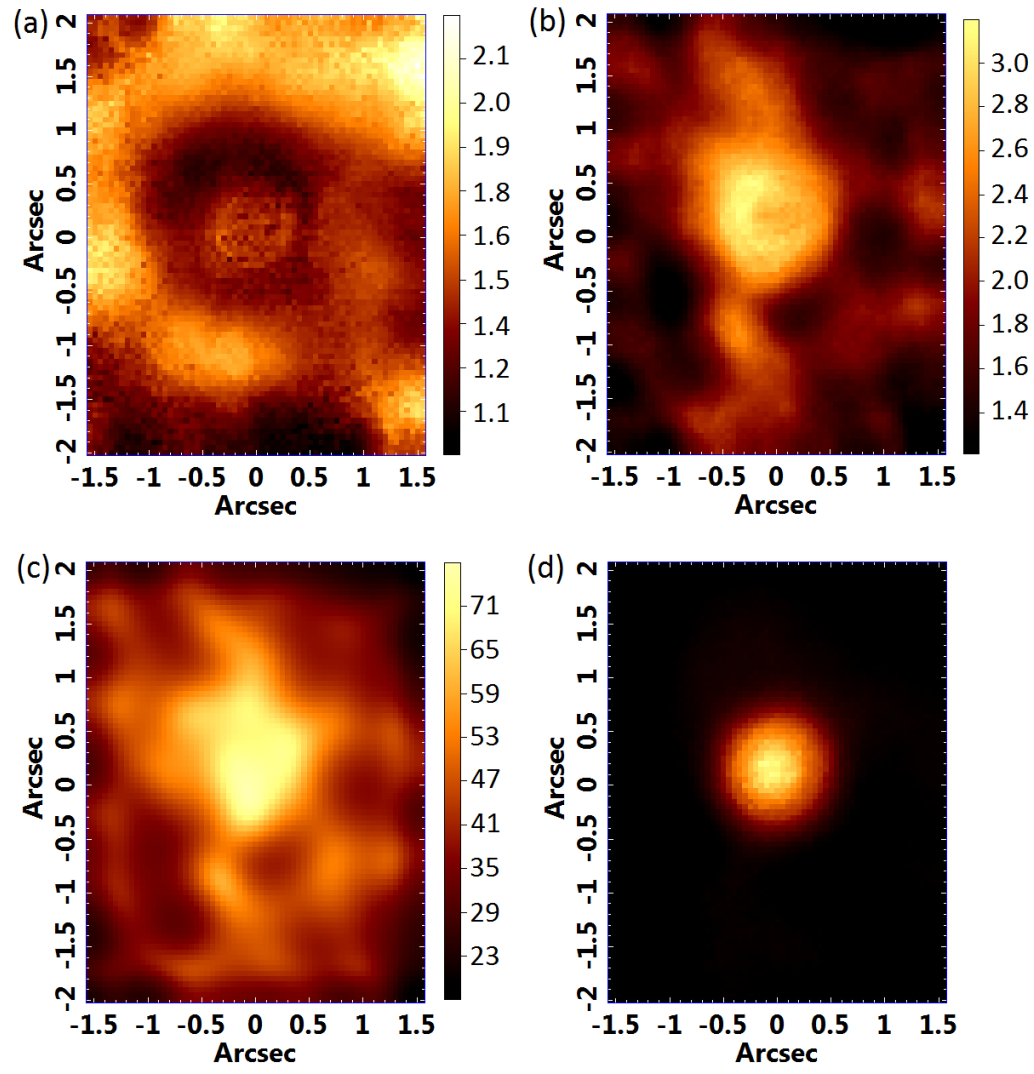

Figura 5.32: Maps of the parameters provided by the spectral synthesis. (a) shows the extinction map of NGC 1566, (b) is the $\chi^{2}$ map of the STARLight fits, (c) is the S/N map and (d) is the map of the flux associated with the power law with spectral index of 1.7 , representing the featureless continuum emission.

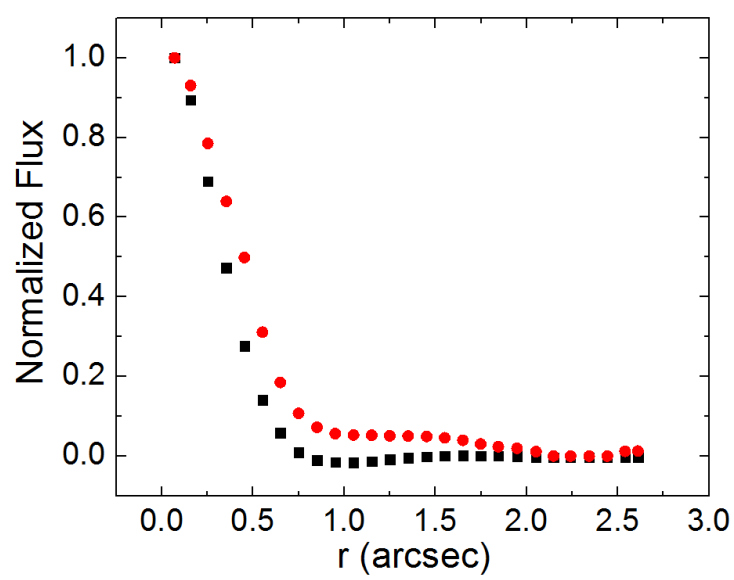

Figura 5.33: In red, radial profile of the featureless continuum image and, in black, radial profile of the image representing the red wing of the broad component of $\mathrm{H} \alpha$, used to determine the PSF of the optical data cube. 
uncertainties of the flux values in the spectra were estimated from the rms of these spectra (in a given wavelength interval); so, as the spectra of the central region have higher $\mathrm{S} / \mathrm{N}$ (and, consequently, lower values of uncertainty), and the $\chi^{2}$ is inversely proportional to the square of the uncertainty, we obtained higher values of $\chi^{2}$ in the central region. The $\mathrm{S} / \mathrm{N}$ map (Fig. 5.32k) shows that $\mathrm{S} / \mathrm{N}$ is higher in the central region and decays towards the edges of the FOV.

The flux map of the power law with spectral index of 1.7, representing the featureless continuum of the AGN in this galaxy, is shown in Fig. 5.32(d). The featureless continuum emission is central and compact, and its profile can be well fitted by a Gaussian function with FWHM $=0$ ".86. When comparing the radial profile of the featureless continuum map with the radial profile of the image corresponding to the red wing of the broad component of $\mathrm{H} \alpha$ (Fig. 5.33), we see what we previously mentioned: the featureless continuum emission area is larger than that of the PSF. So, as there is no evidence of scattering of the featureless continuum emission, it is probable that part of this detected emission is, actually, the continuum emitted by young stars, wrongly identified by the STARLIGHT software.

When we observe Fig. 5.34, which is the collapsed image of the stellar synthetic data cube (obtained from the spectral synthesis fits), we see that the centre of the stellar emission does not coincide exactly with the position of the AGN, but is compatible with it at $1 \sigma$ level.

In order to have an idea of the uncertainty of the parameters obtained with the spectral synthesis, we performed the following procedure: first, the spectral synthesis was applied to the mean spectrum of the data cube of NGC 1566. The resulting synthetic stellar spectrum was subtracted from the mean spectrum. We then calculated a Gaussian distribution representing the residual spectral noise obtained. After that, we made different Gaussian distributions of random noise, with the same width of the initial Gaussian distribution. These different noise distributions were added to the synthetic stellar spectrum, obtained from the data cube mean spectrum fit, and the spectral synthesis was applied to each resulting spectrum. The mean age uncertainty (given by the weighted mean of the stellar population ages based on the flux fraction associated with each one of them) and the uncertainty of the interstellar extinction at the observed object were taken as the standard deviation of the values obtained with all those applications of the spectral synthesis. The obtained values are 0.11 dex for the mean age and 0.07 mag for the interstellar extinction. 


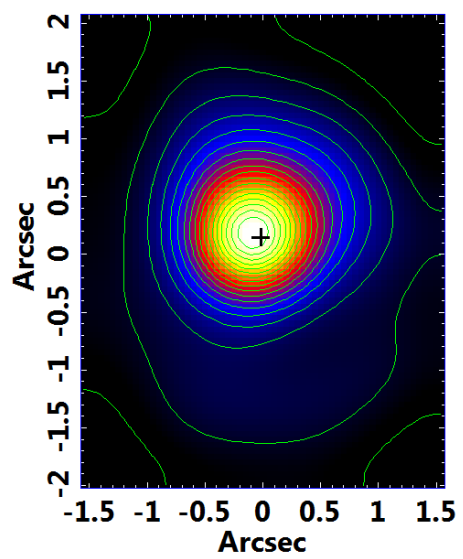

Figura 5.34: Collapsed image of the stellar synthetic data cube, obtained from the spectral synthesis, with the cross representing the position of the AGN. The cross size is equivalent to $3 \sigma$ of the uncertainty of this position, obtained from the image representing the red wing of the broad component of $\mathrm{H} \alpha$.

\subsubsection{Spectral synthesis of the nuclear and circumnuclear regions}

We extracted two spectra from the same data cube used to apply the spectral synthesis: one from a circular region, centred on the nucleus, with a radius of 0".3, and the other from the entire FOV. We then subtracted the nuclear spectrum from that with the total emission, in order to obtain a spectrum having only the circumnuclear emission. At last, we applied the spectral synthesis to the two spectra, obtaining the two histograms shown in Fig. 5.35.

The histogram of the spectral synthesis applied to the nuclear region shows that the highest flux fraction is due to the featureless continuum emission, $\sim 54$ per cent of total. There is only one other relevant flux fraction in this region, comprised of young stellar populations $\left(10^{6}\right.$ and $\left.10^{7} \mathrm{yr}\right)$ with high metallicity (0.02 and 0.05): $\sim 46$ per cent of total.

In the circumnuclear region, the highest flux fractions are due to the young $\left(10^{6}\right.$ and $\left.10^{7} \mathrm{yr}\right), \sim 45$ per cent of total, and old stellar populations $\left(10^{9}\right.$ and $\left.10^{10} \mathrm{yr}\right), \sim 29$ per cent of total, with high metallicity.

The greatest difference between the results of the spectral synthesis of these two regions is the presence of the old stellar populations only in the circumnuclear region. This may be explained by a possible obfuscation of the absorption lines of these stars in the nuclear region due to the featureless continuum emission. It is also important to mention that at least part of the featureless continuum detected with these two applications of the spectral synthesis can, in fact, be associated with the continuum emitted by young stellar populations, wrongly identified by the STARLIGHT software, as already mentioned before. 
(a)

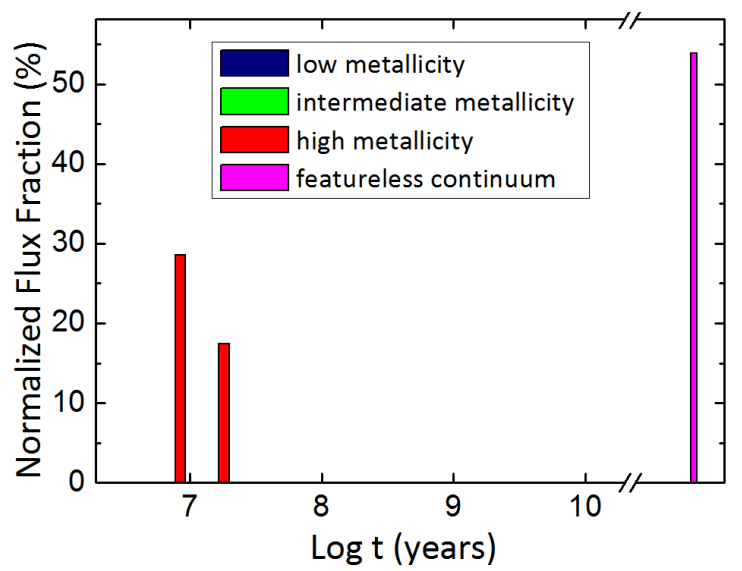

(b)

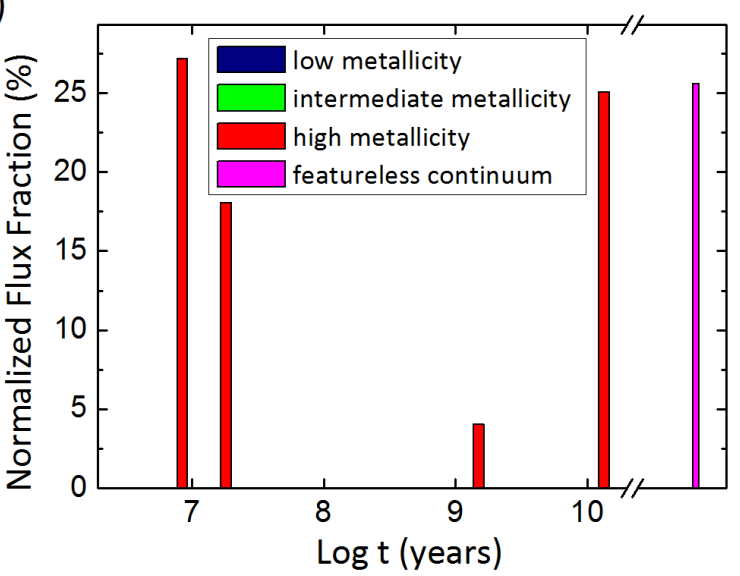

Figura 5.35: Histogram of the flux fractions of the stellar populations detected with the spectral synthesis (a) at the central region and (b) at the circumnuclear regions. In red, stellar populations with high metallicity (0.02 and 0.05); in blue, populations with low metallicity $\left(10^{-4}\right.$ and $10^{-4}$ and $\left.4 \times 10^{-4}\right)$; in green, stellar populations with intermediate metallicity $\left(4 \times 10^{-3}\right.$ and $\left.8 \times 10^{-3}\right)$; and, in magenta, the flux fraction attributed to the power law with spectral index of 1.7 , representing the featureless continuum emission of the AGN of this galaxy. 


\section{Capítulo 6}

\section{Resumo do paper sobre NGC 6744}

\section{NGC 6744 - A nearby Milky Way twin with a very low-luminosity AGN}

Este estudo é focado na região nuclear de NGC 6744, a galáxia gêmea morfológica da Via Láctea do hemisfério Sul mais brilhante e mais próxima. A análise foi conduzida com cubos de dados do IFU do GMOS, juntamente com imagens do HST (da Silva et al., 2018).

A partir do estudo de emissão de linhas no óptico, foi possível detectar 4 regiões emissoras no núcleo de NGC 6744. Todas as regiões possuem razões de linhas compatíveis com as de LINERs.

O estudo das imagens do HST permitiu detectar uma fonte compacta com emissão principal no filtro F555W. Essa emissão pode ser atribuída tanto a estrelas jovens quanto a emissão do featureless continuum do AGN. No entanto, não foi detectada a presença de estrelas jovens nos resultados da síntese espectral, tampouco a emissão de featureless continuum com índice espectral igual a 1.5 (o espectro de lei de potência que é usado na síntese). Dessa forma, essa emissão compacta central muito possivelmente é a emissão do featureless continuum do AGN que possui um índice espectral diferente de 1.5. A posição dessa fonte azul central é compatível com a região central do cubo de dados (Região 1) e portanto indica que a emissão LINER desta região provém de uma AGN de baixa luminosidade.

As três demais regiões detectadas neste objeto podem ser parte da NLR deste AGN, sendo uma delas, devido a sua morfologia e emissão em [OIII] $\lambda 5007$, o cone de ionização do AGN e, as outras duas, que parecem possuir graus de ionização maiores do que a Região 1, nuvens que estão recebendo a ionização do AGN quando este era mais luminoso.

O fato do centro de NGC 6744 não possuir populações estelares jovens é compatível com o fato de seu bojo ser clássico. A comparação dos resultados da síntese espectral do núcleo 
e região circumnnuclear resultou em um excesso da emissão de populações com $\sim 1$ bilhão de anos com metalicidade intermediária $\left(4 \times 10^{-3}\right.$ e $\left.8 \times 10^{-3}\right)$ na região circumnuclear. Esse evento de formação estelar está isolado temporalmente. Isso e o fato do bojo ser clássico sustentam a hipótese desta galáxia ter sofrido um minor merger com uma galáxia satélite na região central há 1 bilhão de anos, que gerou esta população estelar. Além desta população, no FOV do cubo de dados foram detectadas populações velhas (10 ${ }^{10}$ anos $)$ com alta metalicidade (0.02 e 0.05).

As imagens do HST também revelaram uma estrutura compacta de emissão avermelhada ao redor do AGN e seu cone de ionização é perpendicular a ela. Essa estrutura pode ser um disco de poeira e gás que pode estar abastecendo o AGN.

Foi detectada uma rotação de gás, na qual o position angle (PA) do gás em blueshift é diferente do PA do gás em redshift. Isso indica que pode haver inflows ou outflows de gás ou instabilidades na rotação causadas pelo minor merger.

A rotação estelar possui PA diferente daquele do disco de gás e está sobreposta a um fundo de estrelas com velocidades próximas a zero com relação à linha de visada. Foi detectado um decréscimo de valores de dispersão de velocidades estelar em direção ao núcleo. Com a ausência de populações jovens, é difícil explicar este fenômeno. Uma hipótese seria a ocorrência de um merger com uma galáxia com um núcleo estelar não definido. 
Capítulo 7

\title{
NGC 6744 - A nearby Milky Way twin with a very low-luminosity AGN
}

\author{
Patrícia da Silva, J. E. Steiner, R. B. Menezes \\ 2018, ApJ, 861, 83
}

\subsection{Abstract}

NGC 6744 is the nearest and brightest south-hemisphere galaxy with a morphological type similar to that of the Milky Way. Using data obtained with the Integral Field Unit of the Gemini South Multi-Object Spectrograph, we found that this galaxy has a nucleus with LINER (Low Ionization Nuclear Emission Line Region) surrounded by three line emitting regions. The analysis of the Hubble Space Telescope archival images revealed that the nucleus is associated with a blue compact source, probably corresponding to the active galactic nucleus (AGN). The circumnuclear emission seems to be part of the extended narrow line region of the AGN. One of these regions, located $\sim 1$ "southeast of the nucleus, seems to be associated with the ionization cone of the AGN. The other two regions are located $\sim 1$ "south and $\sim 0$ ".6 northeast of the nucleus and are not aligned with the gaseous rotating disk. Spectral synthesis shows evidence that this galaxy may have gone through a merger about one billion years ago. On the basis of the kinematic behavior, we found a gaseous rotating disk, not co-aligned with the stellar disk. Given the relative degree of ionization and luminosities of the nuclear and circumnuclear regions, we suggest that the AGN was more luminous in the past and that the current circumnuclear emissions are echoes of that phase. 


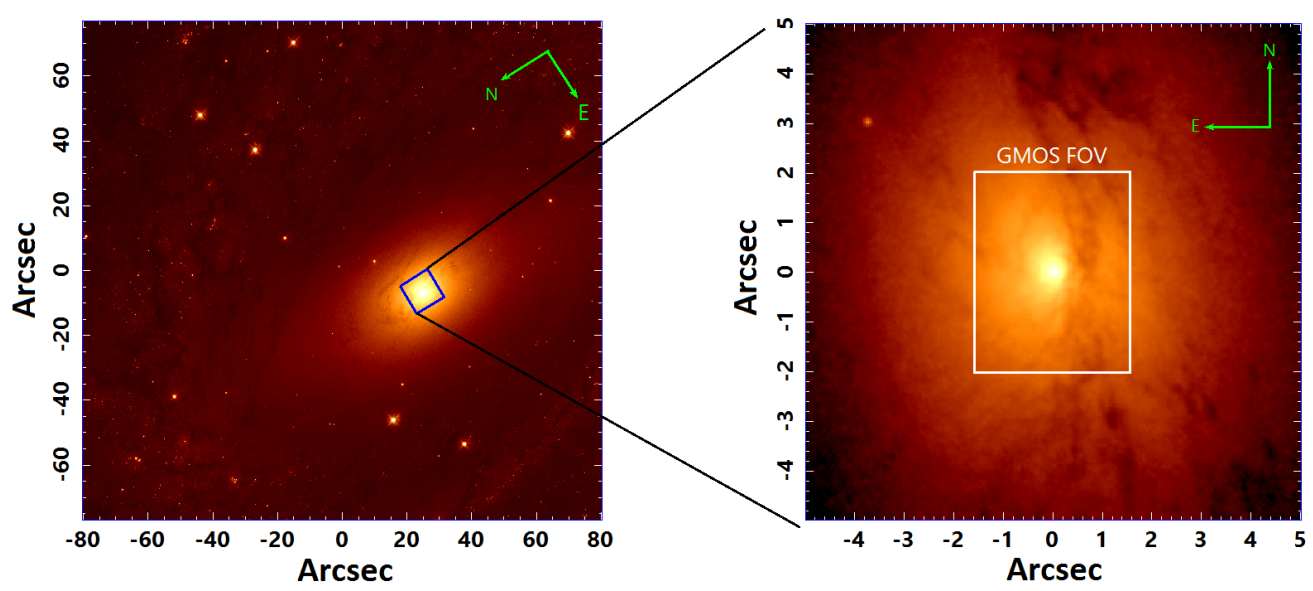

Figura 7.1: HST/WFC3 images, in the F555W filter, of NGC 6744. In order to have an idea of the FOV of the GMOS observations, the figure on the left shows an image of all HST FOV, with a little blue square on the central region, whose magnification is shown on the right with the GMOS FOV limits and its orientation. The size of the rectangle of GMOS FOV on $\mathrm{x}$-axis is $\sim 130 \mathrm{pc}$ and on $\mathrm{y}$-axis is $\sim 167 \mathrm{pc}$.

\subsection{Introduction}

NGC 6744 is an SAB(r)bc galaxy that belongs to the Pavo group and is located at 8.5 Mpc (Nasa Extragalactic Database- NED $\left.{ }^{1}\right)$. It has a gas ring, with 3'.3 ( $\left.8.2 \mathrm{kpc}\right)$ of diameter, where two spiral arms begin, as observed in H I images (Ryder et al., 1999).

Its bulge is classic, very similar to an elliptical galaxy, with a Sérsic index of 3.1, measured on images obtained with the Spitzer telescope in $3.6 \mu \mathrm{m}$ (Fisher e Drory, 2010). In this respect, this galaxy is different from the Milky Way, which has a peanut-shaped pseudo-bulge. It has a tenuous trace of dust toward the center. The galaxy has a star forming-ratio of $6.8 \mathrm{M}_{\odot} /$ year (Ryder e Dopita, 1994).

According to Vaceli et al. (1997), NGC 6744 has a nucleus whose emission line ratios are typical of low ionization nuclear emission line regions (LINERs), which are often active galactic nuclei (AGNs) that present an emission spectrum with a lower ionization degree when compared to Seyferts (Heckman, 1980). Ferland e Netzer (1983) and Halpern e Steiner (1983) demonstrated that photoionization by an AGN, with a low ionization parameter, results in the observed lower ionization spectrum of LINERs; though, other scenarios may be applicable to some objects (see Ho 2008 for a review).

Infrared studies (LW2 and LW3 filters of Spitzer telescope) have shown that there is

\footnotetext{
1 The NASA/IPAC Extragalactic Database (NED) is operated by the Jet Propulsion Laboratory, California Institute of Technology, under contract with the National Aeronautics and Space Administration.
} 
little emission in the region between the nucleus and the ring and this area is dominated by old stellar populations (Roussel et al., 2001). Besides that, in this region, there is not much star formation, which may be due to the orbital resonance that ejected the gas (Ryder e Dopita, 1993).

Our group is conducting the Deep IFS View of Nuclei of Galaxies (DIVING ${ }^{3 D}$ ) survey (J. E. Steiner et al. 2018, in preparation), which has the goal of observing the nuclear region of all southern galaxies brighter than $\mathrm{B}=12.0$. The observations are being taken, in the optical, with the integral field unit (IFU) of the Gemini Multi-Object Spectrograph (GMOS), on the Gemini-South telescope. One of the goals is to analyze in detail the subsample with a morphological type similar to that of the Milky Way (SABbc or SBbc which we call Milky Way twins). NGC 6744 is the brightest ( $\mathrm{B}=9.24$ - NED) object of this subsample and, consequently, deserves special attention.

In this work, we analyze the data cube of the central region of NGC 6744, in order to characterize the nature of the emission from this region and to study the kinematics of the gas and stars. In section 7.3 , we show details of the observations, of the reduction processes, and of the data analysis. Section 7.4 presents the analysis of the emitting spectrum of different spatial regions of the data cube. In sections 7.5 and 7.7 , we present the analysis of the kinematics of the gas and stars, respectively. We show the results of the spectral synthesis applied to the spectra of two distinct regions in section 7.6. In section 7.8, we present the analysis of the Hubble Space Telescope (HST) images of the central region of NGC 6744. We discuss all the obtained results in section 7.9. Lastly, section 7.10 summarizes the main conclusions of this work.

\subsection{Observations and data reduction}

The observations were taken on 2014 May 8, with GMOS/IFU, installed on the GeminiSouth telescope, in one slit mode (GS-2014A-Q-5). Three $815 \mathrm{~s}$ exposures were made, with position angles (PA) equal to $0^{\circ}$ and with fields of view (FOVs) of $5 " \times 3 " .5$. The grating used for this observation was R831+G5322, with the central wavelength of $5850 \AA$, and the resulting spectral resolution was $\mathrm{R}=4340$. The seeing, determined from the acquisition image (observed at $\lambda=6300 \AA$ ), was FWHM $\sim 0$ ".55. Fig. 7.1 shows the GMOS FOV on an HST image, obtained with the WFC3 camera. One can notice that the observation 

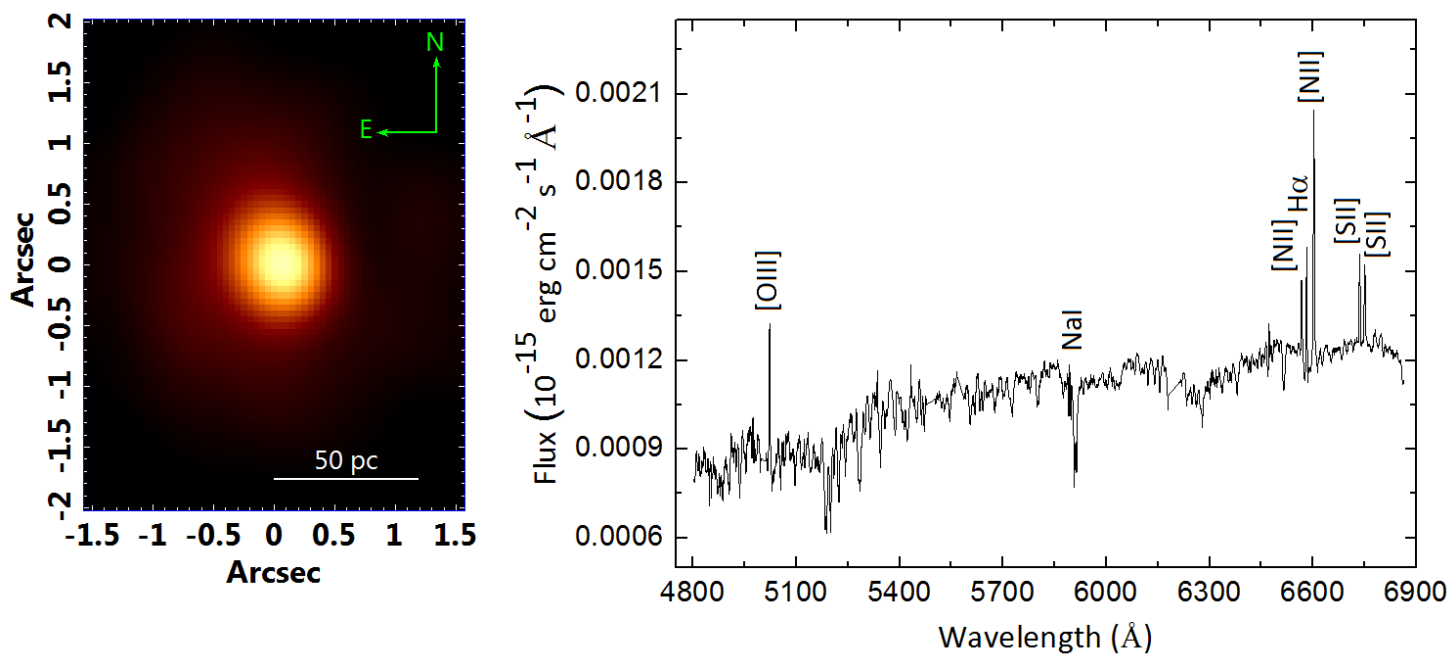

Figura 7.2: Image of the data cube, collapsed along the spectral axis, observed with GMOS IFU, together with its mean spectrum. The NE orientation and the $50 \mathrm{pc}$ scale are also shown in the image.

area is restricted only to the $\sim 130 \times 167 \mathrm{pc}$ of the central region of the bulge of NGC 6744 .

The reduction was performed in the IRAF environment, and it started with the determination of the trim and bias subtraction. After that, the cosmic-ray removal was applied using the LACOS routine (van Dokkum, 2001). Then spectra were extracted and corrected for gain variations between the pixels (with response curves obtained with GCAL-flat images). Corrections for gain variations between fibers and asymmetric illumination patterns of the instrument were also performed (using twilight-flat images). The spectra were wavelength calibrated (using CuAr lamp images) and the sky subtraction was applied (using the mean spectrum of the sky FOV, located at 1' from the science FOV). Corrections of the atmospheric extinction and telluric absorption removal were then applied. After the flux calibration, three data cubes were created. These cubes have spatial pixels (spaxels) with 0 ".05 × 0".05 and their spectral coverage is from $4804 \AA$ to $6865 \AA$.

The data cubes' treatment involved the use of some scripts, which were written by our group, in IDL (Interactive Data Language). This treatment consisted of the correction of the differential atmospheric refraction, the combination of the data cubes to determine a median (in order to obtain only one data cube), Butterworth spatial filtering Gonzalez e Woods, 2002), and instrumental fingerprint removal (see Menezes et al.|2014, 2015). Lastly, we applied the Richardson-Lucy deconvolution (Richardson 1972 and Lucy 1974), with 10 iterations, where the wavelength variation of the FWHM of the point spread function 
(PSF) was estimated from the data cube of the standard star, and the FWHM value of a point-like source from the acquisition image was used to determine the PSF in a specific wavelength. After comparing with an $H S T$ image in the F555W (V) filter convolved with Gaussian PSFs, we estimate that the FWHM of the PSF of the treated data cube is 0".43, which corresponds to 17.7 pc.

Fig. 7.2 shows the resulting image of the sum of all images of the data cube after the treatment and also its mean spectrum. This mean spectrum reveals the following emission lines: [O III] $\lambda 5007,[\mathrm{O}$ I] $\lambda 6300,[\mathrm{~N}$ II] $\lambda \lambda 6548,6584, \mathrm{H} \alpha$ e $[\mathrm{S}$ II $] \lambda \lambda 6716,6731$. Those lines are emitted, mostly, in the central region and are quite narrow.

\subsection{Nuclear and circumnuclear emission line properties}

\subsubsection{Spectral synthesis and subtraction of stellar continuum}

In order to study the emission lines, both in terms of the regions where they are emitted and in terms of the emission line ratios and profiles, it is necessary to analyze the data cube without stellar continuum. For that, we performed a spectral synthesis (STARLight - Cid Fernandes et al. 2005) of the data cube with masked emission lines using a base with stellar population spectra based on the Medium-resolution Isaac Newton Telescope Library of Empirical Spectra - MILES (Sánchez-Blázquez et al., 2006). From our previous experience, a minimum signal-to-noise ratio $(\mathrm{S} / \mathrm{N})$ of 10 is necessary to obtain reliable results from the spectral synthesis. We verified that the $\mathrm{S} / \mathrm{N}$ of the continuum, between $5804 \AA$ and $5835 \AA$, of the data cube is $11 \leqslant \mathrm{~S} / \mathrm{N} \leqslant 54$, with the values increasing toward the center; therefore, all the parameters provided by the spectral synthesis seem to be reliable.

We built a data cube with the synthetic stellar spectra corresponding to the fits provided by the spectral synthesis. Such a data cube was subtracted from the original one, which resulted in a data cube with emission coming mainly from gas, which we refer to here as the gas data cube.

\subsubsection{The line emitting regions}

From the gas data cube, it was possible to obtain images of some emission lines (see Fig. 7.3). The main source of all emission lines is called Region 1. The position of this region is very close to the center of the FOV, which coincides approximately with the center 

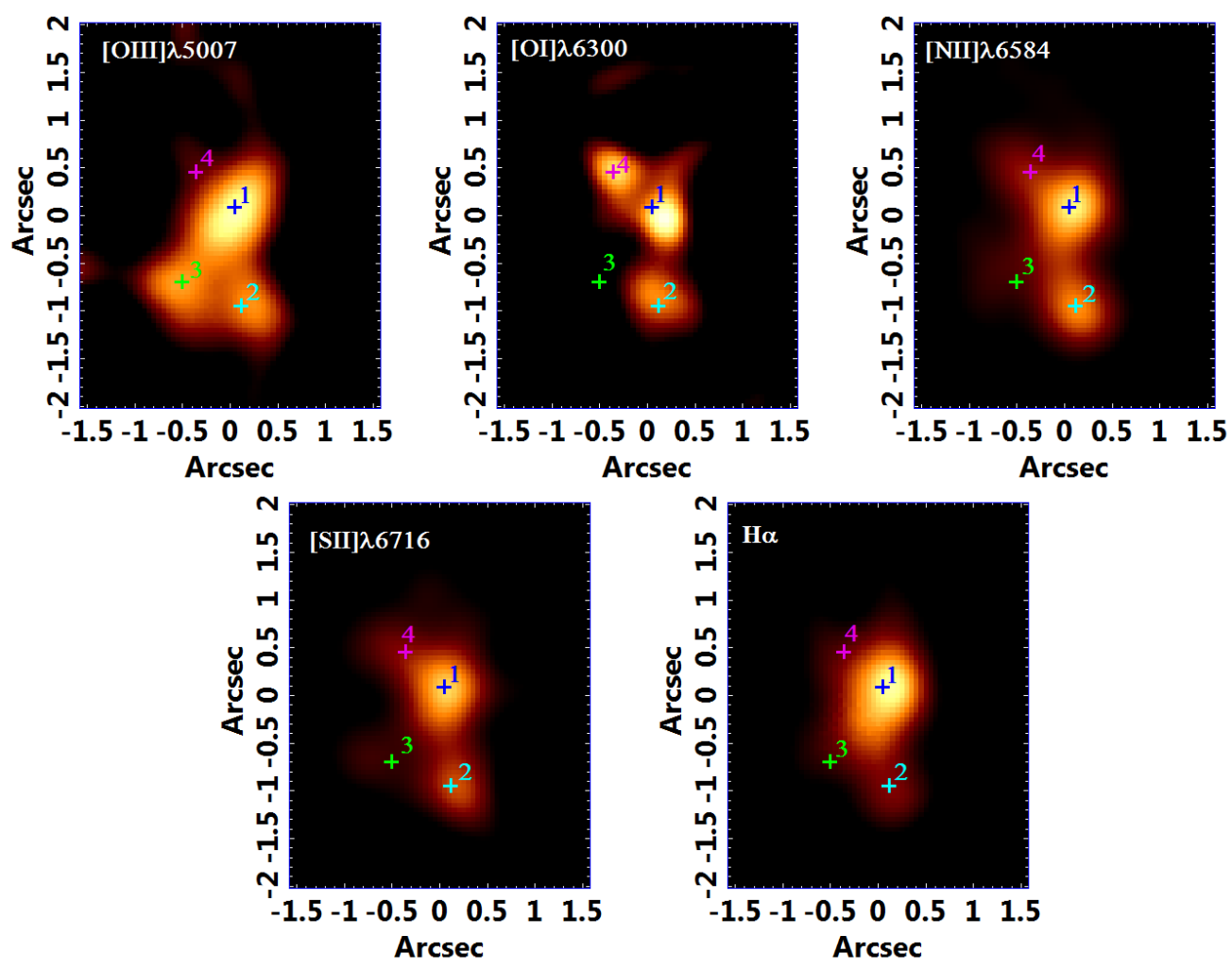

Figura 7.3: Images of the main emission lines of the NGC 6744 data cube after the stellar continuum subtraction. All the images have indications of the centroids of all emitting regions. The positions of Regions 1 and 2 were determined from the [N II] 26584 image, the position of Region 3 from [O III] $] 55007$, and the position of Region 4 from [O I] 66300 image. Note that Region 3 does not appear in evidence in the images (except in the $[\mathrm{O} \mathrm{III}] \lambda 5007$ image) and, in the $\mathrm{H} \alpha$ image, only Region 1 appears in evidence. Region 4, which is very bright in the [O I] $\lambda 6300$ image (together with Regions 1 and 2), seems to be very diluted in the other images. Besides that, there is an extension of Region 1 toward Region 3 in the [O III $] \lambda 5007$ image. 
(a)

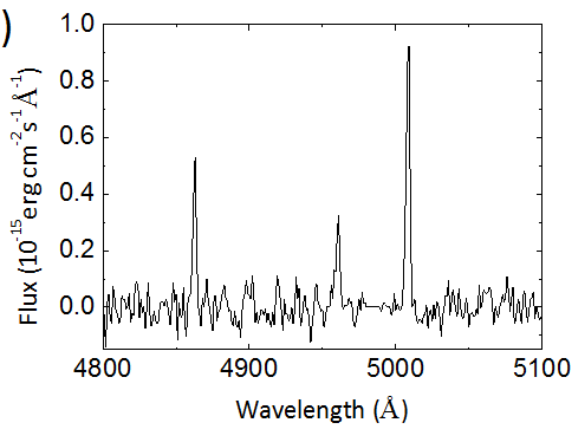

(b)

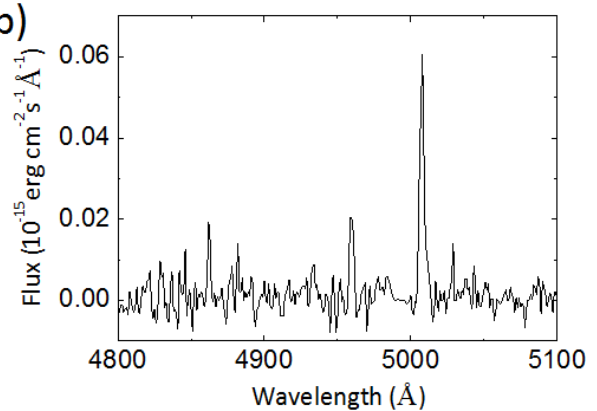

(c)

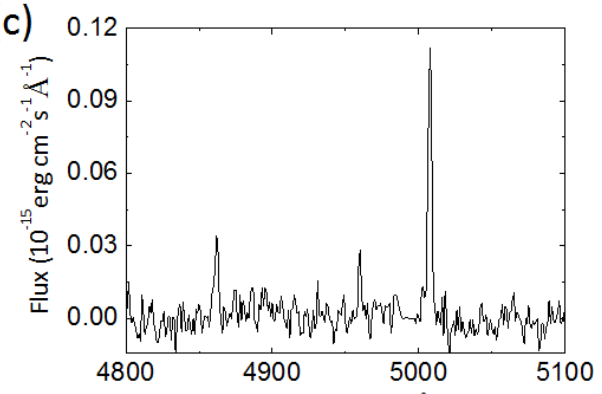

(d)

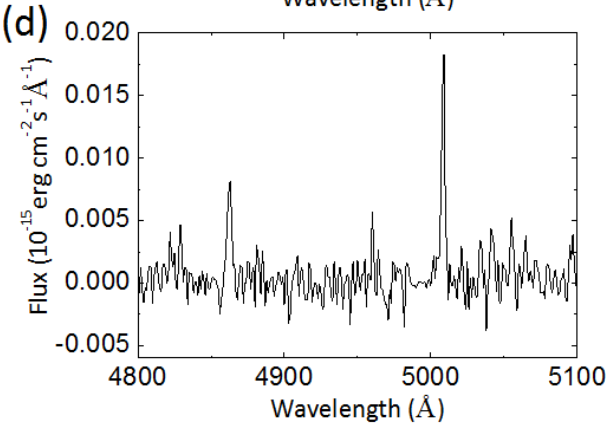

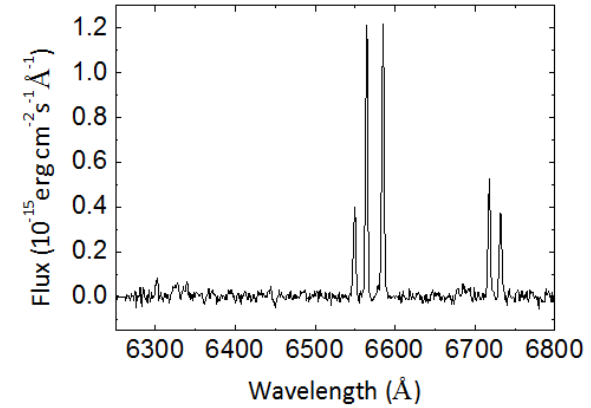
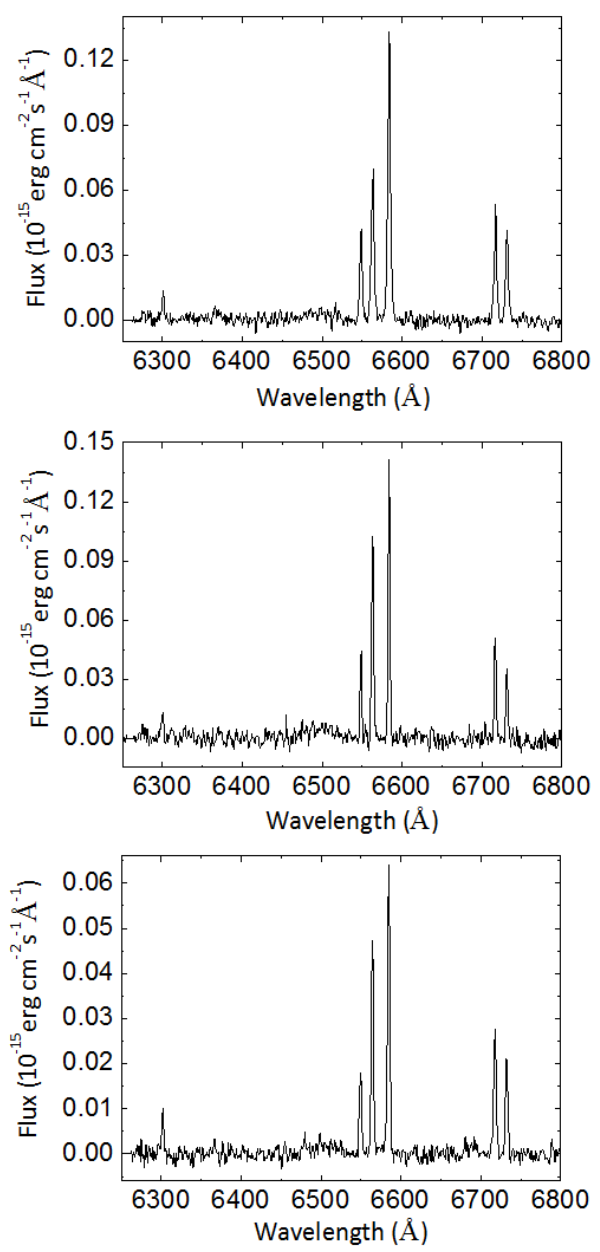

Figura 7.4: Blue and red parts of the emission line spectra of (a) Region 1, (b) Region 2, (c) Region 3, and (d) Region 4, showing the main emission lines. 
Tabela 7.1 - Projected Distances $(D)$ in Parsecs of Regions 2, 3, and 4 Relative to Region 1 ( $X_{C}=0$ "and $\left.Y_{C}=0 "\right) . X_{C}$ and $Y_{C}$ are the central coordinates of each region. The uncertainty for $D$ was calculated taken into account only the instrumental uncertainties.

\begin{tabular}{cccc}
\hline Regions & $X_{C}(")$ & $Y_{C}(")$ & $D(\mathrm{pc})$ \\
\hline 2 & -0.1 & 0.9 & $41.2 \pm 1.5$ \\
3 & 0.5 & 0.8 & $40.5 \pm 1.5$ \\
4 & 0.4 & -0.5 & $22.2 \pm 1.5$ \\
\hline
\end{tabular}

Tabela 7.2 - FWHM of the [N II] $\lambda 6584$ Line (Corrected for the Instrumental Resolution), H $\alpha$ Luminosity, Eletronic Density Intervals (Obtained from [S II] $] 6716 /[\mathrm{S}$ II]6731 Ratio), and Upper Limit for the Temperature (Obtained from the Ratio of $[\mathrm{N}$ II $] \lambda 5755$ and $[\mathrm{N}$ II $] \lambda 6548+\left[\mathrm{N}_{\mathrm{II}}\right] \lambda 6584$ Lines) of the Observed Regions.

\begin{tabular}{ccccc}
\hline Region & 1 & 2 & 3 & 4 \\
\hline FWHM ([N II] $] 6584)$ in $\mathrm{km} \mathrm{s}^{-1}$ & $152 \pm 10$ & $180 \pm 13$ & $123 \pm 15$ & $150 \pm 17$ \\
Luminosity of $\mathrm{H} \alpha\left(10^{36} \mathrm{erg} \mathrm{s}^{-1}\right)$ & $33.9 \pm 0.8$ & $2.62 \pm 0.15$ & $2.97 \pm 0.18$ & $1.4 \pm 0.4$ \\
Electronic density $\left(n_{e}\right.$ in cm & \\
Upper limit for temperature $(\mathrm{K})$ & $258 \geq \mathrm{d} \geq 81$ & $409 \geq \mathrm{d} \geq 230$ & $\mathrm{~d} \leq 64$ & $\mathrm{~d} \leq 170$ \\
Un & 40305 & 8048 & 9367 & 6539 \\
\hline
\end{tabular}

of the bulge (the galactic nucleus). A second region (Region 2) appears in all emission line images and is located $\sim 0 " .9$ south from the nucleus. Region 3, more visible in [O III] $]$ 5007 image, is $\sim 1$ "to the southeast from Region 1. Lastly, Region 4, more easily detected in $[\mathrm{O}$ I $] \lambda 6300$ image, is located $\sim 0$ ".6 northeast from the nucleus. The nucleus appears elongated in the $[\mathrm{O}$ III $] \lambda 5007$ image, with $\mathrm{PA} \sim-53^{\circ}$ (toward Region 3). Table 7.1 shows the coordinates of the centroids of each region, assuming that the centroid of Region 1 is at $X_{C}=0$ " and $Y_{C}=0$ ". The projected distances ( $D$ in parsecs) of each object relative to Region 1 are also presented.

Tabela 7.3 - Emission Line Ratios for the Four Observed Regions.

\begin{tabular}{ccccc}
\hline Emission Line Ratios & Region 1 & Region 2 & Region 3 & Region 4 \\
\hline$[\mathrm{O}$ III $] \lambda 5007 / \mathrm{H} \beta$ & $2.3 \pm 0.4$ & $5.3 \pm 1.9$ & $3.4 \pm 0.6$ & $2.4 \pm 0.6$ \\
{$[\mathrm{~N}$ II $] \lambda 6584 / \mathrm{H} \alpha$} & $1.15 \pm 0.03$ & $1.90 \pm 0.07$ & $1.20 \pm 0.05$ & $1.44 \pm 0.07$ \\
$([\mathrm{~S}$ II $] \lambda 6716+6731) / \mathrm{H} \alpha$ & $0.83 \pm 0.03$ & $1.25 \pm 0.05$ & $0.80 \pm 0.04$ & $1.16 \pm 0.07$ \\
{$[\mathrm{O}$ I $] \lambda 6300 / \mathrm{H} \alpha$} & $0.088 \pm 0.004$ & $0.192 \pm 0.018$ & $0.153 \pm 0.021$ & $0.21 \pm 0.03$ \\
{$[\mathrm{~S}$ II $] \lambda 6716 /[\mathrm{S}$ II $] \lambda 6731$} & $1.26 \pm 0.08$ & $1.14 \pm 0.06$ & $1.49 \pm 0.13$ & $1.36 \pm 0.11$ \\
\hline
\end{tabular}



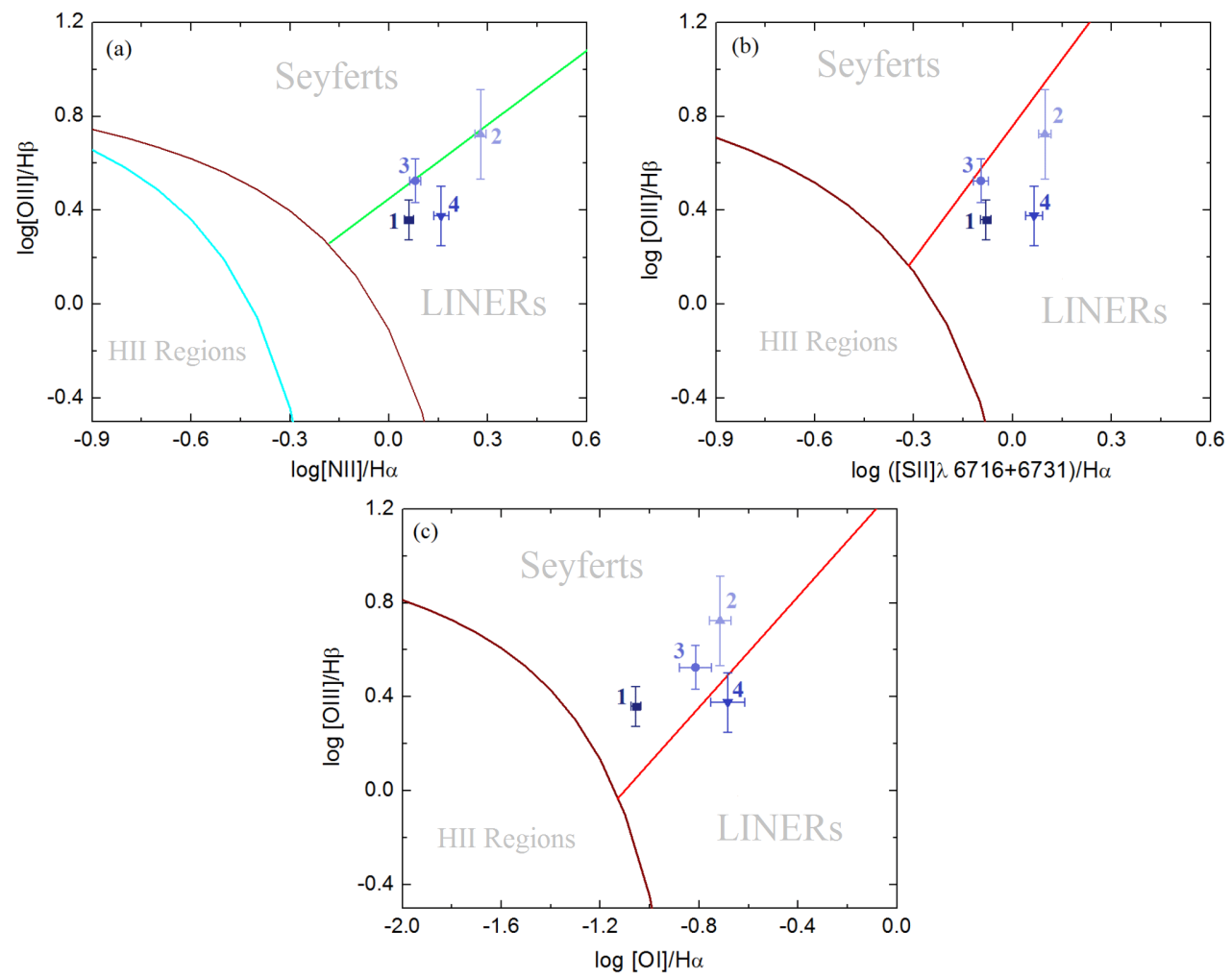

Figura 7.5: Diagnostic diagrams with the emission line ratios of the regions observed in the data cube of the central region of NGC 6744, using the values of Table 7.3. The four regions are represented by points in violet color variations. Each region is identified in the graph with its respective number next to each point. The wine fit in the (a), (b), and (c) diagrams shows the upper limit for the ionization by a starburst obtained by Kewley et al. (2001). The cyan fit represents the division between H II regions and AGNs obtained by Kauffmann et al. (2003) and the red line, the division between LINERs and Seyferts in diagrams (b) and (c) determined by Kewley et al. (2006). The green line in diagram (a) is the division between LINERs and Seyferts determined by Schawinski et al. (2007). 


\subsubsection{Diagnostic diagrams}

In order to characterize the nature of the emission of the four observed regions, we extracted spectra (from the gas data cube) of circular regions, whose central coordinates are in Table 7.1 and whose extraction radius was equal to half of the FWHM of the PSF value: 0".25. Fig. 7.4 shows the extracted spectra (the blue and red parts of the spectrum) of the four main regions.

The representative values of the FWHM corresponding to the emission lines of each region were calculated using $[\mathrm{N}$ II] $] 6584$ line, because this is the most intense line in all spectra. As we can see in Table 7.2 , the lines are quite narrow in all regions of the data cube. The emission line ratios were calculated using the integrated flux of each line of the extracted spectra (see Table 7.3).

The diagnostic diagrams (Baldwin et al. 1981; Kewley et al. 2001, 2006; Kauffmann et al. 2003 Fig. 7.5 were made based on the calculated emission line ratios and show that, in terms of ionization degree, all regions are compatible with each other, at the $3 \sigma$ level and all emission line ratios are compatible with those of Seyferts and LINERs. Regions 2 and 3 seem to have slightly higher ionization degrees when compared to the others.

When analyzing the diagnostic diagrams together with the images of the emission lines presented in Fig. 7.3, we see that Region 3, which seems to have a higher ionization degree than Region 1, can be an ionization cone. This is because it appears in evidence only in the [O III $] \lambda 5007$ image, which is a higher ionization line, and also because Region 1 appears, in this same image, elongated toward Region 3. Region 4 appears in evidence only in the [O I] $\lambda 6300$ image, suggesting that this might be a region of lower ionization.

\subsection{Gas Kinematics}

From the gas data cube spectra, it is possible to study the gas kinematics using channel maps. In the present case, we made channel maps with $1 \AA$ intervals (based on the fact that the emission lines were quite narrow) in each image, for each line, as is presented in Fig. 7.6. For each emission line, we see that the first channel map represents the gas in blueshift, the second represents the gas with velocity close to zero, and the last represents the gas in redshift. The morphologies of the channel maps are similar and reveal a pattern consistent with a rotation around Region 1 . However, some asymmetries in this pattern 

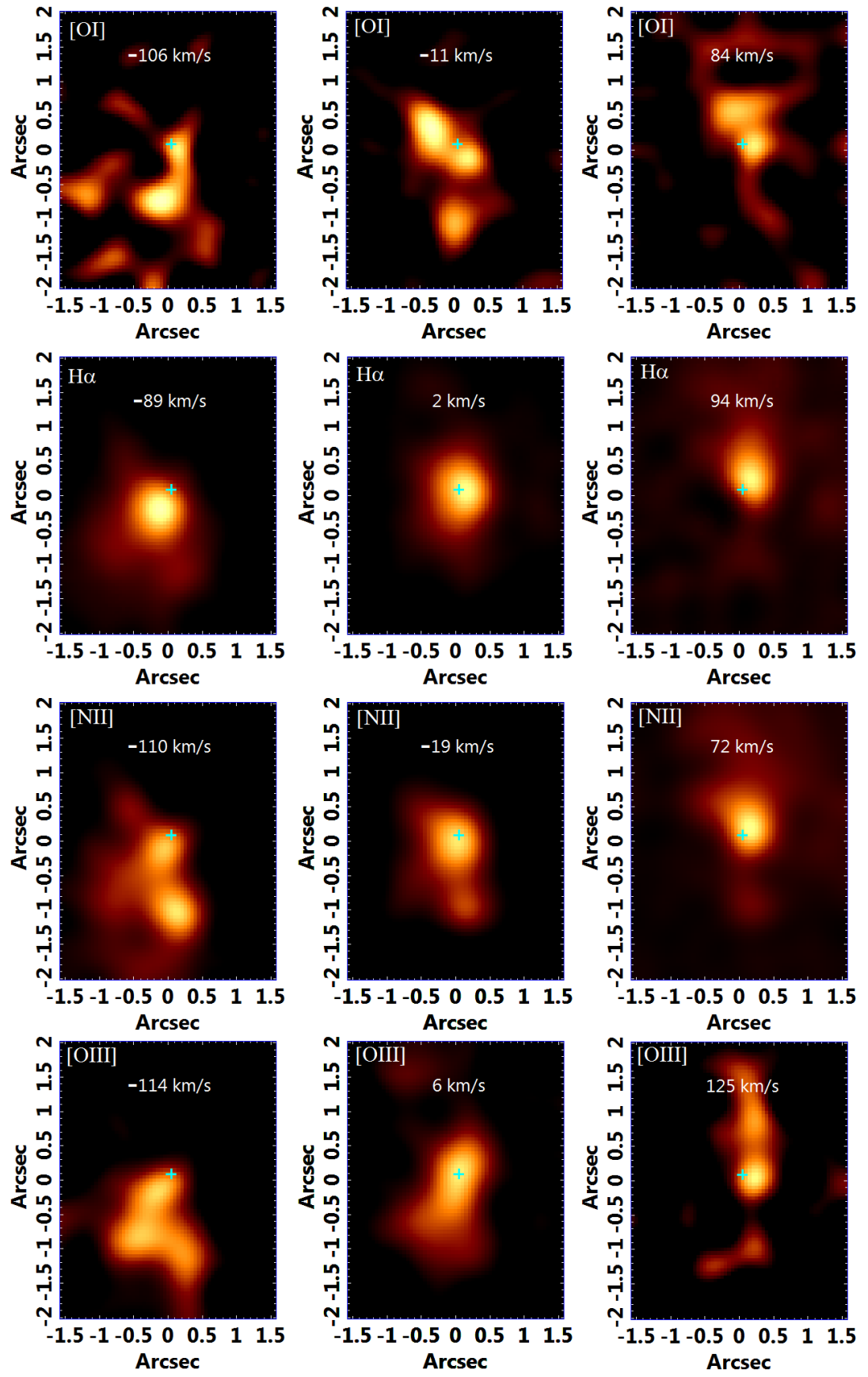

Figura 7.6: Channel maps of the following emission lines from the data cube of NGC 6744 after the stellar continuum subtraction: [O I] $] \lambda 6300, \mathrm{H} \alpha,[\mathrm{N}$ II $] \lambda 6584$, and $[\mathrm{O}$ III $] \lambda 5007$. The interval of each image is equivalent to $1 \AA$. Region 1's central position is indicated by the cyan cross, and its size is $3 \sigma$. 

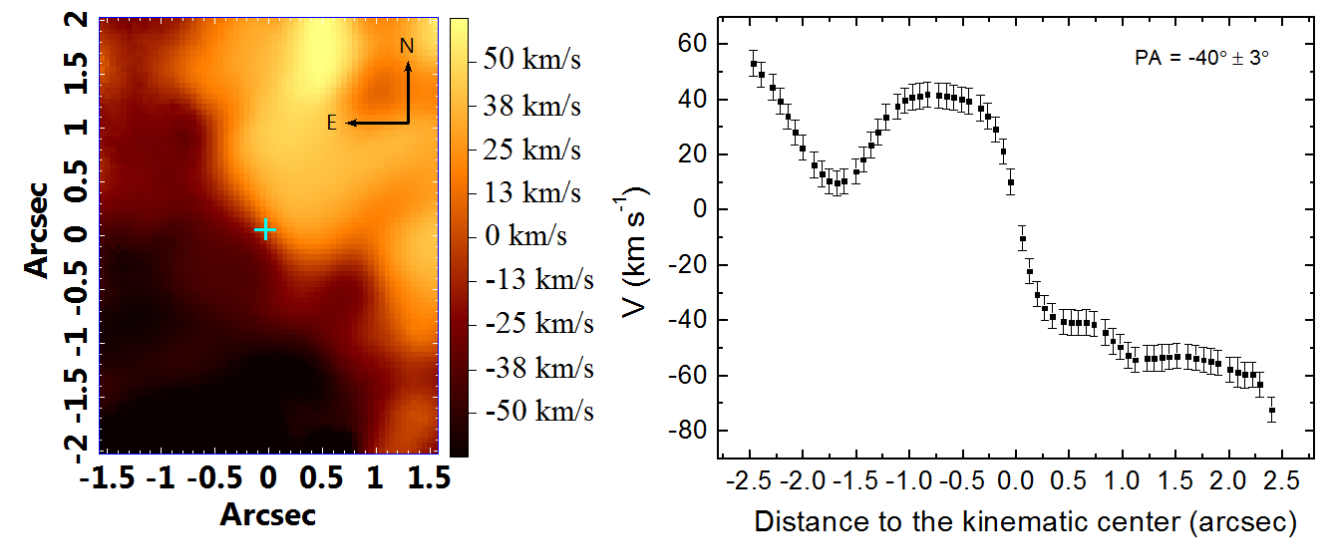

Figura 7.7: Velocity map of $\mathrm{H} \alpha$ with its respective velocity curve, extracted along $\mathrm{PA}=-40^{\circ} \pm 3^{\circ}$. The cyan cross represents the position of the kinematic center obtained for this map and its size indicates the uncertainty of $1 \sigma$.
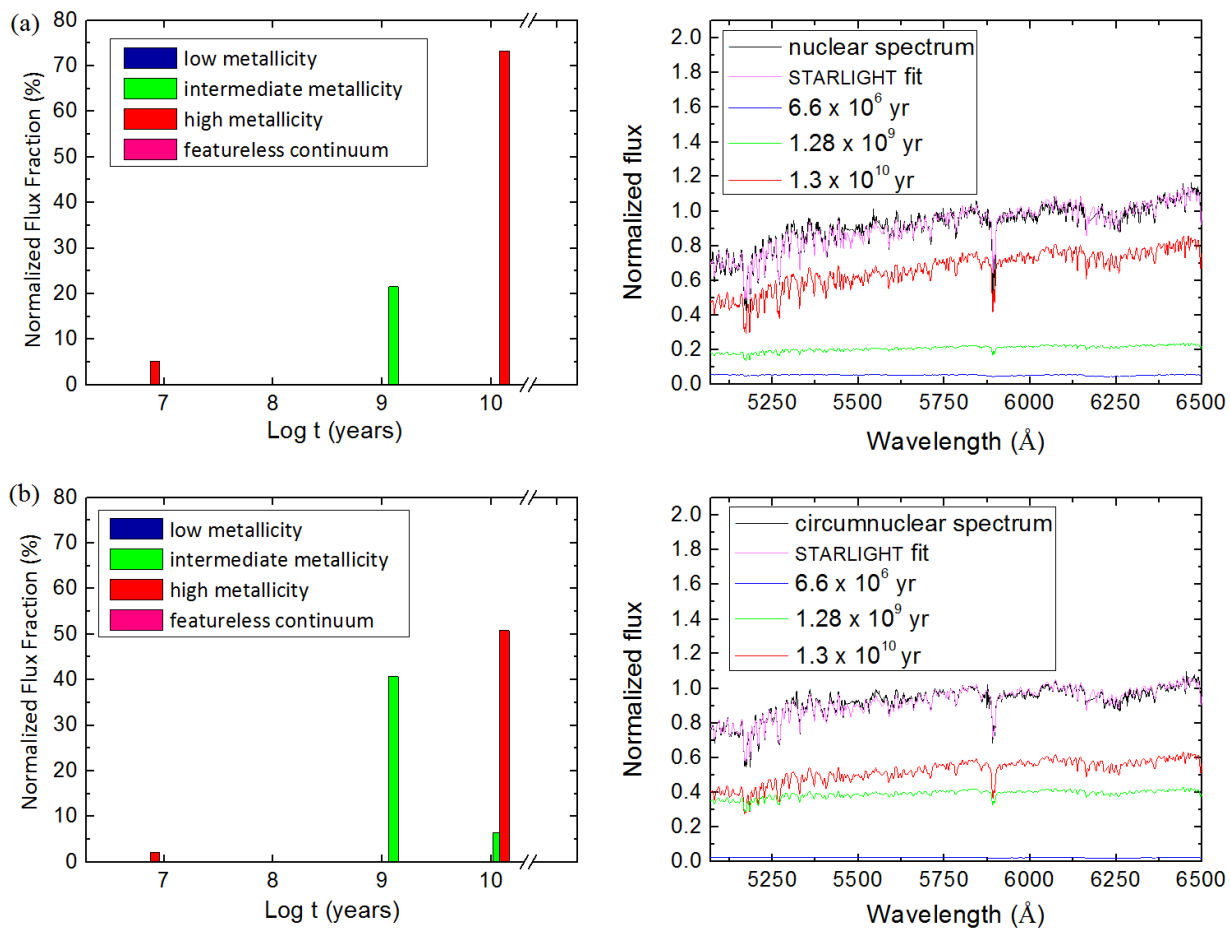

Figura 7.8: Spectral synthesis results of (a) the nuclear region spectrum and (b) the circumnuclear region spectrum. Both histograms show only stellar populations with high $(0.02$ e 0.05$)$ and intermediate $(4 \times$ $10^{-3}$ e $8 \times 10^{-3}$ ) metallicities, evidencing two significant stellar formation processes. Besides that, we can see that the higher flux fraction of the $10^{9}$ year old stellar population is in the circumnuclear region. The extracted spectra, together with the corresponding STARLIGHT fits, in pink, and the spectra of the stellar populations required for the the fit are shown next to each histogram. 
are also observed, like the fact that the PA value of the line of nodes in the redshifted gas region does not seem to be the same as that of the line of nodes in the blueshifted gas region (more clearly seen in the $[\mathrm{O}$ III $] \lambda 5007$ line channel maps). This may be explained by the fact that blueshifted gas with high velocities is associated with the possible ionization cone, thus being evidence of outflows of gas in that region.

We also note that Regions 2 and 3 are in blueshift and part of Region 4 has gas with low velocities in redshift.

From the $\mathrm{H} \alpha$ velocity map (Fig. 7.7) and its velocity curve, obtained from the Gaussian functions fitted to the $\mathrm{H} \alpha$ emission line, we note that the probable gas rotation seems to be contained in the inner region and, in the FOV edges, there are some irregularities. The PA of the line of nodes is $-40^{\circ} \pm 3^{\circ}$. The kinematic center determined for this map is $X_{C}=0 " .00 \pm 0 " .11, Y_{C}=-0 " .03 \pm 0 " .11$, compatible, at the $1 \sigma$ level, with Region 1 centroid coordinates. Therefore, the inner gas is rotating around Region 1. We found that an amplitude/noise $(\mathrm{A} / \mathrm{N})$ ratio higher than 5 is necessary to obtain reliable radial velocity values from Gaussian functions fitted to the emission lines. Because the A/N ratio of the $\mathrm{H} \alpha$ line is $\sim 5$ at the edges of the FOV and $\sim 60$ at the areas close to the stellar nucleus, we conclude that the values of the $\mathrm{H} \alpha$ radial velocity are reliable, with a probable lower accuracy at the FOV edges, where the $\mathrm{A} / \mathrm{N}$ ratio is close to the limit mentioned above.

The velocities of Regions 2, 3, and 4 relative to Region 1 are $-54 \pm 7 \mathrm{~km} \mathrm{~s}^{-1},-55 \pm$ $7 \mathrm{~km} \mathrm{~s}^{-1}$, and $-5 \pm 5 \mathrm{~km} \mathrm{~s}^{-1}$, respectively. The velocities of Regions 2 and 3 are similar (considering the uncertainties) and Region 4 seems to be at rest or in low velocity relative to Region 1.

We estimated values for the electronic density, based on the $[\mathrm{S}$ II $] \lambda 6716 /[\mathrm{S}$ II $] \lambda 6731$ ratio and a gas temperature of $10^{4} \mathrm{~K}$. Upper limits for temperatures were calculated using the $[\mathrm{N}$ II $] \lambda 5755,[\mathrm{~N}$ II] $]$ 6548 and [N $\mathrm{II}] \lambda 6584$ line ratio (with an estimate for the upper limit of the integrated flux of $[\mathrm{N}$ II $] \lambda 5755$ line). Table 7.2 shows those values, as well as the values of the $\mathrm{H} \alpha$ luminosity and the FWHM of the $[\mathrm{N} \mathrm{II}] \lambda 6584$ line of all observed regions. Note that, with the exception of Region 1, all of the regions have temperatures lower than $10^{4} \mathrm{~K}$. 


\subsection{Stellar archeology}

In order to study the stellar populations in different areas of the FOV, we applied the spectral synthesis (using STARLIGHT) to two spectra of the data cube after treatment: one spectrum of the nuclear region (in this case, since Region 1 is the nuclear region, we used its spectrum) and one spectrum of the circumnuclear region (obtained by subtracting the spectrum of Region 1 from the total spectrum of the data cube). The spectral synthesis was applied as described in section 7.4, but only to those two spectra and with an additional spectrum in the base, which is a power law with a spectral index of 1.5, representing a possible featureless continuum emission.

The mean age uncertainty of the stellar populations (which is the weighted mean of the stellar population ages based on their flux fraction) was obtained with a Monte Carlo procedure and is of the order of 0.03 dex. The exact process for determining this uncertainty was the following: first, a synthetic stellar spectrum was obtained with the spectral synthesis applied to the mean spectrum of the data cube. A Gaussian distribution of the spectral noise was estimated from the result obtained by subtracting the synthetic stellar spectrum from the mean spectrum. Then, different Gaussian distributions were made, with the same width of the initial one; such distributions were added to the synthetic stellar spectrum mentioned above. The spectral synthesis was applied to each resulting spectrum and the uncertainty of the mean age was taken as the standard deviation of the mean ages obtained with those spectral synthesis applications.

The spectral synthesis histogram of the nuclear region (Fig. 7.8 a) shows that most of the flux fraction is due to $10^{10}$ year old stellar populations and only $\sim 20 \%$ of the total flux fraction is due to populations of $10^{9}$ years. However, the spectral synthesis of the circumnuclear region (Fig. 7.8p) reveals that the flux fraction is, approximately, double $(\sim 40 \%)$ for $10^{9}$ year old stellar populations and the older ones are associated with a much lower flux fraction than in the nuclear region. There is no indication of younger populations or featureless continuum in these data. The fact that there is a greater flux fraction of the $10^{9}$ year old population in the circumnuclear region suggests that this galaxy may have gone through a merger process that occurred one billion years ago, which generated this population (see section 7.9.4).

The results provided by the spectral synthesis are subject to degeneracies. The Monte 

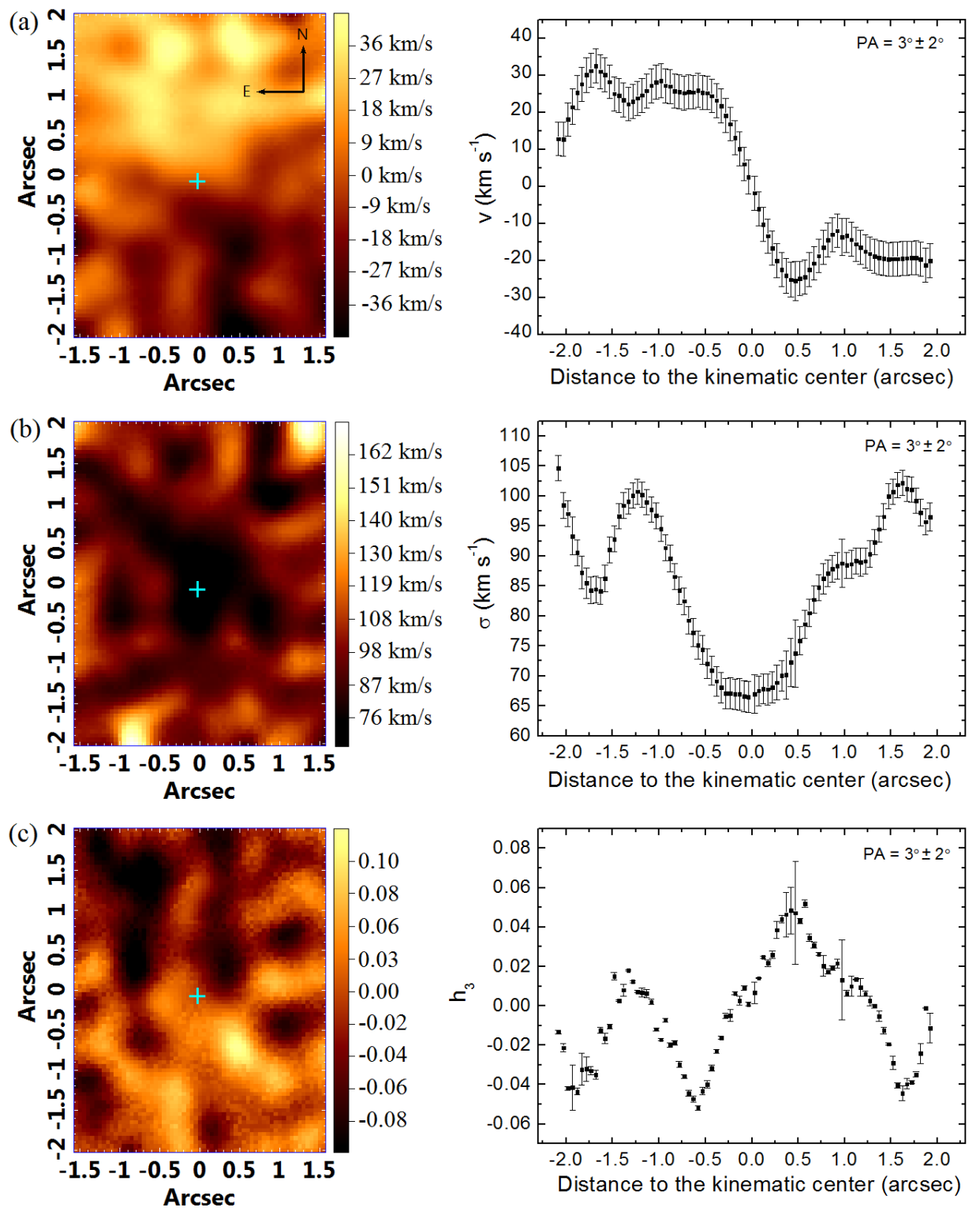

Figura 7.9: Maps of the following parameters obtained with pPXF: (a) $V_{*}$, (b) $\sigma_{*}$, and (c) $h_{3}$, with their respective curves extracted along the line of nodes, with PA indicated. The cyan cross represents the kinematic center position, obtained from the stellar velocity map and its size represents $1 \sigma$. The error bars in the curves of each map were determined from a Monte Carlo procedure, similar to the one described in section 7.6 . 

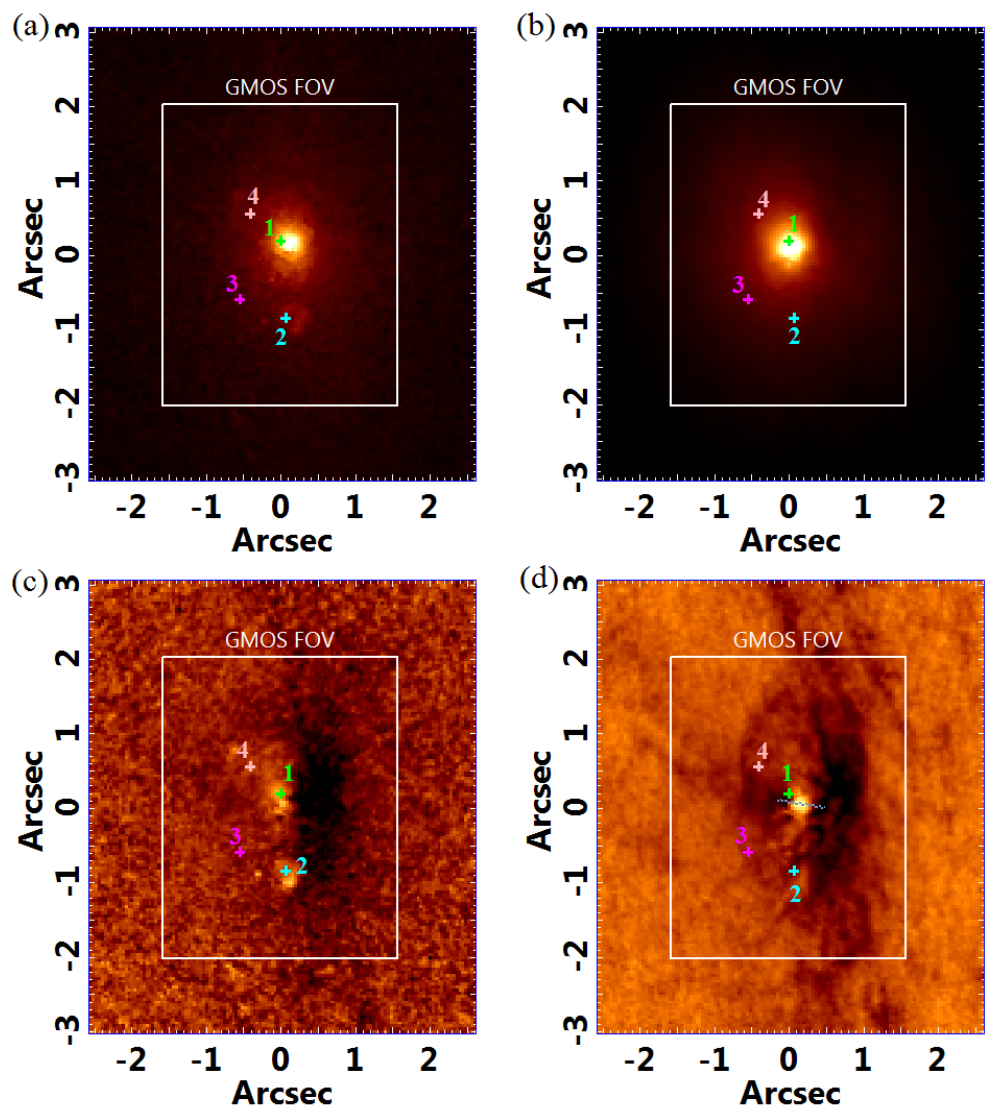

Figura 7.10: HST images with the same orientation as the GMOS data cube analyzed in this work. The size of the GMOS data cube FOV is also indicated. All the images have the coordinates of the four emitting regions observed in the GMOS data cube indicated by crosses, and their sizes represent their uncertainties $(3 \sigma)$. The positions were determined assuming that the coordinates of Region 1 are compatible, at $3 \sigma$ level, with the center of the stellar bulge (see Fig. 7.11a). (a) $\mathrm{H} \alpha+[\mathrm{N}$ II] emission image obtained by subtracting the image in the F555W filter, multiplied by a constant, from the image in the F657N filter; (b) image in the F814W filter; (c) image corresponding to the subtraction F814W - F657N, in magnitude scale; (d) image corresponding to F814W - F555W (equivalent to I-V), in magnitude scale, with the apparent dust disk near the center indicated by a gray dashed line. 
(a)

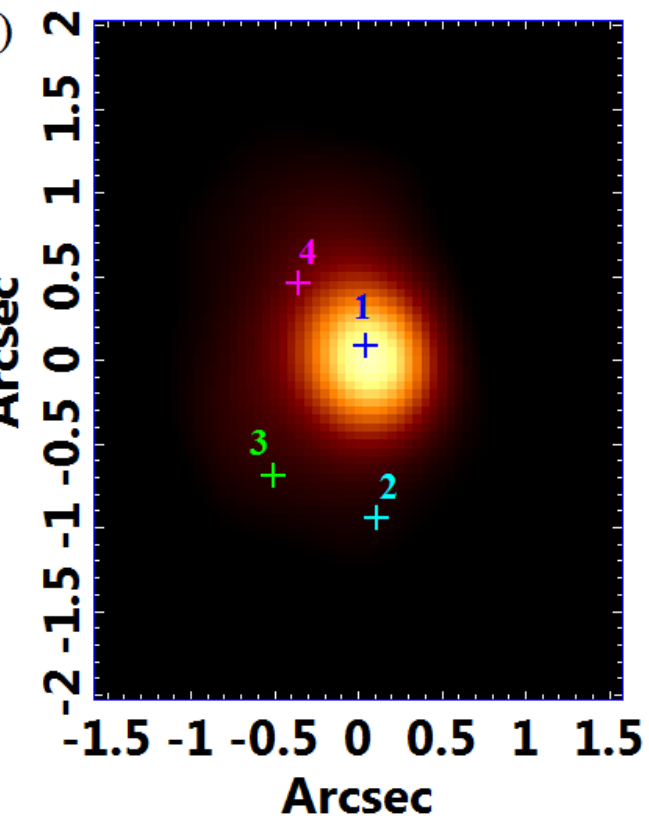

(b)

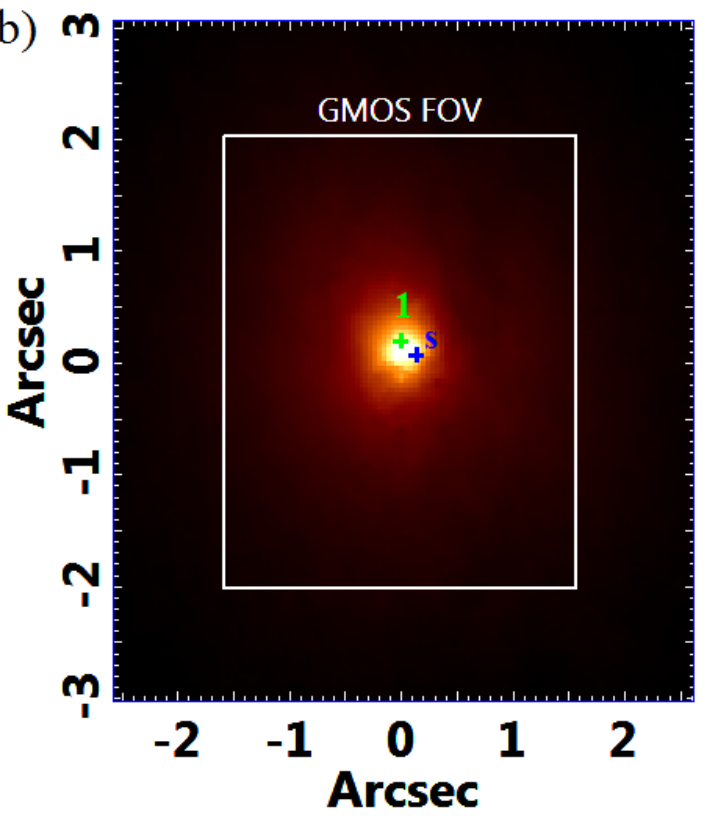

Figura 7.11: (a) Image of the stellar continuum of the data cube of NGC 6744 with the position of the four emitting regions indicated by crosses, and their sizes represent the uncertainty of $3 \sigma$.Note that Region 1 coincides with the stellar bulge center. (b) Image in the F814W filter (I band) with an indication of Region 1's position and the position of the blue source (S) detected in Fig 7.10 $\mathrm{A}$.

Carlo simulations described before can help to evaluate the uncertainties related to the $\mathrm{S} / \mathrm{N}$ ratio but not the uncertainties due to such degeneracies. As a consequence, all the results presented in this section must be handled with caution. Therefore, although the exact ages determined for the stellar populations detected in the nuclear and circumnuclear spectra may not be totally reliable, the relative ages between these populations may be. One point in favor of this method is that the same technique was applied to analyze the nuclear and the circumnuclear spectrum, which makes the spectral synthesis results obtained for such spectra subject to the same kind of imprecisions. In addition, the observable differences between the stellar components of these two spectra make it clear that the stellar populations in these two regions are indeed different. Note that the absorption lines in the nuclear spectrum are deeper than the circumnuclear, which is evidence that there is a higher concentration of an old stellar population in the nuclear region compared to the circumnuclear region. Based on this, we conclude that, despite the degeneracies, a comparison between these results is a relevant procedure, worthy of being included in this work. 


\subsection{Stellar Kinematics}

In order to analyze the stellar kinematics of the data cube of NGC 6744, we applied the Penalized Pixel Fitting (pPXF) method (Cappellari e Emsellem, 2004). It fits the stellar spectrum of an object with a combination of template stellar spectra from a determined base. In this case, the procedure was applied with the same base used to perform the spectral synthesis. The spectra of the base are convolved with a Gauss-Hermite expansion, providing the following parameters: stellar radial velocity $\left(V_{*}\right)$, stellar velocity dispersion $\left(\sigma_{*}\right)$, and the $h_{3}$ coefficient, which shows the profile deviations of the stellar absorption lines relative to Gaussian functions. Because this method was applied to all the spectra of the data cube, we obtained maps of those parameters (see Fig. 7.9). We found that a stellar continuum $\mathrm{S} / \mathrm{N}$ ratio higher than 10 is necessary to obtain reliable kinematic parameters with pPXF. As the $\mathrm{S} / \mathrm{N}$ ratio values of the analyzed data cube are $\sim 13$ on the edges of the FOV and $\sim 50$ close to the center of the stellar bulge, we concluded that the obtained maps of $V_{*}, \sigma_{*}$, and $h_{3}$ are reliable; though, the inaccuracies are higher at the edges of the FOV, due to the lower values of the $\mathrm{S} / \mathrm{N}$ ratio (very close to the limit).

Fig. 7.9 (a) shows the $V_{*}$ map obtained with pPXF. There is a velocity bipolarity and the line of nodes has a $\mathrm{PA}=3^{\circ} \pm 2^{\circ}$. The velocity curve, extracted along its line of nodes, seems to reveal a rotation in the inner region of the FOV. On the FOV edges, we see a lot of irregularities. The position of the kinematic center $\left(X_{C}=0\right.$ ".00 \pm 0"10, $Y_{C}=0$ ".11 \pm 0".10) is compatible, at the $1 \sigma$ level, with that of Region 1 , so we see an apparent stellar rotation around this region.

Fig. 7.9(b) shows the $\sigma_{*}$ map. We can see an evident decrease of $\sigma_{*}$ toward the kinematic center (Region 1 ), which can be called the $\sigma_{*}$-drop. The lowest detected value was $\sim 65$ $\mathrm{km} \mathrm{s}^{-1}$, approximately at the position of Region 1 .

The $h_{3}$ map (Fig. 7.9k), though very noisy, reveals an apparent anticorrelation with the $V_{*}$ map. This indicates the presence of a probable stellar rotation superposed to a stellar background with $V_{*}$ close to zero.

\subsection{HST images: the smoking gun}

The analysis of HST images allows us a better and clearer visualization of structures in a larger FOV with higher spacial resolution. This certainly helps, in many cases, to 
identify those structures in the galaxy context and not only in the nuclear region.

The analyzed images were obtained with the Wide Field Camera 3 (WFC3) of the HST on 2014 July 11 (F555W and F814W filters) and on 2015 July 11 (F657N filter). All images were retrieved from the HST archive and were also rotated to the same orientation of GMOS data cubes in order to provide a more direct comparison. A rectangle representing the GMOS FOV was added (see Fig. 7.10), together with crosses indicating the position of the four main emitting regions.

We subtracted the image in the F555W filter (multiplied by a constant) from the one in the $\mathrm{F} 657 \mathrm{~N}$ filter, in order to obtain an image representing the $\mathrm{H} \alpha+[\mathrm{N} \mathrm{II}]$ emission without the stellar continuum (Fig. 7.10a). Two emitting regions can be easily seen: the first one coincides with the position of Region 1 and the second, which is south from Region 1 and more diffuse, is close to the position of Region 2. The brightest central area extends slightly towards Region 4, and Region 3 cannot be detected.

The F814W filter image (I band - Fig. 7.10 p) shows only a central bright area. This image was taken as a reference, as we observed in the GMOS data that the position of the center of Region 1 is compatible with the center of the stellar bulge (see Fig. 7.11 ).

Fig. 7.10(c) shows the image corresponding to the subtraction F814W-F657N, in magnitude scale. The dark area represents the redder emission and the bright area indicates a more intense $\mathrm{H} \alpha+[\mathrm{N} \mathrm{II}]$ emission. We see again the two regions observed in Fig. 7.10(a). Besides that, there is a dark trail, in the western edges of those regions, indicating redder emission, possibly due to dust extinction. In this image, we can see more clearly the extension of Region 1 toward Region 4 and a little emission near Region 3.

We obtained Fig. 7.10(d) by subtracting the image in the F555W filter from the one in the F814W, in magnitude scale. The resulting image shows a dark strip that crosses the FOV and bends toward Region 4, indicating that the spectra are redder there. Besides that, there is a compact blue source slightly west of Region 1 (for a better comparison of their positions, see Fig. 7.11 b). There is also, as is indicated in the image by the dashed gray line, a possible dark structure that crosses the compact source, which might be a dust disk.

The projected distance between Regions 1 and 2, calculated from the HST images, is $0 " .91 \pm 0 " .03(39.1 \mathrm{pc} \pm 2.0 \mathrm{pc})$, which is compatible with the one calculated from the GMOS data cube (see Table 7.1). 


\subsection{Discussion}

Despite being one of the brightest and closest Milky Way twins, NGC 6744 has been studied only briefly in the literature. In the present work, we saw that this object has a complex nuclear region from the standpoint of emission lines. The first notable characteristic is that, in the GMOS images, there are 4 relevant emitting regions. All the regions have emission lines ratios compatible with LINERs; though, Regions 2 and 3 apparently have higher ionization degrees than the others. Another important fact is that Region 3 appears more clearly in the [O III $] \lambda 5007$ line image, the morphology of this emission seems elongated toward Region 1 (which is also elongated), it is possible that this region is associated with an ionization cone. This hypothesis is completely acceptable within all involved uncertainties. If Region 3 has a higher ionization degree than Region 1 (if we consider the $1 \sigma$ level), this hypothesis is still valid if Region 3 has an electronic density lower than Region 1 or if it is being ionized by a region with a higher ionization degree, in this case, Region 2. Another hypothesis, ignoring the morphology in the $[\mathrm{O}$ III $] \lambda 5007$ line image, is that Region 3 is the ionization cone of Region 2 (which could alternatively be another AGN - see Section 7.9.1), and does not have any relation with Region 1.

On the other hand, Region 4, which seems to be in evidence in the [O I] 66300 image, shows a lower ionization spectrum, so it can be part of the NLR of the AGN in Region 1.

In the HST images analyzed here, we see that only the areas associated with Regions 1 and 2 are easily identified in the image of the extended emission of $\mathrm{H} \alpha+\left[\begin{array}{ll}\mathrm{N} & \mathrm{II}\end{array}\right]$ (Fig. 7.10a). The projected distance between those regions determined from the HST images is compatible with the one determined from the GMOS data cube $(\sim 0 " .9)$.

There is an emission that extends from Region 1 toward Region 4, seen in Fig. 7.10(c), evidencing the relation between those regions and indicating that Region 4, as said before, seems to be part of the NLR of the AGN.

The I-V image from the HST (see Fig. 7.10d) clearly shows a point-like source, with blue emission. This source does not seem to be associated with stars, since the spectral synthesis results detected no young stellar population. As the position of this blue source is compatible, within the uncertainties, with Region 1, we conclude that the most probable scenario is that this source is the AGN. Although we did not detect featureless continuum emission in the spectral synthesis results, this blue source can be due to a featureless 
continuum, as this AGN has low luminosity and this emission is diluted in GMOS PSF (making it harder for the spectral synthesis to detect the featureless continuum).

We see a red trail west of Region 1 and a little above Region 4. This reddening can be explained by the presence of dust (Fisher e Drory, 2010). We can also see a compact structure of dust crossing the blue compact source. This may indicate a gas and dust disk, which might be associated with the process of feeding of the AGN (see Fig. 7.10d). We note that Region 3, identified as an ionization cone, is approximately perpendicular to this dust and gas disk. Besides that, it is not possible to identify an opposite emission of Region 3 (which might be the other side of the ionization cone), as this area is strongly obscured by dust.

\subsubsection{Photoionization or Shocks?}

When one has an evident LINER emission in the studied object, it is natural to question whether this emission is due to photoionization by a central AGN or it is the result of shock waves caused, for example, by supernovae. In the present case, we have some different regions with different ionization degrees that deserve to be properly investigated, considering the properties of the line emission and its morphologies.

By analyzing the electronic densities, determined from the $[\mathrm{S}$ II $] \lambda \lambda 6716,6731$ doublet, we see that, in all regions, the obtained values are considerably low, with Region 2 being the densest region with electronic density between 230 and $409 \mathrm{~cm}^{-3}$ (Table 7.2). Besides that, Regions 2, 3, and 4 have very low temperature limits, lower than $10^{4} \mathrm{~K}$ - certainly compatible with the idea of being clouds photoionized by a central AGN (located in Region $1)$.

The emission lines of all observed regions are quite narrow (typically with FWHM of $\sim 150 \mathrm{~km} \mathrm{~s}^{-1}$ ). This leads naturally to the following question: are those gas velocities sufficiently high for a model of heating by shock waves to explain the detected emission spectrum? We then made some tests using the Mappings III (Allen et al., 2008) library, with only solar abundance data and with the velocities observed here. We saw that those velocities are not sufficient to reproduce the emission line ratios in a shock wave scenario. An important fact to be considered is that the spectral synthesis did not detect stellar populations younger than one billion years, invalidating the hypothesis of the existence of regions with concentrations of supernovae remnants. With this result, we can discard this 
hypothesis, with the only remaining models involving AGN photoionization or post-AGB stars (Binette et al. 1994 and Cid Fernandes et al. 2011). Since NGC 6744 has a central compact blue source, it is unlikely that the ionization mechanism is due to post-AGB stars.

\subsubsection{One or Two AGNs?}

As mentioned before, four regions with relevant emission were observed in this data cube. There are many possible scenarios, involving even two AGNs, that can explain the coexistence of those emitting regions and that depend on the uncertainties considered in the calculation of the emission line ratios.

If we consider the $3 \sigma$ level, the emissions of all regions are compatible. Under these circumstances, a possible scenario assumes that there is only one source ionizing all those regions, Region 1, since it has higher luminosity and is an AGN (because of the blue compact source observed in the HST image). Then, Region 1 would be the central AGN with LINER emission and the other regions would be part of its NLR.

We also hypothesize that Region 2 is another AGN that is not clearly detected in the HST images. This region can have an ionization degree higher than that of Region 1 , supporting the hypothesis of a merger event with a galaxy without a defined stellar nucleus around its central black hole. In this case, the central black holes of both galaxies did not coalesce yet.

\subsubsection{A Very Low-luminosity AGN, Fossil of a More Luminous Phase}

In order to explain why an AGN of such low luminosity can excite clouds that are so distant with an ionization parameter similar to the central region, we consider the hypothesis called "AGN echo," proposed, for example, for SDSS J094103.80+344334.2 (Lintott et al. 2009 and Keel et al. 2012). In this case, Regions 2 and 3 would be ionized by an emission coming from Region 1, which would have had a higher luminosity and ionization degree in the past. However, over time, the luminosity of this emission decreased (with lower feeding rate, for example) and reached the current ionization degree (lower than before). This hypothesis is consistent with the width of the lines that we observed, since an AGN with lower activity usually shows fewer outflows, which broadens the emission lines. In this scenario, the other regions, which are part of the NLR of the AGN, are still receiving (except Region 4, the closest one) the old emission from this AGN, when it had a higher 
luminosity and ionization degree.

The $\mathrm{H} \alpha$ luminosity of the nucleus is $3.4 \times 10^{37} \mathrm{erg} \mathrm{s}^{-1}$, about 10 times higher than in the other regions (Table 7.2 ). Considering that the representative $\sigma_{*}$ value of the bulge of this galaxy is $\sim 95 \mathrm{~km} \mathrm{~s}^{-1}$ (excluding the $\sigma_{*}$-drop observed in the pPXF maps - see Fig. 7.9), we conclude that the black hole has a mass of $\sim 6 \times 10^{6} \mathrm{M}_{\odot}$ (Gültekin et al. 2009). Assuming the bolometric luminosity given by Netzer (2013) to narrow line objects (type 2), the case $\mathrm{B}$ recombination, where $\mathrm{H} \alpha / \mathrm{H} \beta=2.87$, a temperature of $\mathrm{T}=10^{4} \mathrm{~K}$ in the low density limit (Osterbrock e Ferland, 2006) and the $\mathrm{H} \alpha$ luminosity from Region 1, we obtain a bolometric luminosity of $\mathrm{L}_{b o l} \sim 3.2 \times 10^{40} \mathrm{erg} \mathrm{s}^{-1}$ and an Eddington ratio of $\sim 4 \times 10^{-5}$. This is an Eddington ratio typical of LINERs $(\mathrm{Ho}, 2008$; Ricci et al., 2015).

\subsubsection{Evidence of a Merger}

There is evidence of a merger, revealed by the spectral synthesis results, which showed only two significant star formation episodes: the first one occurred $10^{10}$ years ago, during the formation of the galaxy, and the second one occurred $10^{9}$ years ago.

The spectral synthesis was applied to two spectra: one of the nucleus and one of the circumnuclear region. There is a significant difference between these regions: the higher concentration of the $10^{9}$ year old stellar populations in the circumnuclear region and the higher concentration of the older stellar populations $\left(10^{10}\right.$ year old $)$ in the nucleus. This difference can be noticed in the spectra because the nuclear spectrum has deeper absorption lines. The difference of the fluxes associated with $10^{9}$ year old stellar populations between the nuclear and circumnuclear regions suggests that this galaxy went through a merger one billion years ago, which resulted in a circumnuclear starburst and the formation of this stellar population. After this possible merger, there was no other relevant star formation episode in the central region of the galaxy. In fact, as Fisher e Drory (2010) verified, NGC 6744's bulge is similar to an elliptical galaxy, with little star formation and old stellar populations. It is important to notice, however, that NGC 6744 does not show evidence of a double stellar nucleus. As mentioned before, despite the degeneracies of the spectral synthesis results, the observable differences between the stellar components of the nuclear and circumnuclear spectra, together with the fact that the same procedure was applied to these spectra (and, therefore, the results are subject to the same types of imprecisions), make this analysis reliable. 
Since NGC 6744 is classified as SAB(r)bc, with a prominent disk, it is not an expected outcome of a major merger. However, studies have shown that, under certain circumstances, major mergers can result in late-type galaxies (Barnes 2002; Springel e Hernquist 2005 and Robertson et al. 2006). Usually, this requires that the galaxies involved in the merger have a high gas fraction. Therefore, although scenarios involving major mergers do not appear to be the most likely to explain the results obtained for the data cube of NGC 6744, they cannot be discarded. On the other hand, minor merger scenarios certainly deserve special attention. Studies about such scenarios indicate that, unlike major mergers, minor mergers, with high mass ratios, result only in modest star formation in the central region of the galaxy (Taniguchi e Wada 1996 and Cox et al. 2008). Although the flux fraction associated with the stellar population probably related to the merger (with $10^{9}$ years and intermediate metallicity) represents $\sim 40 \%$ of the total stellar flux in the circumnuclear region of the data cube of NGC 6744, we cannot precisely evaluate how extended this starburst event was due to our limited FOV.

\subsubsection{Gas Kinematics}

From the $\mathrm{H} \alpha$ velocity map (Fig. 7.7), one can notice that Regions 2 and 3 are in blueshift relative to Region 1 and have very close and compatible (at $1 \sigma$ level) radial velocity values, suggesting that those regions are part of the same structure, which is different from the one corresponding to Regions 1 and 4. The $\mathrm{H} \alpha$ velocity map also shows that there is a gas rotation around Region 1, but there are many irregularities on the edges of the FOV, which can be due to the presence of other kinematic phenomena, such as inflows or outflows, for example. It is also possible that those deviations from a simple Keplerian rotation are consequences of the probable merger that has occurred in this galaxy, as discussed above, or even the result of imprecisions of the fits of the Gaussian functions to the $\mathrm{H} \alpha$ emission lines in the areas with lower $\mathrm{A} / \mathrm{N}$ ratios (which are, indeed, the edges of the FOV). The channel maps in Fig. 7.6 show the same rotation pattern as that observed in the $\mathrm{H} \alpha$ velocity map. However, we see that the PA of the line of nodes in the region with blueshifted gas seems to be different from the PA of the areas with redshifted gas. Again, this can be a consequence of either the presence of different kinematic phenomena or the fact that the system is still going through the results of the merger. 


\subsubsection{Stellar Kinematics}

Stellar kinematic analysis revealed a rotation around Region 1 with a PA considerably different from that of the gas rotation. Assuming that there is a gas disk and a stellar disk, we conclude that structures are not coplanar. As seen in the $\mathrm{H} \alpha$ velocity map, there are irregularities at the edges of the FOV of the $V_{*}$ map that could be due to either consequences of a merger or imprecisions of the pPXF method, because those areas have low $\mathrm{S} / \mathrm{N}$ ratios (close to the lower limit of 10 ).

We detected a $\sigma_{*}$-drop toward the center of the bulge (Region 1 ). The decrease of $\sigma_{*}$ toward the center is explained in the literature as the result of the presence of young stellar populations that herd the kinematics of their progenitor clouds that had low velocity dispersions (Wozniak et al., 2003; Allard et al., 2005, 2006). However, in this case, the spectral synthesis detected very low flux fractions associated with young stellar populations; so this hypothesis is not valid. A more exotic scenario to explain this $\sigma$-drop pattern may be that the possible merger involved another galaxy without a well defined stellar nucleus (an Sm galaxy, for example). Thus, this event would result in a starburst of which the effect would be more significant in the circumnuclear region but would not affect the stellar kinematics of the central region of the original nucleus of NGC 6744, as no coalescence would occur with another galactic nucleus. In this scenario, the observed $\sigma_{*}$-drop would simply be related to the original nucleus of NGC 6744 , while the $10^{9}$ year old stellar population would be a result of this merger.

The $h_{3}$ coefficient map showed that there is an apparent anticorrelation with the stellar velocity map, which suggests that the stars that are in rotation are superposed to a background of stars with velocity close to zero (the bulge stars).

\subsection{Conclusions}

In this work, we analyzed a data cube of the nuclear region of NGC 6744 obtained with GMOS/IFU, together with HST/WFC3 images. The main conclusions of this work are the following:

(1) There are four relevant emitting regions in the center of NGC 6744. Region 1 is coincident (within the uncertainties) with the center of the stellar bulge and, also, with the kinematic center of the gas and stellar rotations. All regions have emission line ratios 
compatible with LINERs, but Regions 2 and 3 seem to have higher ionization degrees when compared with the other two.

(2) An I-V image obtained with $H S T$ revealed the emission of a compact blue source; as this galaxy does not show any evidence of young stellar populations in its central region, our interpretation is that this fact confirms the existence of an AGN of low luminosity (Region 1).

(3) The most probable scenario that explains the coexistence of the four observed regions assumes that Regions 2, 3, and 4 are part of the NLR of the AGN (Region 1). Region 3 seems to be an ionization cone of this AGN, due to its considerable emission in the $[\mathrm{O}$ III $] \lambda 5007$ line and to its morphology. The fact that Regions 2 and 3 have higher ionization degrees than Region 1 can be justified by the hypothesis of them being ionized by an emission coming from the AGN in Region 1, when it was in a more luminous phase.

(4) We detected a compact structure of dust crossing the galactic nucleus in the I-V image from the HST. This seems to indicate a probable gas and dust disk that may be feeding the AGN. Region 3, which we identified as a possible ionization cone, appears to be perpendicular to this disk of dust and gas.

(5) The spectral synthesis was applied to two spectra of the GMOS data cube, one from the nucleus (Region 1) and the other from the circumnuclear region. This revealed that this galaxy has passed for two main star formation periods: one during the formation of the galaxy and another, $10^{9}$ years ago. After this period, there were not any significant stellar formation events. This last starburst can be associated with a significant merger that happened one billion years ago.

(6) There is a gas rotation around Region 1, as seen in the $\mathrm{H} \alpha$ velocity map. Channel maps of the main emission lines of the GMOS data cube revealed that the PA of the line of nodes of the blueshifted gas is different from that of the redshifted gas, which may be the result of inflows or outflows of gas or the result of the possible merger.

(7) The stellar kinematic analysis with the pPXF method revealed that there is a stellar rotation around Region 1, but the PA is different from the one determined for the gas rotation. This stellar rotation seems to be superposed to a background composed of stars with velocity values close to zero, which can be seen by the anticorrelation between the $h_{3}$ coefficient map and the $\mathrm{V}_{*}$ map. The $\sigma_{*}$ map showed a $\sigma_{*}$-drop toward the center. A relatively exotic scenario to explain this involves a merger process with a galaxy without 
a well defined stellar nucleus.

\subsection{Acknowledgments}

This work is based on observations obtained at the Gemini Observatory (processed using the Gemini IRAF package), which is operated by the Association of Universities for Research in Astronomy, Inc., under a cooperative agreement with the NSF on behalf of the Gemini partnership: the National Science Foundation (United States), the National Research Council (Canada), CONICYT (Chile), the Australian Research Council (Australia), Ministério da Ciência, Tecnologia e Inovação (Brazil) and Ministerio de Ciencia, Tecnología e Innovación Productiva (Argentina). This work is also based on observations made with the NASA/ESA Hubble Space Telescope, obtained from the Data Archive at the Space Telescope Science Institute, which is operated by the Association of Universities for Research in Astronomy, Inc., under NASA contract NAS 5-26555. These observations are associated with the following programs: 13364 and 13773. We thank CNPq (Conselho Nacional de Desenvolvimento Científico e Tecnológico), CAPES (Coordenação de Aperfeiçoamento de Pessoal de Nível Superior) and FAPESP (Fundação de Amparo à Pesquisa do Estado de São Paulo), under grant 2011/51680-6, for supporting this work. This research also has made use of the NASA/IPAC Extragalactic Database (NED), which is operated by the Jet Propulsion Laboratory, California Institute of Technology, under contract with the National Aeronautics and Space Administration. RBM thanks PNPD/CAPES (PPF - Física UFABC). 


\section{Capítulo 8}

\section{Resumo dos artigos sobre NGC 613}

\section{The nuclear region of NGC 613. I - Multiwavelength analysis}

\section{The nuclear region of NGC 613. II - Kinematics and stellar archaeology}

Ambos os artigos são sobre o complexo núcleo de NGC 613 (da Silva et al., 2020|?). Por ter várias componentes de emissão e uma vasta informação cinemática, o estudo foi dividido em duas partes: I e II.

A parte I é focada no estudo sobre as naturezas das emissões nucleares em NGC 613. Cinco instrumentos foram utilizados, em diferentes bandas espectrais: no óptico, os cubos de dados do IFU do GMOS do telescópio Gemini-Sul, imagens do HST e os cubos de dados do SOAR Integral Field Spectrograph (SIFS) do telescópio SOAR; no infravermelho, cubo de dados do SINFONI do VLT; no raio-X, cubo de dados do telescópio espacial Chandra e; no rádio, cubos de dados do ALMA.

A partir do cubo de dados do GMOS e imagens do HST, foi detectada uma fonte nuclear estendida, que tem uma aparência dupla (chamada de N1 e N2). Ao comparar imagens do HST observadas em épocas diferentes (intervalo de 17 anos) foi constatado que existe uma fonte pontual variável entre estas duas fontes, que foi nomeada como V1. Essa fonte está presente no centro do sistema e acredita-se que seja a posição do AGN do núcleo de NGC 613, que possui uma emissão compatível com a de LINERs. Na literatura há também hipóteses que reforçam a variabilidade deste AGN (Audibert et al., 2019). O cone de ionização deste AGN possui emissão em raios-X moles, o que é resultado de nuvens sendo altamente ionizadas pelo AGN na região do cone. É também sabido que este AGN possui um jato em rádio (Hummel e Jorsater, 1992), porém este jato possui orientação que não coincide com o eixo do cone. 
N1 e N2 são núcleos estelares que estão separados pela espiral nuclear detectada por Audibert et al. (2019). Há evidências, então, que sejam parte da mesma estrutura. A espiral nuclear está conectada à barra da galáxia, como foi visto ao comparar imagens do HST e ALMA.

Existe uma outra fonte variável coincidente com a região N1, chamada de V2. Esta fonte pode estar associada com a emissão de uma supernova, pois N1 é um núcleo estelar.

Há um anel de formação estelar na região nuclear desta galáxia, previamente estudado por Falcón-Barroso et al. (2014); Böker et al. (2008). Este anel é composto por 8 regiões HII. Além disso, existem mais 2 regiões HII próximas que aparentam ter alguma conexão com o anel. Este anel também possui emissão em raios-X duros. Essa emissão pode estar relacionada com restos de supernovas e isso é reforçado pelo fato do anel também possuir emissão em [FeII] $\lambda 16436$. Foi observado que o anel possui conexão com a barra, como também foi apontado por Böker et al. (2008).

A parte II é sobre a cinemática do gás, cinemática estelar e arqueologia estelar, com intuito de observar como as várias componentes se comportam. Neste trabalho são apenas utilizados os cubos do óptico (GMOS e SIFS) e o cubo de dados do SINFONI. A partir do estudo das linhas de emissão foram detectados três outflows: um em H $\alpha$, cujo PA é compatível com o PA do jato em rádio e, outros dois, em [OIII] $\lambda 5007$, sendo que um deles possui PA compatível com o eixo do cone de ionização.

Em termos de velocidade estelar e do gás e em termos de arqueologia estelar, não foram encontradas diferenças significativas entre N1 e N2. Isso significa que é muito provável que estas regiões sejam partes de uma mesma estrutura central que, no óptico, aparece dividida devido à espiral nuclear que passa entre elas.

Os resultados da síntese espectral nas 10 regiões HII circumnucleares permitem concluir basicamente que há estrelas jovens nestas regiões, mas não há resolução temporal suficiente para determinar diferenças de idades entre elas.

Além disso, os resultados da síntese espectral do cubo de dados do GMOS revelam uma emissão significativa de estrelas com aproximadamente $10^{9}$ anos apenas na região circumnuclear. Ao observar os resultados do cubo de dados do SIFS (cujo campo de visão é maior do que o campo do GMOS), foi visto que esta emissão está contida dentro do anel circumnuclear. Dessa forma, essa concentração de populações de $\sim 10^{9}$ anos é um anel de alta metalicidade (0.02 e 0.05) contido dentro do anel externo. 
A cinemática do gás no anel circumnuclear acompanha a cinemática estelar, porém há evidências de uma diferença de velocidades estelares dos dois anéis com relação às estrelas de fundo. No caso do anel interno, a diferença é evidente e sugere que o mesmo esteja rodando com menores velocidades.

Foi estimado um valor de dispersão de velocidades estelar no núcleo, a partir dos dados do infravermelho: $92 \pm 3 \mathrm{~km} / \mathrm{s}$. 
Capítulo 9

\title{
The nuclear region of NGC 613. I - Multiwavelength
}

$$
\text { analysis }
$$

\author{
Patrícia da Silva, R. B. Menezes, J. E. Steiner \\ 2020, MNRAS, 492, 5121
}

\subsection{Abstract}

In this paper, we report a detailed study with a variety of data from optical, nearinfrared, X-ray, and radio telescopes of the nuclear region of the galaxy NGC 613 with the aim of understanding its complexity. We detected an extended stellar emission in the nucleus that, at first, appears to be, in the optical band, two stellar nuclei separated by a stream of dust. The active galactic nucleus (AGN) is identified as a variable point-like source between these two stellar components. There is a central hard X-ray emission and an extended soft X-ray emission that closely coincides with the ionization cone, as seen in the $[\mathrm{O}$ III $] \lambda 5007$ emission. The centroid of the [O I] $\lambda 6300$ emission does not coincide with the AGN, being shifted by 0.24 arcsec towards the ionization cone; this shift is probably caused by a combination of differential dust extinction together with emission and reflection in the ionization cone. The optical spectra extracted from the central region are typical of low-ionization nuclear emission-line regions. We also identify $10 \mathrm{H}$ II regions, eight of them in a star forming ring that is visible in $\mathrm{Br} \gamma,[\mathrm{Fe} \mathrm{II}] \lambda 16436$ and molecular $\mathrm{CO}(3-2)$ images observed in previous studies. Such a ring also presents weak hard X-ray emission, probably associated with supernova remnants, not detected in other studies. The position of the AGN coincides with the centre of a nuclear spiral (detected in previous works) that 


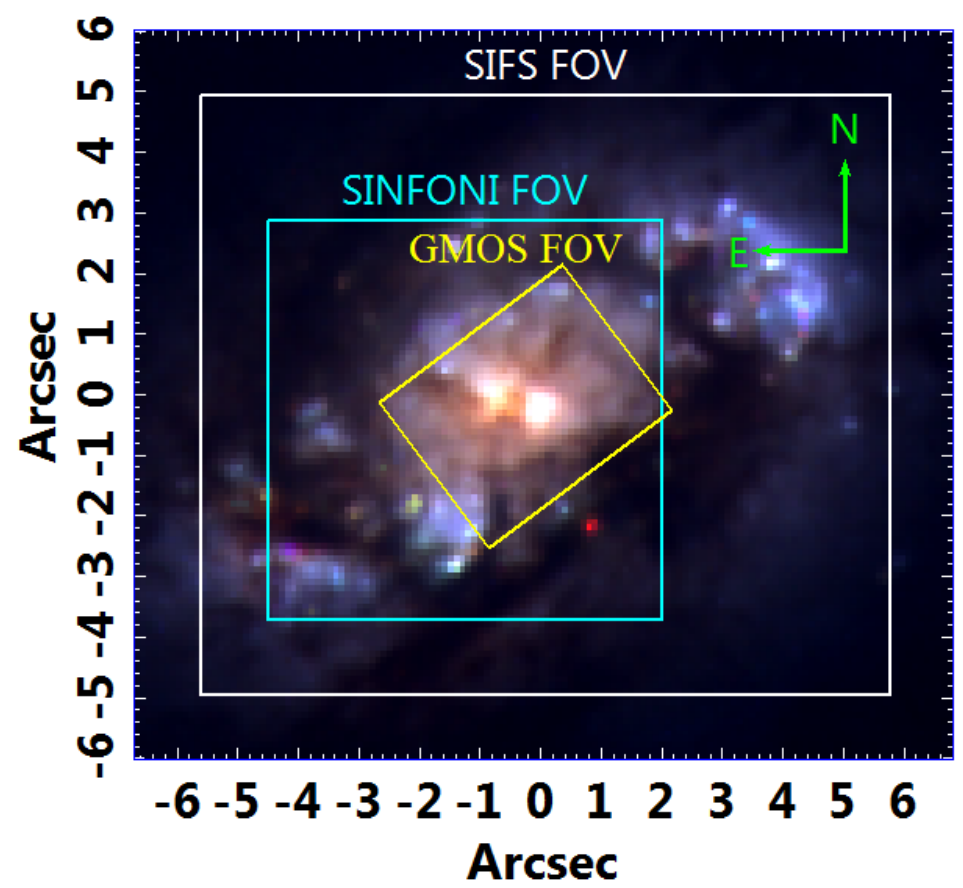

Figura 9.1: RGB composition of the images in the filters $F 814 W$ (red), $F 606 W$ (green), and $F 450$ $W$ (blue) of HST/WFPC2. The positions and sizes of each field of view (FOV) of GMOS, SINFONI, and SIFS data cubes are represented by the squares, with the orientation N-E. The PA of the GMOS observation is $127^{\circ}$. The total size of the FOV of this image is $13.55 \operatorname{arcsec} \times 12.05$ arcsec.

brings gas and dust from the bar to the nucleus, causing the high extinction in this area.

\subsection{Introduction}

Active galactic nuclei (AGNs) are phenomena in which a significant amount of energy is produced by a non-stellar source. Such energy is believed to be produced by gas accretion onto a supermassive black hole (Lynden-Bell 1969; see Netzer 2013 for more details). The study of the environment around AGNs is relevant for the evaluation of their interaction with the rest of the host galaxy through the processes of feeding and feedback StorchiBergmann et al. 2009, 2010). The feeding process can be studied by observations of molecular emission in the near-infrared (NIR) or millimetre bands. The feedback can be studied, for instance, by observing optical emission lines associated with outflows (Harrison et al., 2018) and ionization cones or by observing radio jets (Beall, 2003). The emission of the AGN itself can be observed from radio to $\gamma$-rays. By analysing multiwavelength data it is possible to disentangle the complexity of the AGN, its environment, and their 
interaction.

Statistical properties of AGNs are well derived from studies of large samples (e.g. Ho 2008; Gültekin et al. 2009). However, the interaction of an AGN with its environment can be quite complex and individual objects must be studied in detail if we want to understand this complexity.

In this work, we present a multiwavelength study of the nuclear region of NGC 613. This is an SB(rs)bc galaxy, located at $26 \pm 5 \mathrm{Mpc}$ (Nasonova et al., 2011), and is known to have a composite nucleus (Veron-Cetty e Veron, 1986) with an AGN that interacts with the galaxy through outflows, an ionization cone, and a radio jet, as well as a circumnuclear ring of $\mathrm{H}$ II regions that has a radius of about 300 pc (Hummel e Jorsater 1992, Falcón-Barroso et al. 2014 and Audibert et al. 2019).

That the galaxy contains an AGN is confirmed, for example, by the detection of highionization emission lines, such as $[\mathrm{Ne}$ v] and [O IV], observed with the Spitzer space telescope (Goulding e Alexander, 2009). Besides that, a radio jet, showing a structure that extends along 5 arcsec with position angle (PA) of $6^{\circ}$ (almost perpendicular to the bar) was observed with the Very Large Array (VLA) at 6 and $20 \mathrm{~cm}$ (Hummel et al. 1987). At 4.86 and $14.94 \mathrm{GHz}$, three blobs were detected in the central kpc, forming a linear structure whose PA is $12^{\circ}$ (Hummel e Jorsater, 1992). Miyamoto et al. (2017) also detected an elongated structure in $95 \mathrm{GHz}$ with $\mathrm{PA}=20^{\circ} \pm 8^{\circ}$. All these data show the presence of a nuclear radio jet. Associated with this jet, there is an anisotropic maser with luminosity of $\sim 15.9 L_{\odot}($ Kondratko et al., 2006). There is also a megamaser (in the same position as the previous one) with isotropic emission and luminosity of $\sim 35 L_{\odot}$, which can also be associated with the nuclear jet (Castangia et al., 2008).

The AGN in NGC 613 is of low luminosity. Using an X-ray luminosity of $\mathrm{L}_{2-10 k e v}=$ $8.92 \times 10^{40} \mathrm{erg} \mathrm{s}^{-1}$ (Castangia et al., 2013) and a bolometric correction of 20 (Vasudevan et al., 2010), Davies et al. (2017) determined that the AGN bolometric luminosity is 1.6 $\times 10^{42} \mathrm{erg} \mathrm{s}^{-1}$. From the analysis of the X-ray Multi-Mirror Mission (XMM-Newton) data, Castangia et al. (2013) obtained an intrinsic column density of $36_{-4}^{+5} \times 10^{22} \mathrm{~cm}^{-2}$ and an emission ratio of soft X-rays $(2-10 \mathrm{keV})$ to [O III] $\lambda 5007$ of 5.6 for NGC 613 centre. Asmus et al. (2015) determined a column density of $23.5 \pm 0.5 \times 10^{22} \mathrm{~cm}^{-2}$, confirming the highly obscured AGN.

The Atacama Large Millimeter/Submillimeter Array (ALMA) observation of molecular 

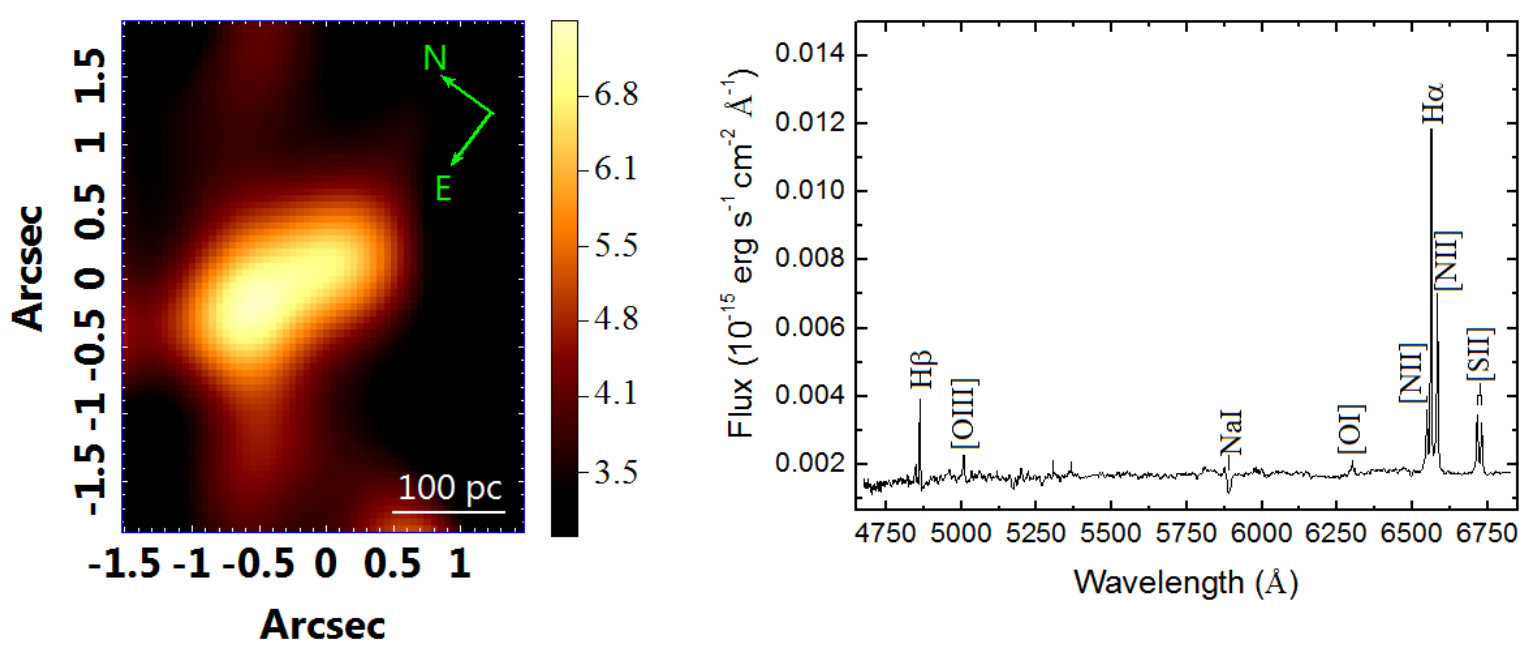

Figura 9.2: Image of the GMOS data cube, obtained after the treatment, of the central region of NGC 613 collapsed along the spectral axis with its flux scale and with its average spectrum corrected for redshift. Note the indication of N-E and the scale of 100 pc.

lines revealed that the nucleus has emission compatible with the ones of Seyfert/LINER composite and is also being ionized by shock heating. There are very energetic molecular outflows that are possibly fossils from a phase when this AGN was in a higher activity and they are also associated with the radio jet, possibly being driven by it Audibert et al. 2019).

Through the decomposition of gas ionization mechanisms of the central $\sim 35 \operatorname{arcsec} \times$ 25 arcsec, by using a spectral basis that consider ionization by shock, AGN, and stars, an ionization cone aligned with the radio jet was detected (Davies et al., 2017). There are also shock waves in the ionization cone edges (inside the central $1 \mathrm{kpc}^{2}$ ), probably formed by outflows of gas coming from the AGN that are shocking gas in the interstellar medium.

It is believed that circumnuclear star-forming rings are the result of the strong interaction between the bar (or strong spiral arms) and the inner gas located in the Lindblad resonance region (Elmegreen, 1994). According to Böker et al. (2007, 2008) and FalcónBarroso et al. (2008, 2014), the circumnuclear ring of NGC 613 is formed by seven H II regions. This ring can also be observed in radio wavelengths (Hummel e Jorsater 1992 Miyamoto et al. 2017, 2018; Audibert et al. 2019) and, if its structure is circular, the inclination should be $55^{\circ} \pm 5^{\circ}$ (Hummel e Jorsater, 1992). Combes et al. (2019) and Audibert et al. (2019) found that this ring is connected to the bar in two points, at NW and SE, as Böker et al. (2008) previously estimated by using the Hubble Space Telescope (HST) ima- 

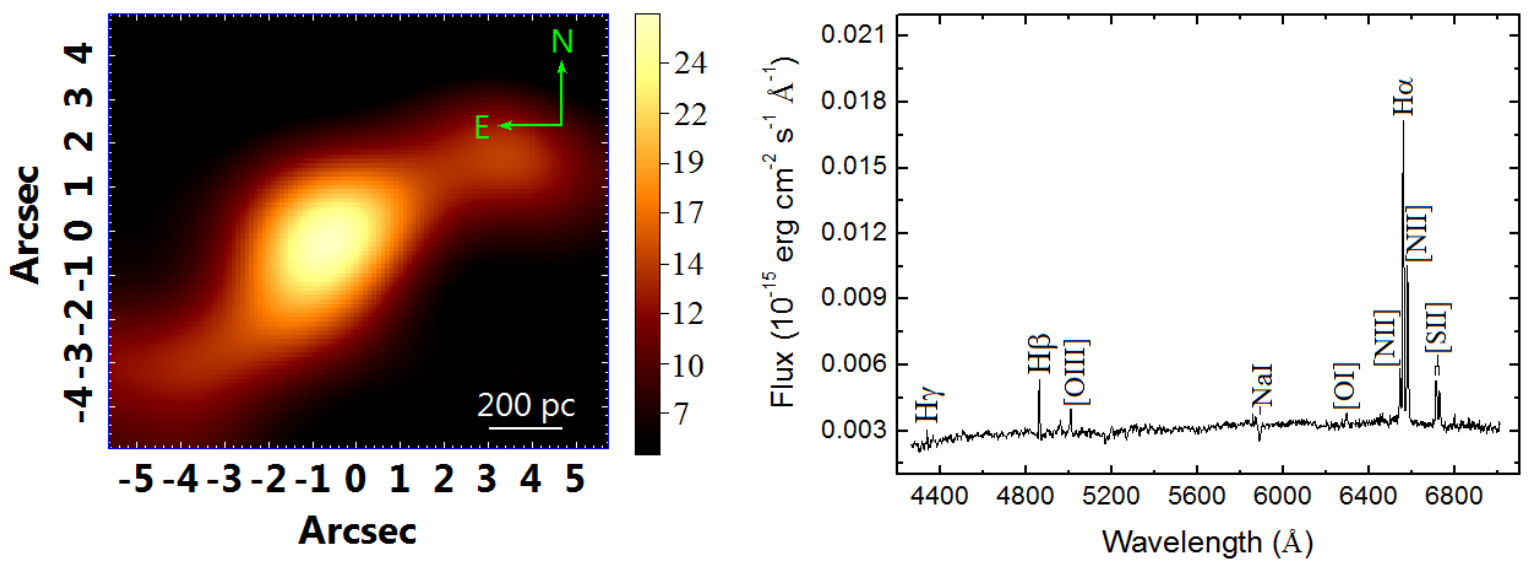

Figura 9.3: Image of the SIFS data cube, obtained after the treatment, of the central region of NGC 613 collapsed along the spectral axis with its flux scale and with its average spectrum corrected for redshift. Note the indication of N-E and the scale of 200 pc.

ges, and that the ring is indeed clumpy as it is shown in the image of Br $\gamma$ Falcón-Barroso et al., 2014). There is also a nuclear spiral of molecular gas connected with the ring in two different spots (Audibert et al., 2019).

In this article, we analyse the central region of NGC 613 using data cubes obtained with the Gemini Multi-Object Spectrograph (GMOS) from the Gemini-South telescope and Soar Integral Field Spectrograph (SIFS) from the SOAR telescope and the archived data from the HST, from ALMA, from the Spectrograph for Integral Field Observations in the Near Infrared (SINFONI) of the Very Large Telescope (VLT), and from the Chandra Space Telescope. The purpose of our analysis is to correlate our results with the information and data from the literature in order to explain the nature of the observed emission in the centre of this galaxy. This paper (Paper I) is part of a comprehensive analysis of NGC 613 nucleus and presents the study of the emission of this galaxy centre. The study of the stellar and gas kinematics and stellar archaeology will be presented in Paper II.

Section 9.3 describes the observations and treatment methods of the data obtained with the many instruments used in this work. Section 9.4 shows the optical emission-line analysis of the observed regions in the centre of NGC 613. The study of X-ray emission is presented in section 9.5. We discuss the data in section 9.6, presenting the possible scenarios, and section 9.7 summarizes the conclusions of this work. In Appendix 9.8, we present the optical extracted spectra of the observed regions and the method that we used to calculate the integrated flux of the emission lines, in order to calculate their ratios. 

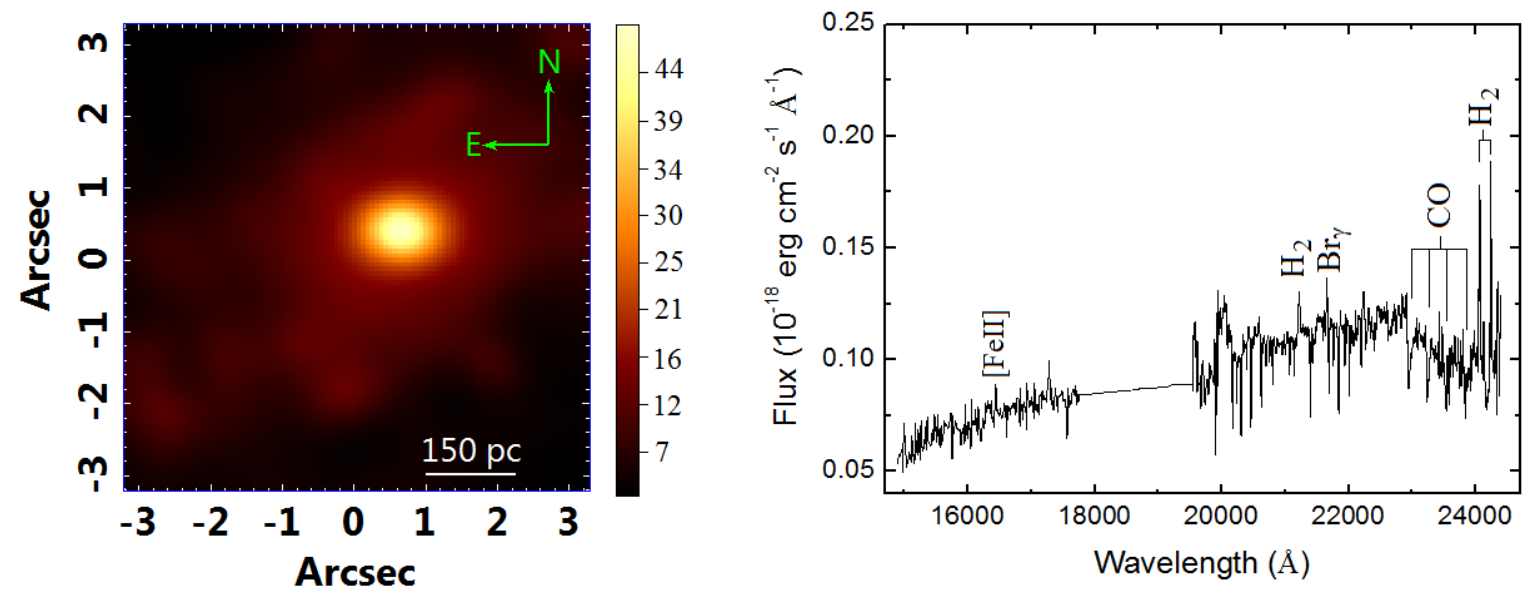

Figura 9.4: Image of the SINFONI data cube, obtained after the treatment, of the central region of NGC 613 collapsed along the spectral axis with its flux scale and with its average spectrum corrected for redshift. Note the indication of N-E and the scale of $150 \mathrm{pc}$.

\subsection{Observations and data reduction}

This work presents data obtained with different instruments: Wide-Field Planetary Camera 2 (WFPC2) from HST, GMOS from Gemini-South telescope, SINFONI from VLT, SIFS from SOAR telescope, Advanced CCD Imaging Spectrometer (ACIS) from Chandra space telescope and ALMA. The following subsections describe the treatment and conditions of each observation.

Fig. 9.1 shows the image of NGC 613 nucleus, obtained with HST, and the fields of view (FOVs) of the GMOS, SINFONI, and SIFS data cubes. The GMOS data cube has PA $=127^{\circ}$, so its orientation is different from the other FOVs, whose PAs $=0^{\circ}$. By comparing the three data cubes (optical and NIR), the SIFS FOV is the largest, followed by SINFONI (which has the highest spatial resolution) and by GMOS.

\subsubsection{Hubble Space Telescope images}

In this study, we used images obtained from the HST public archive. Those images were part of the observation programs 9042 (PI: Smartt, S. J.) and 15133 (PI: Erwin, P.), obtained with the WFPC2 instrument on 2001 August 21 and WFC3 on 2018 August 22. For the program 9042, the images in the filters $F 450 \mathrm{~W}, F 606 \mathrm{~W}$ and $F 814 \mathrm{~W}$ were taken with an integration time of 160 s. Fig. 9.1 shows the FOV in the central area of the galaxy, whose size is 13.6 arcsec $\times 12.1$ arcsec, in those observed filters. On the other 
hand, for the program 15133, the integration time for the image of $F 814 \mathrm{~W}$ filter was 500 $\mathrm{s}$ and for the image of $F 475 \mathrm{~W}$ filter was $700 \mathrm{~s}$.

\subsubsection{Optical data cubes}

Although having similar spectral range, the data cubes obtained with the integral field units (IFUs) of GMOS and SIFS present some significant differences. The SIFS FOV is almost 6.7 times larger than the GMOS FOV, in area, which allows us to analyse the circumnuclear region of this galaxy on a larger scale. In order to evaluate the signal-tonoise ratio $(\mathrm{S} / \mathrm{N})$ of these data cubes, we extracted a spectrum of a rectangular area with $0.3 \operatorname{arcsec} \times 0.3$ arcsec (equivalent to 1 spaxel of a raw data cube obtained with SIFS and a square of 6 spaxels (spatial pixels) $\times 6$ spaxels of one of the raw GMOS data cubes), centred in the brightest point visible in the data cubes. Then, we calculated the $\mathrm{S} / \mathrm{N}$ ratio in each spectrum, in the spectral range from 5610 to $5700 \AA$. The results were $S / N_{G M O S}=29$ and $S / N_{\text {SIFS }}=27$. Considering that and also taking into account the exposure times for the GMOS data (930 s) and for the SIFS data (900 s), we conclude that these two instruments are very similar, regarding the $\mathrm{S} / \mathrm{N}$ ratio. As discussed in the following sections, the difference between the spatial resolution of those data cubes is highly significant, since the seeing of the observation taken with SIFS was considerably larger than the seeing of the GMOS observation, resulting in the full width at half-maximum (FWHM) of the point spread function (PSF) in the SIFS data cube being three times larger than the FWHM of the PSF obtained with the GMOS data cube.

\subsubsection{GMOS data}

These data were taken using the IFU of the GMOS, in one-slit mode. The data are part of the Deep IFS View of Nuclei of Galaxies (DIVING ${ }^{3 D}$ ) survey, which aims to analyse the nuclear regions of all Southern-hemisphere galaxies brighter than B=12 (Steiner, J. E. et al., in preparation).

The observations of NGC 613 were taken on 2015 January 25 as part of the observation program GS-2014B-Q-30 in the Gemini-South telescope. Three 930 s exposures were taken with spatial dithering and $\mathrm{PA}=127^{\circ}$. Using the grating R831+G5322, centred in $5850 \AA$, we obtained a spectral resolution of $\mathrm{R}=4340$ and a spectral coverage from 4675 to $6828 \AA$. 
We used data reduction packages, developed by the Gemini observatory, in IRAF environment. This reduction was conducted using the following processes: trim determination, bias subtraction, cosmic ray removal (LACOS - van Dokkum 2001), spectra extraction, corrections of gain variations between the spectral pixels (using GCAL-flat images), corrections of gain variations between the spaxels (using twilight-flat images), wavelength calibration (using images of the CuAr lamp), subtraction of the average spectrum of the FOV corresponding to the sky observation (located at 1 arcmin from the object), flux calibration, atmospheric extinction correction, telluric absorption removal, and data cube construction. The resulting three data cubes had spaxels of $0.05 \operatorname{arcsec} \times 0.05 \operatorname{arcsec}$ and FOV of 3.5 arcsec $\times 5$ arcsec. The FWHM of the PSF calculated from the acquisition image $(0.72$ arcsec), in this case, is compatible with the FWHM calculated from the image of $[\mathrm{O}$ I $] \lambda 6300$ from the data cube after the reduction $(0.71$ arcsec $)$. So we used the last one $(0.71 \mathrm{arcsec})$ in the process of deconvolution described in section 9.3.4.

Fig. 9.2 shows the GMOS data cube after the treatment (see section 9.3.4) collapsed along the spectral axis, with its average spectrum. We can see an extended source in the central region and the main optical emission lines, quite broad (see Figs. 9.18 and 9.19 of Appendix 9.8), indicating high-velocity gas emission.

\subsubsection{SIFS data}

The data were taken on 2017 November 23 with SIFS on the SOAR telescope, during the Science Verification program. Six 900 s exposures were taken with spatial dithering, in order to obtain a mosaic of the central region of NGC 613. Three of these exposures were centred 3 arcsec north of the nucleus of the galaxy and the other three were centred 3 arcsec south of the nucleus. The dither step for each of these groups of three exposures was 0.3 arcsec. The PA of all the observations was $0^{\circ}$. The plate scale was 0.3 arcsec/fibre and the grating used was $700 \mathrm{l} / \mathrm{mm}$, centred in $5650 \AA$, which resulted in a spectral coverage from 4250 to $7050 \AA$ and spectral resolution of $\mathrm{R}=4200$. During the same night, data from the standard star LTT 2415 were taken with exposure time of 300 s. Since SIFS has an Atmospheric Dispersion Corrector (ADC), the differential atmospheric refraction effect was removed from the observed data.

The reduction was performed using scripts developed in Iteractive Data Language (IDL) and included the following steps: correction of dead fibres, spectra extraction, flat-field cor- 
rections (in order to remove gain variations between the spectral pixels and between fibres), wavelength calibration (using images of an HgAr lamp), sky subtraction, and creation of data cubes. After this, processes of flux calibration, atmospheric extinction correction, and telluric absorption removal were applied using scripts developed in IRAF environment. At the end, we constructed a mosaic with the six reduced data cubes and obtained a final data cube with spaxels of $0.3 \operatorname{arcsec} \times 0.3 \operatorname{arcsec}$ and FOV with $15 \operatorname{arcsec} \times 7.8 \operatorname{arcsec}$.

Since the standard star was observed in the same night, we estimated the FWHM of the PSF of this observation from its data cube, and the result was 2.4 arcsec.

After that, the data cube treatment was applied as described in section 9.3.4. Fig. 9.3 shows the image of the treated data cube, collapsed along the spectral axis, and its average spectrum, with the optical main emission lines indicated. Note a central source with extended emission in the SE and NW directions.

\subsubsection{SINFONI data}

The data were obtained from the public archive and were taken on 2005 October 23 and on 2005 November 13 as part of the observation program 076.B-0646(A), PI: Böker,T., with four and five exposures of $300 \mathrm{~s}$, respectively, in the $\mathrm{H}+\mathrm{K}$ band, which resulted in a spectral resolution of $\mathrm{R}=1500$ and a spectral range from 15000 to $24500 \AA$. The PA of the observation was $0^{\circ}$ with fore-optics of 0.25 arcsec. This data set was already published by Böker et al. (2008) and Falcón-Barroso et al. (2014). Here, we use these data superposed to SIFS data to locate the $\mathrm{H}$ II regions, in order to calculate the emission-line ratios in the SIFS data cube and to make some comparisons with the other data. In paper II, we use these data to study the stellar and gas kinematics.

The reduction of the data was performed using the GASGANO software in a process involving the following steps: bad pixel correction, flat-field correction, spatial rectification in order to remove potential distortions along the FOV, wavelength calibration (using Ne lamp images), sky subtraction, and data cube construction. The flux calibration and telluric absorption removal were applied later, using scripts developed in IRAF environment. We obtained nine data cubes with spaxels of $0.125 \operatorname{arcsec} \times 0.125 \operatorname{arcsec}$ and FOV of 8 $\operatorname{arcsec} \times 8$ arcsec .

The FWHM of the PSF of the data cube before treatment, estimated from the image of $\mathrm{H}_{2} \lambda 21218$, was 0.69 arcsec. 
Although the data reduction procedure we used is analogous to the one adopted by Böker et al. (2008) and Falcón-Barroso et al. (2014), we also applied a treatment procedure to the reduced data cubes (not used by the aforementioned authors), in order to obtain certain improvements, as described in section 9.3.4. Fig. 9.4 shows the image of the data cube collapsed along the spectral axis and the data cube average spectrum, showing the main emission lines in this spectral range.

\subsubsection{Optical and NIR data cubes treatment}

The data cube treatment was applied using scripts written in IDL developed by our group (see Menezes et al. 2014, 2015, 2019). We started by performing the differential atmospheric refraction correction in the data cubes (except in the SIFS data cube that has ADC). After that, the data cubes were combined in only one: we combined the three GMOS data cubes in form of a median. As said previously, we had, after the reduction, nine SINFONI data cubes; they were combined in order to minimise sky subtraction problems, as some of them had sky emission in excess and some others exaggerated sky subtraction. The combinations were done from 3 to 3 data cubes using medians (alternating between the dates of the observations) until we had only one final data cube.

SINFONI and SIFS data cubes were spatially re-sampled to have spaxels of 0.0625 arcsec and 0.1 arcsec, respectively. All the data cubes were spatially filtered using the Butterworth method (Gonzalez e Woods, 2002), in order to remove the high spatial frequency noise. Then, the instrumental fingerprint removal was applied. Lastly, we applied the Richardson-Lucy deconvolution (Richardson 1972 and Lucy 1974). For more details about the Richardson-Lucy deconvolution and the other treatment techniques, see Menezes et al. (2014, 2015, 2019). In GMOS and SIFS data cubes, the PSF variation law was estimated using the standard stars data cubes that were used in the data cubes reduction processes. For the SINFONI data cube, we used a constant PSF.

As said previously, the SIFS standard star was observed in the same night, so we used these data to estimate the FWHM of the PSF, at $5647 \AA$, that was equal to 2.4 arcsec. The process of deconvolution was performed with six iterations. All the treatment was also performed in the standard star data cube, in order to obtain the FWHM of the PSF after the deconvolution process (1.6 arcsec).

Regarding the GMOS data cube, the best estimate of the FWHM of PSF was obtained 
from the $[\mathrm{O}$ I $] \lambda 6300$ image. At first, we assumed that this emission is point-like. After applying the deconvolution, however, we noticed that the difference of the values of the FWHM of the PSF before and after of the deconvolution ( 0.71 arcsec and 0.68 arcsec) was not so significant as we usually get for other objects (we often get differences between 0.10 and 0.15 arcsec). This probably means that the emission of $[\mathrm{O} \mathrm{I}] \lambda 6300$ is not point-like. Nevertheless, this is the most point-like emission in GMOS data cube. The number of iterations of the deconvolution process was 10 .

For the SINFONI data cubes, we had no other way to determine the PSF, only using an image of some emission line. In this case, we used the image of $\mathrm{H}_{2} \lambda 21218$, which presents a point-like emission in the inner centre of the FOV. The difference of the FWHM of the PSF before and after the deconvolution process was also lower than we expected. The deconvolution was applied with 10 iterations and the resulting FWHM of the PSF was 0.60 arcsec. It is important to mention that, as discussed in Menezes et al. (2014, 2015, 2019), the Richardson-Lucy deconvolution does not compromise the data in anyway (keeping the flux values and also the spatial morphology of the structures unchanged). Therefore, although the improvement in the spatial resolution, in this case, is not dramatic, such a technique is worth to be applied.

\subsubsection{Optical and NIR gas data cubes}

In order to study the gas emission in the data cubes, we applied a spectral synthesis using the STARLIGHT software (Cid Fernandes et al., 2005), with a stellar population spectral base created using the Medium-resolution Isaac Newton Telescope Library of Empirical Spectra (MILES, Sánchez-Blázquez et al. 2006) in the optical spectral range (GMOS and SIFS), to trace the stellar continuum and remove it. The spectral synthesis is applied to each spectrum of the data cube and consists of a linear combination of the base spectra to obtain the observed spectrum. First, we mask all the emission lines of the treated data cube and then we apply the spectral synthesis. After that, we create a synthetic stellar data cube containing only the synthetic spectra obtained in the process. Then, subtract this data cube from the original treated one, obtaining a data cube with mainly gas emission that we call gas data cube.

In order to obtain the SINFONI gas data cube, we performed the spectral synthesis using the Penalized Pixel Fitting (pPXF, Cappellari e Emsellem 2004) method. The 
spectral base covers only the $K$ band (Winge et al. 2009). pPXF is a spectral synthesis that uses the spectra from the base convolved with Gauss-Hermite functions. Then, in the same way as in the optical, we create a synthetic stellar data cube and subtract it from the original one, obtaining a gas data cube, in this case, only in the $K$ band.

\subsubsection{Chandra data}

The data from Chandra space telescope were obtained from the public archive. The observations were taken on 2014 August 21 (PI: Garmire, G., program: 15610062), with a 14.1 $\mathrm{h}$ exposure, using the ACIS instrument. From the information of the images headers, referring to the positions and energy of the detected photons, we created a data cube.

The data cube was spatially re-sampled. The original size of the spaxels was 0.492 arcsec and, after the re-sampling, was 0.246 arcsec. After that, a spatial filtering using the Butterworth method was applied and the data cube was spatially resized, in order to make superpositions (or more direct comparisons) between this data cube and the others analysed in this work. To do this, we took a reference point in this data cube and its values of RA and Dec. and compared to the other data cubes and also the HST images, then we centred the images at the same point.

We used the data of Mrk 202 to compare PSFs, as shown in section 9.5. These data were obtained with the same instrument, ACIS, and the same process of creation, re-sampling and resizing used in the data cube of NGC 613 was performed. The data were taken on 2003 March 16 (PI: Predehl, P., program: 04700038) with a 2.2 h exposure.

\subsubsection{ALMA data}

The data from ALMA were obtained from its public archive. The observations were part of the program 2015.1.00404.S (PI: Combes, F.) and these data were already been published in Combes et al. (2019) and Audibert et al. (2019) works. We used here only the data cube of $\mathrm{CO}(3-2)$ emission line, whose beam size was $0.43 \operatorname{arcsec} \times 0.37 \operatorname{arcsec}$ and resolution was 0.14 arcsec. Since we just needed the image of the cube collapsed along the spectral axis and the data has a good quality, we did not perform any treatment in this data cube. The spaxel size of the images of this data cube is 0.07 arcsec.

In the previous works these data were used to determine the geometry of the dust torus of this nucleus (Combes et al. 2019) and the identification of the nuclear spiral 

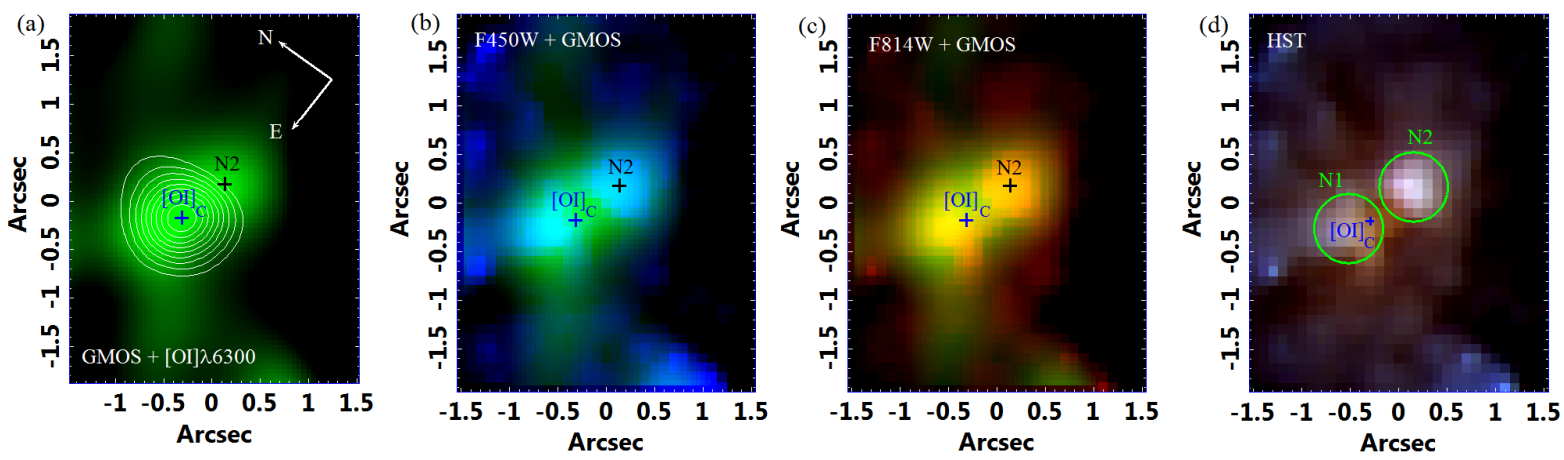

Figura 9.5: (a) Image of the GMOS data cube integrated along the spectral axis. The white contours represent the emission of $[\mathrm{O} \mathrm{I}] \lambda 6300$ and its centre is indicated as $[\mathrm{O} \mathrm{I}]_{C}\left(X_{C}=-0.35 \operatorname{arcsec}\right.$ and $Y_{C}=-0.2$ arcsec). The position of $\mathrm{N} 2$ was defined as the centre of the emission northwest of $\mathrm{N} 1$ ( $X_{C}=0.1 \operatorname{arcsec}$ and $Y_{C}=0.15$ arcsec). (b) GB composition of the image in the $H S T$ filter $F 450 \mathrm{~W}$ (blue) and the image of the integrated GMOS data cube (green). (c) RG composition of the same GMOS data cube image (green) and the image in the $H S T$ filter $F 814 W$ (red). (d) RGB composition in the HST filters: $F 814$ $W$ (red), F $606 \mathrm{~W}$ (green) and $F 450 \mathrm{~W}$ (blue). The circles indicate the regions N1 and N2. All the images have crosses that indicate the positions $[\mathrm{O} \mathrm{I}]_{C}$ and $\mathrm{N} 2$, whose sizes represent the uncertainty of $3 \sigma$, taking into account the size of the spaxels of the GMOS data cube. Since the last panel contains only the images from HST, whose spaxels are larger than the GMOS spaxels, the size of the cross differs.

by Audibert et al. (2019), they also compared this data with SINFONI data. Here, we essentially compare these data with the HST images, reinforcing a connection between the bar and the nuclear spiral.

\subsection{Emitting regions}

The central region of NGC 613 is a complex environment, since it has emissions of many sources and natures. The emitting regions were studied according to the instruments, depending on the spatial resolution and FOV. In other words, the inner central region was mainly studied using the GMOS data cube and HST images, whereas the circumnuclear region was better studied using SIFS and SINFONI, Chandra, and ALMA data cubes. The gas emission, as said previously (see section 9.3.5), was analysed using the gas data cubes of GMOS, SIFS and SINFONI.

\subsubsection{Nuclear emission - matching the images of distinct instruments}

The integrated GMOS data cube shows an extended emission with an elongated morphology, consistent with the presence of a double structure (see Fig. 9.2). This same pattern 
is present both in the emission-line images and in the continuum image of this data cube. Since we did not detect any featureless continuum in this object in the GMOS data cube (see Paper II), we can say that the continuum emission from this double structure is essentially stellar.

The HST images also present a double structure that is the same one observed in the GMOS data cube, since it has the same length (1.65 \pm 0.05 arcsec) and orientation (PA $=255^{\circ} \pm 5^{\circ}$ ), as shown in Fig. 9.5. It is worth mentioning that the uncertainties given here and throughout the text are the relative uncertainties, based on the spatial sampling of the images. The absolute uncertainties correspond to the uncertainties of the pointing of the instruments. The emission of [O I] 76300 looks point-like in the GMOS data cube

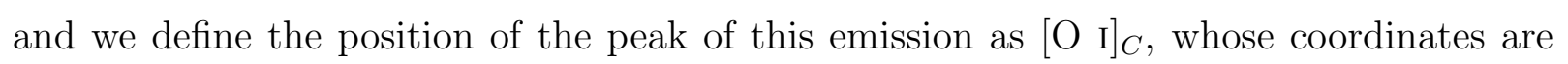
$X_{C}=-0.35 \pm 0.03$ arcsec and $Y_{C}=-0.20 \pm 0.03$ arcsec in the GMOS FOV. When we superpose the GMOS and the HST data (Fig. 9.5a), we see that the [O I] $\lambda 6300$ emission nearly coincides with one of the components of the double stellar structure (the one at $\mathrm{NE}$ ). We call this component of the double stellar structure as N1. N2 was defined as the brightest stellar nucleus observed in the HST image (see Fig. 9.5d). In the GMOS data cube, the centre of $\mathrm{N} 2$, with coordinates $X_{C}=0.1 \pm 0.05 \operatorname{arcsec}$ and $Y_{C}=0.15 \pm 0.05$ arcsec, was defined as the centre of the extended emission, northwest of the $[\mathrm{O}$ I $] \lambda 6300$ emission peak (obeying the orientation observed in the HST images), see Fig. 9.5(a).

The centre of N2, visible both in the HST and GMOS images, was used as reference to match the images of the two telescopes. The HST-based coordinates for the centre of N1 and $\mathrm{N} 2$ and the position of $[\mathrm{O} \mathrm{I}]_{C}$ are given in Table 9.1 . We used the position of $[\mathrm{O} \mathrm{I}]_{C}$ to superpose the images of HST and SIFS FOV (Fig 9.1). The SIFS data cube does not have enough spatial resolution to allow the visualisation of the extended emission that we see in the GMOS data cube. Because of that, we were only able to determine the position of $[\mathrm{O} \mathrm{I}]_{C}$ and, therefore, we could not study region $\mathrm{N} 2$ by analysing this data cube.

In the case of the SINFONI data cube, we noted that the $\mathrm{Br} \gamma$ inverted image, in flux units, shows a lack or low emission, or even $\operatorname{Br} \gamma$ in absorption, in the inner centre of NCG 613. The Br $\gamma$ in absorption is the most likely feature and it might be related to the presence of young stellar populations in regions N1 and N2 (see Paper II), since those stars present deeper hydrogen absorption lines than the older ones. The pattern of the region of $\operatorname{Br} \gamma$ in absorption located at the centre is similar to the extended emission that we see in 

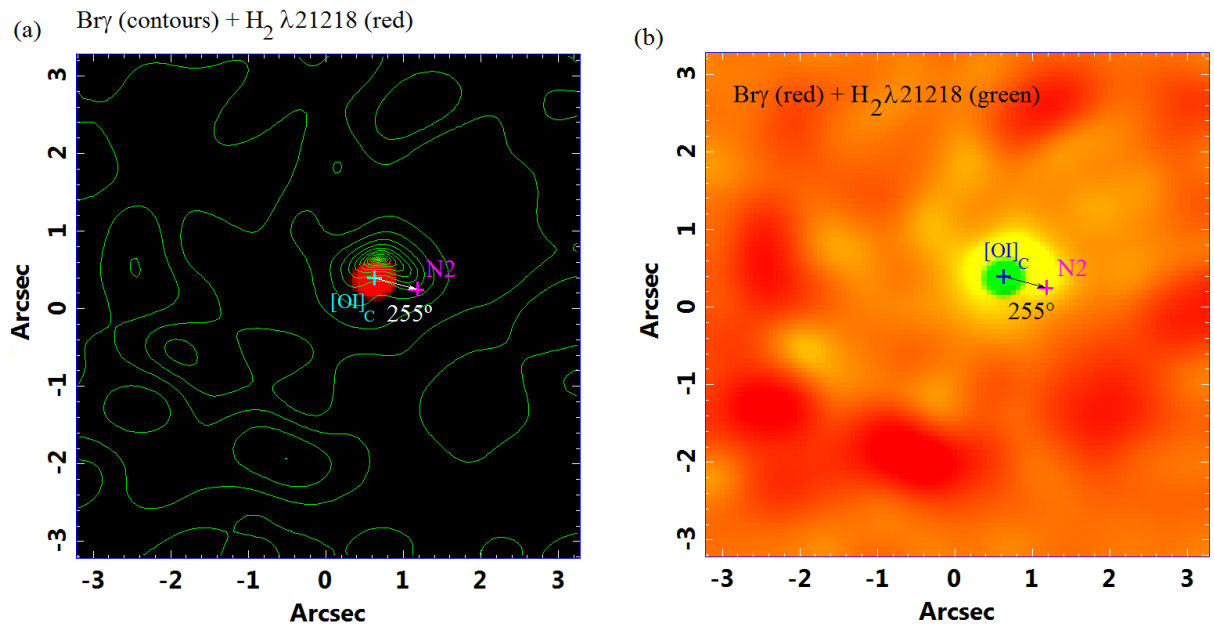

Figura 9.6: (a) Image of the centre emission of $\mathrm{H}_{2} \lambda 21218$ of the SINFONI gas data cube in red, with green contours of the $\mathrm{Br} \gamma$ inverted image in flux units (or $\mathrm{Br} \gamma$ in absorption). (b) RG composition of $\mathrm{H}_{2} \lambda 21218$ (green) and $\operatorname{Br} \gamma$ (red). The yellow region is where $\operatorname{Br} \gamma$ is in absorption or not being emitted. Both images have indications of the positions of $[\mathrm{O} \mathrm{I}]_{C}$ and of the centre of N2, assuming that the position of $[\mathrm{O} \mathrm{I}]_{C}$ is coincident with the peak of the $\mathrm{H}_{2} \lambda 21218$ emission and by propagating the position of $\mathrm{N} 2$, knowing the PA $\left(255^{\circ}\right.$, indicated in the image) and distance between the $[\mathrm{O} \mathrm{I}]_{C}$ and $\mathrm{N} 2$ (centre of the brightest stellar nucleus from the HST images).

the GMOS data cube (see Fig. 9.6). When we superpose the image of the point-like source of the SINFONI data cube $\left(\mathrm{H}_{2} \lambda 21218\right.$ in the centre) to the image of the only point-like source of the GMOS data cube ([O I $] \lambda 6300)$, we find a resemblance between them (compare Fig. 9.6 and Fig. 9.5 ), with $[\mathrm{O} \text { I }]_{C}$ slightly displaced towards the centre and with the N2 position compatible with the other end of this extended morphology. From that and also from the fact that the superposition of SINFONI and SIFS (after assuming the positions for $[\mathrm{O} \mathrm{I}]_{C}$ and for the centre N2) is correct, as it delineates successfully the circumnuclear ring as observed in the SIFS data cube (see Fig. 9.10), we concluded that the position of $[\mathrm{O} \mathrm{I}]_{C}$ is, within the uncertainties, the centre of the $\mathrm{H}_{2} \lambda 21218$ emission. After we made the superposition we noted that, the values of RA and Dec. of $\mathrm{N} 2$ and $[\mathrm{O} \mathrm{I}]_{C}$ are different from the ones we obtained in the optical (Table 9.1), indicating that the values of RA and Dec. from the SINFONI data cube are not reliable.

Fig. 9.5(a) shows the result of the GMOS data cube collapsed along its spectral axis, the positions of $[\mathrm{O} \mathrm{I}]_{C}$ and $\mathrm{N} 2$ (discussed previously) and the white contours that represent the emission of the $[\mathrm{O} \mathrm{I}] \lambda 6300$ line. In addition to the fact that there is no $[\mathrm{O} \mathrm{I}] \lambda 6300$ emission coming from N2, we see that this region has blue emission (from the image of 
Tabela 9.1 - Right ascension (RA) and declination (Dec.) of $[\mathrm{O} \mathrm{I}]_{C}$, and the centres of N1 and N2. These coordinates were derived from the HST images, as pointed in Fig. 9.5 d. The relative uncertainties of the values are $\sim 0.02$ arcsec. The absolute uncertainties correspond to the uncertainty of the pointing of the $H S T$.

\begin{tabular}{ccc}
\hline & RA & Dec. \\
\hline$[\mathrm{O} \mathrm{I}]_{C}$ & 1h 34m 18.172s & $-29 \mathrm{~d} 25 \mathrm{~m} 5.885 \mathrm{~s}$ \\
$\mathrm{~N} 1$ & 1h 34m 18.201s & $-29 \mathrm{~d} 25 \mathrm{~m} \mathrm{5.74s}$ \\
$\mathrm{N} 2$ & 1h 34m 18.139s & $-29 \mathrm{~d} 25 \mathrm{~m} \mathrm{5.99s}$ \\
\hline
\end{tabular}

the HST filter $450 \mathrm{~W}$ ), whereas such emission is displaced to north-east of $[\mathrm{O} \mathrm{I}]_{C}$, but still a significant part of it is inside the region that delineates N1 (see Fig.9.5b). At longer wavelengths ( $H S T$ filter $814 W$ ), we see clearly N1 and N2 (Fig. 9.5k). In this case, N1 seems to have stronger emission in red than N2 (better seen in panel d). We see in Fig. 9.5(d) that $\mathrm{N} 1$ is in a region predominantly red, possibly highly affected by dust, that may cause the displacement of the blue emission we see in Fig. 9.5(b), which might have been coming from the position $[\mathrm{O} \mathrm{I}]_{C}$ (represented by the cross in the image).

The Chandra data cube matched the data by the RA and Dec. In section 9.5, we see that the position of $[\mathrm{O} \mathrm{I}]_{C}, \mathrm{~N} 1$, and $\mathrm{N} 2$ centres are compatible with the centre of the hard $\mathrm{X}$-ray emission, since these data do not have enough spatial resolution to separate those sources. So we took the position of $[\mathrm{O} \mathrm{I}]_{C}$ as reference to the superposition that was made based on the RA and Dec.

In order to compare the molecular gas emission obtained with the ALMA data cube of $\mathrm{CO}(3-2)$, we made a superposition with the molecular emission observed with $\mathrm{H}_{2} \lambda 21218$ from SINFONI data cube as shown in Fig. 9.7. This superposition was made to match as much as possible the structure of the circumnuclear ring in both images and also was already done by Audibert et al. (2019). Here we do this superposition to locate $[\mathrm{O} \mathrm{I}]_{C}$ and N2 in this context. For discussion of Fig. 9.7, see section 9.6.2.

\subsubsection{Nuclear variability}

When we compare the collapsed GMOS data cube images and the HST RGB composition we see a difference between the emissions of N1 and N2: in the HST images, N2 is the brightest source and, in the GMOS data cube image, N1 is brighter than N2. In order to make a more direct comparison of this feature, the GMOS data cube was integrated 


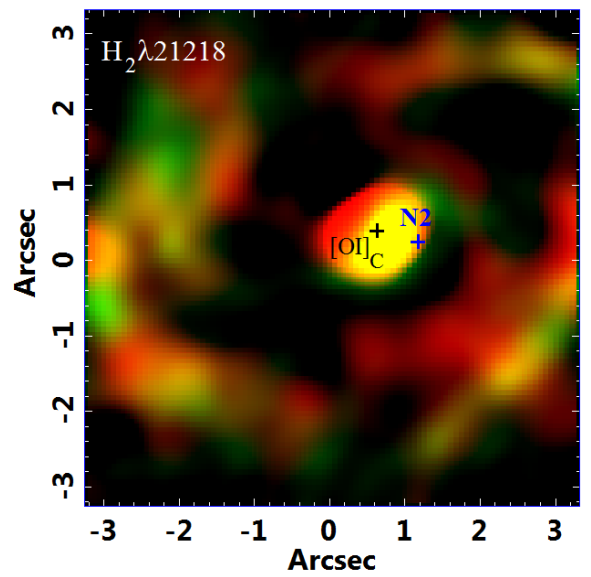

Figura 9.7: RG compositions with the $\mathrm{CO}(3-2)$ image obtained from ALMA data cube (in green) and the $\mathrm{H}_{2} \lambda 21218$ image obtained from SINFONI data cube (in red). The image shows the positions of $[\mathrm{O} \mathrm{I}]_{C}$ and of the centre of N2. The size of the crosses represents the $3 \sigma$ uncertainty taking into account the size of SINFONI spaxels. This image was made to match the SINFONI and ALMA data using the circumnuclear ring position and also to locate $[\mathrm{O} \mathrm{I}]_{C}$ and the centre of N2 in ALMA data.

along the spectral axis, taking into account the transmission curve of the HST filter F 606 $W$. Besides that, the image of the HST filter $F 606 \mathrm{~W}$ was re-sampled to have pixels with the same sizes of the spaxels of the GMOS data cube $(0.05 \operatorname{arcsec} \times 0.05$ arcsec $)$, filtered with the Butterworth method (since the re-sampling generates high frequency noise) and, then, convolved with the PSF of the GMOS data cube (0.68 arcsec). Both images were normalized in N2 (the emission peak in N2 became equal to one), since the flux units are different in these two instruments. From this, we made a direct comparison between N1 and N2, as shown in Fig. 9.8. The difference between the final image from the GMOS data cube and the final image from the HST filter F $606 \mathrm{~W}$ (Fig. 9.8c) shows a source whose centre is compatible with the position of $[\mathrm{O} \mathrm{I}]_{C}$, within the uncertainties (the distance between $[\mathrm{O} \mathrm{I}]_{C}$ and this source is 0.11 arcsec). Such a source, which we call V2, was not detected before. The brightness variation of this source happened in the interval of about 14 yr (between 2001 August and 2015 January, when the observations of HST and GMOS were taken, respectively). Such a variation could be an evidence of a supernova. However, one can notice a vertical pattern in Fig. 9.8(c) that is similar to the instrumental fingerprint signature in the GMOS data cube images (see Menezes et al. 2019). We cannot discard that this image may have some instrumental fingerprint remnants, still present in the GMOS data cube after treatment, that generated this pattern. Nevertheless, we 

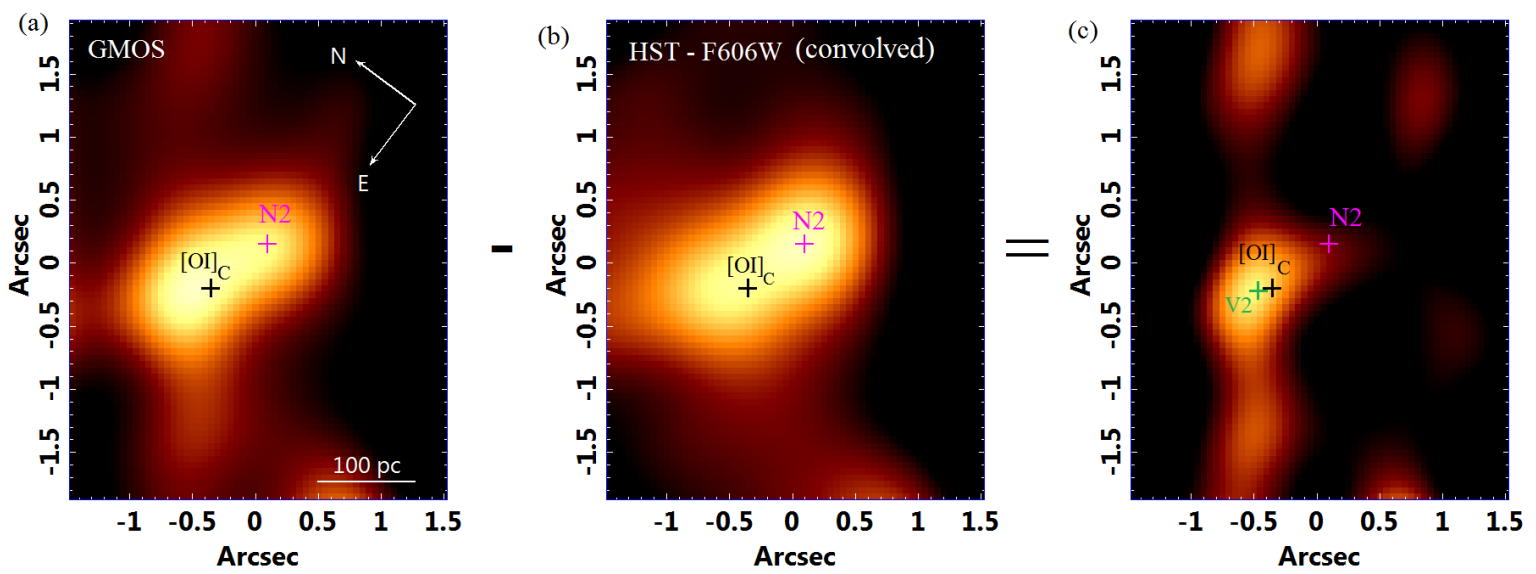

Figura 9.8: (a) GMOS data cube integrated image considering the transmission curve of the $H S T$ filter $F$ $606 \mathrm{~W}$. (b) Image in the HST filter F $606 \mathrm{~W}$ convolved with the PSF of the GMOS data cube (0.71 arcsec). Both (a) and (b) had their fluxes normalized at N2. One can note that, in the GMOS image, there is an emission excess near $[\mathrm{O} \mathrm{I}]_{C}$ and, in the HST image, this excess is located at N2. The subtraction of these two images $(\mathrm{c})$ shows a source near $[\mathrm{O} \mathrm{I}]_{C}$ (the green cross represents its centre), whose projected distance to $[\mathrm{O} \mathrm{I}]_{C}$ is 0.11 arcsec. We named this source v2. The sizes of the crosses represent the uncertainty of $3 \sigma$ for the positions of the sources.

know that the instrumental fingerprint cannot generate emissions that are approximately point-like as the one that we are seeing.

Another way to study variability was possible due to the availability of recent images from the HST. By comparing images obtained with the same filter $(F 814 W)$ in 2001 and 2018, we aimed to evaluate in more detail possible flux variations of the sources during this period. The 2001 image was obtained with WFPC2, while the 2018 image was obtained with WFC3, which has a higher spatial resolution. In order to perform a comparison, first of all, we convolved the 2018 image with an estimate of the PSF of the 2001 image. After that, we extracted, from each image, a brightness profile from a rectangular region along a $\mathrm{PA}=255^{\circ}$ and with a width of 0.75 arcsec. The two extracted profiles were normalized in a way that the flux peak (in N2) in both profiles was equal to 1. The top panel of Fig. 9.9 shows the two extracted profiles, together with the curve corresponding to the difference between them. We notice a flux increase, from 2001 to 2018, in a source between N1 and $\mathrm{N} 2$, whose position is not compatible, even at the $3 \sigma$ level, with the position of $[\mathrm{O} \mathrm{I}]_{C}$. We named this variable source as V1. The distance between V1 and [O I $]_{C}$ is $0.24 \pm 0.04$ arcsec. This variation is better seen by comparing the images of the bottom panel in Fig. 9.9. If the real position of the AGN is $\mathrm{V} 1$, we are seeing that this AGN is variable. If not, 


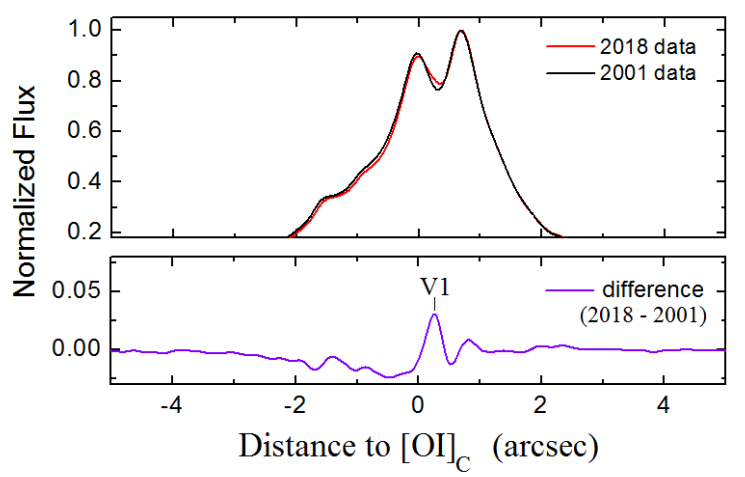

(a) 2001

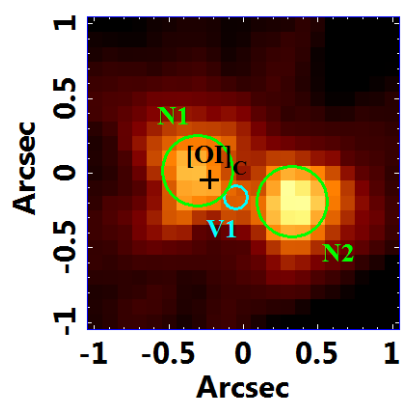

(b) 2018

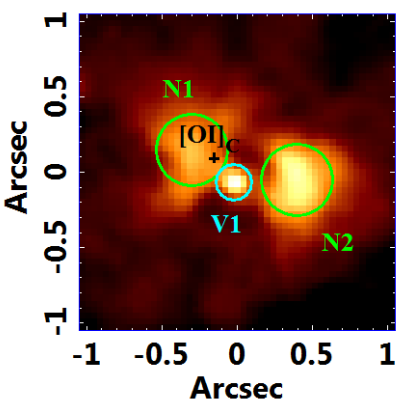

Figura 9.9: Top: $F$ 814 $W$ filter profile extracted along the $\mathrm{PA}=255^{\circ} \pm 5^{\circ}$ (the orientation that passes through $[\mathrm{O} \mathrm{I}]_{C}$ and N2) from the HST images observed on 2001 (WFPC2) and 2018 (WFC3). The images were normalized considering the flux in N2. Also the image from WFC3 was convolved with an estimate of the PSF of the image from WFPC2 for a better comparison. The difference between the 2018 data and the 2001 profiles is represented by the purple curve with the indication of the source of variation V1. We noticed a source between $\mathrm{N} 1$ and $\mathrm{N} 2\left(\sim 0.24 \operatorname{arcsec}\right.$ from $\left.[\mathrm{O} \mathrm{I}]_{C}\right)$ that has higher luminosity than before. We named this source V1. Bottom: images of F 814 W HST filter of the inner centre of NGC 613 (a) taken in 2001 and (b) taken in 2018. Both images show indication of regions N1 and N2, [O I] $]_{C}$ position and V1. The diameter of the green circles was determined based on the size of N2 in the 2018 image and the diameter of the cyan circle was taken as the size of V1 in the 2018 image. The cross indicating $[\mathrm{O} \mathrm{I}]_{C}$ corresponds to $3 \sigma$ of the GMOS spaxel.

we are seeing another indication of supernova or even variations of dust extinction in the line of sight. Similar to V2, the presence of V1 has not been previously reported in the literature.

\subsubsection{Optical emission-line ratios}

From the optical gas data cubes, in this case GMOS and SIFS, it is possible to use the emission-line ratios to characterize the nature of the emission from the regions we detected. Fig. 9.10 shows the sizes and positions of the areas that we delineated to extract the spectrum of each region. The spectra of these regions were extracted from this data 
Tabela 9.2 - Emission-line ratios of the regions detected in the nucleus of NGC 613, calculated from the integrated flux of the emission-lines of the spectra extracted from each region (see Figs. 9.18, 9.20 and 9.21 and appendix 9.8 .

\begin{tabular}{cccccc}
\hline Regions & {$[\mathrm{O} \mathrm{III}] / \mathrm{H} \beta$} & {$[\mathrm{N} \mathrm{II}] / \mathrm{H} \alpha$} & {$[\mathrm{O} \mathrm{I}] / \mathrm{H} \alpha$} & $([\mathrm{S} \mathrm{II}] \lambda 6716+\lambda 6731) / \mathrm{H} \alpha$ & {$[\mathrm{S} \mathrm{II}] \lambda 6716 /[\mathrm{S} \mathrm{II}] \lambda 6731$} \\
\hline $\mathrm{N} 1$ & $0.72 \pm 0.07$ & $1.87 \pm 0.03$ & $0.30 \pm 0.03$ & $1.03 \pm 0.07$ & $1.199 \pm 0.017$ \\
$\mathrm{~N} 2$ & $1.55 \pm 0.23$ & $1.19 \pm 0.06$ & $0.184 \pm 0.023$ & $0.69 \pm 0.15$ & $1.09 \pm 0.05$ \\
1 & $0.24 \pm 0.05$ & $0.38 \pm 0.03$ & $0.031 \pm 0.004$ & $0.194 \pm 0.012$ & $1.36 \pm 0.15$ \\
2 & $1.04 \pm 0.06$ & $0.73 \pm 0.04$ & $0.075 \pm 0.009$ & $0.35 \pm 0.05$ & $1.33 \pm 0.04$ \\
3 & $1.13 \pm 0.09$ & $0.888 \pm 0.021$ & $0.089 \pm 0.010$ & $0.46 \pm 0.07$ & $1.34 \pm 0.04$ \\
4 & $0.240 \pm 0.020$ & $0.417 \pm 0.016$ & $0.025 \pm 0.006$ & $0.225 \pm 0.013$ & $1.25 \pm 0.12$ \\
5 & $0.136 \pm 0.010$ & $0.394 \pm 0.005$ & $0.0124 \pm 0.0016$ & $0.172 \pm 0.004$ & $1.18 \pm 0.05$ \\
6 & $0.166 \pm 0.019$ & $0.371 \pm 0.008$ & $0.024 \pm 0.004$ & $0.185 \pm 0.006$ & $1.12 \pm 0.07$ \\
7 & $0.37 \pm 0.06$ & $0.525 \pm 0.022$ & $0.092 \pm 0.010$ & $0.29 \pm 0.07$ & $1.23 \pm 0.06$ \\
8 & $1.91 \pm 0.18$ & $1.47 \pm 0.06$ & $0.15 \pm 0.03$ & $0.75 \pm 0.13$ & $1.44 \pm 0.05$ \\
9 & $0.3 \pm 0.3$ & $0.42 \pm 0.08$ & & & \\
10 & $0.19 \pm 0.11$ & $0.25 \pm 0.03$ & & $0.143 \pm 0.013$ & $1.25 \pm 0.23$ \\
\hline
\end{tabular}

cube and the diameter of the extraction area was equal to the FWHM of the PSF of these data (see Fig. 9.10, magenta circles). For the regions named 1 to 10, we had to make a superposition of the $\operatorname{Br} \gamma$ emission image (which clearly shows regions 1 to 8 in the ring, in green) and of the $\mathrm{H} \alpha /[\mathrm{N} \mathrm{II}] \lambda 6584$ image from the SIFS data cube, in red (this image shows where $\mathrm{H} \alpha$ emission is more relevant and therefore the presence of the $\mathrm{H}$ II regions), since we had to know the positions of those regions in this data cube, in order to extract the spectra to calculate the emission-line ratios. As the spectra were extracted from the SIFS data cube, the diameter of the extraction areas of those 10 regions was equal to the FWHM of the PSF of these data (see green circles in Fig. 9.10), with exception of regions 9 and 10 that had their areas and positions estimated directly from the image of $\mathrm{H} \alpha /[\mathrm{N}$ II] $\lambda 6584$ and, as they are at the edges of the FOV, we could not extract circular areas (see green rectangles in Fig. 9.10.

\subsubsection{H II regions}

It is known, in the literature, that NGC 613 nucleus has a circumnuclear ring with many star-forming regions (Böker et al. 2008; Falcón-Barroso et al. 2008, 2014). The FOV of the GMOS data cube $(3 \operatorname{arcsec} \times 5 \operatorname{arcsec})$ is restricted only to the inner centre of the galaxy and its size does not cover the region of the circumnuclear ring, but only part of its inner edges. For this reason we analysed the circumnuclear ring with the SIFS data cube, which has a larger FOV than the GMOS data cube. So, to study these regions, we 


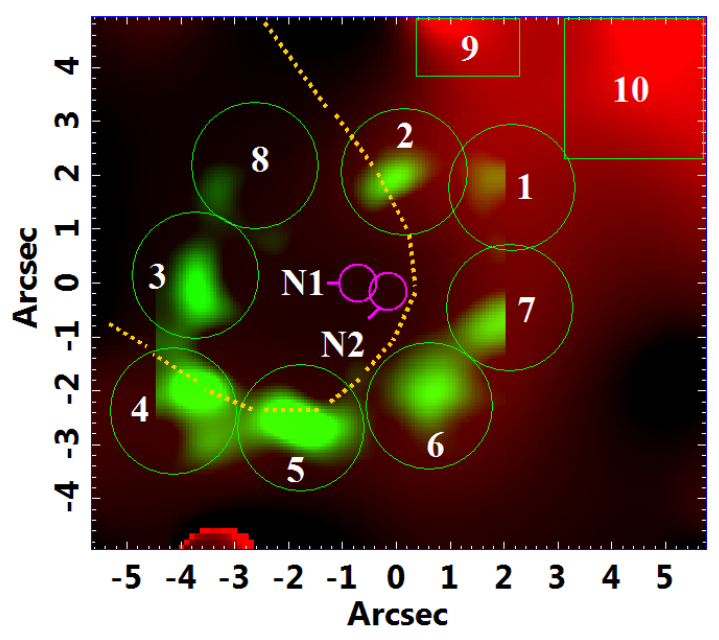

Figura 9.10: RG composite image, with red representing the image of the $\mathrm{H} \alpha /[\mathrm{N}$ II $] \lambda 6584$ ratio, taken from the SIFS data cube (indicating the areas where the $\mathrm{H} \alpha$ emission is higher or more relevant than the $[\mathrm{N}$ II $] \lambda 6584$ emission), and the green corresponding to the $\mathrm{Br} \gamma$ emission image, from the SINFONI data cube, which delineates the star formation ring. We added a dashed yellow line representing approximately the $[\mathrm{O}$ III $] \lambda 5007$ emission (the ionization cone edges). From the $\mathrm{Br} \gamma$ image, we identified eight emitting regions (named from 1 to 8). In addition to these, we detected regions 9 and 10, from the image of the SIFS data cube, as they are not part of the SINFONI FOV and neither of the ring. We added circles to the image representing the positions of N1 and N2, whose sizes are the same of the PSF from the GMOS data cube. All the circles represent the extraction area of the spectrum of each region, in order to calculate their emission-line ratios. For N1 and N2, we used the GMOS gas data cube to extract their spectra, because the spatial resolution was better and high enough to separate those emissions. Since the spectra of regions 1 to 10 were extracted from the SIFS gas data cube (because the GMOS FOV does not contain those regions, but only the inner edges of some of them), we used the PSF of this data cube for the extraction. Note that the number that indicates each regions follows the same orientation as Falcón-Barroso et al. (2014), however Region 8 is not the same one the authors named in their article. 


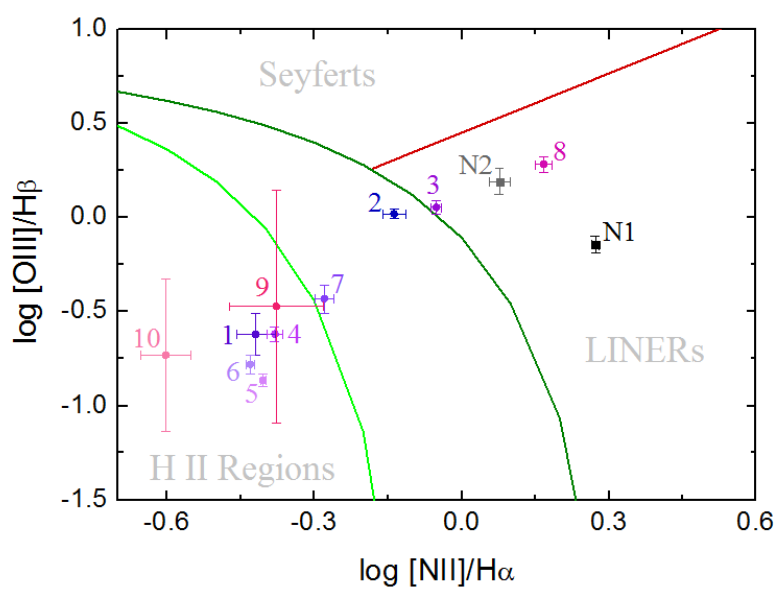

Figura 9.11: Diagnostic diagram obtained from the emission-line ratios on table 9.2 The names of each studied region are indicated near their respective point. The dark green line represents the theoretical limit for the starburst emission obtained by Kewley et al. (2001). The separation between H II regions and AGNs determined by Kauffmann et al. (2003) is indicated by the light green curve. The red line represents the separation between the Seyferts and LINERs emission determined by Schawinski et al. (2007). The other two diagnostic diagrams, $\log [\mathrm{O} \mathrm{III}] / \mathrm{H} \beta \times \log ([\mathrm{S}$ II $] \lambda 6716+\lambda 6731) / \mathrm{H} \alpha$ and $\log [\mathrm{O}$ III $] / \mathrm{H} \beta \times \log$ $[\mathrm{O} \mathrm{I}] / \mathrm{H} \alpha$ represents essentially the same results, and therefore are not displayed in this work.

used the SIFS and SINFONI data cubes (the latter was the one used in the literature to characterize the ring in the NIR).

The $\operatorname{Br} \gamma$ emission image of the SINFONI data cube clearly shows eight star-forming regions that compose the ring (see Fig. 9.10 in green). The ring can be observed in the SIFS data cube, however this data cube does not have enough spatial resolution to separate each region. On the other hand, as we can see in Fig. 9.10 (in red), we detected, besides the ring, two regions (named 9 and 10) that seem to be connected to the ring. Falcón-Barroso et al. (2014) detected seven H II regions, that are regions 1 to 7 in Fig. 9.10. However, we are considering another region in the ring (Region 8) and their region 8 is actually a region inside the ring, but not part of it, that they use for comparison.

The extracted spectra are presented in Appendix 9.8. As one can see, many spectra presented blended emission lines, without indications of broad components of the $\mathrm{H} \alpha$ and $\mathrm{H} \beta$ lines. In order to calculate the emission-line ratios, we decomposed those blended lines in Gaussians functions. The decomposition method and the flux and decomposition uncertainties are also discussed in Appendix 9.8. Table 9.2 contains the emission-line ratios with their respective uncertainties of the 12 regions and Fig. 9.11 shows the diagnostic diagram of $[\mathrm{O}$ III $] \lambda 5007 / \mathrm{H} \beta \times[\mathrm{N}$ II $] \lambda 6584 / \mathrm{H} \alpha$. 
Tabela 9.3 - FWHM and luminosity of the $\mathrm{H} \alpha$ line determined for each region (N1 and N2 from the GMOS data cube spectra and the other regions from the SIFS data cube spectra). The spectra were corrected of reddening using $\mathrm{H} \alpha / \mathrm{H} \beta$ ratio.

\begin{tabular}{ccc}
\hline Regions & $\begin{array}{c}\text { FWHM of } \mathrm{H} \alpha \\
\left(\mathrm{km} \mathrm{s}^{-1}\right)\end{array}$ & $\begin{array}{c}\mathrm{H} \alpha \text { luminosity } \\
\left(10^{39} \mathrm{erg} \mathrm{s}^{-1}\right)\end{array}$ \\
\hline $\mathrm{N} 1$ & $592 \pm 8$ & $3.95 \pm 0.06$ \\
$\mathrm{~N} 2$ & $258 \pm 7$ & $9.2 \pm 0.3$ \\
1 & $138 \pm 5$ & $40.0 \pm 1.2$ \\
2 & $143 \pm 5$ & $32.8 \pm 1.0$ \\
3 & $172 \pm 5$ & $26.0 \pm 0.4$ \\
4 & $106 \pm 5$ & $73 \pm 2$ \\
5 & $113 \pm 5$ & $65.1 \pm 0.4$ \\
6 & $122 \pm 5$ & $59.0 \pm 0.3$ \\
7 & $226 \pm 5$ & $37.1 \pm 0.7$ \\
8 & $331 \pm 7$ & $6.61 \pm 0.21$ \\
9 & $114 \pm 7$ & $0.50 \pm 0.04$ \\
10 & $183 \pm 5$ & $14.8 \pm 0.5$ \\
\hline
\end{tabular}

We can see that, excepting regions $\mathrm{N} 1, \mathrm{~N} 2,2,3$, and 8, the emission of all other ones is compatible with the emission from $\mathrm{H}$ II regions. N1 and N2 have emission-line ratios compatible with the ones of LINERs. Based on the $[\mathrm{O}$ III $] \lambda 5007 / \mathrm{H} \beta$ ratio, $\mathrm{N} 2$ seems to have a higher ionization degree than N1, although the values of this ratio for N1 and N2 are compatible, at the $3 \sigma$ level. Regions 2 and 3 have emission-line ratios compatible with the ones of transition objects. The yellow contour of Fig. 9.10 corresponds to the edges of the emission of [O III] $\lambda 5007$ (an emission line of relatively high ionization degree) that, by its morphology, characterises an ionization cone (see Fig. 9.12). The fact that regions 2, 3, and 8 have such ionization degrees (based on the $[\mathrm{O}$ III $] \lambda 5007 / \mathrm{H} \beta$ ratio) and emission-line ratios compatible with the ones of AGNs indicates that the emission from those regions is highly contaminated by the ionization cone (being either the result of an overlap of emissions or of an ionization of these regions directly by the AGN). Region 8 is also very close to the position of the radio jet and outflow and this resulting ionization degree might be due to a contamination from the radio jet and outflows coming from the AGN (see section 9.5.

We will discuss in section 9.5 that the $[\mathrm{O}$ III $] \lambda 5007$ emission is co-spatial with the emission of soft X-ray. There is also a source in the FOV edge at south that can be 


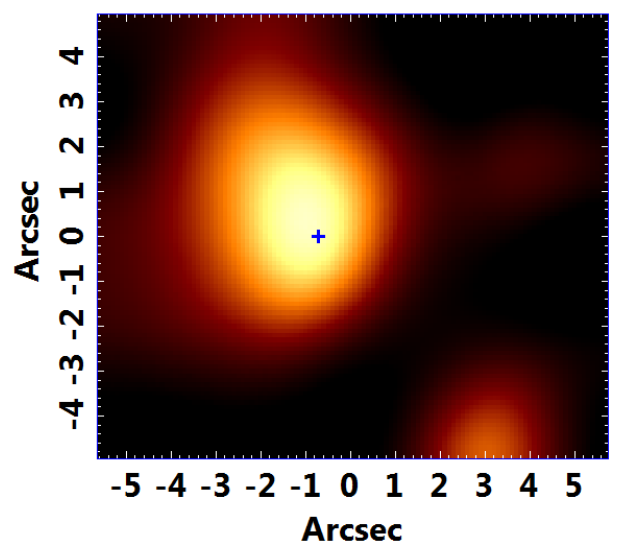

Figura 9.12: $[\mathrm{O}$ III $] \lambda 5007$ image obtained from the SIFS data cube. The blue cross represents the position of $[\mathrm{O} \mathrm{I}]_{C}$ and its size the uncertainty of $3 \sigma$.

the other side of this ionization cone or a region of the narrow-line region (NLR) that is receiving the ionizing radiation from the AGN with less obscuration. In Fig. 10 from Gadotti et al. (2019), we see that this source is also extended and it has a high ionization degree, but it was not detected in soft X-ray images. That might be due to extinction in the line of sight or to the distance of this region from the AGN. But the absence of the X-ray emission of this region indicates that it is not the position of the AGN.

Table 9.3 presents the FWHM and luminosity of the $\mathrm{H} \alpha$ emission line in the spectra of the observed regions. One can note that N2 is brighter than N1 (regarding H $\alpha$ emission) and that region 4 is the brightest of the ring. N1 has the highest FWHM values, which indicates the presence of outflows of gas.

\subsubsection{Absence of featureless continuum emission in the $K$ band}

A map of the $D_{C O}$ coefficient (Mármol-Queraltó et al., 2009) obtained from the same SINFONI data analysed in this work is shown in Fig. 5 of Falcón-Barroso et al. (2014). The values of such a coefficient are higher for spectra with a deeper CO absorption band at $2.29 \mu \mathrm{m}$. The authors note a slight decrease in the values of the $D_{C O}$ coefficient at the nucleus, in comparison to the surroundings. If this object presented a significant emission of a featureless continuum, we would expect shallower absorption CO bands at the nucleus (see Burtscher et al. 2015), which would result in lower values of $D_{C O}$ in that region. Considering the fact that the $D_{C O}$ map presented by Falcón-Barroso et al. (2014) is quite noisy (due probably to the $\mathrm{S} / \mathrm{N}$ of SINFONI data cube), it is difficult to confirm whether or 


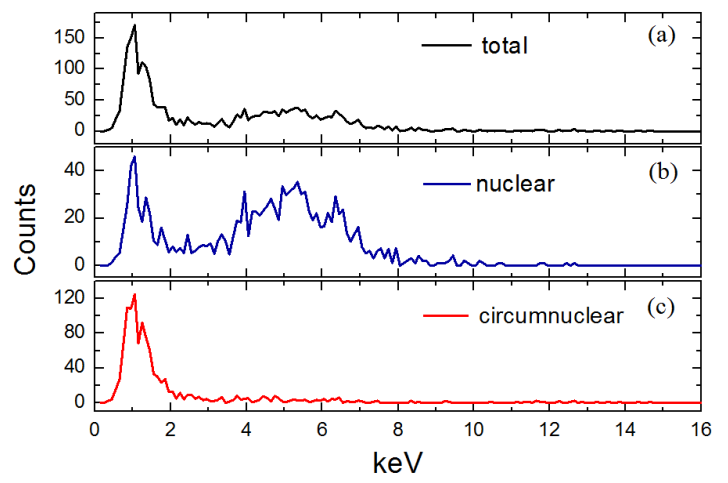

Figura 9.13: (a) Total spectrum of the Chandra data cube of NGC 613, (b) spectrum of the circular region whose centre is indicated by the blue cross in Fig. 9.14 with the extraction radius of $\sim 1.7$ arcsec and $(\mathrm{c})$ the total spectrum of the area of $\sim 20 \operatorname{arcsec} \times 20 \operatorname{arcsec}$ (same area of the FOV of the Fig. 9.14) minus the one from the nuclear region, representing the circumnuclear spectrum.

not the drop of the values at the nucleus is real. We conclude that the effect of a featureless continuum in these data is, at most, very weak. Therefore, the featureless continuum at the nucleus of NGC 613, in the $K$ band, is either too weak (due to an AGN lower state of activity, if it is variable) to be detected or should be highly obscured in the $K$ band. See section 9.6.1 for a detailed discussion and a comparison with previous studies.

\subsection{The X-ray emission}

In order to further investigate the nature of the emission in the centre of NGC 613, we analysed a data cube obtained with the Chandra space telescope. We subtracted the spectrum of a circular region centred on the nucleus with a radius of $\sim 1.7 \operatorname{arcsec}($ Fig $9.13 \mathrm{~b})$ from the spectrum of the total data cube (Fig. 9.13a), resulting in the spectrum of the circumnuclear region (Fig 9.13 c). It is clear that the nucleus shows both hard $(2-10 \mathrm{keV})$ and soft $(0.5-2 \mathrm{keV}) \mathrm{X}$-ray emission while the circumnuclear region is dominated by soft X-ray emission. By comparing the circumnuclear spectrum with high-resolution data from NGC 1068 Kinkhabwala et al. 2002) we identified the lines of Ne IX at $0.91 \mathrm{keV}$, Ne X $\mathrm{Ly}_{\alpha}$ at $1.03 \mathrm{keV}$ and $\mathrm{Ne} \mathrm{x} \mathrm{Ly}$ cont at $1.35 \mathrm{keV}$.

Fig. 9.14 shows that the hard X-ray emission is concentrated, mainly, in the inner centre. In order to see how compact the central emission is, we compared its profile with that of Mrk 202, a Seyfert 1 galaxy (Véron-Cetty e Véron, 2006) observed with the same instrument as NGC 613 (see section 9.3.6). The image of Mrk 202 AGN in hard X-rays 

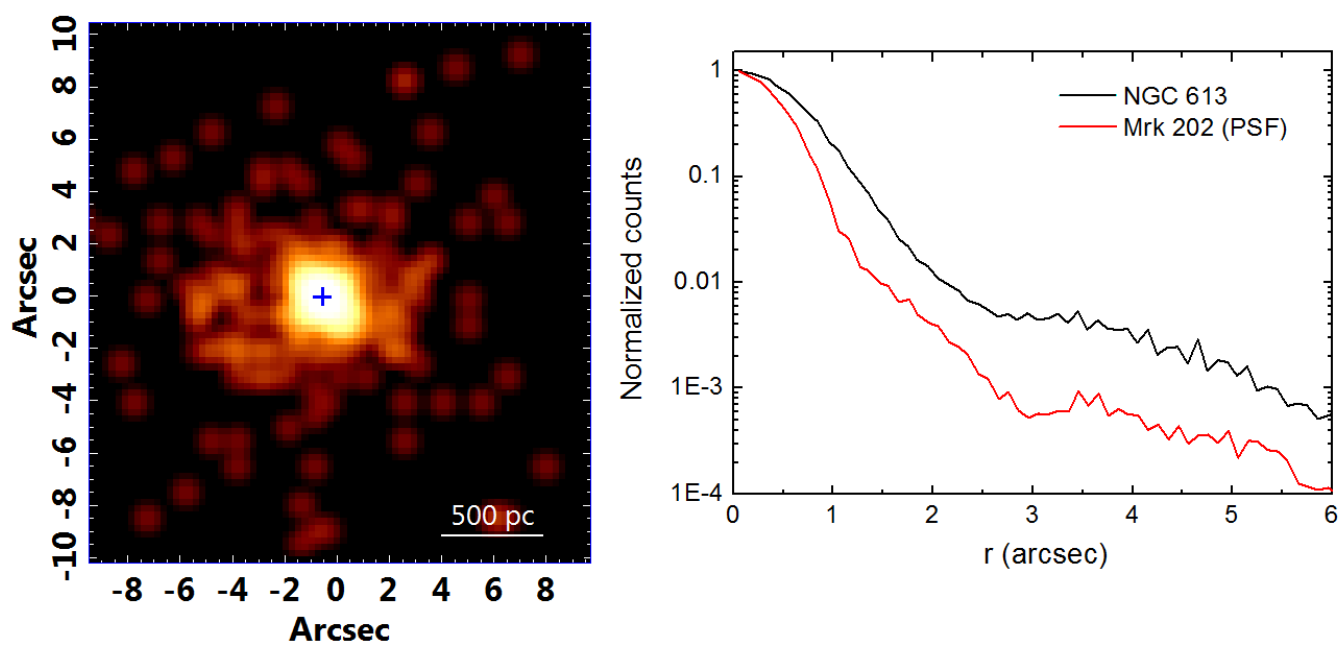

Figura 9.14: Hard X-ray image, 2 to $10 \mathrm{keV}$, of the Chandra data cube of NCG 613 and radial profiles of the images of hard X-ray from NGC 613 and Mrk 202 (a Seyfert 1 galaxy observed with the same instrument, used here as an estimate of the PSF of the data, since it has only a central emission). The blue cross indicates the position of the peak of the emission and its size the uncertainty of $3 \sigma$.

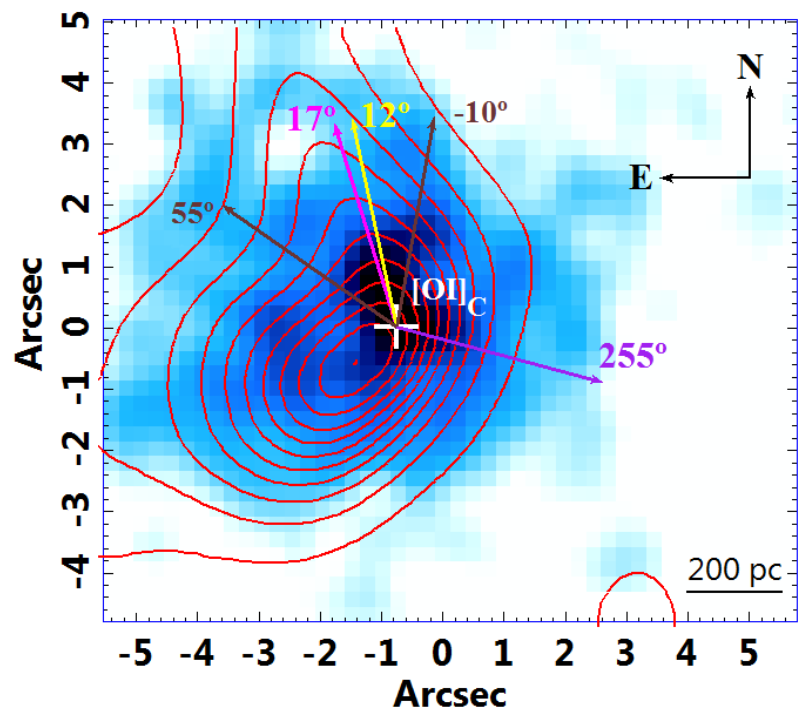

Figura 9.15: Image from Chandra space telescope of the central region of NGC 613 in the soft X-rays, with indication of the orientation N-E and scale of 200 pc. The PA of the radio jet detected by Hummel e Jorsater $(1992)$ is represented by the yellow vector $\left(\mathrm{PA}=12^{\circ}\right)$, the PA of the outflow observed in the $\mathrm{H} \alpha$ channel map with $\mathrm{v}=306 \mathrm{~km} \mathrm{~s}^{-1}$ (see Paper II), with $\mathrm{PA}=17^{\circ}$, is represented by the magenta vector and the outflows observed in $[\mathrm{O}$ III $] \lambda 5007$ with $\mathrm{v}=-889 \mathrm{~km} \mathrm{~s}^{-1}\left(\mathrm{PA} \sim-10^{\circ}\right)$ and with $\mathrm{v}=-710 \mathrm{~km} \mathrm{~s}^{-1}(\mathrm{PA} \sim$ $\left.55^{\circ}\right)$ are represented by the brown vectors. The purple vector with $\mathrm{PA}=255^{\circ}$ connects $[\mathrm{O} \mathrm{I}]_{C}$ to N2, but $[\mathrm{O} \mathrm{I}]_{C}$ and the centre of $\mathrm{N} 2$ are approximately at the same point, because of the low spatial resolution. [O $\mathrm{I}]_{C}$ position was taken as the centre of hard X-rays emission, represented by the white cross and its size is the $3 \sigma$ uncertainty. We also added the red contours that represent the ionization cone observed in the image of the $[\mathrm{O}$ III $] \lambda 5007$ line. 
shows only a central source and no relevant circumnuclear features. The radial profiles of the hard X-ray emission of those galaxies are clearly distinct (right-hand panel of Fig. 9.14). The FWHM of the hard X-ray emission of NGC 613 is $1.32 \operatorname{arcsec}(\sim 170 \mathrm{pc})$, while the FWHM of Mrk 202 is 0.99 arcsec; the difference is 0.33 arcsec.

There is also a clear extended emission with an elongated structure that is consistent with being an inclined disc, as seen in radio, [Fe II] $\lambda 16436, \operatorname{Br} \gamma$ and molecular lines (Fig. 9.14). The best estimates of the radius and inclination, assuming it is a circular disc, are consistent with the disc parameters seen in the NIR and radio (see table 9.4). This detection of the circumnuclear ring in hard X-rays has not been previously reported in the literature. One may wonder what the origin of such circumnuclear hard X-ray emission is. Our interpretation is that it is most likely originated from supernova remnants (SNRs) associated with the young stellar population. The presence of SNRs in the central region of NGC 613 has already been proposed by Böker et al. (2008) and Falcón-Barroso et al. (2014). See section 9.6 .2 for a detailed discussion.

Fig. 9.15 shows an image of the soft X-ray $(0.5-2 \mathrm{keV})$ emission (in blue) with the [O III] 25007 emission contours (in red). There is a good coincidence between the soft X-ray emission and the $[\mathrm{O}$ III $] \lambda 5007$ emission which is probably representing the ionization cone in the optical; this clearly shows that there is highly ionized gas in the ionization cone. The emission peak of the ionization cone is not coincident with the emission peak in soft and hard X-rays. On the other hand, there is an enhancement of soft X-ray emission towards the $\mathrm{PA}$ of the radio jet and the outflows seen in the $\mathrm{H} \alpha$ and $[\mathrm{O}$ III $] \lambda 5007$ channel maps (see Paper II). Besides that, one can see that there is also an extended emission towards the PA of the vector that connects N1 and N2.

\subsection{Discussion}

NGC 613 has a rich nuclear region. The presence of an AGN (Veron-Cetty e Veron, 1986), of a star-forming ring ( Hummel e Jorsater 1992, Böker et al. 2007, 2008, FalcónBarroso et al. 2008, 2014, Miyamoto et al. 2017, 2018), of a radio jet (Hummel et al. 1987, Hummel e Jorsater 1992, Miyamoto et al. 2017, 2018), of a nuclear spiral (Audibert et al., 2019), of an outflow (detected from the study of the [O III] $\lambda 5007$ emission by Hummel et al. 1987) and of shock waves (Davies et al., 2017) has already been reported in the literature, 
making this environment interesting to be studied and challenging to be understood.

In this section we are presenting all the hypotheses that can explain what we observed considering all the information that we gathered. Section 9.6.1 discusses mainly the coexistence of N1 and N2. In Section 9.6.2 we present all the hypotheses about the circumnuclear ring and molecular gas emission, taking into account previous studies. Finally, Section 9.6.3 summarizes the whole picture of the nuclear scenario that we believe to be observing, considering all the main structures observed in this work and also previous ones.

\subsubsection{The double stellar nucleus and the AGN}

The HST images of NGC 613 show two sources of stellar emission separated by a stream of dust. The projected distance between these two stellar nuclei is $94 \pm 5$ pc $(0.74 \pm 0.04$ arcsec), as seen in HST images. These two stellar sources could be seen in HST images shown in Falcón-Barroso et al. (2014), Combes et al. (2019) and Audibert et al. (2019), but were not discussed by those authors. When we observe the image of the GMOS data cube, we see that the most intense stellar emission is extended and its orientation is the same of the one between the double stellar source in the $H S T$ images $\left(\mathrm{PA}=255^{\circ} \pm 5^{\circ}\right)$, as shown in Fig. 9.5. We named this emission as regions N1 and N2. We also defined the peak of the $[\mathrm{O} \mathrm{I}] \lambda 6300$ emission as $[\mathrm{O} \mathrm{I}]_{C}$, which is an emission line typically associated with regions of partial ionization normally seen in AGNs.

When we compared the HST images from 2001 and 2018, we found that there is a source between N1 and N2 that suffered a variation in brightness (Fig. 9.9). We call this source, not previously reported in the literature, V1 (see Fig. 9.16).

The composition of the HST images and the $\mathrm{CO}(3-2)$ image from the ALMA data cube (Fig 9.17a) reveals that there is a nuclear spiral that passes between N1 and N2 and the centre of this nuclear spiral is this variable source (V1) that appears strongly in the F $814 W$ filter image from 2018. This nuclear spiral was first detected by Combes et al. (2019) and Audibert et al. (2019). V1 suffers obscuration by dust (as we can see in Fig. 9.1 and that is compatible also with previous studies that said that NGC 613 AGN is very obscured - see Castangia et al. 2013; Asmus et al. 2015) that can be a result of the nuclear spiral that seems to bring gas and dust to the centre.

Our analysis shows that $\mathrm{V} 1$ and $[\mathrm{O} \mathrm{I}]_{C}$ are separated by $0.24 \pm 0.04$ arcsec. The positions of these two sources are not quite compatible, even at the $3 \sigma$ level. One may 
wonder where the actual position of the AGN really is, in this case. If the emission of $[\mathrm{O}$ I] $\lambda 6300$ is extended, this shift can be explained by differential dust extinction. However, we also have to acknowledge that, if we think that the original emission of $[\mathrm{O} \mathrm{I}] \lambda 6300$ is coming from V1 (and here assuming that V1 is the AGN), we note that the displacement of such emission is towards the ionization cone. To explain such displacement we know that there is a zone of partial ionization in the walls of the cones where low ionization species are emitted (May e Steiner, 2017). In addition, some reflection of the nuclear source is also expected in the cones (Ricci et al., 2011). If differential extinction affects more one cone than the other, a small shift of the $[\mathrm{O} \mathrm{I}]_{C}$ is expected in the direction of the cone with less extinction. The source V1 may be equally reflected but its image was taken with the F $814 W H S T$ filter, suffering, thus, less extinction than [O I] $] 6300$. So, the main hypothesis here is that AGN is the central variable source (V1) and also the centre of the nuclear spiral. This scenario is in disagreement with Fig. 1 of Audibert et al. (2019), which suggests that the AGN is located at the position of N2.

Besides the variation of V1, another evidence for the AGN variability is the fact that the $D_{C O}$ map obtained by Falcón-Barroso et al. (2014) revealed almost no variations towards the nucleus, as expected in the case of obfuscation by a featureless continuum from an AGN (Burtscher et al., 2015). This is somewhat surprising as the $K$ band is less affected by interstellar extinction than the optical. When we look at the image of $F 814 \mathrm{~W}$ filter of HST observed in 2018 we see that there is a strong emission in V1 and the possible explanation, then, is that the AGN, in the epoch when the SINFONI data were observed (2005), was probably in a lower state of activity than in 2018.

N1 and N2 show emission-line ratios compatible with those of LINERs (Fig. 9.11). Davies et al. (2017) obtained optical emission-line ratios for the central region of NGC 613 , but using 3D spectroscopy data with a lower spatial resolution than that of the data used in this work. The values of the $[\mathrm{O}$ III $] \lambda 5007] / \mathrm{H} \beta$ ratio, which is used in this work as a measure of the ionization degree, in the spectra of N1 and N2 are compatible, at the $3 \sigma$ level, mainly due of the high uncertainty of this ratio in the spectrum of N2. Even so, we must consider the possibility that N2 may indeed have a higher ionization degree than N1.

By comparing the HST images with the GMOS data cube images (Fig. 9.8), we see a variable stellar source, not previously reported in the literature, very close to $[\mathrm{O} \mathrm{I}]_{C}$, inside the area corresponding to N1 (V2 in Fig. 9.16). The time interval of this variability was 
$14 \mathrm{yr}$ and it might be due to a supernova, since N1 is a stellar nucleus with the presence of young stellar populations (see Paper II).

As we see in Fig 9.14, the hard X-ray radial profile shows a width that is larger than the PSF of the instrument, represented here by the radial profile of Mrk 202, a type 1 AGN observed with the same instrument. Since there is no detectable second AGN, it is most likely that this additional emission might be associated with the radio jet in the inner region or that these photons are the result of scattering of the central AGN emission in the circumnuclear region.

The AGN ionization cone is well represented by the $[\mathrm{O}$ III $] \lambda 5007$ emission. Davies et al. (2017) and Gadotti et al. (2019) observed the ionization cone in NGC 613 using [O III] $\lambda 5007$ images. In our analysis, we detected an extended soft X-ray emission around the nucleus of NGC 613. Such an extended emission around AGNs has been reported in the literature in many previous works (e.g. Young et al. 2001, Hardcastle e Croston 2005,

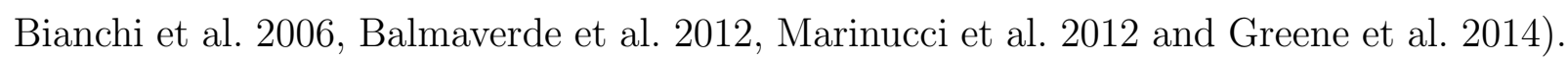
However, different physical mechanisms have been proposed for such emission, depending on the observed properties. In some objects, for example, a spatial correspondence between the extended soft X-ray emission and the [O III] $\lambda 5007$ emission was observed (e.g. Young et al. 2001, Bianchi et al. 2006, Wang et al. 2011 and Balmaverde et al. 2012). The most probable scenario for cases like these establishes that the extended X-ray emission comes from gas in the NLR photoionized by the central AGN. Other objects show a spatial correspondence between the extended X-ray emission and a radio jet or outflows from the AGN. In such cases, the most accepted scenarios involve inverse Compton scattering of radio photons by relativistic electrons in the jet (e.g. Hardcastle e Croston 2005) or shock heating due to the interaction between the jet (or outflow) and the interstellar medium (Evans et al. 2006 and Greene et al. 2014). In the case of NGC 613, Fig. 9.15 shows a significant spatial correspondence between the ionization cone, represented by the $[\mathrm{O}$ III] $\lambda 5007$ emission, and the extended soft X-ray emission. Such a result suggests, together with the presence of some emission lines ( $\mathrm{Ne} I \mathrm{X}, \mathrm{Ne} \mathrm{X} \mathrm{Ly} /$ and $\mathrm{Ne} \mathrm{X} \mathrm{Ly}_{\text {cont }}$ ), that there is a strong photoionization in the ionization cone. Considering the lower resolution of the $\mathrm{X}$-ray data, the emission peak in soft X-rays is coincident with the position of $[\mathrm{O} \mathrm{I}]_{C}$ and of the N1 and N2 centres, but we can also see a strong emission towards the jet and the outflows detected in $\mathrm{H} \alpha$ and [O III] $\lambda 5007$ (see Paper II for gas kinematics). 
Tabela 9.4 - Parameters of the circumnuclear ring calculated from the images of $\mathrm{Br} \gamma$ emission, $[\mathrm{Fe}$ II] $\lambda 16436$ and hard X-ray, assuming that the ring is circular.

\begin{tabular}{ccc}
\hline Wavelength & Inclination $(\mathrm{deg})$ & $\mathrm{R}(\mathrm{pc})$ \\
\hline $\operatorname{Br} \gamma$ & $55 \pm 5$ & $225 \pm 60$ \\
{$[\mathrm{Fe} \mathrm{II}] \lambda 16436$} & $61 \pm 5$ & $247 \pm 60$ \\
$\mathrm{H}_{2} \lambda 21218$ & $48 \pm 5$ & $223 \pm 50$ \\
Hard X-Ray & $62 \pm 9$ & $301 \pm 80$ \\
Radio (Hummel e Jorsater, 1992) & $55 \pm 5$ & $\sim 350$ \\
Radio (Audibert et al. 2019) & & $\sim 300$ \\
\hline
\end{tabular}

\subsubsection{Circumnuclear ring and nuclear spiral}

As described in section 9.2, NGC 613 has a well-known circumnuclear ring of star formation. It is clearly seen in the image of $\operatorname{Br} \gamma$ emission (presented in previous works and here in green in the composition of Fig. 9.10, indicating, in this case, the presence of young stars that ionize the gas of the star-forming regions. Böker et al. (2008) and Falcón-Barroso et al. (2014) identified seven H II regions along this circumnuclear ring. In this work, we could identify eight distinct $\mathrm{H}$ II regions (one $\mathrm{H}$ II region in addition to the other seven detected by Böker et al. 2008 and Falcón-Barroso et al. 2014). The ring observed in the [Fe II] $\lambda 16436$ image (see Figs. 2 from Falcón-Barroso et al. 2014 and 13 from Audibert et al. 2019) shows a higher granularity than in the $\mathrm{Br} \gamma$ image. Considering such granularity and also the fact that the [FeII] emission is usually associated with shock heating from SNRs, we conclude that there may be SNRs distributed along the ring. Böker et al. (2008) have already suggested the presence of SNRs along the cirumnuclear ring, based on the [FeII] emission from this area and Falcón-Barroso et al. (2014) verified that the $[\mathrm{FeII}] / \mathrm{Br} \gamma$ ratio from the nuclear spectrum of NGC 613 also suggests shock heating from SNRs. We emphasize however that the higher granularity of the circumnuclear ring in the $[\mathrm{Fe} \mathrm{II}] \lambda 16436$ image is an additional argument supporting the presence of SNRs. The fact that the ring was observed both in hard X-ray (see Fig. 9.14) and radio (Hummel e Jorsater, 1992) reinforces the idea of SNRs along this region. Assuming that the ring is circular, we determined the parameters in Table 9.4 and they are compatible with what was estimated by Hummel e Jorsater (1992). Besides that, the radius is also compatible with the determination from Audibert et al. (2019).

By calculating the emission-line ratios of the eight regions identified in the circumnu- 


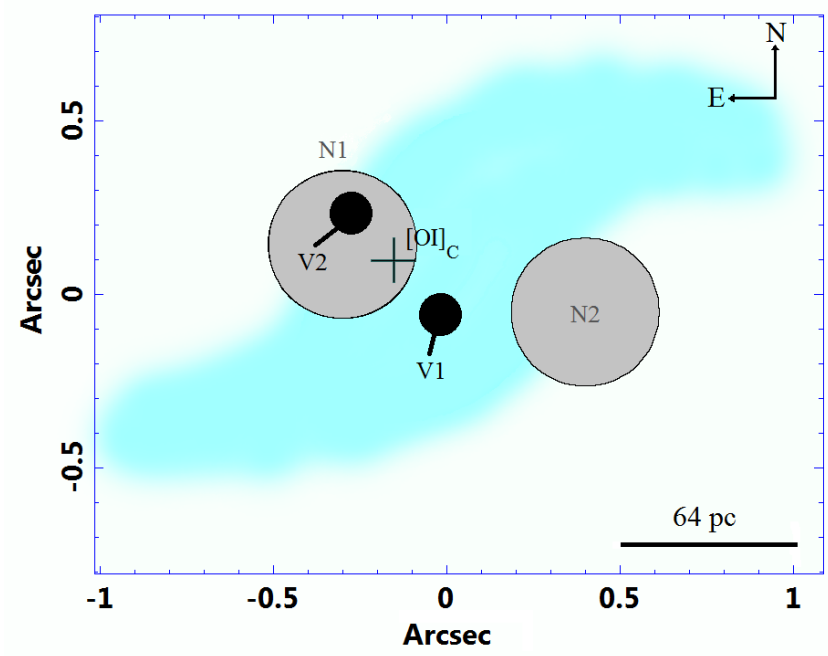

Figura 9.16: Scheme of the scenario proposed by this work in the central 2 arcsec. The spiral of molecular gas observed with ALMA is represented by the blue area. The double stellar nucleus is represented by the two grey circles, whose sizes are based on the emission area of $\mathrm{N} 2$ in the HST images. V1 and V2 are the two variable sources that were detected by comparing $H S T$ images of filter $F 814 \mathrm{~W}$ in different epochs and of filter $F 606 \mathrm{~W}$ with GMOS data, respectively. Their sizes represent the $3 \sigma$ uncertainty of the position considering the GMOS spaxel size in arcsec. $[\mathrm{O} \mathrm{I}]_{C}$ is the centre of the emission of $[\mathrm{O} \mathrm{I}] \lambda 6300$ represented by the black cross, whose size is the $3 \sigma$ uncertainty taking into account the spaxels of GMOS. The scale of $0.5 \operatorname{arcsec}(64 \mathrm{pc})$ is indicated in the figure.

clear ring, we verified that all ratios are compatible with the ones of $\mathrm{H}$ II regions, except regions 3 and 8, which have ratios compatible with the ones of LINERs (Fig. 9.11). That can be easily explained when we look at Fig. 9.10, which shows that those regions are inside or close to the contour that delineates the ionization cone. The gas of those regions might be ionized inside the ionization cone, generating those emission-line ratios. Another possibility is that the emission-line ratios in these two regions result from a contamination by the ionization cone emission. Region 8 that has the highest ionization degree might be also contaminated by the radio jet and outflows as we see in Fig. 9.15.

In order to study how the molecular emission is related to the whole scenario that we are analysing here, we used images from an ALMA data cube of $\mathrm{CO}(3-2)$ and the image of $\mathrm{H}_{2} \lambda 21218$ from SINFONI data cube (Fig. 9.7). The superposition criterion is described in Section 9.4.1. We see that neither $[\mathrm{O} \mathrm{I}]_{C}$ nor $\mathrm{N} 2$ are the centre of the nuclear spiral. And, by matching the circumnuclear ring, certainly, N2 is not the centre of the emission of $\mathrm{H}_{2} \lambda 21218$ and is not the centre of the nuclear spiral as it is represented in Fig. 1 of Audibert et al. (2019). What we see, as said previously, is V1 is the centre of the nuclear spiral. 

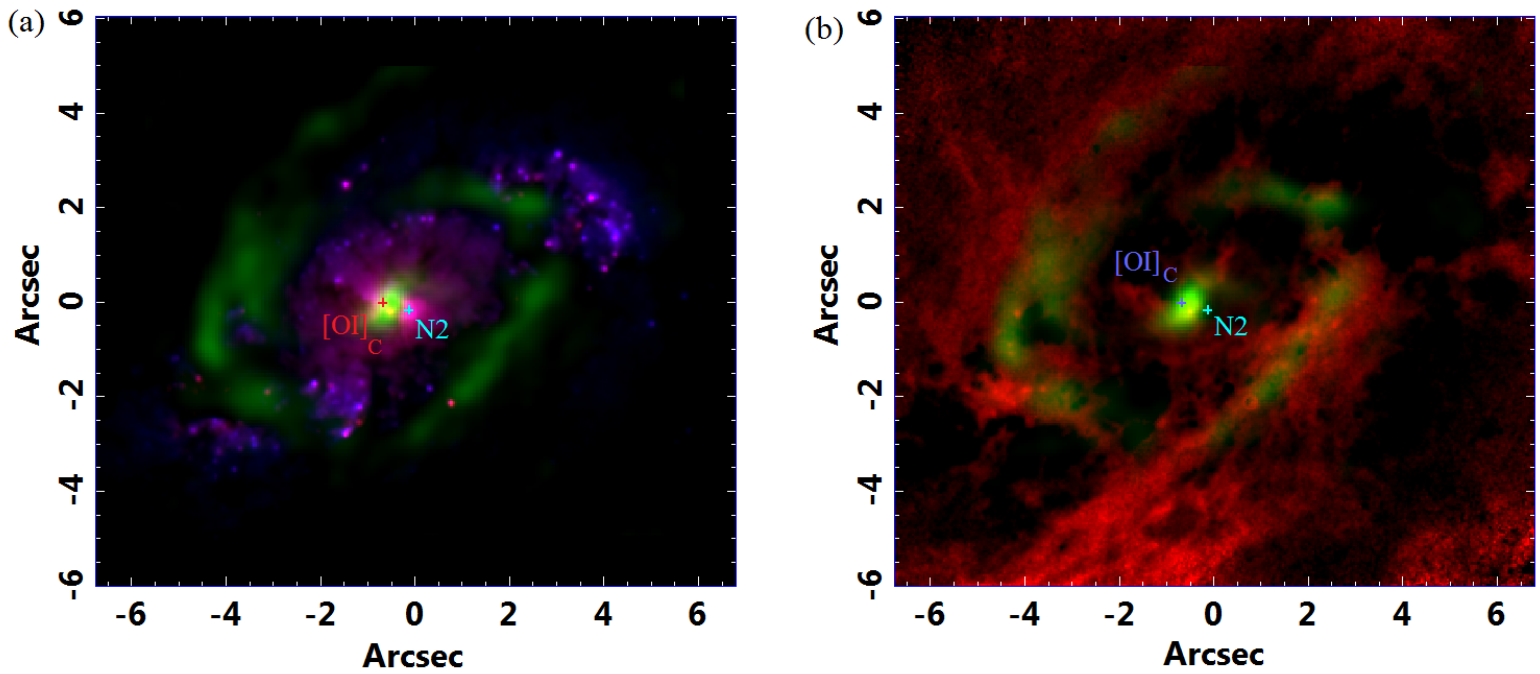

Figura 9.17: (a) RGB composition of the $H S T$ filters $F 814 W$ in red, $F 475 W$ in blue, and $\mathrm{CO}(3-2)$ from ALMA data cube in green. The red and cyan crosses represent the position of $[\mathrm{O} \mathrm{I}]_{C}$ and the centre of N2, respectively, and its size the uncertainty of $3 \sigma$, considering the size of the pixel of the HST images $(0.03962$ arcsec), since those positions were plotted taking the $H S T$ images as reference. (b) RB composition of $F$ $475 W-F 814 W(B-I$ in magnitude scale) in red and $\mathrm{CO}(3-2)$ from the ALMA data cube in green. The pink and white crosses represent the position of $[\mathrm{O} \mathrm{I}]_{C}$ and the centre of $\mathrm{N} 2$, respectively, and its size the uncertainty of $3 \sigma$, considering the size of the pixel of the HST images.

As noted by Audibert et al. (2019) the nuclear spiral flows from the ring towards the centre. The inner part of the spiral passes between N1 and N2, as we can see in Fig. 9.17(a) and in the proposed scheme in Fig. 9.16. When we compare this structure with the compositions of the HST filters in Figs. 9.1 and 9.5(d), we can see that there is a significant reddening and obscuration by dust between N1 and N2. This may indicate that the spiral is probably bringing dust and gas to the centre of the galaxy. Since the spiral is located between N1 and N2 and we cannot see a clear double structure in SINFONI data, together with the fact that we did not detect any difference in the stellar populations of N1 and N2 (Paper II), we may have only one source in the centre of NGC 613. In that case, the dust extinction caused by the nuclear spiral results in an apparent division of the central source in the components N1 and N2.

Fig. 9.17(b) shows, in red, areas affected by dust extinction. We clearly see a connection between these areas and the molecular ring. This reinforces the hypothesis of the feeding of the circumnuclear ring by the bar proposed by Böker et al. (2008) and Audibert et al. (2019). The morphology also suggests little connection between the feeding coming from the bar and the nuclear spiral. We observe the same feature in $\mathrm{H} \alpha$ image in Fig. 10 from 
Gadotti et al. (2019).

\subsubsection{The global scenario for the central region}

We drew a scheme to define the scenario in the central 2 arcsec, taking into account all the phenomena that we described in this paper (see Fig. 9.16). This scheme is what we defined here as being the scenario that explains the coexistence of the multiple structures studied in this work. The nuclear spiral (in blue) passes between N1 and N2 and may bring gas and dust from the circumnuclear region. Regions N1 and N2 are represented by the two grey circles, corresponding to the two components of the double stellar nucleus as appears in the HST images. Since they are separated by a stream of dust and the nuclear spiral, we are not entirely sure if they are separated regions. There are, therefore, two hypotheses to explain them: they are probably part of one central extended structure (as seen in Fig. 9.6) and the separation might be an obscuration effect caused by the dust. The second hypothesis assumes that they are two separated structures orbiting the central AGN in the plane of the observation, since we did not detect any difference of velocities in both regions (see Paper II). In Paper II we will resume this discussion.

V1 and V2, in Fig. 9.16, are the two variable sources. We believe that V1 is the AGN, since it is in the centre of the nuclear spiral and it is a very strong point-like source in the HST images. If this is correct, the AGN has variable activity that was also proposed by Audibert et al. (2019) when looking for possible fossil molecular outflows. N1 and N2 might be ionized by the central AGN. $[\mathrm{O} \mathrm{I}]_{C}$ is not compatible with the position of $\mathrm{V} 1$ and this is probably due to differential extinction together with emission and reflection of the [O I] $\lambda 6300$ emission in the ionization cone. The position of V2 suggests that it might be a supernova, since it is inside a cluster of young stellar populations (that is N1, see Paper II).

\subsection{Conclusions}

Multiwavelength analysis has shown that the galaxy NGC 613 has a rich nuclear environment. The study of data cubes from telescopes in the NIR, optical, X-ray, and radio bands, besides HST images, led us to the following findings:

- In the optical band, the central region of NGC 613 is characterized by an apparent 
double stellar nucleus. We called the two stellar nuclei as N1 and N2. The least brightest nucleus, as seen in the HST images, coincides, within the errors, with the emission of [O I] $\lambda 6300$, whose centre was defined as $[\mathrm{O} \mathrm{I}]_{C}$ in this work. The brightest nucleus as seen in the HST image was defined as N2. The separation between the two stellar components, as seen in the HST images, is $\sim 94 \mathrm{pc}(\sim 0.74$ arcsec $)$.

- The spectrum extracted from N1 has emission-lines ratios compatible with the ones of LINERs, presenting fairly broad forbidden lines (FWHM $\sim 665 \mathrm{~km} \mathrm{~s}^{-1}$ ). On the other hand, the spectrum from N2 has also emission-line ratios of LINERs, but with slightly higher ionization degree than N1.

- By comparing the images in the filter F $814 W$ from the HST observed in 2001 and in 2018, we detected evidence of variability in a point between N1 and N2, whose distance from $[\mathrm{O} \mathrm{I}]_{C}$ is 0.24 arcsec. In 2001 this source was not detected and in 2018 it was clearly visible. The position of $[\mathrm{O} \mathrm{I}]_{C}$ and of this variable source are not compatible, but they are very close to each other. Since this variable source is point-like in the HST images and is the centre of all nuclear structure, it might be the central variable AGN. Therefore, the shift between the centre of the $[\mathrm{O}$ I] $\lambda 6300$ emission (typically associated with partial ionization regions in $\mathrm{AGNs}$ ), $[\mathrm{O} \mathrm{I}]_{C}$, and this variable central source (the AGN in this case) might be due to scattering of the AGN emission and emission of the ionization cone, since the shift is towards the ionization cone.

- When we compare the optical data from HST and GMOS, observed in 2001 and 2015, respectively, we verify that N1 also suffered a variability in brightness. In 2001 this source was fainter than in 2015. Considering the time interval and also that N1 has young stellar populations, this might be an evidence of a supernova.

- We found extended soft X-ray emission, closely associated with the ionization cone, seen in $[\mathrm{O}$ III $] \lambda 5007$. There is also an excess of this emission towards the radio jet and gas outflows, which might be disturbing the circumnuclear ring.

- The hard X-ray emission, besides having a strong central component, also presents a circumnuclear structure in the form of a ring that has geometric parameters similar to those seen in $\mathrm{Br} \gamma$, [Fe II $] \lambda 16436$, and $\mathrm{H}_{2} \lambda 21218$ and radio images. This is likely originated from SNRs associated with star formation in the ring. The high granularity of the $[\mathrm{Fe}$ II] $\lambda 16436$ image, when compared with the $\operatorname{Br} \gamma$ image, reinforces this hypothesis.

- The profile of the central hard X-ray emission is slightly broader than the PSF by 
0.33 arcsec. We interpret this as possibly due to circumnuclear scattering.

- From the optical (SIFS) and NIR (SINFONI) data we identified 10 H II regions. Eight of them are part of the circumnuclear ring (already observed in other works), while the other two are further away.

- There are at least three H II regions in the circumnuclear ring whose emission-line ratios are affected by emission from the ionization cone or partially ionized by the central source. As a consequence, they present spectra that resemble the ones of LINERs.

- We confirm, by analysing the HST data together with the $\mathrm{CO}(3-2)$ image from ALMA, that the molecular gas ring is being fed by the bar along two arms. The nuclear spiral, which passes between N1 and N2, might be bringing dust and gas to the centre, causing the obscuration. Also it might be dividing an extended central stellar structure in two, that is the double stellar nucleus that we see in the optical band, due to dust obscuration.

\section{Appendix}

\subsection{Spectra of the observed regions and emission-line decompositions}

As explained in section 9.4.3, we extracted a spectrum of each identified region in Fig. 9.10. The extraction was performed using circular areas, whose diameter was taken as the FWHM of each instrument: for regions 1 to 10, we used the SIFS data cube and, for N1 and N2 regions, we used the GMOS data cube. Figs. 9.18, 9.20 and 9.21 show the blue and red parts of the extracted spectra of each region.

One can notice that the spectra from regions $\mathrm{N} 1, \mathrm{~N} 2,2,3,7$, and 8 have blended emission lines. In order to calculate the emission-line ratios of each region, it was necessary to decompose the blended lines in two Gaussian sets. First, we determined an uncertainty to the flux associated with each wavelength of the spectrum. For this, we calculated the standard deviation of the values in a specific wavelength range, without any emission line, of the extracted spectra. These values of standard deviation were taken as the uncertainty of the fluxes in the average wavelengths of the ranges used in this estimate. Then, we made an interpolation of the values, in order to obtain a value of uncertainty to each wavelength of the spectrum. 
The first Gaussian fit involved the lines $[\mathrm{S}$ II $] \lambda \lambda 6716 ; 6731$. Each line was fitted by a sum of two Gaussian functions: the green Gaussians set and the blue Gaussians set in Figs. 9.19 and 9.22 . For each set, we adopted a specific width and velocity (free parameters of the fits). In other words, each line of [S II] was fitted by a sum of two Gaussians functions (green+blue), each one with a specific width and velocity.

It is important to mention that the maximum and minimum values admitted for the ratio of the integrated fluxes of the $[\mathrm{S}$ II $] \lambda 6716$ and $[\mathrm{S} \mathrm{II}] \lambda 6731$ Gaussians, in each one of the two sets, was 1.44 and 0.44, respectively, as theoretically established by Osterbrock e Ferland (2006).

After that, we fitted the lines [N II] $\lambda \lambda$ 6548, 6584 $+\mathrm{H} \alpha$ as a sum of two Gaussians for each line, which resulted in a set of three green Gaussians and a set of three blue Gaussians in Figs. 9.19 and 9.22 . We assumed that, in each set, the Gaussians have the same width and redshifts as the corresponding Gaussians of the $[\mathrm{S} \mathrm{II}] \lambda \lambda 6716 ; 6731$ emission lines. In other words, the $[\mathrm{S}$ II $] \lambda \lambda 6716 ; 6731$ lines were taken as an empiric template to these fits.

We determined, then, for each spectrum, the value of the $\mathrm{H} \alpha / \mathrm{H} \beta$ ratio (Balmer decrement). By using this ratio and also the extinction law determined by Cardelli et al. (1989), we applied the interstellar extinction correction to each spectra. Then, we calculated the integrated fluxes of the $\mathrm{H} \beta,[\mathrm{O}$ III $] \lambda 5007,[\mathrm{O}$ I $] \lambda 6300,[\mathrm{~N}$ II] $] \lambda \lambda 6548 ; 6584, \mathrm{H} \alpha$ e $[\mathrm{S}$ II] $\lambda \lambda 6716 ; 6731$ lines of the corrected spectra, after applying the previous process of decomposition when it was necessary. The integrated fluxes of the non-blended lines were calculated by a direct integration. From these values we calculated the emission-line ratios as shown in section 9.4 .3 .

The uncertainty of the integrated flux of each blended line was obtained from the propagation of the uncertainties determined for the parameters of the Gaussian fits. On the other hand, the uncertainty of the integrated flux of each non-blended line was taken considering the different ranges of integration. This procedure was adopted since such uncertainties take into account not only the spectral noise but also possible irregularities in the spectrum caused by inaccuracies in the process of stellar continuum subtraction. 

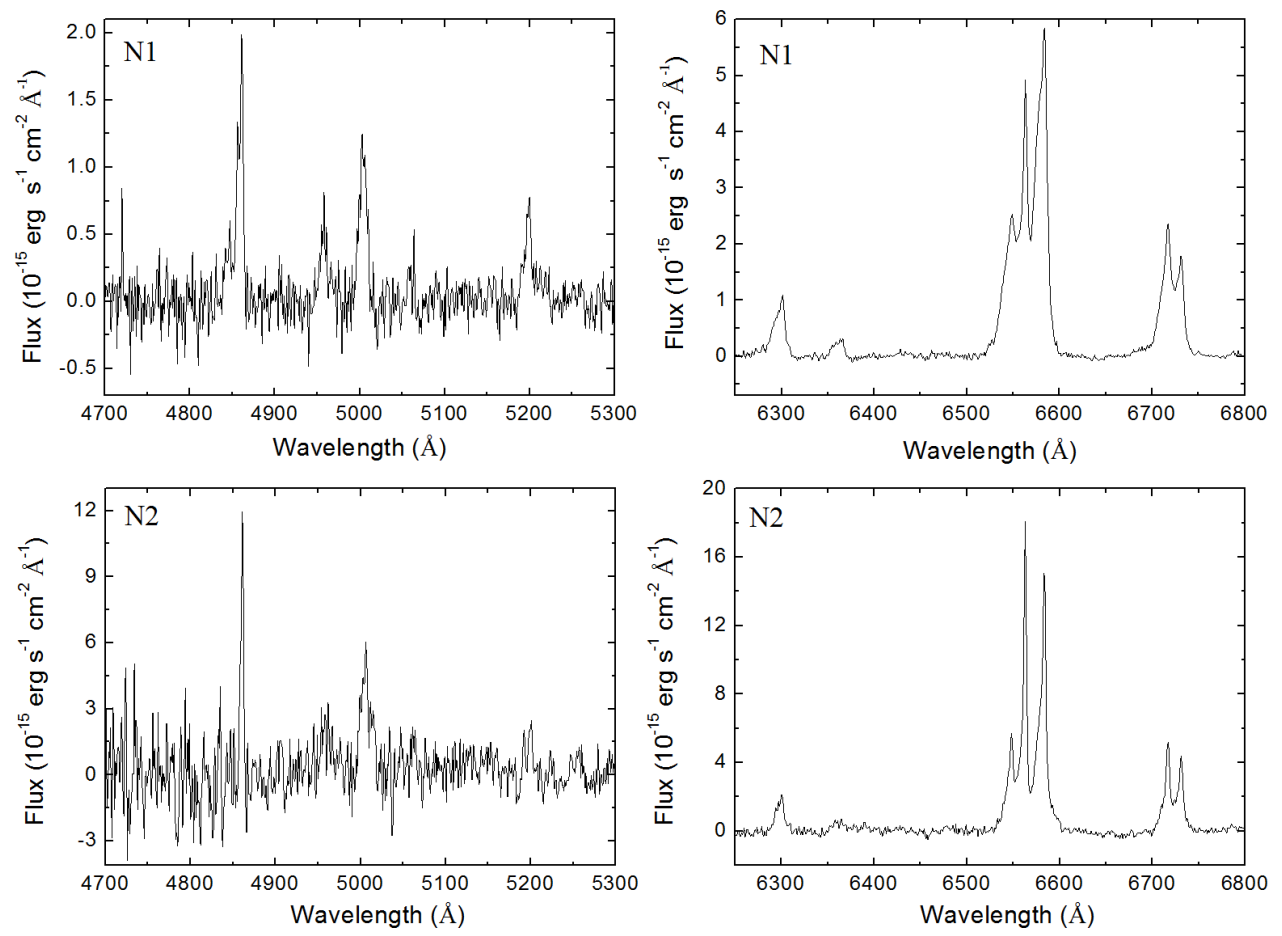

Figura 9.18: Blue and red intervals of the spectra of regions N1 and N2 extracted from the GMOS data cube.
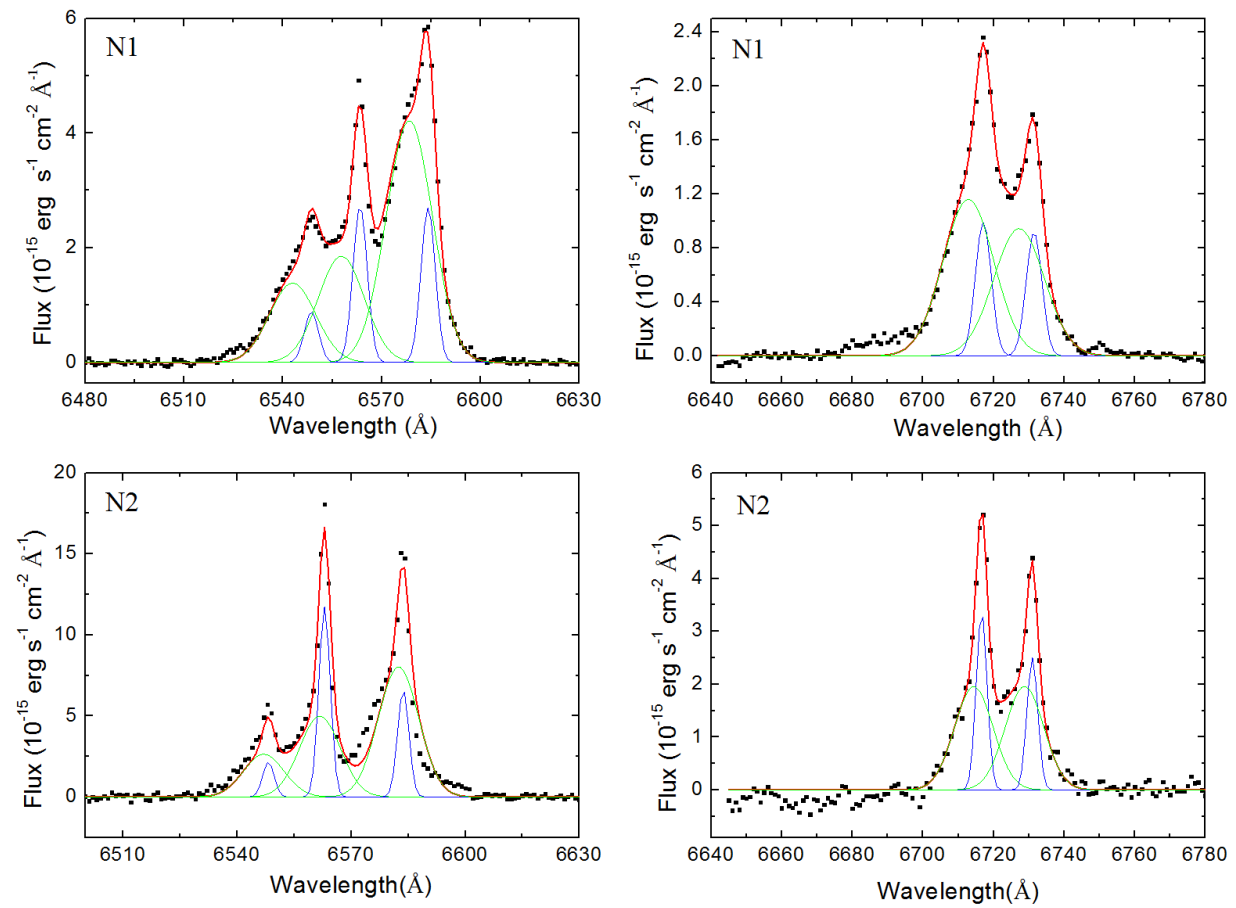

Figura 9.19: Decomposition of the blended $\mathrm{H} \alpha+[\mathrm{N}$ II $] \lambda \lambda 6548,6584$ and $[\mathrm{S} \mathrm{II}] \lambda \lambda 6716,6731$ lines in order to calculate the emission-line ratios of regions N1 and N2 (indicated in each panel) of the GMOS data cube. The blue and green Gaussians are the narrow components of the fitted lines, the red curve represents the total fit and the points are the observed data. 

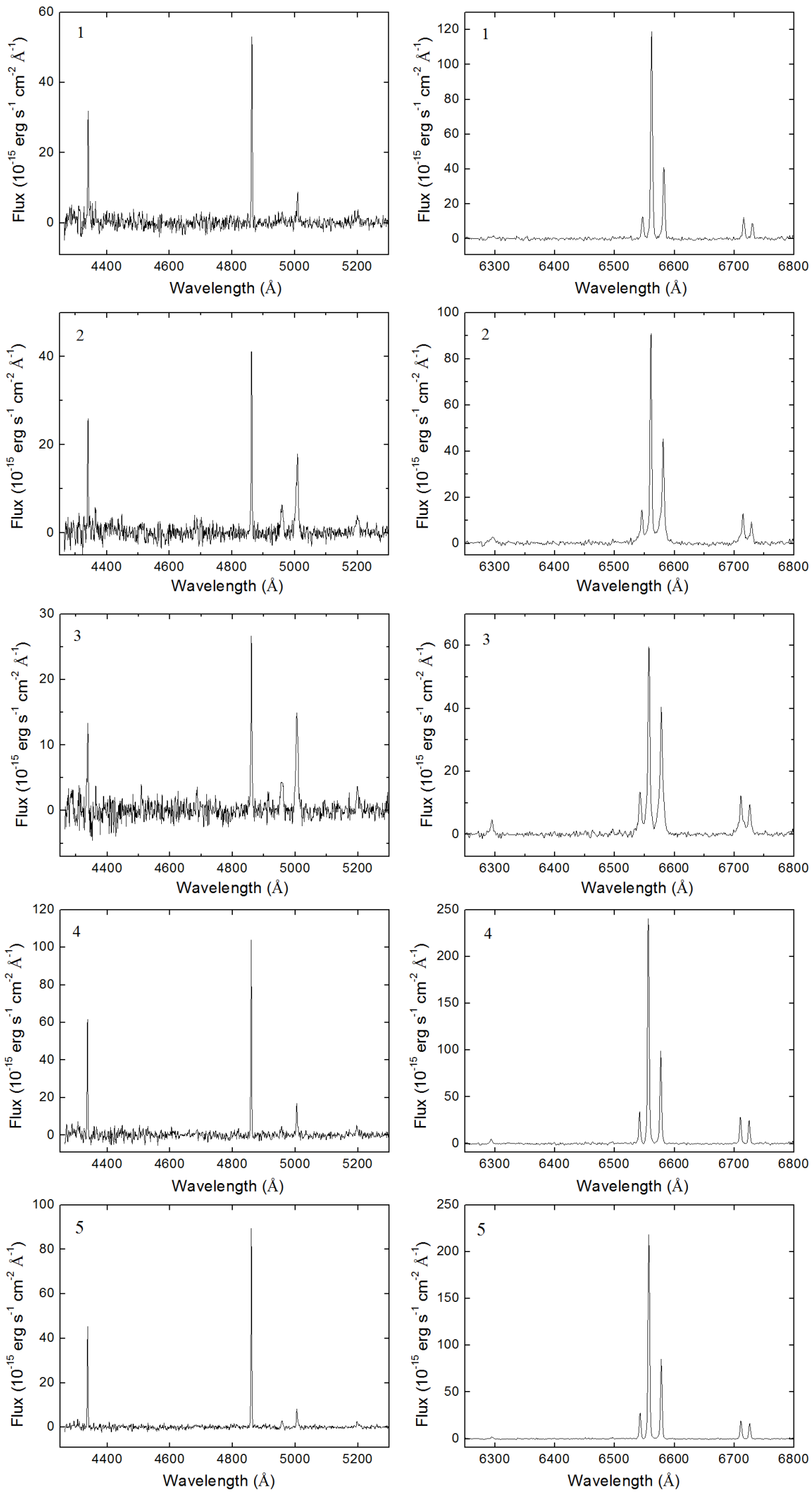

Figura 9.20: Blue and red intervals of the spectra of regions 1, 2, 3, 4, and 5 extracted from the SIFS data cube. 

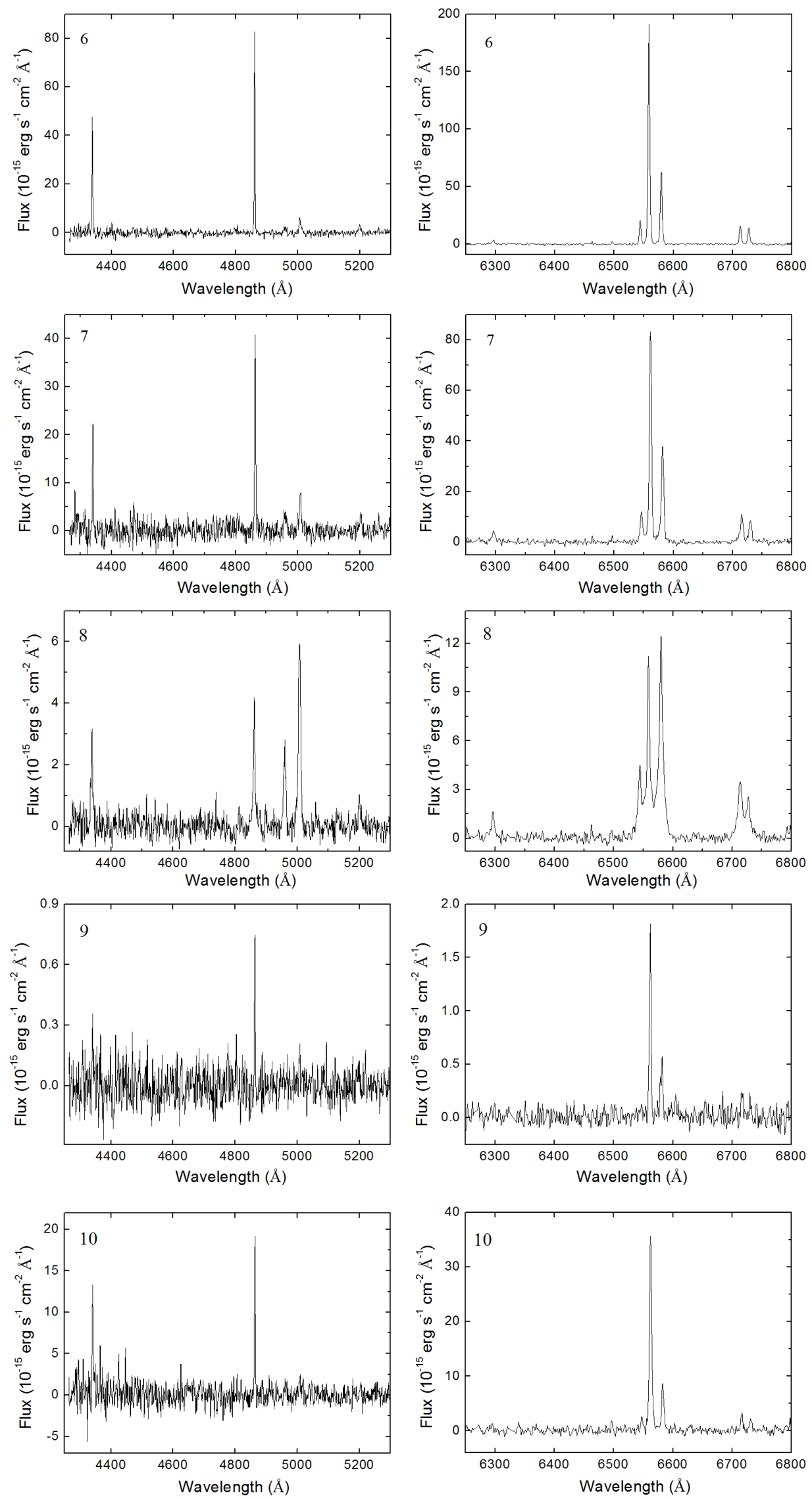

Figura 9.21: Blue and red intervals of the spectra of regions 6, 7, 8, 9, and 10 extracted from the SIFS data cube. 

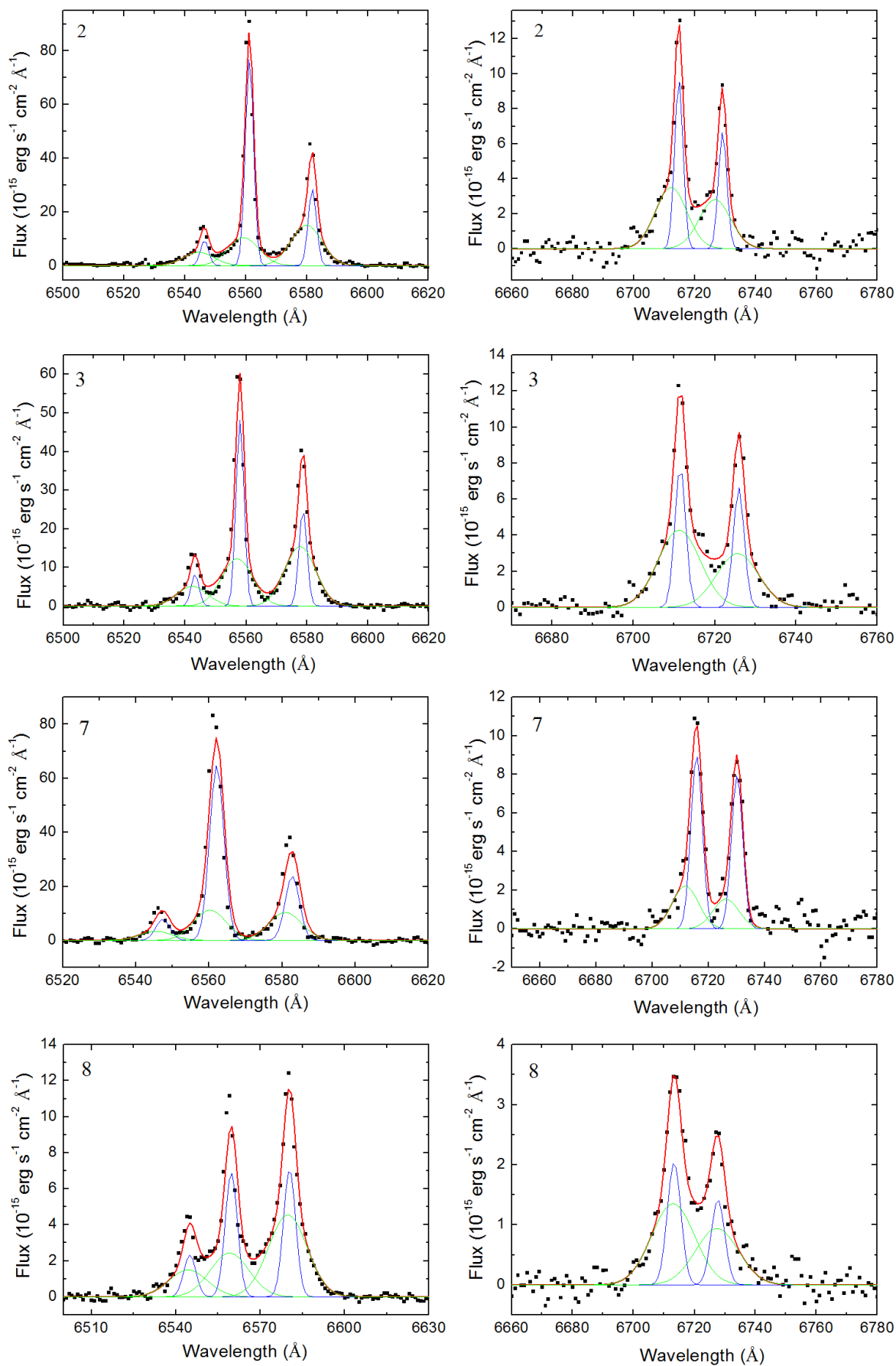

Figura 9.22: Decomposition of the blended $\mathrm{H} \alpha+[\mathrm{N} \mathrm{II}] \lambda \lambda 6548,6584$ and $[\mathrm{S}$ II $] \lambda \lambda 6716,6731$ lines, in order to calculate the emission-line ratios of regions $2,3,7$, and 8 (indicated in each panel) of the GMOS data cube. The blue and green Gaussian fits are the narrow components of the fitted lines, the red curve represents the total fit and the points are the observed data. 
Capítulo 10

\title{
The nuclear region of NGC 613. II - Kinematics and stellar archaeology
}

\author{
Patrícia da Silva, R. B. Menezes, J. E. Steiner \\ 2020, MNRAS, 496, 943
}

\subsection{Abstract}

In this work we continue the study of the central region of NGC 613 (Paper I), by analysing the stellar and gas kinematics and the stellar archaeology in optical and nearinfrared data cubes. The high spatial resolution of the Gemini Multi-Object Spectrograph (GMOS) data cube allowed the detection, using spectral synthesis methods, of an inner circumnuclear ring, with a radius of $\sim 1$ arcsec, composed by $\sim 10^{9}$ yr stellar populations. Such a ring is located between the nucleus and the circumnuclear ring composed by H II regions detected in previous works. Besides that, there is a stellar rotation around the nucleus and the rings follow the same direction of rotation with different velocities. The intensity weighted average stellar velocity dispersion at the centre is $92 \pm 3 \mathrm{~km} \mathrm{~s}^{-1}$. Three distinct gas outflow components were detected. The direction of the outflow observed with the $\mathrm{H} \alpha$ emission line is compatible with the direction of the previously observed radio jet. The direction of one of the outflows detected in the $[\mathrm{O}$ III $] \lambda 5007$ emission coincides with the axis of the ionization cone. There is no difference regarding the stellar populations and the stellar kinematics along the double stellar emission, probably separated by a dust lane as mentioned in Paper I, confirming that they are part of the same structure. 


\subsection{Introduction}

Active galactic nuclei (AGNs) interact with the host galaxy through processes of feeding and feedback (Storchi-Bergmann e Schnorr-Müller, 2019). The study of the gas dynamics determines the proportion of such processes in the galaxy nucleus. In addition, the stellar dynamics determines how the galaxy behaves with the presence of such objects. Together with the stellar archaeology, it is possible to infer evolutionary aspects of the host galaxies from the co-evolution of their nuclei and their circumnuclear regions (Kormendy e Ho, 2013).

This work is a continuation of da Silva et al. (2020), from now on called Paper I, and is focused on the study of the stellar and gas kinematics and of the stellar archaeology of the central region of NGC 613, with the aim of determining a dynamic and evolutionary scenario to this galaxy nucleus.

NGC 613 is an SB(rs)bc galaxy, located at $26 \pm 5 \mathrm{Mpc}$ (Nasonova et al., 2011). One of its most outstanding morphological features is the bar, whose size is 139 arcsec $(\sim$ $17 \mathrm{kpc}$ ) (Kormendy, 1979). The bar interacts with the nuclear region bringing gas from the outer regions to the centre through a nuclear spiral Audibert et al. 2019; da Silva et al. 2020), interfering in the star formation, which seems to take place in bursts and not in a continuous form (Alloin e Kunth, 1979).

As discussed in Paper I and by Audibert et al. (2019), the AGN of NGC 613 has emission-line ratios compatible with the ones of LINERs and previous works indicate that it is considerably obscured (Castangia et al., 2013; Asmus et al., 2015). The bolometric luminosity of the AGN estimated by Davies et al. (2017) is $1.6 \times 10^{42} \mathrm{erg} \mathrm{s}^{-1}$.

As mentioned in Paper I and in previous works (Hummel e Jorsater 1992; Böker et al. 2007, 2008 Falcón-Barroso et al. 2008, 2014 da Silva et al. 2020) NGC 613 has a star forming ring that contains eight $\mathrm{H}$ II regions. There is no consensus on how those regions were formed. Falcón-Barroso et al. (2008) and Böker et al. 2008 suggest two scenarios: the "popcorn" and "pearls on string" models. In the first one the H II regions were formed randomly or at the same time. In the second scenario, the star forming clouds were created from two primordial clouds (in two distinct points on the ring) that bring gas and dust to the ring; the clouds closer to those feeding regions are younger than the ones far from them, due to the ring rotation. According to those authors, the difference between the 
He I, Br $\gamma$ and [Fe II] $\lambda 16436$ emission supports this last scenario. On the other hand, Mazzuca et al. (2008) did not find any age gradient between the $\mathrm{H}$ II regions, whose stars are older than 10 Myrs, and they affirm that those regions where formed by gravitation instabilities in the Lindblad resonance region. The star forming rate seems to be higher at the East portion of the ring Miyamoto et al. (2017).

Regarding the gas kinematics, optical observations and images of the $[\mathrm{O}$ III $] \lambda 5007$ emission line show that there is a high velocity outflow, co-spatial with the radio jet (Hummel et al. 1987). This outflow seems to disturb the ring structure (Böker et al. 2008 and Falcón-Barroso et al. 2014). Miyamoto et al. (2018) also identified an outflow of molecular gas in the inner 100 pc. The authors claim that this outflow can be quenching the star formation in this region.

Besides that, the molecular gas kinematics, observed with the Atacama Large Millimeter/Submillimeter Array (ALMA), indicates a rotation of gas in the ring. The portion of the ring at west presents redshifted emission and the east portion, blueshifted Miyamoto et al. 2017, 2018, Combes et al. 2019 and Audibert et al. 2019). Such a kinematic behaviour is compatible with the one observed from the images of $\mathrm{Br} \gamma$ by Böker et al. (2008). An outflow was also detected in the $\mathrm{CO}(3-2)$ emission (Audibert et al. 2019), aligned with the radio jet observed by Hummel e Jorsater (1992). A nuclear spiral of molecular gas was observed and seems to be feeding the nucleus, bringing gas and dust from the bar to the centre (Audibert et al. 2019; da Silva et al. 2020).

With infrared integral field unit (IFU) data Batcheldor et al. (2005) determined two values of the stellar velocity dispersion, one using cross correlation method: $\sigma=99 \pm 2 \mathrm{~km} \mathrm{~s}^{-1}$, and the other using maximum penalized likelihood method: $\sigma=149_{-22}^{+19} \mathrm{~km} \mathrm{~s}^{-1}$. These values are compatible with $\sigma=126 \pm 19 \mathrm{~km} \mathrm{~s}^{-1}$ (Schechter, 1983), obtained using the Fourier quotient technique (Sargent et al., 1977).

In this work, as in Paper I, the analysis of the central region of NGC 613 was done using data cubes observed with the IFU from the Gemini Multi-Object Spectrograph (GMOS) at the Gemini-South telescope, with the SOAR Integral Field Spectrograph (SIFS) at the SOAR telescope and the public archive data obtained with the Spectrograph for Integral Field Observations in the Near Infrared (SINFONI) at the Very Large Telescope (VLT).

In section 10.3 we briefly describe the observations and processes of reduction and data treatment. In section 10.4 we present the analysis regarding the gas kinematics. In section 
10.5 we show the results obtained from the stellar archaeology. Section 10.6 presents the stellar kinematics analysis. Sections 10.7 and 10.8 presents the discussion of the results and their main conclusions, respectively. In appendix 10.9 we present the results of the stellar archaeology applied to the whole SIFS data cube.

\subsection{Observations and data reduction}

Paper I describes all the details of the data and their treatment processes (see section 2 from Paper I). All data cubes were treated with the same methodologies developed by our group (see Menezes et al. 2014, 2015, 2019 for more details).

The reduction process of the GMOS data was performed in IRAF environment and of the SIFS data with scripts developed in Interactive Data Language (IDL). The SINFONI data were reduced using the GASGANO software.

After the data reduction and data cubes creation, those were treated using scripts also written in IDL. The atmospheric differential refraction correction was applied (except to the SIFS data cube, that already had this correction in its hardware) and the data cubes were combined in one, in the form of a median. The SINFONI and SIFS data cubes were re-sampled. The sizes of the spatial pixels (spaxels) of the SINFONI and SIFS data cubes, at the end of the treatment procedure, were 0.625 arcsec and 0.1 arcsec, respectively. The GMOS data cube remained with the same spaxel size of 0.05 arcsec.

The Butterworth spatial filtering was applied (Gonzalez e Woods, 2002) to all data cubes. After that, the fingerprint removal method was performed and, at the end, we also applied the Richardson-Lucy deconvolution (Richardson, 1972; Lucy, 1974). This last one was performed with the aim of obtaining a better spatial resolution without interfering in the data signal (for more details of the data treatment procedure, see Menezes et al. 2014, 2015, 2019). Paper I presents the parameters that we used in this last process. As a result, the GMOS data cube has a full width at half-maximum (FWHM) of the point spread function (PSF) equal to 0.68 arcsec, after 10 iterations. The SINFONI data cube, with the same number of iterations, has as FWHM of the PSF equal to 0.60 arcsec. Lastly, the SIFS data cube has the FWHM of the PSF equals to 1.6 arcsec, using 6 iterations.

After the data treatment, the spectra of the GMOS, SIFS and SINFONI data cubes were all passed to the rest frame, using a redshift value of 0.00494 derived from Koribalski 
et al. (2004).

As in Paper I, we also studied, in this present paper, the ALMA data cube observed in the $\mathrm{CO}(3-2)$ line. These data were obtained from the ALMA public archive under program 2015.1.00404.S (PI: Combes, F.). It was not necessary to apply any treatment to the data since it has already good spatial resolution and high quality. The size of the spaxels of this data cube is 0.07 arcsec.

\subsubsection{Spectral synthesis methods}

In order to study the gas emission from the data cubes and also to analyse the stellar archaeology, spectral synthesis was applied, using the STARLIGHT software (Cid Fernandes et al. 2005), with a base created from the Medium-resolution Isaac Newton Telescope Library of Empirical Spectra (MILES, Sánchez-Blázquez et al. 2006) in the optical wavelengths (GMOS and SIFS data cubes). The spectral synthesis is applied to each spectrum of the data cube, and is performed by a linear combination of the base spectra, in order to fit the observed spectra. With that, it is possible to create flux maps of the detected stellar populations, to obtain histograms of the flux fractions of those stellar populations in a determined region of the FOV of the data cube (which may be the whole FOV or a specific area) and to remove the stellar continuum of the data cube to study the gas emission (as done in Paper I). This last process corresponds to creating a synthetic stellar data cube, using the synthetic spectra obtained from the spectral synthesis, and then by subtracting this data cube from the original one. We obtain a cube with mainly gas emission that we call gas data cube. In this work, the gas data cube was used to study the gas kinematics.

The Penalized Pixel Fitting method (pPXF, Cappellari e Emsellem 2004) was used in the SINFONI data cube. This method consists of a spectral synthesis with the base spectra convolved with Gauss-Hermite functions. The base used covers only the K-band (Winge et al. 2009). In this case the pPXF was used to obtain a K-band gas data cube, to study the stellar kinematics in the optical (SIFS and GMOS data cubes) and in the determination of the stellar velocity dispersion with the SINFONI data cube. For more details see section 10.6 .

In section 10.5 we present the results of the stellar archaeology obtained from the spectral synthesis applied to the extracted spectra from different regions of the data cubes (GMOS and SIFS). We characterized the detected stellar populations by obtaining his- 
tograms showing the flux fractions associated with each stellar population. In order to estimate the uncertainty of this process, first of all, we determined the medians of the ages of the detected stellar populations in all these regions of the data cubes. Such medians were calculated using graphs of the accumulated flux fractions as a function of the ages of the stellar populations and taking the ages at which the accumulated flux fractions were equal to $50 \%$. The uncertainties of these medians were obtained with the following Monte Carlo procedure: first we constructed, for each extracted spectrum, a histogram representing the spectral noise and fitted a Gaussian function to this histogram. After that, we obtained Gaussian distributions of random noise with the same width of the Gaussian fitted to the initial histogram. Such noise distributions were added to the synthetic stellar spectrum provided by the spectral synthesis of the original spectrum. Finally, we applied the spectral synthesis to all the obtained "noisy" spectra and calculated the median of the ages of the detected stellar populations. The uncertainty of the median of the ages was taken as the standard deviation of all the median values obtained with this process. The representative uncertainty of the process was taken as the highest value of the uncertainties determined for the median ages. The result obtained is 0.02 dex.

When we take the results from the spectral synthesis it is important to notice that there are degeneracies in the method. Different linear combinations of the base spectra could result in the same continuum. However, in many cases, it is possible to notice the consistence of the spectral synthesis, since it can differentiate spectra with deeper stellar absorptions (associated with old stellar populations) from spectra with flatter stellar absorptions (associated with younger stellar populations) with good precision. It is not possible to determine an uncertainty to those degeneracies, and we are in need of more precise stellar bases and methods to perform this analysis.

\subsection{Gas kinematics}

\subsubsection{General scenario}

In Paper I we came out with a general scenario to the main structures of the NGC 613 nucleus in terms of gas emission. There is an optical double emission, separated by a stream of dust, that we called N1 and N2. We believe that the AGN, identified as a variable point-like source (V1), is located between N1 and N2. The eight HII regions in 
the circumnuclear ring orbit around this nuclear structure (composed by N1, N2 and V1). As we will see in this work, N1 and N2 are part of the same structure, as we stated in Paper I. The stream of dust that divides this structure is probably associated with the nuclear spiral that is also located between N1 and N2.

The centroid of the $[\mathrm{O} \mathrm{I}] \lambda 6300$ emission, $[\mathrm{O} \mathrm{I}]_{C}$, which is a line typical of regions of partial ionization, is not located at the position of V1 (the AGN). The projected distance between $\mathrm{V} 1$ and $[\mathrm{O} \mathrm{I}]_{C}$ is $\sim 0.24$ arcsec. This difference may be due to the ionization cone being partially obscured by dust near the AGN. In Paper I, $[\mathrm{O} \mathrm{I}]_{C}$ was a reference point to the images superpositions, to compare directly the data from different instruments, since it was the most point-like source in the GMOS data cube (see section 3 of Paper I, for more details). In the images of the present work, we indicate the position of $[\mathrm{O} \mathrm{I}]_{C}$ and V1.

In this section we will study the gas dynamics to determine, with better precision, how the structures behave in the nuclear environment of NGC 613. The study is made according to the FOV of each instrument. Since GMOS has the inner central FOV, we are able to study the inner central gas kinematics. In the cases of the SIFS and SINFONI FOVs, we have, besides the central, the circumnuclear gas kinematics in greater detail.

\subsubsection{Inner central optical gas kinematics (GMOS)}

The GMOS data cube has a FOV that shows the regions that are internal to the circumnuclear ring. Channel maps of emission lines are a good tool to visualise in greater detail the gas kinematics. Fig. 10.1 shows the channel maps of $\mathrm{H} \alpha$ emission line. As presented in Appendix A of Paper I, the spectra of the central region of NGC 613 have blended lines, so we have to consider that the first and last channels might be contaminated by the $[\mathrm{N}$ II $] \lambda 6748$ and $[\mathrm{N}$ II $] \lambda 6784$ emission lines, respectively. Between the second and eighth channel maps, we see that there is a gas rotation of the regions at the edges of the FOV, which are the $\mathrm{H}$ II regions of the circumnuclear ring. We also notice a central emission with a defined orientation between the eighth and tenth channel. This emission is in redshift and probably represents an outflow of gas that comes from V1. In order to represent this outflow, we took the channel with $\mathrm{v}=306 \mathrm{~km} \mathrm{~s}^{-1}$ and the PA of this emission is $\sim 17^{\circ}$.

The channel maps of the $[\mathrm{O}$ III $] \lambda 5007$ emission line of the GMOS data cube are very 


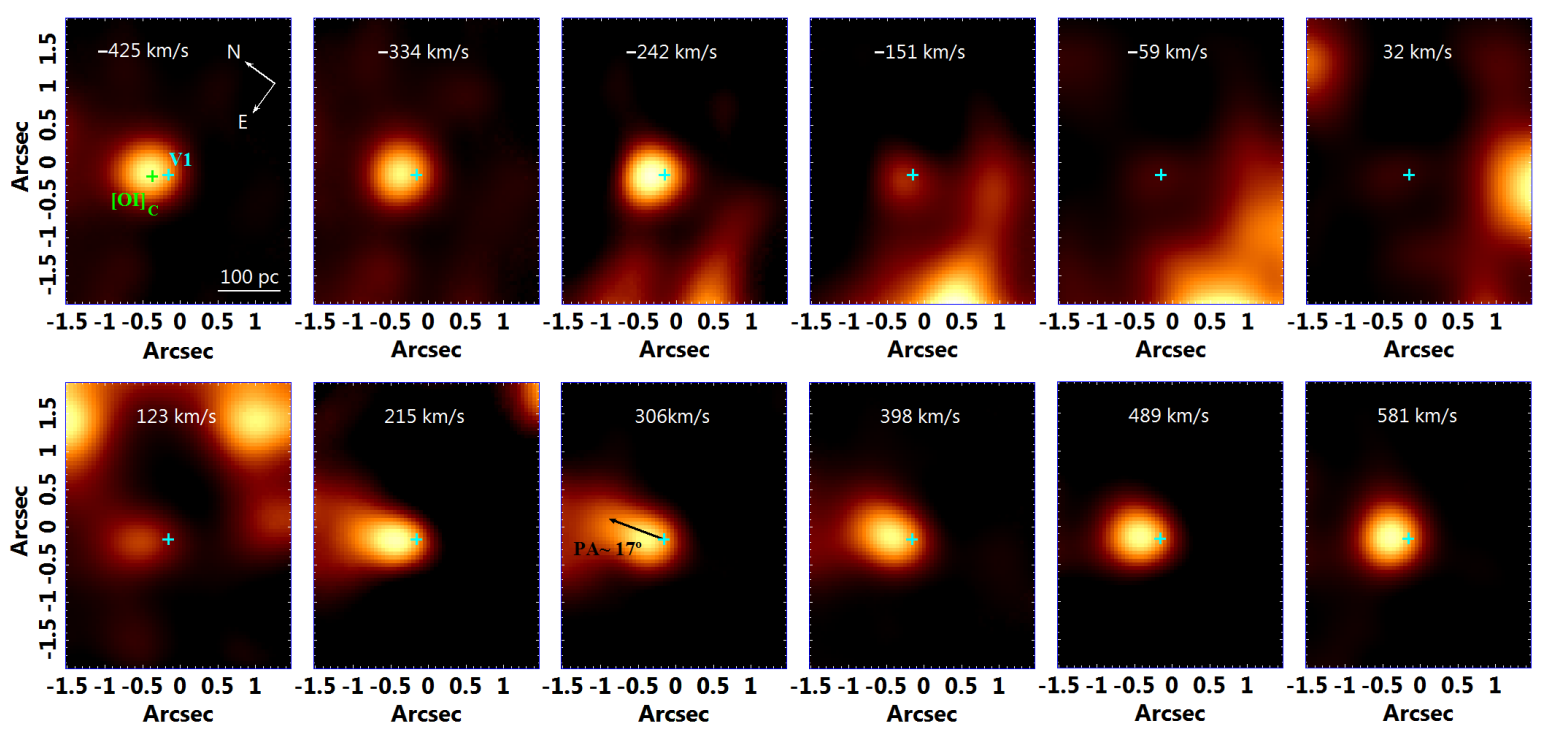

Figura 10.1: Channel maps of the $\mathrm{H} \alpha$ emission line from the GMOS data cube with $1 \AA$ interval between each channel. The velocities were calculated related to the rest wavelength of the emission line. The position of $[\mathrm{O} \mathrm{I}]_{C}$ and $\mathrm{V} 1$ are indicated by the green and cyan crosses, respectively, and its size represents the $3 \sigma$ uncertainty. The NE orientation of the GMOS data cube is indicated in the first channel, as well as the $100 \mathrm{pc}$ scale. As the $\mathrm{H} \alpha$ emission line seems blended in the central region of NGC 613, the first and last channels might be contaminated with $[\mathrm{N}$ II] $]$ 6748 and $[\mathrm{N}$ II] $\lambda 6784$ emission. The channels between 215 and $398 \mathrm{~km} \mathrm{~s}^{-1}$ show a central emission with a well defined orientation that suggests an outflow with redshift velocities. The representative velocity is $306 \mathrm{~km} \mathrm{~s}^{-1}$ and $\mathrm{PA} \sim 17^{\circ}$.

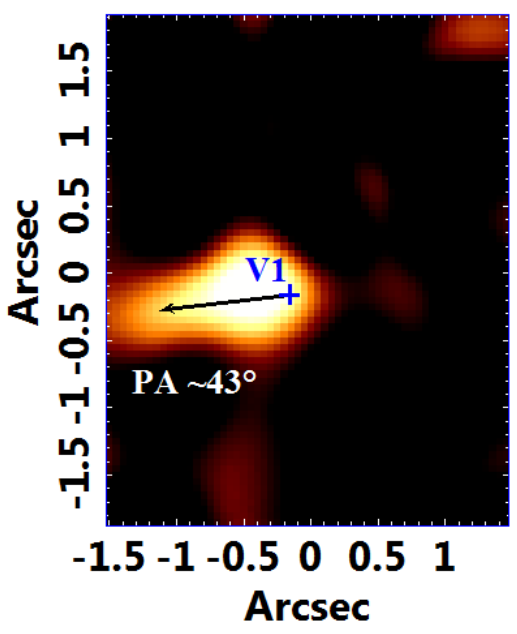

Figura 10.2: Image of the [O III] $] 5007$ emission line with $-650 \mathrm{~km} \mathrm{~s}^{-1} \lesssim \mathrm{v} \lesssim-590 \mathrm{~km} \mathrm{~s}^{-1}$ related to the rest wavelength obtained from the GMOS data cube. This emission has a preferred direction and its is $\mathrm{PA} \sim 43^{\circ}$. The blue cross represents the position of the AGN (V1) and its size, the uncertainty of $3 \sigma$. 

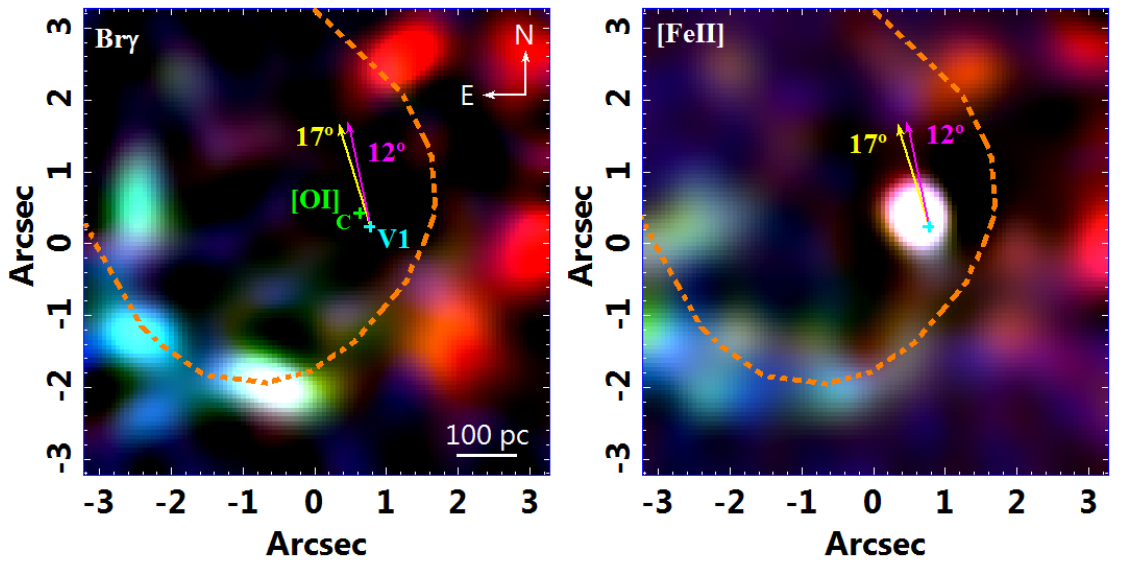

Figura 10.3: RGB composition of $\mathrm{Br}_{\gamma}$ and [Fe II] $\lambda 16436$ emission lines from the SINFONI data cube. The velocity intervals for the colours of both images are the same; red: $100 \mathrm{~km} \mathrm{~s}^{-1}<\mathrm{v}<319 \mathrm{~km} \mathrm{~s}^{-1}$, green: $49 \mathrm{~km} \mathrm{~s}^{-1}<\mathrm{v}<49 \mathrm{~km} \mathrm{~s}^{-1}$ and blue: $-411 \mathrm{~km} \mathrm{~s}^{-1}<\mathrm{v}<-100 \mathrm{~km} \mathrm{~s}^{-1}$. The orange contours represent approximately the edges the ionization cone extracted from the [O III] $\lambda 5007$ image with $-170 \mathrm{~km} \mathrm{~s}^{-1}$ (see Fig. 10.5, the magenta and yellow lines indicate, respectively, the PAs of the outflow observed with $\mathrm{H} \alpha$ $\left(\mathrm{PA} \sim 17^{\circ}\right)$ and from the radio jet observed by Hummel e Jorsater $(1992)\left(\mathrm{PA} \sim 12^{\circ}\right)$. The green and cyan crosses represent the positions of $[\mathrm{O} \mathrm{I}]_{C}$ and $\mathrm{V} 1$, respectively and, their sizes, the uncertainty of $3 \sigma$. Note, in the $\operatorname{Br} \gamma$ image, the indication of the NE orientation and of the 100 pc scale.

noisy and hard to interpret due to the low signal-to-noise ratio $(\mathrm{S} / \mathrm{N})$ in the blue region of the optical spectra. However, we notice a very clear emission when we observe the channel with $-650 \mathrm{~km} \mathrm{~s}^{-1} \lesssim \mathrm{v} \lesssim-590 \mathrm{~km} \mathrm{~s}^{-1}$ (see Fig. 10.2). This emission has a preferred direction, whose $\mathrm{PA} \sim 43^{\circ}$ is not compatible with the one of the outflow observed in the $\mathrm{H} \alpha$ channel maps, neither is the velocity, since it is in blueshift.

\subsubsection{Near-infrared and molecular gas kinematics (SINFONI and ALMA)}

The SINFONI data cube shows the positions of the $\mathrm{H}$ II regions with great precision when we look to the $\operatorname{Br} \gamma$ emission line images (Böker et al., 2008; Falcón-Barroso et al. 2014). Thus, we made an RGB composition of this line to determine the gas kinematics in the circumnuclear ring (see left pannel of Fig. 10.3). We notice that there is a gas rotation of the $\mathrm{H}$ II regions around the AGN: the regions located at West present gas emission in redshift and the gas with velocities close to zero seems to be located at East, together with the gas with emission in blueshift. The [Fe II] 116436 RGB (right pannel of Fig. 10.3) presents also the same trend, however the ganularity of the image of the $\mathrm{H}$ II regions is higher than in the $\operatorname{Br} \gamma$ image.

Besides the RGB compositions of [Fe II] $\lambda 16436$ and $\mathrm{Br} \gamma$, we also created RGBs of the 
$\mathrm{H}_{2} \lambda 21218$ emission line (Figs. 10.4 pannels a and c). In the inner centre of the FOV we see that the gas with emission in blueshift is located at North, whereas the gas with emission in redshift is located at South. That might indicate a rotation of molecular gas around the AGN. When we look at the RGB composition of the ALMA data cube of the inner centre, we see that the nuclear spiral has an opposite pattern in the nucleus: blueshift at south and redshift at north (the same trend was detected by Audibert et al. 2019). We see also that the nuclear spiral is connected to the bar also and its arms has the same kinematics, which suggest that the nuclear spiral is bringing gas and dust to the centre, feeding the AGN. This process has no connection with the molecular gas observed in the $\mathrm{H}_{2} 21218$, therefore we are presenting two different phenomena. In the ring (pannels c and d of Fig. 10.4) the molecular gas shows emission (in the circumnuclear ring) in redshift at West and emission in blueshift at East, as in the previous RGBs. However the low velocity gas is located at West, together with the gas in redshift, the opposite of the RGBs of [Fe II] $] 16436$ and $\operatorname{Br} \gamma$. In this case, we could not separate completely the images representing higher positive velocities (red colour in the RGBs) from the images corresponding to lower moduli of velocities, due to the insufficient spectral resolution.

\subsubsection{Circumnuclear optical gas kinematics (SIFS)}

One of the most relevant spectral features in the SIFS data cube is the $[\mathrm{O}$ III $] \lambda 5007$ emission line. As we know that there is an AGN (V1), we can associate this emission with an ionization cone that comes from it (see Paper I). The [O III $] \lambda 5007$ kinematics was also studied here with the channel maps of Fig. 10.5. The morphology of the ionization cone can be seen in the channels with low velocities $\left(-170 \mathrm{~km} \mathrm{~s}^{-1}\right.$ and $\left.9 \mathrm{~km} \mathrm{~s}^{-1}\right)$. The [O III] $] 5007$ emission line has a profile with a prominent blue wing, indicating outflows with high negative velocities. The outflow appears clearly in the channel with $\mathrm{v}=-889 \mathrm{~km} \mathrm{~s}^{-1}$ with $\mathrm{PA}=-10^{\circ}$. When we compare the channels with velocities $-530 \mathrm{~km} \mathrm{~s}^{-1}$ and $429 \mathrm{~km} \mathrm{~s}^{-1}$, we see that there might be a rotation of gas in the inner central region, although we cannot exclude the possibility of other gas outflows. There is no correlation between the [O III $] \lambda 5007$ emission and the star forming regions, except that there is a region of a break in the ring that might be associated with the emission of the ionization cone.

We studied the $\mathrm{H} \alpha$ emission line kinematics of the SIFS data using the channel maps of Fig. 10.6. As in the GMOS data cube, we have to consider that, in the inner regions 

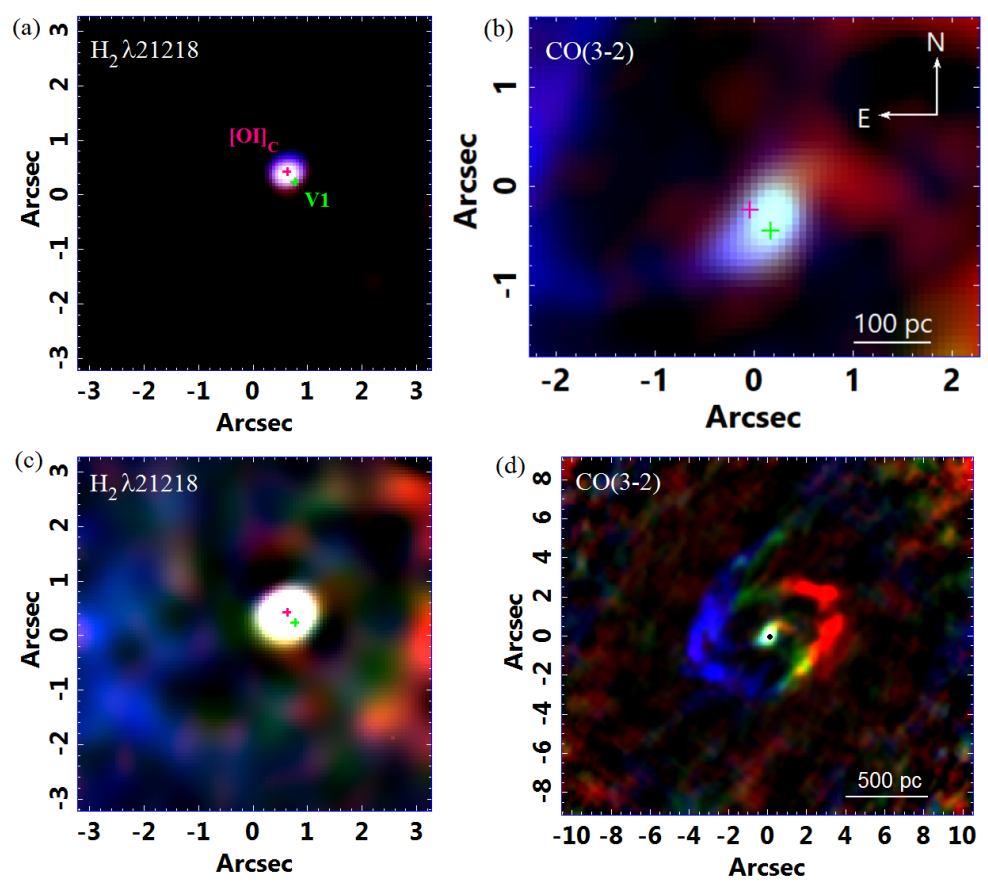

Figura 10.4: RGB composition of $\mathrm{H}_{2} \lambda 21218$ with the LUT (Look Up Table) set up to show only the inner central molecular gas kinematics (a) and with the overdone LUT to show the molecular gas kinematics in the circumnuclear ring (c). (b) RGB composition of $\mathrm{CO}(3-2)$ emission line observed with ALMA zoomed in the central region and $(\mathrm{d})$ with all ALMA FOV. The magenta and green crosses represent the positions of $[\mathrm{O} \mathrm{I}]_{C}$ and $\mathrm{V} 1$, respectively and, their sizes, the $3 \sigma$ uncertainty considering the spaxels of the SINFONI data cube (pannels a and c) and ALMA data cube (pannels b and d). The black dot on pannel (d) represents the position of V1. Its size was enlarged to facilitate the visualisation and does not correspond to the uncertainty.
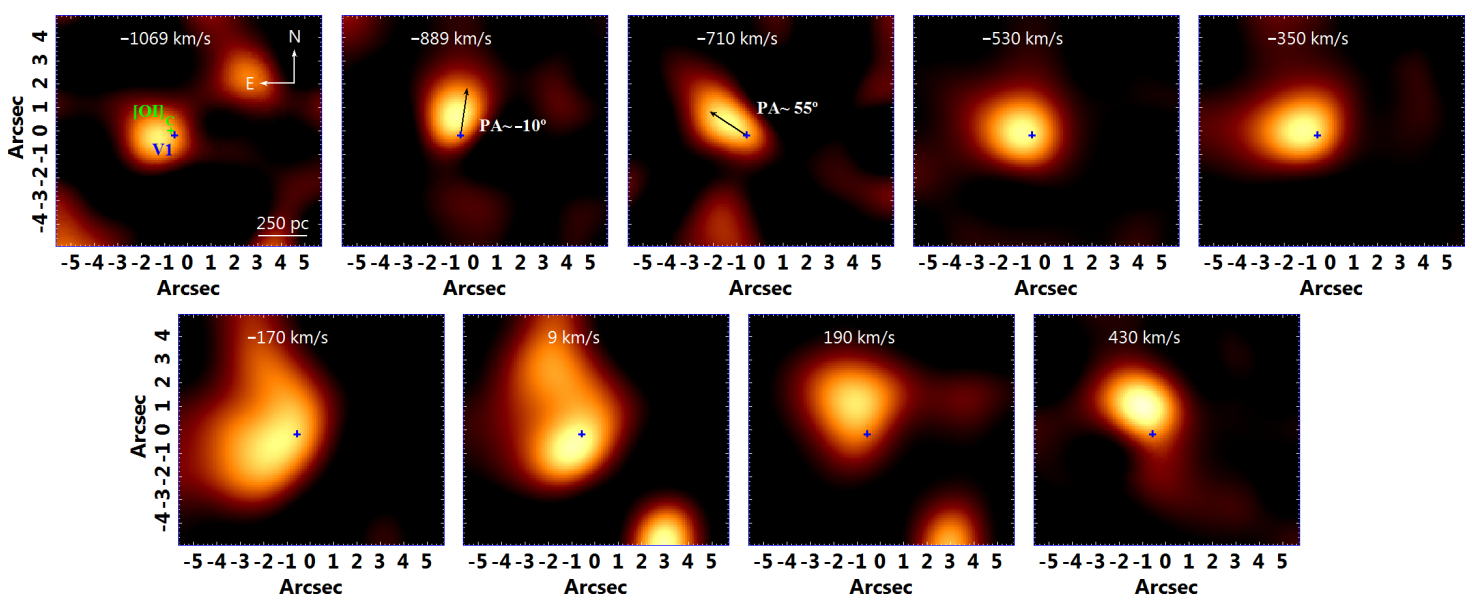

Figura 10.5: Channel maps of [O III] $\lambda 5007$ emission line of the SIFS data cube with $2 \AA$ intervals between each channel. The velocities were determined relative to the rest wavelength of the emission line. The positions of $[\mathrm{O} \mathrm{I}]_{C}$ and $\mathrm{V} 1$ are indicated by the green and blue crosses, respectively, and their sizes represent $3 \sigma$ uncertainty. The channels with $\mathrm{v}=-889 \mathrm{~km} \mathrm{~s}^{-1}$ and $\mathrm{v}=-710 \mathrm{~km} \mathrm{~s}^{-1}$ have indications of the PAs of the outflows of gas with PAs $\sim-10^{\circ}$ and $\sim 55^{\circ}$, respectively. 


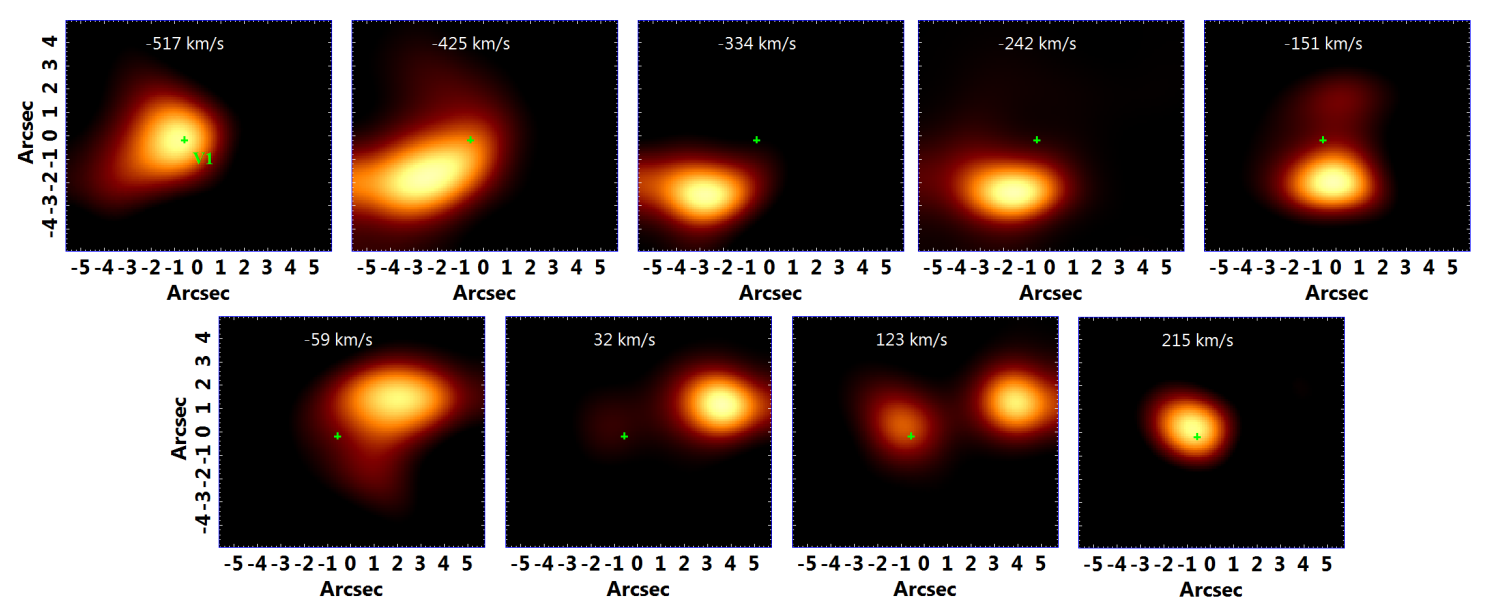

Figura 10.6: $\mathrm{H} \alpha$ channel maps obtained from SIFS data cube with intervals of $1 \AA$ between each channel. The velocities were estimated relative to the rest wavelength of the emission line. The V1 position is indicated by the green cross, whose size represents the $3 \sigma$ uncertainty. As the $\mathrm{H} \alpha$ line is blended in some regions, it might have some contamination of the $[\mathrm{N} \mathrm{II}] \lambda \lambda 6548,6584$ emission in the first and last channels.

of the FOV (mostly in the regions closer to the AGN), the $\mathrm{H} \alpha$ line is blended with the $[\mathrm{N}$ II] $] \lambda \lambda 6548,6584$ lines, so the first and last channels might be contaminated with this emission. When we look to the channel maps of Fig 10.6, we see that the kinematics of the $\mathrm{H}$ II regions in the circumnuclear ring (which we cannot spatially separate, due to the low spatial resolution), is consistent with what we see in the SINFONI and ALMA data (see Figs. 10.3 and 10.4). The H II regions at southeast of V1 show emission in blueshift and the regions at northwest, emission in redshift.

\subsection{Stellar archaeology}

As said in section 10.3.1, it is possible to study the stellar archaeology with the spectral synthesis. In this case, we used the STARLIGHT software, with a base created from MILES. For more information see section 10.3.1.

The spatial resolution of the GMOS data cube is high enough to reveal regions N1 and N2. However, the positions of the H II regions cannot be clearly determined from this data cube, as its FOV includes only the inner edges of the circumnuclear ring (3 arcsec $\times 3.8$ arcsec). Thus, the H II regions study was made with the SIFS data cube, as its FOV is larger $(11.4$ arcsec $\times 9.9$ arcsec $)$.

In this section we present the results of the spectral synthesis applied to the spectra of 

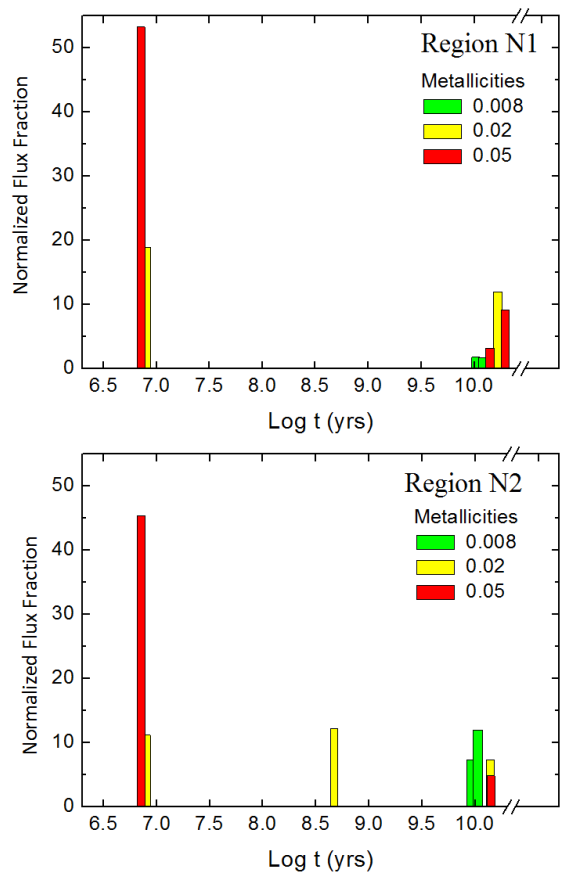

Figura 10.7: Histograms of the results of the spectral synthesis applied to the N1 and N2 spectra of GMOS data cube. No flux fraction associated with a power law with spectral index equal to 1.5 (representing the featureless continuum of the AGN) was detected (that should be observed in the histogram after the break).

regions $\mathrm{N} 1$ and N2, extracted from the GMOS data cube and to the spectra of the $\mathrm{H}$ II regions, extracted from the SIFS data cube.

\subsubsection{Results from the GMOS data cube}

N1 and N2 spectra were extracted from the GMOS data cube according to Fig. 10 in Paper I before creating the gas data cube. The diameter of the extraction region was equal to the FWHM of the PSF of the data.

From the results of the spectral synthesis, we made histograms of the flux fraction (normalized in each region) of the detected stellar populations. In both regions, the young stellar populations $\left(10^{7} \mathrm{yr}\right)$ with high metallicity (0.02 and, mostly, 0.05) are responsible for the highest flux fractions. There are a few differences between regions N1 and N2: the presence of the $10^{8.5} \mathrm{yr}$ stellar populations with 0.02 metallicity and the old stellar populations $\left(10^{10} \mathrm{yr}\right)$ with intermediate metallicity (0.008) in the N2 region (Fig. 10.7).

When we compare these data with the SIFS data (see section 10.5.2), we see that regions N1 and N2 show flux fractions associated with mainly young stellar populations, 

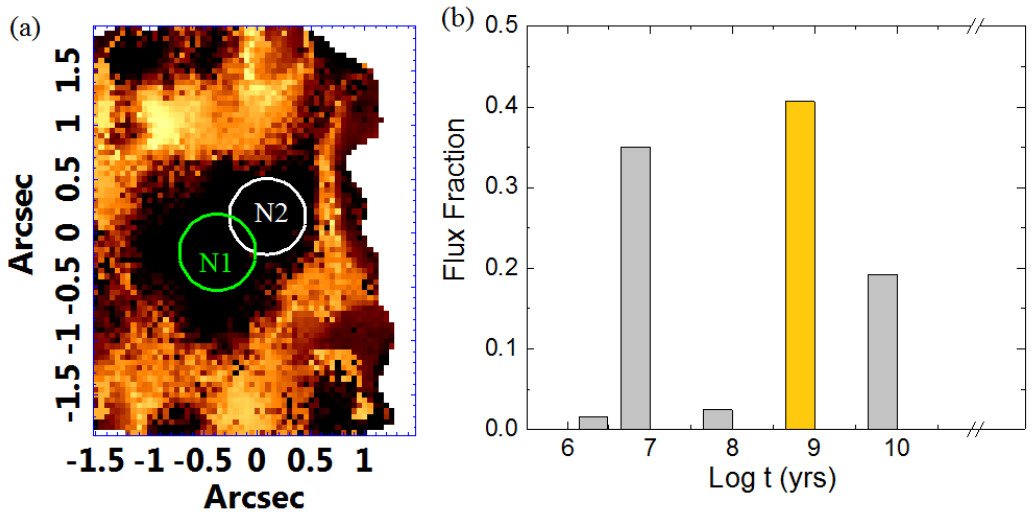

Figura 10.8: (a)Flux map obtained with the spectral synthesis applied to the whole FOV of the GMOS data cube showing the detected stellar population of $10^{9} \mathrm{yr}$. The bright areas of the map show the flux from $10^{9} \mathrm{yr}$ stellar populations with all metallicity values, but the dominant metallicity is high $(0.02$ and 0.05). The circles represent regions N1 and N2, and their diameter the FWHM of the PSF of the GMOS data cube. These were the exact extraction areas of the spectra of regions N1 and N2, therefore, the regions of the results presented in Fig. 10.7. The white region of the map was not considered in the results, since it has $\mathrm{S} / \mathrm{N}<10$. (b) Histogram of the results of the spectral synthesis applied to the whole FOV of the GMOS data cube. The flux fraction is not separated by metallicity, it only shows what is the flux fraction associated with each age considered. Only ages with $10^{9}$ yrs were taken into account in Fig. (a), the others, in grey, are not presented in this work, only in the results of the spectral synthesis of the SIFS data cube in the Appendix.

while, in the ring, we see a balance between old and young stellar populations.

Fig. 10.8(a) shows the flux map of the populations of $10^{9} \mathrm{yr}$ detected with the spectral synthesis applied to the entire FOV of the GMOS data cube. The map includes the flux of the $10^{9}$ yr stellar populations with all metallicity values, although the dominant metallicity is high (0.02 and 0.05). We notice, by looking at the histograms of Fig. 10.7 and by looking at this map, that the concentration of this stellar population is completely circumnuclear and resembles a ring of radius $\sim 1$ arcsec intermediate between the nucleus and the previously known circumnuclear ring (see section 10.7.1.1).

The histogram of Fig. 10.8(b) shows that the $10^{9}$ yr stellar populations are responsible for the largest flux fraction in the inner region of the nucleus of NGC 613, followed by the $10^{7}$ stellar populations. It also shows how relevant is the inner circumnuclear ring of this intermediate age stellar populations.A comparison between this histogram and the one in Fig. 10.7 reveals that the 10 Gyr stellar populations are responsible for a larger flux fraction in the circumnuclear region when compared to regions N1 and N2. 


\subsubsection{Results from the SIFS data cube}

It is already known in the literature that NGC 613 has a circumnuclear star forming ring (Böker et al., 2008; Falcón-Barroso et al., 2014). So, from the SIFS data cube, whose FOV covers all the area of the ring (besides the two additional regions detected in this work, see Fig. 10 from Paper I), we applied a spectral synthesis with the STARLIGHT software to the extracted spectra of the $\mathrm{H}$ II regions named from 1 to 10 (whose extraction areas are shown in Fig. 10 of Paper I).

We created a histogram from the results of the spectral synthesis applied to the spectrum of each region, as shown in Fig. 10.9. We notice that all regions have mainly both young $\left(10^{7} \mathrm{yr}\right)$ and old $\left(\sim 10^{10} \mathrm{yr}\right)$ stellar populations, whereas some regions do not show flux fractions associated with intermediate ages. Regions 7, 9 and 10 show most (or all, in the case of region 9) of their flux fractions attributed to high metallicity stars (0.02 and 0.05). The other regions present, apparently, flux fractions divided between high and low $\left(10^{-4}\right.$ and $\left.4 \times 10^{-4}\right)$ metallicities.

\subsection{Stellar kinematics}

It is possible to study the stellar kinematics from the absorption lines using the spectral synthesis. In this case, we used the pPXF method (Cappellari e Emsellem, 2004), which is more precise, as the spectral base is convolved with a Gauss-Hermite expansion. In this case, we used the same spectral base used for the stellar archaeology. We, then, have for results the coefficients of this expansion: $h_{1}$, the radial velocity, $h_{2}$, the velocity dispersion and $h_{3}$, the value that represents the degree of asymmetry of the absorption lines that were fitted. Since this method was applied to data cubes, the results are maps of those coefficients.

The pPXF was applied to the GMOS data cube, in order to study the stellar kinematics of the inner region of NGC 613 nucleus and to the SIFS and SINFONI data cubes, in order to obtain the stellar kinematics of the circumnuclear region (and of the circumnuclear ring). 

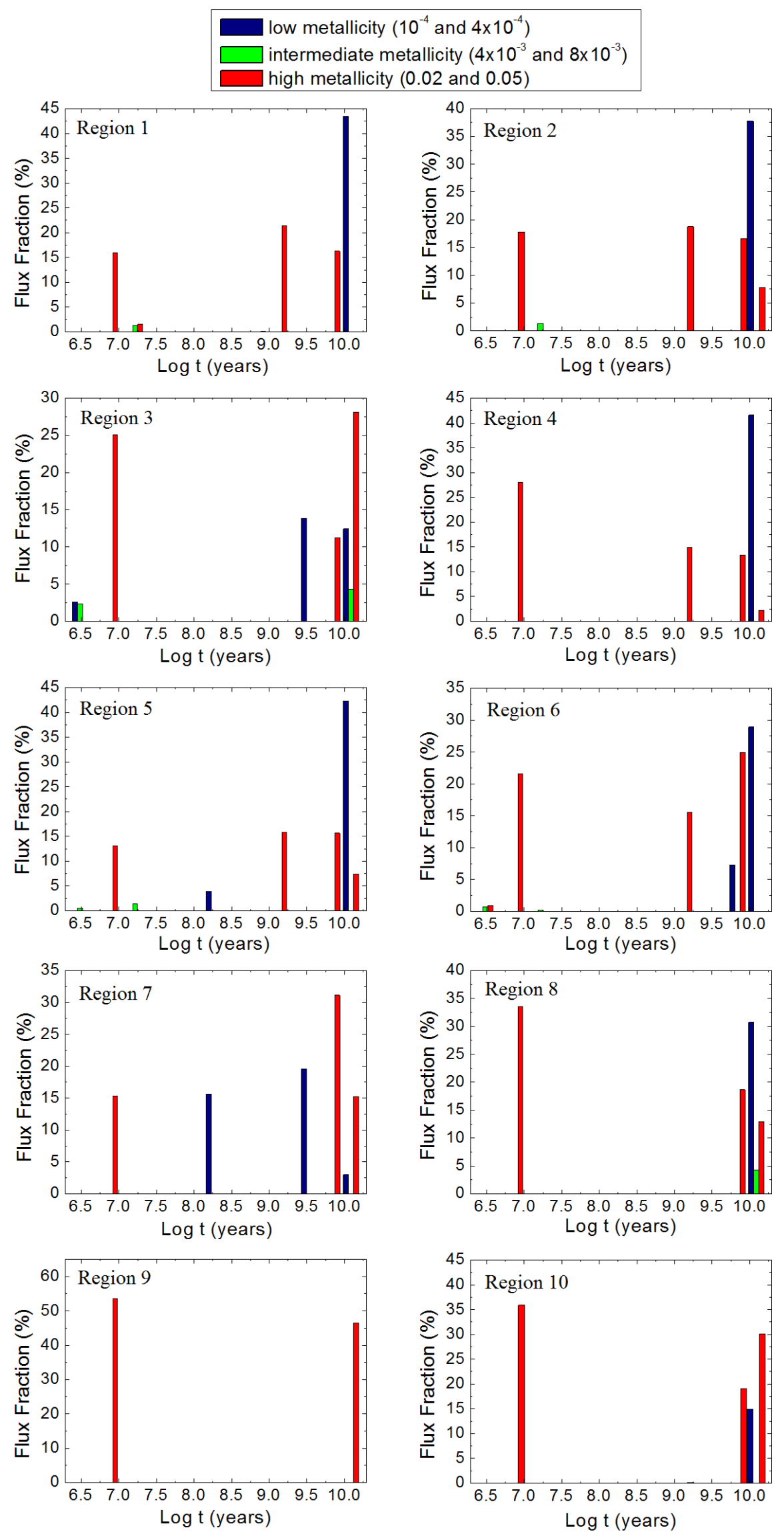

Figura 10.9: Histograms of the result of the spectral synthesis applied to the extracted spectra of the SIFS data cube of the regions named 1 to 10 in Fig. 10 of Paper I. 
(a)

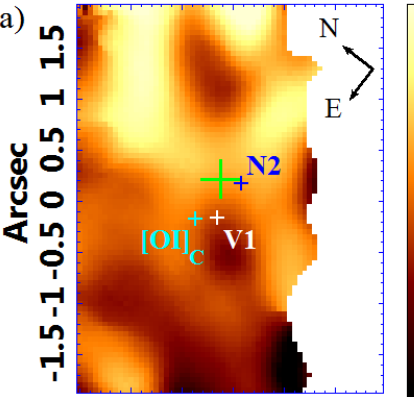

-1.5 - $1-0.500 .51$

Arcsec

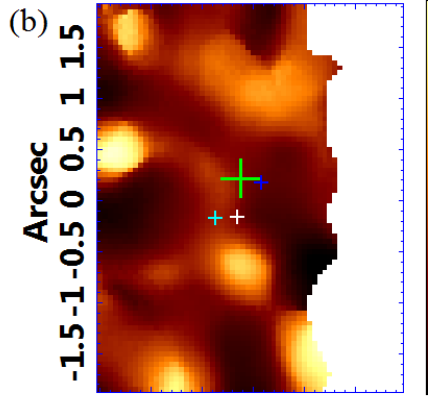

$-1.5-1-0.500 .51$

Arcsec

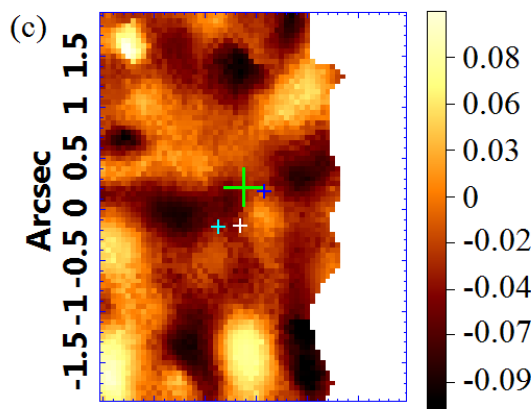

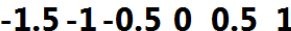

Arcsec
$64 \mathrm{~km} / \mathrm{s}$

$48 \mathrm{~km} / \mathrm{s}$

$32 \mathrm{~km} / \mathrm{s}$

$16 \mathrm{~km} / \mathrm{s}$

$0 \mathrm{~km} / \mathrm{s}$

$-16 \mathrm{~km} / \mathrm{s}$

$-32 \mathrm{~km} / \mathrm{s}$

$-48 \mathrm{~km} / \mathrm{s}$

$-64 \mathrm{~km} / \mathrm{s}$

$245 \mathrm{~km} / \mathrm{s}$

$222 \mathrm{~km} / \mathrm{s}$

$199 \mathrm{~km} / \mathrm{s}$

$177 \mathrm{~km} / \mathrm{s}$

$154 \mathrm{~km} / \mathrm{s}$

$131 \mathrm{~km} / \mathrm{s}$

$108 \mathrm{~km} / \mathrm{s}$

$85 \mathrm{~km} / \mathrm{s}$

0.08
.06
0.03
0.02
0.04
0.07
0.09

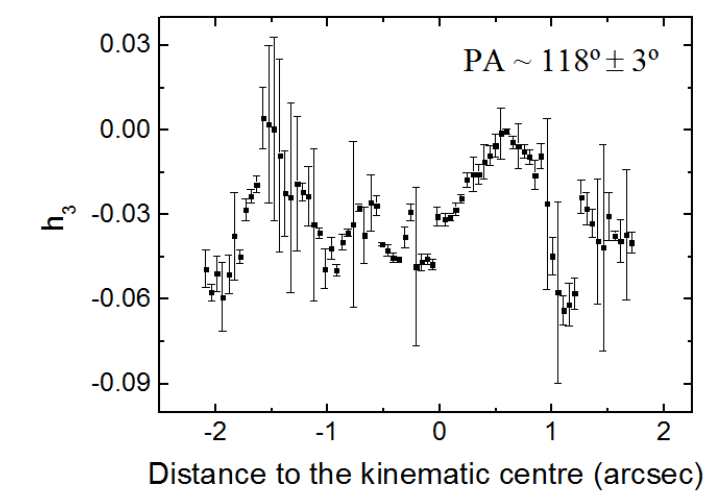

Figura 10.10: Maps of the coefficients of the Gauss-Hermite expansion of the pPXF applied to the GMOS data cube: (a) stellar velocity, (b) stellar velocity dispersion and (c) $\mathrm{h}_{3}$ coefficient that measures the asymmetry degree of the absorption lines. All maps have their curves extracted along the nodes line, whose $\mathrm{PA} \sim-62^{\circ} \pm 3^{\circ}$. The kinematic centre is indicated by the green cross, and its size represents the $1 \sigma$ uncertainty. The cyan, blue and white crosses indicate the positions of $[\mathrm{O} \mathrm{I}]_{C}$, the centroid of $\mathrm{N} 2$ and $\mathrm{V} 1$, respectively and, their sizes, the $3 \sigma$ uncertainty. The areas of the FOV where the $\mathrm{S} / \mathrm{N}<10$ were removed from the map, since their data are not reliable. 


\subsubsection{Inner central stellar kinematics obtained from the GMOS data cube}

The stellar velocity map of Fig. 10.10 (a) is very irregular. One can note a rotation pattern in the inner central 0.5 arcsec. Despite the irregularities, we notice that there is a predominance of negative velocities at east/southeast and positive velocities at west/northwest of $[\mathrm{O} \mathrm{I}]_{C}$. The kinematic centre was defined as the point, along the line of nodes, with a velocity value equal to the average between the maximum and minimum velocity values. This average velocity was subtracted from the velocity map, so Fig. 10.10 (a) actually shows the radial velocities relative to the kinematic centre, which is between $[\mathrm{O} I]_{C}$ and $\mathrm{N} 2$ and closer to N2. However, considering the uncertainty, the kinematic centre is compatible also with $\mathrm{V} 1,[\mathrm{O} \mathrm{I}]_{C}$ or even with the N1 centroid, which is not represented in the image.

The stellar velocity dispersion curve has two peaks (Fig,10.10b), one at $\sim 1$ arcsec and the other at $\sim-1$ arcsec, and the values decrease towards the centre and towards the edges. There are also perturbations in the velocity curve, with values lower than expected, in the case of a keplerian motion. The positions of such perturbations are coincident with the ones of the velocity dispersion peaks and also with the possible inner circumnuclear ring of $10^{9} \mathrm{yr}$ stellar populations. The velocity dispersion at the centre of the curve is $\sim 126 \mathrm{~km} \mathrm{~s}^{-1}$ and, at the edge, is $\sim 100 \mathrm{~km} \mathrm{~s}^{-1}$ (Fig.10.10 b).

In the more peripheral areas of the $h_{3}$ map we can see a possible anti-correlation with the velocity map (Fig. 10.10 ). The uncertainties in those regions are high and, as the velocity map itself has irregularities, we cannot draw conclusions from this result.

\subsubsection{Circumnuclear stellar kinematics obtained from the SIFS data cube}

Since it has a larger FOV, the stellar velocity map from the SIFS data cube reveals more clearly the stellar rotation that we could not see in the GMOS results (Fig. 10.11a). The kinematic centre is not compatible with V1 in this case, being at a distance of $0.66 \pm 0.11$ arcsec. At southeast the stars have negative velocities and at northwest, positive velocities. The PA of the line of nodes is $-70^{\circ} \pm 1^{\circ}$, compatible, at the $3 \sigma$ level, with the PA of the line of nodes of the GMOS results, which is $-62^{\circ} \pm 3^{\circ}$.

The velocity dispersion curve of Fig 10.11(b) shows, as in the GMOS velocity dispersion curve, two peaks at the same position of the perturbations in the velocity curve, although, in the SIFS results, those peaks and perturbations are diluted due to the lower spatial 

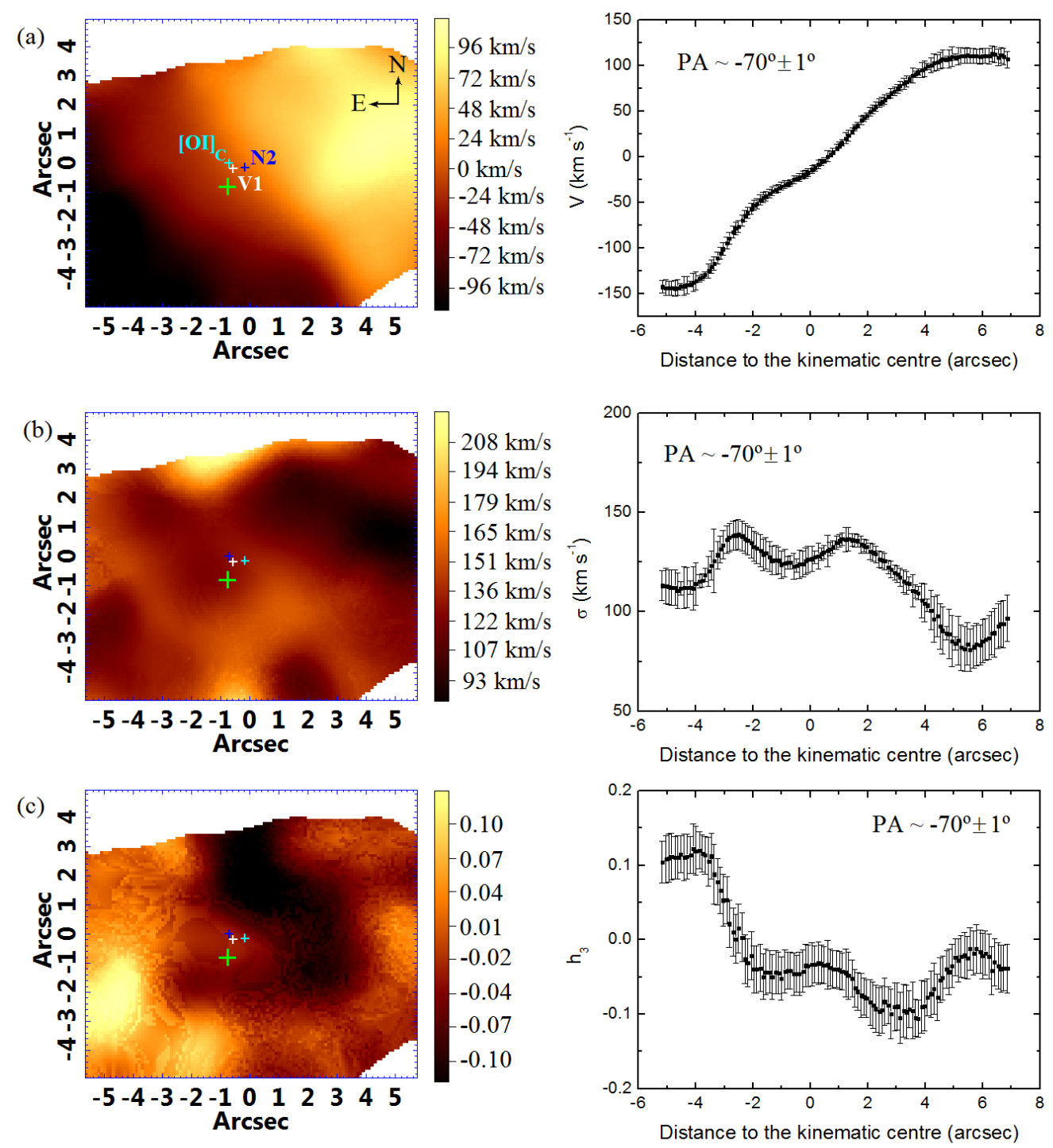

Figura 10.11: pPXF maps from the SIFS data cube: (a) stellar velocity, (b) stellar velocity dispersion and (c) $\mathrm{h}_{3}$ Gauss-Hermite coefficient, with their respective curves extracted along the nodes line, whose $\mathrm{PA} \sim-70^{\circ} \pm 1^{\circ}$. The kinematic centre is indicated by the green cross, the cyan, blue and white crosses indicate the position of $[\mathrm{O} \mathrm{I}]_{C}$, the centroid of $\mathrm{N} 2$ and $\mathrm{V} 1$, respectively, and their sizes the $3 \sigma$ uncertainty. The areas where the FOV has $\mathrm{S} / \mathrm{N}<10$ were removed from the map. 
resolution of these data. Those peaks are not located at the same positions of the peaks observed in the GMOS data cube. In fact, their locations are consistent with the circumnuclear ring (not the inner ring as in GMOS). The value of the velocity dispersion at the centre is $\sim 123 \mathrm{~km} \mathrm{~s}^{-1}$.

The $h_{3}$ map (Fig. 10.11k) has irregularities, but, in general, shows an anti-correlation with the velocity map in the region of the ring, which may indicate that the stars of the ring rotate superposed to a stellar background with velocities close to zero towards the line-of-sight.

\subsubsection{Near-infrared stellar velocity dispersion obtained from SINFONI data cube}

Although the SINFONI data cube could have a significant amount of information related to the stellar kinematics, the low $\mathrm{S} / \mathrm{N}$ prevented the construction of pPXF parameters maps that could be interpreted. In order to obtain, at least, more reliable information about the stellar velocity dispersion, the pPXF method was applied to spectra extracted from concentric rings around V1, with 3 spaxels of thickness. With that, we could minimise the spectral noise and obtain the curve of Fig. 10.12.

The uncertainties of the values of the velocity dispersion were obtained by applying a Monte Carlo method to each of the extracted spectra. Firstly, for each spectrum, we subtracted the stellar continuum, using the corresponding pPXF fitting. Then, we created a histogram with the values of the spectrum (after the stellar continuum subtraction) in many spectral intervals, without emission lines. We fitted a Gaussian function to this histogram and created Gaussian distributions of random values with the same width of the Gaussian fitted to the histogram. Those distributions were added to the synthetic stellar spectrum provided by the pPXF, resulting in "synthetic noisy spectra". At the end, the pPXF was applied to each one of those "synthetic noisy spectra" and the final uncertainty of the stellar velocity dispersion was taken as the standard deviation of all the obtained values.

Unlike what we see in the previous results in the optical, we see here (Fig. 10.12) a peak of the stellar velocity dispersion at the centre, with a value of $\sim 144 \mathrm{~km} \mathrm{~s}^{-1}$. The stellar velocity dispersion decreases with the radius and reaches a nearly constant value of $\sim 95 \mathrm{~km} \mathrm{~s}^{-1}$. At $\sim 1.8 \operatorname{arcsec}$ from V1, there appears to be a second peak of velocity dispersion, with a value of $\sim 121 \mathrm{~km} \mathrm{~s}^{-1}$; however, considering the uncertainties of the 


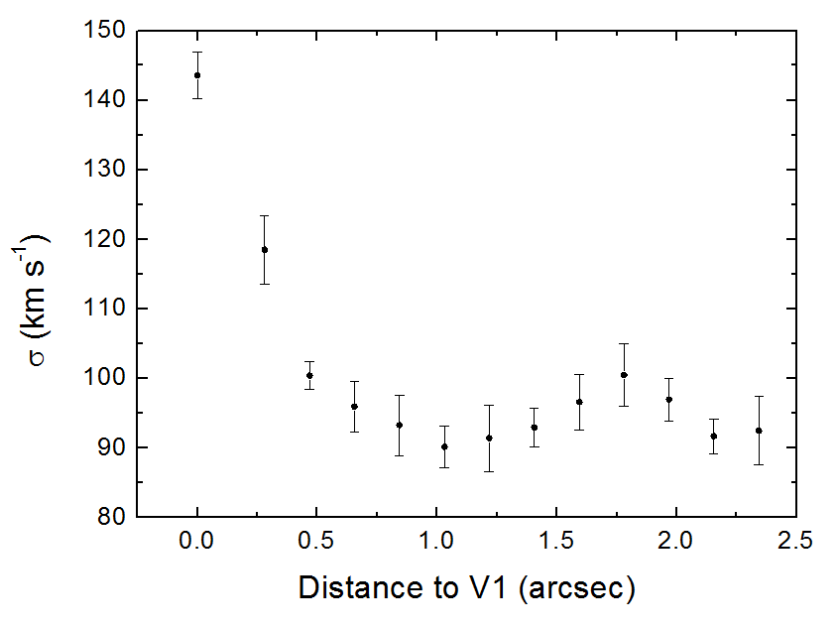

Figura 10.12: Velocity dispersion curve obtained from the spectra of concentric rings centred at V1 with 3 spaxels of thickness extracted from the SINFONI data cube.

values, it is not possible to confirm the existence of this second peak.

In order to obtain a stellar velocity dispersion value representing the central region of NGC 613, we calculated a weighted mean of the values of the map obtained with the pPXF from the SINFONI data cube, taking as weights the integrated fluxes of each spaxel. The value obtained was $92 \pm 3 \mathrm{~km} \mathrm{~s}^{-1}$. The uncertainty was calculated after the creation of two additional maps, one with the sum of the uncertainty map and the other with the subtraction of the uncertainty map. Then, we calculated the weighted means of the dispersion of the obtained maps. The uncertainty was the standard deviation of those values.

\subsection{Discussion}

In this section we discuss all the data present here, by starting with the scenario of the stellar archaeology and describing the gas and stellar kinematics.

\subsubsection{Stellar archaeology}

N1 and N2 are two regions with significant stellar emission, so it was convenient to apply the spectral synthesis to their spectra (Fig. 10.5.1). The flux fractions of those two regions are due to, essentially, the same stellar populations, without significant differences. We did not detect any region of the data cube with a significant contribution of the 
featureless continuum of the AGN (represented by a power law with spectral index of 1.5). We actually performed a few tests, applying the spectral synthesis with power laws with different spectral indexes (with values between 1.0 and 1.9); however, we did not find credible evidence for the presence of a featureless continuum. That might indicate that this AGN is so obscured that we cannot detect such an emission. This result is compatible with the conclusions of Paper I, in which, by analysing the map of $\mathrm{D}_{C O}$ created by FalcónBarroso et al. (2014), we could not see the effect of the featureless continuum, that would create a decrease of the values of this map towards the centre (or where the AGN is located). Another hypothesis is related to the fact that the AGN might be a variable source (V1), as we claimed in Paper I. The absence of a featureless continuum might be due to a low state of activity of the AGN at the epoch of observation.

The results of the stellar archaeology do not show a continuous star formation in the central region of NGC 613, as only four events of star formation were detected, most of the $\mathrm{H}$ II regions showing evidence of just two or three of such events. In the cases of N1 and N2, evidence of two and three star formation events, respectively, were detected. This suggests that the influence of the bar on the star formation in the central region may not be significant, or just might be very recent (10 million years). The absence of a continuous star formation in the nucleus of NGC 613 is not in disagreement with the fact that this galaxy hosts a pseudo-bulge. Actually, as shown by Breda e Papaderos (2018), the bulge formation process in a galaxy probably does not follow only two possible routes: one involving a quasi-monolithic gas collapse, which would result in a classical bulge, and the other involving secular processes with continuous star formation, which would form a pseudo-bulge. Instead, the authors conclude that bulges and disks evolve simultaneously in a process that results in a continuous sequence of observed properties, such as stellar age, metallicity, surface brightness, etc. In addition, it is worth mentioning that studies have shown that the properties of certain pseudo-bulges, specially in isolated galaxies, suggest that most of their mass was formed in an early epoch, without much subsequent star formation (Fernández Lorenzo et al., 2014).

\subsubsection{The intermediate age inner circumnuclear ring}

The results of the spectral synthesis applied to the whole FOV of the GMOS data cube show that there is a circumnuclear concentration of the $10^{9} \mathrm{yr}$ stellar populations 


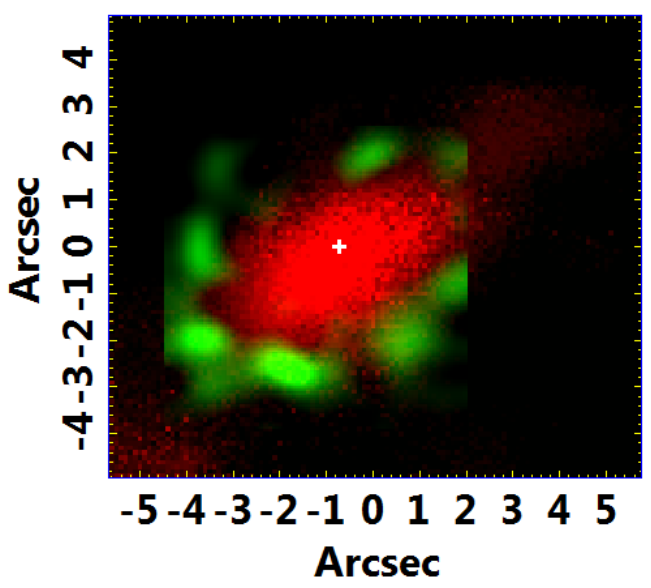

Figura 10.13: RG composition with the $\mathrm{Br} \gamma$ image showing the circumnuclear ring in green and the image of the flux from the $10^{9} \mathrm{yr}$ stellar population with all metallicities considered (but predominantly high metallicity — see Figs. 10.14 and 10.15 of the Appendix), obtained from the results of the spectral synthesis of the SIFS data cube, in red. One can notice that this stellar population is concentrated inside the region of the ring. The white cross represents the position of V1 and its size the uncertainty of $3 \sigma$, considering the size of SIFS spaxels.

(intermediate ages). By looking only to Fig. 10.8, we cannot say if this population is part or not of the circumnuclear ring observed in the NIR, since such a ring is in the FOV edges of the GMOS data cube. We can say that in the inner central regions this stellar population was not detected, only in the inner circumnuclear regions. Since we have a wider FOV with the SIFS data cube, we could gather the same flux map of this stellar population (with less inner central resolution because of the differences of the PSFs between GMOS and SIFS data) and compare it directly with the image of $\mathrm{Br} \gamma$ from the SINFONI data cube as shown in Fig. 10.13 .

We can see that the concentration of this intermediate ages stellar populations is central, limited to the spatial resolution of the SIFS observations, and it is not part of the circumnuclear ring observed in the $\mathrm{Br} \gamma$ image. It seems that this ring is a barrier of this star formation in the outer regions. The same happens to the $10^{8} \mathrm{yr}$ stellar populations (Fig. 10.15b of the Appendix), but the flux fraction of this stellar population is very low and the uncertainty is larger than its value.

When we compare both results (Figs. 10.8 and 10.13), we see that the circumnuclear concentration of the $10^{9} \mathrm{yr}$ stellar population looks like an inner ring, inside the already known circumnuclear ring. So the event that generated this stellar population happened only in the inner region between the nucleus and the circumnuclear ring. 
The detection of this inner circumnuclear ring could only be confirmed due to the high spatial resolution of the data. In the SIFS data cube, we can see that the $10^{9} \mathrm{yr}$ stellar populations are contained inside the circumnuclear ring, but we do not see a ring due to the dilution of the emission caused by the low spatial resolution.

\subsubsection{Gas kinematics}

The circumnuclear star forming ring kinematics reveals the same pattern in all the spectral bands and emission lines analysed in this work. The regions located at east have negative velocities and the regions at west, positive velocities (see Figs. 10.3 and 10.4). This result is also compatible with the one obtained by Miyamoto et al. (2017, 2018) using velocity maps of molecular gas.

We notice that the nuclear spiral (Audibert et al. 2019) has its own kinematics that suggests feeding of the central region. The gas emission of this nuclear spiral at northwest is in blueshift and at southeast in redshift. This same pattern was detected in the $\mathrm{H}_{2} \lambda 21218$ emission (see Fig. 10.4), which suggests that such a pattern may also be related to the feeding of the central region.

The $\mathrm{H} \alpha$ channel maps of the GMOS data cube reveal the gas kinematics of the inner central region (Fig, 10.1). We notice, at the edges of this FOV, the ring kinematics observed in NIR and ALMA data. Besides that, the outflow we detected, with $\mathrm{v}=306 \mathrm{~km} \mathrm{~s}^{-1}$, is located at a position compatible with $\mathrm{V} 1$ and has a $\mathrm{PA} \sim 17^{\circ}$, compatible with the PA of the radio jet observed by Hummel e Jorsater (1992) (see also Fig. 16 of Paper I). The rotation pattern detected with the $\mathrm{H} \alpha$ channel maps of the SIFS data cube (Fig. 10.6) is consistent with what we saw in the GMOS, SINFONI and ALMA data cubes. The outflow of gas, detected in the GMOS data cube, though, cannot be seen here in the SIFS data, due to the lower spatial resolution.

The ionization cone detected in some of the $[\mathrm{O}$ III $] \lambda 5007$ channel maps $\left(\mathrm{v}=-170 \mathrm{~km} \mathrm{~s}^{-1}\right.$ and $\mathrm{v}=9 \mathrm{~km} \mathrm{~s}^{-1}$ ) is mostly located northeast of V1. The emission detected at southwest, with velocities higher than $-170 \mathrm{~km} \mathrm{~s}^{-1}$, could be the other side of the ionization cone. The size of the "break" in the circumnuclear ring, detected in the $\mathrm{Br} \gamma, \mathrm{H}_{2} \lambda 21218$ and [Fe II] $\lambda 16436$ images (Falcón-Barroso et al., 2014), northeast of V1, is compatible with the apparent size of the ionization cone. This might indicate that this region is being ionized, along the ionization cone, by the radiation coming from the AGN. However, one of the 
detected outflows in $[\mathrm{O}$ III $] \lambda 5007$ has a PA that is compatible with the axis of the ionization cone $\left(\mathrm{PA} \sim 55^{\circ}\right.$ and $\mathrm{v}=-710 \mathrm{~km} \mathrm{~s}^{-1}$, observed with the SIFS data cube, and PA $\sim 43^{\circ}$

and $-650 \mathrm{~km} \mathrm{~s}^{-1} \lesssim \mathrm{v} \lesssim-590 \mathrm{~km} \mathrm{~s}^{-1}$, observed with the GMOS data cube) and, therefore, within this "break" region. The outflow might be pushing the gas out of the ring and possibly preventing star formation in this region or the ionization coming from the AGN is heating the gas at some point that is not possible for the gas to cool down and form stars. This seems to be just a local impact of the feedback of this AGN in this galaxy, but Davies et al. (2017) found evidence that the outflowing material from the ionization cone might be interacting with the interstellar medium at larger scales by shocks.

There is a second outflow of gas observed in the [O III $] \lambda 5007$ channel with velocity of $\mathrm{v}=-889 \mathrm{~km} \mathrm{~s}^{-1}$, with $\mathrm{PA} \sim-10^{\circ}$. Though this outflow has a PA compatible with the one observed in the $\mathrm{H} \alpha$ channel map and the radio jet, its velocity is very different, so it must be an isolated event or associated with other phenomenon that we did not detect.

According to Hopkins e Quataert (2010), inflows of gas in a galaxy start at kiloparsecs scales and may be driven by major mergers or even by secular processes (involving the formation of bars). At distances between $1 \mathrm{kpc}$ and $10 \mathrm{pc}$ from the central supermassive black hole (which correspond to the region analysed in this work) the inflow continues, but the gas can have many spatial morphologies, such as spirals, rings, clumps or even secondary bars. The observed properties of the central region of NGC 613 are consistent with this scenario, as the line emitting regions show different morphologies, such as a nuclear spiral and a circumnuclear ring. As discussed in Section 6.1, this inflow of gas may also result in a gas reservoir for the star formation.

\subsubsection{Stellar kinematics}

The stellar kinematic pattern detected in this work is essentially the same of the one observed for the gas kinematics along the circumnuclear ring (Figs. 10.3 and 10.4): blueshift at southeast and redshift at northwest of V1 in the velocity maps obtained from the pPXF of the SIFS data cube (the only cube that allowed the determination of the kinematics along the entire ring extension - see Fig. 10.11a). However, in order to establish a more precise comparison between the stellar and gas kinematics along the circumnuclear ring, we made a radial velocity map of the gas by fitting a Gaussian function to the $\mathrm{H} \alpha$ emission line. We verified that the PA of the line of nodes and also the curve extracted along the 
line of nodes for both the stellar and gas kinematics are consistent. This indicates that the stars and the gas along the circumnuclear ring share the same kinematics.

The velocity maps obtained with the GMOS and SIFS data cubes (Figs. 10.10a and 10.11 , respectively) show evidence of perturbations (similar to "depressions"), which are probably related to the two peaks observed in the velocity dispersion curves (Figs. 10.10p and 10.11b). As said previously, the positions of these peaks coincide with the positions of the inner circumnuclear ring (in the GMOS results) and of the circumnuclear ring (in the SIFS results). A possible explanation for this behaviour is that the observed rings have lower radial velocities when compared to the bulge stars. Therefore, the superposition of the spectra of the stellar populations in the bulge and in the rings results in the increase of the velocity dispersion values.

The stellar velocity dispersion maximum determined from the curve obtained from the SINFONI data cube $\left(\sim 144 \mathrm{~km} \mathrm{~s}^{-1}\right)$ is compatible with the ones obtained by Schechter (1983) and Batcheldor et al. (2005) (using the maximum penalized likelihood method), while our average value of the stellar velocity dispersion taken from the SINFONI data cube $\left(92 \pm 3 \mathrm{~km} \mathrm{~s}^{-1}\right)$ is compatible with the value obtained by Batcheldor et al. (2005) using the cross correlation method. By observing the velocity dispersion curve of SINFONI, we can see that there is one central peak, followed by a higher value at $\sim 0.3 \operatorname{arcsec}$ and a series of values that, within the uncertainties, are constant. We do not see clearly the perturbations mentioned before and it is probably due to the fact that those stellar populations have some different effects when we look at the NIR spectrum.

Comparisons between active and non-active galaxies suggest that active galaxies show, in their central regions, lower values of stellar velocity dispersion than non-active galaxies. Hicks et al. (2013) found in their sample of active galaxies that the values of the stellar velocity dispersion did not exceed $100 \mathrm{~km} \mathrm{~s}^{-1}$ (see Fig. 17 from Hicks et al. 2013). This might be due to the presence of young stars that inherited the cold kinematics of their parent clouds, which probably constitute a gas reservoir for the star formation and also for the accretion onto the central supermassive black hole. In this case, the central region of NGC 613 shows stellar velocity dispersion values more compatible with the ones of active galaxies (in the Hicks et al.2013 sample) and also the presence of young stellar populations. In addition the presence of the circumnuclear rings and the evidence of inflows of gas help to corroborate this idea. 
The portion of the ring with negative velocities has positive values of $h_{3}$, while the positive velocity regions of the ring have negative values of $h_{3}$. This anti-correlation of velocity and values of $h_{3}$ could indicate that the stars of the ring rotate around the nucleus superposed to an stellar background with stars with velocities close to zero. Such anticorrelation is not seen at northwest, which might indicate deviations of a simple stellar rotation around the nucleus.

By using the stellar velocity map obtained from the SIFS data cube, we could estimate a representative velocity for the stars of the circumnuclear ring, $\mathrm{v} \sim 100 \mathrm{~km} \mathrm{~s}^{-1}$, rotating around the nucleus. Considering this velocity and the average values of the ring radius and inclination taken from Table 4 of Paper I $\left(\bar{R}=249\right.$ pc and $\left.\bar{i}=57^{\circ}\right)$, we conclude that the time necessary for a group of stars to complete a turn around the ring is $\sim 8 \times 10^{6}$ years. The temporal resolution of the spectral synthesis method is lower than this value. The scenario "pearls on string" (Böker et al., 2007, 2008; Falcón-Barroso et al., 2014) predicts that there are two gas concentrations at opposite points of the ring that form $\mathrm{H}$ II regions. Such H II regions rotate in the ring and this rotation generates an age gradient along the ring. Considering the estimated time to a full turn of a group of stars along the ring and the temporal resolution of the spectral synthesis, we conclude that more precise methods are necessary in order to determine stellar ages in this case, to confirm this scenario.

\subsection{Conclusions}

In this work we continue the analysis of the NGC 613 nucleus started in Paper I, focusing on the kinematics and on the stellar archaeology. The main findings are:

- From channel maps of the $\mathrm{H} \alpha$ emission line obtained from the GMOS-IFU data cube, we detected an outflow in redshift (with velocity $\left.\sim 300 \mathrm{~km} \mathrm{~s}^{-1}\right)$, with the PA $\left(\sim 17^{\circ}\right)$ compatible with the $\mathrm{PA}$ of the radio jet $\left(\mathrm{PA} \sim 12^{\circ}\right)$.

- We detected, also, two outflows of gas also from channel maps of [O III $] \lambda 5007$. One of them is probably associated with the ionization cone, having the $\mathrm{PA} \sim 55^{\circ}$ and $\mathrm{v} \sim-$ $710 \mathrm{~km} \mathrm{~s}^{-1}$ (SIFS) and PA $\sim 43^{\circ}$ and $\mathrm{v} \sim-620 \mathrm{~km} \mathrm{~s}^{-1}$ (GMOS), in blueshift. This outflow might be responsible for the "break" of the circumnuclear ring, observed in the $\mathrm{Br} \gamma$ image, near Region 8, expelling the gas of the circumnuclear ring and preventing star formation. The other outflow has $\mathrm{PA} \sim-10^{\circ}$ with $\mathrm{v} \sim-890 \mathrm{~km} \mathrm{~s}^{-1}$, also in blueshift. 
- The spectral synthesis results confirm that there is no featureless continuum emission detected in the optical data cubes. That agrees with the absence of decreasing values of the $\mathrm{D}_{C O}$ in the NIR towards the centre, as discussed in Paper I.

- The spectral synthesis of the optical data shows that there is no significant difference between the stellar populations of N1 and N2, formed mainly of high metallicity stars (0.02 and 0.05) with ages of $\sim 10$ Myrs and of $\sim 10$ Gyrs. Such result supports the hypothesis that N1 and N2 are part of the same central structure, apparently separated by a dust lane (probably associated with the nuclear spiral). Another result that reinforces this idea is that there was no measurable difference in the results of the stellar velocity between N1 and N2. This suggests that any significant kinematics, if there is any, might be occurring perpendicular to the line of sight.

- The spectral synthesis of optical data shows that the H II regions that are part of the circumnuclear ring have young stellar populations with similar ages. We do not have enough temporal resolution to determine age differences between them.

- The star formation history of the NGC 613 centre is not continuous. In all regions of the circumnuclear ring (except Region 8), besides the $10^{10} \mathrm{yr}$ star formation (old stellar populations), another event of star formation happened between $\sim 1$ Gyrs and $\sim 3$ Gyrs (intermediate age stellar populations), and after that, there was an interval of $\sim 9 \times 10^{9}$ yr without star formation (except in Region 7). Outside the ring (regions 9 and 10), this interval of no star formation is even bigger: $\sim 10^{10}$ years.

-A concentration of the $10^{9} \mathrm{yr}$ (intermediate age) high metallicity stellar population was detected in the inner central region. That resembles a ring between the already know circumnuclear ring and the nucleus. This inner circumnuclear ring may be responsible for the observed inner two peaks (perturbations) of stellar velocity and stellar velocity dispersion in the GMOS stellar kinematics results.

- A stellar rotation of the $\mathrm{H}$ II regions around the centre was detected from the kinematic maps obtained with the pPXF method. This rotation is compatible with what was already observed in $\operatorname{Br} \gamma$ and molecular gas kinematics.

- The stellar velocity dispersion values obtained from the SINFONI data cube shows a central peak with $\sim 144 \mathrm{~km} \mathrm{~s}^{-1}$. The average central value for the velocity dispersion, weighted by flux, calculated in all FOV of SINFONI data cube is $92 \pm 3 \mathrm{~km} \mathrm{~s}^{-1}$. 


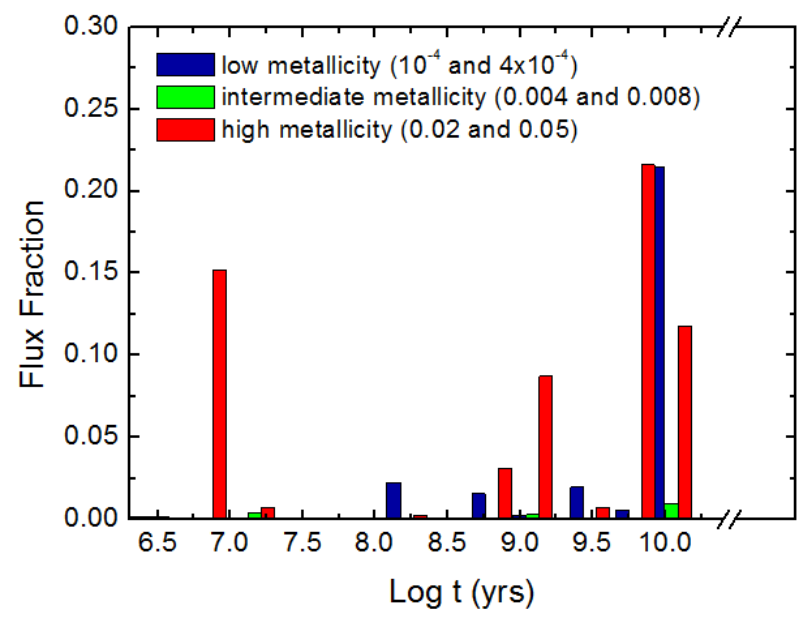

Figura 10.14: Histogram of the flux fractions of the stellar populations detected from the spectral synthesis applied to the entire FOV of the SIFS data cube. As in the GMOS data cube results, we did not find any flux fraction associated with the power law with 1.5 index representing a featureless continuum emission of the AGN, which should be after the break on the histogram.

\section{Appendix}

\subsection{Spectral Synthesis on SIFS data cube}

The SIFS data cube of NGC 613 has a wide FOV with which it is possible to study both nuclear and circumnuclear structures, such as the circumnuclear star forming ring (see section 10.5.2). In order to see the general results of this FOV, we applied the spectral synthesis with the STARLIGHT software (see section 10.3.1 for more details) to the entire FOV of this data cube.

From the results of the spectral synthesis applied to the entire data cube, we created a histogram of the flux fraction of the detected stellar populations, separated by age and metallicity, as shown in Fig. 10.14. We notice that there are, mainly, four star forming events, two around 10 Gyrs, one around 1 Gyrs and one $\sim 10$ Myrs. There is a general predominance of high metallicity stars (0.02 and 0.05). However there is a considerable flux fraction associated with low metallicity $\left(10^{-4}\right.$ and $\left.4 \times 10^{-4}\right)$ old stellar populations $(\sim 10$ Gyrs $)$.

As the spectral synthesis was applied to each spectrum of the data cube, it was possible to create maps of the flux due to each stellar population taken into account (see Fig. 10.15). We notice that there is a concentration of young stellar populations $\left(\sim 10^{7} \mathrm{yr}\right)$ with high 
- High metallicity $(0.02$ and 0.05$)$

- Intermediate metallicity $(0.004$ and 0.008$)$

- Low metallicity $\left(10^{-4}\right.$ and $\left.4 \times 10^{-4}\right)$
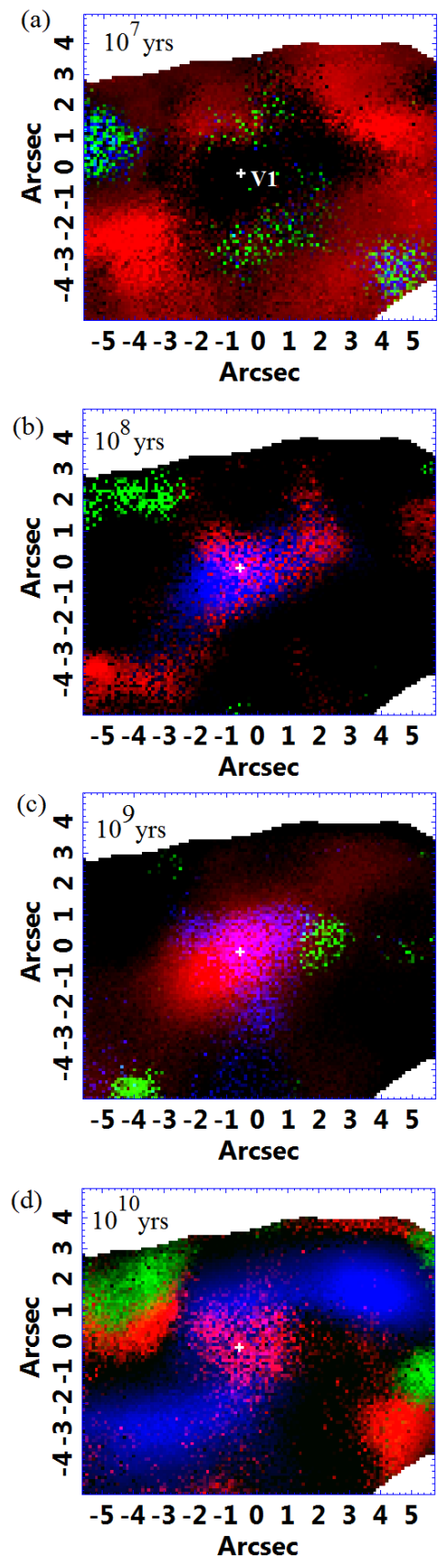

Figura 10.15: Maps of the flux fractions of the stellar populations obtained from the spectral synthesis applied to the SIFS data cube:(a) $10^{6} \mathrm{yr}$, (b) $10^{8} \mathrm{yr}$, (c) $10^{9} \mathrm{yr}$ and (d) $10^{10} \mathrm{yr}$. The blue colour represents low metallicity stellar populations $\left(10^{-4}\right.$ and $\left.4 \times 10^{-4}\right)$, the green colour, intermediate metallicity stellar populations $(0.004$ e 0.008$)$ and, the red colour, the high metallicity stellar populations (0.02 e 0.05$)$. The white cross represents the V1 position and its size $3 \sigma$ uncertainty. 

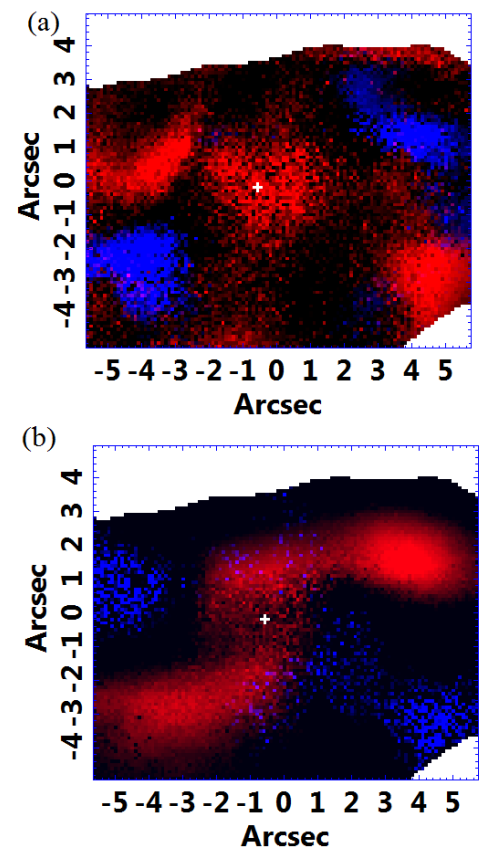

Figura 10.16: Maps of the flux fractions obtained with the spectral synthesis applied to the SIFS data cube of the stellar populations: (a) with high metallicity (0.02 and 0.05) and (b) with low metallicity $\left(10^{-4}\right.$ and $\left.4 \times 10^{-4}\right)$. The red colour represents the old stars, with $\sim 10^{10}$ years and the blue colour represents the young stars with $\sim 10^{7}$ years. The white cross represents the position of V1 and its size the $3 \sigma$ uncertainty.

metallicity in the circumnuclear regions, not only in the circumnuclear ring (Fig. 10.15a). There is a concentration of low and high metallicities stellar populations with ages between $10^{8}$ and $10^{9} \mathrm{yr}$ in the centre of the FOV (Figs. 10.15b and c). We notice a structure that is similar to two arms coming from the centre of the FOV, whose age is $\sim 10$ Gyrs with low metallicity stars.

Fig. 10.16 shows, mainly, the structures located at the circumnuclear ring of NGC 613. The map of Fig. 10.16(a) indicates the high metallicity stars. We see that the old stellar populations (in red) are located at regions opposite to the young stellar populations (in blue). We also see that, by comparing this image with Fig. 17(b) of Paper I, the areas of young stellar formation of this image are close to the two points where the ring meets the bar. The situation is inverse when we look to the low metallicity stellar populations map (Fig. 10.16b). Again, we can see that young and old stellar populations are located at opposite regions. However, where, in the image of high metallicity, there were young stars, in this image of low metallicity, there are old stars, and vice-versa. Such result is compatible with the "pearls on string" scenario (Böker et al. 2008, 2007 and Falcón- 

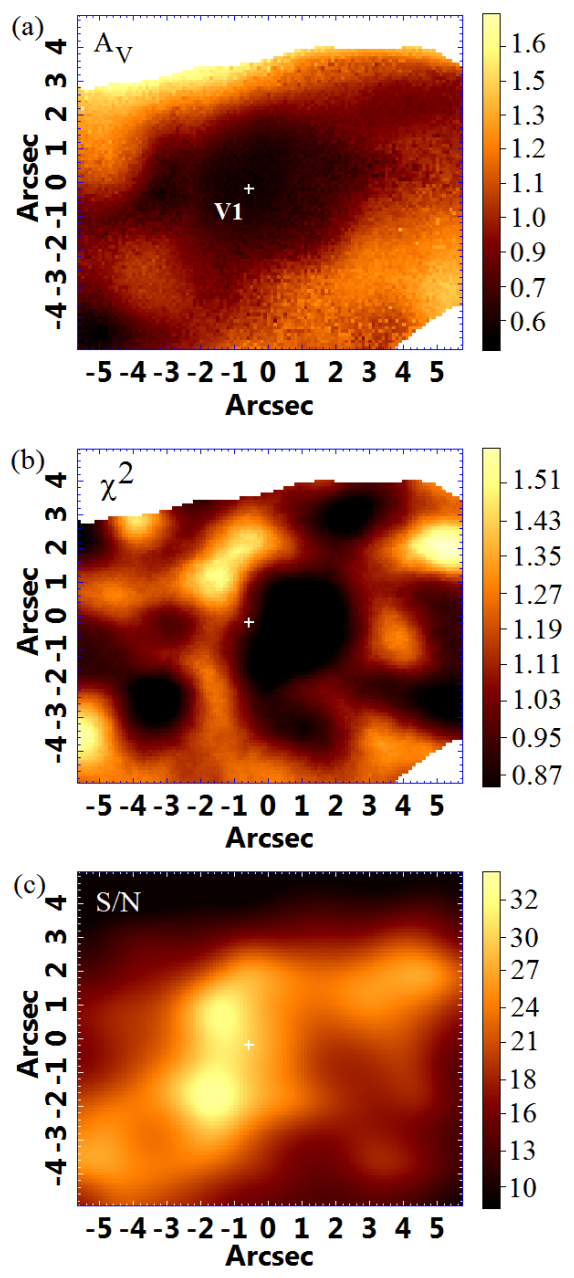

Figura 10.17: (a)Map of the extinction obtained from the spectral synthesis applied to SIFS data cube with STARLIGHT, (b)map of $\chi^{2}$ of the fits of this method and (c)map of the $\mathrm{S} / \mathrm{N}$ obtained from the spectral synthesis with pPXF method. This last map was used to mask the regions of the SIFS data cube maps used in the results with $\mathrm{S} / \mathrm{N}$ less than 10 . The white cross represents $\mathrm{V} 1$ position and its size $3 \sigma$ uncertainty.

Barroso et al. 2014), in which stellar populations are formed in the two points where the ring is being fed by the bar and, due to the rotation of the ring, as the star forming regions rotate the stellar populations get old and, then, the old stars are located at opposite sides from the young stellar populations. In the low metallicity results, the inversion of those positions relative to the high metallicity image, can be explained by the fact that those star forming regions (with low metallicity) might be turned around in the ring more than the high metallicity stars.

The $\mathrm{A}_{v}$ map (Fig. 10.17a) shows that most of the extinction comes from the circumnuclear regions, since in the centre the values are lower. The $\chi^{2}$ map (Fig. 10.17b) shows that the STARLIGHT fits were well succeed in the areas of the FOV where the results were 
considered. Such areas were determined by the map of S/N of Fig. 10.17(c), obtained with pPXF, that shows that the superior and the left lower FOV edge have values lower than 10. Thus, those regions were removed from the results due to high uncertainties. 
Capítulo 11

\section{NGC 157}

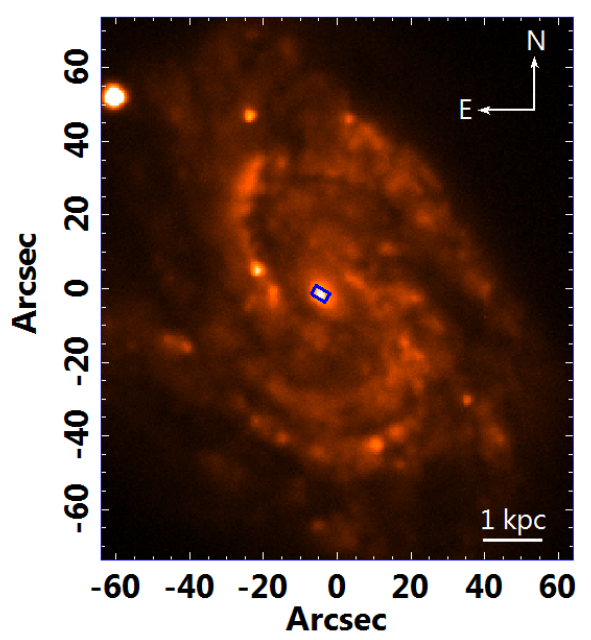

Figura 11.1: Imagem da galáxia NGC 157 obtida com o telescópio de 1.8m Perkins do Lowell Observatory na banda B do óptico. O quadrado azul representa o FOV do cubo dados do GMOS analisado neste estudo, orientado seguindo o PA da observação destes dados: $57^{\circ}$. A área do FOV do GMOS é de $2^{\prime} .8 \times$ $4 " .4$.

NCG 157 é uma galáxia do tipo SAB(rs)bc de Vaucouleurs et al., 1991) e está localizada a 12.90 Mpc de distância (Erwin e Debattista, 2017). Segundo Erwin e Debattista (2017), esta galáxia não possui uma barra e Eskridge et al. (2002) não detectaram uma barra

Tabela 11.1 - Propriedades de NGC 157. Com exceção do valor de $\sigma_{*}$, determinado por van den Bosch et al. (2015), os valores foram obtidos do catálogo Hyperleda.

\begin{tabular}{|c|c|}
\hline $\mathrm{M}_{B}$ & $-21.81 \pm 0.204$ \\
\hline $\mathrm{m}_{B}$ & $11.07 \pm 0.09$ \\
\hline $\mathrm{B}-\mathrm{V}$ & 0.67 \\
\hline$\sigma_{*}(\mathrm{~km} / \mathrm{s})$ dentro dos 3.5" centrais & $81.6 \pm 10.5$ \\
\hline Brilho superficial efetivo médio $\left(\mathrm{mag} / \mathrm{arcsec}^{2}\right)$ & $21.65 \pm 0.26$ \\
\hline
\end{tabular}



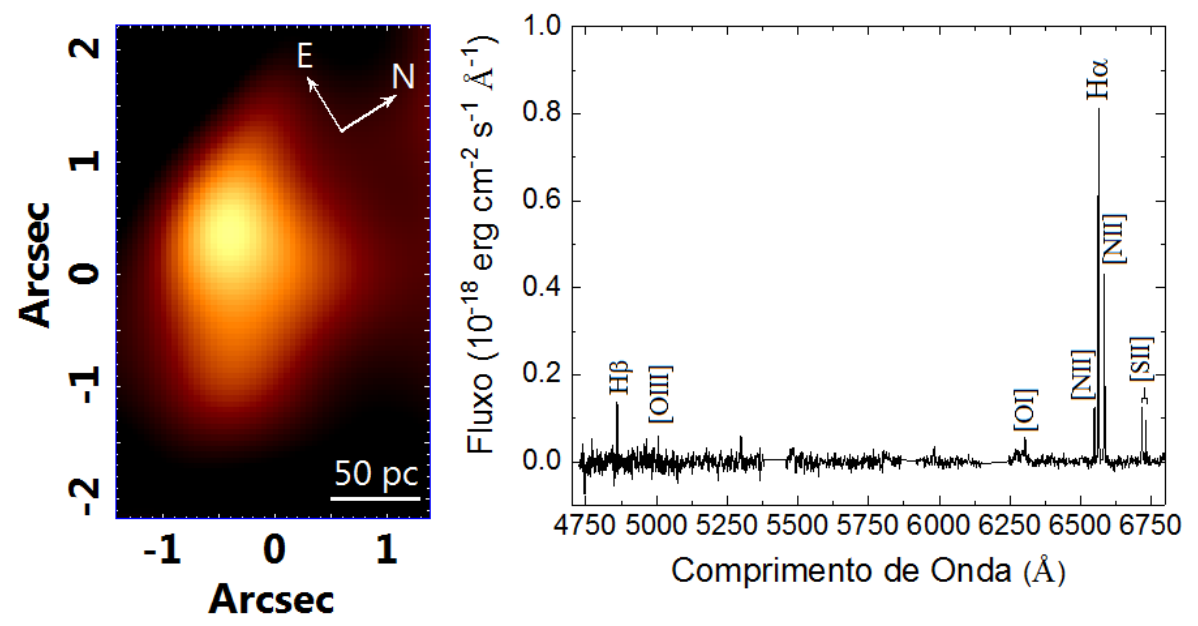

Figura 11.2: Imagem do cubo de dados obtido com GMOS do núcleo de NGC 157 colapsado ao longo do eixo espectral, juntamente com o espectro do núcleo estelar extraído do cubo, após a subtração do contínuo estelar, corrigido do redshift.

utilizando dados no NIR. Esses últimos autores ainda afirmam que o que aparenta ser uma barra no óptico pode ser apenas um efeito de projeção no NIR. Essa ausência da barra é até mesmo notável na Fig. 11.1. Porém, além de afirmar que esta galáxia possui uma barra no centro, Mulchaey et al. (1997) calcularam o seu tamanho: 12.5" ( 782 pc). Utilizando dados do Spitzer Survey of Stellar Structure in Galaxies (S4G), Buta et al. (2015) classificam NGC 157 como SA(s)bc, portanto, sem barra.

Pulatova et al. (2015) classificam a emissão nuclear de NGC 157 como Seyfert 2 com regiões HII no núcleo, mas não descrevem como chegaram a esse resultado. Esses autores ainda relatam que NGC 157 já foi classificada, de forma equivocada, como quasar por Véron-Cetty e Véron (2010). A partir de uma relação empírica do pitch angle dos braços espirais, Davis et al. (2014) derivaram a massa do buraco negro $\log \left(M / M_{\odot}\right)=7.67 \pm 0.19$.

Os dados desse objeto aqui analisados foram obtidos em 23 de Dezembro de 2014 com o IFU do GMOS do telescópio Gemini-Sul. O valor do FWHM da PSF usado no processo de deconvolução, calculado a partir da imagem de aquisição no comprimento de onda de $6300 \AA$, foi 0".95.

Após o tratamento de dados, foi feita uma imagem do cubo colapsado ao longo do eixo espectral e também foi extraído um espectro de uma região circular, com centro no núcleo estrelar e diâmetro igual ao FWHM da PSF dos dados (Fig. 11.2. É possível notar uma fonte central aparentemente estendida com linhas de emissão de $\mathrm{H} \beta$, [NII] $\lambda \lambda 6548,6584, \mathrm{H} \alpha$ 

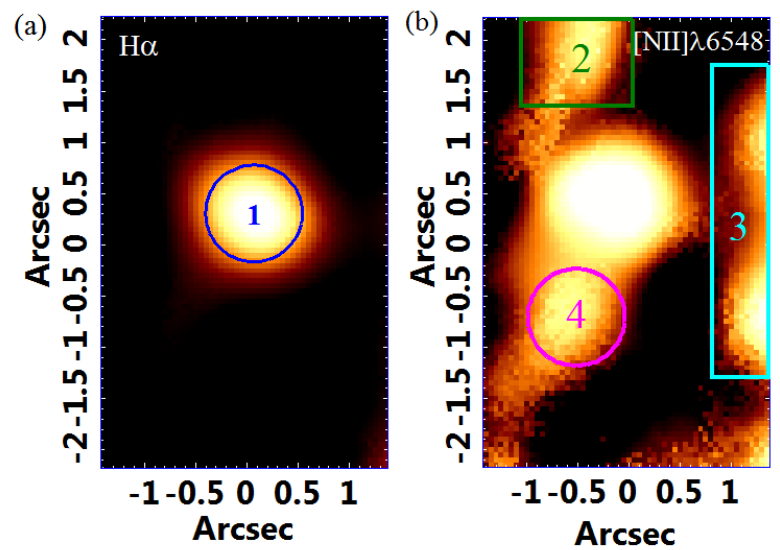

Figura 11.3: (a) Imagem de $\mathrm{H} \alpha$ extraída do cubo de gás de NGC 157. A imagem contém apenas uma região central emissora chamada de região 1. (b) Imagem da linha [NII] 6548 que apresenta a mesma morfologia espacial da imagem da linha $[\mathrm{NII}] \lambda 6584$, porém essa última apresenta valores consideravelmente mais elevados no núcleo, o que dificulta uma clara delimitação das reigões ao redor. Foram identificadas 4 regiões emissoras sinalizadas nas imagens (a) e (b). As áreas de extração dos espectros para o cálculo das razões de linhas estão indicadas pelos círculos (cujo diâmetro foi tomado como sendo o FWHM da PSF do cubo de dados) e pelos retângulos (cujas áreas são maiores do que a área da PSF dos dados).

e $[\operatorname{SiI}] \lambda \lambda 6716,6731$.

Como este cubo é consideravelmente ruidoso, não foi possível criar channel maps, mapas de velocidades do gás e curvas dos mapas de cinemática estelar. Além disso, os valores das razões de linhas também ficaram comprometidos. São necessárias novas observações com maior sinal-ruído $(\mathrm{S} / \mathrm{N})$ para estudar detalhadamente os fenômenos presentes no núcleo dessa galáxia.

\subsection{Emissão do gás}

Apesar do cubo de NCG 157 não possuir S/N excelente, foi possível identificar quatro regiões de emissão distintas a partir das imagens de emissão de $\mathrm{H} \alpha$ e da linha de [NII] $] 6548$ (Fig. 11.3), obtidas do cubo de gás.

A partir do cubo de gás foram extraídos espectros das 4 regiões emissoras. Os espectros das regiões 1 e 4 foram extraídos de áreas circulares cujo diâmetro foi tomado como sendo o FWHM da PSF dos dados. Já os espectros das regiões 2 e 3 foram extraídos de áreas retangulares, nesse caso maiores do que a área da PSF, por serem regiões que estavam na borda do FOV. Este cuidado foi tomado para aumentar o $\mathrm{S} / \mathrm{N}$ de tais regiões periféricas no FOV e assim evitar que seus espectros ficassem demasiadamente dominados por ruído. 


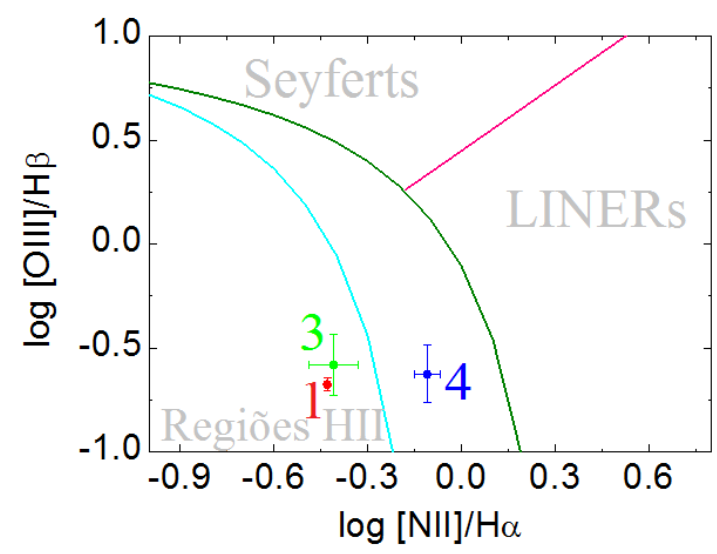

Figura 11.4: Diagrama de diagnóstico das regiões observadas no núcleo de NGC 157 a partir do cubo de dados do GMOS. Devido ao baixo S/N de [OIII] $\lambda 5007$ no espectro da região 2, não foi possível incluir essa região nos diagramas. As regiões 1, 3 e 4 estão identificadas por números próximos aos pontos. A curva em verde-escuro representa a estimativa para o limite de ionização por um starburst determinada por Kewley et al. (2001). A divisão entre regiões HII e AGNs determinada por Kauffmann et al. (2003) está representada pela curva em ciano. A divisão entre Seyferts e LINERs determinada por Schawinski et al. (2007) está indicada em magenta.

Tabela 11.2 - Razões de linhas e luminosidades calculadas a partir dos fluxos integrados de $\mathrm{H} \alpha$ dos espectros das 4 regiões observadas no núcleo de NGC 157.

\begin{tabular}{|c|c|c|c|c|}
\hline Razões de Linhas & Região 1 & Região 2 & Região 3 & Região 4 \\
\hline$[\mathrm{OIII}] / \mathrm{H} \beta$ & $0.211 \pm 0.016$ & & $0.26 \pm 0.11$ & $0.24 \pm 0.09$ \\
{$[\mathrm{NII}] / \mathrm{H} \alpha$} & $0.372 \pm 0.004$ & $0.62 \pm 0.13$ & $0.39 \pm 0.08$ & $0.78 \pm 0.08$ \\
{$[\mathrm{OI}] / \mathrm{H} \alpha$} & $0.10 \pm 0.05$ & $0.34 \pm 0.18$ & $0.28 \pm 0.11$ & $0.19 \pm 0.11$ \\
$([\mathrm{SII}] \lambda 6716+\lambda 6731) / \mathrm{H} \alpha$ & $0.243 \pm 0.014$ & $0.14 \pm 0.08$ & $0.28 \pm 0.06$ & $0.30 \pm 0.05$ \\
{$[\mathrm{SII}] \lambda 6716 /[\mathrm{SII}] \lambda 6731$} & $1.10 \pm 0.13$ & $1.0 \pm 1.1$ & $1.3 \pm 0.5$ & $1.2 \pm 0.4$ \\
\hline Luminosidade de $\mathrm{H} \alpha\left(10^{3} \mathrm{~L}_{\odot}\right)$ & $256.0 \pm 1.3$ & $0.77 \pm 0.06$ & $38 \pm 3$ & $2.88 \pm 0.15$ \\
\hline
\end{tabular}

Como não havia linhas blendadas nem componentes largas das linhas de emissão, o cálculo das razões de linhas foi feito através de integração direta. A partir das razões de linhas no óptico é possível construir diagramas de diagnóstico Baldwin et al. 1981, Kewley et al. 2001, Kauffmann et al. 2003 e Kewley et al. 2006) para determinar a natureza de emissão das regiões observadas (Fig.11.4). Os valores das razões de linhas estão na Tabela 11.2. O cálculo das incertezas foi realizado como descrito na seção 3.5.4.

A região 1 é a de maior destaque no núcleo de NGC 157 por ter maior luminosidade (ver Tabela 11.2). Essa região possui razões de linhas compatíveis com as de regiões HII. Não se pode concluir qual classificação seria compatível com a emissão da Região 2, devido à falta da emissão de [OIII] $\lambda 5007$, que apresenta intensidade similar ao do ruído espectral. 

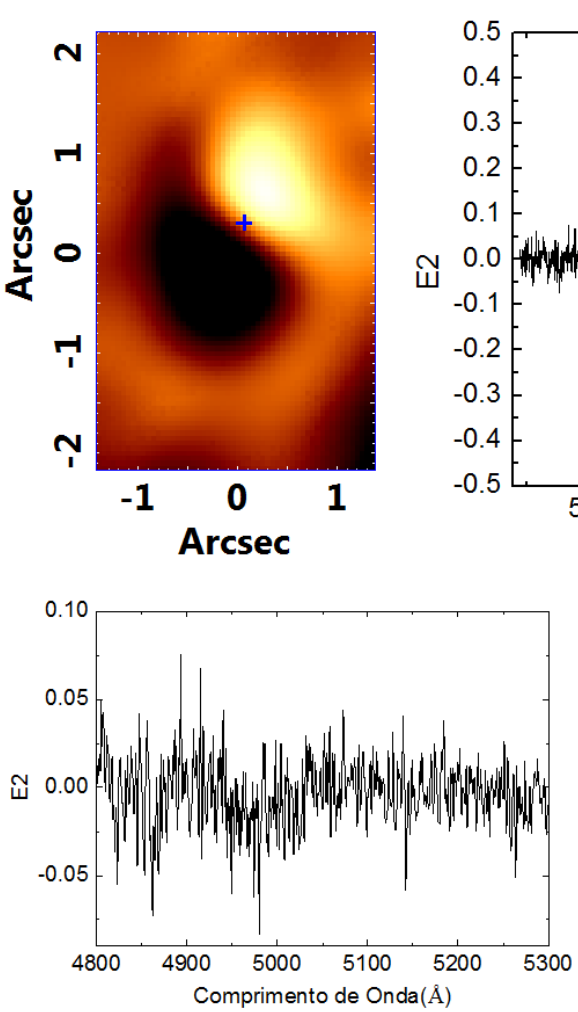
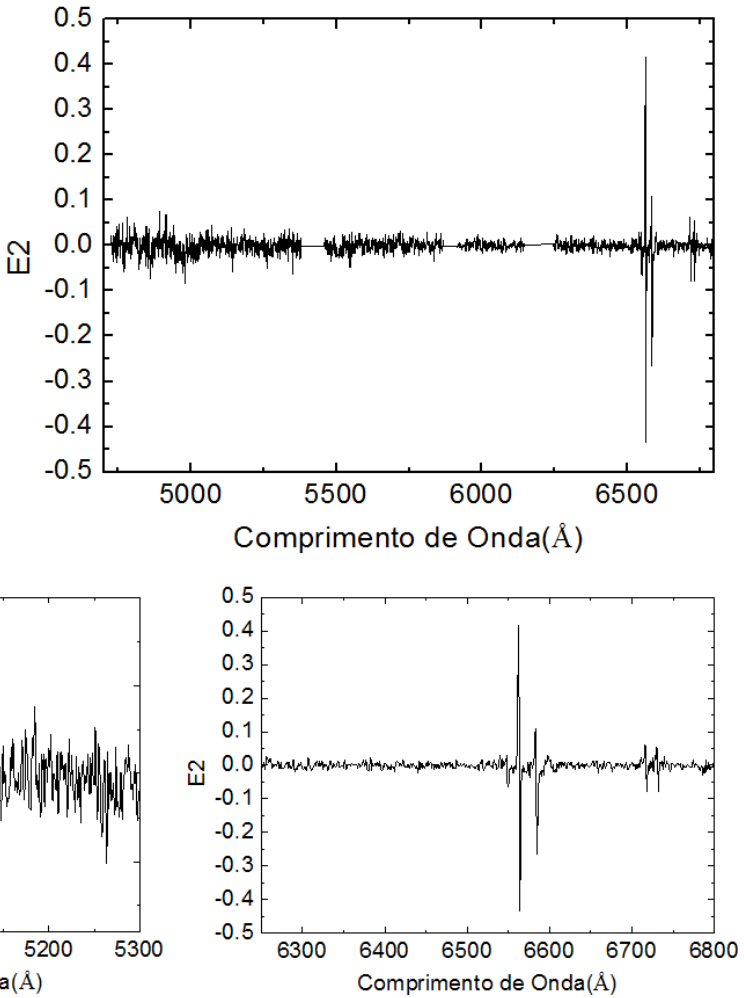

Figura 11.5: Tomograma e autovetor 2 da Tomografia PCA aplicada ao cubo de gás de NGC 157. A cruz azul representa o centro da Região 1 e seu tamanho, a incerteza de $3 \sigma$.

Se o fluxo de [OIII] $\lambda 5007$ for igual ao ruído na mesma região espectral da linha em questão, o valor do $\log [\mathrm{OIII}] / \mathrm{H} \beta \sim-0.08$. Considerando as demais razões de linhas, a emissão dessa região é consistente com a de regiões HII. Considerando as incertezas, todas as demais regiões possuem também emissão compatível com as de regiões HII. Portanto, não há evidências de um núcleo ativo na região nuclear desta galáxia.

\subsection{Cinemática do gás}

A partir do cubo de gás fez-se o estudo da cinemática do gás aplicando a Tomografia PCA. O segundo autovetor da Tomografia PCA aplicada ao cubo de gás (Fig. 11.5) mostra um padrão cinemático, já que há correlações com as asas azuis das linhas de emissão e anti-correlação com as asas vermelhas das mesmas. Ou seja, as áreas claras do tomograma associado a esse autovetor, mostram gás com emissão em blueshift e, as áreas escuras, gás com emissão em redshift. Nota-se uma possível rotação de gás, ao redor do núcleo, na região mais central do FOV. Porém nas bordas a informação não é interpretável (podendo 


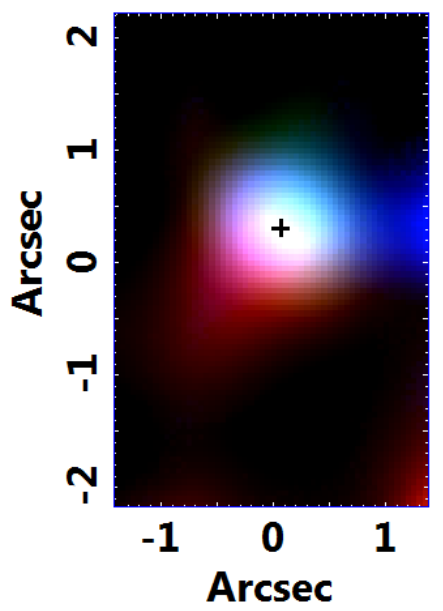

Figura 11.6: Composição RGB de H $\alpha$ do cubo de gás de NGC 157. A cor vermelha representa o gás com emissão em redshift ( $55 \mathrm{~km} \mathrm{~s}^{-1} \lesssim \mathrm{v} \lesssim 100 \mathrm{~km} \mathrm{~s}^{-1}$ ), a cor verde, gás com velocidades próximas de zero $\left(-36 \mathrm{~km} \mathrm{~s}^{-1} \lesssim \mathrm{v} \lesssim 10 \mathrm{~km} \mathrm{~s}^{-1}\right)$ e a cor azul, gás com emissão em blueshift $\left(-130 \mathrm{~km} \mathrm{~s}^{-1} \lesssim \mathrm{v} \lesssim-80 \mathrm{~km}\right.$ $\mathrm{s}^{-1}$ ). As velocidades foram calculadas com relação ao comprimento de onda de repouso da linha de $\mathrm{H} \alpha$. A cruz preta representa o centro da Região 1 e seu tamanho a incerteza espacial em $3 \sigma$.

ser devido ao baixo $\mathrm{S} / \mathrm{N}$ ). A fração de variância explicada por este autovetor é de $\sim 5 \%$.

Uma outra forma de analisar a cinemática do gás é criando composições RGB das linhas de emissão. Neste caso, foi criada uma composição RGB da linha de $\mathrm{H} \alpha$, a mais relevante neste cubo de dados. Essa composição RGB reflete o mesmo padrão observado no Tomograma 2: nota-se uma bipolaridade na região mais central do FOV e algumas irregularidades nas bordas. Não se pode confirmar se essas irregularidades são reais, mas novamente tem-se uma possível rotação na região mais central do FOV.

\subsection{Arqueologia estelar}

A síntese espectral foi aplicada, utilizando o software STARLIGHT, ao cubo após o tratamento, para maiores detalhes ver seção 3.5.2. Como foi dito anteriormente, este cubo de dados é consideravelmente ruidoso. Por isso, consideramos apenas regiões onde o S/N > 10 e isso reduziu bastante a área estudada, como visto nos mapas da Fig. 11.7 . O histograma da Fig. 11.7(a) mostra o resultado geral da síntese espectral, considerando apenas as regiões cujo $\mathrm{S} / \mathrm{N}>10$. Nota-se que a maior fração de fluxo é de populações com $10^{9}$ anos de metalicidade intermediária (0.004 e 0.008). Ao observar o mapa da Fig. 11.7(c), nota-se que tais populações com $10^{9}$ anos estão espalhadas pela região circumnuclear. As populações com alta metalicidade $(0.02$ e 0.05$)$ com $\sim 10^{6}$ anos estão concentradas 

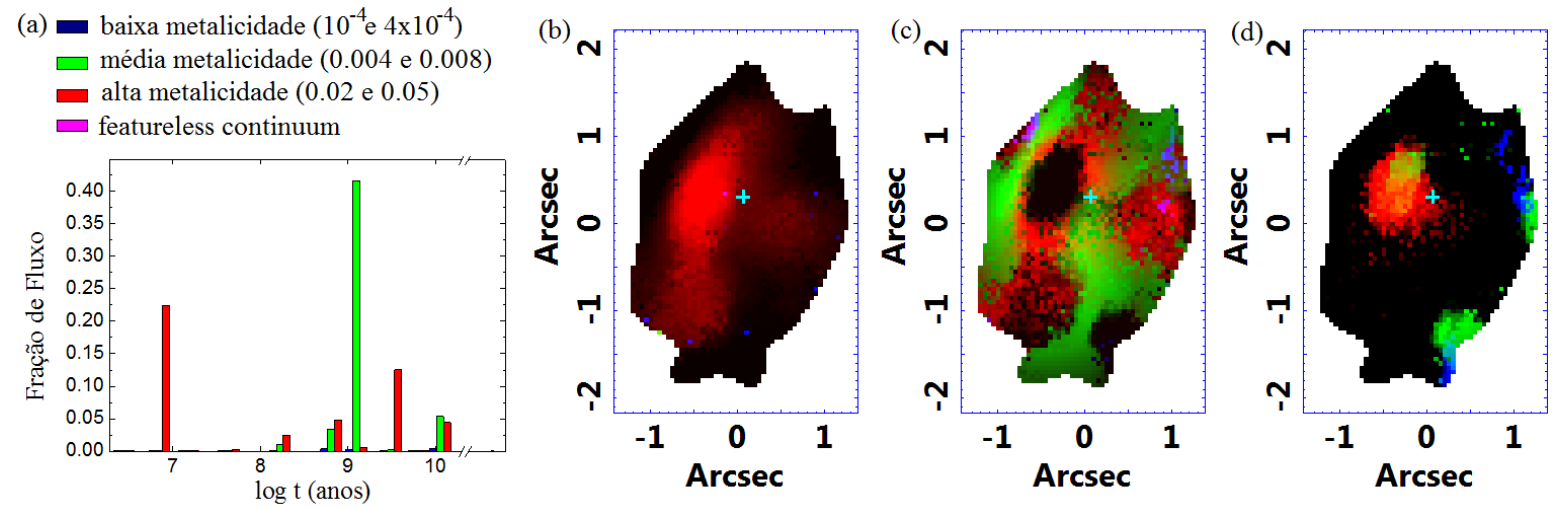

Figura 11.7: (a) Histograma dos resultados da síntese espectral aplicada a todo o cubo de dados de NGC 157 , exceto a regiões onde $\mathrm{S} / \mathrm{N}<10$. Não foi detectada nenhuma fração de fluxo atribuída à lei de potência com índice espectral igual a 1.5 (featureless continuum), que deveria aparecer após o break no histograma. Também são mostrados mapas de fluxo de populações com idades de (b) $10^{6}$ anos, (c) $10^{9}$ anos e (d) $10^{10}$ anos. A legenda de cores representa as metalicidades tanto para o histograma quanto para os mapas. A cruz em ciano representa o centróide da Região 1, e seu tamanho a incerteza de $3 \sigma$.

principalmente em uma região próxima ao centro da Região 1 (ver mapa da Fig 11.7b) e representam $\sim 25 \%$ da fração de fluxo total. As populações com $10^{10}$ anos também estão concentradas na mesma região próxima à Região 1, porém a fração de fluxo atribuída a elas é consideravelmente baixa.

O único evento passado que foi relevante para formação estelar neste núcleo ocorreu há $\sim 10^{9}$ anos em toda região circumnuclear. Apenas recentemente $\left(\sim 10^{6}\right.$ anos $)$ houve outra formação estelar relevante em uma região específica do FOV. Entre os dois eventos não houve nenhuma formação estelar considerável, o que sugere que este evento de $10^{9}$ anos esteja isolado temporalmente, podendo indicar a ocorrência de um minor merger com uma galáxia satélite nesse período, o que pode ter trazido gás para a região central.

O mapa de extinção obtido através da síntese espectral (Fig. 11.8 a) mostra que a extinção está presente em todo campo, concentrando-se em regiões aleatórias ao longo do FOV. O mapa de $\chi^{2}$ (Fig. 11.8b) mostra que o ajuste foi aceitável em toda região considerada como resultado, com valores próximos de 1, porém as regiões mais centrais apresentam os maiores valores de $\chi^{2}$. O mapa de S/N (Fig. 11.8c) obtido da síntese espectral foi utilizado para avaliar quais regiões possuíram $\mathrm{S} / \mathrm{N}$ considerável (neste caso utilizamos o limite de $\mathrm{S} / \mathrm{N}>10$ ) para serem levadas em conta nos resultados. A maior parte das bordas do FOV foram descartadas. 

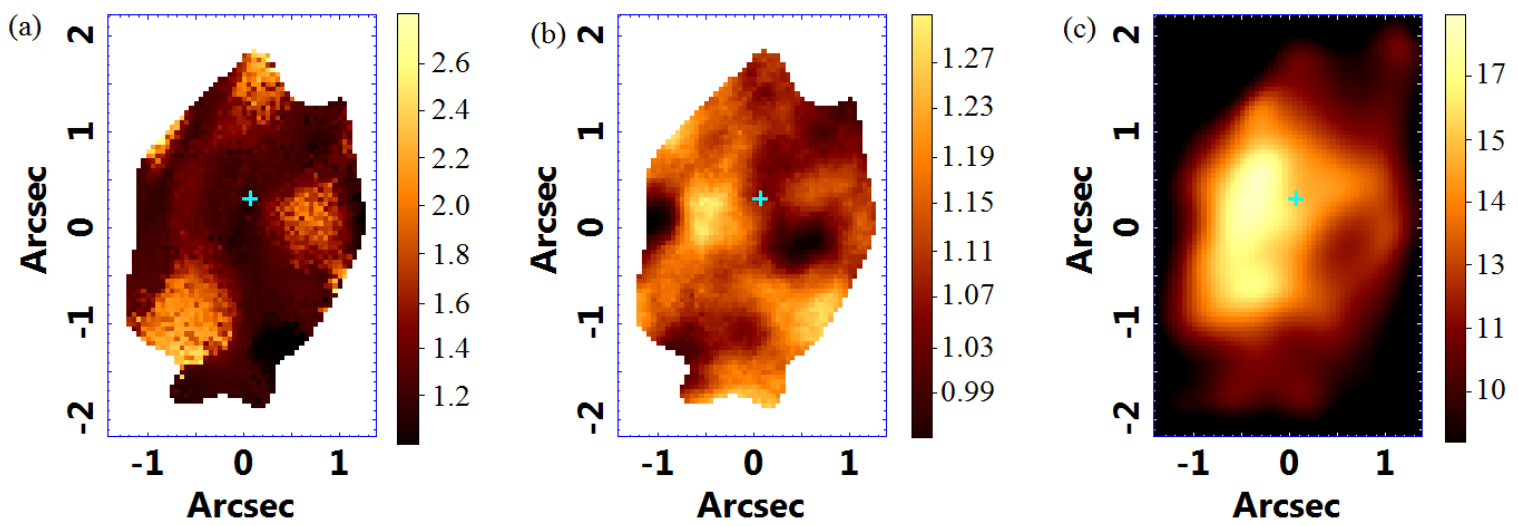

Figura 11.8: (a) Mapa da extinção obtido da síntese espectral de NGC 157, (b) mapa do $\chi^{2}$ dos ajustes da síntese espectral e (c) mapa do $\mathrm{S} / \mathrm{N}$, usado para mascarar regiões cujo $\mathrm{S} / \mathrm{N}<10 \mathrm{~A}$ cruz em ciano representa o centróide da Região 1, e seu tamanho a incerteza de $3 \sigma$.

\subsection{Cinemática estelar}

A síntese espectral realizada com o método pPXF nos permite determinar parâmetros cinemáticos com maior precisão, já que os espectros da base utilizada no método são convoluídos com funções Gauss-Hermite e resultam, quando o processo é aplicado ao cubo dados, em mapas dos coeficientes dessa função. Os três primeiros (os únicos analisados neste trabalho) são: $h_{1}$, que representa a velocidade radial estelar, $h_{2}$, que corresponde à dispersão de velocidades estelar e $h_{3}$, que retorna as assimetrias nos perfis das absorções com relação a perfis gaussianos.

O mapa da Fig. 11.9(a) é bastante irregular e os valores de velocidades obtidos são baixos, o que pode indicar que o principal movimento estelar pode estar ocorrendo perpendicularmente à linha de visada. Como a maior parte do FOV foi prejudicada pelo baixo $\mathrm{S} / \mathrm{N}$ nas bordas, pode ser que a cinemática estelar esteja acontecendo numa escala maior, acompanhando a cinemática do bojo da galáxia.

O mapa de dispersão de velocidades ( Fig. 11.9b) apresenta um pico próximo à Região 1, mas também é bastante irregular, contendo duas regiões com valores de dispersão elevados. O mapa de $h_{3}$ (Fig. 11.9 ) não apresenta um padrão interpretável e seus valores são baixos.

Como o mapa de dispersão de velocidades estelar é significativamente indefinido, foi feita uma média ponderada em intensidades, como descrito na seção 3.5.6, que resultou num valor para o $\sigma$ central $\sigma=90 \pm 6 \mathrm{~km} / \mathrm{s}$. Esse valor é compatível com o obtido por van den Bosch et al. (2015). 

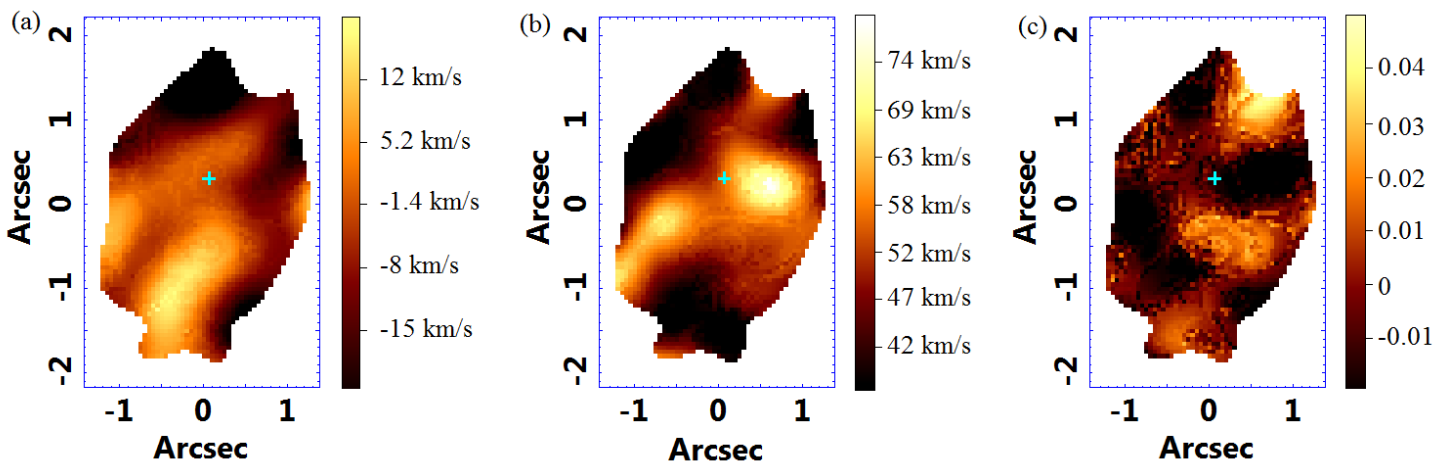

Figura 11.9: (a) Mapa da velocidade radial estelar, (b) mapa da dispersão de velocidades estelar e (c) mapa do coeficiente $h_{3}$ obtidos com o método pPXF. As áreas cujo $\mathrm{S} / \mathrm{N}<10$ foram removidas dos mapas. A cruz em ciano representa o centróide da Região 1, e seu tamanho a incerteza de $3 \sigma$.

\subsection{Conclusões}

- Não há evidências da presença de um AGN nesta galáxia.

- Há, pelo menos, três regiões HII no centro dessa galáxia. Foram observadas mudanças de razões de linhas em diferentes direções do FOV no cubo de dados mas, devido ao baixo $\mathrm{S} / \mathrm{N}$, não foi possível determinar com precisão a natureza das demais regiões.

- Houve três eventos de formação estelar relevantes neste núcleo: um recente $(\sim 10$ milhões anos), outro há $\sim 1$ bilhão de anos e o evento que formou o bojo estelar há $\sim 10$ bilhões de anos. O evento que gerou populações estelares há $\sim 1$ bilhão de anos parece relativamente isolado temporalmente e pode indicar um possível minor merger do núcleo dessa galáxia com uma galáxia satélite.

- Existe uma possível rotação de gás na região HII central (que chamamos de Região 1), enquanto que não há uma confirmação de rotação estelar com relação à linha de visada. É possível que a cinemática estelar esteja ocorrendo preferencialmente na direção perpendicular à linha de visada ou num FOV maior.

- A média ponderada em intensidade para a dispersão de velocidades estelar na região do FOV do GMOS é $90 \pm 6 \mathrm{~km} / \mathrm{s}$. 
Capítulo 12

\section{NGC 2442}

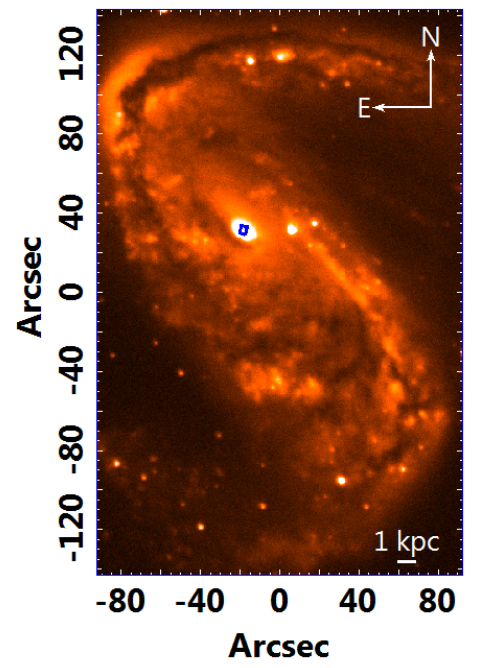

Figura 12.1: Imagem da galáxia NGC 2442 obtida com o telescópio de 1.5m com o Cerro Tololo InterAmerican Observatory (CTIO) na banda B do óptico. O retângulo em azul representa o FOV do cubo de dados do GMOS analisado neste estudo. O PA dos dados do GMOS é $167^{\circ}$. A área do FOV do GMOS é de $2 " .95 \times 4 "$.

NCG 2442 é uma galáxia tipo SAB(s)bc pec (de Vaucouleurs et al., 1991) e está localizada a $21.8 \pm 1.4 \mathrm{Mpc}$ (Cartier et al. 2017). Sua barra possui 66 " de diâmetro, $\sim 7$ kpc, além de apresentar um possível anel interno com um diâmetro de 3.3 Bajaja et al. 1995). A partir de estudos da cinemática de $\mathrm{H} \alpha$ e de propriedades de formação estelar, Mihos e Bothun (1997) concluíram que NGC 2442 está passando por uma interação com outra galáxia (AM 0738-692) que se iniciou por volta de 150-250 milhões de anos e essas galáxias irão passar por um merger em $\sim 3$ bilhões de anos. Ainda segundo os autores esse merger será tão violento que irá transformar a morfologia de NGC 2442 para Sa ou, até mesmo, S0. 


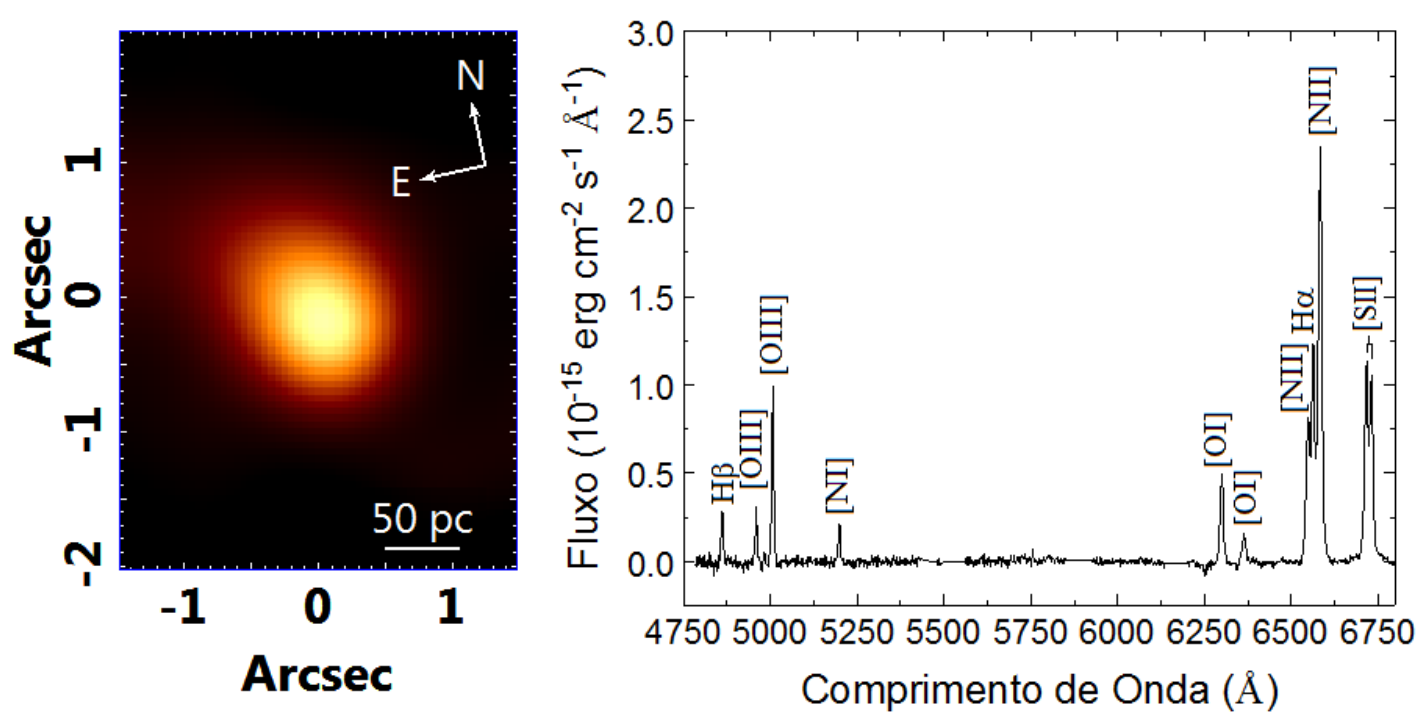

Figura 12.2: Imagem do cubo de dados após o tratamento colapsado ao longo do eixo espectral e espectro do núcleo estelar extraído do cubo de gás, corrigido de redshift.

A atividade nuclear foi classificada como tipo LINER a partir de razões de linhas no óptico (Bajaja et al., 1999). Esses autores também detectaram a presença de um anel ou disco nuclear com raio de $12 " .5$ ( $1.3 \mathrm{kpc}$, considerando a distância da galáxia) a partir da curva de rotação de CO. Além disso, Pancoast et al. (2010) afirmam que o núcleo é a região mais obscurecida desta galáxia e que $\mathrm{H} \alpha$ possui uma emissão com morfologia aproximadamente espiral na galáxia e está contida, em sua maior parte, dentro de um anel circumnuclear, observado em $8 \mu \mathrm{m}$, com raio, determinado pelos autores, de $\sim 0.8 \mathrm{kpc}$. A partir da correlação entre o pitch angle e a massa do buraco negro, Davis et al. (2014) calcularam a massa do buraco negro de NGC 2442: $\log \left(M / M_{\odot}\right)=7.28 \pm 0.33$.

Os dados desse objeto aqui analisados foram obtidos em 23 de Fevereiro de 2014 com o IFU do GMOS do telescópio Gemini-Sul. O valor do FWHM da PSF usado no processo de deconvolução, obtido a partir da imagem de aquisição no comprimento de onda de $6300 \AA$ foi de $0 " .74$.

A imagem do cubo colapsado ao longo do eixo espectral do cubo após o tratamento (Fig. 12.2 mostra uma região emissora central. O espectro do núcleo (Região 1 da Fig. 12.3 mostra as principais linhas de emissão dessa região espectral. Não foram detectadas componentes largas das linhas da BLR. 
Tabela 12.1 - Propriedades de NGC 2442. Os valores foram obtidos do catálogo Hyperleda. Não foi encontrado o valor da dispersão de velocidades estelar nuclear dessa galáxia na literatura.

\begin{tabular}{|c|c|}
\hline $\mathrm{M}_{B}$ & $-20.91 \pm 0.96$ \\
\hline $\mathrm{m}_{B}$ & $11.44 \pm 0.20$ \\
\hline $\mathrm{B}-\mathrm{V}$ & 0.89 \\
\hline$\sigma_{*}(\mathrm{~km} / \mathrm{s})$ & \\
\hline Brilho superficial efetivo médio $\left(\mathrm{mag} / \mathrm{arcsec}^{2}\right)$ & $23.12 \pm 0.30$ \\
\hline
\end{tabular}

\subsection{Emissão do gás}

A Região 1, representada pela imagem de [OI] $\lambda 6300$ (Fig.12.3), possui a emissão mais relevante do cubo de dados, cujo espectro está representado na Fig. 12.2.

A imagem de $\mathrm{H} \alpha$ (ver RGB da Fig. 12.8) do cubo de gás possui a mesma morfologia da imagem de $[\mathrm{OI}] \lambda 6300$ e não aparenta ser estendida. Essa imagem não é suficiente para detectar outras possíveis regiões de emissão, pois o brilho da Região 1 é muito elevado e ofusca as demais regiões do FOV.

A imagem da razão de $\mathrm{H} \alpha /[\mathrm{N}$ II $] \lambda 6584$ destaca as regiões que possuem emissão significativa em $\mathrm{H} \alpha$. Com isso, é possível ver algumas regiões que se encontram nas bordas do FOV deste cubo de dados (Fig,12.3). Com algumas mudanças na LUT, foi possível delimitar 5 regiões nomeadas de 2 a 6 .

A partir dos espectros extraídos do cubo de gás, utilizando as áreas delimitadas na Fig 12.3, calcularam-se as razões de linhas das 6 regiões em questão. Devido ao baixo S/N na parte azul do espectro das regiões 3, 4 e 6, não foi possível calcular o fluxo integrado da linha de $\mathrm{H} \beta$ e, portanto, a correção da extinção, feita a partir da razão $\mathrm{H} \alpha / \mathrm{H} \beta$, não pôde ser aplicada a esses espectros. A tabela 12.2 mostra as razões de linhas calculadas, bem como a luminosidade da linha de $\mathrm{H} \alpha$ das regiões detectadas.

Tabela 12.2 - Razões de linhas e luminosidades obtidas a partir do fluxo integrado de H $\alpha$ das 6 regiões detectadas no núcleo de NGC 2442.

\begin{tabular}{|c|c|c|c|c|c|c|}
\hline Razões de Linhas & Região 1 & Região 2 & Região 3 & Região 4 & Região 5 & Região 6 \\
\hline$[\mathrm{OIII}] / \mathrm{H} \beta$ & $2.81 \pm 0.12$ & $1.72 \pm 0.18$ & & & $1.72 \pm 0.22$ & \\
\hline$[\mathrm{NII}] / \mathrm{H} \alpha$ & $2.23 \pm 0.10$ & $1.61 \pm 0.07$ & $1.27 \pm 0.08$ & $1.73 \pm 0.13$ & $1.83 \pm 0.06$ & $1.91 \pm 0.03$ \\
\hline$[\mathrm{OI}] / \mathrm{H} \alpha$ & $0.460 \pm 0.019$ & $0.270 \pm 0.012$ & $0.16 \pm 0.06$ & $0.39 \pm 0.05$ & $0.377 \pm 0.016$ & $0.43 \pm 0.03$ \\
\hline$([\mathrm{SII}] \lambda 6716+\lambda 6731) / \mathrm{H} \alpha$ & $1.71 \pm 0.08$ & $1.24 \pm 0.05$ & $0.98 \pm 0.11$ & $1.40 \pm 0.07$ & $1.60 \pm 0.06$ & $1.72 \pm 0.06$ \\
\hline$[\mathrm{SII}] \lambda 6716 /[\mathrm{SII}] \lambda 6731$ & $1.03 \pm 0.05$ & $1.16 \pm 0.03$ & $1.5 \pm 0.3$ & $1.20 \pm 0.06$ & $1.39 \pm 0.05$ & $1.29 \pm 0.08$ \\
\hline Luminosidade de $\mathrm{H} \alpha\left(10^{4} \mathrm{~L}_{\odot}\right)$ & $167 \pm 7$ & $34.6 \pm 1.3$ & $1.20 \pm 0.03$ & $2.38 \pm 0.10$ & $50.7 \pm 1.6$ & $1.681 \pm 0.017$ \\
\hline
\end{tabular}



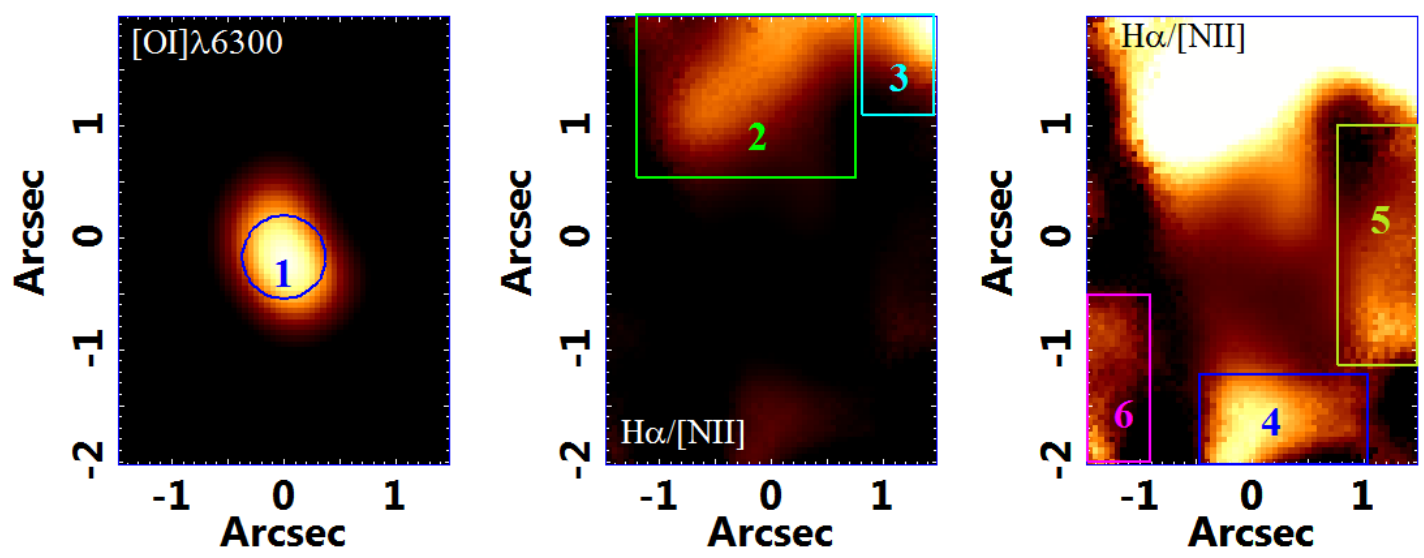

Figura 12.3: Imagens das principais regiões emissoras do núcleo de NGC 2442. Foram detectadas 6 regiões, sendo a Região 1, o núcleo e as demais algumas regiões circumnucleares. A imagem de $\mathrm{H} \alpha /[\mathrm{NII}] \lambda 6584$ mostra as regiões nas quais a emissão de $\mathrm{H} \alpha$ é mais relevante, que são as regiões na borda do FOV (duas LUTs foram utilizadas para a detecção das 5 regiões). Por outro lado, a imagem de [OI] $] 6300$ revela a emissão da região de ionização parcial, geralmente presente em torno de AGNs. O círculo azul e as áreas retangulares foram utilizados para a extração dos espectros para o cálculo das razões de linhas. A área do círculo da Região 1 é igual à área da PSF e as áreas retangulares possuem áreas maiores do que a da PSF.

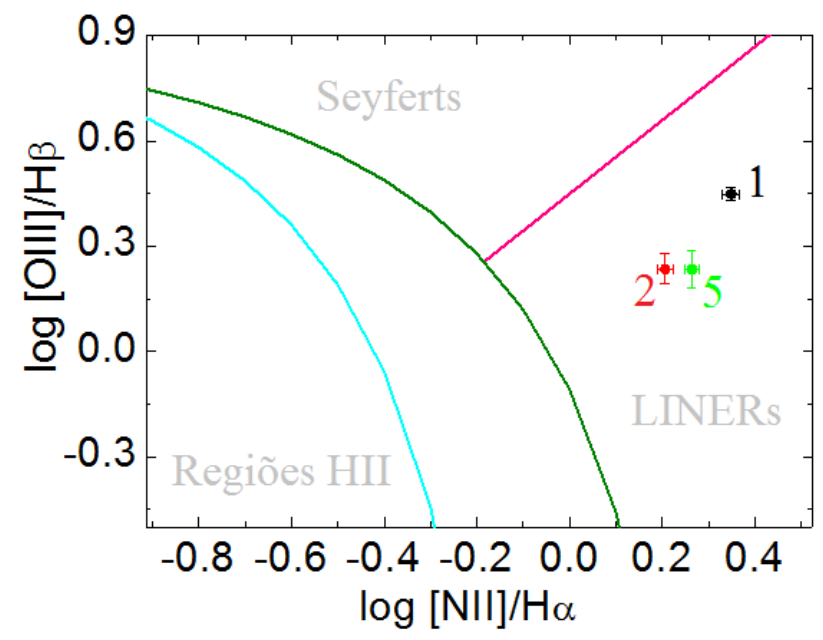

Figura 12.4: Diagrama de diagnóstico das regiões observadas no núcleo de NGC 2442 a partir do cubo de dados do GMOS. Devido ao baixo $\mathrm{S} / \mathrm{N}$ de $\mathrm{H} \beta$ nos espectros das regiões 3, 4 e 6, não foi possível incluir essas regiões nos diagramas. As regiões 1, 2 e 5 estão identificadas por números próximos aos pontos. A curva em verde-escuro representa a estimativa para o limite de ionização por um starburst determinada por Kewley et al. (2001). A divisão entre regiões HII e AGNs determinada por Kauffmann et al. (2003) está representada pela curva em ciano. A divisão entre Seyferts e LINERs determinada por Schawinski et al. (2007) está indicada em magenta. 

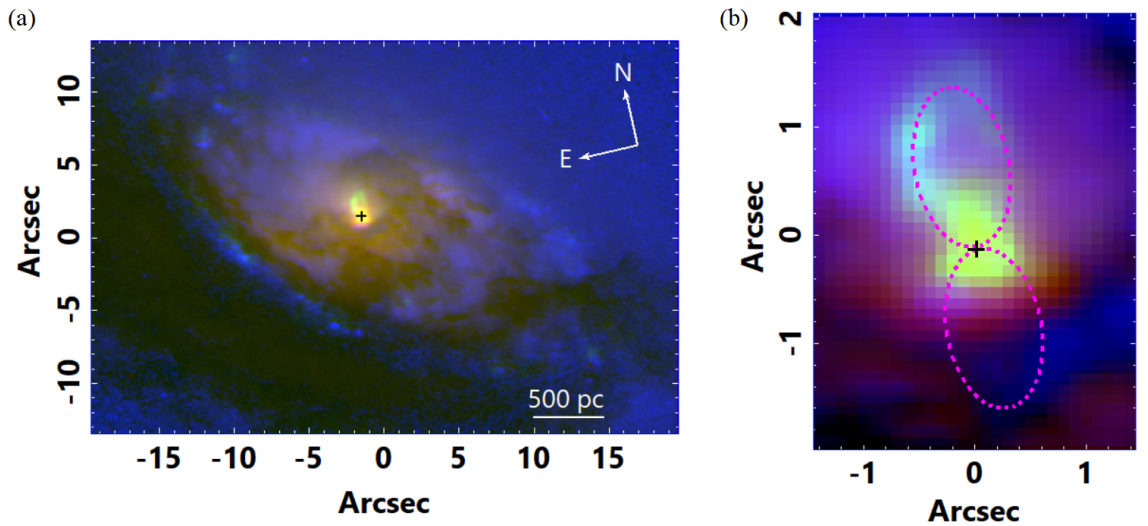

Figura 12.5: Composição RGB dos filtros do HST: em vermelho o filtro F814W, em verde o filtro F658N e em azul F814W-F435W (I-B). O painel (a) mostra um FOV mais amplo, enquanto que o painel (b) mostra o FOV do cubo de dados do GMOS. A cruz representa o centróide da emissão de [OI] $\lambda 6300$ propagado para as imagens do HST. O seu tamanho não representa a incerteza no painel (a), apenas no painel (b) onde os pixels podem ser resolvidos, mas a incerteza considerada é levando em conta os spaxels do GMOS. Em (b) foi estimada a morfologia de uma ampulheta, que representa as paredes do cone de ionização. O vértice desta estrutura é compatível com o núcleo.

O diagrama de diagnóstico da Fig. 12.4 mostra que as regiões 1, 2 e 5 possuem razões de linhas compatíveis com as de LINERs, sendo a Região 1 com maior grau de ionização. Considerando as razões de linhas das regiões 3, 4 e 6 que puderam ser calculadas, nota-se que também são compatíveis com as razões de linhas de LINERs. Com isso, existem muitas hipóteses para emissão dessas regiões, dentre elas, serem partes da NLR do AGN central.

\subsubsection{Imagens do Hubble Space Telescope}

Para continuação da análise deste objeto, obtiveram-se dados do arquivo público do HST desta galáxia, com objetivo de estudar melhor as estruturas nucleares. Os dados foram tomados em 20 de Outubro de 2006 com o Wide Field Channel do HST dentro do programa 10803 (principal investigator (PI): Stephen Smartt). O tempo de exposição varia entre os filtros: em F435W foi 1580 s, em F658N foi 1350 s e em F814W foi 1200 s. O tamanho dos spaxels das imagens do HST é de 0.1".

Para fazer uma comparação direta com os dados do GMOS, a imagem do filtro F435W foi convoluída com a PSF do cubo de dados do GMOS e, então, foi redimensionada para que o centróide e tamanho da imagem coincidissem com o centróide e tamanho da imagem do contínuo azul do cubo de dados do GMOS.

A Fig. 12.5(a) é uma composição RGB dos filtros obtidos com o HST. Ela mostra 


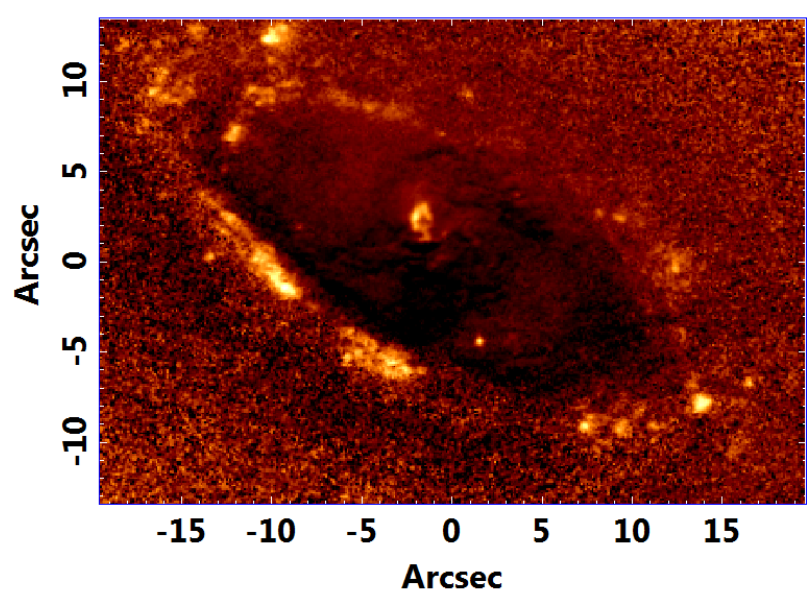

Figura 12.6: Imagem da diferença entre os filtros F814W e F658N em escala de magnitude (I-H $\alpha$ ). As regiões escuras representam os locais onde há extinção por poeira.

uma emissão na região central e um aparente disco estelar. As regiões escuras são as que apresentam extinção por poeira. As áreas vermelhas revelam a emissão mais intensa em maiores comprimentos de onda, que é coincidente com as áreas escuras da imagem. A emissão de $\mathrm{H} \alpha(\mathrm{F} 658 \mathrm{~N})$ é central e, ao observar a região do FOV do GMOS (Fig. 12.5p), nota-se que, além da emissão central no núcleo, há uma emissão estendida ao Norte, que tem uma morfologia que aparenta um arco. Esta estrutura sugere que esta emissão esteja associada às paredes do cone de ionização. Essas paredes são conhecidas por formar uma morfologia parecida com uma ampulheta (delineada na imagem). O gás em baixas velocidades no cone de ionização está localizado nesta ampulheta, enquanto que o gás em altas velocidades está localizado na região interna (ver May e Steiner 2017). Devido ao obscurecimento na região Sul do núcleo, não é possível ver o outro lado do cone de ionização.

Ao observar a imagem ampliada no campo do GMOS (Fig. 12.5b) nota-se também o disco de gás interno e sua inclinação parece ser diferente daquela do disco externo.

A Fig. 12.6 revela a estrutura de um anel elíptico em $\mathrm{H} \alpha$ consideravelmente fragmentado, cujo eixo maior possui um diâmetro de $\sim 16$ " ( $\sim 1.7 \mathrm{kpc})$ e o eixo menor, um diâmetro de $\sim 8 "(\sim 850$ pc). Se for um anel circular, seu raio é $\sim 8 "(\sim 850$ pc $)$ e possui uma inclinação de $30^{\circ}$. Nota-se também a estrutura mencionada anteriormente na região nuclear. Há uma concentração de emissão avermelhada na região central ao anel em direção ao Sul. Segundo o catálogo Hyperleda, o ângulo de inclinação do eixo polar da galáxia é 

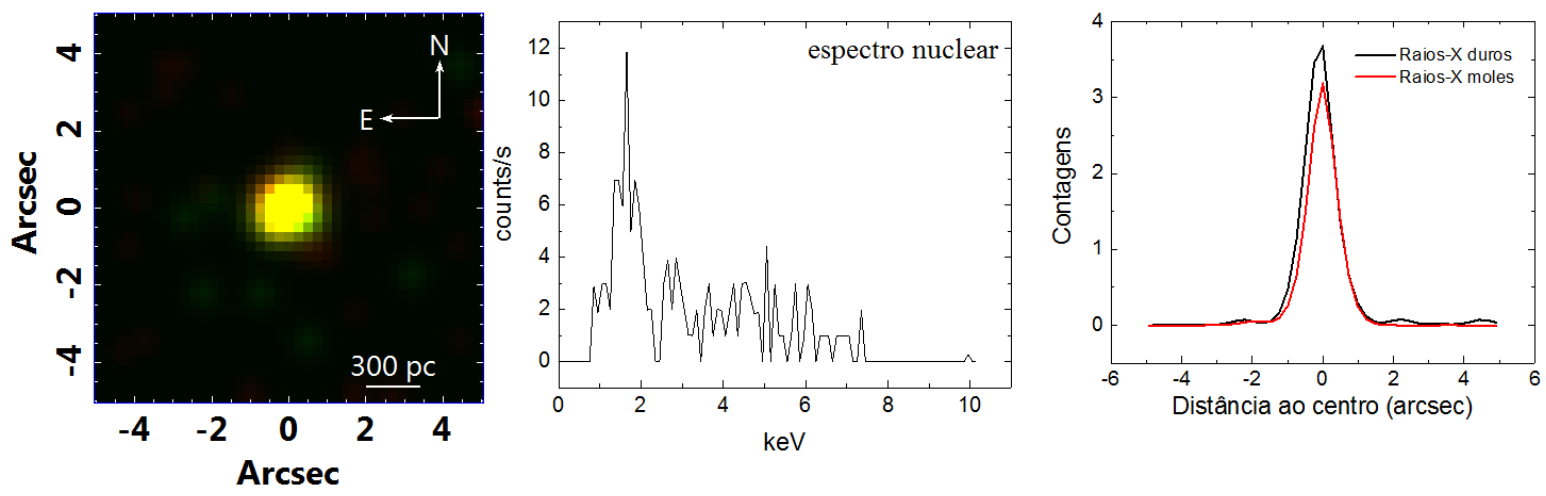

Figura 12.7: Composição RG dos dados em raios-X obtido com o telescópio espacial Chandra. A emissão de raios-X duros está representada em vermelho e a emissão em raios-X moles, em verde. $\mathrm{O}$ espectro da região nuclear (extraído de uma área circular com raio de 6 pixels ou $\sim 1 " .5$, maior que a PSF dos dados estimada a partir da emissão de Mrk 202 - ver da Silva et al. 2020) mostra considerável emissão em raios-X moles. A direita: perfis horizontais das imagens de raios-X moles e raios- $\mathrm{X}$ duros. $\mathrm{O}$ centro foi definido como a posição do pico de emissão de raios-X duros.

50.3․ A partir deste valor foi derivado o ângulo de inclinação do disco da galáxia como sendo 39.7․ Este ângulo é compatível com o ângulo de inclinação do anel. Ou seja, estas estruturas estão no mesmo plano.

\subsubsection{Emissão em raios- $X$}

Os dados do telescópio espacial Chandra foram obtidos do arquivo público, a fim de estudar a emissão em raios-X do núcleo de NGC 2442. Os dados foram obtidos em 3 de Julho de 2015 com o instrumento Advanced CCD Imaging Spectrometer (ACIS, composto por 4 CCDs - I) no programa 15610062 (PI: Gordon Garmire), com tempo de exposição de 39.56 ks. Os dados foram tratados como descrito na seção 3.6.

A Fig. 12.7 resume as principais informações obtidas com os dados em raios-X. Tanto a emissão em raios-X moles quanto em raios-X duros estão sendo emitidas na mesma área. O espectro nuclear mostra emissão principalmente em raios-X moles.

Como foi visto nos dados do HST, o núcleo desta galáxia é consideravelmente obscurecido. Esse obscurecimento, nos dados em raios-X, geralmente levaria a um decréscimo da emissão em raios-X moles. Porém, os dados mostram que há, na verdade, baixa emissão em raios-X duros, embora os valores de contagens na região nuclear seja ligeiramente maior em raios-X duros. Isso significa que a emissão do AGN é bastante obscurecida (podendo ser um AGN Compton-thick) possivelmente pelo toro de poeira, mas também por gás na 

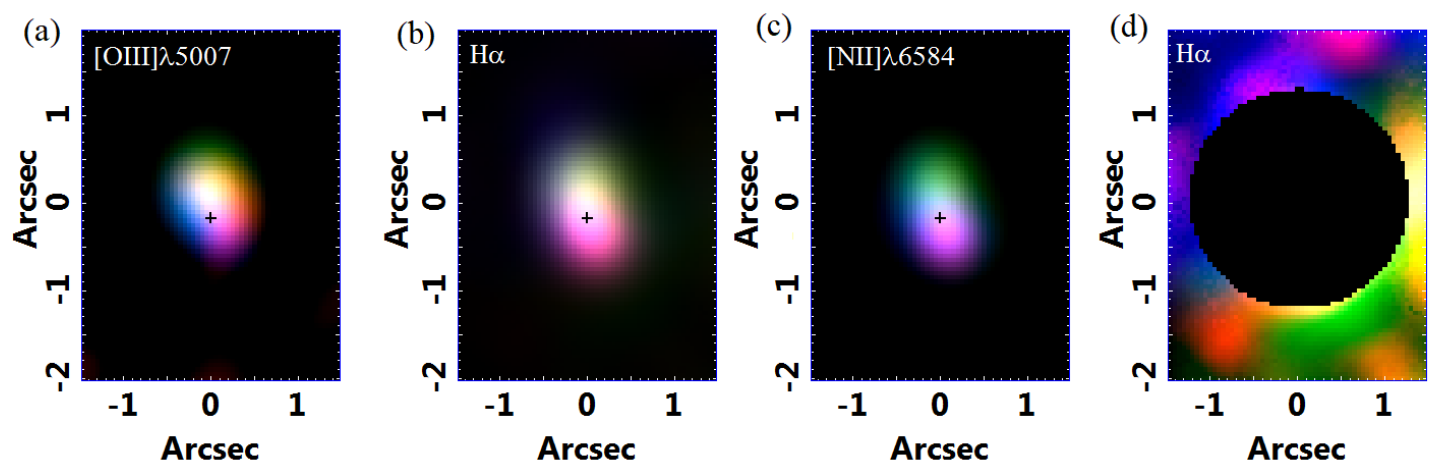

Figura 12.8: Composições RGB nas quais a cor azul representa emissão em blueshift entre -300 e -170 $\mathrm{km} / \mathrm{s}$, a cor verde, entre 79 e $260 \mathrm{~km} / \mathrm{s}$ (velocidades baixas) e vermelho, entre 380 e $760 \mathrm{~km} / \mathrm{s}$ (emissão em redshift) calculados para as linhas de (a) $[\mathrm{OIII}] \lambda 5007,(\mathrm{~b}) \mathrm{H} \alpha$, (c) $[\mathrm{NII}] \lambda 6584$ e (d) $\mathrm{H} \alpha$ sem a região do núcleo, que fica saturada, com ênfase nas regiões circumnucleares. A cruz representa a posição do centróide de $[\mathrm{OI}] \lambda 6300$ e, seu tamanho, a incerteza de $3 \sigma$.

linha de visada. Já o cone de ionização não sofre esse obscurecimento e é a emissão predominante dos raios-X moles. Porém, devido à baixa resolução, não é possível resolver o cone de ionização nas imagens.

\subsection{Cinemática do gás}

As imagens da Fig. 12.8 mostram que, na região central, o gás em baixas velocidades aparece deslocado do centro, enquanto que parece haver uma rotação na parte ao Sul da região representada pela cor verde. O gás em baixas velocidades geralmente fica entre o gás em blueshift e redshift, o que não ocorre neste caso. A região com baixas velocidades é coincidente com a região da estrutura observada na imagem do HST (F658N). Isso reforça a hipótese de que essa estrutura esteja associada à parede do cone de ionização. Não se pode descartar a hipótese de que as regiões representadas pelas cores azul e vermelha sejam outflows de gás. Na região circumnuclear, por sua vez, vemos um padrão que não é simétrico. Existe emissão em blueshift nas regiões ao Norte e emissão com baixas velocidades ao Sul. Existe uma forte emissão em redshift em uma direção preferencial na borda direita do FOV, porém dados com maior FOV (e melhor S/N) devem confirmar essa emissão, que pode ser um outflow de gás. 
(a)

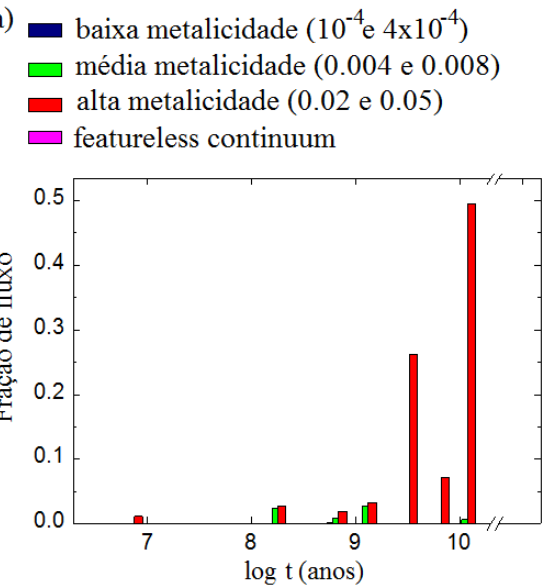

(b)

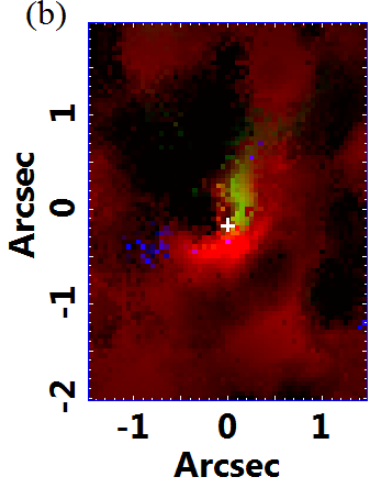

(c)

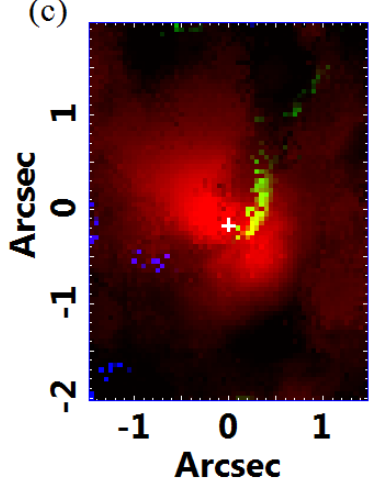

Figura 12.9: Resultados da síntese espectral aplicada ao cubo de dados de NGC 2442: (a) histograma das frações de fluxos das populações estelares detectadas, (b) mapa de fluxo das populações com $10^{9}$ anos e (c) mapa de fluxo das populações com $10^{10}$ anos. As cores dos mapas correspondem às mesmas cores do histograma. A cruz branca representa o centro da região principal de emissão: Região 1 e seu tamanho incerteza de $3 \sigma$.

\subsection{Arqueologia estelar}

Os resultados da síntese espectral (Fig. 12.9) mostram que o núcleo de NGC 2442 possui populações predominantemente velhas (entre $10^{9.5}$ anos e $10^{10}$ anos) e com alta metalicidade (0.02 e 0.05). Embora o mapa do fluxo das populações estelares com $10^{10}$ anos possua uma concentração mais central, as populações estelares estão espalhadas por todo o FOV.

Nos últimos $10^{9.5}$ anos não houve formação estelar significativa neste núcleo. Além disso, sabe-se que esta galáxia está em interação com outra galáxia. Neste caso, esse fenômeno não está exercendo, até o momento, nenhuma influência na região nuclear.

O mapa de extinção obtido pela síntese espectral (Fig. 12.10a) apresenta uma morfologia de um anel ou espiral de poeira em direção ao AGN. Os maiores valores de extinção estão presentes nas bordas do FOV. Esse resultado é compatível com o obtido a partir das imagens do HST, que mostra que, ao Sul, estão as regiões mais obscurecidas, porém naquele caso, não foi possível distinguir uma espiral de poeira tão bem delineada.

O mapa de $\chi^{2}$ (Fig. 12.10b) mostra que os ajustes da síntese espectral foram bem sucedidos em todo campo de visão e o mapa de S/N (Fig. 12.10 c) revela que, embora os maiores valores estejam localizados na região central do FOV, os valores das bordas excedem 10, por isso nenhuma área foi descartada nos resultados. 

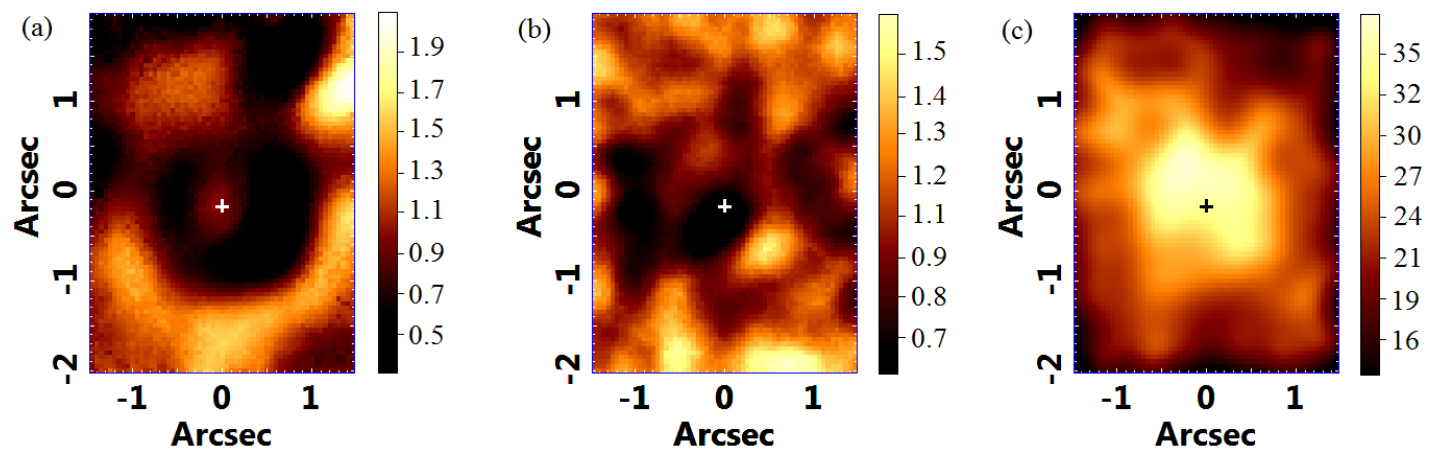

Figura 12.10: Mapas de extinção (a), $\chi^{2}$ dos ajustes (b) e $\mathrm{S} / \mathrm{N}$ dos dados (c) obtidos pela síntese espectral com o software StARLight. A cruz representa o centro da Região 1 e seu tamanho a incerteza de $3 \sigma$.

\subsection{Cinemática estelar}

O mapa de velocidades estelar (Fig. 12.11 a) mostra que há uma rotação estelar na região central de NGC 2442. As estrelas com emissão em redshift estão na região ao Sul do FOV e as estrelas com emissão em blueshift ao Norte.

O mapa de dispersão de velocidades estelar (Fig. 12.11b) é consideravelmente irregular e não apresenta um pico na região central. O valor da dispersão de velocidades estelar central, calculado como descrito na seção 3.5.6, é de $151 \pm 6 \mathrm{~km} / \mathrm{s}$.

O mapa de $h_{3}$ (Fig. 12.11k), que mede o grau de assimetria das linhas de absorção com relação a Gaussianas, não apresenta nenhum padrão. Isso significa que pode haver outros movimentos estelares além da rotação estelar detectada no mapa de velocidades.

\subsection{Conclusões}

- Há um AGN com emissão LINER no núcleo de NGC 2442, confirmado pela emissão em raios-X, que é nuclear e compacta, emitindo tanto em raios-X duros quanto em raios-X moles.

- Foram detectadas 5 regiões com emissão relevante no cubo de dados. Todas elas possuem emissão compatível com as de LINERs.

- Foi observada uma estrutura na imagem do filtro F658N (H $\alpha)$ do HST que pode estar associada às paredes do cone de ionização sob forma de ampulheta. Essa estrutura possui baixas velocidades, o que é compatível com esta hipótese.

- Dados em raios-X obtidos com o telescópio espacial Chandra mostram que a emissão 

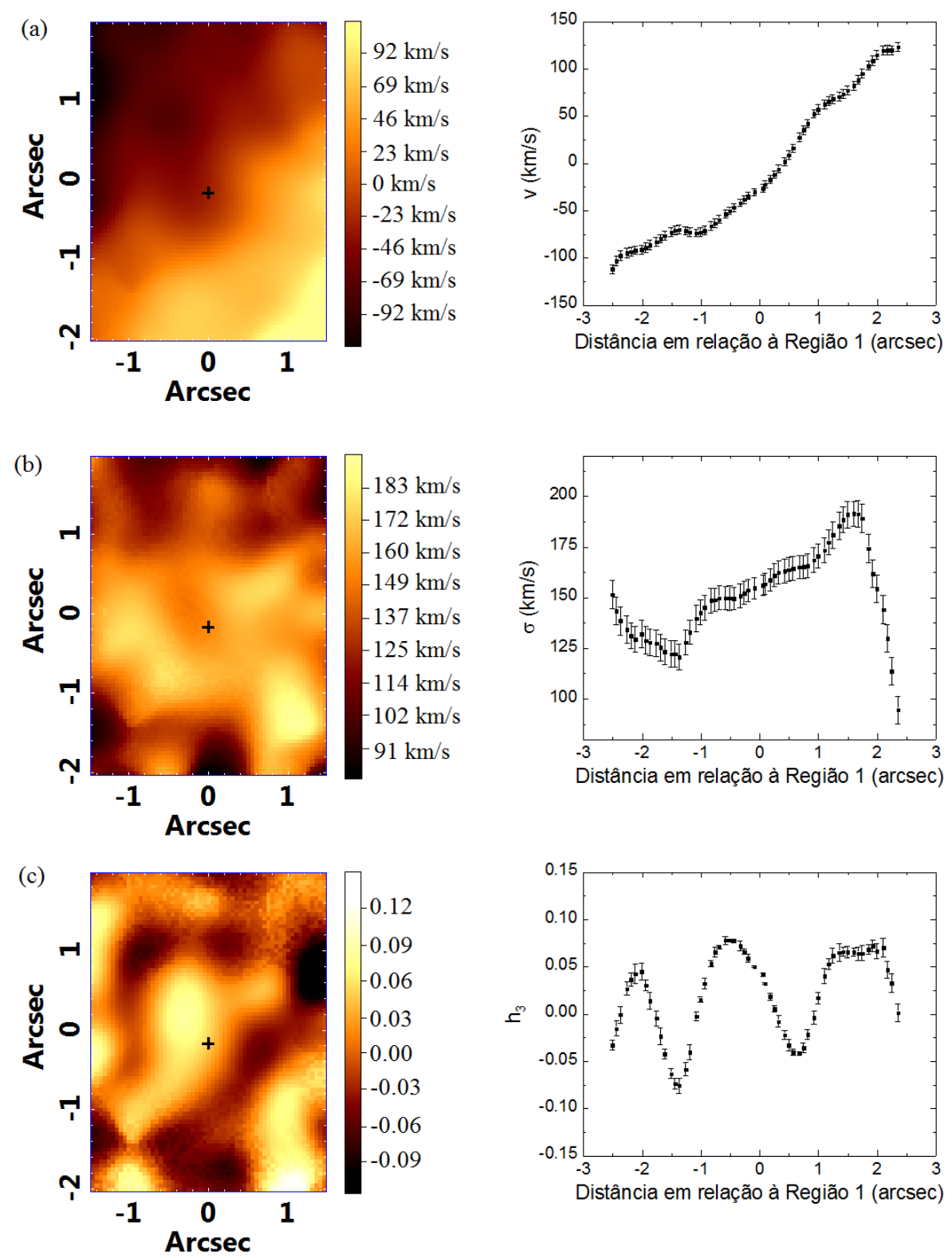

Figura 12.11: Mapas de velocidade estelar (a), dispersão de velocidades estelar (b) e coeficiente $h_{3}$ (c) obtidos pela síntese espectral com o método pPXF. A cruz representa o centro da Região 1 e seu tamanho a incerteza de $3 \sigma$. O PA das curvas extraídas é $\sim 24^{\circ}$. 
em raios-X duros do AGN é consideravelmente obscurecida (possivelmente Compton-thick, causado pelo toro de poeira e por gás na linha de visada) e que o cone de ionização é responsável pela maior emissão em raios-X moles que sofre menos obscurecimento. Observações do HST sugerem que seja um AGN consideravelmente obscurecido.

- As populações estelares do núcleo desta galáxia são predominantemente velhas $\left(10^{10}\right.$ anos), o que sugere que nem a barra e nem a interação com a outra galáxia estão influenciando a formação estelar no núcleo ao longo dos último 1 bilhão de anos.

- Há uma correspondência entre o mapa de extinção e a imagem de I-B, como esperado. A extinção é maior na região Sul.

- Há um anel com emissão predominante de $\mathrm{H} \alpha$ (observado na imagem do filtro F658N do HST), possivelmente de regiões HII, que possui um formato elíptico com eixo maior com diâmetro de $\sim 16 "(\sim 1.7 \mathrm{kpc})$ e eixo menor com diâmetro de $\sim 8 "(\sim 850 \mathrm{pc})$. Se o anel for circular, seu raio é $\sim 850$ pc e sua inclinação é de $30^{\circ}$.

- Há um disco com rotação estelar bem definido, com estrelas em blueshift ao Norte e estrelas em redshift ao Sul.

- O valor da dispersão de velocidades estelar ponderado em intensidade no FOV do GMOS é $151 \pm 6 \mathrm{~km} / \mathrm{s}$. 
Capítulo 13

\section{NGC 1300}

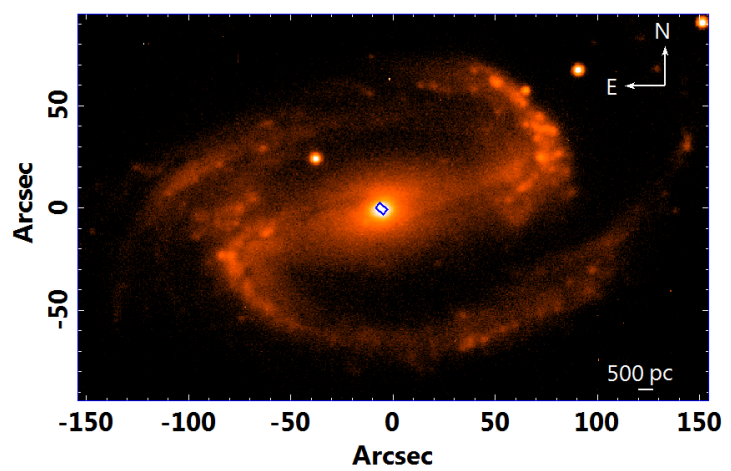

Figura 13.1: Imagem da galáxia NGC 1300 obtida com o telescópio 1.8m Perkins do Lowell Observatory na banda B do óptico. O quadrado em azul representa o FOV do cubo de dados do GMOS analisado neste estudo. O PA dos dados do GMOS é $51^{\circ}$. A área do FOV do GMOS é de $3 " .1 \times 4 " .8$.

NGC 1300 é uma galáxia do tipo SB(rs)bc (de Vaucouleurs et al., 1991) e está localizada a aproximadamente 14.5 Mpc de distância (Nasonova et al., 2011). Esta galáxia é conhecida por sua barra proeminente, cujo raio é 81" \pm 2 " (Herrera-Endoqui et al. 2017, levando em conta o valor da distância, $5.67 \pm 0.13 \mathrm{kpc}$ ), da onde partem dois braços espirais formando um pseudo-anel externo (Eskridge et al., 2002), cujo raio está entre 130" e 150" (Elmegreen et al. 1996). A barra possui pouca emissão de $\mathrm{H} \alpha$, indicando baixa formação estelar (Knapen et al., 2002). Entretanto, Maeda et al. (2018) detectaram a presença de gás molecular na barra e sugerem que a formação estelar na barra é impedida por choques de gases moleculares em altas velocidades.

Segundo Laurikainen et al. (2004) o índice de Sérsic, obtido de imagens da banda B no óptico, é 1.3, o que significa que essa galáxia possui um pseudo-bojo, posteriormente confirmado por Fisher e Drory (2008). Entretanto, Läsker et al. (2014) determinaram, 
Tabela 13.1 - Propriedades de NGC 1300. Os valores foram obtidos do catálogo Hyperleda. O valor da dispersão de velocidades estelar foi obtido por Batcheldor et al. (2005).

\begin{tabular}{|c|c|}
\hline $\mathrm{M}_{B}$ & $-20.32 \pm 0.33$ \\
\hline $\mathrm{m}_{B}$ & $11.21 \pm 0.09$ \\
\hline $\mathrm{B}-\mathrm{V}$ & 0.78 \\
\hline$\sigma_{*}(\mathrm{~km} / \mathrm{s})$ & $90 \pm 6$ \\
\hline Brilho superficial efetivo médio $\left(\mathrm{mag} / \mathrm{arcsec}^{2}\right)$ & $22.98 \pm 0.23$ \\
\hline
\end{tabular}

através de modelos utilizando dados do infravermelho, que o índice de Sérsic é de 4.3, indicando um bojo clássico. Batcheldor et al. (2005) determinaram que o valor da dispersão de velocidades estelar na região nuclear, a partir do método de correlação cruzada, é $\sigma=90 \pm 6 \mathrm{~km} / \mathrm{s}$ e Gültekin et al. (2009) obtiveram, a partir de espectros long-slit, o valor de $\sigma=218 \pm 10 \mathrm{~km} / \mathrm{s}$.

NCG 1300 possui anel de formação estelar nuclear observado em $\mathrm{H} \alpha$ formado por 12 regiões distintas de emissão (Mazzuca et al., 2008), cujo diâmetro é de 820 pc (Pogge, 1989). Ele também foi observado com o SINFONI, a partir de imagens de $\operatorname{Br} \gamma$ e [FeII] $] 16436$ (Böker et al., 2008) elipse ao anel, os autores calcularam que o anel tem um diâmetro de $666 \mathrm{pc}, \mathrm{PA}=117^{\circ}$ e elipticidade igual a 0.13 (inclinação de aproximadamente $83^{\circ}$, quase face-on, assumindo que seja circular). Dados em rádio $(20 \mathrm{~cm}$ e $6 \mathrm{~cm})$ mostram três componentes que podem fazer parte de outflows partindo do núcleo com distâncias entre 1"e 4" (Saikia et al., 1994).

A partir de razões de linhas do óptico, Gadotti et al. (2019) determinaram que o núcleo possui emissão LINER e Gültekin et al. (2012) calcularam a luminosidade do núcleo na banda 2-10 keV (raios X duros com dados do Chandra): $5.2_{-1.1}^{+1.2} \times 10^{39} \mathrm{ergs} / \mathrm{s}$.

Os dados desse objeto foram obtidos em 29 de Outubro de 2013 com o IFU do GMOS do telescópio Gemini-Sul. O valor do FWHM da PSF usado no processo de deconvolução, calculado a partir da imagem de aquisição, no comprimento de onda de $6300 \AA$, foi 0".56.

A imagem colapsada ao longo do eixo espectral do cubo de dados após o tratamento (Fig. 13.2) mostra uma região central de emissão. O espectro da região nuclear, após a subtração do contínuo estelar, possui todas as principais linhas de emissão do óptico. 

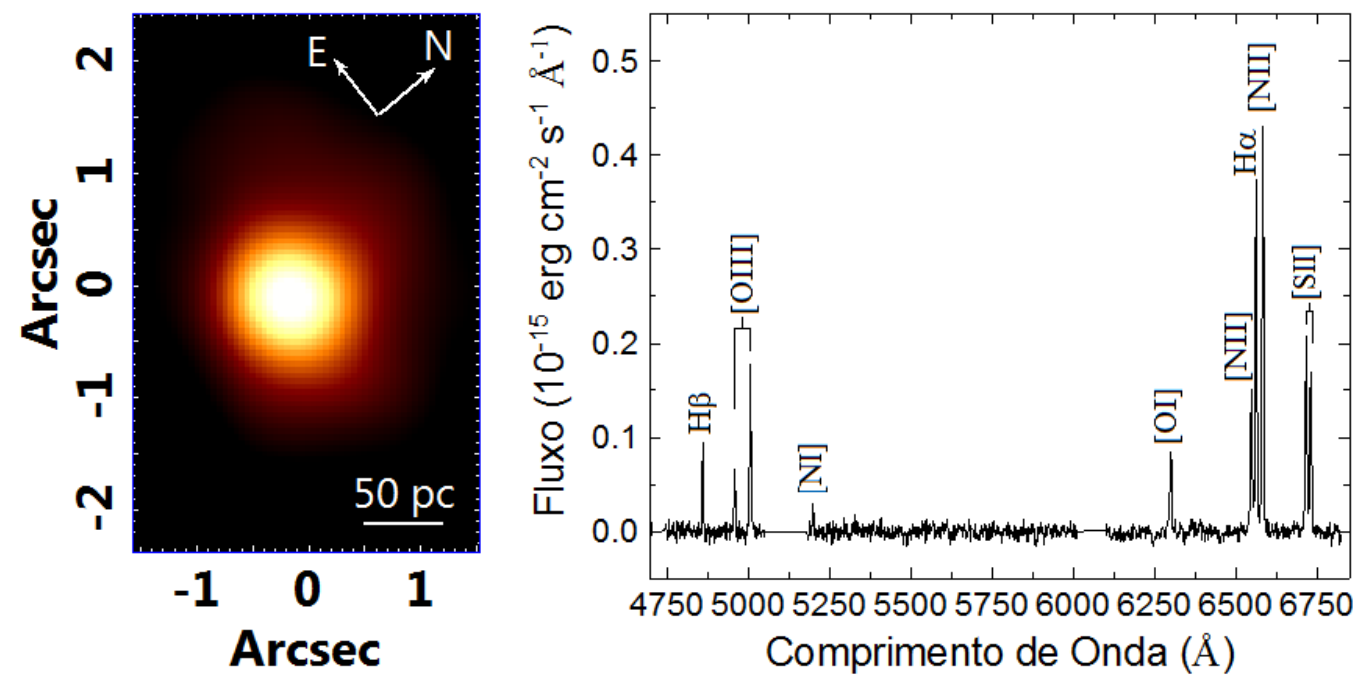

Figura 13.2: Imagem do cubo de dados obtido com GMOS do núcleo de NGC 1300, após o tratamento, colapsado ao longo do eixo espectral, juntamente com o espectro do núcleo estelar, após a subtração do contínuo estelar, corrigido do redshift.

\subsection{Emissão do gás}

A partir das imagens das principais linhas de emissão do cubo de gás de NGC 1300 (Fig. 13.3 nota-se que a principal fonte de emissão é pontual e central e será chamada de Região 1.

Na imagem de $\mathrm{H} \alpha$ nota-se, além da Região 1, outras regiões nas bordas do FOV, que foram identificadas como regiões 2 e 3 .

A partir do cubo de gás foram extraídos espectros dessas regiões para o cálculo de razões de linhas. No caso da Região 1, foi extraído um espectro de uma área circular cujo diâmetro é igual ao FWHM da PSF dos dados. Nos casos das regiões 2 e 3, como as mesmas fazem parte das bordas do FOV, foram extraídos espectros de regiões retangulares, com o cuidado de o tamanho da área de extração não ser menor do que a área da PSF dos dados. A tabela 13.2 mostra os valores das razões de linhas calculadas para cada região e a Fig. 13.4 mostra o diagrama de diagnóstico obtido.

A Região 1 é a única região no domínio de AGNs e possui razões de linhas compatíveis com a emissão de LINERs. Já as regiões 2 e 3 possuem razões de linhas compatíveis com as de objetos de transição. Como esse objeto possui uma fonte central compacta em raios$\mathrm{X}$ (ver seção 13.1.1), se trata de um AGN de baixa luminosidade. O fato das regiões 2 

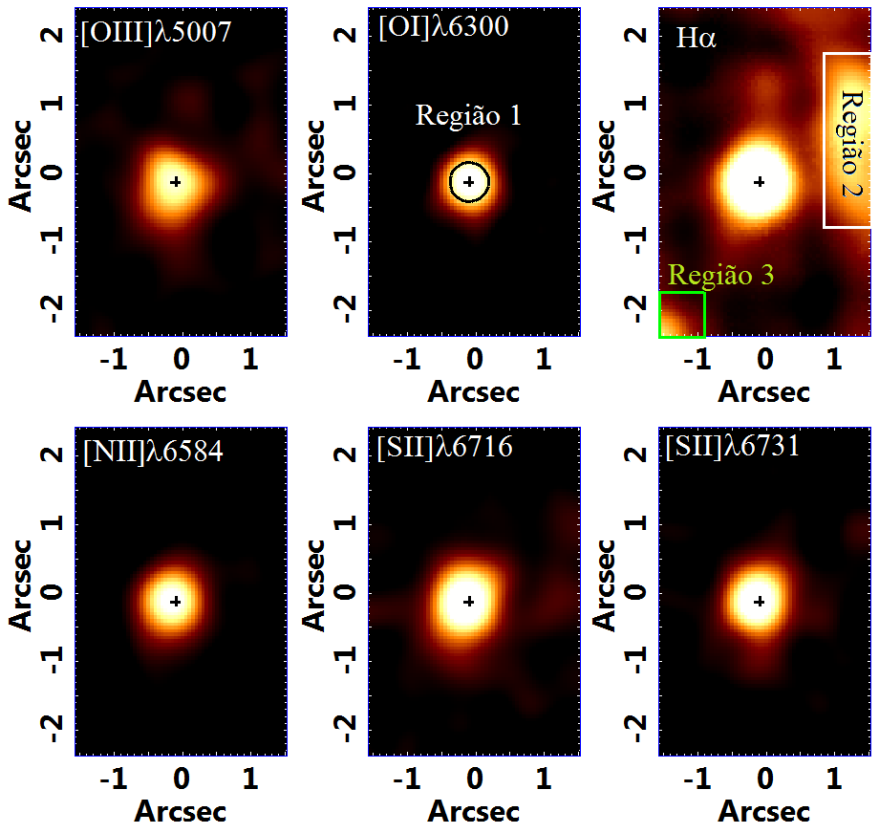

Figura 13.3: Imagens das principais linhas de emissão de NGC 1300. Foram identificadas três regiões emissoras a partir das imagens das linhas de [OI] $\lambda 6300$ (Região 1) e de H $\alpha$ (regiões 2 e 3). As áreas que delimitam essas regiões foram utilizadas para extração dos espectros que, por sua vez, foram utilizados para o cálculo de razões de linhas. O ponto central representa o centróide da Região 1 e, seu tamanho, a incerteza de $3 \sigma$.

e 3 possuírem razões de linhas características de objetos de transição pode indicar uma ionização do gás vinda do AGN, ou contaminação da emissão de regiões HII pela emissão do AGN próximo.

\subsubsection{Emissão em raios- $X$}

Os dados do telescópio espacial Chandra foram obtidos do arquivo público, a fim de estudar a emissão em raios-X do núcleo de NGC 1300. Os dados foram obtidos em 11 de Outubro de 2009 com o instrumento ACIS-S (com 6 CCDs) no programa 11900514 (PI: Gultekin, K.), com tempo de exposição de 29.66 ks. Os dados foram tratados como descrito na seção 3.6 .

A Fig. 13.5 mostra que há emissão de raios-X duros e ela parte do núcleo. Além disso, essa emissão está presente em dois pontos a Leste do núcleo. Por serem emissões pontuais, podem ser indicações de restos de supernovas. Por outro lado, a emissão de raios-X moles também está concentrada no núcleo, mas ainda há uma emissão estendida em duas direções: a Sudeste e a Oeste do núcleo. 
Tabela 13.2 - Razões de linhas e luminosidades calculadas a partir dos fluxos integrados de $\mathrm{H} \alpha$ dos espectros das 3 regiões observadas no núcleo de NGC 1300.

\begin{tabular}{|c|c|c|c|}
\hline Razões de Linhas & Região 1 & Região 2 & Região 3 \\
\hline$[\mathrm{OIII}] / \mathrm{H} \beta$ & $2.45 \pm 0.13$ & $0.81 \pm 0.08$ & $0.89 \pm 0.03$ \\
{$[\mathrm{NII}] / \mathrm{H} \alpha$} & $1.26 \pm 0.08$ & $0.56 \pm 0.03$ & $0.64 \pm 0.04$ \\
{$[\mathrm{OI}] / \mathrm{H} \alpha$} & $0.314 \pm 0.022$ & $0.090 \pm 0.012$ & $0.101 \pm 0.07$ \\
$([\mathrm{SII}] \lambda 6716+\lambda 6731) / \mathrm{H} \alpha$ & $1.04 \pm 0.06$ & $0.47 \pm 0.03$ & $0.60 \pm 0.03$ \\
{$[\mathrm{SII}] \lambda 6716 /[\mathrm{SII}] \lambda 6731$} & $1.11 \pm 0.07$ & $1.46 \pm 0.04$ & $1.33 \pm 0.12$ \\
\hline Luminosidade de $\mathrm{H} \alpha\left(10^{4} \mathrm{~L}_{\odot}\right)$ & $14 \pm 0.7$ & $19.7 \pm 1.3$ & $2.80 \pm 0.06$ \\
\hline
\end{tabular}

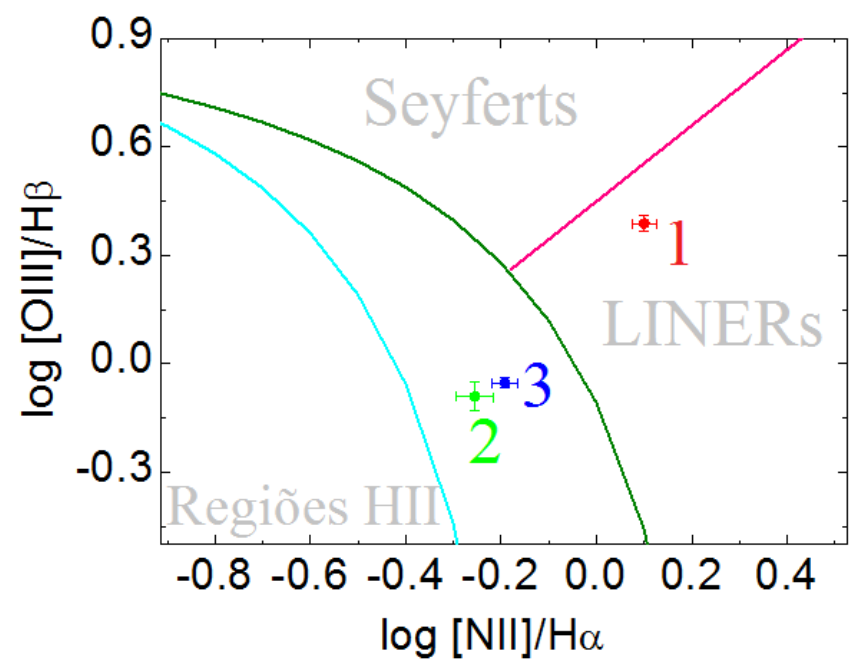

Figura 13.4: Diagrama de diagnóstico das três regiões observadas no núcleo de NGC 1300 a partir do cubo de dados do GMOS: Região 1, identificada pelo ponto vermelho, Região 2, identificada pelo ponto verde e Região 3, identificada pelo ponto azul. A curva em verde-escuro representa a estimativa para o limite de ionização por um starburst determinada por Kewley et al. (2001). A divisão entre regiões HII e AGNs determinada por Kauffmann et al. (2003) está representada pela curva em ciano. A reta que divide Seyferts e LINERs determinada por Schawinski et al. (2007) está indicada em magenta. 

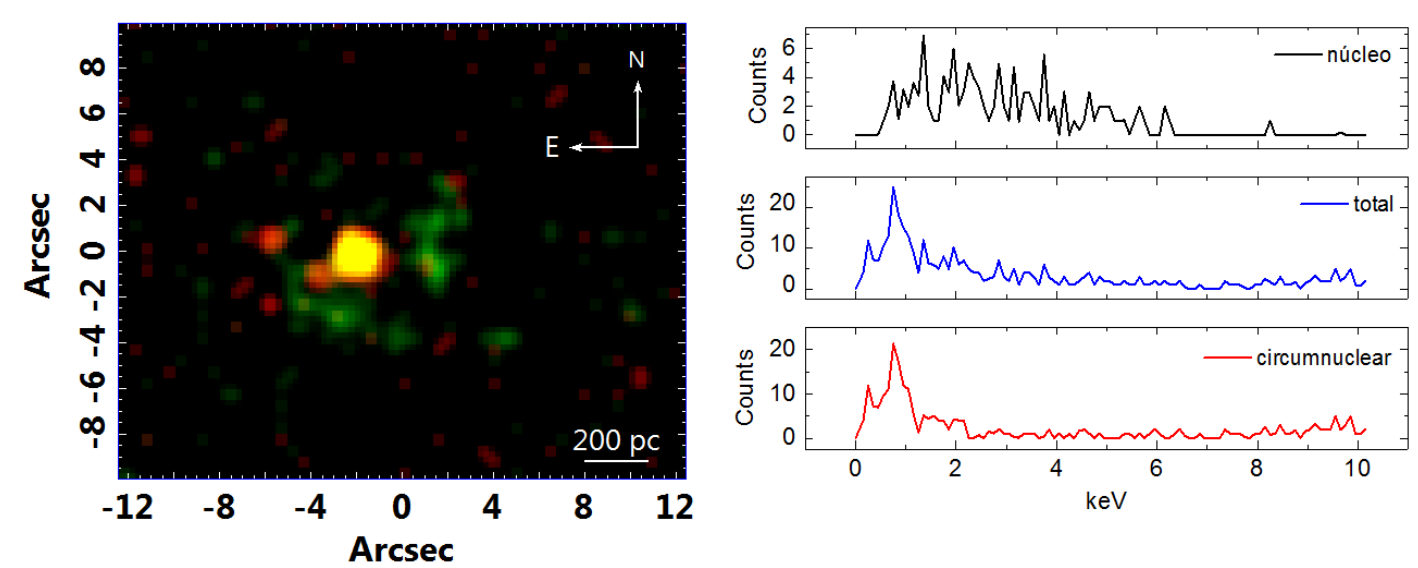

Figura 13.5: Composição RG dos dados em raios-X obtido com o telescópio espacial Chandra. A emissão de raios-X duros está representada em vermelho e a emissão em raios-X moles, em verde. O espectro da região nuclear (extraído de uma área circular com raio de 6 pixels) mostra emissão predominante de raios-X duros, já a região circumnuclear, emissão de raios-X moles.

A emissão presente no espectro da região nuclear é principalmente composta por raiosX duros. Por ser uma fonte compacta, com emissão LINER, caracteriza a presença de um AGN central. A emissão circumnuclear, composta predominantemente por raios-X moles possui emissão estendida, possivelmente coincidente com parte do anel circumnuclear. Essa emissão pode estar associada a restos de supernovas que explodiram há um tempo considerável e já não emitem mais tanta energia. Enquanto que algumas fontes circumnucleares (com áreas maiores do que o ruído de fundo - à leste do AGN, principalmente) de raios-X duros podem estar associadas a restos de supernovas recentes também localizadas no anel.

\subsection{Cinemática do gás}

A Fig. 13.6 é uma representação concisa da cinemática do gás do núcleo de NGC 1300 (dentro do FOV do cubo de dados do GMOS). Esta é caracterizada por gás com emissão em redshift a Oeste, enquanto que o gás com emissão em blueshift está concentrado ao Leste. A Região 3 possui essencialmente gás com velocidades baixas, assim como a região oposta a ela, no canto superior direito do FOV, podendo indicar que gases em regiões externas ao FOV possuem velocidades baixas.

A região nuclear apresenta possivelmente uma rotação. O gás com emissão em redshift está a sudoeste, enquanto que o gás com emissão em blueshift está a nordeste. Além disso, 


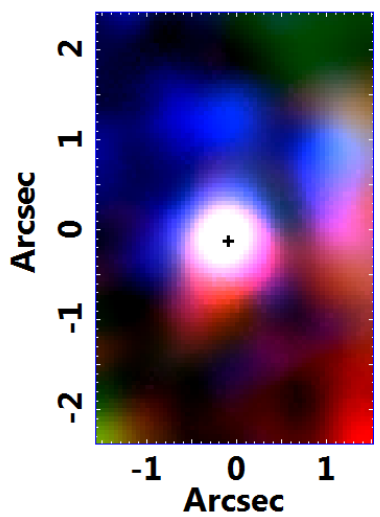

Figura 13.6: Composição RGB da linha de H $\alpha$. A cor azul representa o intervalo de velocidades de, aproximadamente, $-360 \mathrm{a}-175 \mathrm{~km} / \mathrm{s}$, a cor verde representa velocidades de $\sim-130$ a $\sim 10 \mathrm{~km} / \mathrm{s}$ e a cor vermelha, o intervalo de $\sim 55 \mathrm{a} \sim 240 \mathrm{~km} / \mathrm{s}$. A cruz representa o centro da emissão de [OI] $\lambda 6300$ e, seu tamanho, a incerteza de $3 \sigma$.

a concentração de gás com baixas velocidades é central, com centro compatível com o da emissão de [OI] $\lambda 6300$.

\subsection{Arqueologia Estelar}

Ao observar o histograma resultante da síntese espectral aplicada ao cubo tratado de NGC 1300 (Fig. 13.7a), nota-se que a principal formação estelar ocorreu durante a formação do bojo estelar há, aproximadamente, 10 bilhões de anos. O mapa de fluxo da população estelar associada a esse evento (Fig. 13.7p) mostra que estrelas com metalicidade alta (0.05 e 0.02) foram formadas na região nuclear e as estrelas com metalicidade intermediária (0.004 e 0.008) foram formadas nas regiões circumnucleares.

Outra formação estelar menos relevante há $\sim 1$ bilhão de anos também aconteceu na região nuclear formando estrelas com alta metalicidade e também metalicidade intermediária (Fig. 13.7d). O mesmo aconteceu com as populações de $\sim 100$ milhões de anos.

Por fim, a formação estelar mais recente aconteceu há $\sim 10$ milhões de anos e formou estrelas com metalicidade alta apenas na região nuclear.

As frações de fluxo desses três últimos eventos são baixas e podem estar dentro do erro da síntese espectral e, portanto, devem ser vistas com cautela. O que pode ser afirmado é que não há formação estelar relevante recente no núcleo dessa galáxia e que não há formação estelar com estrelas de baixa metalicidade. No geral, o bojo dessa galáxia possui estrelas predominantemente velhas. Ao interligar essa informação com a literatura, a ideia 


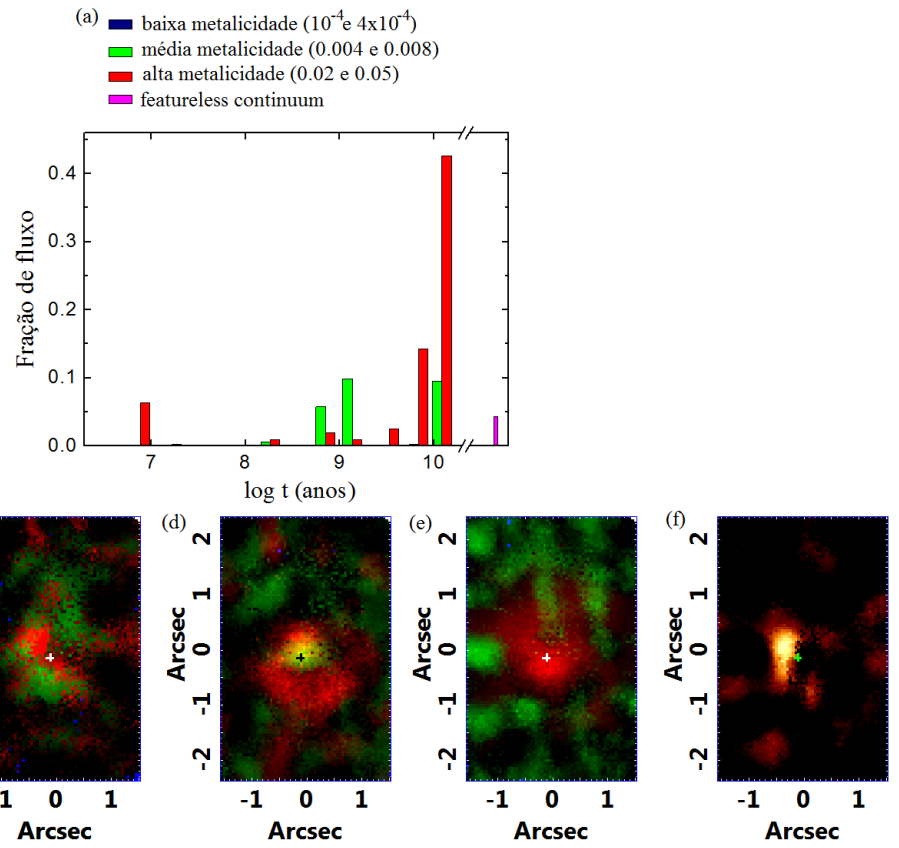

Figura 13.7: (a) Histograma das frações de fluxos obtidas a partir da síntese espectral aplicada ao cubo de NGC 1300. Mapas dos fluxos correspondentes às populações estelares com (b) $10^{6}$ anos, (c) $10^{8}$ anos, (d) $10^{9}$ anos e (e) $10^{10}$ anos. (f) Mapa do fluxo associado à lei de potência com índice espectral igual a 1.5, representando uma possível emissão de featureless continuum. As cruzes nas imagens representam o centro de [OI] $\lambda 6300$ e, seu tamanho, a incerteza de $3 \sigma$.

de ser um bojo clássico é válida.

Além dos espectros de populações estelares da base criada a partir da MILES, foi acrescentado a essa base um espectro de lei de potência, com índice espectral igual a 1.5, simulando a emissão do featureless continuum de um AGN. Neste caso foi identificada uma fração de fluxo de 0.04 associada a essa lei de potência. O mapa dessa emissão da Fig. 13.7(f) mostra uma região próxima ao centro da Região 1. Isso pode indicar uma emissão de featureless continuum deslocado possivelmente por poeira. Entretanto, esses dados não são confiáveis.

O mapa de extinção obtido com a síntese espectral (Fig. 13.8 a) mostra que a extinção é praticamente constante e maior do que 0.6 em todo o campo, exceto na região superior do FOV. O mapa de $\chi^{2}$ (Fig. 13.8b) mostra que os ajustes no centro estão mais prejudicados do que nas regiões circumnucleares, enquanto que o mapa de S/N (Fig. 13.8c) mostra que não há regiões com baixo $\mathrm{S} / \mathrm{N}$ no $\mathrm{FOV}(\mathrm{S} / \mathrm{N}<10)$, o que proporcionou resultados mais completos para a análise dos mapas da síntese espectral. 

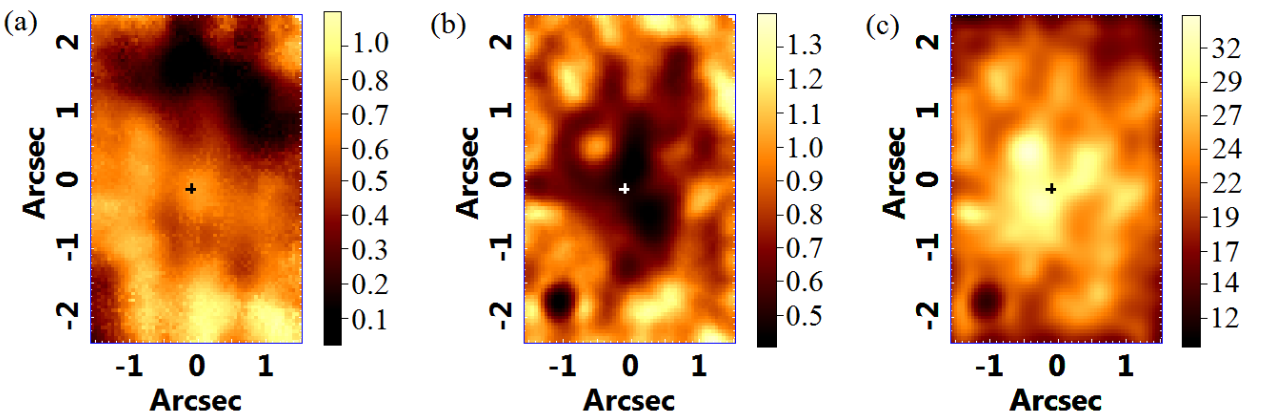

Figura 13.8: Mapas de extinção (a), $\chi^{2}$ (b) e S/N (c) obtidos dos ajustes da síntese espectral no cubo de dados de NGC 1300. As cruzes nas imagens representam o centro da Região 1 e, seu tamanho, a incerteza de $3 \sigma$.

\subsection{Cinemática estelar}

O mapa de velocidades estelar de NGC 1300 (Fig. 13.9 a) apresenta um padrão consistente com o de uma rotação estelar em torno do AGN (Região 1), sendo que as estrelas a Leste apresentam emissão em blueshift, enquanto que as estrelas a Oeste, emissão em redshift. Isso indica que o gás acompanha a mesma orientação de rotação que o disco estelar.

O mapa de dispersão de velocidades (Fig. 13.9b) não apresenta nenhum padrão interpretável. No entanto, a curva associada a esse mapa mostra um decréscimo de valores em direção ao centro, mas na região mais central esse decréscimo é descontinuado por um pico aproximadamente na posição do núcleo estelar, cujo valor é de $95 \mathrm{~km} / \mathrm{s}$, compatível com o valor obtido por Batcheldor et al. (2005). É possível que os picos nas extremidades da curva estejam associados ao anel de formação estelar, que possui velocidades diferentes do que as demais estrelas do FOV. Essa diferença de velocidades gera um pico nos valores da dispersão de velocidades, a análise de dados com maior FOV podem confirmar essa tendência.

O mapa de $h_{3}$ (Fig. 13.9c), por sua vez, apresenta uma anti-correlação com relação ao mapa de velocidades. A curva associada a esse mapa apresenta mais irregularidades do que a curva de velocidades, porém segue o mesmo padrão de anti-correlação com a curva de velocidades. Isso indica que as estrelas em rotação estão sobrepostas a um fundo de estrelas com velocidades próximas a zero em relação à linha de visada.

Conforme detalhado na seção 3.5.6, foi calculado um valor para dispersão de velocidades estelar ponderado pela intensidade de cada spaxel do cubo de dados. O valor obtido foi de 

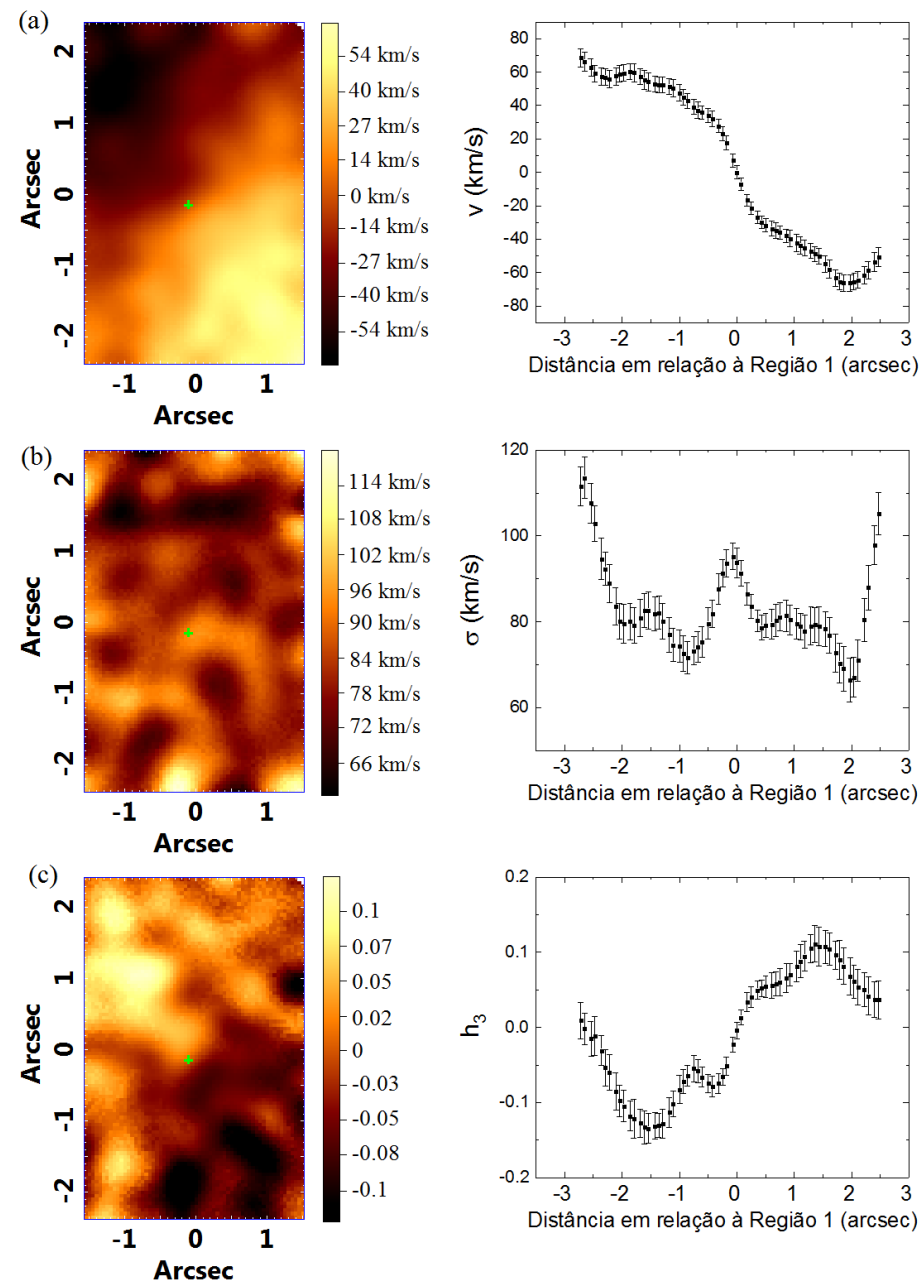

Figura 13.9: (a) Mapa de velocidades estelar, (b) mapa de dispersão de velocidades estelar e (c) mapa de $h_{3}$, que mede a assimetria das linhas de absorção. Como o mapa de velocidades estelar possui boa qualidade e os dados possuem bom $\mathrm{S} / \mathrm{N}$, foi possível extrair curvas associadas a cada mapa. As incertezas dos valores foram calculadas como explicado na seção 3.5.5. As cruzes nas imagens representam o centro da Região 1 e, seu tamanho, a incerteza de $3 \sigma$. O PA das curvas extraídas é de $\sim 81^{\circ}$. 
$82 \pm 7 \mathrm{~km} / \mathrm{s}$. Esse valor também é compatível com o obtido por Batcheldor et al. (2005) dentro de $1 \sigma$ e não é compatível com o obtido por Gültekin et al. (2009).

\subsection{Conclusões}

- Há um objeto com emissão LINER no centro de NGC 1300. A presença de uma fonte compacta com emissão considerável em raios-X duros confirmam a natureza de um AGN.

- Há duas regiões emissoras com razões de linhas compatíveis com as de objetos de transição. É possível que sejam regiões HII contaminadas pela emissão do AGN.

- A emissão em raios-X moles possui uma componente estendida que pode ser coincidente com parte do anel circumnuclear. Essa emissão pode ser proveniente de restos de supernovas antigas.

- A formação estelar mais relevante no núcleo dessa galáxia aconteceu durante a formação do bojo estelar há, aproximadamente, 10 bilhões de anos.

- A cinemática do gás é compatível com um disco de rotação coplanar ao disco estelar.

- Há uma rotação estelar bem definida com estrelas em redshift a Oeste e estrelas em blueshift a Leste. O disco estelar em rotação está sobreposto a um fundo de estrelas com velocidades próximas a zero na direção da linha de visada.

- O valor de dispersão de velocidades estelar ponderado pelos valores de intensidade no FOV do GMOS é $82 \pm 7 \mathrm{~km} / \mathrm{s}$. 
Capítulo 14

\section{NGC 7314}

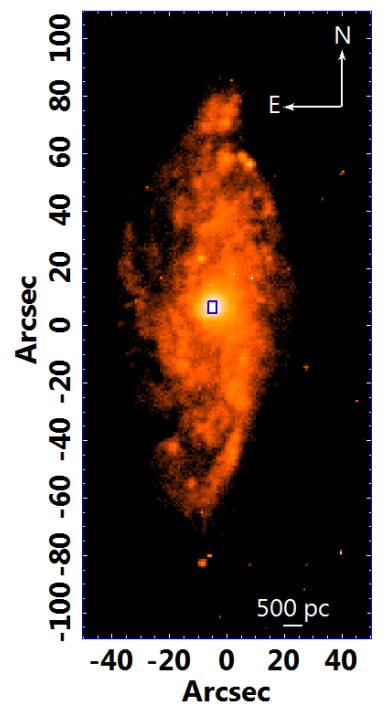

Figura 14.1: Imagem da galáxia NGC 7314 obtida com CTIO 0.9m, na banda V do óptico. O quadrado em azul representa o FOV do cubo de dados do GMOS analisado neste estudo. O PA dos dados do GMOS é $0^{\circ}$. A área do FOV do GMOS é de $2 " .95 \times 4 " .0$.

NGC 7314 é uma galáxia "multi-armed" do tipo SAB(rs)bc (Buta et al., 2015) localizada a 16 Mpc de distância (Tully et al., 2016). Devido à sua inclinação (69.8 - Hyperleda), há poucos estudos sobre sua morfologia.

Um estudo em rádio com o Very Large Array (VLA) em 8.5 GHz mostra duas fontes na região nuclear de NGC 7314, sendo uma delas coincidente com o núcleo, formando uma estrutura aparentemente linear de 353 pc e com PA $=173^{\circ}$ (Thean et al., 2000).

Não há consenso na literatura a respeito da classificação da atividade nuclear de NGC 7314. A princípio, a emissão nuclear de NGC 7314 foi classificada como Seyfert 1 por VeronCetty e Veron (1986), a partir da emissão no óptico, e Morris e Ward (1985) detectaram a 


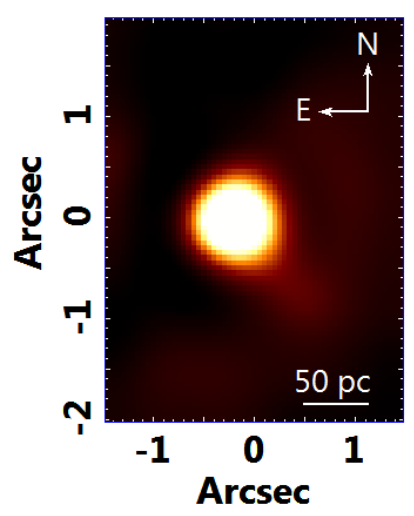

Figura 14.2: Imagem do cubo de dados após o tratamento colapsado ao longo do eixo espectral. Note a orientação NE e a representação de 50 pc.

emissão de Or $\lambda 8446$, uma linha típica da BLR, ou seja, emitida em objetos tipo 1. Stauffer (1982) e Joguet et al. (2001), entretanto, a classificam como Seyfert 2, devido às linhas de emissão aparecerem estreitas e à ausência da componente larga de $\mathrm{H} \alpha$, confirmado por Tommasin et al. (2010), que detectaram polarização na linha de $\mathrm{H} \alpha$. Maiolino e Rieke (1995) a classificam como Seyfert 1.9 (possui componente larga em $\mathrm{H} \alpha$ mas não em $\mathrm{H} \beta$ ) e Joguet et al. (2001) a classificam como Seyfert 2 e afirmam que a variabilidade da atividade nuclear pode ser responsável pela ausência da emissão de linhas largas. Trippe et al. (2010) a classificam como NLSy1 (Narrow Line Seyfert 1), pois foi observada uma componente larga de H $\alpha$, mas com FWHM de 1600 km/s. Por fim, Ebrero et al. (2011) concluem que essas variações na classificação de NGC7314 são resultado de um toro clumpy ou de um material adjacente ao toro (contendo gás neutro) em movimento ao redor do núcleo, fazendo a emissão nuclear variar de tipo 1 para tipo 2 e vice-versa.

Existem muitos estudos em raios-X dessa galáxia. O núcleo possui emissão em raiosX duros detectada por McHardy et al. (1981) e Piccinotti et al. (1982) e, a partir de observações no intervalo de 2-10 keV, foi observada uma rápida variabilidade com aumento da emissão em 4 vezes no período de 5000s (Turner, 1987). Com base na variabilidade da linha Fe K (6.4 keV), Yaqoob et al. (1996) concluíram que boa parte da emissão da BLR de NGC 7314 está contida dentro de um raio $r=4.1 \times 10^{15} \mathrm{~cm}$ e obtiveram estimativas para a massa do buraco negro central de $4.7 \times 10^{9} M_{\odot}$ e $2.3 \times 10^{10} M_{\odot}$. Segundo Risaliti et al. (2002) a densidade de coluna $\left(\mathrm{N}_{h}\right)$ teve uma variação de $31 \%$ num período de 4.5 anos. Observações com o satélite ASCA (Advanced Satellite for Cosmology and Astrophysics) 

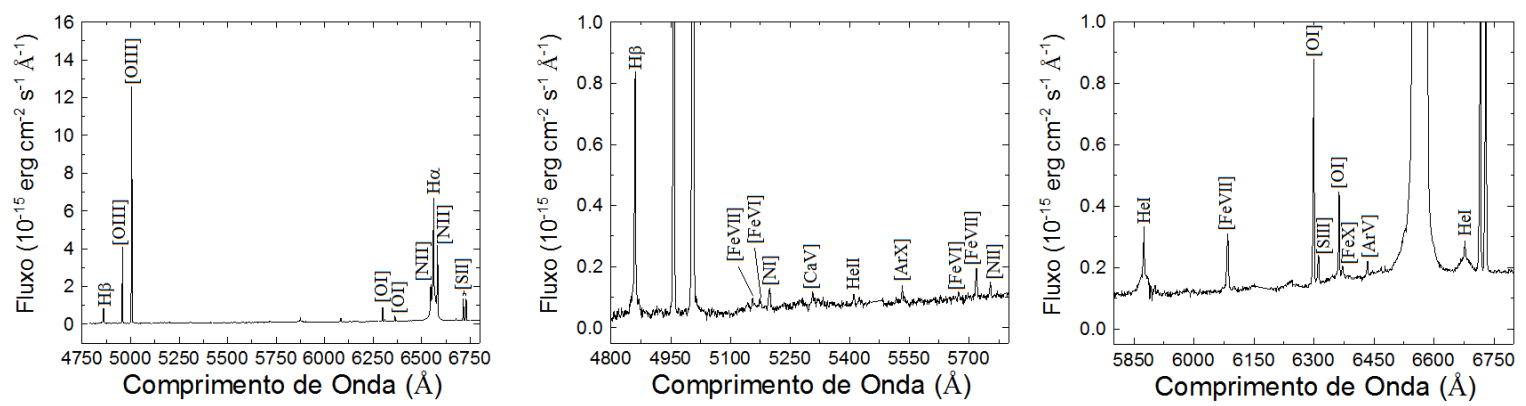

Figura 14.3: Espectro do núcleo de NGC 7314 com ampliações que permitem a visualização de várias linhas de emissão.

Tabela 14.1 - Propriedades de NGC 7314. Os valores foram obtidos do catálogo Hyperleda. O valor da dispersão de velocidades estelar foi determinado por Gu et al. (2006).

\begin{tabular}{|c|c|}
\hline $\mathrm{M}_{B}$ & $-20.15 \pm 0.25$ \\
\hline $\mathrm{m}_{B}$ & $11.60 \pm 0.04$ \\
\hline $\mathrm{B}-\mathrm{V}$ & 0.74 \\
\hline$\sigma_{*}(\mathrm{~km} / \mathrm{s})$ & $60 \pm 20$ \\
\hline Brilho superficial efetivo médio $\left(\mathrm{mag} / \mathrm{arcsec}^{2}\right)$ & $22.98 \pm 0.23$ \\
\hline
\end{tabular}

revelaram que a emissão em raios-X duros é obscurecida e a emissão em raios-X moles possui um excesso. Zou e Xue (2002) concluem que o AGN dessa galáxia está parcialmente obscurecido e que a emissão em raio-X mole observada parece ser um "vazamento" de emissão vinda do AGN, que é uma fonte variável. McKernan et al. (2007) mencionam que o contínuo de raios-X moles do núcleo de NGC 7314 é altamente obscurecido com a densidade de coluna fria $N_{h}=107 \pm 5 \times 10^{20} \mathrm{~cm}^{-2}$ e com o fluxo em raios-X moles $(0.5$ $\mathrm{keV}-2.0 \mathrm{keV}$ ) igual a $4.9 \times 10^{-12} \mathrm{erg}_{\mathrm{cm}^{-2} \mathrm{~s}^{-1}}$.

Os dados estudados aqui foram obtidos com o IFU do GMOS do telescópio GeminiNorte em 6 de Julho de 2016. O valor do FWHM da PSF usado no processo de deconvolução, calculado a partir da asa larga de $\mathrm{H} \alpha$, foi 0".6.

A imagem colapsada ao longo do eixo espectral do cubo de dados após o tratamento (Fig. 14.2 mostra uma fonte central e alguma emissão estendida. O espectro do núcleo (Fig. 14.3) é bastante rico, com várias linhas de emissão identificadas. Não é possível observar neste espectro nenhuma linha de absorção. Isso indica que a emissão do AGN neste núcleo é tão alta que ofusca a emissão estelar. 


\subsection{Arqueologia e cinemática estelar}

Embora este cubo apresente excelente $\mathrm{S} / \mathrm{N}$ quando se olha as linhas de emissão, o contínuo e linhas de absorção possuem $\mathrm{S} / \mathrm{N}$ baixíssimos. Como o critério desse trabalho considera confiáveis apenas resultados fornecidos pela síntese espectral de espectros com $\mathrm{S} / \mathrm{N}>10$ no contínuo estelar, tais resultados obtidos a partir do cubo de dados de NGC 7314 não são suficientemente confiáveis para serem incluídos nesse estudo. Uma forma de corrigir esse efeito seria uma nova observação com maiores tempos de exposição.

Como os resultados da síntese espectral não são confiáveis, não foi criado um cubo de gás. Para fazer as imagens das linhas de emissão foi subtraído o contínuo mais próximo da linha em questão. Para o cálculo das razões de linhas, como as linhas de emissão utilizadas para esse cálculo possuem fluxos altos, a incerteza da subtração do contínuo estelar é pequena, já que este contínuo praticamente não é detectável nos dados. Portanto, as razões de linhas foram calculadas a partir de espectros extraídos do cubo após o tratamento, que é essencialmente um cubo de emissão de gás.

\subsection{Emissão do gás}

As morfologias das regiões emissoras das diferentes linhas de emissão são bastante similares. Na Fig. 14.4, nota-se uma região central (Região 1) e duas regiões emissoras que partem da região central (que puderam ser melhor detectadas na imagem de [OIII] $\lambda 5007$ ) nas direções noroeste (Região 2) e sudoeste (Região 3). Por apresentar maior emissão em [OIII] $\lambda 5007$ e por sua morfologia, essa emissão estendida deve representar o cone de

ionização do AGN central. É possível que haja reflexão das emissões tanto do cone de ionização quanto de $\mathrm{H} \alpha$ larga e tal reflexão pode estar ocorrendo na Região 4. Essa reflexão pode ser causada por elétrons livres no cone de ionização ou por poeira.

As regiões 5 e 6 parecem fazer parte do "anel" observado em redshift em $\mathrm{H} \alpha$ (ver Figs. 14.9 a e c). Além disso, dada a morfologia da emissão do cone de ionização representado pela imagem de [OIII] $\lambda 5007$, nota-se que a parte interna do cone não é claramente visível. Isso pode ser devido ao fato da região interna do cone possuir maior ionização, apresentando, portanto, emissão de linhas com maiores graus de ionização. Além disso, a emissão de [OIII] $\lambda 5007$ detectada na Fig. 14.4 pode estar revelando um efeito de projeção, ao longo da linha de visada, das paredes do cone de ionização. 

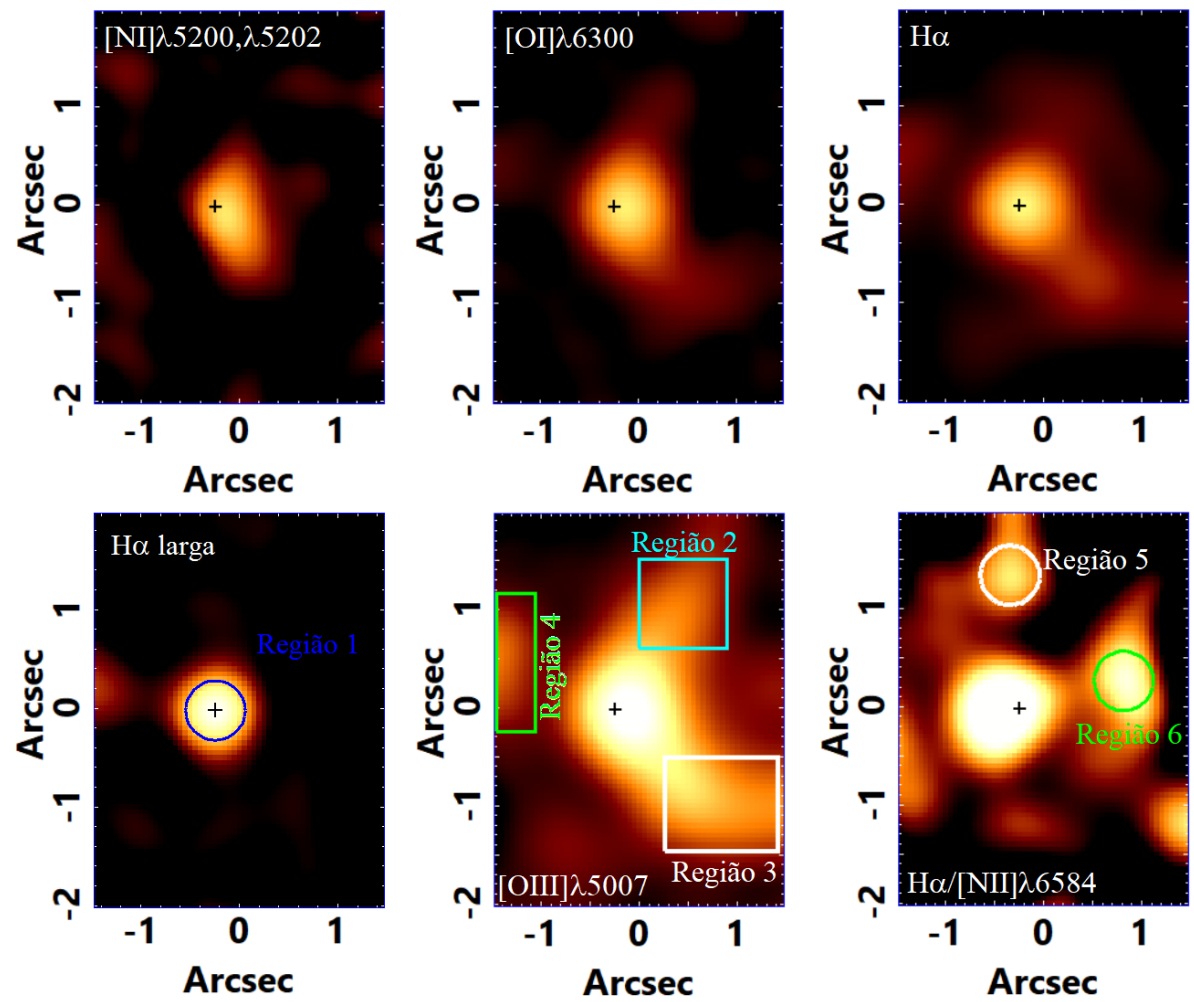

Figura 14.4: Imagens de algumas linhas de emissão do cubo de dados de NGC 7314. A imagem da asa larga de $\mathrm{H} \alpha$ foi utilizada para determinar a área de extração do espectro do núcleo (Região 1). A imagem de [OIII] $\lambda 5007$ foi utilizada para determinar as áreas de extração das regiões 2 e 3 (que pertencem ao cone de ionização) e Região 4 na borda do FOV, que também aparece na imagem de H $\alpha$ larga. Por fim, a imagem da razão $\mathrm{H} \alpha /[\mathrm{N}$ II] $] \lambda 6584$, que indica onde a emissão de $\mathrm{H} \alpha$ é mais relevante que [NII] $\lambda 6584$, foi utilizada para determinar as áreas de extração das regiões 5 e 6 . As áreas de extração das regiões 1, 5 e 6 são iguais à área da PSF do cubo de dados, enquanto que as áreas das regiões 2, 3 e 4 são maiores. A cruz representa o centro da emissão de $\mathrm{H} \alpha$ larga, ou seja, o centróide da Região 1, e seu tamanho representa a incerteza de $3 \sigma$. 
Tabela 14.2 - Razões de linhas e luminosidades obtidas a partir do fluxo integrado de $\mathrm{H} \alpha$ das 6 regiões emissoras detectadas no núcleo de NGC 7314.

\begin{tabular}{|c|c|c|c|c|c|c|}
\hline Razões de Linhas & Região 1 & Região 2 & Região 3 & Região 4 & Região 5 & Região 6 \\
\hline$[\mathrm{OII}] / \mathrm{H} \beta$ & $15.20 \pm 0.24$ & $11.2 \pm 0.5$ & $9.0 \pm 0.3$ & $8.2 \pm 0.6$ & $14 \pm 5$ & $6.8 \pm 1.4$ \\
\hline$[\mathrm{NII}] / \mathrm{H} \alpha$ & $0.768 \pm 0.006$ & $0.95 \pm 0.04$ & $0.758 \pm 0.014$ & $0.81 \pm 0.04$ & $0.73 \pm 0.06$ & $0.447 \pm 0.019$ \\
\hline$[\mathrm{OI}] / \mathrm{H} \alpha$ & $0.159 \pm 0.003$ & $0.096 \pm 0.005$ & $0.071 \pm 0.008$ & $0.071 \pm 0.010$ & $0.10 \pm 0.03$ & $0.010 \pm 0.005$ \\
\hline$([\mathrm{SII}] \lambda 6716+\lambda 6731) / \mathrm{H} \alpha$ & $0.434 \pm 0.003$ & $0.633 \pm 0.021$ & $0.565 \pm 0.009$ & $0.617 \pm 0.022$ & $0.58 \pm 0.15$ & $0.294 \pm 0.023$ \\
\hline$[\mathrm{SII}] \lambda 6716 /[\mathrm{SII}] \lambda 6731$ & $0.874 \pm 0.009$ & $1.19 \pm 0.03$ & $1.30 \pm 0.03$ & $1.12 \pm 0.04$ & $1.1 \pm 0.6$ & $1.17 \pm 0.19$ \\
\hline Luminosidade de $\mathrm{H} \alpha\left(10^{5} \mathrm{~L}_{\odot}\right)$ & $19.00 \pm 0.10$ & $1.01 \pm 0.03$ & $1.751 \pm 0.021$ & $5.06 \pm 0.15$ & $0.90 \pm 0.05$ & $0.448 \pm 0.013$ \\
\hline
\end{tabular}

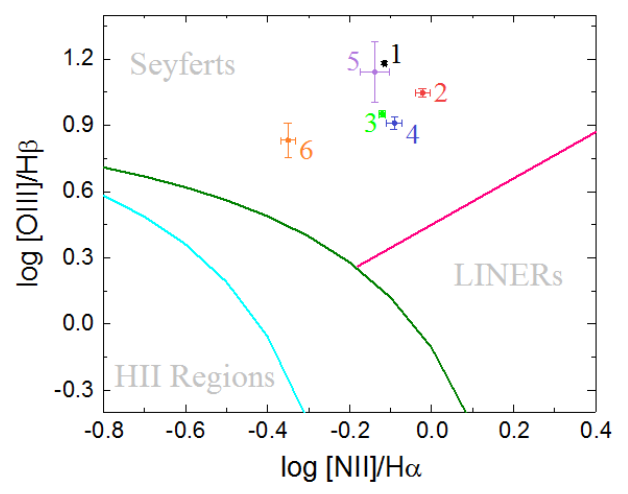

Figura 14.5: Diagrama de diagnóstico das regiões emissoras detectadas no núcleo de NGC 7314 a partir do cubo de dados do GMOS. A curva em verde-escuro representa a estimativa para o limite de ionização por um starburst determinada por Kewley et al. (2001). A divisão entre regiões HII e AGNs determinada por Kauffmann et al. (2003) está representada pela curva em ciano. A reta que divide Seyferts e LINERs determinada por Schawinski et al. (2007) está indicada em magenta.

Foram extraídos espectros das regiões delimitadas da Fig. 14.4 e calcularam-se as razões das linhas de emissão dessas regiões, como mostra a tabela 14.2. O diagrama de diagnóstico da Fig. 14.5 mostra que todas as regiões possuem emissão compatível com a de Seyferts. Dessa forma, as regiões 2 e 3 devem fazer parte do cone de ionização do AGN propriamente dito, enquanto que as demais regiões devem também fazer parte da NLR desse AGN. Além disso, não se pode descartar a possibilidade da ocorrência de uma reflexão da emissão proveniente do AGN ao longo da Região 4.

\subsubsection{Emissão em raios- $X$}

Os dados do telescópio espacial Chandra foram obtidos em 19 de Julho de 2002 com o instrumento ACIS-S no programa 03700392 (PI: Yaqoob, T.), com tempo de exposição de 28.41 ks. Esses dados são públicos e foram tomados para o estudo da emissão de raios-X no núcleo de NGC 7314 e comparação com os resultados aqui observados. Os dados foram 

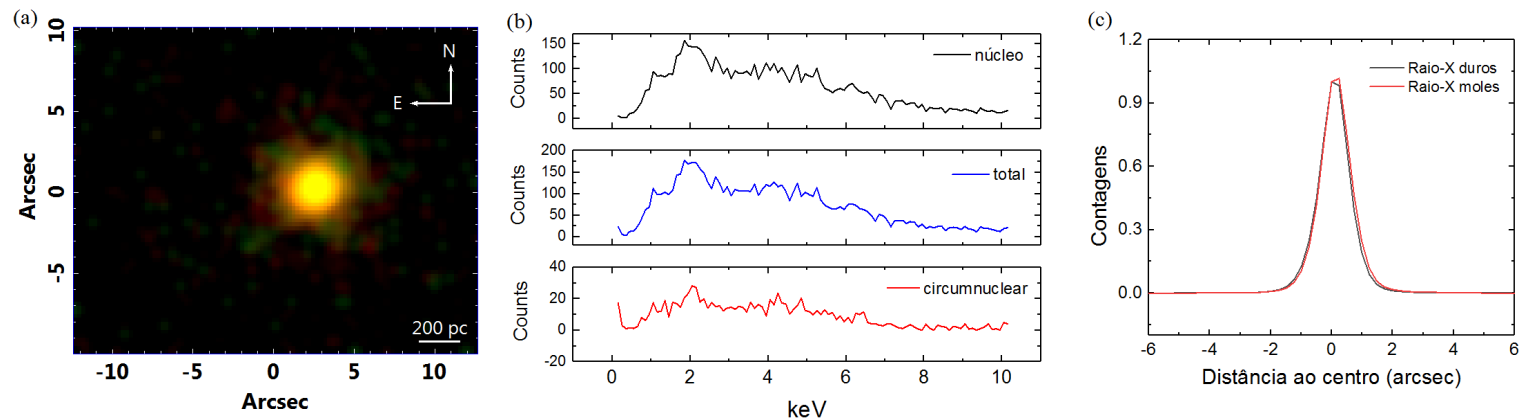

Figura 14.6: (a) Composição RG das imagens de raios-X duros (em vermelho) e raios-X moles (em verde). (b) Espectro da região nuclear, cujo centro foi determinado como o centro da emissão de raios-X duros e o raio de extração igual a 6 pixels (da mesma forma que em NGC 2442); espectro da região circumnuclear, resultante da subtração do espectro nuclear do espectro total; espectro de todo FOV mostrado no painel (a). (c) Perfis horizontais das imagens da emissão de raios-X duros e raios- $\mathrm{X}$ moles centrado no pico da emissão de raios-X duros. O número de contagens foi normalizado de modo que fosse igual a 1 no centro.

tratados como descrito na seção 3.6 .

A Fig. 14.6(a) mostra que tanto raios-X moles quanto raios-X duros possuem a mesma PSF. Isso é melhor representado na Fig. 14.6(c), onde se pode notar que os perfis das duas áreas emissoras são compatíveis.

Ao comparar os espectros do núcleo e total (Fig.14.6b), nota-se que há poucas diferenças de emissão entre eles. Isso porque a emissão nuclear é a mais relevante na região central desta galáxia. A emissão de raios-X duros está presente em todos os espectros e é possível notar um contínuo no espectro do núcleo, que pode representar o featureless continuum emitido pelo AGN.

\subsubsection{Imagens do HST e do ALMA}

Dados do arquivo público do HST desta galáxia foram obtidos a fim de estudar melhor a morfologia das estruturas nucleares. Os dados do filtro F606W foram obtidos em 24 de Agosto de 1994 com tempo de exposição de 500s e pertencem ao programa 5479 (PI: Malkan, M.). Os dados dos filtros F450W e F814W foram obtidos em 3 de julho de 2001 com tempo de exposição de 230s cada. Esses dados fazem parte do programa 9042 (PI: Smartt, S.). Para fazer uma comparação direta com os dados do GMOS, as imagens dos filtros foram cortadas de modo que o centro das emissões dos filtros fossem compatíveis com o centro da emissão da asa larga vermelha de $\mathrm{H} \alpha$. O tamanho dos spaxels das imagens é de 0".1. 

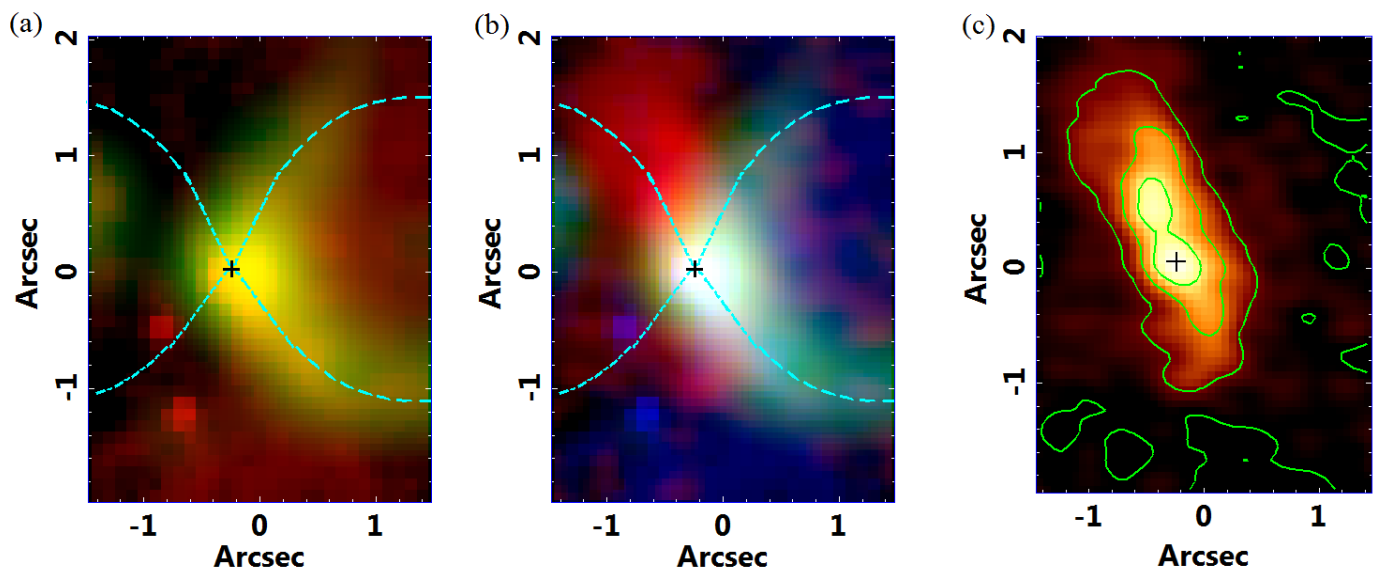

Figura 14.7: (a) Composição RGB da imagem do filtro F450W do HST (em vermelho) e da imagem de [OIII] $\lambda 5007$, obtida do cubo de dados do GMOS (em verde). (b) Composição RGB da imagem de CO(3-2) obtida do cubo de dados do ALMA (em vermelho), da imagem de [OIII] $\lambda 5007$ (em verde) e da imagem do filtro $\mathrm{F} 450 \mathrm{~W}$ (em azul). Os contornos em ciano representam a emissão das paredes do cone de ionização e foram estimados da imagem de [OIII] $\lambda 5007$. (c) Imagem de $\mathrm{CO}(3-2)$ cortada para o FOV do GMOS. O passo dos isocontornos é de 0.25 . O contorno que descreve a menor estrutura central tem um comprimento de $\sim 78$ pc e o contorno que descreve toda estrutura tem um comprimento de $\sim 220$ pc. A cruz representa a posição do centro de $\mathrm{H} \alpha$ larga.
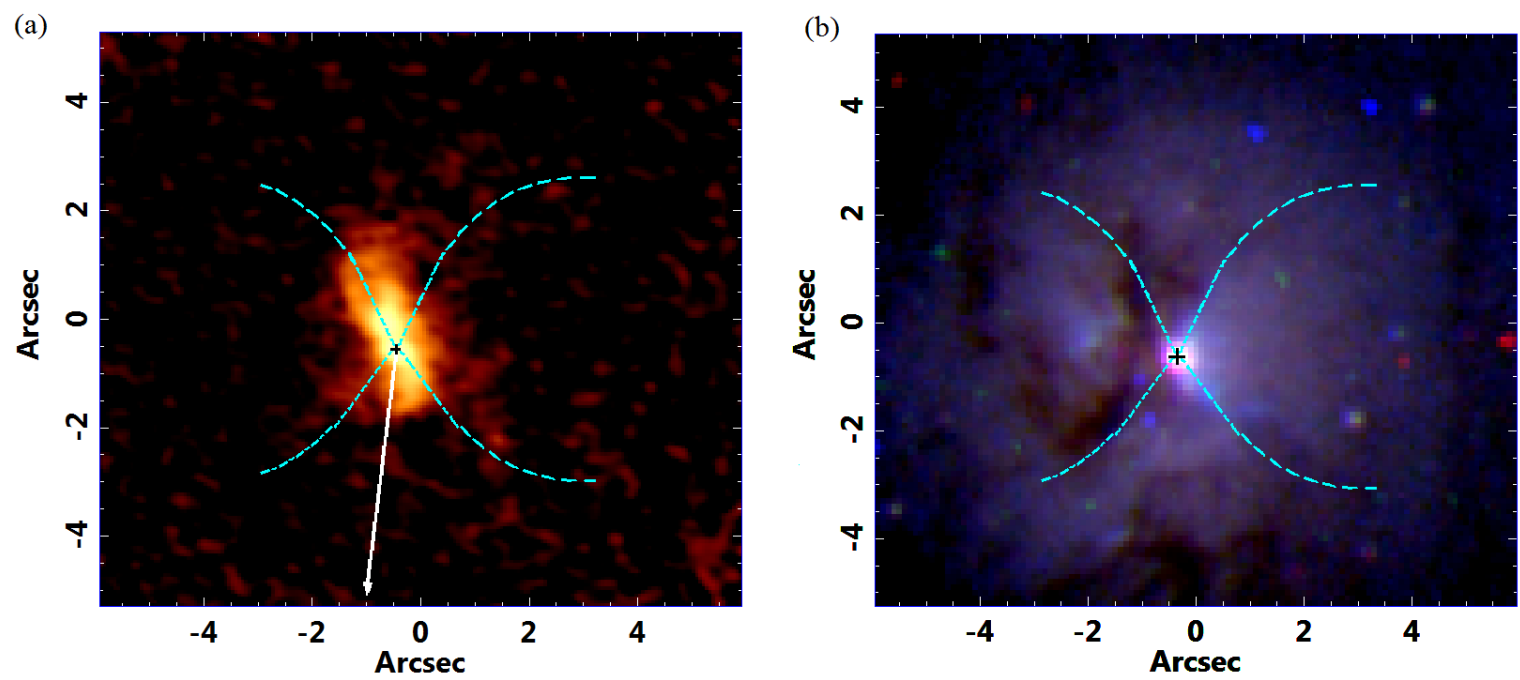

Figura 14.8: (a) Imagem de $\mathrm{CO}(3-2)$ obtida com o rádio-telescópio ALMA. (b)Composição RGB dos filtros F814W (em vermelho), F606W (em verde) e F450W (em azul) do HST. Os contornos em ciano representam a emissão das paredes do cone de ionização e foram estimados a partir da imagem de [OIII] $\lambda 5007$. A cruz representa a posição do centro de $\mathrm{H} \alpha$ larga. A orientação é Norte para cima e Leste para direita, como as demais imagens desta galáxia apresentadas aqui. A estrutura linear em rádio observada por Thean et al. (2000) está indicada pelo vetor em branco, seu tamanho representa 353 pc e sua orientação, o PA de $173^{\circ}$. 
Os dados públicos do rádio-telescópio ALMA foram obtidos em 30 de Agosto de 2018 (PI: Garcia-Burillo, S.) e fazem parte do programa 2017.1.00082.S. O tempo de exposição foi de 756s. A fim de fazer uma comparação direta com os demais dados aqui apresentados, a imagem de $\mathrm{CO}(3-2)$ foi cortada para que o centro da emissão fosse compatível com o centro da emissão da asa vermelha larga de $\mathrm{H} \alpha$. O tamanho dos spaxels das imagens é de 0".062.

A Fig. 14.7(a) mostra que a emissão do filtro F450W do HST possui um excesso na mesma direção que as paredes do cone de ionização representadas por [OIII] $\lambda 5007$. Contornos que representam essas paredes foram desenhados e projetados na direção oposta para representar a possível morfologia e posição do cone de ionização.

A emissão de $\mathrm{CO}(3-2)$ representada na Fig. 14.7(b) mostra uma estrutura aproximadamente perpendicular à direção do cone de ionização, com excesso de emissão em direção ao Norte. Essa emissão de $\mathrm{CO}(3-2)$ possui uma estrutura estendida, com possivelmente duas componentes: uma interna, cujo comprimento é de $\sim 78$ pc e, outra, externa cujo comprimento se estende por $\sim 220$ pc. Devido à sua orientação, é possível que, ao menos, a parte mais compacta dessa emissão corresponda a um toro de poeira ao redor do AGN. Não é possível determinar qual o limite externo do toro de poeira, portanto, não se pode afirmar que toda a estrutura de $\mathrm{CO}(3-2)$ faça parte do toro. Uma possibilidade a ser considerada é que a estrutura observada seja composta por um toro e um disco molecular, sobrepostos para o observador. Além disso, como a emissão de raios-X não é obscurecida, é possível que esse toro tenha uma estrutura clumpy, o que explica a variabilidade deste AGN, como Ebrero et al. (2011) afirmaram.

A imagem da Fig. 14.8(a) mostra a emissão de CO(3-2) em um FOV maior e há uma possível leve concentração de nuvens de gás molecular nas paredes do cone de ionização.

A Fig. 14.8(b) mostra que há uma nuvem de poeira na direção Leste do núcleo e isso reforça a ideia de que a outra parte do cone de ionização está sendo obscurecida por poeira e de que pode haver reflexão da emissão do núcleo, na região do cone de ionização a Leste. Além disso, nota-se o excesso de emissão ao longo das paredes do cone de ionização a Oeste e que há uma única emissão relevante no núcleo (AGN).

A estrutura linear observada por Thean et al. (2000), que pode ser um provável jato em rádio, não está alinhada nem com o cone de ionização, podendo possivelmente estar sendo emitido nas paredes do cone, nem com a emissão em $\mathrm{CO}(3-2)$. 

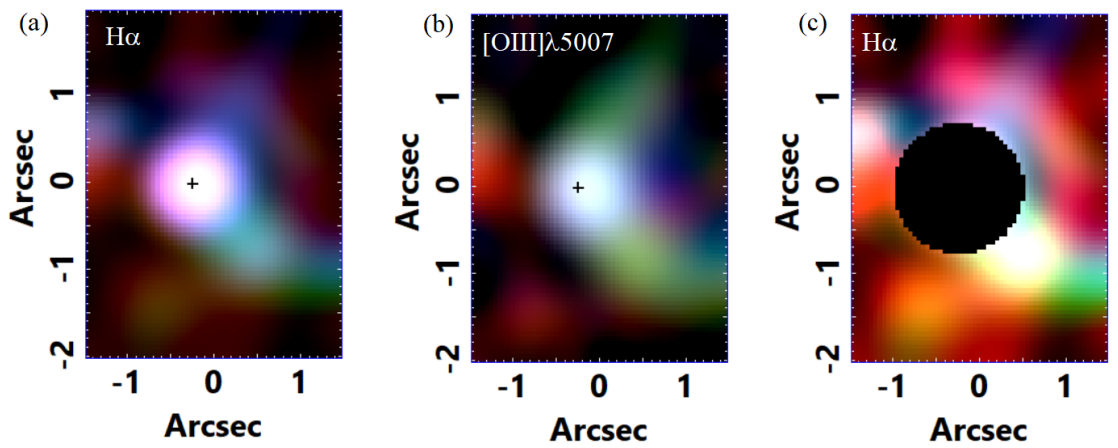

Figura 14.9: Composições RGBs das linhas de (a) $\mathrm{H} \alpha$, (b) [OIII] $\lambda 5007$ e (c) $\mathrm{H} \alpha$ com o centro truncado para destacar a emissão circumnuclear. A cor vermelha representa emissão com velocidades entre $214 \mathrm{e}$ $239 \mathrm{~km} / \mathrm{s}$ (redshift), a cor verde representa a emissão entre 29 e $53 \mathrm{~km} / \mathrm{s}$ e a cor azul, -210 e $-107 \mathrm{~km} / \mathrm{s}$ (blueshift).

\subsection{Cinemática do gás}

As composições RGBs de H $\alpha$ e [OIII] $\lambda 5007$ da Fig. 14.9(a) e (b) mostram que o núcleo (região central do FOV) possui uma cinemática que não pode ser resolvida com essa resolução espacial. Na imagem de H $\alpha$ (Fig. 14.9 a) há uma estrutura parecida com um anel fragmentado em redshift. Além disso, o gás em velocidades baixas e em blueshift apresenta uma estrutura parecida com um arco, que é o cone de ionização observado na imagem de [OIII] $\lambda 5007$. Dessa forma, o cone de ionização possui, em parte de sua extensão, gás com baixas velocidades e também gás com emissão em blueshift, sobretudo na parte ao norte do núcleo, o que pode estar associado à ocorrência de outflows nessa região.

A composição RGB de H $\alpha$ das regiões circumnucleares Fig. 14.9(c) apresenta um "meioanel" em redshift e a região do cone (em blueshift e baixas velocidades). É possível que o outro lado do anel não seja observável, devido a obscurecimento de poeira presente nesta região, como visto anteriormente. Além disso, não há nenhum outro padrão reconhecível.

\subsubsection{Cinemática do gás molecular}

A partir do cubo de dados do ALMA foi possível criar channel maps da emissão de $\mathrm{CO}(3-2)$, como mostra a Fig. 14.10 .

Os channel maps da Fig. 14.10 mostram o quão complexa é a cinemática do gás molecular na região central dessa galáxia. Primeiramente, nota-se que há uma grande assimetria de velocidades e do perfil da linha para o azul (para velocidades negativas), enquanto que há apenas dois channels com velocidades positivas. Parece haver uma possível rotação, 

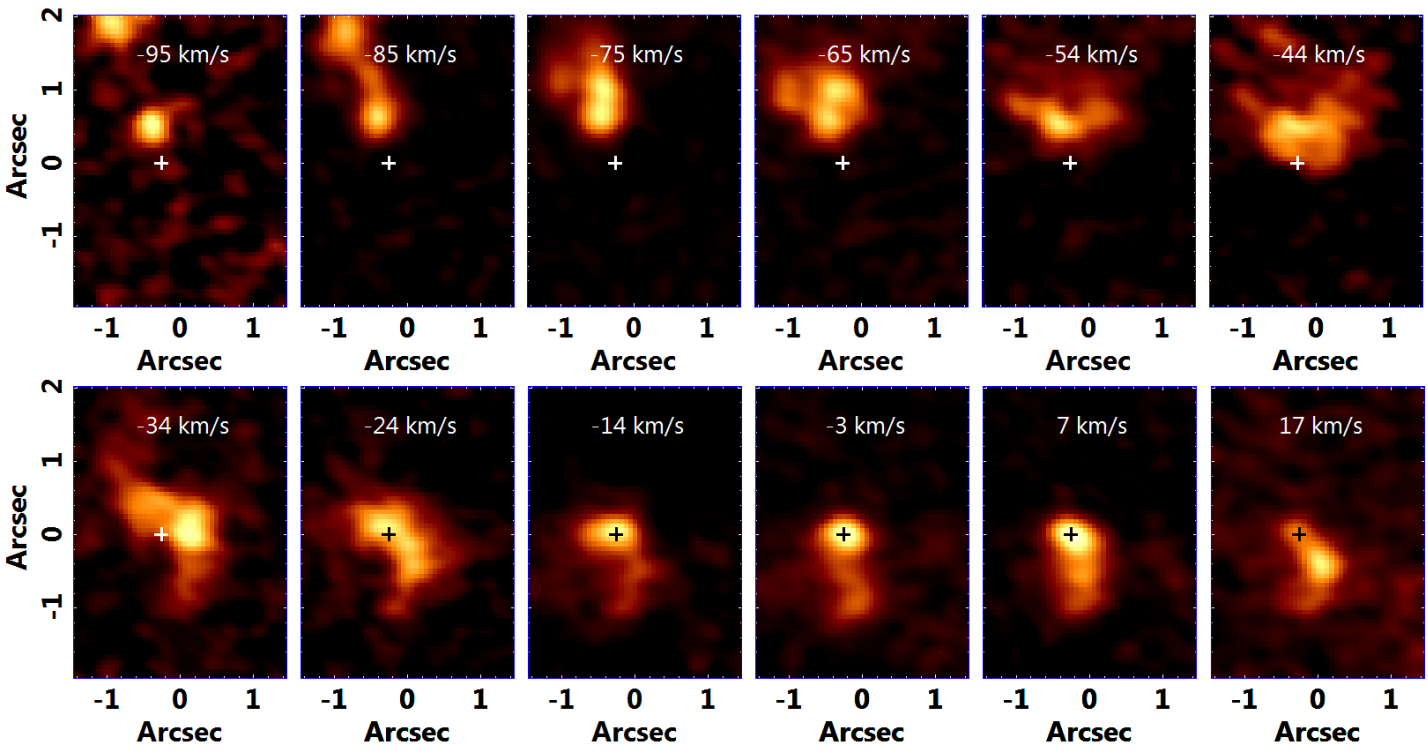

Figura 14.10: Channel maps da linha de $\mathrm{CO}(3-2)$ com passos de 2 pixels espectrais. As velocidades foram calculadas em relação ao núcleo, cujo centro está representado pela cruz e seu tamanho representa a incerteza de $3 \sigma$.

o que caracterizaria um disco de gás molecular, representada pelos channels com velocidades de $-95 \mathrm{~km} / \mathrm{s}$ a $-65 \mathrm{~km} / \mathrm{s}$ (correspondendo à porção em blueshift) e velocidades de $-3 \mathrm{~km} / \mathrm{s}$ a $17 \mathrm{~km} / \mathrm{s}$ (correspondendo à porção em redshift). Os demais channels possuem morfologias complexas, que podem representar outflows de gás, sobretudo o channel com velocidade $-34 \mathrm{~km} / \mathrm{s}$, que possui uma direção de emissão compatível com a do eixo do cone de ionização.

\subsection{Conclusões}

- O núcleo de NGC 7314 apresenta uma emissão de uma Seyfert tipo 1. Este núcleo apresenta uma abundância da emissão de linhas coronais, tais como [FeviI $] \lambda 5720$, $[\mathrm{Fex}] \lambda 6375$, [ArV] $\lambda 6435$, etc. Além disso, há emissão de raios-X duros que possui mesmo perfil espacial que a emissão de raios-X moles.

- A morfologia a baixas velocidades da emissão de [OIII] $\lambda 5007$ sugere que há um cone de ionização cujo eixo se estende a Noroeste. Entretanto, essa emissão parece revelar apenas as paredes deste cone, cujo interior deve possuir emissão de oxigênio com maiores graus de ionização. O lado oposto do cone não é visível, possivelmente devido ao obscurecimento por poeira, observado nas imagens do HST; o tamanho reduzido do FOV não permite 
detectar este a distâncias maiores do núcleo.

- Além do núcleo e do cone de ionização, foram observadas outras 3 regiões emissoras, cujas razões de linhas são compatíveis com as de Seyferts.

- Há um disco de gás molecular possivelmente associado a um toro de poeira clumpy perpendicular ao cone de ionização. A cinemática deste disco é complexa, possivelmente composta por outflows de gás, além de uma provável rotação.

- A cinemática do gás ionizado é complexa e há uma emissão com estrutura aparentemente anelar em redshift observada em $\mathrm{H} \alpha$. 
Capítulo 15

\section{NGC 2207}

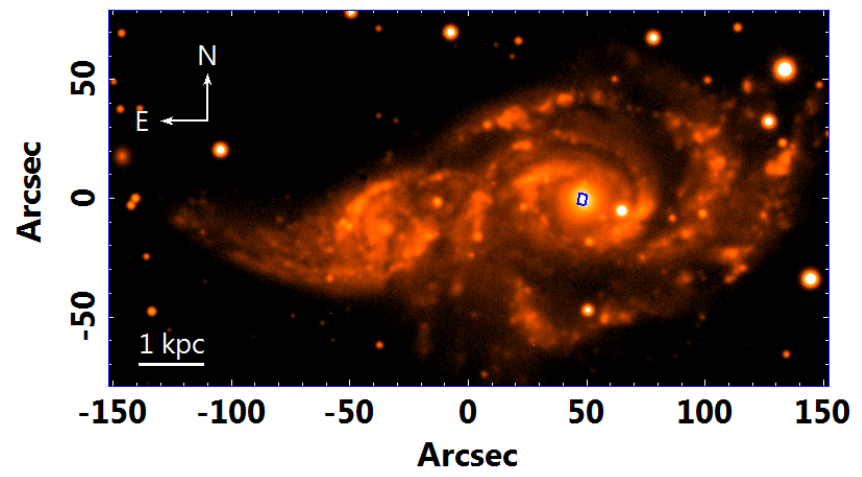

Figura 15.1: Imagem da galáxia NGC 2207 (a oeste), em interação com a galáxia IC 2163 (a leste), obtida com o telescópio CTIO de $1.5 \mathrm{~m}$ com o filtro na banda B. O quadrado azul representa o campo de observação do GMOS. O PA dos dados do GMOS é $-13^{\circ}$ e a área do FOV do GMOS é de $3 " .1 \times 4 " .35$.

NGC 2207 é uma galáxia do tipo SAB(rs)bc pec (de Vaucouleurs et al., 1991), localizada a 16.80 Mpc (Theureau et al., 2007) e está colidindo com outra galáxia (IC 2163 - ver Fig. 15.1). O diâmetro da sua barra é de 46".4, $3.8 \mathrm{kpc}$ (Laurikainen et al., 2004). Imagens em Hi mostram uma estrutura de anel clumpy no disco da galáxia que possui uma quebra ao Sul (Struck et al., 2005).

Observações com o HST revelam que há um conjunto de espirais de poeira na região nuclear de NGC 2207. Os braços se estendem de 50 pc a 300 pc do centro com uma largura projetada de 20 pc (Elmegreen et al., 1998). Observações da linha de CO com o rádio-telescópio ALMA revelam um anel nuclear, uma mini-barra e uma região de "ministarburst" que domina a emissão em $24 \mu \mathrm{m}$ e em H $\alpha$ (Elmegreen et al., 2017).

Foi observada uma fonte em raios-X no núcleo de NGC 2207 com $L_{X}=9 \pm 1.3 \times 10^{39}$ $\mathrm{erg} / \mathrm{s}$ no intervalo entre $0.5 \mathrm{keV}$ e $8 \mathrm{keV}$, indicando a presença de um AGN com baixa luminosidade (Mineo et al., 2013). Não há muitos estudos sobre o núcleo desta galáxia, 

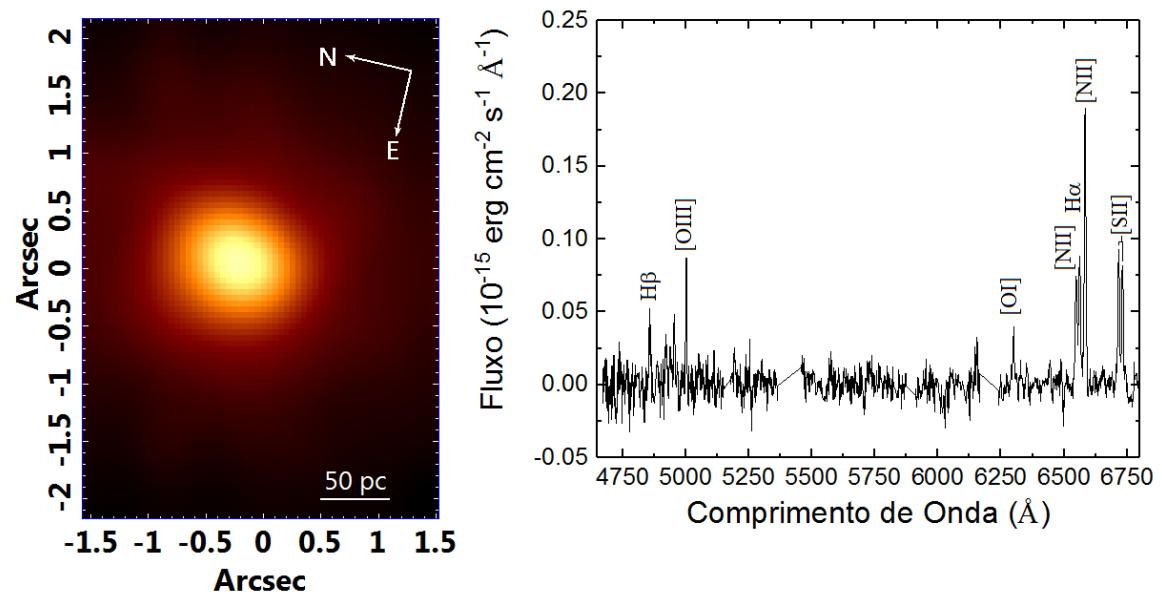

Figura 15.2: Imagem do cubo de dados colapsado ao longo do eixo espectral e espectro do núcleo (centro da emissão estelar) de NGC 2207, corrigido de redshift.

Tabela 15.1 - Propriedades de NGC 2207. Os valores foram obtidos do catálogo Hyperleda. Não foram encontrados dados na literatura da dispersão de velocidades estelar no núcleo.

\begin{tabular}{|c|c|}
\hline $\mathrm{M}_{B}$ & $-21.48 \pm 0.53$ \\
\hline $\mathrm{m}_{B}$ & $12.14 \pm 0.31$ \\
\hline $\mathrm{B}-\mathrm{V}$ & 0.67 \\
\hline$\sigma_{*}(\mathrm{~km} / \mathrm{s})$ & \\
\hline Brilho superficial efetivo médio $\left(\mathrm{mag} / \mathrm{arcsec}^{2}\right)$ & $22.30 \pm 0.85$ \\
\hline
\end{tabular}

apenas Veron-Cetty e Veron (1986), a partir de razões de linhas no óptico, determinaram que ela possui um núcleo do tipo Seyfert.

Os dados aqui apresentados foram observados com o IFU do GMOS do telescópio Gemini-Sul em 10 de Novembro de 2016. O FWHM da PSF usado no processo de deconvolução deste cubo de dados, obtido a partir da imagem de aquisição no comprimento de onda de $6300 \AA$, foi $\sim 0 " .45$.

A Fig 15.2 mostra uma imagem representativa do cubo de dados após o tratamento, colapsado ao longo do eixo espectral, juntamente com o espectro do núcleo, extraído a partir de uma região circular centrada no núcleo estelar, com diâmetro igual ao FWHM da PSF dos dados. A fonte principal de emissão é central no FOV e o espectro é consideravelmente ruidoso no azul, porém é possível observar, com exceção de $\mathrm{H} \beta$, todas as principais linhas de emissão no óptico e também o dubleto NaI $\lambda \lambda 5890,5896$. 

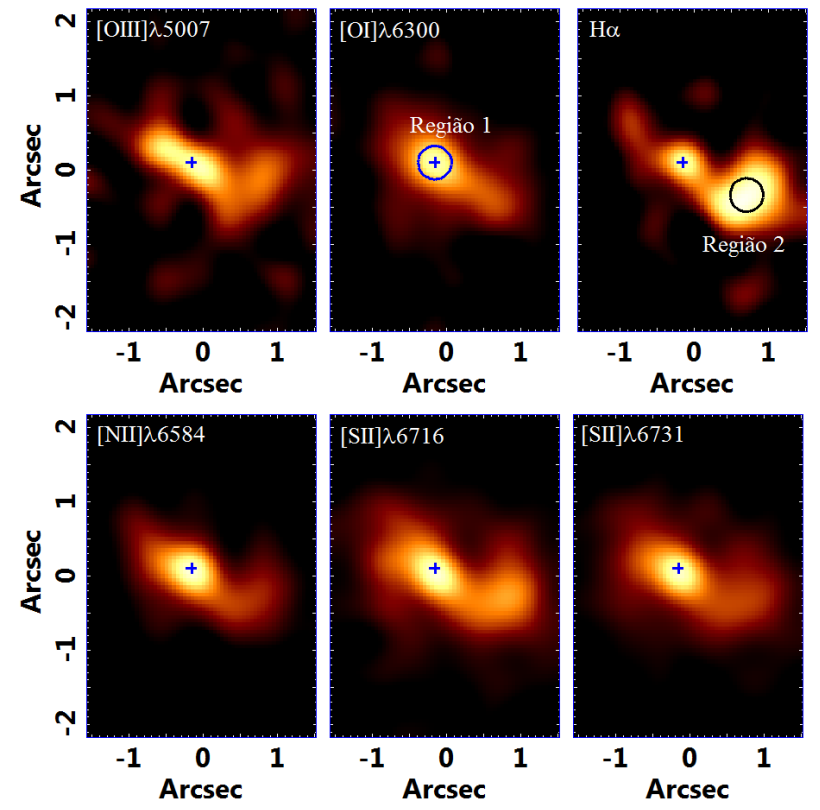

Figura 15.3: Imagens das principais linhas de emissão de NGC 2207. A cruz azul indica o centro da emissão de [OI] $\lambda 6300$, que também corresponde ao centro da principal região de emissão deste cubo, Região 1, e seu tamanho representa a incerteza de $3 \sigma$. Existe ainda uma segunda região emissora, Região 2, identificada na imagem de $\mathrm{H} \alpha$. Os círculos nas imagens de [OI] $\lambda 6300$ e $\mathrm{H} \alpha$ representam as áreas de extração dos espectros utilizados no cálculo das razões de linhas das regiões 1 e 2 .

\subsection{Emissão do gás}

Ao compararmos a Fig. 15.2 com as imagens da Fig. 15.3, vemos que a emissão do contínuo possui morfologia circular, mas a emissão de gás possui uma morfologia mais estendida num eixo preferencial.

A emissão de [OIII] $\lambda 5007$, por ser uma linha de mais alta ionização, geralmente é um bom indicativo do cone de ionização do AGN, ainda mais quando sua morfologia é semelhante à de um cone projetado num plano. Neste caso o centro da principal região emissora de gás (tomado como o centro da emissão de [OI] 16300$)$ está no centro desta emissão que se estende no $\mathrm{PA} \sim-14^{\circ}$, podendo ser, então, a emissão dos dois lados do cone de ionização.

A emissão de [OI] $\lambda 6300$ é principalmente central, mas também se apresenta em direção ao sul, bem como $\mathrm{H} \alpha$, cuja emissão ao sul é mais significativa do que a emissão central. Desta imagem ([OI] $\lambda 6300$ na Fig. 15.3) pode-se identificar com clareza a região central, Região 1. Como a emissão de [Or] 76300 é típica de ambientes em torno de AGNs, o fato da concentração dela ser pontual sugere a presença de um AGN na Região 1. Portanto, 
Tabela 15.2 - Razões de linhas e luminosidades obtidas a partir do fluxo integrado de $\mathrm{H} \alpha$ das 2 regiões emissoras observadas no núcleo de NGC 2207.

\begin{tabular}{|c|c|c|}
\hline Razões de Linhas & Região 1 & Região 2 \\
\hline$[\mathrm{OIII}] / \mathrm{H} \beta$ & $1.52 \pm 0.23$ & $2.38 \pm 0.19$ \\
{$[\mathrm{NII}] / \mathrm{H} \alpha$} & $2.08 \pm 0.15$ & $1.57 \pm 0.13$ \\
{$[\mathrm{OI}] / \mathrm{H} \alpha$} & $0.37 \pm 0.07$ & $0.37 \pm 0.06$ \\
$([\mathrm{SII}] \lambda 6716+\lambda 6731) / \mathrm{H} \alpha$ & $2.00 \pm 0.13$ & $1.54 \pm 0.15$ \\
{$[\mathrm{SII}] \lambda 6716 /[\mathrm{SII}] \lambda 6731$} & $1.09 \pm 0.13$ & $1.29 \pm 0.18$ \\
\hline Luminosidade de $\mathrm{H} \alpha\left(10^{3} \mathrm{~L}_{\odot}\right)$ & $7.4 \pm 0.4$ & $34.0 \pm 2.2$ \\
\hline
\end{tabular}

foi extraído um espectro dessa região para o cálculo de razões de linhas.

No caso das emissões de $[\mathrm{NII}] \lambda 6584$, $[\mathrm{SII}] \lambda 6716$ e $[\mathrm{SII}] \lambda 6731$, vê se uma mesma morfologia do gás, que se estende ao longo de um PA compatível com o do cone de ionização, bem como as imagens das demais linhas. Essa morfologia estendida pode refletir a posição do cone de ionização de gás e ionização de nuvens da NLR na mesma orientação.

A partir da imagem de $\mathrm{H} \alpha$ foi possível identificar uma segunda região, Região 2. Ela aparece difusa em outras imagens. Como é uma estrutura presente em todas as imagens e aparece mais claramente na imagem de $\mathrm{H} \alpha$, foi extraído um espectro (cujas coordenadas foram retiradas dessa imagem) para o cálculo das razões de linhas.

As coordenadas da Região 1 são $\mathrm{X}_{C}=-0 " .153 \pm 0 " .025$ e $\mathrm{Y}_{C}=0 " .083 \pm 0 " .025$, obtidas do centro da emissão de [OI] $\lambda 6300$, e da Região 2 são $\mathrm{X}_{C}=0 " .701 \pm 0$ ".025 e $\mathrm{Y}_{C}=$ $0 " .318 \pm 0 " .025$, tomadas a partir da imagem de $\mathrm{H} \alpha$, conforme mencionado anteriormente. Espectros de áreas circulares centradas em cada uma das duas regiões foram extraídos a partir do cubo de gás de NGC 2207, com diâmetro igual ao FWHM da PSF dos dados. As linhas de emissão de $[\mathrm{SII}] \lambda 6717, \lambda 6731$ bem como as linhas [NII] $\lambda 6548, \lambda 6584$ e $\mathrm{H} \alpha$ apareceram blendadas nestes espectros. Foi necessário, então, decompor as linhas em gaussianas. Neste caso específico, não foi possível convergir o ajuste para conjuntos de duas gaussianas por linhas de emissão. Então, apenas uma gaussiana foi ajustada a cada linha. A tabela 15.2 apresenta as razões de linhas calculadas para as duas regiões.

O diagrama de diagnóstico da Fig. 15.4 mostra que as duas regiões possuem razões de linhas compatíveis com as de LINERs. A Região 2 apresenta grau de ionização maior do que a Região 1, conforme mostrado pela razão de [OIII]/H $\beta$, mas ambos são compatíveis dentro de $3 \sigma$. Entretanto, como o centro da emissão de [OI] $\lambda 6300$ está na Região 1, é muito 


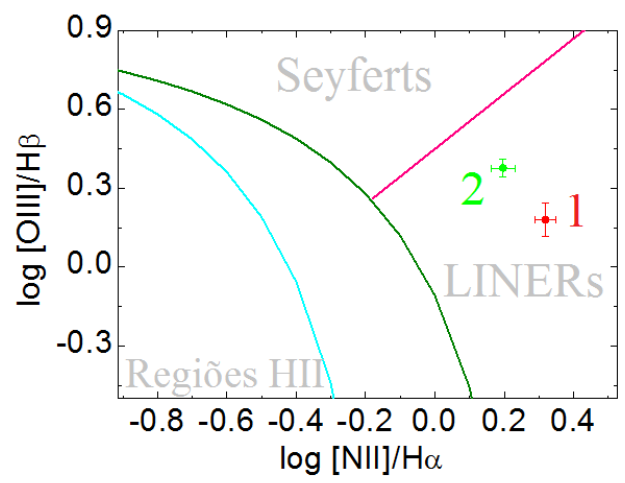

Figura 15.4: Diagrama de diagnóstico das regiões emissoras observadas no núcleo de NGC 2207 a partir do cubo de dados do GMOS: Região 1, identificada pelo ponto vermelho e Região 2, identificada pelo ponto verde. A curva em verde-escuro representa a estimativa para o limite de ionização por um starburst determinada por Kewley et al. (2001). A divisão entre regiões HII e AGNs determinada por Kauffmann et al. (2003) está representada pela curva em ciano. A reta que divide Seyferts e LINERs determinada por Schawinski et al. (2007) está indicada em magenta.

mais provável que esta seja um AGN e a Região 2 seja parte da NLR do mesmo. Como a Região 2 está dentro do cone de ionização, ela pode estar recebendo ionização direta do AGN ou pode apresentar um menor valor de densidade eletrônica, o que justificaria o maior grau de ionização observado.

Essa galáxia possui emissão compacta em raios-X duros (Mineo et al., 2013), portanto a emissão LINER é proveniente de um AGN, distinta da emissão de populações estelares jovens.

Por serem linhas sensíveis à densidade eletrônica do gás, relações matemáticas das linhas de emissão de [SII] $] 6716, \lambda 6731$ podem ser utilizadas para determinar áreas de baixa e alta densidades de nuvens de gás. A partir da equação (1) de Steiner et al. (2009a), utilizando os valores empíricos para os parâmetros da equação e as imagens de [SıI] $6716, \lambda 6731$ do cubo de gás de NGC 2207, foi possível obter os mapas da Fig. 15.5.

A emissão de baixa densidade (Fig. 15.5a) é estendida por toda a região de emissão do gás observada nas imagens da Fig. 15.3. Já a emissão de alta densidade (Fig. 15.5b) é consideravelmente compacta e central e seu centro é compatível com o centróide da Região 1. Ou seja, o gás mais denso se encontra mais próximo ao AGN e o gás menos denso nas regiões da NLR. 

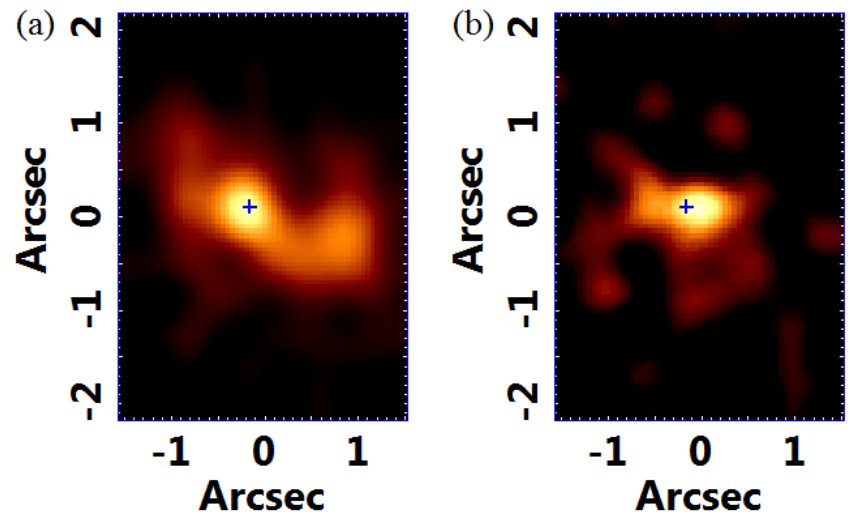

Figura 15.5: Mapas de baixa (a) e alta (b) densidades obtidos a partir da equação (1) de Steiner et al. (2009a), calculada para as linhas [SII] $\lambda 6716$ e [SII] $\lambda 6731$. A cruz representa o centro da Região 1 e seu tamanho, a incerteza de $3 \sigma$.
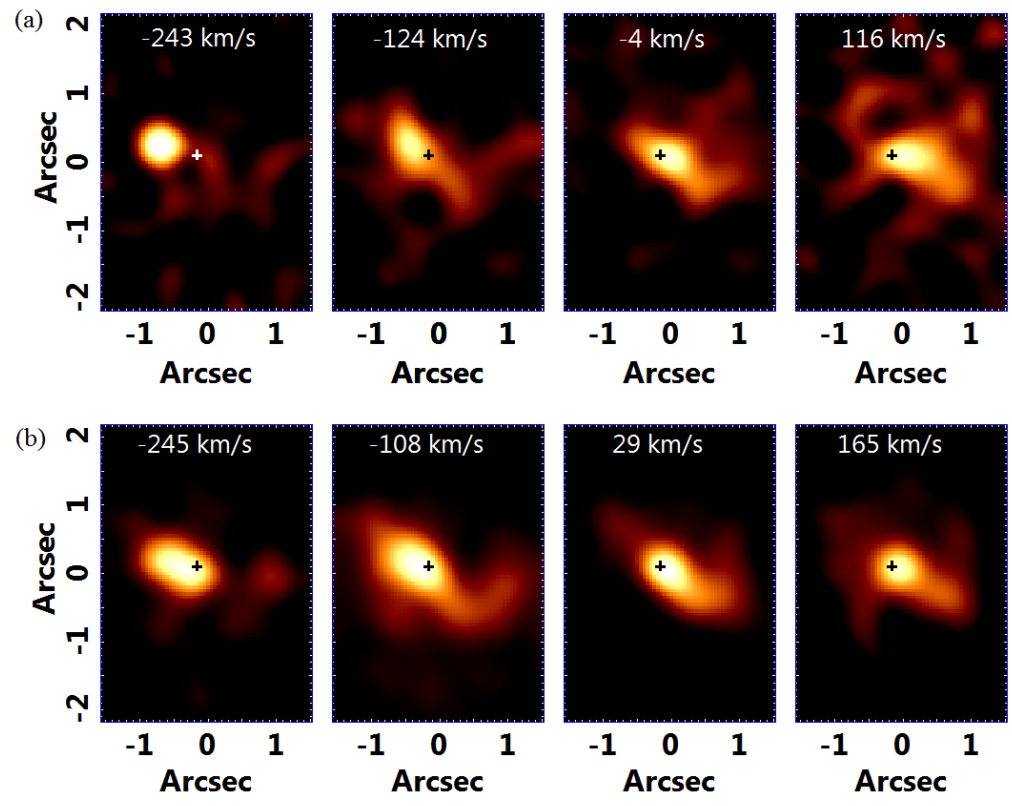

Figura 15.6: (a)Channel maps da linha de [OIII] $\lambda 5007$. O passo entre os channels é de $2 \AA$. (b) Channel maps da linha de [NII] 26584 , com passos de $3 \AA \AA$. Os valores das velocidades apresentados em cada channel foram calculados a partir da média dos intervalos utilizados para cada channel. Esses valores foram calculados em relação ao valor do comprimento de onda central das linhas na Região 1. A cruz nos mapas representa o centróide da Região 1 e seu tamanho, a incerteza de $3 \sigma$. 

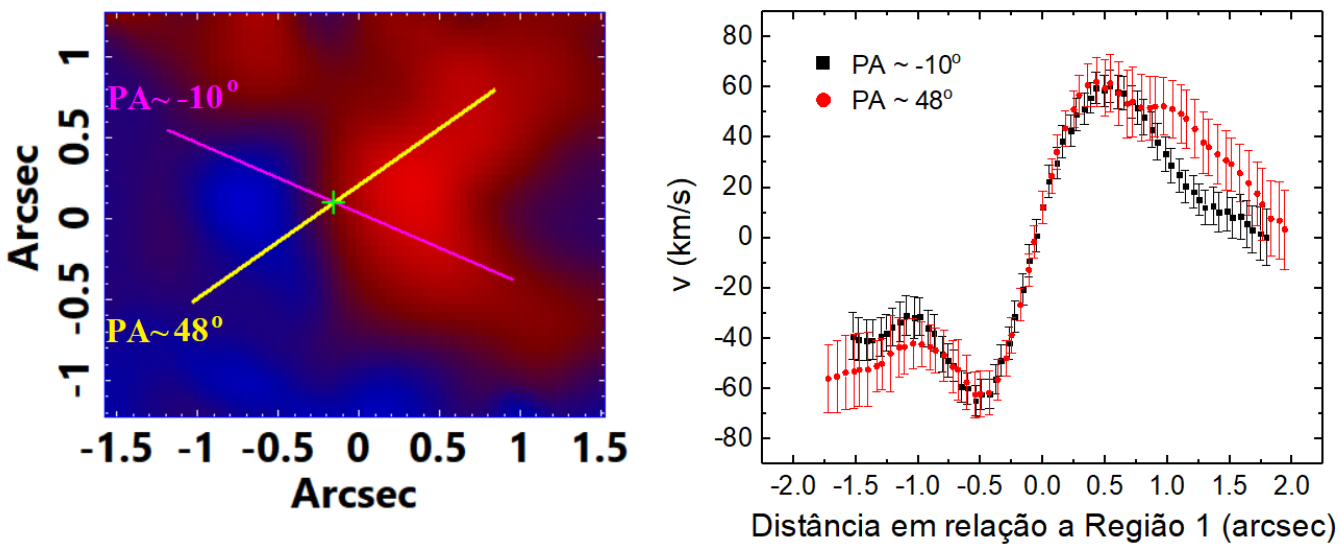

Figura 15.7: Mapa e curva de velocidades da linha de [NII] 26584 extraída de dois PAs: $-10^{\circ}$, representado pela reta em magenta no mapa (PA do eixo do cone de ionização da imagem [Oıı] $\lambda 5007$ ) e $48^{\circ}$, representado pela reta em amarelo no mapa (possível direção da rotação do gás extraído do mapa de velocidades). A cor azul no mapa de velocidades representa emissão em blueshift e a cor vermelha representa emissão em redshift. A cruz verde representa o centróide da Região 1 e, seu tamanho, a incerteza de $3 \sigma$.

\subsection{Cinemática do gás}

Uma forma detalhada de se estudar a cinemática do gás utilizando cubos de dados é através do uso de channel maps (Fig. 15.6]). Os channel maps das linhas de [OIII] $\lambda 5007$ e [NII] 6584 possuem semelhanças pois revelam uma possível rotação de gás em torno da Região 1 (melhor representada nos três últimos channels). A direção dessa possível rotação de gás central é tal que o gás apresenta emissão em blueshift ao Norte e emissão em redshift ao Sul. O PA do disco de gás projetado é de $\sim-26^{\circ}$, próximo ao PA do cone de ionização, mas não coincidente. Não se pode descartar, no entanto, que sejam dois outflows de gás em direções opostas.

O mapa de velocidades da linha de $[\mathrm{NII}] \lambda 6584$ apresenta uma bipolaridade de velocidades representadas pelas cores azul e vermelha, emissão em blueshift e emissão em redshift, respectivamente (ver Fig. 15.7). Foram extraídas duas curvas com dois PAs, um delimitado pelo eixo do cone de ionização e outro determinado pela direção aparente da rotação do gás no mapa de rotação de [NII] $\lambda 6584$. Pode-se notar que as curvas são muito parecidas, principalmente dentro do segundo de arco central. Isso pode ser devido ao tamanho da PSF dos dados, que impede a diferenciação das duas componentes. Uma interpretação para este resultado é que o mesmo é uma composição de duas componentes: o cone de ionização e o disco de gás. No caso do cone de ionização, a cinemática, possivelmente, é 

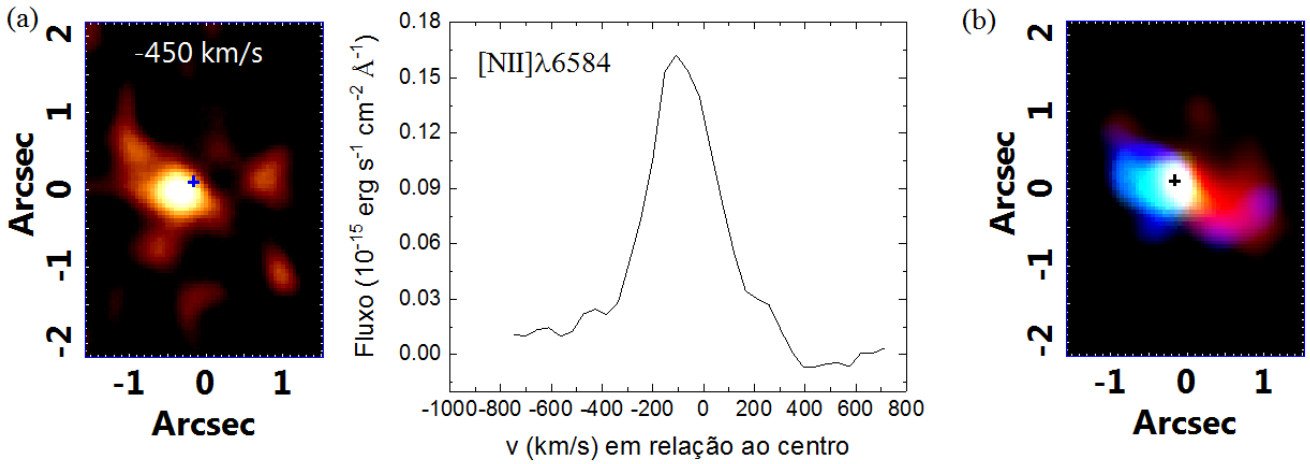

Figura 15.8: (a)Imagem do outflow criada a partir da asa mais azulada da linha de [NII] 6584 e perfil da linha de [NII] 6584 do espectro extraído da região do outflow. As velocidades foram calculadas em relação ao comprimento de onda central da linha na Região 1. (b) RGB da linha de $\mathrm{H} \alpha$. A cor verde representa a região de maiores velocidades no azul (entre -409 e $-226 \mathrm{~km} / \mathrm{s}$ ), a cor azul velocidades entre -181 e -44 $\mathrm{km} / \mathrm{s}$ e a cor vermelha as velocidades entre 1 e $140 \mathrm{~km} / \mathrm{s}$. A cruz representa o centro da Região 1 e seu tamanho, a incerteza de $3 \sigma$.

devida a outflows de gás, observados nas imagens dos channel maps de [OIII] $\lambda 5007$ (Fig. 15.6.

Ao observar os perfis das linhas de emissão de NGC 2207, é possível notar que as linhas possuem uma assimetria, que aparece como uma protuberância na região mais azul (como uma segunda asa com velocidades mais altas em blueshift). No caso de [NiI] 65584 , essa protuberância aparece entre as velocidades de -500 e $-380 \mathrm{~km} / \mathrm{s}$ no perfil da linha apresentado na Fig. 15.8(a). Ao se fazer a imagem dessa região espectral em todas as linhas que apresentaram essa assimetria, nota-se a mesma estrutura aproximadamente circular, porém estendida (ver Fig. 15.8a). A estrutura dessa emissão, em altas velocidades em blueshift, aparece deslocada em direção ao Norte da Região 1. Todas as evidências apontam para um outflow de gás sendo emitido pela Região 1 na direção Norte.

A Fig. 15.8(b) resume o cenário cinemático apresentado. Através do RGB da linha $\mathrm{H} \alpha$, notam-se as mesmas estruturas apresentadas anteriormente. Nesta imagem, o outflow está representado pela cor verde, uma emissão que está mais centralizada (ou seja, mais próxima à Região 1), e a cinemática do disco de rotação de gás em torno da Região 1 está representada pelas cores azul e vermelha (que é compatível com o obtido mapa de velocidades de [NII] 76584$)$. O gás em azul apresenta emissão em blueshift (a amplitude de velocidades da rotação é $80 \mathrm{~km} / \mathrm{s}$, o que é significativamente inferior aos valores das velocidades observadas na região do outflow) e o gás em vermelho, emissão em redshift. 

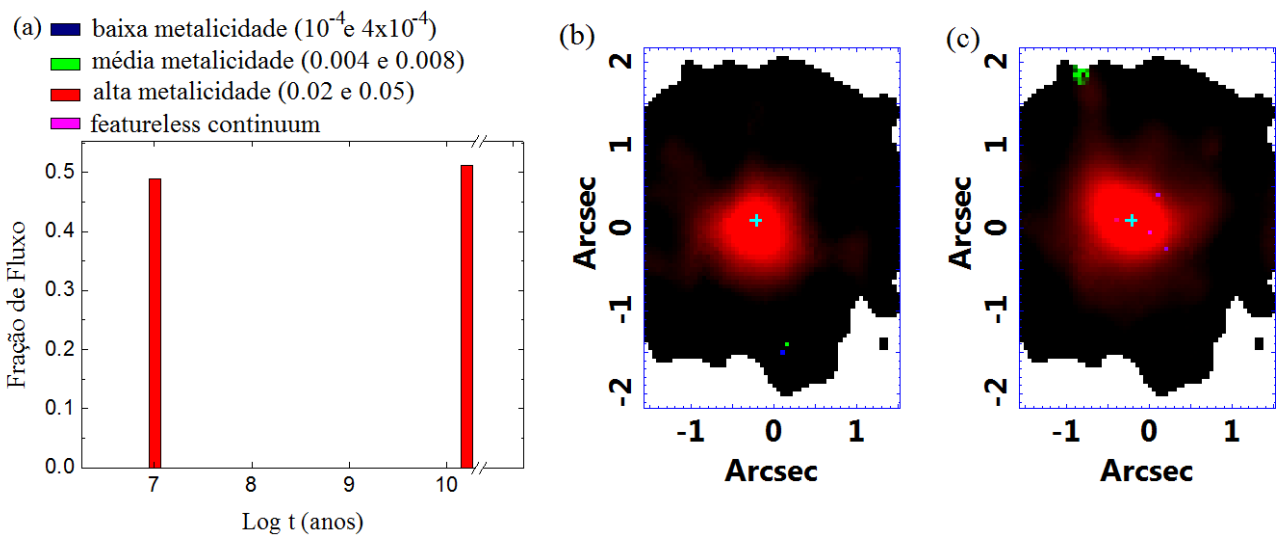

Figura 15.9: (a)Histograma das frações de fluxo das populações estelares detectadas na síntese espectral de NGC 2207 com os mapas de fluxo das populações estelares com (b) $\sim 10^{7}$ anos e (c) com $\sim 10^{10}$ anos. A cor vermelha representa alta metalicidade (0.02 e 0.05). A cruz em ciano representa o centróide da Região 1 e seu tamanho, a incerteza de $3 \sigma$.

\subsection{Arqueologia Estelar}

A síntese espectral aplicada ao cubo de dados de NGC 2207 mostra um resultado bem claro: foram detectados apenas dois eventos de formação estelar nesta galáxia (ver Fig.15.9 $)$, sendo que ambos geraram populações estelares com alta metalicidade (0.02 e 0.05). O mais recente desses eventos ocorreu há aproximadamente 10 milhões de anos, enquanto que o outro ocorreu durante a formação do bojo da galáxia, há cerca de 10 bilhões de anos. As populações estelares detectadas pela síntese espectral, estão concentradas na região central em torno do AGN.

O fato dessa galáxia estar em interação com uma galáxia próxima pode ter desencadeado a formação estelar recente, visto que o núcleo, a princípio (até 10 milhões de anos atrás), era predominantemente formado por populações estelares velhas. O evento estelar em questão é isolado temporalmente e indica que foi algo singular que rapidamente gerou essas populações estelares ou que o núcleo da galáxia está numa fase de starbursts.

O mapa de extinção obtido com a síntese espectral mostra que a extinção no FOV considerado é quase constante, porém apresenta algumas irregularidades (Fig. 15.10). Já o mapa do $\chi^{2}$ mostra que os ajustes são aceitáveis na região analisada. O mapa de $\mathrm{S} / \mathrm{N}$, que delimitou as áreas a serem consideradas nos resultados, mostra que as regiões das bordas superior e inferior possuem $\mathrm{S} / \mathrm{N}<10$. Essas regiões foram descartadas dos resultados. Os maiores valores do S/N estão concentrados na região central do FOV. 

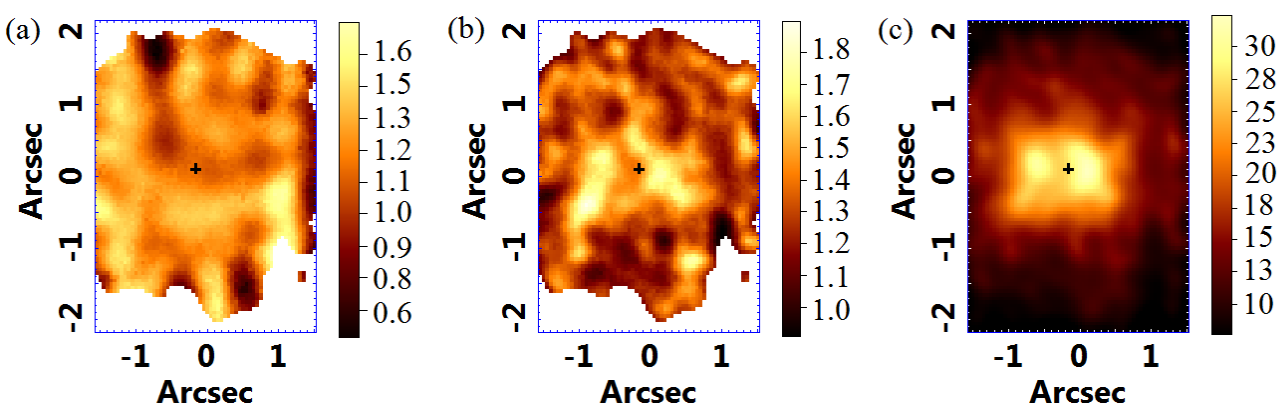

Figura 15.10: Mapas de (a) extinção, (b) $\chi^{2}$ e (c) S/N resultantes da síntese espectral. A cruz representa o centróide da Região 1 e seu tamanho, a incerteza de $3 \sigma$.
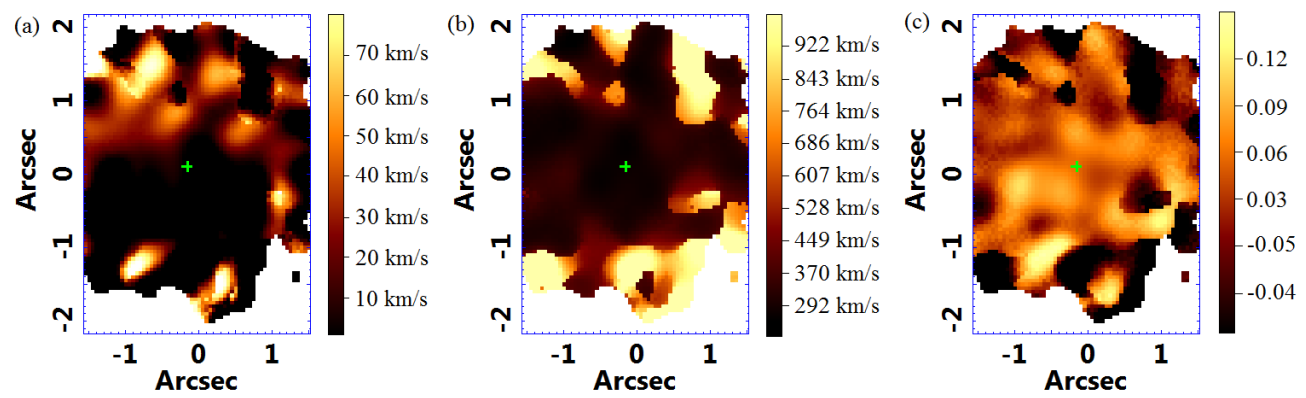

Figura 15.11: Mapas dos resultados da síntese espectral feita a partir do método pPXF aplicado ao cubo de NGC 2207. (a) Mapa da velocidade radial estelar, (b) mapa da dispersão de velocidades estelar e (c) mapa de $h_{3}$. A cruz verde representa o centróide da Região 1 e seu tamanho a incerteza de $3 \sigma$. As regiões brancas do mapa são as que apresentam $\mathrm{S} / \mathrm{N}<10$, cujos resultados foram desprezados.

\subsection{Cinemática estelar}

O mapa de velocidades estelar Fig. 15.11(a) não é conclusivo. Há um gradiente de velocidades da parte inferior do FOV em direção à parte superior. Não há como afirmar que se trata de uma rotação, visto que os valores são bastante irregulares, sobretudo na região superior do FOV. Se esse mapa, de fato, representar uma rotação estelar ao redor do núcleo de NGC 2207, então temos um cenário no qual o disco estelar não possui a mesma orientação que o disco de gás.

O mapa de dispersão de velocidades da Fig. 15.11(b) possui valores demasiadamente elevados para uma galáxia com esse tipo morfológico e não é confiável. Já o mapa de $h_{3}$ (Fig. 15.11k) possui uma variação pequena e se estende praticamente de forma homogênea por todo o FOV considerado, não revelando nenhuma tendência.

Foi calculada uma média de dispersão de velocidades estelar representativa deste cubo de dados como descrito na seção 3.5.6, porém, neste caso, foi selecionada uma área de um 
quadrado de 1".5 de lado e o valor obtido foi de $232 \pm 5 \mathrm{~km} / \mathrm{s}$. Enquanto que o valor obtido do espectro do núcleo foi de $274 \pm 5 \mathrm{~km} / \mathrm{s}$. Esses valores, bem como o mapa de dispersão de velocidades da Fig. 15.11(b), são muito elevados para uma galáxia desse tipo morfológico e estão associados com a baixa precisão dos resultados da síntese espectral deste objeto.

Devido ao baixo $\mathrm{S} / \mathrm{N}$ e à falta de definição no mapa de velocidades, não foi possível criar curvas desses mapas. São necessárias observações com melhor S/N para determinar com mais clareza os fenômenos cinemáticos.

\subsection{Conclusões}

- Há um AGN do tipo LINER no centro dessa galáxia. Associado a esse AGN foi observado, a partir da imagem de [Oıı] $\lambda 5007$, um bicone de ionização.

- Resultados da síntese espectral mostram apenas dois eventos de formação estelar no núcleo de NGC 2207: um na formação do bojo da galáxia ( 10 bilhões de anos) e outro mais recente há aproximadamente 10 milhões de anos. Ambos formaram estrelas de metalicidade alta (0.02 e 0.05).

- A morfologia da emissão do gás é estendida em uma direção preferencial. Há uma concentração de gás com altas densidades na região do AGN, enquanto que o gás em baixas densidades se encontra nas regiões circumnucleares.

- A cinemática do gás apresenta um disco de rotação em torno do núcleo. Há também a emissão de outflow de gás na direção NE com velocidade $\sim 450 \mathrm{~km} / \mathrm{s}$.

- A média ponderada em intensidades da dispersão de velocidades estelar dentro de um quadrado com 1".5 de lado, centrado no núcleo, é de $232 \pm 5 \mathrm{~km} / \mathrm{s}$. 
Capítulo 16

\section{NGC 1255}

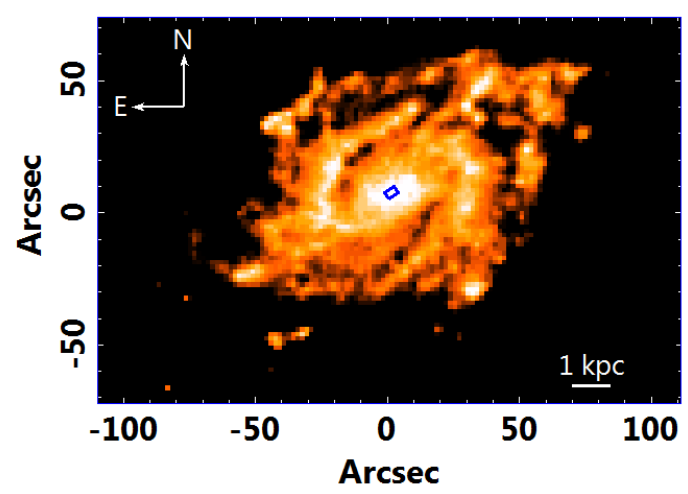

Figura 16.1: Imagem da galáxia NGC 1255 obtida com o telescópio UK Schmidt operado pelo Australian Astronomical Observatory, na banda IIIaJ. O quadrado azul representa o FOV do cubo de dados do GMOS analisado neste estudo. O PA dos dados do GMOS é $-55^{\circ}$. A área do FOV do GMOS é de 3".05 × 4".2.

NGC 1255 é uma galáxia SAB(rs)bc de Vaucouleurs et al. (1991) localizada a 14.10 Mpc de distância (Tully et al. 2016). O valor da raio da barra (corrigido dos efeitos de projeção) é de 8".1 \pm 2".1 ( 1 kpc de diâmetro - Muñoz-Mateos et al. 2013). Buta et al. (2015) classificam NGC 1255 como uma galáxia do tipo Scd com a presença de um pseudo-bojo. Existem poucos trabalhos sobre essa galáxia na literatura. Com relação ao seu núcleo, Veron-Cetty e Veron (1986) classificaram a atividade como de região HII.

Os dados neste trabalho foram tomados no dia 29 de Dezembro de 2016, com o IFU do GMOS do telescópio Gemini-Sul. O valor do FWHM da PSF usado no processo de deconvolução, calculado a partir da imagem de aquisição no comprimento de onda de $6300 \AA$, é de 0".6.

Após o tratamento de dados, foi feita uma imagem do cubo colapsado ao longo do eixo espectral e também foi extraído um espectro de uma região circular, com centro no núcleo 
Tabela 16.1 - Propriedades de NGC 1255. Os valores foram obtidos do catálogo Hyperleda. O valor da dispersão de velocidades estelar foi obtido por Batcheldor et al. (2005) pelo método de correlação cruzada.

\begin{tabular}{|c|c|}
\hline $\mathrm{M}_{B}$ & $-19.97 \pm 0.35$ \\
\hline $\mathrm{m}_{B}$ & $11.60 \pm 0.21$ \\
\hline $\mathrm{B}-\mathrm{V}$ & 0.56 \\
\hline$\sigma_{*}(\mathrm{~km} / \mathrm{s})$ & $69 \pm 5$ \\
\hline Brilho superficial efetivo médio $\left(\mathrm{mag} / \mathrm{arcsec}^{2}\right)$ & $22.37 \pm 0.34$ \\
\hline
\end{tabular}

do contínuo estrelar e diâmetro igual ao FWHM da PSF dos dados (Fig. 16.2). É possível notar uma fonte central aparentemente estendida, porém seu espectro é bastante ruidoso, principalmente na região azul da banda óptica. Foi possível distinguir apenas as linhas de $[\mathrm{NII}] \lambda \lambda 6548,6584, \mathrm{H} \alpha$ e $[\mathrm{SII}] \lambda \lambda 6716,6731$.
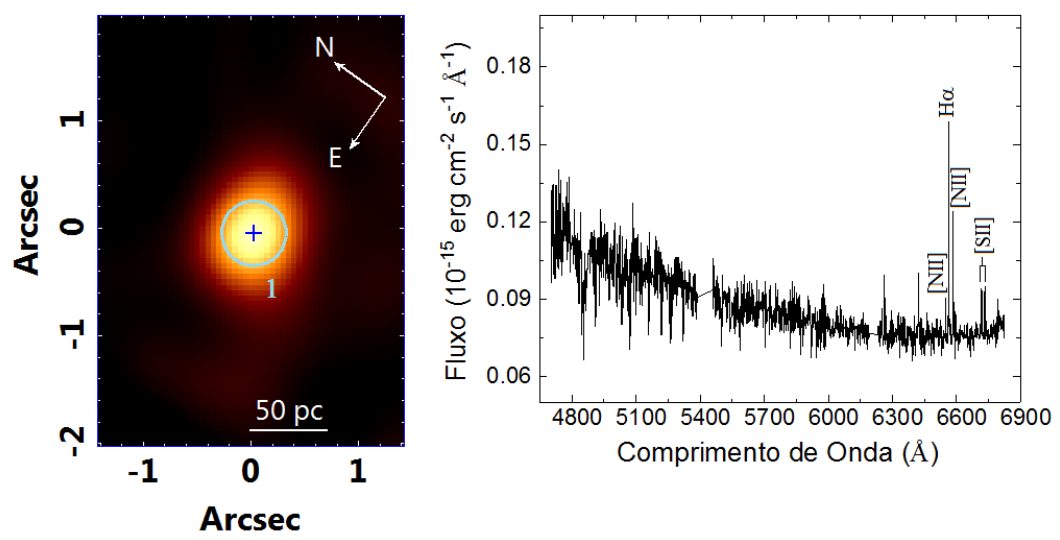

Figura 16.2: Imagem do cubo de dados do GMOS colapsado ao longo do eixo espectral e espectro da Região 1 (núcleo), cuja área de extração e centróide estão representados na imagem. O tamanho da cruz representa a incerteza de $3 \sigma$, baseada no tamanho do spaxel do cubo de dados do GMOS.

\subsection{Arqueologia e cinemática estelar}

O cubo de NGC 1255 não possui S/N suficiente para determinar nenhuma informação de populações estelares. Da mesma forma que NGC 7314, como não foram obtidos bons resultados da síntese espectral, não foi possível criar um cubo de gás. Para fazer as imagens das linhas de emissão, no entanto, foi subtraído o contínuo mais próximo da linha em questão.

No caso do cálculo de razões de linhas, para subtrair o contínuo, foi utilizado um ajuste de síntese espectral (com o software STARLIGHT) no espectro extraído de cada região. Os 
dados não são precisos o bastante para determinar populações estelares, mas o ajuste do contínuo foi razoável para o cálculo das razões de linhas. Obviamente, esses resultados são preliminares para este objeto e dados com maiores tempos de exposição serão necessários para concretizar sua análise.

\subsection{Emissão do gás}
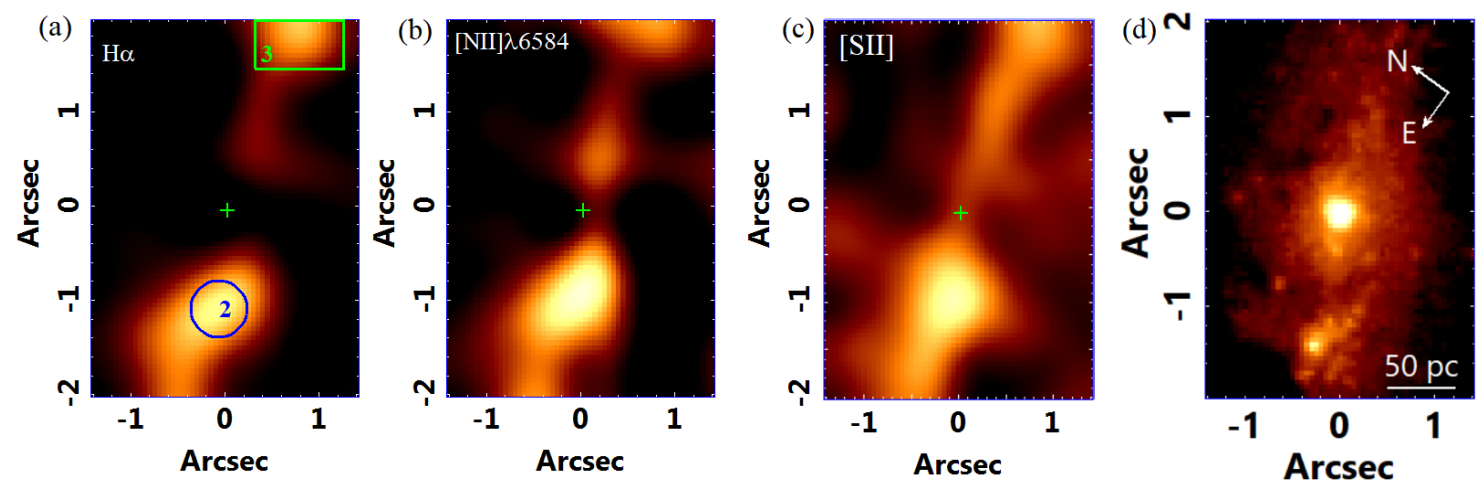

Figura 16.3: Imagens das linhas de emissão (a) de $\mathrm{H} \alpha$, onde estão indicadas as posições e áreas de extração das regiões 2 e 3, (b) de $[\mathrm{NII}] \lambda 6584$ e (c)de [SII $] \lambda 6716+[\mathrm{SII}] \lambda 6731$. A posição do centróide da Região 1 está representada pela cruz verde e seu tamanho representa a incerteza de $3 \sigma$. (d) Imagem centrada no comprimento de onda $5852 \AA$ com largura de $1873 \AA$ obtida com STIS do HST, sua orientação é a mesma da observação do cubo de dados do GMOS.

Foram detectadas 3 regiões emissoras na região central de NGC 1255; a primeira delas, Região 1, está apresentada na Fig.16.2. As imagens das linhas de emissão não mostram essa região (Fig. 16.3), mas mostram outras 2 que parecem, de alguma forma, conectadas com a Região 1. A morfologia da emissão das linhas sugere uma espiral, onde as regiões 2 e 3 são braços em lados opostos. Para as regiões 1 e 2 foi extraído um espectro de uma área circular cujo diâmetro foi estimado a partir do FWHM da PSF do cubo de dados. O espectro da Região 3, por estar na borda do cubo, foi extraído de uma região retangular, cuja área é maior do que área da PSF dos dados.

A ausência da emissão da Região 1 nas imagens das linhas de emissão (Fig. 16.3) pode indicar que esta região seja um núcleo estelar sem linhas de emissão e o espectro obtido na Fig. 16.2, devido ao tamanho da PSF, pode ter uma contribuição da emissão das regiões circumnucleares.

As estruturas no núcleo de NGC 1255 podem ser observadas com maiores detalhes na 
Tabela 16.2 - Razões de linhas e luminosidades calculadas a partir dos fluxos integrados de $\mathrm{H} \alpha$ dos espectros das 3 regiões emissoras observadas no núcleo de NGC $1255 .{ }^{*} \mathrm{O}$ espectro da Região 1 não foi corrigido da extinção pela razão $\mathrm{H} \alpha / \mathrm{H} \beta$, devido ao baixo $\mathrm{S} / \mathrm{N}$ na região de $\mathrm{H} \beta$.

\begin{tabular}{|c|c|c|c|}
\hline Razão de Linhas & Região $1^{*}$ & Região 2 & Região 3 \\
\hline$[\mathrm{OIII}] / \mathrm{H} \beta$ & & $0.19 \pm 0.04$ & \\
\hline$[\mathrm{NII}] / \mathrm{H} \alpha$ & $0.62 \pm 0.03$ & $0.363 \pm 0.006$ & $0.380 \pm 0.006$ \\
\hline$([\mathrm{SII}] \lambda 6716+\lambda 6731) / \mathrm{H} \alpha$ & $0.46 \pm 0.04$ & $0.345 \pm 0.013$ & $0.318 \pm 0.007$ \\
\hline$[\mathrm{SII}] \lambda 6716 /[\mathrm{SII}] \lambda 6731$ & $1.25 \pm 0.20$ & $1.44 \pm 0.10$ & $1.44 \pm 0.08$ \\
\hline Luminosidade de $\mathrm{H} \alpha\left(10^{3} L_{\odot}\right)$ & $1.21 \pm 0.03$ & $5.66 \pm 0.04$ & $9.97 \pm 0.06$ \\
\hline
\end{tabular}

imagem do HST da Fig. 16.3(d). Esses dados foram obtidos com Space Telescope Imaging Spectrograph (STIS) do HST, sob o programa 8549 (PI:Baum, S.) com tempo de exposição de 200 s, centrado no comprimento de onda de $5852 \AA$ com largura de $1873 \AA$. Nesta imagem é possível perceber a forte emissão estelar vinda da região 2 e o núcleo (Região 1) e não é possível identificar a região 3. Isso indica que a emissão da região 3 é predominantemente vinda de gás ionizado, enquanto que as duas outras regiões possuem emissão de populações estelares.

A tabela 16.2 mostra as razões de linhas calculadas para todos espectros. No caso da Região 1 não foi possível calcular o fluxo integrado da linha de $\mathrm{H} \beta$ e, por isso, não foi possível aplicar a correção de extinção de $\mathrm{H} \alpha / \mathrm{H} \beta$, que foi aplicada para todos os demais espectros da tese. No caso da Região 3, não foi possível calcular o fluxo integrado de [OIII] $\lambda 5007$. Com isso, apenas a Região 2 está presente no diagrama de diagnóstico da Fig 16.4. Nota-se que a mesma possui emissão compatível com as de regiões HII e, ao comparar a razão $[\mathrm{NII}] / \mathrm{H} \alpha$ das demais regiões, nota-se que são compatíveis tanto com objetos de transição quanto regiões HII. Elas não podem ser Seyferts devido ao baixo fluxo de [OIII] $\lambda 5007$. Então, muito provavelmente NGC 1255 não possui um núcleo ativo e as regiões 2 e 3 fazem parte de uma espiral nuclear com braços de regiões HII. É notável, a partir do espectro do núcleo (Fig. 16.2) a forte absorção em $\mathrm{H} \beta$, que indica que há uma considerável presença de estrelas jovens no núcleo.

\subsection{Cinemática do gás}

Ao observar os espectros de emissão das regiões detectadas no núcleo de NGC 1255, nota-se que as linhas são bastante estreitas. A composição RGB da Fig. 16.5 da linha 


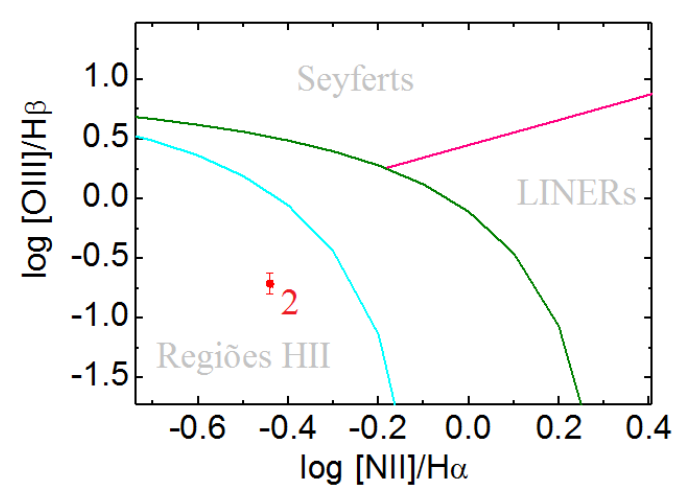

Figura 16.4: Diagrama de diagnóstico da Região 2, a única região em que foi possível calcular todas as razões de linhas necessárias para o diagrama, do cubo de dados de NGC 1255. A curva em verde-escuro representa a estimativa para o limite de ionização por um starburst determinada por Kewley et al. (2001). A divisão entre regiões HII e AGNs determinada por Kauffmann et al. (2003) está representada pela curva em ciano. A reta que divide Seyferts e LINERs determinada por Schawinski et al. (2007) está indicada em magenta.

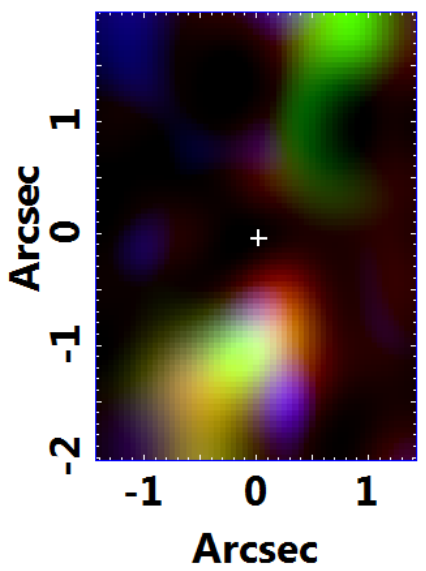

Figura 16.5: Composição RGB da linha de $\mathrm{H} \alpha$ do cubo de dados do GMOS de NGC 1255. Uma imagem do contínuo adjacente à linha foi subtraída de todas as imagens da composição. A cor azul representa velocidades de $\mathrm{v} \sim-105 \mathrm{~km} / \mathrm{s}$, a cor verde, $\mathrm{v} \sim-13 \mathrm{~km} / \mathrm{s}$ e, a cor vermelha, $\mathrm{v} \sim 78 \mathrm{~km} / \mathrm{s}$. A cruz representa o centróide da Região 1 com a incerteza de $3 \sigma$. 
de emissão de $\mathrm{H} \alpha$ mostra então as duas regiões circumnucleares e, predominantemente, a emissão em baixas velocidades (em verde). Isso sugere que, qualquer movimento que esteja acontecendo entre essas regiões, está ocorrendo no plano do céu e, possivelmente, ao redor da fonte central.

Os dados não foram suficientes para determinar com clareza os principais fenômenos desta galáxia. São necessárias novas observações com maior tempo de exposição e S/N, para então, obter maiores informações estelares e de emissões de linhas.

\subsection{Conclusões}

- Há, pelo menos, uma região HII circumnuclear no centro de NGC 1255, a segunda região também pode ser uma região HII. Há evidências de que o núcleo possua razões de linhas compatíveis com as de objeto de transição e regiões HII, o que pode indicar que, se há um buraco negro supermassivo no centro, ele está inativo.

- As baixas velocidades das duas regiões emissoras circumnucleares sugerem que a cinemática destas regiões parece ocorrer na direção do plano do céu. 
Capítulo 17

\section{Discussão estatística das gêmeas morfológicas da Via Láctea}

Neste trabalho foram estudadas as regiões centrais das 10 galáxias gêmeas morfológicas da Via Láctea mais brilhantes (na banda B) do survey DIVING ${ }^{3 D}$. O principal objetivo era estudar a emissão destes objetos com cubos de dados no óptico (GMOS) e, a partir de dados complementares (raios-X, rádio e outras imagens no óptico), avaliar outras características relevantes nas regiões centrais destas galáxias. O projeto visa estudar as regiões centrais dessas galáxias e comparar suas características com as da região central da Via Láctea, determinando possíveis tendências envolvidas. Vale ressaltar que apenas 10 galáxias não são suficientes para determinar com grande precisão a estatística dos fenômenos observados; porém, por ser uma amostra estatisticamente completa, é possível fazer uma análise estatística preliminar confiável para determinar, portanto, as principais tendências e o que se espera para as 5 demais galáxias dessa sub-amostra do survey DIVING ${ }^{3 D}$.

Antes de discutir os dados das regiões centrais das galáxias da amostra, algo em maior escala precisa ser mencionado: duas galáxias da amostra possuem classificações morfológicas ambíguas: NGC 157 talvez não possua uma barra e NGC 1255 foi classificada com Scd (Buta et al., 2015). Curiosamente, ambas as galáxias são as únicas da amostra que possuem evidências de serem não-ativas.

\subsection{Linhas de emissão nucleares}

Todos os objetos da amostra apresentaram um única fonte nuclear, com exceção de NGC 1255. No caso de NGC 613 essa região é estendida no óptico. Notou-se então que essa emissão central pode ser duas componentes que fazem parte da mesma estrutura (N1 


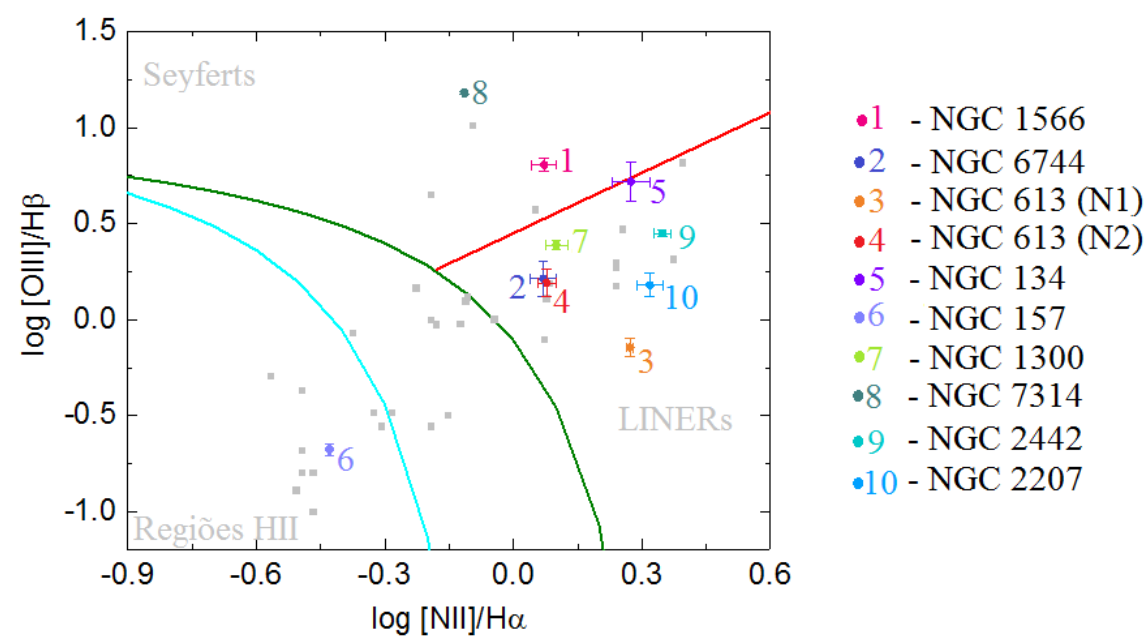

Figura 17.1: Diagrama de diagnóstico dos núcleos (Região 1, no caso de NGC 613, N1 e N2) das gêmeas morfológicas da Via Láctea (identificadas pelos pontos circulares e números correspondentes na legenda), juntamente com os dados das gêmeas morfológicas da Via Láctea do survey Palomar (Ho, 2008) (identificadas pelos pontos quadrados em cinza). A curva em verde-escuro representa a estimativa para o limite de ionização por um starburst determinada por Kewley et al. (2001). A divisão entre regiões HII e AGNs determinada por Kauffmann et al. (2003) está representada pela curva em ciano. A reta que divide Seyferts e LINERs determinada por Schawinski et al. (2007) está indicada em magenta.

e N2). As razões de linhas de emissão desta estrutura dupla são compatíveis entre si. Os valores das razões de linhas das regiões centrais (designadas sempre como Região 1 e, no caso de NGC 613, como as fontes N1 e N2) de cada objeto foram colocados, juntamente com os valores das razões de linhas das regiões centrais das galáxias com o mesmo tipo morfológico da Via Láctea classificadas pelo survey Palomar (Ho, 2008), no diagrama de diagnóstico da Fig. 17.1.

Nota-se que a maior parte dos núcleos das galáxias desse projeto estão no domínio de AGNs, sendo 6 galáxias com emissão nuclear compatível com a de LINERs, 2 compatíveis com a de Seyferts e apenas 1 galáxia com emissão compatível com a de regiões HII. Não foi possível classificar a emissão do núcleo de NGC 1255 (que não está presente no diagrama). Além disso, todos os objetos classificados como LINERs, com exceção de NGC 134 (por não possuir dados em raios-X), possuem uma emissão compacta nuclear em raios-X duros, caracterizando a presença de um AGN. Com isso, no presente momento, tem-se 7 AGNs confirmados, 1 LINER não confirmado como AGN, 1 núcleo não ativo e 1 núcleo nãoclassificado. Isso significa que 70\% dos núcleos das galáxias deste projeto são ativos, 10\% não são ativos, $10 \%$ são não-confirmados e $10 \%$ são não-classificados. 
Os resultados com a estatística das 33 galáxias gêmeas morfológicas da Via Láctea do survey Palomar mostram que 52\% das galáxias possuem emissão compatível com a de regiões HII, 24\% compatível com a emissão de AGNs (12\% LINERs e 12\% Seyferts) e 24\% compatível com a emissão de objetos de transição.

As diferenças entre os resultados, relacionados às sub-amostras das gêmeas morfológicas da Via Láctea, obtidos com os surveys Palomar e DIVING ${ }^{3 D}$, são um reflexo direto da resolução espacial, superior do último. Em outras sub-amostras do survey DIVING ${ }^{3 D}$, temse observado o baixo número de objetos de transição, quando comparado com os resultados do survey Palomar. Na literatura, os objetos de transição são geralmente interpretados como sendo AGNs cuja emissão é contaminada pela emissão proveniente de regiões HII circumnucleares. O tamanho da fenda utilizada nas observações do survey Palomar abrange quase todo o FOV do IFU do GMOS. Dessa forma, é provável que contaminações da emissão proveniente de AGNs centrais pela emissão de regiões HII circumnucleares sejam capazes de explicar, pelo menos, parte dos objetos de transição no survey Palomar. Por outro lado, no survey DIVING ${ }^{3 D}$, a maior resolução espacial permitiu separar melhor a emissão da região nuclear da emissão da região circumnuclear, o que resultou em uma diminuição no número de objetos de transição detectados. No que se refere ao número de AGNs detectados, é provável que a maior resolução espacial do survey DIVING ${ }^{3 D}$, juntamente com as metodologias de tratamento e análise de dados, tenham permitido a detecção de AGNs consideravelmente fracos, que provavelmente não seriam detectados em espectros com menor resolução espacial, como no caso do survey Palomar.

Ao comparar esses dados com o fato de que a Via Láctea não possui grau de atividade suficiente para ser considerada um núcleo ativo, nota-se que a mesma não está dentro da tendência da amostra. A Via Láctea, portanto, é distinta da amostra e deve estar num momento transitório. Como 70\% das gêmeas morfológicas da Via Láctea possuem AGNs e, apenas, 10\% possuem núcleos não-ativos, a tendência mostra que essas galáxias passam a maior parte do tempo (70\% do tempo) sendo ativas. O fato da Via Láctea não ser ativa e o fato da mesma possuir estrelas WR, enquanto que suas gêmeas morfológicas não possuem, indica que a Via Láctea está numa fase de starburst atípica dentro do tipo morfológico. Como não foram detectadas estrelas WR na amostra, o estágio da Via Láctea pode ser considerado menor do que $10 \%$ do tempo.

Apenas duas galáxias da amostra das gêmeas da Via Láctea possuem claramente 
emissão Seyfert: NGC 1566 e NGC 7314. Notavelmente ambas galáxias são conhecidas por serem AGNs variáveis e tais variações ocorrem muito rapidamente (período de dias) de tipo 1 para tipo 2. Coincidentemente, apenas essas duas galáxias Seyferts apresentaram a emissão da BLR da amostra, mesmo sendo variáveis. Dessa forma, os períodos de observação desses dois objetos foram em datas nas quais a emissão recebida era da época em que estavam em alta atividade. A variabilidade também foi detectada em um LINER (NGC 613), mas este objeto não foi observada variabilidade na emissão da BLR (ou seja, variações entre tipo 1 e 2), apenas na luminosidade.

Não foi encontrada nenhuma evidência de AGNs duplos ou de núcleos estelares duplos na amostra. De acordo com o modelo hierárquico de formação e evolução de galáxias, galáxias mais massivas são formadas por vários mergers envolvendo galáxias menos massivas. Dessa forma, considerando esse modelo, é de se esperar encontrar galáxias em um estágio pós-merger, mas com seus núcleos estelares (possivelmente associados a AGNs) ainda não coalescidos. Embora galáxias late-type, como as analisadas nesse trabalho, não sejam um resultado provável de um major merger de galáxias, minor mergers podem ocorrer em objetos desse tipo, sem que suas morfologias sejam significativamente alteradas. Tais eventos também poderiam resultar em AGNs duplos ou núcleos estelares duplos. Considerando tudo isso, a detecção de um ou mais objetos nesse trabalho com morfologia nuclear dupla não seria, de fato, surpreendente. A não detecção dessas características pode ser devida ao baixo número de objetos aqui analisados.

\subsection{Regiões emissoras circumnucleares}

Como foi dito anteriormente, a emissão da região circumnuclear tem um papel importante na região nuclear quando se trata de avaliar a natureza da emissão de um núcleo de uma galáxia.

No diagrama da Fig. 17.2 nota-se que $48 \%$ das regiões emissoras circumnucleares possuem emissão compatível com a de AGNs (18\% Seyferts e 30\% LINERs). Estas são regiões de emissão da NLRs dos AGNs correspondentes, sendo que as 5 regiões circumnucleares com emissão Seyfert são de um único objeto: NGC 7314. Cerca de $52 \%$ das regiões circumnucleares apresentam emissões compatíveis com as de objetos de transição e regiões HII, o que indica que tanto a emissão da NLR quanto a emissão das regiões HII se distribuem 


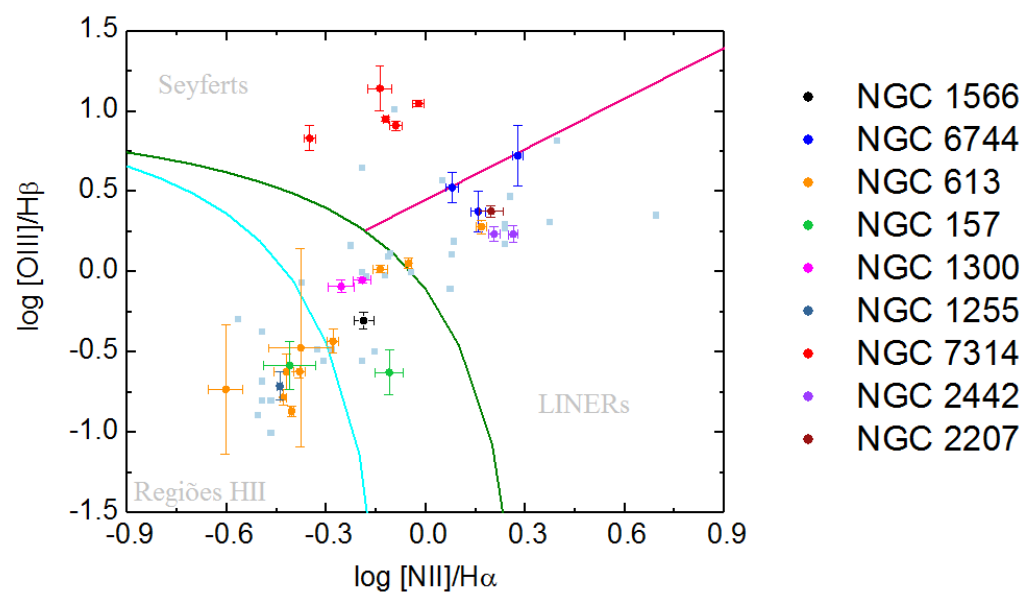

Figura 17.2: Diagrama de diagnóstico das regiões emissoras circumnucleares das gêmeas morfológicas da Via Láctea (identificadas pelos pontos circulares, onde cada cor corresponde a uma galáxia da amostra), juntamente com os dados das gêmeas morfológicas do survey Palomar (Ho, 2008) (identificadas pelos pontos quadrados em cinza). A curva em verde-escuro representa a estimativa para o limite de ionização por um starburst determinada por Kewley et al. (2001). A divisão entre regiões HII e AGNs determinada por Kauffmann et al. (2003) está representada pela curva em ciano. A reta que divide Seyferts e LINERs determinada por Schawinski et al. (2007) está indicada em magenta.

igualmente na amostra, ambas são igualmente relevantes. Ao assumir que os objetos de transição são regiões HII contaminadas pela emissão do AGN central, já que não há outro AGN circumnuclear nestes objetos, tem-se então a leve predominância de regiões HII circumnucleares.

A distribuição das regiões circumucleares no diagrama de diagnóstico (Fig. 17.2) é mais compatível com os dados do survey Palomar do que os núcleos das galáxias da amostra. Isso confirma a relevância da emissão circumnuclear nos dados do survey Palomar. A presença de LINERs é maior no núcleo das galáxias gêmeas morfológicas da Via Láctea, enquanto que, na região circumnuclear, é uma minoria.

A incidência de estruturas circumnucleares é bastante significativa nesta amostra: 30\% das galáxias possuem anéis circumnucleares (com um possível anel em NGC 7314, o que resultaria em 40\%) e 20\% possuem espirais nucleares (com uma possível espiral de poeira em NGC 2442, o que resultaria em 30\%). Dessa forma, pelo menos metade das galáxias da amostra apresentam estruturas circumnucleares, o que pode estar correlacionado com o fato das galáxias serem barradas. 

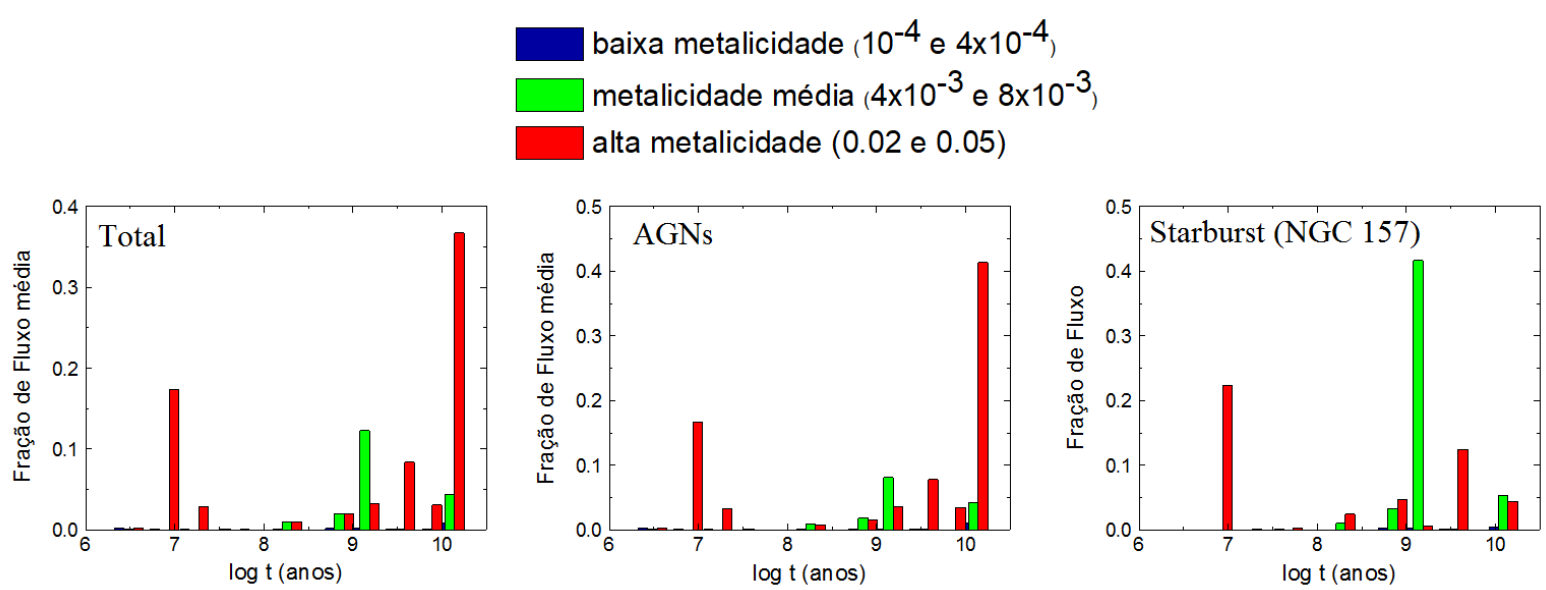

Figura 17.3: Histogramas da síntese espectral (a) da média de todos objetos, (b) da média somente das galáxias ativas (incluindo NGC 134) e (c) da galáxia NGC 157, a única classificada como starburst que teve $\mathrm{S} / \mathrm{N}$ suficiente para a síntese espectral.

\subsection{Cinemática do gás}

Quanto à cinemática do gás nos ambientes circumnucleares dessas galáxias, nota-se que há evidências de possíveis outflows de gás em $60 \%$ da amostra até o momento, sendo nas duas galáxias Seyferts (NGC 1566 e NGC 7314) e em 4 galáxias com emissão compatível com a de LINERs (NGC 2207, NGC 2442, NGC 6744, NGC 613). Além disso, há também evidências de discos de gás em rotação em $80 \%$ das galáxias da amostra, sendo que a existência de $40 \%$ desses discos em rotação está comprovada por mapas de velocidades de H $\alpha$ (NGC 6744), [NII] 65584 (NGC 2207) e gás molecular (para NGC 1566, NGC 613).

Apenas em três galáxias (NGC 613, NGC 1300 e NGC 134) os discos de gás em rotação são coplanares com a rotação de seus discos estelares e em duas galáxias (NGC 1566 e NGC 6744) os discos de gás em rotação não possuem a mesma orientação que a rotação de seus discos estelares.

\subsection{Arqueologia estelar}

A síntese espectral foi aplicada a todos objetos, com exceção de NGC 1255 e NGC 7314, utilizando o software STARLight. Uma média dos histogramas dos resultados da síntese espectral aplicada a todo FOV do GMOS para cada objeto foi calculada e apresentada na Fig. 17.3(a). Nota-se que a presença de populações com alta metalicidade (0.02 e 0.05) é dominante nos dados, sobretudo de populações com cerca de 10 bilhões de anos. 


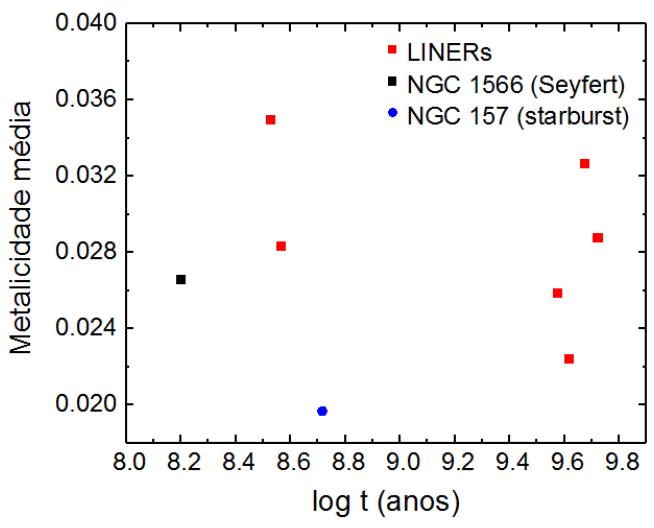

Figura 17.4: Média ponderada por fração de fluxo da metalicidade versus média ponderada por fração de fluxo das idades de todas as galáxias da amostra (com exceção de NGC 1255 e NGC 7314, nas quais não foi possível aplicar a síntese espectral). Os pontos quadrados representam as galáxias classificadas como AGNs (incluindo NGC 134) e o ponto circular representa a galáxia classificada como starburst: NGC 157.

Há, também, uma fração de fluxo relevante de populações jovens com a mesma faixa de metalicidade. Comparando com os resultados da Via Láctea, sabe-se que o bojo da Galáxia é predominantemente velho (ver Barbuy et al.2018) com alta metalicidade (Clarkson et al., 2008), o que é compatível com os resultados das gêmeas morfológicas.

Ao comparar os resultados das galáxias com AGN e a galáxia starburst (NGC 157), nota-se que a fração de fluxo de populações com alta metalicidade não é tão relevante em NGC 157, sendo que populações estelares com metalicidades intermediárias $\left(4 \times 10^{-3}\right.$ e 8 $\left.\times 10^{-3}\right)$ são predominantes. Além disso, a fração de fluxo de populações velhas $\left(10^{10} \operatorname{anos}\right)$ é muito significativa em núcleos com AGNs e não em NGC 157. A única correlação entre os dois histogramas é que há uma fração de fluxo considerável de populações jovens $\left(10^{7}\right.$ anos) com alta metalicidade. São necessários mais dados de galáxias gêmeas morfológicas da Via Láctea com núcleos sem atividade para ver se há alguma tendência, pois apenas um objeto não é suficiente para comprovar a diferença entre as histórias de formação estelar destes núcleos.

Ao comparar a média ponderada por fração de fluxo das idades e a média ponderada por fração de fluxo da metalicidade das galáxias (ver Fig. 17.5), nota-se que galáxias com LINERs possuem núcleos predominantemente velhos com metalicidades altas. No caso de NGC 157, a metalicidade e a idade do núcleo é intermediária e, em NGC 1566, uma galáxia Seyfert, tem-se idades mais jovens e metalicidade alta. Isso indica que núcleos 
velhos também podem possuir atividade, o que parece ser uma grande tendência nesta amostra. Além disso, a alta metalicidade em todos os núcleos ativos indica que a massa dos bojos destas galáxias tem uma influência no quesito de atividade nuclear.

Há uma concentração relevante de estrelas WR no núcleo da Via Láctea, sendo que, dentro dos 300 parsecs centrais, é possível observar, pelo menos, 68 estrelas WR que estão associadas aos aglomerados Quintuplets, Arches e o nuclear. Muitas estrelas massivas passam pela fase de expelir envelopes e entram na fase WR, com ventos com velocidades

terminais de $2000 \mathrm{~km} / \mathrm{s}$ e uma taxa de perda de massa típica de $10^{-5} M_{\odot} /$ ano Fullard et al., 2020). Devido a esses ventos, algumas linhas de emissão são consideravelmente largas, tornando possível sua identificação em outras galáxias. Entretanto, na presente amostra não foi detectada nenhuma evidência da emissão dessas estrelas. Dessa forma, a Via Láctea é a única galáxia analisada aqui que possui estrelas WR em seu núcleo, o que indica que a presença destas estrelas nos núcleos das galáxias não é comum. Isso pode sugerir que a Via Láctea possui processos de formação estelar diferentes das suas gêmeas morfológicas ou que esteja numa fase de curta duração no processo evolutivo.

Apenas quatro galáxias da amostra não apresentaram frações de fluxos consideráveis atribuídas a estrelas jovens (com até 10 milhões de anos). Uma dessas galáxias possui classificação de seu bojo como clássico. Todas as populações jovens detectadas nas demais regiões centrais das galáxias da amostra (com exceção de NGC 1255 e NGC 7314, onde não foi possível realizar a síntese espectral) possuem alta metalicidade (0.02 e 0.05).

\subsection{Cinemática estelar}

Segundo a comparação feita por Hicks et al. (2013) entre galáxias ativas e inativas, as galáxias ativas possuem valores de dispersão de velocidades estelares menores do que as galáxias inativas e os valores são próximos de $100 \mathrm{~km} / \mathrm{s}$, enquanto que as galáxias inativas possuem valores próximos de $140 \mathrm{~km} / \mathrm{s}$. Aqui encontrou-se uma média das dispersões de velocidades estelar das galáxias ativas igual a $119 \pm 21 \mathrm{~km} / \mathrm{s}$, o que é compatível com os dados das galáxias ativas de Hicks et al. (2013). A Via Láctea possui, por sua vez, dispersão de velocidades estelar de $105 \pm 20 \mathrm{~km} / \mathrm{s}$ (Ghez et al., 2008; Gillessen et al. 2009), o que é mais compatível com os valores de galáxias ativas.

Nenhuma galáxia da amostra apresentou um pico central definido no núcleo dos valores 
Tabela 17.1 - Tabela com os valores das médias ponderadas em fração de fluxo das idades e metalicidades e valores das dispersões de velocidades estelar dos objetos, calculados como descrito na seção 3.5.6.

\begin{tabular}{|c|c|c|c|}
\hline Galáxias & $\begin{array}{c}\text { Média ponderada } \\
\text { em fração de fluxo } \\
\text { das idades em log t (anos) }\end{array}$ & $\begin{array}{c}\text { Média ponderada } \\
\text { em fração de fluxo } \\
\text { das metalicidades }\end{array}$ & $\begin{array}{c}\text { Dispersão de } \\
\text { velocidades estelar } \\
(\mathrm{km} / \mathrm{s})\end{array}$ \\
\hline NGC 134 & 9.72 & 0.029 & $113 \pm 7$ \\
\hline NGC 157 & 8.72 & 0.020 & $90 \pm 6$ \\
\hline NGC 613 & 8.57 & 0.028 & $92 \pm 3$ \\
\hline NGC 1300 & 9.57 & 0.026 & $82 \pm 7$ \\
\hline NGC 1566 & 8.19 & 0.027 & $86 \pm 7$ \\
\hline NGC 2207 & 8.53 & 0.035 & $232 \pm 5$ \\
\hline NGC 2442 & 9.67 & 0.033 & $151 \pm 6$ \\
\hline NGC 6744 & 9.62 & 0.022 & $79 \pm 6$ \\
\hline
\end{tabular}

da dispersão de velocidades estelar. Apenas duas galáxias da amostra apresentaram um tendência que se pôde identificar como um decréscimo dos valores de dispersão de velocidades estelar em direção ao centro (NGC 1566 e NGC 6744) e, como foi dito anteriormente, estas galáxias possuem disco estelar em rotação não-coplanares com seus discos de gás em rotação. No caso de NGC 1566, o $\sigma$-drop pode ser explicado pela presença de estrelas jovens que herdaram a cinemática fria das nuvens progenitoras. Porém, no caso de NGC 6744, como não há a presença de estrelas jovens, este decréscimo pode possuir razões mais complexas. A Via Láctea, no entanto, apresenta o decréscimo dos valores de dispersão de velocidades estelar para fora do centro.

Ao comparar os valores de dispersão de velocidades estelar com a média ponderada por fração de fluxo da metalicidade de cada galáxia (Fig. 17.5), é possível notar uma correlação: quanto maior o valor da média da metalicidade, maior o valor da dispersão de velocidade estelar. O resultado dessa correlação está provavelmente associado à massa do bojo da galáxia. Quanto maior a massa estelar na região central do bojo, mais a galáxia tende a reter nessa área os metais liberados por explosões de supernovas. Além disso, como é sabido pela relação M- $\sigma$, quanto maior a massa, maior a dispersão de velocidades estelar. Com base nisso, uma correlação entre dispersão de velocidades estelar e metalicidade na região central é esperada. De fato, modelos teóricos preveem a existência de uma correlação entre a massa de uma galáxia e a sua metalicidade (e.g. Hartwick 2015, 2017), que foi observada em galáxias anãs no Universo local (Kirby et al., 2013). Essa correlação é consistente com 


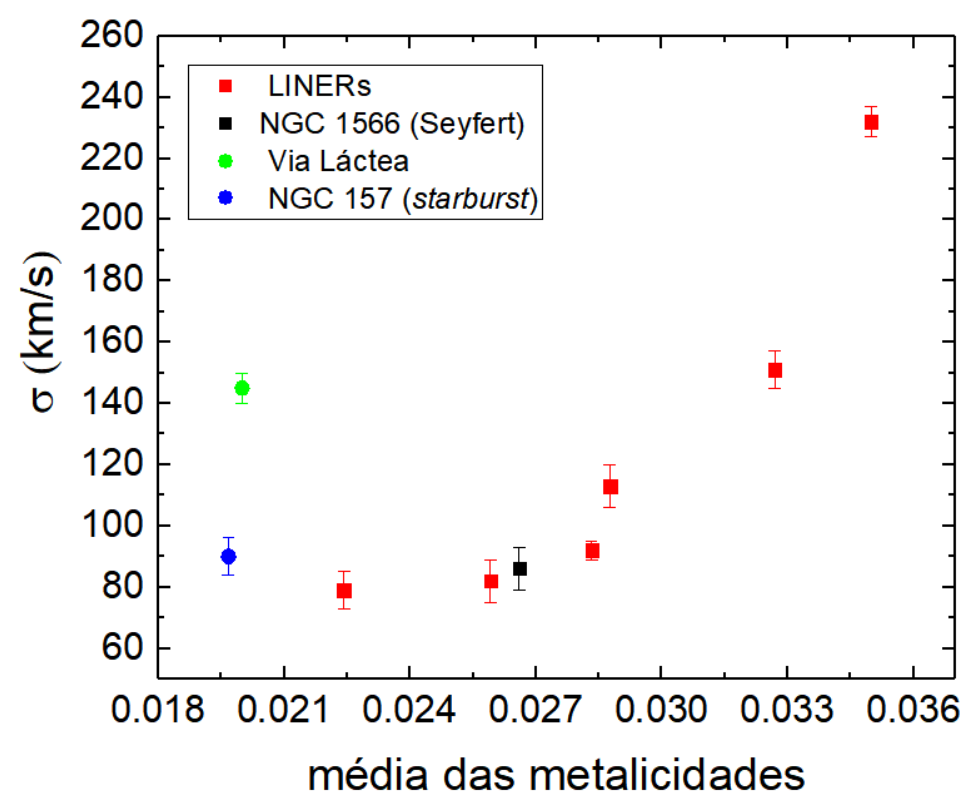

Figura 17.5: Dispersão de velocidades estelar média versus média ponderada por fração de fluxo da metalicidade. Os pontos quadrados representam as galáxias classificadas como AGNs (incluindo NGC 134), o ponto circular azul representa a galáxia classificada como starburst: NGC 157 e o ponto circular verde representa os dados da Via Láctea obtidos por Zoccali et al. (2014) ( $\sigma$ para estrelas do bojo com alta metalicidade, o erro foi estimado a partir dos valores da figura 6 do artigo citado) e assumindo que a metalicidade média do bojo da Via Láctea é solar Clarkson et al. (2008).

o cenário do downsizing (Cowie et al., 1996), que prevê que galáxias mais massivas tiveram grandes eventos de formação estelar em períodos anteriores a galáxias menos massivas. No trabalho aqui realizado, está sendo constatado que essa correlação entre a massa (indicada pela dispersão de velocidades estelar) e a metalicidade é válida para a região central de galáxias gêmeas morfológicas da Via Láctea (ou seja, dentro de um subtipo morfológico específico e dentro de uma região específica da galáxia). Trata-se de um resultado de grande relevância e que deverá ser confirmado com a análise futura de uma amostra maior de objetos. Ainda é possível notar uma tendência, que também deverá ser comprovada em análises futuras, de que galáxias inativas possuem metalicidades médias menores ou iguais à solar (0.02).

Em seis galáxias da amostra foi possível detectar um disco estelar em rotação. Cinco destas galáxias apresentam rotação dos seus discos sobreposta a um fundo de estrelas com velocidades próximas a zero com relação à linha de visada. Por outro lado, na Via Láctea, observa-se uma cinemática complexa, sendo que diferentes populações estelares possuem diferentes padrões rotacionais. Essa tendência de composições de movimentos estelares é 
comum na amostra, portanto. 
Capítulo 18

\section{Conclusões e Perspectivas}

A partir de estudos de núcleos de galáxias de uma amostra estatisticamente completa de 10 objetos com o mesmo tipo morfológico que a Via Láctea, foi possível obter as seguintes informações:

- A partir das razões de linhas no óptico das regiões nucleares das 10 galáxias estudadas, foi visto que $70 \%$ delas são AGNs (cinco núcleos com emissão compatível com a de LINERs, confirmados por terem fontes compactas observadas em raios-X duros, e duas Seyferts). As duas galáxias Seyferts possuem variabilidade nas linhas da BLR. Apenas uma galáxia possui núcleo não-ativo confirmado (NGC 157) e uma galáxia possui razões de linhas compatíveis com as de LINERs (NGC 134), sendo que nesse não há confirmação de que seja um AGN. Há também uma galáxia da amostra para a qual não foi possível obter razões de linhas do núcleo.

- A emissão detectada das regiões circumnucleares dos objetos analisados está associada à NLR dos AGNs centrais e também a regiões de formação estelar. Esses dois tipos de emissão possuem relevância similar nessa amostra. Além disso a presença de grandes estruturas como anéis circumnucleares e espirais é bastante significativa na amostra. A Via Láctea, por sua vez, apresenta várias regiões de formação estelar e se enquadra nesta tendência.

- Cerca de $60 \%$ das galáxias da amostra apresentam evidências de outflows de gás. Essas galáxias possuem AGNs e isso indica que os AGNs, mesmo sendo LINERs, causam algum impacto na galáxia, através do feedback. Cerca de $80 \%$ dos objetos possuem evidências de disco de gás em rotação e, em 30\% das galáxias da amostra, esses discos de gás são co-planares aos discos estelares em rotação.

- Apenas quatro galáxias da amostra não apresentaram frações de fluxos significativas 
atribuídas a populações estelares jovens (até 10 milhões de anos). Em todas as regiões nucleares das galáxias nas quais estas populações estelares foram detectadas, as mesmas apresentaram alta metalicidade (0.02 e 0.05).

- NGC 157 (starburst) foi a única galáxia da amostra que apresentou altas frações de fluxo atribuídas a populações estelares com metalicidade intermediária $\left(4 \times 10^{-3}\right.$ e $8 \times 10^{-3}$ ). As demais galáxias (ativas) possuem frações de fluxos principalmente atribuídas a populações estelares com metalicidade alta. Ao comparar com os dados da Via Láctea, onde o bojo pode ser representado por uma população com metalicidade média solar Clarkson et al., 2008; Barbuy et al. 2018) o que é considerado alta metalicidade, a metalicidade intermediária pode não ser uma tendência em núcleos não-ativos e neste tipo morfológico.

- Ao comparar a amostra das gêmeas morfológicas da Via Láctea com a Via Láctea em termos de populações estelares, vemos que a maior diferença é que no núcleo da Via Láctea há estrelas do tipo Wolf-Rayet (cerca de 110 - Rate et al. 2020). Tais estrelas não foram detectadas na amostra. Isso pode indicar que a Via Láctea esteja numa fase diferente no processo evolutivo ou numa fase de curta duração.

- Duas galáxias apresentaram decréscimo de valores de dispersão de velocidades estelar em direção ao centro $(\sigma-d r o p)$ : NGC 1566 e NGC 6744. Essas galáxias também foram as únicas a apresentar discos estelares em rotação com orientações diferentes dos discos de gás em rotação. Na Via Láctea, não há indícios de $\sigma-d r o p$, pois os valores de dispersão de velocidades estelar decrescem do centro para fora.

- Há uma possível correlação entre a dispersão de velocidades estelar e a média das metalicidade das galáxias da amostra (incluindo a Via Láctea, cujo ponto está próximo da galáxia não-ativa). Quanto maior a dispersão de velocidades média, maior a metalicidade média, o que provavelmente está associado à massa total na região central dessas galáxias.

- A média da dispersão de velocidades estelar das galáxias ativas (considerando NGC 134) é $119 \pm 21 \mathrm{~km} / \mathrm{s}$. Esse valor é compatível com o obtido por (Hicks et al., 2013) para galáxias ativas $(\sim 100 \mathrm{~km} / \mathrm{s})$ e também com o valor da dispersão de velocidades estelar média da Via Láctea $(105 \pm 20 \mathrm{~km} / \mathrm{s})$.

- Em seis galáxias (60\% da amostra), foi possível detectar um disco estelar em rotação sendo que, em cinco desses objetos, estes discos estão sobrepostos a um fundo de estrelas com velocidades próximas a zero com relação à linha de visada. Há, portanto, uma tendência de movimentos compostos de estrelas nos bojos destas galáxias, incluindo a Via 
Láctea, na qual diferentes populações estelares possuem diferentes padrões rotacionais.

A amostra de 10 galáxias é completa de modo que não há nenhum bias que gere alguma tendência nos dados. Porém, o número de objetos é limitado e restam apenas 5 galáxias gêmeas morfológicas da Via Láctea para serem analisadas no survey DIVING ${ }^{3 D}$.

Há várias perguntas que uma amostra maior poderia responder: as predominância de LINERs será sustentada neste tipo morfológico? A baixa incidência de núcleos nãoativos pode indicar algum aspecto evolutivo? O fato das únicas duas galáxias Seyferts detectadas, até agora, serem variáveis pode indicar uma perda de atividade progressiva e que, no futuro, estas galáxias se tornarão LINERs a caminho de deixarem de ser ativas. Se houver mais galáxias Seyferts, seriam essas variáveis, confirmando esta proposta? Será que a ausência ou presença da barra interfere na atividade nuclear? A correlação entre metalicidade média e dispersão de velocidades estelar é a mesma para galáxias ativas e nãoativas e galáxias barradas e não-barradas? Há diferenças na história de formação estelar de galáxias barradas e não barradas e galáxias ativas e não-ativas?

A perspectiva futura é analisar essas galáxias para completar a amostra de gêmeas morfológicas da Via Láctea do survey e, além disso, estudar os núcleos das galáxias do tipo SAbc (10 galáxias também presentes no mesmo survey), que são do mesmo tipo morfológico da Via Láctea, porém não possuem barra. Para a continuidade do trabalho estatístico serão consideradas classificações morfológicas atualizadas. A comparação será feita com objetivo de observar, com dados com grande resolução espacial, o impacto da barra nestas galáxias e se há diferenças nas amostras. 


\section{Referências Bibliográficas}

Agüero E. L., Díaz R. J., Bajaja E., NGC 1566: Spectroscopy of a symmetric system with Seyfert nucleus, A\&A, 2004, vol. 414, p. 453

Allard E. L., Knapen J. H., Peletier R. F., Sarzi M., The star formation history and evolution of the circumnuclear region of M100, MNRAS, 2006, vol. 371, p. 1087

Allard E. L., Peletier R. F., Knapen J. H., Cool Gas and Massive Stars: The Nuclear Ring in M100, ApJ, 2005, vol. 633, p. L25

Allen M. G., Groves B. A., Dopita M. A., Sutherland R. S., Kewley L. J., The MAPPINGS III Library of Fast Radiative Shock Models, ApJS, 2008, vol. 178, p. 20

Alloin D., Kunth D., On peculiar hot-spots nuclei of galaxies., A\&A, 1979, vol. 71, p. 335

Alloin D., Pelat D., Phillips M., Whittle M., Recent spectral variations in the active nucleus of NGC 1566, ApJ, 1985, vol. 288, p. 205

Alloin D., Pelat D., Phillips M. M., Fosbury R. A. E., Freeman K., Recurrent outbursts in the broad-line region of NGC 1566, ApJ, 1986, vol. 308, p. 23

Andredakis Y. C., Sanders R. H., Exponential bulges in late-type spirals: an improved description of the light distribution, MNRAS, 1994, vol. 267, p. 283

Asmus D., Gandhi P., Hönig S. F., Smette A., Duschl W. J., The subarcsecond midinfrared view of local active galactic nuclei - II. The mid-infrared-X-ray correlation, MNRAS, 2015, vol. 454, p. 766

Audibert A., Combes F., García-Burillo S., Hunt L., Eckart A., Aalto S., Casasola V., Boone F., Krips M., Viti S., Muller S., Dasyra K., van der Werf P., Martín S., ALMA 
captures feeding and feedback from the active galactic nucleus in NGC 613, A\&A, 2019, vol. 632, p. A33

Baganoff F. K., Bautz M. W., Brandt W. N., Chartas G., Feigelson E. D., Garmire G. P., Maeda Y., Morris M., Ricker G. R., Townsley L. K., Walter F., Rapid X-ray flaring from the direction of the supermassive black hole at the Galactic Centre, Nature, 2001, vol. 413 , p. 45

Bajaja E., Agüero E., Paolantonio S., Spectroscopic observations of southern nearby galaxies. I. NGC 2442, A\&AS, 1999, vol. 136, p. 179

Bajaja E., Wielebinski R., Reuter H. P., Harnett J. I., Hummel E., Observations of CO lines in southern spiral galaxies., A\&AS, 1995, vol. 114, p. 147

Baldwin J. A., Phillips M. M., Terlevich R., Classification parameters for the emission-line spectra of extragalactic objects, PASP, 1981, vol. 93, p. 5

Balick B., Brown R. L., Intense sub-arcsecond structure in the galactic center, ApJ, 1974, vol. 194 , p. 265

Balmaverde B., Capetti A., Grandi P., Torresi E., Chiaberge M., Rodriguez Zaurin J., Tremblay G. R., Axon D. J., Baum S. A., Giovannini G., Extended soft X-ray emission in $3 \mathrm{CR}$ radio galaxies at $\mathrm{z}$ \&lt; 0.3: high excitation and broad line galaxies, A\&A, 2012, vol. 545, p. A143

Barbuy B., Chiappini C., Gerhard O., Chemodynamical History of the Galactic Bulge, ARA\&A, 2018, vol. 56, p. 223

Barnes J. E., Formation of gas discs in merging galaxies, MNRAS, 2002, vol. 333, p. 481

Bartko H., Martins F., Fritz T. K., Genzel R., Levin Y., Perets H. B., Paumard T., et al. N., Evidence for Warped Disks of Young Stars in the Galactic Center, ApJ, 2009, vol. 697 , p. 1741

Batcheldor D., Axon D., Merritt D., Hughes M. A., Marconi A., Binney J., Capetti A., Merrifield M., Scarlata C., Sparks W., Integral Field Spectroscopy of 23 Spiral Bulges, ApJS, 2005, vol. 160, p. 76 
Beall J. H., Jets in Astrophysics: A Review, Chinese Journal of Astronomy and Astrophysics, 2003, vol. 3, p. 373

Becklin E. E., Gatley I., Werner M. W., Far-infrared observations of Sagittarius A - The luminosity and dust density in the central parsec of the Galaxy, ApJ, 1982, vol. 258, p. 135

Becklin E. E., Neugebauer G., Infrared Observations of the Galactic Center, ApJ, 1968, vol. 151, p. 145

Beckman J. E., Bransgrove S. G., Phillips J. P., H II region spectroscopy and two dimensional stellar photometry of the barred Seyfert NGC 1566, A\&A, 1986, vol. 157, p. 49

Bensby T., Feltzing S., Gould A., Yee J. C., Johnson J. A., Asplund M., Meléndez J., Lucatello S., Howes L. M., The age and abundance structure of the stellar populations in the central sub-kpc of the Milky Way, ArXiv e-prints, 2017

Bianchi S., Guainazzi M., Chiaberge M., The soft X-ray/NLR connection: a single photoionized medium?, A\&A, 2006, vol. 448, p. 499

Binette L., Magris C. G., Stasińska G., Bruzual A. G., Photoionization in elliptical galaxies by old stars, A\&A, 1994, vol. 292, p. 13

Boehle A., Ghez A. M., Schödel R., Meyer L., Yelda S., Albers S., Martinez G. D., Becklin E. E., Do T., Lu J. R., Matthews K., Morris M. R., Sitarski B., Witzel G., An Improved Distance and Mass Estimate for Sgr A* from a Multistar Orbit Analysis, ApJ, 2016, vol. 830 , p. 17

Böker T., Falcon-Barroso J., Knapen J. H., Schinnerer E., Allard E., Ryder S., A SINFONI view of the nuclear star formation ring in NGC 613. In Stellar Populations as Building Blocks of Galaxies , vol. 241 of IAU Symposium, 2007, p. 497

Böker T., Falcón-Barroso J., Schinnerer E., Knapen J. H., Ryder S., A SINFONI View of Galaxy Centers: Morphology and Kinematics of Five Nuclear Star Formation-Rings, AJ, 2008, vol. 135, p. 479 
Bon N., Bon E., Marziani P., Jovanović P., Gravitational redshift of emission lines in the AGN spectra, Ap\&SS, 2015, vol. 360, p. 7

Bordoloi R., Fox A. J., Lockman F. J., Wakker B. P., Jenkins E. B., Savage B. D., Hernandez S., Tumlinson J., Bland-Hawthorn J., Kim T.-S., Mapping the Nuclear Outflow of the Milky Way: Studying the Kinematics and Spatial Extent of the Northern Fermi Bubble, ApJ, 2017, vol. 834, p. 191

Bottema R., The Stellar Kinematics of Galactic Disks, A\&A, 1993, vol. 275, p. 16

Breda I., Papaderos P., The continuous rise of bulges out of galactic disks, A\&A, 2018, vol. 614, p. A48

Burtscher L., Orban de Xivry G., Davies R. I., Janssen A., Lutz D., Rosario D., Contursi A., Genzel R., Graciá-Carpio J., Lin M.-Y., Schnorr-Müller A., Sternberg A., Sturm E., Tacconi L., Obscuration in active galactic nuclei: near-infrared luminosity relations and dust colors, A\&A, 2015, vol. 578, p. A47

Buta R. J., Sheth K., Athanassoula E., Bosma A., Knapen J. H., Laurikainen E., Salo H., Elmegreen D., Ho L. C. e. a., A Classical Morphological Analysis of Galaxies in the Spitzer Survey of Stellar Structure in Galaxies (S4G), ApJS, 2015, vol. 217, p. 32

Cappellari M., Emsellem E., Parametric Recovery of Line-of-Sight Velocity Distributions from Absorption-Line Spectra of Galaxies via Penalized Likelihood, PASP, 2004, vol. 116 , p. 138

Cardelli J. A., Clayton G. C., Mathis J. S., The relationship between infrared, optical, and ultraviolet extinction, ApJ, 1989, vol. 345, p. 245

Cartier R., Sullivan M., Firth R. E., Pignata G., et al. Early observations of the nearby Type Ia supernova SN 2015F, MNRAS, 2017, vol. 464, p. 4476

Castangia P., Panessa F., Henkel C., Kadler M., Tarchi A., New Compton-thick AGN in the circumnuclear $\mathrm{H}_{2} \mathrm{O}$ maser hosts UGC 3789 and NGC 6264, MNRAS, 2013, vol. 436, p. 3388

Castangia P., Tarchi A., Henkel C., Menten K. M., New H2O masers in Seyfert and FIR bright galaxies II. The intermediate luminosity range, A\&A, 2008, vol. 479, p. 111 
Christopher M. H., Scoville N. Z., Stolovy S. R., Yun M. S., HCN and HCO ${ }^{+}$Observations of the Galactic Circumnuclear Disk, ApJ, 2005, vol. 622, p. 346

Cid Fernandes R., Mateus A., Sodré L., Stasińska G., Gomes J. M., Semi-empirical analysis of Sloan Digital Sky Survey galaxies - I. Spectral synthesis method, MNRAS, 2005, vol. 358 , p. 363

Cid Fernandes R., Stasińska G., Mateus A., Vale Asari N., A comprehensive classification of galaxies in the Sloan Digital Sky Survey: how to tell true from fake AGN?, MNRAS, 2011, vol. 413, p. 1687

Clarkson W., Sahu K., Anderson J., Smith T. E., Brown T. M., Rich R. M., Casertano S., Bond H. E., Livio M., Minniti D., Panagia N., Renzini A., Valenti J., Zoccali M., Stellar Proper Motions in the Galactic Bulge from Deep Hubble Space Telescope ACS WFC Photometry, ApJ, 2008, vol. 684, p. 1110

Clavel J., Joly M., The 1200-3200 A spectra of Seyfert I galaxies - MK 304, NGC 7603, MCG 8-11-11, ESO 12-G 21, and NGC 1566, A\&A, 1984, vol. 131, p. 87

Clavel J., Schulz B., Altieri B., Barr P., Claes P., Heras A., Leech K., Metcalfe L., Salama A., 2.5-11 micron spectroscopy and imaging of AGNs. Implication for unification schemes, A\&A, 2000, vol. 357, p. 839

Combes F., García-Burillo S., Audibert A., Hunt L., Eckart A., Aalto S., Casasola V., Boone F., Krips M., Viti S., Sakamoto K., Muller S., Dasyra K., van der Werf P., Martin S., ALMA observations of molecular tori around massive black holes, A\&A, 2019, vol. 623, p. A79

Combes F., García-Burillo S., Casasola V., Hunt L. K., Krips M., Baker A. J., Boone F., Eckart A., Marquez I., Neri R., Schinnerer E., Tacconi L. J., ALMA reveals the feeding of the Seyfert 1 nucleus in NGC 1566, A\&A, 2014, vol. 565, p. A97

Comerón S., Knapen J. H., Beckman J. E., Laurikainen E., Salo H., Martínez-Valpuesta I., Buta R. J., AINUR: Atlas of Images of NUclear Rings, MNRAS, 2010, vol. 402, p. 2462 
Comte G., Duquennoy A., The galaxy NGC 1566 - Distribution and kinematics of the ionized gas, A\&A, 1982, vol. 114, p. 7

Cowie L. L., Songaila A., Hu E. M., Cohen J. G., New Insight on Galaxy Formation and Evolution From Keck Spectroscopy of the Hawaii Deep Fields, AJ, 1996, vol. 112, p. 839

Cox T. J., Jonsson P., Somerville R. S., Primack J. R., Dekel A., The effect of galaxy mass ratio on merger-driven starbursts, MNRAS, 2008, vol. 384, p. 386

da Silva P., Menezes R. B., Steiner J. E., The nuclear region of NGC 613 - I. Multiwavelength analysis, MNRAS, 2020, vol. 492, p. 5121

da Silva P., Menezes R. B., Steiner J. E., Fraga L., The nuclear region of NGC 613 [U+2500] II. Kinematics and stellar archaeology, MNRAS, 2020, vol. 496, p. 943

da Silva P., Steiner J. E., Menezes R. B., NGC 1566: analysis of the nuclear region from optical and near-infrared Integral Field Unit spectroscopy, MNRAS, 2017, vol. 470, p. 3850

da Silva P., Steiner J. E., Menezes R. B., NGC 6744: A Nearby Milky Way Twin with a Very Low-luminosity AGN, ApJ, 2018, vol. 861, p. 83

Davies R. L., Dopita M. A., Kewley L., Groves B., Sutherland R., Hampton E. J., Shastri P., Kharb P., Bhatt H., Scharwächter J., Jin C., Banfield J., Zaw I., James B., Juneau S., Srivastava S., The Role of Radiation Pressure in the Narrow Line Regions of Seyfert Host Galaxies, ApJ, 2016, vol. 824, p. 50

Davies R. L., Groves B., Kewley L. J., Medling A. M., Shastri P., Maithil J., Kharb P., Banfield J., Longbottom F., Dopita M. A., Hampton E. J., Scharwächter J., Sutherland R., Jin C., Zaw I., James B., Juneau S., Dissecting galaxies: separating star formation, shock excitation and AGN activity in the central region of NGC 613, MNRAS, 2017, vol. 470 , p. 4974

Davis B. L., Berrier J. C., Johns L., Shields D. W., Hartley M. T., Kennefick D., Kennefick J., Seigar M. S., Lacy C. H. S., The Black Hole Mass Function Derived from Local Spiral Galaxies, ApJ, 2014, vol. 789, p. 124 
de Vaucouleurs G., Southern Galaxies.VI. Luminosity Distribution in the Seyfert Galaxy NGC 1566, ApJ, 1973, vol. 181, p. 31

de Vaucouleurs G., de Vaucouleurs A., Classification and radial velocities of bright southern galaxies., MmRAS, 1961, vol. 68, p. 69

de Vaucouleurs G., de Vaucouleurs A., Corwin Herold G. J., Buta R. J., Paturel G., Fouque P., Third Reference Catalogue of Bright Galaxies, 1991

de Zeeuw P. T., Bureau M., Emsellem E., Bacon R., Carollo C. M., Copin Y., Davies R. L., Kuntschner H., Miller B. W., Monnet G., Peletier R. F., Verolme E. K., The SAURON project - II. Sample and early results, MNRAS, 2002, vol. 329, p. 513

Ebrero J., Costantini E., Kaastra J. S., de Marco B., Dadina M., Probing the unified model in NGC 7314, A\&A, 2011, vol. 535, p. A62

Ehle M., Beck R., Haynes R. F., Vogler A., Pietsch W., Elmouttie M., Ryder S., Magnetic fields and hot gas in the spiral galaxy NGC 1566 as derived from ATCA radio polarization and ROSAT X-ray observations., A\&A, 1996, vol. 306, p. 73

Ekers R. D., Lynden-Bell D., High Resolution Observations of the Galactic Center at 5 GHz, Astrophys. Lett., 1971, vol. 9, p. 189

Elmegreen B. G., Starbursts by Gravitational Collapse in the Inner Lindblad Resonance Rings of Galaxies, ApJ, 1994, vol. 425, p. L73

Elmegreen B. G., Elmegreen D. M., Brinks E., Yuan C., Kaufman M., Klarić M., Montenegro L., Struck C., Thomasson M., Dust Spirals and Acoustic Noise in the Nucleus of the Galaxy NGC 2207, ApJ, 1998, vol. 503, p. L119

Elmegreen D. M., Elmegreen B. G., Chromey F. R., Hasselbacher D. A., Star Formation in the Outer Resonance Ring of NGC 1300, ApJ, 1996, vol. 469, p. 131

Elmegreen D. M., Elmegreen B. G., Kaufman M., Brinks E., Struck C., Bournaud F., Sheth K., Juneau S., ALMA CO Clouds and Young Star Complexes in the Interacting Galaxies IC 2163 and NGC 2207, ApJ, 2017, vol. 841, p. 43

Elvis M., Fassnacht C., Wilson A. S., Briel U., Extended X-ray emission in nearby Seyfert galaxies, ApJ, 1990, vol. 361, p. 459 
Emsellem E., Greusard D., Combes F., Friedli D., Leon S., Pécontal E., Wozniak H., Dynamics of embedded bars and the connection with AGN. I. ISAAC/VLT stellar kinematics, A\&A, 2001, vol. 368, p. 52

Erwin P., Double-barred galaxies. I. A catalog of barred galaxies with stellar secondary bars and inner disks, A\&A, 2004, vol. 415, p. 941

Erwin P., Debattista V. P., The frequency and stellar-mass dependence of boxy/peanutshaped bulges in barred galaxies, MNRAS, 2017, vol. 468, p. 2058

Erwin P., Sparke L. S., Double Bars, Inner Disks, and Nuclear Rings in Early-Type Disk Galaxies, AJ, 2002, vol. 124, p. 65

Eskridge P. B., Frogel J. A., Pogge R. W., Quillen A. C., Berlind A. A., Davies R. L., DePoy D. L., Gilbert K. M., Houdashelt M. L., Kuchinski L. E., Ramírez S. V., Sellgren K., Stutz A., Terndrup D. M., Tiede G. P., Near-Infrared and Optical Morphology of Spiral Galaxies, ApJS, 2002, vol. 143, p. 73

Evans D. A., Lee J. C., Kamenetska M., Gallagher S. C., Kraft R. P., Hardcastle M. J., Weaver K. A., The Chandra, Hubble Space Telescope, and VLA View of the Circumnuclear Extended Emission in the Narrow Emission Line Galaxy NGC 2110, ApJ, 2006, vol. 653 , p. 1121

Falcke H., Goss W. M., Matsuo H., Teuben P., Zhao J.-H., Zylka R., The Simultaneous Spectrum of Sagittarius A* from 20 Centimeters to 1 Millimeter and the Nature of the Millimeter Excess, ApJ, 1998, vol. 499, p. 731

Falcón-Barroso J., Bacon R., Bureau M., Cappellari M., Davies R. L., de Zeeuw P. T., Emsellem E., Fathi K., Krajnović D., Kuntschner H., McDermid R. M., Peletier R. F., Sarzi M., The SAURON project - VII. Integral-field absorption and emission-line kinematics of 24 spiral galaxy bulges, MNRAS, 2006, vol. 369, p. 529

Falcón-Barroso J., Böker T., Schinnerer E., Knapen J. H., Ryder S., A SINFONI view of circum-nuclear star-forming rings in spiral galaxies. In Formation and Evolution of Galaxy Bulges , vol. 245 of IAU Symposium, 2008, p. 177 
Falcón-Barroso J., Ramos Almeida C., Böker T., Schinnerer E., Knapen J. H., Lançon A., Ryder S., The circumnuclear environment of NGC 613: a nuclear starburst caught in the act?, MNRAS, 2014, vol. 438, p. 329

Fathi K., Peletier R. F., Do bulges of early- and late-type spirals have different morphology?, A\&A, 2003, vol. 407, p. 61

Ferland G. J., Netzer H., Are there any shock-heated galaxies, ApJ, 1983, vol. 264, p. 105

Fernández Lorenzo M., Sulentic J., Verdes-Montenegro L., Blasco-Herrera J., ArgudoFernández M., Garrido J., Ramírez-Moreta P., Ruiz J. E., Sánchez-Expósito S., Santander-Vela J. D., Are (Pseudo)bulges in Isolated Galaxies Actually Primordial Relics?, ApJ, 2014, vol. 788, p. L39

Ferrarese L., Merritt D., A Fundamental Relation between Supermassive Black Holes and Their Host Galaxies, ApJ, 2000, vol. 539, p. L9

Figer D. F., Kim S. S., Morris M., Serabyn E., Rich R. M., McLean I. S., Hubble Space Telescope/NICMOS Observations of Massive Stellar Clusters near the Galactic Center, ApJ, 1999, vol. 525, p. 750

Figer D. F., McLean I. S., Morris M., Massive Stars in the Quintuplet Cluster, ApJ, 1999, vol. 514, p. 202

Figer D. F., Najarro F., Gilmore D., Morris M., Kim S. S., Serabyn E., McLean I. S., Gilbert A. M., Graham J. R., Larkin J. E., Levenson N. A., Teplitz H. I., Massive Stars in the Arches Cluster, ApJ, 2002, vol. 581, p. 258

Fisher D. B., Drory N., The Structure of Classical Bulges and Pseudobulges: the Link Between Pseudobulges and SÉRSIC Index, AJ, 2008, vol. 136, p. 773

Fisher D. B., Drory N., Bulges of Nearby Galaxies with Spitzer: Scaling Relations in Pseudobulges and Classical Bulges, ApJ, 2010, vol. 716, p. 942

Fullard A. G., St-Louis N., Moffat A. F. J., Piirola V. E., Manset N., Hoffman J. L., A Multiwavelength Search for Intrinsic Linear Polarization in Wolf-Rayet Winds, AJ, 2020, vol. 159 , p. 214 
Gadotti D. A., Sánchez-Blázquez P., Falcón-Barroso J., Husemann B., Seidel M. K., Pérez I. e. a., Time Inference with MUSE in Extragalactic Rings (TIMER): properties of the survey and high-level data products, MNRAS, 2019, vol. 482, p. 506

Ganda K., Falcón-Barroso J., Peletier R. F., Cappellari M., Emsellem E., McDermid R. M., de Zeeuw P. T., Carollo C. M., Late-type galaxies observed with SAURON: twodimensional stellar and emission-line kinematics of 18 spirals, MNRAS, 2006, vol. 367, p. 46

Garrison R. F., Walborn N. R., Morphological Properties of Some Bright Southern Galaxies, JRASC, 1974, vol. 68, p. 117

Gebhardt K., Bender R., Bower G., Dressler A., Faber S. M., Filippenko A. V., Green R., Grillmair C., Ho L. C., Kormendy J., Lauer T. R., Magorrian J., Pinkney J., Richstone D., Tremaine S., A Relationship between Nuclear Black Hole Mass and Galaxy Velocity Dispersion, ApJ, 2000, vol. 539, p. L13

Genzel R., The Central Black Hole and Nuclear Star Cluster in The Milky Way. In Revista Mexicana de Astronomia y Astrofisica Conference Series, vol. 26 of Revista Mexicana de Astronomia y Astrofisica Conference Series, 2006, p. 202

Genzel R., Eisenhauer F., Gillessen S., The Galactic Center massive black hole and nuclear star cluster, Reviews of Modern Physics, 2010, vol. 82, p. 3121

Genzel R., Hollenbach D., Townes C. H., The nucleus of our Galaxy, Reports on Progress in Physics, 1994, vol. 57, p. 417

Genzel R., Pichon C., Eckart A., Gerhard O. E., Ott T., Stellar dynamics in the Galactic Centre: proper motions and anisotropy, MNRAS, 2000, vol. 317, p. 348

Genzel R., Schödel R., Ott T., Eisenhauer F., Hofmann R., Lehnert M., Eckart A., Alexander T., Sternberg A., Lenzen R., Clénet Y., Lacombe F., Rouan D., Renzini A., Tacconi-Garman L. E., The Stellar Cusp around the Supermassive Black Hole in the Galactic Center, ApJ, 2003, vol. 594, p. 812

Genzel R., Thatte N., Krabbe A., Kroker H., Tacconi-Garman L. E., The Dark Mass Concentration in the Central Parsec of the Milky Way, ApJ, 1996, vol. 472, p. 153 
Georgiev I. Y., Böker T., Nuclear star clusters in 228 spiral galaxies in the HST/WFPC2 archive: catalogue and comparison to other stellar systems, MNRAS, 2014, vol. 441, p. 3570

Gerhard O., The Galactic Center HE I Stars: Remains of a Dissolved Young Cluster?, ApJ, 2001, vol. 546, p. L39

Ghez A. M., Duchêne G., Matthews K., Hornstein S. D., Tanner A., Larkin J., Morris M., Becklin E. E., Salim S., Kremenek T., Thompson D., Soifer B. T., Neugebauer G., McLean I., The First Measurement of Spectral Lines in a Short-Period Star Bound to the Galaxy's Central Black Hole: A Paradox of Youth, ApJ, 2003, vol. 586, p. L127

Ghez A. M., Salim S., Weinberg N. N., Lu J. R., Do T., Dunn J. K., Matthews K., Morris M. R., Yelda S., Becklin E. E., Kremenek T., Milosavljevic M., Naiman J., Measuring Distance and Properties of the Milky Way's Central Supermassive Black Hole with Stellar Orbits, ApJ, 2008, vol. 689, p. 1044

Gillessen S., Eisenhauer F., Trippe S., Alexander T., Genzel R., Martins F., Ott T., Monitoring Stellar Orbits Around the Massive Black Hole in the Galactic Center, ApJ, 2009, vol. 692, p. 1075

Gillessen S., Plewa P. M., Eisenhauer F., Sari R., Waisberg I., Habibi M., Pfuhl O., George E., Dexter J., von Fellenberg S., Ott T., Genzel R., An Update on Monitoring Stellar Orbits in the Galactic Center, ApJ, 2017, vol. 837, p. 30

Gonzalez R. C., Woods R. E., Digital image processing, 2002

Goulding A. D., Alexander D. M., Towards a complete census of AGN in nearby Galaxies: a large population of optically unidentified AGN, MNRAS, 2009, vol. 398, p. 1165

Gravity Collaboration Abuter R., Amorim A., Bauböck M., Berger J. P., Bonnet H., Brand ner W., Clénet Y., et al. A geometric distance measurement to the Galactic center black hole with $0.3 \%$ uncertainty, A\&A, 2019, vol. 625, p. L10

Greene J. E., Pooley D., Zakamska N. L., Comerford J. M., Sun A.-L., Extended X-Ray Emission from a Quasar-driven Superbubble, ApJ, 2014, vol. 788, p. 54 
Gu Q., Melnick J., Cid Fernandes R., Kunth D., Terlevich E., Terlevich R., Emission-line properties of Seyfert 2 nuclei, MNRAS, 2006, vol. 366, p. 480

Gültekin K., Cackett E. M., Miller J. M., Di Matteo T., Markoff S., Richstone D. O., A Chandra Survey of Supermassive Black Holes with Dynamical Mass Measurements, ApJ, 2012, vol. 749, p. 129

Gültekin K., Richstone D. O., Gebhardt K., Lauer T. R., Tremaine S., Aller M. C., Bender R., Dressler A., Faber S. M., Filippenko A. V., Green R., Ho L. C., Kormendy J., Magorrian J., Pinkney J., Siopis C., The M- $\sigma$ and M-L Relations in Galactic Bulges, and Determinations of Their Intrinsic Scatter, ApJ, 2009, vol. 698, p. 198

Güsten R., Downes D., Formaldehyde in the Galactic Center region: interpretation., A\&A, 1980, vol. 87 , p. 6

Hackwell J. A., Schweizer F., Infrared mapping and UBVRi photometry of the spiral galaxy NGC 1566, ApJ, 1983, vol. 265, p. 643

Halpern J. P., Steiner J. E., Low-ionization active galactic nuclei - X-ray or shock heated?, ApJ, 1983, vol. 269, p. L37

Hardcastle M. J., Croston J. H., The Chandra view of extended X-ray emission from Pictor A, MNRAS, 2005, vol. 363, p. 649

Harrison C. M., Costa T., Tadhunter C. N., Flütsch A., Kakkad D., Perna M., Vietri G., AGN outflows and feedback twenty years on, Nature Astronomy, 2018, vol. 2, p. 198

Hartwick F. D. A., A Multiple Burst Accretion Model to Describe the Metallicity Distributions and Stellar Mass-Metallicity Relation for Local Dwarf Galaxies, AJ, 2015, vol. 150, p. 184

Hartwick F. D. A., The Chemical Evolution of Galaxies: The Stellar Mass-Metallicity Relation and Cosmic Downsizing, Research Notes of the American Astronomical Society, 2017 , vol. 1 , p. 8

Hawley S. A., Phillips M. M., Spectrophotometry of H II regions and the nucleus of NGC 1566, ApJ, 1980, vol. 235, p. 783 
Heckman T. M., An optical and radio survey of the nuclei of bright galaxies - Activity in normal galactic nuclei, A\&A, 1980, vol. 87, p. 152

Herrera-Endoqui M., Salo H., Laurikainen E., Knapen J. H., Colors of barlenses: evidence for connecting them to boxy/peanut bulges, A\&A, 2017, vol. 599, p. A43

Hicks E. K. S., Davies R. I., Maciejewski W., Emsellem E., Malkan M. A., Dumas G., Müller-Sánchez F., Rivers A., Fueling Active Galactic Nuclei. I. How the Global Characteristics of the Central Kiloparsec of Seyferts Differ from Quiescent Galaxies, ApJ, 2013, vol. 768, p. 107

Ho L. C., Nuclear Activity in Nearby Galaxies, ARA\&A, 2008, vol. 46, p. 475

Ho L. C., Filippenko A. V., Sargent W. L. W., A Search for "Dwarf" Seyfert Nuclei. III. Spectroscopic Parameters and Properties of the Host Galaxies, ApJS, 1997, vol. 112, p. 315

Hopkins P. F., Quataert E., How do massive black holes get their gas?, MNRAS, 2010, vol. 407 , p. 1529

Hummel E., Jorsater S., The central region of NGC 613 revisited, A\&A, 1992, vol. 261, p. 85

Hummel E., Jorsater S., Lindblad P. O., Sandqvist A., The central region of NGC 613. Evidence for an accelerated collimated outflow, A\&A, 1987, vol. 172, p. 51

Joguet B., Kunth D., Melnick J., Terlevich R., Terlevich E., Stellar populations in Seyfert 2 galaxies. I. Atlas of near-UV spectra, A\&A, 2001, vol. 380, p. 19

Kauffmann G., Heckman T. M., Tremonti C., Brinchmann J., Charlot S., White S. D. M., Ridgway S. E., Brinkmann J., Fukugita M., Hall P. B., Ivezić Ž., Richards G. T., Schneider D. P., The host galaxies of active galactic nuclei, MNRAS, 2003, vol. 346, p. 1055

Kawamuro T., Ueda Y., Tazaki F., Terashima Y., Broadband X-Ray Spectra of Two Lowluminosity Active Galactic Nuclei NGC 1566 and NGC 4941 Observed with Suzaku, ApJ, 2013, vol. 770, p. 157 
Keel W. C., Lintott C. J., Schawinski K., Bennert V. N., Thomas D., Manning A., Chojnowski S. D., van Arkel H., Lynn S., The History and Environment of a Faded Quasar: Hubble Space Telescope Observations of Hanny's Voorwerp and IC 2497, AJ, 2012, vol. 144 , p. 66

Kewley L. J., Dopita M. A., Sutherland R. S., Heisler C. A., Trevena J., Theoretical Modeling of Starburst Galaxies, ApJ, 2001, vol. 556, p. 121

Kewley L. J., Groves B., Kauffmann G., Heckman T., The host galaxies and classification of active galactic nuclei, MNRAS, 2006, vol. 372, p. 961

Kinkhabwala A., Sako M., Behar E., Kahn S. M., Paerels F., Brinkman A. C., Kaastra J. S., Gu M. F., Liedahl D. A., XMM-Newton Reflection Grating Spectrometer Observations of Discrete Soft X-Ray Emission Features from NGC 1068, ApJ, 2002, vol. 575, p. 732

Kirby E. N., Cohen J. G., Guhathakurta P., Cheng L., Bullock J. S., Gallazzi A., The Universal Stellar Mass-Stellar Metallicity Relation for Dwarf Galaxies, ApJ, 2013, vol. 779, p. 102

Knapen J. H., Pérez-Ramírez D., Laine S., Circumnuclear regions in barred spiral galaxies - II. Relations to host galaxies, MNRAS, 2002, vol. 337, p. 808

Kondratko P. T., Greenhill L. J., Moran J. M., Lovell J. E. J., Kuiper T. B. H., Jauncey D. L., Cameron L. B., Gómez J. F., García-Miró C., Moll E., de Gregorio-Monsalvo I., Jiménez-Bailón E., Discovery of Water Maser Emission in Eight AGNs with 70 m Antennas of NASA's Deep Space Network, ApJ, 2006, vol. 638, p. 100

Koribalski B. S., Staveley-Smith L., Kilborn V. A., Ryder S. D., Kraan-Korteweg e. a., The 1000 Brightest HIPASS Galaxies: H I Properties, AJ, 2004, vol. 128, p. 16

Kormendy J., A morphological survey of bar, lens, and ring components in galaxies Secular evolution in galaxy structure, ApJ, 1979, vol. 227, p. 714

Kormendy J., Kinematics of extragalactic bulges: evidence that some bulges are really disks. In Galactic Bulges, vol. 153 of IAU Symposium, 1993, p. 209

Kormendy J., Ho L. C., Coevolution (Or Not) of Supermassive Black Holes and Host Galaxies, ARA\&A, 2013, vol. 51, p. 511 
Kormendy J., Kennicutt Jr. R. C., Secular Evolution and the Formation of Pseudobulges in Disk Galaxies, ARA\&A, 2004, vol. 42, p. 603

Kormendy J., Richstone D., Inward Bound-The Search For Supermassive Black Holes In Galactic Nuclei, ARA\&A, 1995, vol. 33, p. 581

Kunder A., Koch A., Rich R. M., de Propris R., Howard C. D., Stubbs S. A., Johnson C. I., Shen J., Wang Y., Robin A. C., Kormendy J., Soto M., Frinchaboy P., Reitzel D. B., Zhao H., Origlia L., The Bulge Radial Velocity Assay (BRAVA). II. Complete Sample and Data Release, AJ, 2012, vol. 143, p. 57

Läsker R., Ferrarese L., van de Ven G., Supermassive Black Holes and Their Host Galaxies. I. Bulge Luminosities from Dedicated Near-infrared Data, ApJ, 2014, vol. 780, p. 69

Launhardt R., Zylka R., Mezger P. G., The nuclear bulge of the Galaxy. III. Large-scale physical characteristics of stars and interstellar matter, A\&A, 2002, vol. 384, p. 112

Laurikainen E., Salo H., Buta R., Vasylyev S., Bar-induced perturbation strengths of the galaxies in the Ohio State University Bright Galaxy Survey - I, MNRAS, 2004, vol. 355, p. 1251

Levin Y., Beloborodov A. M., Stellar Disk in the Galactic Center: A Remnant of a Dense Accretion Disk?, ApJ, 2003, vol. 590, p. L33

Lintott C. J., Schawinski K., Keel e. a., Galaxy Zoo: 'Hanny's Voorwerp', a quasar light echo?, MNRAS, 2009, vol. 399, p. 129

Lo K. Y., Claussen M. J., High-resolution observations of ionized gas in central 3 parsecs of the Galaxy: possible evidence for infall, Nature, 1983, vol. 306, p. 647

Lu J. R., Do T., Ghez A. M., Morris M. R., Yelda S., Matthews K., Stellar Populations in the Central 0.5 pc of the Galaxy. II. The Initial Mass Function, ApJ, 2013, vol. 764, p. 155

Lucy L. B., An iterative technique for the rectification of observed distributions, AJ, 1974, vol. 79 , p. 745

Lynden-Bell D., Galactic Nuclei as Collapsed Old Quasars, Nature, 1969, vol. 223, p. 690 
Maeda F., Ohta K., Fujimoto Y., Habe A., Baba J., Large velocity dispersion of molecular gas in bars of strongly barred galaxies NGC 1300 and NGC 5383, PASJ, 2018, vol. 70, p. 37

Maiolino R., Rieke G. H., Low-Luminosity and Obscured Seyfert Nuclei in Nearby Galaxies, ApJ, 1995, vol. 454, p. 95

Marinucci A., Risaliti G., Wang J., Nardini E., Elvis M., Fabbiano G., Bianchi S., Matt G., The X-ray reflector in NGC 4945: a time- and space-resolved portrait, MNRAS, 2012, vol. 423, p. L6

Mármol-Queraltó E., Cardiel N., Sánchez-Blázquez P., Trager S. C., Peletier R. F., Kuntschner H., Silva D. R., Cenarro A. J., Vazdekis A., Gorgas J., Evidence for IntermediateAge Stellar Populations in Early-Type Galaxies from K-Band Spectroscopy, ApJ, 2009, vol. 705 , p. L199

Márquez I., Masegosa J., Durret F., González Delgado R. M., Moles M., Maza J., Pérez E., Roth M., The detection of stellar velocity dispersion drops in the central regions of five isolated Seyfert spirals, A\&A, 2003, vol. 409, p. 459

Martin W. L., Spectrophotometry of six Seyfert nuclei, MNRAS, 1974, vol. 168, p. 109

May D., Steiner J. E., A two-stage outflow in NGC 1068, MNRAS, 2017, vol. 469, p. 994

Mazzuca L. M., Knapen J. H., Veilleux S., Regan M. W., A Connection between Star Formation in Nuclear Rings and Their Host Galaxies, ApJS, 2008, vol. 174, p. 337

McHardy I. M., Lawrence A., Pye J. P., Pounds K. A., The Ariel V (3A) catalogue of X-ray sources. II., MNRAS, 1981, vol. 197, p. 893

McKernan B., Yaqoob T., Reynolds C. S., A soft X-ray study of type I active galactic nuclei observed with Chandra high-energy transmission grating spectrometer, MNRAS, 2007, vol. 379, p. 1359

Menezes R. B., Espectroscopia 3D de núcleos ativos de galáxias: tratamento e análise de dados no óptico e infravermelho próximo., São Paulo: Universidade de São Paulo, 2012, Tese de Doutorado, 612 p. 
Menezes R. B., da Silva P., Ricci T. V., Steiner J. E., May D., Borges B. W., A treatment procedure for VLT/SINFONI data cubes: application to NGC 5643, MNRAS, 2015, vol. 450 , p. 369

Menezes R. B., Ricci T. V., Steiner J. E., da Silva P., Ferrari F., Borges B. W., A treatment procedure for GMOS/IFU data cubes: application to NGC 2835, MNRAS, 2019, vol. 483 , p. 3700

Menezes R. B., Steiner J. E., Ricci T. V., Collimation and Scattering of the Active Galactic Nucleus Emission in the Sombrero Galaxy, ApJ, 2013, vol. 765, p. L40

Menezes R. B., Steiner J. E., Ricci T. V., A treatment procedure for Gemini North/NIFS data cubes: application to NGC 4151, MNRAS, 2014, vol. 438, p. 2597

Mezcua M., Prieto M. A., Fernández-Ontiveros J. A., Tristram K., Neumayer N., Kotilainen J. K., The warm molecular gas and dust of Seyfert galaxies: two different phases of accretion?, MNRAS, 2015, vol. 452, p. 4128

Mezger P. G., Duschl W. J., Zylka R., The Galactic Center: a laboratory for AGN?, A\&A Rev., 1996, vol. 7, p. 289

Mihos J. C., Bothun G. D., NGC 2442: Tidal Encounters and the Evolution of Spiral Galaxies, ApJ, 1997, vol. 481, p. 741

Mineo S., Rappaport S., Steinhorn B., Levine A., Gilfanov M., Pooley D., Spatially Resolved Star Formation Image and the Ultraluminous X-Ray Source Population in NGC 2207/IC 2163, ApJ, 2013, vol. 771, p. 133

Miyamoto Y., Nakai N., Seta M., Salak D., Nagai M., Kaneko H., ALMA multiline observations toward the central region of NGC 613, Publications of the Astronomical Society of Japan, 2017, vol. 69, p. 83

Miyamoto Y., Seta M., Nakai N., Watanabe Y., Salak D., Ishii S., ALMA [C I] observations toward the central region of Seyfert galaxy NGC 613, Publications of the Astronomical Society of Japan, 2018, vol. 70, p. L1

Morganti R., Tsvetanov Z. I., Gallimore J., Allen M. G., Radio continuum morphology of southern Seyfert galaxies, A\&AS, 1999, vol. 137, p. 457 
Morris M., Massive Star Formation near the Galactic Center and the Fate of the Stellar Remnants, ApJ, 1993, vol. 408, p. 496

Morris S. L., Ward M. J., CCD spectroscopy of the active galaxies NGC 5506 and NGC 7314., MNRAS, 1985, vol. 215, p. 57P

Muñoz-Mateos J. C., Sheth K., Gil de Paz A., Meidt S., Athanassoula E., Bosma A., Comerón S., Elmegreen D. M., Elmegreen B. G., Erroz-Ferrer S., Gadotti D. A. e. a., The Impact of Bars on Disk Breaks as Probed by $\mathrm{S}^{4} \mathrm{G}$ Imaging, ApJ, 2013, vol. 771, p. 59

Mulchaey J. S., Regan M. W., Kundu A., The Fueling of Nuclear Activity. I. A NearInfrared Imaging Survey of Seyfert and Normal Galaxies, ApJS, 1997, vol. 110, p. 299

Muno M. P., Baganoff F. K., Bautz M. W., Feigelson E. D., Garmire G. P., Morris M. R., Park S., Ricker G. R., Townsley L. K., Diffuse X-Ray Emission in a Deep Chandra Image of the Galactic Center, ApJ, 2004, vol. 613, p. 326

Murchikova E. M., Phinney E. S., Pancoast A., Blandford R. D., A cool accretion disk around the Galactic Centre black hole, Nature, 2019, vol. 570, p. 83

Nasonova O. G., de Freitas Pacheco J. A., Karachentsev I. D., Hubble flow around Fornax cluster of galaxies, A\&A, 2011, vol. 532, p. A104

Nelson C. H., Whittle M., Stellar and Gaseous Kinematics of Seyfert Galaxies. I. Spectroscopic Data, ApJS, 1995, vol. 99, p. 67

Ness M., Freeman K., The Metallicity Distribution of the Milky Way Bulge, PASA, 2016, vol. 33, p. e022

Ness M., Zasowski G., Johnson J. A., Athanassoula E., Majewski S. R., García Pérez A. E., Bird J., Nidever D., Schneider D. P., Sobeck J., Frinchaboy P., Pan K., Bizyaev D., Oravetz D., Simmons A., APOGEE Kinematics. I. Overview of the Kinematics of the Galactic Bulge as Mapped By APOGEE, ApJ, 2016, vol. 819, p. 2

Netzer H., On the profiles of the broad lines in the spectra of QSOs and Seyfert galaxies, MNRAS, 1977, vol. 181, p. 89P 
Netzer H., The Physics and Evolution of Active Galactic Nuclei, 2013

Osmer P. S., Smith M. G., Weedman D. W., The southern Seyfert galaxies NGC 1566 and NGC 3783., ApJ, 1974, vol. 189, p. 187

Osterbrock D. E., Ferland G. J., Astrophysics of gaseous nebulae and active galactic nuclei, 2006

Pancoast A., Sajina A., Lacy M., Noriega-Crespo A., Rho J., Star Formation and Dust Obscuration in the Tidally Distorted Galaxy NGC 2442, ApJ, 2010, vol. 723, p. 530

Pastoriza M., Gerola H., Spectral Variation in the Seyfert Galaxy NGC 1566, Astrophys. Lett., 1970, vol. 6, p. 155

Paumard T., Genzel R., Martins F., Nayakshin S., Beloborodov A. M., Levin Y., Trippe S., Eisenhauer F., Ott T., Gillessen S., Abuter R., Cuadra J., Alexander T., Sternberg A., The Two Young Star Disks in the Central Parsec of the Galaxy: Properties, Dynamics, and Formation, ApJ, 2006, vol. 643, p. 1011

Paumard T., Maillard J. P., Morris M., Kinematic and structural analysis of the ¡ASTROBJ $_{i}$ Minispiral $_{i} /$ ASTROBJ $_{i}$ in the Galactic Center from BEAR spectro-imagery, A\&A, 2004, vol. 426, p. 81

Paumard T., Maillard J. P., Morris M., Rigaut F., New results on the helium stars in the galactic center using BEAR spectro-imagery, A\&A, 2001, vol. 366, p. 466

Pfuhl O., Fritz T. K., Zilka M., Maness H., Eisenhauer F., Genzel R., Gillessen S., Ott T., Dodds-Eden K., Sternberg A., The Star Formation History of the Milky Way's Nuclear Star Cluster, ApJ, 2011, vol. 741, p. 108

Piccinotti G., Mushotzky R. F., Boldt E. A., Holt S. S., Marshall F. E., Serlemitsos P. J., Shafer R. A., A complete X-ray sample of the high-latitude (b)-20 sky from HEAO 1 A-2 : $\log$ N-log S and luminosity functions., ApJ, 1982, vol. 253, p. 485

Pogge R. W., Ionized Gas in the Nuclear Regions of Nearby Non-Seyfert Spiral Galaxies, ApJS, 1989, vol. 71, p. 433

Portegies Zwart S. F., Makino J., McMillan S. L. W., Hut P., How Many Young Star Clusters Exist in the Galactic Center?, ApJ, 2001, vol. 546, p. L101 
Pulatova N. G., Vavilova I. B., Sawangwit U., Babyk I., Klimanov S., The 2MIG isolated AGNs - I. General and multiwavelength properties of AGNs and host galaxies in the northern sky, MNRAS, 2015, vol. 447, p. 2209

Rate G., Crowther P. A., Parker R. J., Unlocking Galactic Wolf-Rayet stars with Gaia DR2 II: Cluster and Association membership, MNRAS, 2020

Ricci T. V., Análise da emissão nuclear e circumnuclear de gás de uma amostra de 10 galáxias elípticas e lenticulares., São Paulo: Universidade de São Paulo, IAG, 2013, Tese de Doutorado, 307 p.

Ricci T. V., Steiner J. E., Menezes R. B., NGC 7097: The Active Galactic Nucleus and its Mirror, Revealed by Principal Component Analysis Tomography, ApJ, 2011, vol. 734, p. L10

Ricci T. V., Steiner J. E., Menezes R. B., Integral field unit spectroscopy of 10 earlytype galactic nuclei - I. Principal component analysis Tomography and nuclear activity, MNRAS, 2014, vol. 440, p. 2419

Ricci T. V., Steiner J. E., Menezes R. B., IFU spectroscopy of 10 early-type galactic nuclei - III. Properties of the circumnuclear gas emission, MNRAS, 2015, vol. 451, p. 3728

Richardson W. H., Bayesian-Based Iterative Method of Image Restoration, Journal of the Optical Society of America (1917-1983), 1972, vol. 62, p. 55

Richstone D., Ajhar E. A., Bender R., Bower G., Dressler A., Faber S. M., Filippenko A. V., Gebhardt K., Green R., Ho L. C., Kormendy J., Lauer T. R., Magorrian J., Tremaine S., Supermassive black holes and the evolution of galaxies., Nature, 1998, vol. 385 , p. A14

Risaliti G., Elvis M., Nicastro F., Ubiquitous Variability of X-Ray-absorbing Column Densities in Seyfert 2 Galaxies, ApJ, 2002, vol. 571, p. 234

Robertson B., Bullock J. S., Cox T. J., Di Matteo T., Hernquist L., Springel V., Yoshida N., A Merger-driven Scenario for Cosmological Disk Galaxy Formation, ApJ, 2006, vol. 645, p. 986 
Roussel H., Sauvage M., Vigroux L., Bosma A., Bonoli C., Gallais P., Hawarden T., Madden S., Mazzei P., The impact of bars on the mid-infrared dust emission of spiral galaxies: global and circumnuclear properties, A\&A, 2001, vol. 372, p. 406

Ryder S. D., Dopita M. A., An H-alpha atlas of nearby southern spiral galaxies, ApJS, 1993, vol. 88, p. 415

Ryder S. D., Dopita M. A., The relationship between past and present star formation in galactic disks from CCD surface photometry, ApJ, 1994, vol. 430, p. 142

Ryder S. D., Walsh W., Malin D., HI study of the NGC 6744 system, PASA, 1999, vol. 16, p. 84

Saikia D. J., Pedlar A., Unger S. W., Axon D. J., Radio-continuum observations of the central regions of Sersic-Pastoriza galaxies., MNRAS, 1994, vol. 270, p. 46

Sánchez-Blázquez P., Peletier R. F., Jiménez-Vicente J., Cardiel N., Cenarro A. J., FalcónBarroso J., Gorgas J., Selam S., Vazdekis A., Medium-resolution Isaac Newton Telescope library of empirical spectra, MNRAS, 2006, vol. 371, p. 703

Sargent W. L. W., Schechter P. L., Boksenberg A., Shortridge K., Velocity dispersions for 13 galaxies., ApJ, 1977, vol. 212, p. 326

Schawinski K., Thomas D., Sarzi M., Maraston C., Kaviraj S., Joo S.-J., Yi S. K., Silk J., Observational evidence for AGN feedback in early-type galaxies, MNRAS, 2007, vol. 382, p. 1415

Schechter P. L., New central velocity dispersions for the bulges of 53 spiral and S0 Galaxies., The Astrophysical Journal Supplement Series, 1983, vol. 52, p. 425

Schmitt H. R., Kinney A. L., A Comparison between the Narrow-Line Regions of Seyfert 1 and Seyfert 2 Galaxies, ApJ, 1996, vol. 463, p. 498

Schödel R., Ott T., Genzel R., Hofmann R., Lehnert M., Eckart A. e. a., A star in a 15.2year orbit around the supermassive black hole at the centre of the Milky Way, Nature, 2002, vol. 419, p. 694

Shapiro K. L., Gerssen J., van der Marel R. P., Observational Constraints on Disk Heating as a Function of Hubble Type, AJ, 2003, vol. 126, p. 2707 
Shen J., Rich R. M., Kormendy J., Howard C. D., De Propris R., Kunder A., Our Milky Way as a Pure-disk Galaxy-A Challenge for Galaxy Formation, ApJ, 2010, vol. 720, p. L72

Shields J. C., Ferland G. J., Nebular Properties and the Ionizing Radiation Field in the Galactic Center, ApJ, 1994, vol. 430, p. 236

Shobbrook R. R., Southern groups and clusters of galaxies. I, Spectra and radial velocities of nineteen southern galaxies, MNRAS, 1966, vol. 131, p. 293

Smajić S., Moser L., Eckart A., Busch G., Combes F., García-Burillo S., Valencia-S. M., Horrobin M., The nuclear gas disk of NGC 1566 dissected by SINFONI and ALMA, A\&A, 2015, vol. 583, p. A104

Springel V., Hernquist L., Formation of a Spiral Galaxy in a Major Merger, ApJ, 2005, vol. 622 , p. L9

Stauffer J. R., A nuclear spectroscopic survey of field disk galaxies., ApJS, 1982, vol. 50, p. 517

Steiner J. E., Menezes R. B., Ricci T. V., Oliveira A. S., Mapping low- and high-density clouds in astrophysical nebulae by imaging forbidden line emission, MNRAS, 2009a, vol. 396 , p. 788

Steiner J. E., Menezes R. B., Ricci T. V., Oliveira A. S., PCA Tomography: how to extract information from data cubes, MNRAS, 2009b, vol. 395, p. 64

Stolte A., Hußmann B., Morris M. R., Ghez A. M., Brandner W., Lu J. R., Clarkson W. I., Habibi M., Matthews K., The Orbital Motion of the Quintuplet Cluster-A Common Origin for the Arches and Quintuplet Clusters?, ApJ, 2014, vol. 789, p. 115

Storchi-Bergmann T., Lopes R. D. S., McGregor P. J., Riffel R. A., Beck T., Martini P., Feeding versus feedback in NGC4151 probed with Gemini NIFS - II. Kinematics, MNRAS, 2010, vol. 402, p. 819

Storchi-Bergmann T., McGregor P. J., Riffel R. A., Simões Lopes R., Beck T., Dopita M., Feeding versus feedback in NGC4151 probed with Gemini NIFS - I. Excitation, MNRAS, 2009, vol. 394, p. 1148 
Storchi-Bergmann T., Schnorr-Müller A., Observational constraints on the feeding of supermassive black holes, Nature Astronomy, 2019, vol. 3, p. 48

Struck C., Kaufman M., Brinks E., Thomasson M., Elmegreen B. G., Elmegreen D. M., The grazing encounter between IC 2163 and NGC 2207: pushing the limits of observational modelling, MNRAS, 2005, vol. 364, p. 69

Taniguchi Y., Wada K., The Nuclear Starburst Driven by a Supermassive Black Hole Binary, ApJ, 1996, vol. 469, p. 581

Tanner A., Figer D. F., Najarro F., Kudritzki R. P., Gilmore D., Morris M., Becklin E. E., McLean I. S., Gilbert A. M., Graham J. R., Larkin J. E., Levenson N. A., Teplitz H. I., High Spectral Resolution Observations of the Massive Stars in the Galactic Center, ApJ, 2006, vol. 641, p. 891

The GRAVITY Collaboration Abuter R., Amorim A., et al. The Flux Distribution of Sgr A*, arXiv e-prints, 2020, p. arXiv:2004.07185

Thean A., Pedlar A., Kukula M. J., Baum S. A., O'Dea C. P., High-resolution radio observations of Seyfert galaxies in the extended $12-\mu \mathrm{m}$ sample - I. The observations, MNRAS, 2000, vol. 314, p. 573

Theureau G., Hanski M. O., Coudreau N., Hallet N., Martin J.-M., Kinematics of the Local Universe. XIII. 21-cm line measurements of 452 galaxies with the Nançay radiotelescope, JHK Tully-Fisher relation, and preliminary maps of the peculiar velocity field, A\&A, 2007, vol. 465, p. 71

Thompson G. D., Levenson N. A., Uddin S. A., Sirocky M. M., Dust Emission from Unobscured Active Galactic Nuclei, ApJ, 2009, vol. 697, p. 182

Tommasin S., Spinoglio L., Malkan M. A., Fazio G., Spitzer-IRS High-Resolution Spectroscopy of the $12 \mu \mathrm{m}$ Seyfert Galaxies. II. Results for the Complete Data Set, ApJ, 2010, vol. 709, p. 1257

Trippe M. L., Crenshaw D. M., Deo R. P., Dietrich M., Kraemer S. B., Rafter S. E., Turner T. J., A Multi-wavelength Study of the Nature of Type 1.8/1.9 Seyfert Galaxies, ApJ, 2010, vol. 725, p. 1749 
Tully R. B., Courtois H. M., Sorce J. G., Cosmicflows-3, AJ, 2016, vol. 152, p. 50

Turner T. J., Dramatic X-ray variability in the narrow emission line galaxy NGC 7314., MNRAS, 1987, vol. 226, p. 9P

Vaceli M. S., Viegas S. M., Gruenwald R., de Souza R. E., Spectroscopy of Seyfert 2 Galaxies, Liners, and H(II) Galaxies., AJ, 1997, vol. 114, p. 1345

Valenti E., Zoccali M., Gonzalez O. A., Minniti D., Alonso-García J., Marchetti E., Hempel M., Renzini A., Rejkuba M., Stellar density profile and mass of the Milky Way bulge from VVV data, A\&A, 2016, vol. 587, p. L6

van den Bosch R. C. E., Gebhardt K., Gültekin K., Yıldırım A., Walsh J. L., Hunting for Supermassive Black Holes in Nearby Galaxies With the Hobby-Eberly Telescope, ApJS, 2015, vol. 218 , p. 10

van Dokkum P. G., Cosmic-Ray Rejection by Laplacian Edge Detection, PASP, 2001, vol. 113, p. 1420

Vasudevan R. V., Fabian A. C., Gandhi P., Winter L. M., Mushotzky R. F., The power output of local obscured and unobscured AGN: crossing the absorption barrier with Swift/BAT and IRAS, MNRAS, 2010, vol. 402, p. 1081

Veron-Cetty M. P., Veron P., Study of a complete sample of galaxies. II. Spectroscopy of the nuclei., A\&AS, 1986, vol. 66, p. 335

Véron-Cetty M.-P., Véron P., A catalogue of quasars and active nuclei: 12th edition, A\&A, 2006, vol. 455, p. 773

Véron-Cetty M. P., Véron P., A catalogue of quasars and active nuclei: 13th edition, A\&A, 2010, vol. 518, p. A10

Wang J., Fabbiano G., Elvis M., Risaliti G., Karovska M., Zezas A., Mundell C. G., Dumas G., Schinnerer E., A Deep Chandra ACIS Study of NGC 4151. III. The Line Emission and Spectral Analysis of the Ionization Cone, ApJ, 2011, vol. 742, p. 23

Wegg C., Gerhard O., Mapping the three-dimensional density of the Galactic bulge with VVV red clump stars, MNRAS, 2013, vol. 435, p. 1874 
Winge C., Riffel R. A., Storchi-Bergmann T., The Gemini Spectral Library of Near-IR Late-Type Stellar Templates and Its Application for Velocity Dispersion Measurements, ApJS, 2009, vol. 185, p. 186

Woo J.-H., Urry C. M., Active Galactic Nucleus Black Hole Masses and Bolometric Luminosities, ApJ, 2002, vol. 579, p. 530

Wozniak H., Combes F., Emsellem E., Friedli D., Stellar kinematics of nuclear bars and discs. In Active Galactic Nuclei: From Central Engine to Host Galaxy , vol. 290 of Astronomical Society of the Pacific Conference Series, 2003, p. 563

Yaqoob T., Serlemitsos P. J., Turner T. J., George I. M., Nandra K., Discovery of Rapid Variability of the Iron K-Line Profile in the Seyfert Galaxy NGC 7314, ApJ, 1996, vol. 470 , p. L27

Young A. J., Wilson A. S., Shopbell P. L., A Chandra X-Ray Study of NGC 1068. I. Observations of Extended Emission, ApJ, 2001, vol. 556, p. 6

Yusef-Zadeh F., Morris M., Slee O. B., Nelson G. J., Nonthermal Radio Emission from the Galactic Center Arc, ApJ, 1986, vol. 310, p. 689

Zhao J.-H., Morris M. R., Goss W. M., An T., Dynamics of Ionized Gas at the Galactic Center: Very Large Array Observations of the Three-dimensional Velocity Field and Location of the Ionized Streams in Sagittarius A West, ApJ, 2009, vol. 699, p. 186

Zoccali M., Gonzalez O. A., Vasquez S., Hill V., Rejkuba M., Valenti E., Renzini A., RojasArriagada A., Martinez-Valpuesta I., Babusiaux C., Brown T., Minniti D., McWilliam A., The GIRAFFE Inner Bulge Survey (GIBS). I. Survey description and a kinematical map of the Milky Way bulge, A\&A, 2014, vol. 562, p. A66

Zoccali M., Vasquez S., Gonzalez O. A., Valenti E., Rojas-Arriagada A., Minniti J., Rejkuba M., Minniti D., McWilliam A., Babusiaux C., Hill V., Renzini A., The GIRAFFE Inner Bulge Survey (GIBS). III. Metallicity distributions and kinematics of 26 Galactic bulge fields, A\&A, 2017, vol. 599, p. A12

Zou X.-H., Xue S.-J., The Variabilities of the Soft and Hard X-ray Components of NGC 7314 and NGC 7582 and the Distribution of Absorbing Matter in Type II AGNs, Chinese J. Astron. Astrophys., 2002, vol. 2, p. 352 
Apêndice 



\section{Apêndice A}

\section{Resumo dos artigos publicados em co-autoria}

\section{A treatment procedure for VLT/SINFONI data cubes: application to NGC 5643}

Menezes, R. B, da Silva, Patrícia, Ricci, T. V., Steiner, J. E., May, D., Borges, B. W. 2015, MNRAS, 450, 369

Este paper é uma continuação da série de artigos sobre o tratamento de cubos de dados, porém este artigo é focado em cubos de dados observados com SINFONI (VLT). O trabalho descreve todas as técnicas que o grupo utiliza para o tratamento destes dados, com exemplos embutidos em cada processo de tratamento. Foi verificado que, após o tratamento de dados, houve uma melhora significante na qualidade das imagens dos cubos de dados, permitindo uma análise mais detalhada. Para um exemplo do impacto do tratamento dos dados, este foi aplicado ao cubo de dados da galáxia NGC 5643. As imagens das linhas de emissão de $\operatorname{Br} \gamma$ e $\mathrm{H}_{2} \lambda 21218$ do cubo de dados após o tratamento mostram a existência de nuvens de gás ionizado e de gás molecular, que não poderiam ser vistas claramente sem o tratamento deste cubo. As nuvens de gás ionizado representam a NLR e possuem morfologia de um bi-cone. Foi observada uma correspondência entre as posições das nuvens de gás ionizado (observadas com as imagens de $\operatorname{Br} \gamma$ ) e a imagem de [OIII] desta galáxia, obtida com o HST, convoluída com a PSF do cubo de dados de NGC 5643, obtido com o SINFONI. A emissão de gás molecular é aparentemente perpendicular à emissão do cone de ionização. Isso é compatível com a existência de um toro/disco molecular que colima a emissão do AGN. Há também a possibilidade do gás molecular estar abastecendo o AGN. Este cenário é compatível com o Modelo Unificado para AGNs. 


\title{
The Off-centered Seyfert-like Compact Emission in the Nuclear Region of NGC 3621
}

\author{
Menezes, R. B, Steiner, J. E., da Silva, Patrícia 2016, ApJ, 817, 150
}

Este trabalho é sobre a região central da galáxia NGC 3621, conduzido com IFU do GMOS. A partir do estudo das morfologias das áreas de emissão na região central desta galáxia, foi constatado que a maior contribuição da emissão de linhas vem de um blob, cuja distância projetada ao núcleo estelar é de $2 " .14 \pm 0 " .08(70.1 \pm 2.6$ pc). No resto do FOV foi detectada apenas emissão difusa com um deficit de emissão na posição do núcleo estelar. A análise feita a partir de razões de linhas no óptico revelaram que a emissão off-centered do blob é compatível com a de Seyferts tipo 2. Uma hipótese para explicar esta emissão foi proposta e considera que a mesma seja uma região de emissão de linhas fóssil ou um "eco" do AGN, que esteve mais brilhante no passado. Foi estimado que a luminosidade bolométrica deste AGN deva ter decrescido num fato de $\sim 13-500$ durante os últimos $\sim 230$ anos. Uma segunda hipótese para explicar as morfologias das áreas observadas, através de imagens de linhas de emissão desta galáxia, considera que não houve decréscimo na luminosidade bolométrica do AGN e que o AGN está altamente obscurecido para o observador, mas não em direção ao blob. Outro cenário proposto neste trabalho assume que o off-centered blob é um buraco negro que está retornando ao núcleo após a interação entre dois buracos negros. A última hipótese para explicar as propriedades observadas na região nuclear desta galáxia é de que a fonte central em raios-X não seja um AGN e, sim, uma binária de raios-X. Esta ideia é consistente com todos os cenários propostos aqui. 


\section{The molecular $\mathrm{H}_{2}$ and stellar discs in the nuclear region of NGC 4258}

Menezes, R. B, da Silva, Patrícia, Steiner, J. E. 2018, MNRAS, 473, 2198

Este trabalho é sobre o estudo da região central da galáxia NGC 4258. Essa galáxia do tipo SABbc possui emissão Seyfert e está localizada a uma distância de $7.2 \pm 0.3$ Mpc. NGC 4258 é bastante conhecida na literatura por possuir um disco de gás molecular nuclear quase edge-on, localizado entre 0.16 e 0.28 pc do núcleo, cuja emissão $M A S E R$ de $\mathrm{H}_{2} \mathrm{O}$ permitiu uma estimativa para massa do buraco negro supermassivo central de M. $($ maser $)=3.78 \pm 0.01 \times 10^{7} M_{\odot}$. Neste trabalho foram analisadas as propriedades de emissão de linhas e cinemática estelar do cubo de dados na banda $\mathrm{K}$, obtidos com o Near-Infrared Integral Field Spectrograph (NIFS) do telescópio Gemini-Norte. O espectro do núcleo, após a subtração do contínuo estelar, mostra apenas a emissão das linhas de $\operatorname{Br} \gamma$ e $\mathrm{H}_{2} \lambda 21218$, sendo que o $\mathrm{FWHM}_{B r \gamma(\text { broad })}=1600 \pm 29 \mathrm{~km} / \mathrm{s}$. A morfologia espacial da emissão de $\mathrm{H}_{2} \lambda 21218$ é consistente com um disco de gás molecular em rotação ao redor do buraco negro supermassivo, com um limite máximo do seu diâmetro sendo igual a 15.7 pc. A parte central do jato em rádio desta galáxia é, projetada no plano do céu, quase perpendicular ao disco de emissão de gás molecular detectado neste trabalho e também ao disco de $M A S E R$ de $\mathrm{H}_{2} \mathrm{O}$. As principais características dos mapas dos parâmetros da cinemática estelar são bem reproduzidas por um modelo de um disco de rotação estelar

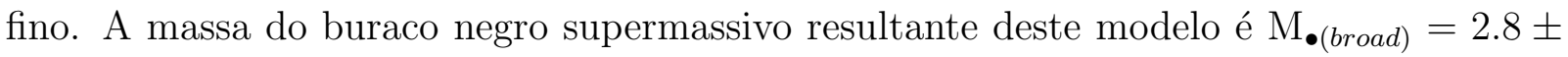
$1.0 \times 10^{7} M_{\odot}$, compatível, em $1 \sigma$, com a massa derivada da emissão $M A S E R$ de $\mathrm{H}_{2} \mathrm{O}$. 


\title{
A treatment procedure for GMOS/IFU data cubes: application to NGC 2835
}

\author{
Menezes, R. B., Ricci, T. V., Steiner, J. E., da Silva, Patrícia,; Ferrari, \\ Fabricio, Borges, B. W. 2019, MNRAS, 483, 3700
}

Este trabalho é o último da série de artigos que descrevem as práticas de tratamentos de dados desenvolvidas pelo grupo. Aqui é apresentado o tratamento dos cubos de dados obtidos com o IFU do GMOS, incluindo todas as técnicas descritas no capítulo 3 . A comparação dos dados tratados com as imagens do HST mostra que o tratamento preserva as morfologias espaciais das estruturas dos cubos de dados, sem gerar nenhum tipo de distorção. Como exemplo, os dados da região central de NGC 2835 foram tratados e, como resultado, foi detectada uma região nuclear emissora de linhas que não podia ter sido detectada antes do tratamento. Esta região possui razões de linhas compatíveis com as de LINER, de Seyfert e de objetos de transição. A detecção desta região, que ocorreu somente após o tratamento de dados, mostra que o procedimento não é apenas cosmético, afetando diretamente a qualidade da análise, como a determinação de frações de galáxias, com diferentes tipos morfológicos, com uma emissão central de Seyfert/LINER/objeto de transição. 